
$56,218 / \mathrm{C}$

T.m. 12

fieir 


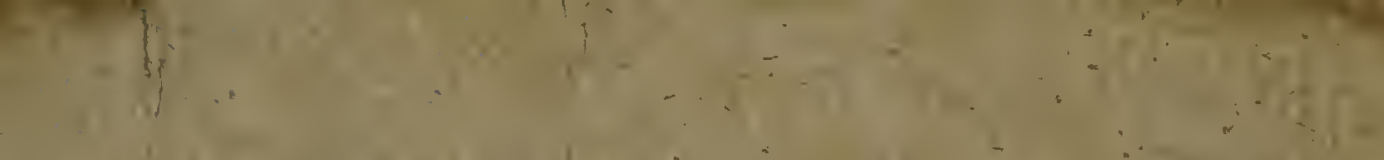

40

1

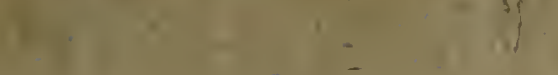

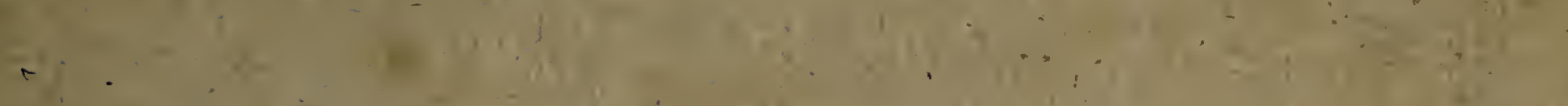

$\because+1-2+2$

.

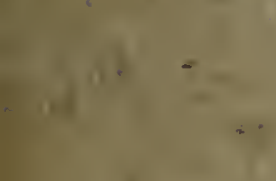

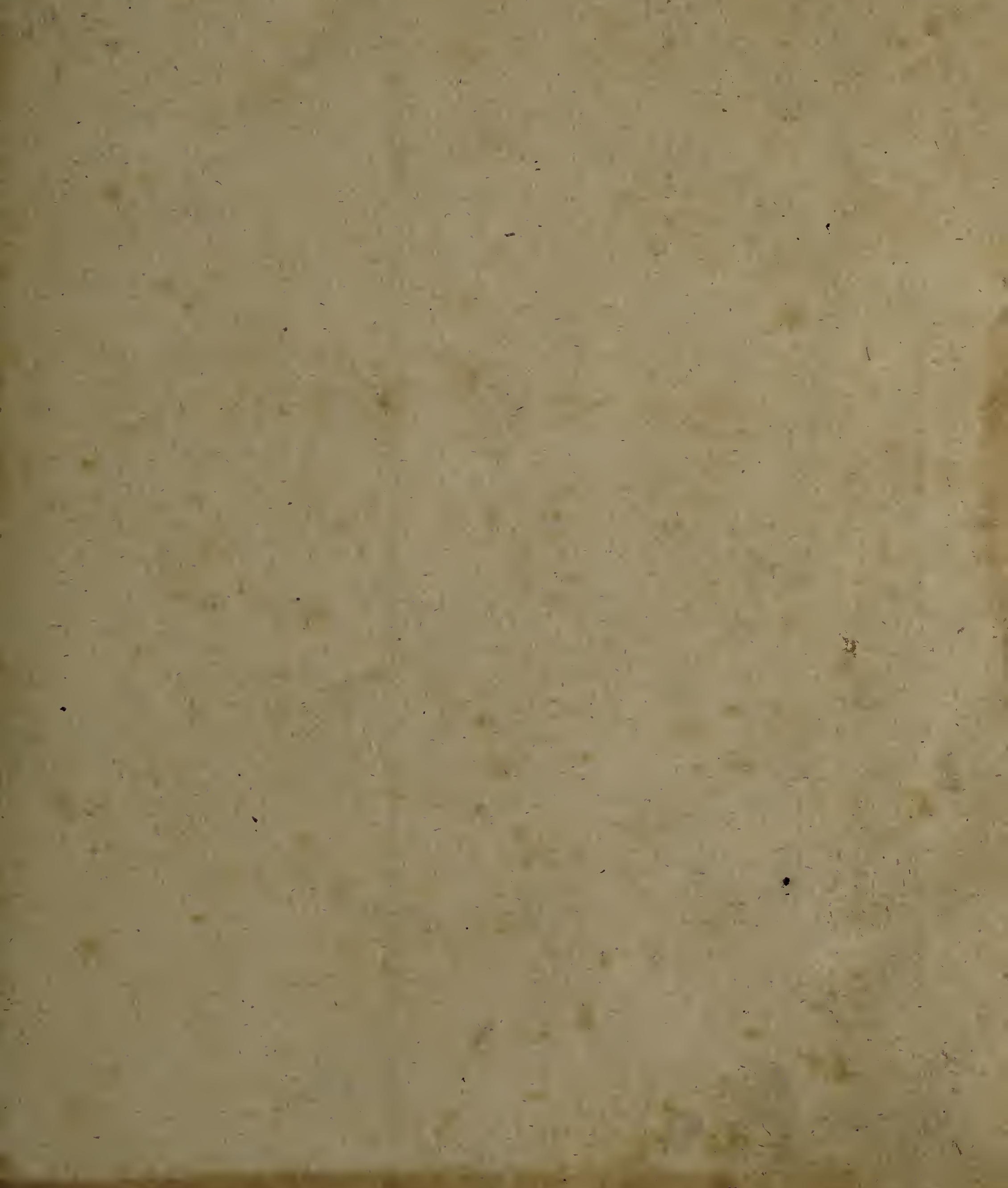



$\mathbb{S} \mathbb{P} \mathbb{E} \mathbb{C} \mathbb{I} \mathbb{N} \mathbb{N}$

\section{ZOOLOGIAE GEOGRAPHICAE, QUADRUPEDUM}

\section{DOMICILIA ET MIGRATIONES S I S T E N S.}

DEDIT, TABULAMQUE MUNDI ZOOGRAPHICAM ADJUNXIT

EBERH. AUG. GUILIELM. ZIMMERMANN, PROFESSOR MATHES. ET PHYS. COLLEGII CAROLINI BRUNSVICENSIS.

Mirum, rerum naturam non folum alia aliis dedife terris animalia, fed in eodom quoque firu quaedain aliquibus locis negaffe.

PLIN. SE C UND. Lib. VIII. Cap. LVIII.

LUGDUNI BATAVORUM,

APUD THEODORUM HAAK, ET Socios. $\begin{array}{lllllllllllllllll}M & D & C & C & L & X & X & V & I & \text { I. }\end{array}$ 



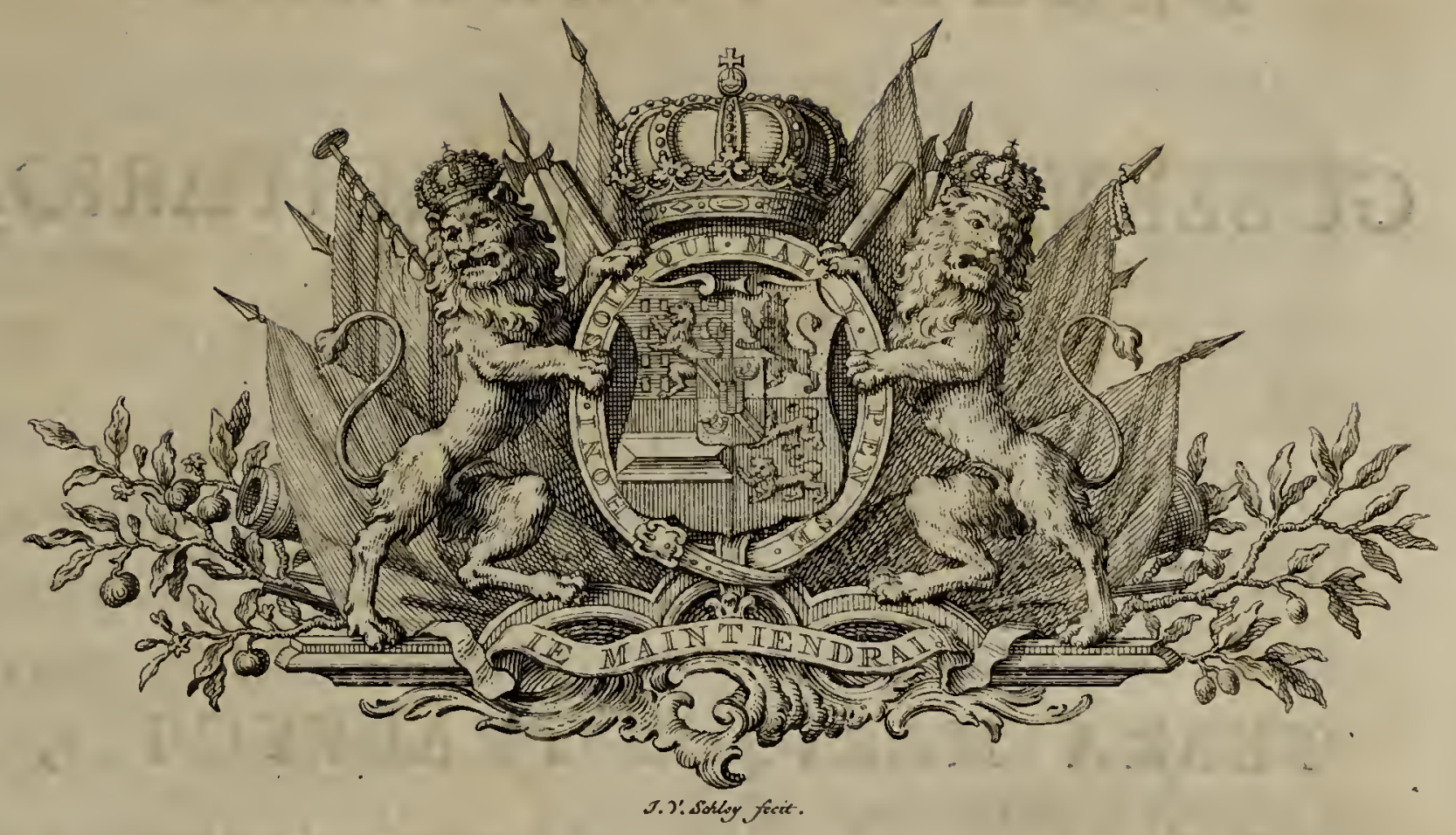

$\begin{array}{lllllllllll}S & E & R & E & N & I & S & S & I & M & O\end{array}$

s

C ELS I S S I M O

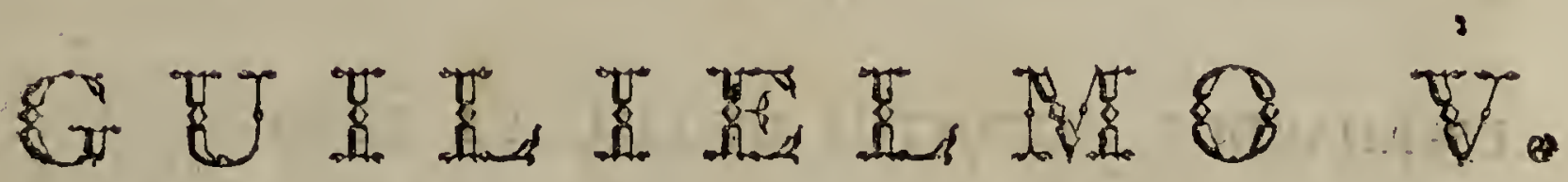

A R A USION UM.

N $\triangle S S A V I A E Q U E$

P R I N I P I,

*2 BELGII 


\title{
BELGII FOEDERATI
}

\section{GUBERNATORI HAEREDITARIO,}

\author{
E T \\ SUPREMO REI BELLICAE \\ TERRA MARIQUE PRAEFECTO, \\ R E L.
}

D. D. D.

- EBERHARDUS AUGUSTUS GULIELMUS ZMMIERIRNY.

MLirum tibi, Celsissime Princeps, \&. quidem merito videbitur, quid fit, quod me, homin sm nec fama, nec meritis, nec ulla re alia TI I notum, nee dulci illo pietatis vinculo, quo cives, quibus tutela Tua, falutis \& publi- 


\section{E D I C A T I O.}

cae libertatis cuftodia, frui contigit, laetantur, propius T I B conciliatum eo provexerit confidentiae, ut indulgentiae Tuae fecurus opufculum tenue venerandum ingentium Tuarum $\mathrm{cu}-$ rarum faluberrimorumque generi humano confiliorum facrarium ingredi patiar. Sed fas fit, fecuritatis hujus veniam a TE fperare, dummodo per eandem clementiam facilitatemque impetrem, ut vel uno oculorum conjectu fcripti hujus, quamvis levis nec fatis perpoliti, fcopum contueri ne gravere. Cui enim fructus lucubrationum mearum, quibus hujus terrarum orbis earumque illius partium, quae latius extendendo commercio, illuftrandae naturae hiftoriae, \& amplificandis aliarum fcientiarum latifundiis, in primis forent proficuae, adhuc mancam dubiamque fatis effe cognitionem oftenditur, potius quam TIB I offerre auderem? Quem prae aliis rerumpublicarum tutoribus noftrae a divina providentia refervatum actati credibile eft, ut eluendo huic ab humano ingenio elanguentis \& extinclae propemodum fagacitatis opprobrio unus fere par fis. Cives quippe Tui jam pridem felicis induftrine \& omnem fidem exfuperantis dexteritatis in ipfa fundanda Republica fua, in coër- 
cendo mari \& defendendo ab aeftuum furore, objectis undique molibus, littore, indelebile fratuerunt pofteritati monumentum. Soli Batavi, quantum polleant humanae vires, fuae virtutis documentis oftenderunt, facemque nobisad fperandum praetulere, tempus futurum effe \& forfitan jam inftare, quo Africa \& Afia, verfus aufrri orientisque plagas fita, magnis ftrenuorum virorum conatibus nobis recludatur, \& ita illuftretur, ut cum rubore fateamur, ipfi, noftrae aetatis imbecillitatem, qua novitatum, in magnis illis terrarum tractibus obviarum, plane incuriofi, illos vel negleximus vel ignoravimus. Liceat enim vel ab exigua illa, quae hactenus nobis innotuit, Africae particula conjecturam ficere, quam larga expectari poffit rerum fcitu diginifimarum meffis ab univerfa Africa, fiquidem acri hominum cura perveftigaretur. Jam praeter Baiavos Trios, Domine, \& Lufitaniae incolas nullus occurrit cognitioni meae populus, nulla natio, quae retegendo novi quafi orbis novo \& illutri fpedaculo, omni ex parte ab opibus, a viribus \& prudentia fatis foret inftructa. Ea eft infuper terrarum Tua fub tutela florentium beata tranquillitas, uf $a b$ nullo armorum ftrepitu 


\section{E D I C A T I O.}

concuffae in dies fummo felicitatis fuae faftigio propius admoveantur, omnibusque pacis artibus prae aliis in tantum emineant, in quantum $L u$ fitanorum ditiones ab hac parte fenefcere videntur. Et alii quidem populi non operae parcunt, non fumtibus, ut vel claffibus vel terrefiri itinere novas terras exquirant, nemini fatis cognitas, nullo hominum tritas veftigio, nuspiam locorum fortaffe comparentes, de quarum etiam fructu commodisque, \& quid lucri ex iis proventurum fit commercio \& fcientiis, magna faepe fperari, ftatui certo nulla poffunt. Tuo autem arbitrio, Celsissime Princeps, detegenda hic fefe offerunt longe fane ampliora terrarum fpatia, aliis hucusque repertis pulcriora \& uberiora, beatiflimoque altricis naturae proventu ad prolatandos fcientiarum commerciique limites magis accommodata; quae infuper non curiofum fui inveftigatorem, fed gratum opum fuarum poffefforem defiderent, Quicquid igitur, Tuo indultu, Tuo auxilio, Tua fapientia animati \& excitati hujus generis conatus feculo Tuo addent fplendoris, quisquis inde exfurget bonarum artium honos, quicquid abundantiae redundaturum eft, in illud commune generis humani vin- 
VIII

\section{E D I C A T I O.}

culum, commercium, quicquid orbis hujus terrarum \& incolarum ejus animantium herbarumque \& metallorum hiftoria hinc fumere poterit incrementi: id omne Tuae, Domine, debebitur magnitudini. Hac fretus eam habeo animi Tui fiduciam, ut morari me qualicunque hoc litterarum diverticulo aliquot Tuorum temporum Batavis Tuis nullo pretio redimendorum momenta, per Te mihi dari clementerque concedi, mihi perfuadeam; quorum aliquam partem ad homines etiam exteros, ad univerfum genus humanum, ad me denique derivari, magnitudinis Tuae effe, non fine fummo pietatis Ienfu intelligo.

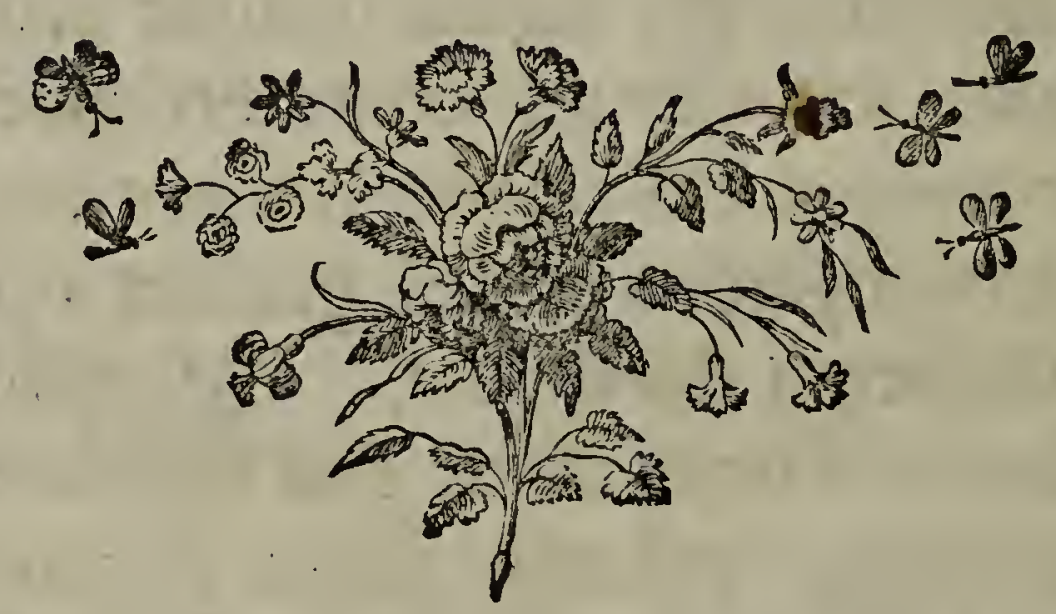



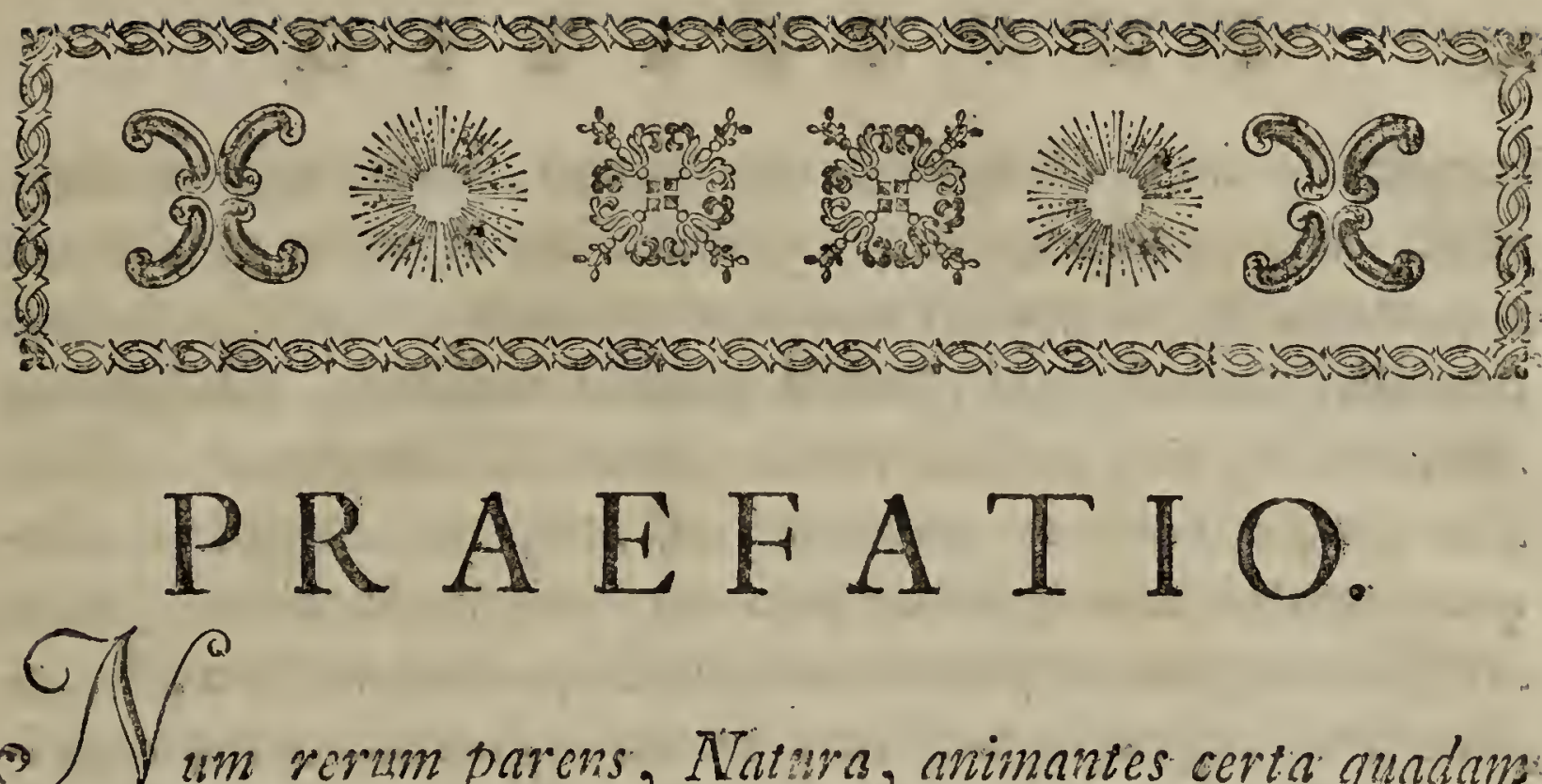

dispofitione per terrarum orben diftribuerit? quibus regiomibus bujus illiusque generis wel plures rel pauciores ad/fgnaverit? ans cuivis generi fingularem funm dederit pasriam? e qua deinceps progreffi latius per terram evagati fint? quaeftiones erant, quae mibi Plinii verba, hbelli bujus fronti fubnexa, legenti fuboriebantur; ipfamque Gengrapbicam banc Zoologiam iisdem celeberrimi acvo fuo maturae forutatoris verbis ormm debere, non diffiteor. Duum autem vel oculis dijudicari quent, folos efje quadrutpedes, quorm patria fedes, e qua pedctentim per orlis fuperficicm Se diffuderunt, certins conmodiusque ad disquifitionem vocari polfit $\therefore$ in bos potiffimum confiderasinnem intendendan, Gs, qua ratione dilatentur, dippiciendum, ideaque fequentes imprimis quaefiones fumdamenti loco ponentas efje, putavi. Prima, aui fiat, ut omia as fingula quadrupedum genera unam eandemine re-: gionem inbabitare vequeant? Deinde, quaenam illorum per totum orbem difeminata invenicintur? Porro, fi quitbusdam terris aliqua ip forum goncra vel adeffe vel deefle ob:fervantur, amon exinde, quibus fatis telluris fuperficies alim ufa fuerit, probabili fultim ratione conjectari poffit? Inis Juppolits, quadrupedes cunctos, in tres clajes divi/r, qu6 30. 


\section{$\begin{array}{lllllllllll}x & & P & R & A & E & F & A & T & I & O\end{array}$}

quarum primac illos fubjicere placuit, quos vol per inte. gram telluris fuperficiem diffundi, vel ingentes ex utrovis nequatoris latere tractus occupare animadvertimus. Secun. dine illos tribui, qui primis quidem minora, nibilominus tamen adbuc magna fatis terrae fpatia fibi vindicant. Tertiae denique reliquos omnes adjudicavi, qui exigruis aretisque tantummodo regionum finibus circum/cribuntur. Quam divifionem quum apprime cum quadrupedum natura $\hat{\xi}^{2}$ conAitutione congruere vidcrem, tribus argumentum boc capitibus abjolvendum mecum conifitui. Non equidem inficior, me primo adfpeclu rem effectu facilliman credidife, quoniam a Buffonio, Linnaeo, aliisque praeftantiffimis naturae contemplatoribus cujusvis animantis patriam jan exploratan indicatamque efse autumabam. Simulac vero mamum operi admovi, beu! quot nodos folvendos, quot fcopulos fuperandos offendi, qui primo Se obtutui fubtrnxerant. Nons enim una modo alteraque, quam animalis cujusdam genus incolit, 'regio difpicienda crat, Sed magna potius multarum regionum feries pervefiganda, commonftrandumque fuit, animalium in primo jecundoque capite percenfitoruin genus banc integram regionum compagem fic inbabitare, ut ordine vel nunquam, vel parum faltim interrupio, inibi progrediantur. Necelfitas itaque flagitabat, ut vaftam $\varepsilon^{\circ}$ a veteribus relictam $\varepsilon^{\circ}$ a recentioribus bucusque publici juris factam itinerariorum molem, magnam Geographorum ac Topographorum farraginem ingentemque aliorum buc pertinentium fcriptorun copiam, perfcrutarcr: quaeque Buffonius bac de materia bucusque in lucem emifit, confulerem, $\xi^{\circ}$, fic undique collectis $\mathrm{O}^{\circ}$ inter fe collatis, quae ufui moo infervirent, Zoologiam banc cunctis. cjus, quoad fieri pos. fet, mumeris partibusque explerem. Hunc propofutum fi- 


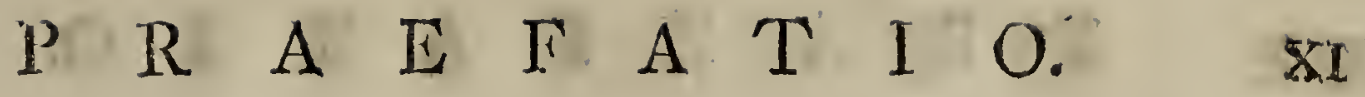

nem adfecuturo mibi aut librorum the fauro, qui non antiqua Solum, Sed recentiffima quoque naturae peritorum opera Suppeditaret, aut faculeatibus ad ea comparanda Jufficientibus, quin Eg otio a continuo labore opus erat, " jutto cuncta ordine $\xi^{\circ}$ exquirorentur $\xi^{2}$ edolararentur; quibus tamen auxiliis guum defituar, veniam impunitatemque, Lector amice, dabis, fimulta occurrunt, quae partim suppleri, partim curatius longe Eे enodatius illaffrari comprobarique potuiffent.

Interim e dictis bactenus tam fcopum libelli, quam rationes, quas propter in enumerandis quadrupedibus nec Linnaei nec aliorum magni nominis virorum Syftemata Sequi mibi licuerit, cognofces. Quum enim exordium ab iis capere, qui quam latiflime difperguntur, quales homo, canis, aliique funt, deinde ad illos progredi placeret, qui anguffioribus paulo terminis definiuntur, pariterque quantum fieri poJfet, a feptentrione ad aequatorem defcendere mecum. confituifJem, quod in primo Secundoque capite fricte obfervatum exiftimo; tertio in capite alius necefJario ac dispar ordo seligendus crat. Quumque e rationibus jam adductis, prior methodus munc rejicienda effet, Linnaeus, cujus Syftema omnium fore naturalis biforiae cullorum in manibus verfatur, dux $\xi^{9}$ aufpex adoptandus fuit. Licet enim tertio buic capiti eos tantum quadrupedes deftinavifem, quibus in primo fecundoque locus commode nullus dari potuit; lectorum tamen commodis confullurus, omnia, quaccunque bucusque innotuerunt, animalia, quam fieri potuit.brevisfome cmumerare decrevi. Utque eo facilius inter fe dignoscerentur, aliis ea litteris exprimenda curavi. Habes itaque, Lector benevole, boc in capite, notorum nobis animalium indicem omnium qui buc usque prodierunt, forfan abfolutiffimum, in quem e Buffonii, Pennanti, Sebae, 


\section{XIF $\quad P \quad R$ A E F A $T$ I $O$.}

Pallafii, Catesbii multisque aliis operibus cuncta congefie $E^{9}$ ad Linnaei ordinem digefa invenies; quem ea gratiorem illis fore Spera, quibus Pallafii, Gmelini Junioris alionumgue recentionum peregrinantitum foritua, varias propter cauJas, legendi facultas adbuc mulla datur, EO in quo antiqui $\gamma_{2}$. mul orbis beflias ab Americae animantibus, qua potui cura disjunctas vides. $V$ ix dict potelt quantopere doleam. Schreberi, quem bonoris $6 \sigma^{2}$ obfervanitiae causal nomino, quod de mammalibus animantibus in lucem emittit operis praellantiffimi eam tanummodo partem adbuc prodiifse, quae Linnaeani. fyftematis quadrupedum ordinem primum. comprebendit, in reliquis enim capitis brujus fectionibus magrano etiam mibi ufui effe, potuifet; quantwan interim. per vimum debilitatem licuit, feciffe arbintron.

In-fectione, qua de homine agitur, quamvis long as $f_{a-}$ tis fuerim, mibilo tamen fecius, li quem Homius de bonine librum, Sketches of the Hiftory of Man muper cdidit, prius in manus meas viniffet, viri doctiffimi opinionem. qua praeter primos parentes nolltras, nlios, aliis in regio. sibits, diverfo tempore, multos a revum condivore produClos effe Ratuit, amiplioribus adbuc vorylits argumentisque. rejellere, eoque certus evincere tentaviffent: reliquos omnes, subicunque locorum habitent, mortalis, ab uno primogut gencris nofiri patre oriundos, cunctosque falas illiusi vartiontes effe, quarum formae, faciei coiorisque diverfinus. wiurriato inprimis coeli climate deverfaque aèris temperie. artum traxerio: Quisguis interim, gute bac de re athuli, site fectsm reputaverit, fimuligue baboum as forten quadriso.

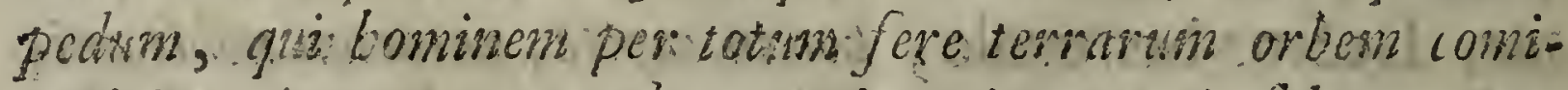
tast, parique propemodun satione immuturi folent, contemplatus fiterit s facile ad mesm jentcrition difcedons nova bomi. 


\section{$\begin{array}{llllllllll}P & R & A & E & F & A & T & I & O & \end{array}$}

bominum creatione minus opus fuiffe fatuet. Duo primo in capite propofita videbis, quae ut aequa mentis acie di/picias admodum cupio; quorum alterum probat: bowinem, fungulari corporis praeftantia $\xi^{2}$ robore fultum, omnibus telluris regionibus, quacunque ceteroqui caloris frigorisque vi inter fe difcrepant, tolerandis parem effe, coque ipfo. quairupedum corporibus mirum quantum antecellere; quam fententiam a Buffonio, nefcio quibus de cauffis, peritus negatam mirabundus perfpicio. Alterum eft : nullum eximine magnitudinis, Spectatique roboris animantem, qui carne pafcitur, umum fa lupum exceperis, ea praedituns. effenatura, ut persmagnos terrae tractis diffipari queat, Jeu, quod unum mibi idemque videtur, millum iis corporis viribus infructum effe, wit ubique terrarum vivere vitamque diu confervare valeat qumm e contrario experientia doceat, manfuetiffimanum bominibusque utiliffimarim ani mantium conditionem eam effe, ut quascunque bomo tervas petiverit, eumi Sequi polleant. Quae, quim certiffma fmgularis fapientine $6^{\circ}$ in bomines benivolentiae dociumenta fint, quae foli renum omnium छे actori छे directori acceptareferimus, co digniora videntur, ad quae bene fentiens lector animum attendat. Quis enim piae probaeque mentis mortalium eft, qui de conditoris. Jui Japientia, providentia $\xi^{2}$ benignitate convictus effe nolit?

Buffonii, Pawiique opinionem, Americae latitudinis gradus prae iisdem antiqui orbis gradibus longe majori frigoris vi premi, in toto auidem libello, potiflimum tamen in Secundo capite fufus comprobatam dedi. Dum enim tarandorum, alcium, fimiarum aliarumque befliarum domicilia, quae utroque in orbe occupanit, inter fe contuli, rem pluri* bus 


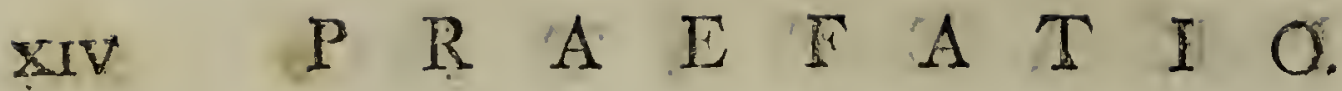

bus certioribusgue argumentis, quain usquam factume, $i_{\text {, }}$ revietam, nec generatim modo, feid figillation commonftratam dedi, quod adnexa libello Tabula Zoolagica, cujus deinceps memorandae locus dabitur, uno qua $\sqrt{2}$ obtutu dilucidius demonfrat. Eix Europa enim orientem verfus per: gentibus frigoris vebementiam manifefto ingravefcere evi: dentiffime probavi. Sic tarandos, qui in Europae terris Jub Jexagefimo prima demum latitudinis gradu xeperivi folent, in Afia ad Uralis montis radices fub quinguagefimo guinto, in Kalcaflenfum Tatarorum oris fub quinquageJimo, $6^{2}$ in America denique Jub quadragefimo circitex quinto jam occurrere, Ganc eandem alcis etiam rationem efje, oftendi. Quoties itaque unum idemque ferarum genus wel propius vel remotius ab aequatore lu-tra fibi fua conders. obfervo; toties certa quoque indicia fuppeditari cxiftimo, e quibus non tantum, quae vel frigoris vel caloris affectio fit, fed etiam, utrum terra incolarum vel copia redundet, vel penuria laboret, taio certogue colligi poffe, creda. Quodj cnim vel Iroquoenfium vel Kalcaffenfium natio acque mimerofa fuifjet, parique pationtia defertas vacuasque terras vomeri fabactas Gallorum Germanorumque mone frugiferas reddidiffet, tarandos, ut in vegionibus minus cultis, majorigue frigonis vi expofit is lufra fobi fuc conderent plagasque, quas minc tenent, defererent, conctos fuifje mibi perfuaffimam ef. Ex ejusmodi generalionibus abjervationibus, quam telluris noftrae biftoria multis nec exigui momenti acceffionibus locupletari queat, easdem pbilofophis gratas acceptasque fore, non dubito Ouoniam coeli pofationes diverfas quadrupedibus babitus ing ignesique so corporum $\sigma^{\circ}$ ingenion sustationes adferre experientin docemur, in primo fecundo- 


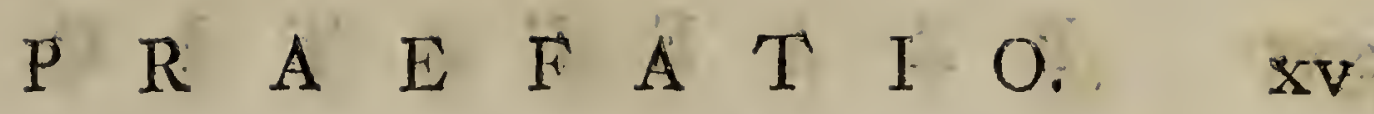

gue libelli capite multos quadrupedes, quos naturae indagatores fingulares plerumque Jpecies effe contendunt, varietatibus, quas mutatum coeli clima, mutatique nutrimenta produxerint, adnumerare Jufinui, quod in fuibus, leporibus. aliisque Jat mnellis factum benevolus Lector ob/ervabit. Quodk iamen, quia in probabili tantum conjeclura pofitum, nec dum Jatis explicatum exploratumque eft; ne quid offenfionis inde aliud fentientes babeant, tam tertio in capite, quam in Tabula Zoologica ita correxi, ut fingula animalia, de quibus, an in varietatum numero babenda fint, nondum $\int_{a}$ tis confat, fingulares ad Species co usque revocaverim, donec tompus diesque monfraverit, quid certi de iis flatui queat. Buffonium interea rationes exacte faits fubduxifje, credo, qui omnia quadrupedum genera ducentorum numero definivit, reliquosque centum quinquaginta varietatibus adjudicandos cenfuit. Varia infuper capiti buic tertio adjunEFa deprebendes, quibus in antecedenibus quidem locus debebatur; quae tamen, quin diverfis temporum intervallis, quoties quid otii mibi contigerat, lucubraveram, interea vero temporis eximia quaedain celebriorum virorum $\xi^{\circ}$ operc o itineraria evulgabantur, quase novum binc inde animaTium biftoriae naturali lumen adferunt, quorum tamen ins Jpiciendorum, abfolutis demum prioribus, copia mibi dabatur; $6^{\circ}$ ipfemet multa me partim omilife, partim in disbio incertoque reliquifle animadverti, ea omnia fupplere $\sigma^{\circ}$; guum aptiorem fore locum nullum putarem: beic loci adjungere $g^{\circ}$ ad veritatis amuffim revocare, quam penitus praeterive, confultius duxi. Noli ivaque, Leetor humaniffrme, mirari, $f_{\varepsilon}$, quam ante opinionem de boc vel illo gradrupede ofenderam, munc vol plane repudiatam, vel faltions. $* * *$ 


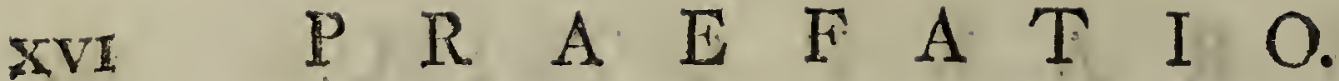

immutatam cernis. Quis enim eft, quem dies non doceat?

Quartum denique caput generatim thefes notatu digniflmas ante oculos ponet, quae e Juperioribus legitima quadam confecutione fuere videntur. Quumque ibi quam fummam animantes $6^{\circ}$ praccipue quadruipedes conficiant, commonArandum effet, eadem de caufja prolufionem praemifi, quas. lectorem ad coput bocce, praeparandum duxi.

Eodem in capite regionum, quas notas plerumque vocasus, fuperficiem iis cum terrae partibus collatam vides, quas a Phyficorum quopiam adbuc nec peragratas nec dimenjas novimus, ex quo, quota telluris noftrae pars adbuc in obfcuro quafz lateat, difces. Utinam baec ip/a confideratio terrae dominorum regumque animos inftimularet, ut virium facultatumque, quibus a rerum arbitro inftructi Junt, partem ad delegendos orbis tractus, quos cognitos quidem. appellamus, licet tamen adbuc tenebris quafi cralfi]Jinis circumfundantur, conferant. Id enim jam cognitum babemus,

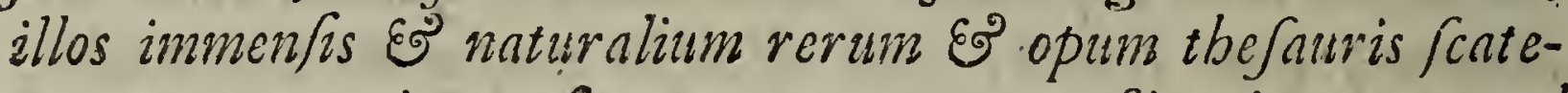
re, nec negari poteft, ex corum perveftigatione tam ad Geograpbos, quam ad Pby/cos, Eo generatim ad omnes naturae indagatores innumera emolumenta redundatura effe. Hoc eodem in capite ad quadrupedum tandem migrationes perrexi, ad quas dispiciendas prioribus in capitibus necefJaria qua/i conjecutione perductus छg bac occafrone quaeftionerm, quaenam prima bujus illiusque animant is fit fueritque patria? curatius pro ingenii viribus explicare conatus fum. A quibus omnibus tandem ad orbis no/tri biforiam tranfii: wec improbabili, ut autumo, conjectura extricare ftudui, quae prima telluris noftrae facies fuerit, quasque inverfiones E' commutationes fuftinuerit: quae infularum cum conti- 


\section{$P$ R A E F A T I $O$. XVII}

rente, quae regionum inter se ab initio ita cobaeferint, ut unam effecerint, ignis autem Jubterranei cruptionibus, aquaruin imundationibus aut aliorum concufjum concurfit disruptae ac divulfae fint? Has omnes $G^{\circ}$ alias, quae buc pertinent, quaeftiones, e fola quadrupedum varias terrae plagas traclusque inbabitantium, contemplatione, quanium rationis cognitionisque bimanae debilitas permittit, folvere fuftinui, quibuscunque itaque LeCtoribus animantinum biftoria naturalis minus curae cordique fuerit, boc quarto in capite, praccipuas maximique momenti pofitiones conjunctas frico timque copulatas babebunt.

Duo junt, quornmin veniam a Lectoribus 69 obfecro Es impetrare cupio: Primum eft, nevitio vertant, fi in rebus, quae illuftrationis ac perJpicuitatis caufa admifcui, et fa minus ad rbombum facere videbaniur, copiofor interdum fui, quam par erat: quod ibi loci e. g. factum effe Sentio, "ubi preffionem aëris in culpa effe docui, ut ovis nofra tantopere a primaeva fua natura $\Xi^{\circ}$ conflitutione degeneraverit. Alterum eft, quod in confellendis celebrium quorundam virorum opinionibus anxius nimis verbofusque fui. Quod in frangenda Linnaei Sententia, quam de prima ratti patria dedit, mibi accidiffe doleo, hubensque largior, minus verborum opus fuifJe, $\xi^{9}$ fuffeciffe, 12 vel binis commonfreviffem, virum coleberrimum gravioribus forte negotiis occupitum Oppingii librum vel fefinanter vel neglig chiter tarhtum infpexiffe. Verbis exprimere nequea, qua obfervantia virum profequar, qui incrediliti doctrinarum copin abundans sniverfae raturae fcicntias in novam eangue commo his. fimam formain redegit. Syftema enim naturae, guod conz focit, lices nec perfectiffimum nec omnibus nimeris obsolu- 


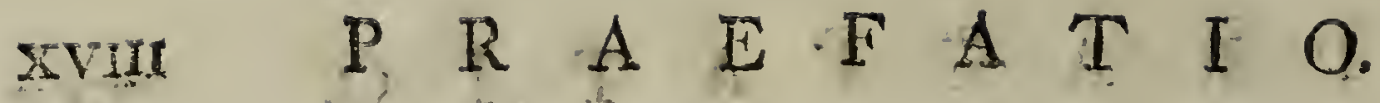

tiffimum fit; nojira tamen aetate prae omnibus, quae bucüsgue prodierunt, aliis facile principaunn obtinet, quod non Jummae tantum viri cruditzonis, fed indefe ffi etiam, quin Herculei laboris documentum elt; quo iplo de universa republica litteraria $6^{\circ}$ inprimis de naturali fcientia optime mernit: quaecunque e praeftanti opere ejus bau/i, baufis autem fat multa, memori grataque merste manuque fum/o. $\boldsymbol{P}$ ari reverentia Buffonii nomini a Jirgo, quem merito $E_{u-}$ ropa maximis, quos jam nutrit, viris annumerat, funmoque jure Galliae Plinium appellandum cenfet. lit hict interdum ab ejus fonientia di/ce/Jerm, idrirco tamen ab/it, sne Phy/corum bujus Principis famae vel minimum detrucium voluiffe. I'lus quam Vatiniano odio juvenilem infulfumque illorum pruritum profequor, qui maximae eruditionis fummaeque laudis viros aggrediendo gloriolae quid inde fibi acquirere geftiunt. Qutod/i vel invitus vel incon/ulte, quan viro buic celeberrimo babeo, reverentiae fines fupergrefjus effem, id vix ac ne vix quidem mibi ip/a ignoficrem. Amicus Plato, amicus Arifoteles, magis tamen amica veritas.

Ad Tabulam mun Zoologicam progredior, de gua vel tribus narrabo, quae maxime e Lectoris re u/nque fuerint, quave ratione ad eandem conficiendam commotus fim. Simulac mibi propofueram, animalium patrias inveftigare, neceffitas ipfa pofcere videbatur ut de mappa bac cogitarem. Qua onim alia ratione quadrupedum domicilia indi. care E⿱乛龰 ad oculum demonftrare potuifJen? Interim fa. teor, primun, quod hac de re agitaverim, confilium, diffurus longiusque evagatum effe: quod tamen ut exfequerer, nec tempis, nic concutenatus, quo confringor, 


\section{P R A E F A T I O. EIX}

Iabor permifit. Quam enim regionum temperies, e certorum animalinm in iisden degentium vel praefentia vel defectu, quod fupra jam faepius demonttratum dede, probabiliter fatis dijudicari queat: univerfali orbis terrarum tabulae conficiendae animum adjiciebam, quae non folos quadrupedes, fed ciajusvis etiam terrac traElus meteorologiam, feu, quod idem efle puto, mediam $\forall$ Barometri $\mho^{\circ}$ Thermometri menfuram $\xi^{\circ}$ ventos, qui certis ami temporibus flatus fuos certus in regionibus agere folent, acus infuper magneticae tam inclinationem, quam declinutionem, quin छo montes exbiberet, quos etiam tabulae buic, licet jufto arctior anguftiorque Jit, inferendos curavi. Finem bunc adfecuturus omnium, quae buc facere opinabar, colligendorum jam initium feceram. Laborom autem ipfum aggrefJurus perfpexi, partim tabulae bujus Jpatium tot rehus comprebendendis minus fufficere, partim imimenlas adbuc ob/ervationes ad fcopum bunc veceffarias defiderari, quae multis demum annis ni feculis exactis /perandae funt.

Mappae quidem ip/i, quae opus erat, magnitudo dari; Sed tunc Jalius Europae juperficies expleri potuiffet. Reliquae vero Afiae, Africae nozıque orbis mappae inanes simis $\xi^{9}$ vacuae manjiffent. Caetera igitur differre primumque bac tabula experimentum capere malui : quodfí Lectoribus baud penitus displicuerit, temporis jucceffu, fi vitam viresque Deus cuncefferit, propofitum bocce effectui daturus reliquas etzam tabulas adornabo. Meo enim judicio, tam naturae inveftigatoribus, quam in universum biftoriae naturali magni momenti res foret, is tot res funmation univerfimque cognofcendi $\xi^{9}$ uno quafs oculorum 


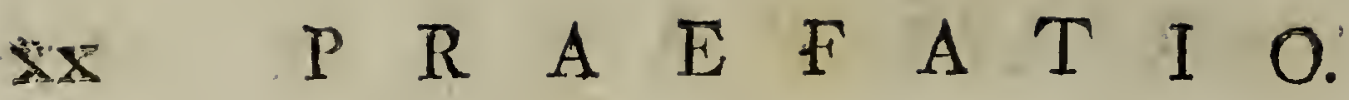

conjectu perlufrandi occafio daretur. Quam libello buic fubjunctam vides mundi tabulam, Bellini eft, quam Mercatoris reductam appellant; fuper avtorpapov in eo eminet, ut regiones antea ignotas छ" muper tam a Ruffis ad Euronotum quam ab Anglis Vulturnum Aufrumque verfus detectas, quosque Buachenius tabulis fuis phyficis snontes inferuit, exbibeat; quippe qui Zoologiae etiams commoda fü adferunt, quum experientia doceat, certos quadrupedes montium juga fequi. Cujus exemplum Securdo in capite, ubi de mure alpino fermo eft, babes. Mon-. tes ipfos co futu depictos confpicis, ac $\int i$ Juperne delineati effent. In tabulis enim, quas Mercator dedit, punEtum vculo defuper ullum nec datur nec dari potuit, ideaque perinde erat, quo ftatu Jituque depicti apparerent.

Animantium nomina, cuivis, quam inbabitant, regioni adpofita $\in f f e$ per fo patet. Et quid lineae, quibus terminos ac fines, quos intra quadrupedes commorantur, definivi, nominumque compendia defrgnent, explicatio tabulae, lateri appofita, docebit. Lineas iftas maximam partem regionum meteorologiae deftinatas effe, jnms aliquoties, $\mathbf{\sigma}^{2}$ fortafjis ad Lectoris naufeam usque monui. Hoc tamen addendum pubo, cas ipfas fimul common/trare, certas animaJium species mortalibus proficuas latius adbuc per orbem diffundi, aliasque in terras commode introduci poffe, ubi multis aliis telluris incolis non exigumn usum adferrent, quod in camelo locumbabet. Si attendimus, quousque befita bacc procedat, eann longius evagari reperimus, quam de ani. mrante, in Arabia orizunda sperari pnternt, fiquidem ad sexagefimum usque gradum afcendit. E linea igizur, qua ejusdon termini definizniur, difcimus, omen propemo- 


\section{P $R$ A E $F$ A}

XXI

dum Europam eadem, nec fine fructu, uti pofe. Unum eft, quod objici poffet; cardem non nifi in fabulofis uniusque formae lerris vivere ufaique effe pafje. Quiis autem adfirmaverit, totum, quod nunc peragrat folum, $f a$ bulofum femper nullisquie rupibus, faxis lacubusque diftingui? A Alia etiam animuntium genera fat multa junt, quoram cancelli, quos intra vivunt, lineis defcribi potuisfent; nif timuiffem, tabulam boc ipfo partim obfcuram, partim confusam nimis futuram; praecipue quam lineae Se crebro nimis inter Jecones Lectorem tam incertam reddidiffent, ut, aninanaisvelfigin vec requi femper, nec ab aliis dignofcere valuiffet. Praeier domefticas pecudes, urfis etian, vulpibus aliisque non paucis quadrupedibus pari ratione fui, quos inira degunt funes, determinari facile potuisfent, quumi ipfo in libro, quousque omnés progrediantur. manifefto fatis explanaverim. Ut tamen quicunque ipfotum vel por univerfum orbem, vel por ingentes ipfurs iractus dilatati confpiciuntur, fuis, quas incolinnt, regionibus adnotarem, $6^{2}$ patio fimul tabulae parcerem, cos vel primis tantum, vel paucis litteris, quibus locis commorantur, notatos babes; $\xi^{2}$ ne quid obfcuritatis exm inde fuboriatur, index notarum tabulae additus docebit, quae litterarum notarumque ip Sarum fic fognificatio. Quamvis interim bis aliisque fcribendi compenäiis uifis fom; nibilo tamen fecius Spatii anguftia coactus, quorindam amimalium nomina vel omitti penitus, quod in Zeilonis infula factum deprebendes, feu regioni, in qua vivunt, paulo altius, quam par erat, infcribi debuerunt. Hinc factum eft, ut Africa nominibus refertior appareat, quaim ejus defcriptio. Jupra data, qua majorem ejus partem nobis ignotim effe dixi, permittere videbatur; quod Lectoris, rei difficulia- 


\section{XXII

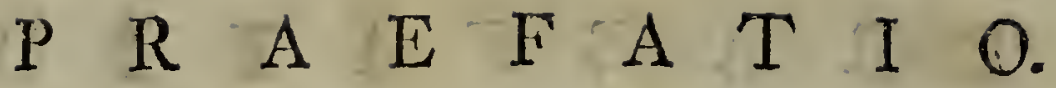

tem perfpicientis ac ponderantis, aequitas facile excufabis.

Qui ad mimalium nomina, quae tabula zoologica continet, oculos animumque attenderit, quam thefin quarto in capite fundamenti loco pofui, incrementa nimirum aut decrementa potius animantium, ex latitudinis gradibus, feu ex sëris coelique temperie dependere $\xi^{\circ}$ explorari pofje, in quadrupedibus etiam certa veritate fua gandere revictus fatebitur. Quamvis enim Europa omnis nominibus expleta appareat, eam tamen non modo ceteris orbis partibus longe minorem; sed, quod probe obfervemus oportet, totam quoque cognitam perfpectamque babemus, infcriptaque ip/a animalium nomina omnia fere cadem effe animadvertes; quum e contrario in Guineae aut Congi promontoriis, aliisque calidioribus vel novi vel antiqui orbrs plagis, totiden paene a fe inrsicem diverfae animantes reperiantur, quot iis vel litterae vel litterarum compendia adfcripta offendis.

Ad enumerntas bactemus, quas tabula ipsa praeflet, ustilitates, accedit, quod illis etiam, qui prima bifloriae naiuralis elementa noffe cupiunt, commoda fua praebeat. Qunum cnim omnium ac fingulorum quadrupedum appellationes tam a Linnaeo quam a Buffonio aliisque collectas percenseat, bifloriae-bujus nofcendae fudiofus, tabulam ipfaim perluftret', $E 9$ cajusvis animantis nomen patriamque memoriae mandet. Sic ex appofito notarum indice befias, earum appellationes, E' Jynonyma etiam facillime cogniofcet, E⿱ quo nomine a quovis naturae ferutatore appellontur, intelliget. Hoc fins illorim etiam animantium nomina tabula Juppeditat, quorum indoles, naturaque nondum ita innotuit, ut certis fuis generibus clafibusque adfcribi potuerint, qualis Kolioboe, Tonkong aliique funt, quos patriis fuis, छo ea ipja quidem appellatione, qusm regionum incolae iis impofuerunt, 


\section{$\begin{array}{lllllllllllll}P & R & A & E & F & A & T & I & O & & \text { XXII }\end{array}$}

apponendos curavi, ne imperfecta nimis 69 manca tabula videretur. Quicunque igitur prima naturalis byforiae prin:cipia vel tradere vel nofcere voluerit, fola is, fine libello, tabula, meo judicio, commode fatis utetur.

Quoniam interim, naturae bifluriam in dies fere nova incrementa capere conftat; binc prono fluit alveo, aliquot annis praeterlapfis tabulam ipfam $\xi^{2}$ mancam $\xi^{\circ}$ imperfectiorem longe fore, quam nunc eft. Huic interim acquieformus fi modo vel minima defiderentur, quid enim bac in re omnibus numeris abfolutum dari expectarique poterat? Aequns itaque Lector impenfam buic opusculo curam, laborem ac diligentism, quae, quod lubens fateor, non exiguia fuit, aequi bonique con/ulat, $6^{\circ}$ licet mendis erroribuisque fuis non careat; idcirco tempus oleumque omne periiffe exiftimare nolit. Contentus enim ero, $\sqrt{2}$ uni alterique modo naturae cultorumb commodi quicquam allatum effe, intellexero.

Ingrati fane immemorisque crimen fubircm, ni fingularia Viri praeftantiJjimi Allamandi, praeceptoris aeternums colendi, tam in me quam in libellum merita laudarem; qui non libri tantum evulgandi curam ullero fuscepit; fed etiam quaecunique alia buc pertinere videbantur, loco fuo tam tabulae zoologicae quam ipfi libello inferenda Jponte curavit: gratias itaque Viro degniffino debitas publice perfolvo, qui utrisque boc ipso non exigunm ornamentum addere bumaniffime voluit.

Caeterum duo funt quae Leclorem bumaniffimum rogata velim; alterum ne libellum inspeciurus, de una alteraque. illius parte, fed de totius infituti ratione univerfim, judicium forat; alterum ne eundem fupplementis expletum efje, vitio vertat. Quum enim duobus vel tribus abbinc annis jam abjolutus effet, interenque temporis varia praefan- 


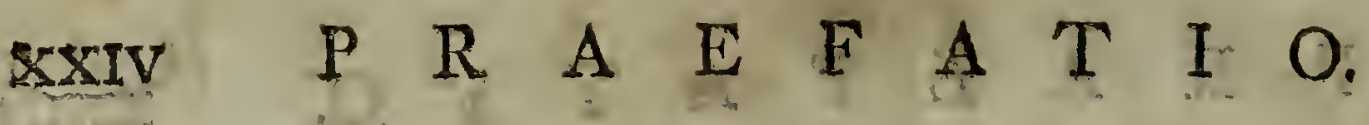

tiffimorum auctorum opera buc spectantia prodiiffent, nec fieri amplius poffet, ut quae ufui fcoprque meo apta erant, loco $छ^{\circ}$ ordine. $\int u 0$ infererentur ea addere, quam penitus oimittere malui.

\section{NDEX CAPITUM.}

$\mathrm{P}_{\mathrm{R} O \mathrm{u} u s r o .}$ Quae de Regni Animalis amplitudine generatim agit. . . . . . . Pag. I

Capux I. De animalibus per totum pene terrarum orbem disperfis, corrumque degenerationibus. . . . . . . . . 37

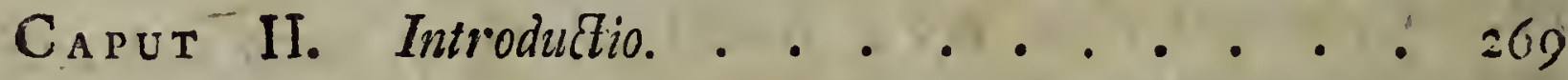

Pars Prior. Dequadrupedibus magnos, tam antiqui quam novic orbis, trallus tenentibus. . . . . $2 i^{2}$

Pars Pofterior. De animantibus magnos antiqui tantum orbis tractus tenentibus. . . . . 340

CapUT III. De quadrupedibus arttioribus plagis nowi antiquive miundi alligatis. $\cdot$. . . . 393

Caput IV. In quo gereratim de quadrupedum per tel. s. laris Jiperfficiem difperfone agitur, cui confectaria nomulla telluris bifforiam illuset. Strantio adduntur. 553

ADDITAMENTA.

P R O L U. 


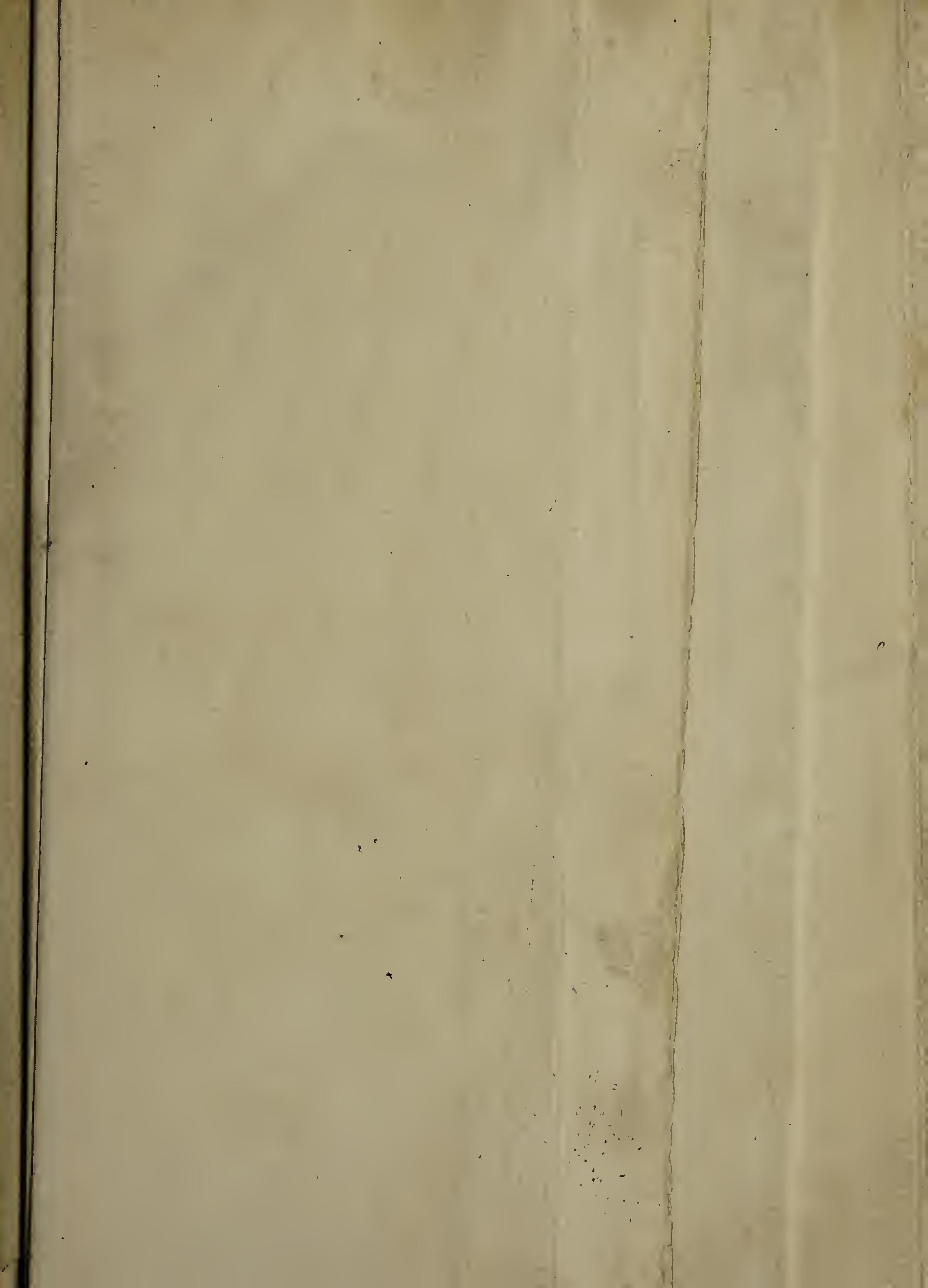









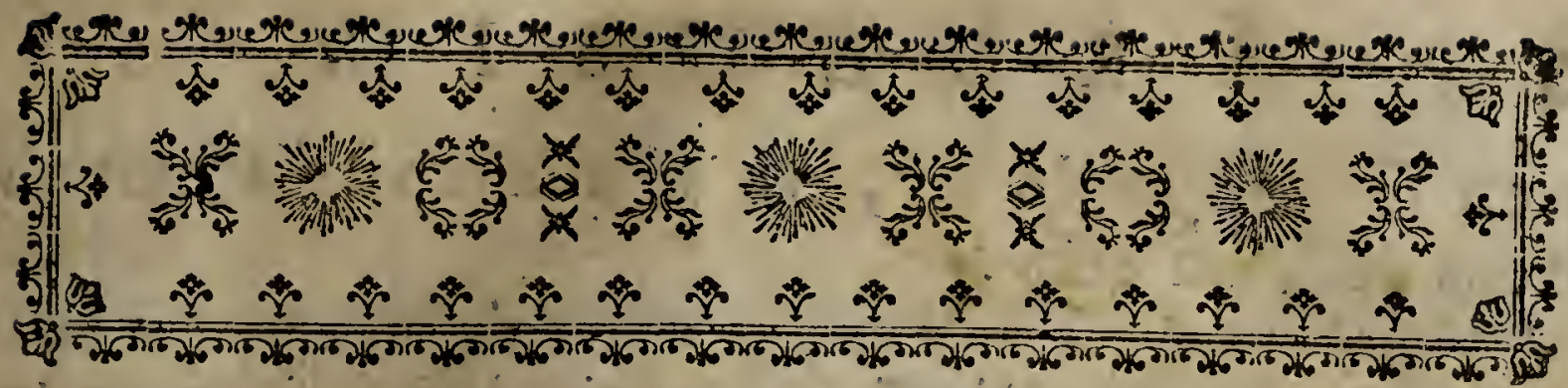

$P R O L$ U S I O,

Q U A E D E

\section{REGNI ANIMALIS}

AMPLITUDINE GENERATIM AGIT.

D. I.

Uisquis vel mediocri animi attentione univerfalis naturae dispofitionem contemplatur; is eundem maximi opificis fcopun, idem femper confilium, omnia, quoad per infinitam ejus fapientiam fieri poterat, rebus creatis explendi, deprehendet. Natura hac in re tam fui fimilis, tam fibi confentanea eft, ut, fola tantum neceffitate compulfa, vacua quaedam Spatia, in quibus, quae procreata funt, moveri poffent, \& idcirco certis locorum intervallis a fe invicem diftarent, reliquiffe videatur. Finge tibi elementa, \& fingula quidem ejusdem generis, figurae, molis \& foliditatis, tecumque reputa, num unum alterum apprehendere \& movere commode queat? Quodfi etiam fieri poffet; nonne ta-

men 


\section{2 \\ $\begin{array}{lllllllll}\mathrm{P} & \mathrm{R} & \mathrm{O} & \mathrm{L} & \mathrm{U} & \mathrm{S} & \mathrm{I} & \mathrm{O} \text {. }\end{array}$}

men femper cardo rei, vis nimirum vitalis motum ciens defutura effet?

Ø. II. Pone diverfae magnitudinis formaeque corpuscula, fic juxta fe pofita, ut majorum intervalla a minoribus, horum intercapedines a minutioribus, \& fic perpetuo velut tenore occupentur; fac immenfae huic, quae exinde pronafceretur, moli ab optimo rerum generatore vitam, feu quod idem mihi fit, univerfale motus principium ipfumque motum infitum effe: num inde univerfum confici poffe, quod cohaereat, \& incitatum continua perennique motione agitetur, tibi perfuadebis? Nonne corpora potius inter fe collifa, feque invicem prementia fibi obftare, omnemque primi impetus vim infringi tollique cernes? Nonne, exclufa omni locorum inanitate, licet omnia immenfa corporum copia redundarent, naturam nihilominus pigram, inertem \& quafi mortuam, \& ita aeternam quietem, fine effeetu caufam, immenfosque rerum creatarum acervos deprehendes, quarum abfentia \& praefentia juxta aeftimanda effet? Utque omnem penitus vacuitatem aliqua faltem fpecie ex hoc univerfo amoliaris; cogitationibus tuis, partes non fubtilifimas modo, fed fumma etiam elafticitate armatas exftrue, quid "his quaefo conficietur? Mirum quidem in modum compulfae $\&$ coarctatae rerum univerfitatem complebunt, fed extremus etiam elafticitatis gradus efficiet, ut ea ipfa corpuscula duritiem induant, eumque in modum comprimantur, ut flecti tandem \& detorqueri nequeant. 


\section{$\begin{array}{lllllllll}P & R & O & L & U & S & I & O\end{array}$}

Nullo itaque, quo recedant paululumque declinent, fpatio relicto, motus omnis ceffabit: \& hanc ipfam vim elafticam, elementis quam liberam concefferas, ullius utilitatis futuram effe, nequicquam fperabis.

6. III. Haec dubio procul univerfi hujus, licet vita motuque praediti, facies vultusque foret; aeterno fomno fopitum jaceret, nifi locum ctiam, in quo libere moveatur, addideris. Non itaque folum veri fimillimum eft, mundi effectorem molitoremque diverfiffimae magnitudinis, formae \& qualitatis elementa produxiffe, fed vacuis etiam, quae jam tunc adfuiffe crediderim, fpatiis fuum, quod pridem obtinuerant, dominium paffim vindicaviffe, ut, quascunque res condiderat, fic ex languore inertiaque fua excitaret.

ઈ. IV. Hic ipfe, qui rerum univerfitatem ex nihilo evocavit, non folum inane iftud (a) movendis corporibus aptum fore praevidit: fed hac etiam aptitudine inductus illas locorum vacuitates, corporum motui totiusque naturae vitae deftinare potuit voluitque. Quemadmodum haec omnia optime inter fe cohaerere tam rei evidentia, quam naturae nexus \& ordo docet; fic animo comprehendere non poffum,

cur

(a) Facile benevolus lector animadvertet, heic loci de vacuo difeminato, quod vocant, non autem de coacervato fermonem effe. De hajus enim natura difceptare idem foret, ac de lana caprina rixari. 


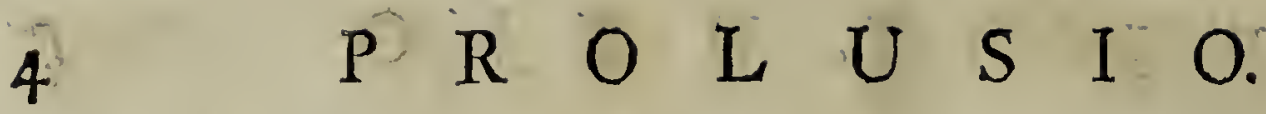

cur philofophorum nonnulli ejusdem elementi particulis omnia complere, quam locorum vacuitates, quaram tamen beneficio naturam vivere, quarumve abfentia univerfum hoc in otio hebescere \& torpere oportebat, concedere maluerint.

0. V. Quo autem agilior fertiliorque haec mundi univerfitas ex optimi parentis fui confilio effe debebat; eo pluribus eadem rebus creatis cumulanda ęoque ftrictioribus inanitas cancellis coarctanda erat; utpote quae aequa femper proportione, qua corpora accrefcebant, decrefcere, ideoque nec tolli penitus ac relegari, fed id tantum fpatii occupare debuit, quod corporum motioni fufficeret; quod antiquiffima philofophorum familia fatis fuperque perfpexilfe trito illo effato confirmavit: natura, inquiens, vaculum abborret. Quid enim his verbis aliud demonftrare vohuit, quam mundi aedificatorem tot modo res prodire juffife, croo per rerum naturam adeffe potuerunt. Eo enim fenfu, er mente quid axiomate hoc verius, quid naturae genitori convenientius effe ac pronunciari poteft? quum partim vacuum aretiffimis finibus. coercitum, partim immenfam corporum vim fupponat, ut idcirco legein, cui rerum auctor naturam devinxit, optimam fapientiffmamque contineat. Reipfa etiam tam cnormi, tam immutabili mundus rerum procreatarum copia redundat, quae attendentium fenfus cogitationesque cunctas abripere \& ftupore quodam opprimere videtur. Quod ut eo plenius percipias, hunc, quem incolimus, terrarum orbem, 
bem, qua potes, mentis acie perfcrutare; cujus fuperficiem contemplatus atmofphaeram perveftiga, quin vifcera rimare; dehinc ad quascunque alias mundi compages, quousque potueris, evade, \& omnia corporibus fcatere, omnia creatis rebus eum in modum referta effe demiraberis, ut vix folius rationis ope inanes quasdam hinc inde lacunas addere licuerit.

Ø. VL. Nec qui Newtoni, nec qui Carte/fi Eulerique placita aemulantur, uberrimam illam rerum multitudinem inficias ire poffunt; quamvis autem Anglorum illud decus vacuum hoc extra dubium collocaverit, id ipfum tamen anguftis admodum limitibus circumfriptum evincere, \& concedere poterat. Quum enim in eodem, ex Cartefii hypothefi, vortices agitentur, ex recentiorum vero fententia, innumerabiles folium catervae circumagantur; fieri non poteft, quin fingulis temporum momentis lucis radii perpetuo confluxu intermundia illa, licet intelligentiae humanae vim \& notionem fugiant, illuftrent \& compleant. Si vero hi ipfi radii, haec ipfa lux, nec $N$ twtono diffidente, ex corpusculis conftat; hinc immanes vaftasque illas inanitates corporibus obfideri, nec intervalla infignia, nec intercapedines, notabiles vacuas reperiri polfe conficietur; quorum quidem, quod lubens largior, infinita copia, propter fenfuum noftrorum hebetudinem aeque ac paucitatem, oculis fefe noftris fubducit.

$$
\text { A } 3 \text { D. VII. }
$$




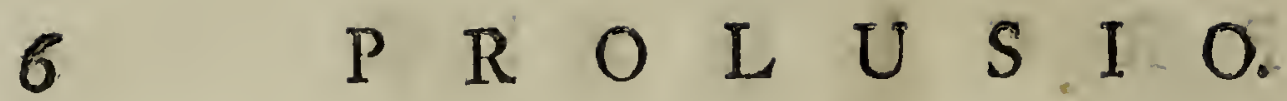

๑. VII. Quid! Si acerrimis vel mieroscopiorum aciem fuperantibus oculis, fi acutiffima vel leviffimum ftridorem accipiente aure, fi tactu, cui vel. minutiffima fubjacent, fi fexcentis aliis fenfibus, quorum quidem imagines nec animo noftro, ex notioribus folum rebus ignotas colligere \& concipere adfueto, comprehendere, nec ante oculos proponere valemus, praediti inftructique effemus; quid tunc nobis haec, quam matrem appellamus, terra? Quid hoc mundi, cujus incolae fumus, \& contemplatores, fyftema? quid hoc denique, cujus nec minimam partem nunc vel cogitationibus perluftrare licet, futurum effet? Conftituamus mente noftra praeftantiffmam quandam fubftantiam, praeftantiori intelligentia praeditam, acutioribus longe pluribusque fenfibus armatam, quibus ad ultimos creationis fines penetrare \& ita late longeque peregrinari poffet, ut fingula obvia percipere polleat: quantam, quaefo, quam ftupendam omnesque numeros \& limites excedentem rerum copiam, quam exquifitum earum ordinem, quam pulchre cohaerentem nullaque unquam vi interrumpendam feriem detectura, qua admiratione, quo ftupore attonita procreatorem veneratura efret?

6. VIII. Suppofitis ergo varii generis elementis, ex quibus immenfa corporum multitudo concreverit $\&$ adhuc coagmentetur, conceffoque ipform motui ac vitae necelfario fpatio, nunc ad fpecies formasque corporum diffuiffmumque ipforum numerum 


\section{$\begin{array}{llllllllllllll} & P & R & O & L & \text { U } & S & \text { I } & \text { O. }\end{array}$}

progrediamur. Quaero igitur: arbitrerisne, fieri potuiffe, ut rerum univerfitas in tam ftabili dispofitione fapientique ordine, quo nihil pulchrius eft, perfiftat, aeternis legibus àb opifice fuo fancitis pareat, motumque per multa annorum millia uno velut tenore fine ulla interruptione, (quod venerabundus demiror:) perfequi potuerit, fi ex atomis confufe permixtis, ex corpusculis incondite nec ordinate coacervatis expleta fuiffet?

§. IX. Pone, mundi aedificatorem, chaos illud poltquam produxerat, pulfu externo agitatum conciviffe, iftud autem poftea, fpatio quod motioni fufficeret conceffo, fusque deque habitum, eventui fortuito reliquife; fac, quod ex abundanti largiar, fingula elementa non organica folum, fed vita etiam praedita fuiffe; hisque ipfis, fi vifum tibi fuerit, novam aliquam vim, attractionem videlicet adde, \& reputa, utrum ex iftarum partium conglobatione \& confociatione corpora prodire potuerint, tanta venuftate confpicua, tam jufta omnium partium proportione decora, tam fingulari folertia \& machinatione admirabilia? An fieri potuiffe perfuafus es, temere ac fortuito eas pronatas effe fubftantias, quae, quod oculos mentemque adhibentes fugere nequit, $a b$ infimo pedetentim ad perfectiorem gradum jufto femper ordine progrediuntur?

6. X. Ponamus interim, cafu interdum ex rudi indigeftaque mole unum alterumque corpus confuxifie, 
xiffe, \& adhuc ita copulari, ut arte ftudioque ad optimas $\varepsilon u t \alpha \xi$ sas regulas formatum compofitumque videatur: idcirco tamen nec Buffonii fingularis dicendi lepor, nec infigne Mailleti ingenium planum nobis faciet, aut aliqua probabilitatis fpecie commonftrabit, qua factum fit ratione, ut vel arbuti vel pulicis fingulae, quae utrosque conftituunt, particulae, tam commode coaluerint, tamque decenter \& ordinate cohaereant, ut earum quaevis locum, qui ipfi debebatur, occupet. Multo minus efficietur, ut univerfum hoc, cujus abfoluta elegantia nos ftupore defigit, cujusque membra non tantum perfecte inter fe contexta \& dispofita miramur, fed in quibus fere ingulis tantum etiam efficacitatis eft, ut ad motum vitamque univerfi hujus fua conferant, tale, quale nunc eft, conflari nafcive queat. Accedit, nec naturali nec neceffaria rerum confecutione cogi poffe, ut ex partibus regularibus fine regula $\&$ ordine compofitis, regulare quoddam totum evadat. Nunquam enim, fi cubos cubis, fi globos globis, fi icolaëdra icofaëdris coagmentaveris, cubos $(b)$, globos \& icofaëdra inde formari cernes.

๑. X. Nunc oculos attollens eos praeftantifimo univerfae hujus naturae fpectaculo, quantum quidem per ipforum imbecillitatem rerumque multitudi-

nem

(b) Exifterat tantum methodus componendi ex cubis cubos, feil calbum alium, ii cuborum naturam confideres. 


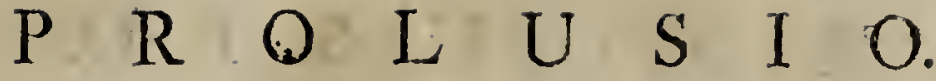

nem fieri poteft, imple, \& fcrutare, quo usquam loco vel minima perturbationis confufionisque veftigia inveniri poffint. Nonne omnia optime compolita, ordine fuo procedunt? Nonne, quod majus eft, plurima corporum vita motuque interno praedita, \& e contrario tot tantummodo fenfu privata deprehendis, quot ad illa fupplenda requiri videntur, quae vel exhalando vel excernendo vel quocunque alio modo vivis fubinde decedere fentis animadvertisque? Num id fine mente divina, quae, quem extruxit mundum, confilio providentiaque adminiftrat, fieri potuiffe, tibi perfuaderi patieris ? Delibera, quaefo, quam ftupendus neque animo usquam comprehendendus rerum fortuitarum concurfus requiratur, ut vel plantula vel homulus tam provide ac circumfpecte formetur, tantaque ordinis ac dispofitionis excellentia effingatur.

j. XI. Quantopere igitur eorum tibi fententia a vero remota videbitur, qui omnia, quae creata cernimus, eodem cafu fortuito exftitiffe \& forte invicem adglutinata effe $\&$ contexta fomniant, ut opus prodiret in quo incredibilis illa fapientia eluceat, \& fempiterna fefe rerum caufarumque feries, quae omnium cordatorum admirationem movet, fubinde excipiat? Quam venulam, quem musculum tam in furculis, quam animantibus fupervacaneum inutilemque pronunciabis, minus jufto loco pofitum invenies, aut deficere contendes? nonne cuncta aequiffima proportione defcripta, tamque folerter dispertita,

tam 
tam confiderate inftructa funt, ut, qui ad confervandam ornandamque rei naturam facit, effectus ultro certoque. fequatur?

§. XII. Quum autem fundamenti loco pofuerim, naturae legem effe, g, ut tot modo, quae vi„, ta motuque careant, corpora in rerum natura ad"fint, quot ad exfarcienda ea, quae viva feque mo"ventia amittunt, fuppetant": neceffaria rei con. fequentia efficit, horum multitudinem illorum copiam mirum quantum antecellere. Itaque tam aequitas, quam rei gravitas poftulat, ut qua differentia a fe invicem diftent, ante oculos exponam.

6. XIII: Ut autem a ratione fuscipiatur inftitutio, ante definire placet, quid per corpus motu vitaque: praeditum, quod organifaitum vocitant, intellectum velim. Eit autem non tale folum, cujus fabrica ad. certam normam conftructum, fed quod hanc etiam: ftrueturae fuae rationem continet, ut per infitas fibi vires intus excrescere, fuique fimile progignere valeat. Qua ex descriptione patet, varia \& lapidum. \& falium ad certas caeteroqui regulas dispofitionum genera hac ex claffe removenda effe. Non equidem nego, cryftallos, femimetallorum nonnulla, totum-que falium numerum certo quodam ordine compofita, nec fortuito partium concurfu permixta \& inter fe copulata effe; quin potius interiori aliqua virtute, quae particulas ejusdem generis allexit contraxitque, concreta effe; quod ita perfpicuum eft, ut oculis 


\section{P. R O O L L U S S I}

judicari poffit. Interea tamen alterum, quod in descriptione propofui, ipfis deficit, vis nimirum intrinfeca, qua extrorfum augeri fuique effigies $\&$ imagines producere polleant. E quibus liquet, jam dicta falia, cryftallos \& femimetalla, quippe quae ex fimilibus particulis coagmentata \& compacta videntur, faxis aliisque lapidibus propius ad corpora organica (fit venia verbo a naturae fcrutatoribus jamdum recepto) accedere, minusve ut exftiterint cafui acceptum ferre.

Q. XIV. Ex mea igitur fententia eae rerum conditarum claffes conftituendae effent, ut infimo loco informes planeque rudes, fecundo ardefrae juxta cum cryftallis, femimetallis, aliisque ejus generis formaeque lapidibus ponerentur. Sequentems vero falia occuparent; lycoperdum fubterraneum (Truffel) excipiat ; cui deinde plantae fuccedant, quae per polypos animantium claffi adnectantur $(c)$.

ఠ. XV. Quodfi tria haec a phyficorum affeclis fic nominata naturae regna uno quafi obtutu perluftraveris, facillime perfpicies, corporum vita motuque infructorun eam exfuperantiam effe $\xi^{2}$ copian, qune caetcra omnia mirum in modum antecellat.

9. XVI. Ex Adanfonii computatione oftodecinz mil-

(c) De qua gradatione Bennetus in confideratione naturae videndus - : $\mathrm{B} 2$ 
millia pluresque jam nobis plantae innoteseunt. De animantibus autem poftea verba facturus., indiciis non. dubitandis commonftrabo, plantarum numerum cum: illo, quem animalium genera fatis probabiliter explent, collatum, perexiguum effe minutumque. Quum autem Mineralium fummam vix aliquot centurias continere conftet: earum loco totidem millia adfumamus, eaque cum immenfa animalium plantarumque turba componamus, \& an cum minima harum, parte aequari conferrique poffint, periclitemur: non. ne fic hanc ad illam ut definitum prope ad indefi. nitum efre, experiundo edocebimur?

f. XVII. Quae quum ita fint, quin noftri in or: bis fyntagmate corporum organicorum acervi multo, pleniores. uberioresque illis lint, quae rudi indiges:taeque moli adfcribuntur, nullum eft dubium.:

6. XVIII. Quaeres fortafie : annon fieri potuerit; ut haec etiam, quorum jam nunc mentio facta eft, corpora, \& quicquid totum univerfumque hoc efficit, organicum factum fit? quam tamen quaeftionem ur inanem \& finc caufa motam judicabis, fimulatque organicorum corporum naturam diligentius perquifiveris; quippe quibus, quoniam perpetuis \& excretio, nibus \& exhalationibus fat multas fui partes amittunt, magna femper penus, unde, quae refarcienda funt, concinnentur, in promtu effe debet: ideoque hinc tam plantis, quam animantibus novae femper materiei acceffiones fiant, neceffe eft; quas in fui fub- 


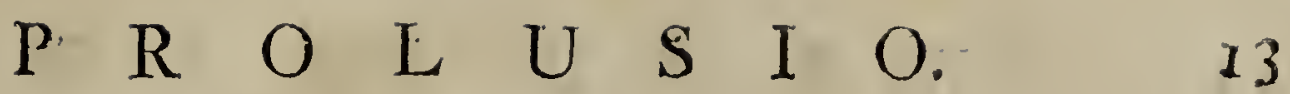

ftantiam convertant \& transmutent. Hac ipfa infuper partium fecretione, quae fingulis fere momentis corporum organicorum masfae ideo fubterduci confueverunt, quia nulli amplius iisdem ufui funt, novus corporum cumulus coacervatur, qui vitac motusque caffus indigeftae moli adnumeretur oportet: qua de caufa, ut natura corporibus minus, ordinatis vacua plene \& inanis fit, nunquam efficietur. Quae quidem opinio uberius deduci clariorique luci exponi poffet, quam tamen, quia me plus jufto a fcopo, quem mihi praefixi, avocatura effet, nunc intactam. relinquo; praecipue quum mihi demonftraviffe fufficiat, corporum organicorum. vim, \& amplitudinem reliquis immenfum quantum effe fuperiorem.

f. XIX. Si:vel fola metallorum genera cum plantarum turba contuleris, quantus jam harum tibi fuborietur exceffus!. octodecim millia plantarum, quae jam nofcitantur, (d) cum quadringentis metallorum (e) fpeciebus comparatae eandem habent rationem, ut 45 ad I. licet etiam fperandum fit, tempo: ris.fucceffu utriusque generis, numerum indagando duplicatum iri; proportio exinde quadrata oriretur, uti $\frac{2}{45}: I^{2}=2025:$ I quae tamen, fi metalla ad aliquam eurythmiae regulam compofita detraxeris,

ma-

(d) Adanfonius 18000 notas nobis plantas numerat; ignotarum-autem fummam ad 25000 adfeendere putat.

(c) Limnasus in editione Lugdunenfi, quae 1756 in lucem prodiit, 321. tantum genera numeravit. 


\section{4

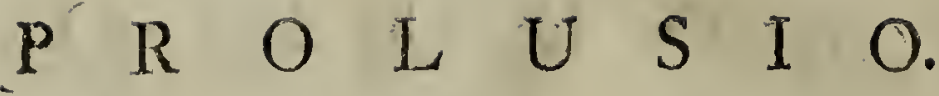

inagnopere increscet; eoque ipfo plantarum feries non exiguo incremento augebitur. Nunc ulterius progredientes eadem plantarum: animaliumque collatione utamur.

6. XX. Muscbenbrokius genera avium 600, pecorum terreftrium $45^{\circ}$, pifcium 600 , conchyliorum 600 , teftudinum $45^{\circ}$, amphibiorum $5^{\circ}$, infectorum aquis innatantium 5000 numerat, quae fummam $775^{\circ}$ efficiunt. Erxlebius $(f)$ eam iniit rationem, ut fugentium animalium 300, avium 2000, amphibiorum 700 , pifcium 2000, infectorum 15000 , vermium 5000 , genera, totamque fummam fatis probabilem 25000 conftituat.

Ø. XXI. Ipfe Mufchenbrokius datum a fe anima. lium, quae hic terrarum orbis continet, numerum jufto minorem effe convictus, eum poftea in phyfica majore ad 300000 genera extendit $(g)$. Subductos quoque tam ab ipfo, quam ab Erxlebio calculos inmenfum quantum ab illis fuperari, quos natura foecundiffima rertim parens pofuit, facili opera commonftrari poteft.

Singulas enim propemodum plantas aliquot faltem infectorum genera nutrire, experientia luculentiffme

tefta-

(f) Nat. Hift. T. г.

(g) Mufchenbr. Introduat. ad Philofoph. natur. Lugd. Bat. I 602. T. I. p. $x$. 


\section{$\begin{array}{lllllllll}P & R & O & L & U & S & I & O . & \text { if }\end{array}$}

teftatur. Roefelius ( $b$ ) foli quercui ducenta tribuit; falix dimidian fere ipforum partem pafcit. Quod autem in patulis majorisque molis arboribus obfervamus; probabiliffima etiam. analogiae ratione in minimae figurae ac fpeciei plantis ufu venire poteft. Ut. vero aequum me ratiocinatorem praebeam, cuivis plantae nec centum nec decem, fed quinque tantum animalcula concedantur, quoniam erucarum quaedam. diverfis plantarum generibus pafcuntur : quam incredibili tunc multitudine regnum, quod animale vocitant, redundabit? Ad 18000, quae jam notae nobis plantarum fpecies funt, fi 25000 adjeceris, quarum. in pofterum detegendarum Adanfonio fpes eft, fummam habebis 43000 . Si tamen cuivis quinque animalculorum genera addixeris, quae oculo inermi.cernere liceat, $2 \mathrm{I} 5 \mathrm{coO}$, numerabis, quibus vermium, avium, pircium, amphibiorum fugentiumque claffes adjunge, quae $215000+55000=270000$ efficient; quorum loco, Muscbenbrokio duce, rotundum numerum. ponere, \&, quum plantarum. arborumque cuivis quinque modo fpecies adfignatae fint, tuto fatis 300000 affumere poteris.

Q XXII. Cujusque animalis vel cutis vel crines, experientia tefte, unum quod minimum fit, genus tolerat. Solius hominis cuticulam. quatuor genera,

(h) Infecten beluftigung T. r. p. 270. Salix, uti Linnaeus in Pans fora InfeEtorum (Amoen. Acad.) docet, . 55, Prunus vero plus guam. 30 genera infectorum nutriunt. 


\section{I6

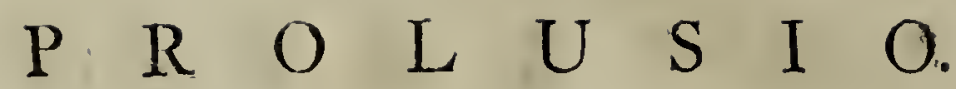

$\&$ fingulos etiam quadrupedes fua animalculorum genera alere, certum eft. Redius aves magna pediculorum mole laborare obfervavit $(i)$. Cetis fuperficiem amplae fatis magnitudinis infectum vexat. Sic Linnaeus $(k)$ in cyprino, Fiflerus in efoce $(l)$, Bafterus ( $m$ ) in cabeliavio (n) \& fturione, Kleinius denique, quod ejus, quam edidit, Herpetologia confirmat ( 0 ), in ferpentibus pifcibusque pediculos modo inferioribus ipforum in partibus, modo fub fquamis latentes offendit. Et quot alia infectorum genera magnam pediculorum copiam alunt? Sic exempli gratia fcarabaeum ftercoreum et Linnaei vefpillonem lingularis cujusdam fpeciei vermiculi $(p)$, quos acarorum nomine appellant, muscasque domefticas $(q)$, aeque atque apes $(r)$ animalcula quaedam, quibus interdum penitus contectae funt, infeftant. Sic polypi pediculis mortem ipfis contrahentibus onerati con-

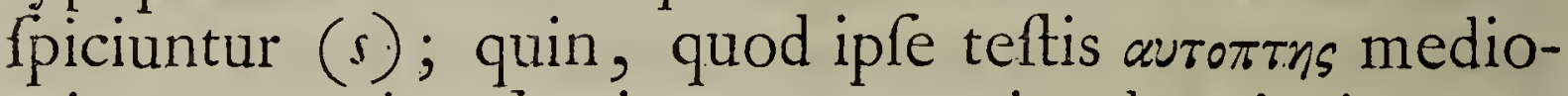
cri tantum microlcopio armatus animadverti, in aqua-

(i) Redi Opufculor. pars prior. $12 \mathrm{no}$.

(k) Fauna St:ec. p. $367 . N^{\circ} .1282$.

(l) Acta Hafniens. I75 r. p. 190 .

(ni) Baftori Opufc. fubfec. T. 2. p. I3\%.

(n) Gadus Callarias Linn. Syft. Ed. Xil.

(o) Tentamen Herpetologix p. I5.

(p) Roefels Infect. beluftig. T. 4. Tab. I.

(q) Winterfchmidts abbildung der Stubenfliege, in Ledsrmullers Vcrtheidigung. Nurnberg 1765 . 4to.

(r) Reaumur Mém. des Infect. T. V. Tab. 38.

(s) Koefel 1. c. Tom. 3. Tab. \& Schæffers Armpolypen des fusfen Waffers 1754. Tab. I. fig. Io. 


\section{$\begin{array}{llllllllllllllll}P & R & O & L & U & S & I & O\end{array}$}

rico pulice $(t)$ exigui admodum corporis animali, certa, quae ipfi propria videntur, animalcula deprehenduntur.

6. XXIII. Non itaque plus dixiffe crediderim, quam veritas patitur, ii iftum trecentorum millium numerum duplicaturus, fexcenta millia animalium genera dari contendam. Modum fortaffe omnemque verifimilitudinem copiam hanc incredibilem excedere exclamabis.

Sed fi indefatigatos Leewenboekii, Hooke/fi, Bonnetii, Ledermuelleri aliorumque Naturae fcrutatorum labores, quibus microfcopiorum beneficio in ipfa naturae arcana penetrare ftuduerunt, attente contemplatus fueris, numerum iftum nifi exiguum, tamen permodicum effe fatebere. Quem enim locum, quam arenulam, quas aquae guttulas animalculis vacuas invenies? Amoeniffimo Hillius fpectaculo fruebatur, quum in aquae pluvialis gutta putrefacta quinque animalculorum fpecies deprehenderet, quae fingulari dexteritate fe invicem corripientes devorabant ( $u$ ). Quanta infectorum aquatilium farrago ante Bometii, J'cbaeferi, Muellerique aetatem in omnium ignoratione verfabatur? Quantisque adhuc incrementis eorum copia fingulis prope diebus hoc praecipue feculo augetur, quo celeberrimi, acutiffmique inge-

nii,

(t) Monoculus Pulex Linn. Syft. XII.

(4) Hamburgs Magazin T. 19. p. 233. 
nii, viri inveftigandis detegendisque naturae arcanis occupantur.

6. XXIV. Quem unquam locum animantibus \& infectis praecipue inacceffum nominabis? Nonne Rulcbius \& Albinus, illa Batavorum lumina, in tubulis medullaribus offis cujusdam ex humano cadavere defumti chryfalidum folliculos $(v)$ invenerunt? Nonne infantium vix in lucem editorum meconium, $\mathrm{p}$ iusquam fames fitisque matris lacte depulfa fuit, vermes jam continet? \& quantus horum numerus aliorum animantium corpora incolit? Fafciola hepatica, (die Egel/cbnecke) ovium hepata arrodere Scbaef (rus, (w) hirudinem victum fuum perfaepe in pifcium branchiis quaerere alii doçuerunt. Nonne, qui Redi, Palla/ii \& Doverenii opera evolvit, obftupefactus immenfam vermium in hominum inteftinis viventium vim mirabitur $(x)$ ? Nonne eo magis mirum habebit, magnam morborum cohortem a folis vermibus originem ducere? cujus rei documentum fcabies, lepra \& phthiriafis efto $(y)$.

0. XXV. Poftquam animalium, quae praecipue microfcopiorum ope confipici poffunt, mentio allata eft

(v) Albini Annotat. Academ. Lib. 2. p. 20. \&c.

(w) Schat fers Egelfchneke 1753. 4to.

(x) Vide etiaun de his Linnaei Sylt. Nat. Ed. Xil. fub titulo Vermits. Intefinna.

(y) Murray Diff, de Lepra. Gottingae 17 G. \&. 


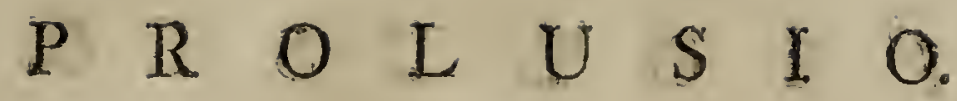

eft, officii mei duxi, nec foecundiffmum illum fontem, ex quo infinita ignotarm hucusque fpecierun cognitio hauritur, qui infu/ionis nomine infigniri folet, ficco pede praeterire. Ex aqua nimirum quibusdam vel animalium vel plantarum fegmentis, ut fic aliquamdiu macerentur, fuperfufa, pronafcuntur animalcuLa, quae ut comperta nobis cognitaque fint, folis mi: croscopiis acceptum referendum eft.

6. XXVI. Leewenboekins, aliique nonnulli toatur rae interpretes illa cum fpermaticis animantibus uno fere eodemque tempore obfervarunt. Nulla propemodum nec vegetabilis nec animalis fic appellati regni particula fpeciesque datur, quae in aquis putrefacta non integras iftius generis milliones edat. Buffonitus quidem cum. Needbamio ( $z$ ) plafticae cuidam, quanatura polleat, vi, feu, quod idem eft, cafui fortuito, cujus beneficio exftiterint, adfcribunt, animalium formam ipfis denegantes, fubftantias eas organicas effe ftatuunt; quae tamen neclibere, nec ex. arbitrio, fed calore coactae moveantur: quum e contrario \& Leewertboekius, \& poft illum tam Bornetus, quam Spallanzanius illas animalium claffi adnumerent, quae proprio fe lubitu quo velint, flectant agitentque, cibum quo vires firment., fumant, \& ficut caetera animalia, moriantur. Quros ultino loco nomi-

na-

(z) Buffun Algem. Hüif, der Nat. Vol. 2. p. 126 . 
navi, celeberrimi viri ea ex ovulis in aëre circumvolitantibus generari ajunt.

ఏ. XXVII. Quum, Spallanzanii praecipue auctoritate commotus, ea quam maxime ad animantium claffes referam, ipfius rationes primarias apponendas aequum cenfui ( $(a)$. . I. Infuforia nempe animaleula fentiunt, quoties humor, in quo vivunt, decrescat, ideoque vitae confervandae gratia tunc ima, quae tardius adficcari folent, petunt, eoque ipfo fenfu fe quodam praedita \& fupra plantarum naturam multum elata effe evidenter commonftrant. 2. Alta placidaque requie aliquamdiu fopita, licet nec ab alio quodam corpore excitata, nec loco fuo deturbata fuerint, fubito affurgunt, \&, velut vehementius agitata, aquis innatant, quod opinionem Buffonii, motum ipforum femper eundem effe adftruentis, penitus redarguit refellitque.

5. XXVIII. 3. Ultro citroque nantes, tenerrimas feminis adjecti \& aqua macerati fibras roftellis feu acuminibus fuis leviter tangunt: ex quo Spallanzanius probabiliter fatis colligit, animalcula ifta, quae locum fuum caeteroqui difficulter, nec nifi invita, mutant, quae in feminibus iftis latent, nutrimenta fibi neceflaria $\&$ quaerere $\&$ invenire.

๑. XXIX.

(a) Spallanzani Phyficalifclie und Mathem. Athandungen. Leipzig 1 $\geqslant 09$. 3te Abhandl. p. x20. \& fegq. 


\section{$\begin{array}{llllllllllllllll}P & R & O & L & U & S & I & O\end{array}$}

๑. XXIX. 4. Obftacula fibi obvia, quin fe ipfa quoque fic evitant, ut aliud alii dexterrime viam dare noverit. Senfstivam quidem e plantarum genere digiti appropinquantis tactui fe fubducentem folia contrahere videmus ; fed circumfpectius multo cautiusque haec animalcula in medio incitatiffimoque curfu declinare, retrogredi occurrentiumque impetus provide fubterfugere, meo ipfius teftimonio, fi opus eo fuerit, confirmare poffum.

g. XXX. 5. Curfus fui directionem raptim mutant, faepiusque adverfo quafi flumine natant. $\mathrm{Si}_{2}$ quod Buffonius ftatuit, folo calore ad motum concitarentur; quas, cur revertantur, retrogredianturque, caufas vir doctiffmus adferre poterit? Hanc potius eorum motionem aeque atque reliquorum animalium omnium liberam effe \& arbitrariam, nemo nifi praejudiciis obcaecatus inficiabitur. Hunc eundem motum liberiorem in animalculis etiam canis femini innatantibus crebriori animadverfione perfpexi, quae modo prorfum modo retrorfum euntia, quoties fibi occurrere videbantur, vias mutaverunt. Quumque ifta etiam ex arbitrio agere videantur; nonne pari jure animalium, quorum naturam ingeniumque monItrant, claffi adnumeranda erunt?

0. XXXI. 6. Integras corpusculisque fuis aptas partes artusque poffident, quorum forma, licet id Buffonius neget, dum vivunt, nec mutata permanet. Difertis Spallanzanius verbis teftatur, fingula- 


\section{2 \\ $P R O L \quad U S A O$.}

rem, qua corpuscula corum gaudeant, pellucidita. tem ipfi inteftinorun curatius contemplandorum an fam dediffe, quae bullulis globulisque itidem pellucidis fimilia, varie dispofita repererit $(b)$, (id quod polypis etiam proprium effe folet). In aliis enim ea in orbes circuinducta, in aliis fine ordine, in quibusdam plana \& aequabilia, in nonnullis vero coacervata confpexit. Cuncta denique exactiffme disquirens, tubulum quemdam album animadvertit, qui totam corpusculi longitudinem percurrens canali propemodum fintilis fuit, qui in lumbricis hominum alvum occupantibus confpici folet, qui nutrimenta procul dubio fuscipit \& fuperftua excernit. Quin majora quaedam in aliquibus inembra, membris rotiferi fere aequalia, ejusdemque ufus, corollam nimirum fibris fubtiliffimis, feu fimbria ornatam vidit, qua aquam concutiunt, \& fortaffe brachiorum loco iutuntur $(c)$ :

0. XXXI. 7. Tandem eadem ratione, qua polypi aliaque infecta aquatica pereunt'; 'vix Spillanzanius urinam is adfperferat, quim enecata conciderent, tnodicosque granuloruin acervos relinquerent.

(b) Wrisbergius in fatura de animalculis infuforiis p. I.3. hoc idem confirimat; quöd inea quóque affenfone approbare liceat, qui exiem fiepius obfervavi.

(c) Quum nulla membroram commutatio aut transformatio iftis in enimalculis locum habeat; ea, quod tamen Limaeus fecit, ra. Chạos aitribuenda efre, nunquan jerfuadebor. 


\section{P R O L U S I O.}

nunc praeter inteftina, membra, liberiorem motum, efculentorumque forbitionem ad comprobandam animantis naturam requiri potef?

0. XXXIII. Opponi quidem porfet : illam adhuc notam iplis deeffe, quam ad conftituendam animantis naturam quam maxime requiri, ipfe fuppofuerim; ut nimirum fui fimile progenerent. Adverfus quae tamen refpondeo : primo, etfinec armatus quidem oculus propter nimiam animalium exignitatem hucusque, utrum partus enitantur, nec ne, indagaverit; id nihilominus tamen, licet rei nos ratio fugiat, factuin effe potuit. Quis enim negare audebit, ea foetus quidem, fed fortaffis alio longe, quam qui nobis adhuc cognitus eft, animisque noftris comprehendi \& concipi potuit, modo edere? Ab initio enim perexiguum eorum numerum confpicimus, qui paulo poft fenfrm ita augetur, ut ftupenda tandem ipforum copia contemplantis oculos miraculo quafi defigat.

6. XXXIV. Nonne majori probabilitatis fpecie haec opinio gaudet, , iftam infufis aquis factam , fegmentoruin macerationem in caufa effe, cur ani-

, malcula ex ovulis, quibus inclufa latebant, eo ciو, tius excludantur"; prace altera illa, quam Nedbamius adduxit, , effici nimirum, ut ex folutis in aqua פ particulis fubftantiae caft componantur, quae tam

, admirabili ordine inter fe cohacreant, ut non ani-

") malculis folum fimiles, fed inter fe etiam acquales

" paresque fint". Deinde miulta numerari animalium

Eone- 
genera, certum eft, de quibus adhuc parum contat, an \& quomodo fobolem propagent; quae tamen idcirco ex animalium claffe neutiquam ejiciuntur, fi modo reliqua omnia adfunt, quae animantis naturam conftituere folent.

D. XXXV. Quis unquam dixerit, quomodo RoeSelii proteus (d), Bakeri ratifer (e), \& animalcula, quorum Hillius quinque fpecies in refide aqua pluviali confpicatus eft, propagentur? Quis ea, quorum origo ignoratur, idcirco ex animalium albo delebit? Priusquam Swammerdamius utriusque fexus in cochleis conjunctionem, Realmurius inufitatum fingularemque, quo apbides progenerentur, modum, Muellerus in praeftanti vermium in aqua dulci viventium defcriptione mirabilem Nä̈dum procreationem inveftigando, detexerunt; nemo unquam adduci poterat, ut beftiolas iftas vel progigni, vel ea, quam praeftantiffimi illi viri obfervando expifati funt, ratione propagari putaret.

๑: XXXVI. Quid? fi infuforia haec animalcula, haud fecus ac apbides volvoxque Linnaei globofus, jam ab initio gravida exifterent, \& fine coïtu, qui adfpectu noftro percipi poffet, foetus eniterentur? \& fac,

(d) In partis IIl. tab. ulima operis de infectis, quod fub titulo Infecter boluftigungen edidit.

(e) In libro, quo microscopium, quod ad faciliorem ufum adaptavit, defcripfit pag. 94 . 


\section{P R O L U S I O. if}

fac, haec omnia nulla effe, quia nullis adhuc obfervationibus haec animalia fui fimilia edidiffe, confirmatum eft : num exinde coges, omnino fieri non poffe, ut in fingulis plantis \& animantibus, quin utrorumque potius in germinibus, $a b$ initio varii generis ovula eo usque inclufa latitent, donec putredine fota excludantur? Paulo ante jam dixi, infantum in meconio vermiculos reperiri, cur horum originem exinde derivandam effe dubitemus? Quot nunc argumenta undique naturae venatores conquirunt, quibus germinum praeexiftentiam \& evolutiones confirmare tentant? Quas qui tuentur, prima fane ovula aeque minuta, atque illa, ex quibus infuforiae animantes prodeunt, affumere coguntur. Quaenam fubeft ratio, cur non in his etiam, ficut majoribus in beftiis, germina ponenda fint, in quibus animalcula haec abdita delitefcant? Num mundi etiam procreatori quaedam ardua, quaedam exigua effe, tibi perfuades? Nonne pari facilitate eademque arte hominem atque ephemeron, ad quod propter parvitatem vix attenditur, effingit? Si quadrupedum germina jam ab initio matribus fuis, cur non \& illa beftiolarum, fimili ratione, plantarum animantiumque partibus ineffe potuerunt, quae quidem ex caufis minus nobis cognitis motus fenfusque expertia latebant, poft autem partibus, quibus involuta continebantur, refolutis excluderentur?

6. XXXVII. Caufas denique fpeciofas nullas habeo, cur fieri poffe negem, animalcula illa a matri- 


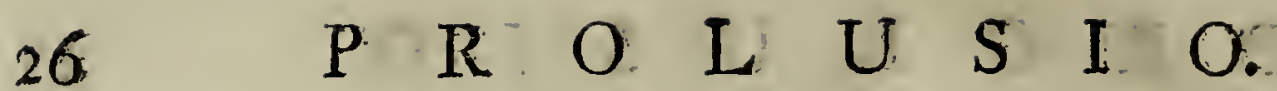

bus mufcularum generi adnumerandis, quae ovula fua infufionibus immiferint, enata effe? Hae quum pror cul dubio non eximiae folum parvitatis, fed infuper etiam pellucidae fint, \& in elemento ejusdem pelluciditatis, aëre puta, vivant; non mirum cuiquam videbitur, fi oculorum noftrorum obtutui magis, quam. foetus eorum fubducuntur. Quid obftat, quo minus: his minutis corpufculis per anguftiffimos aditus, a quibus reliqua majora paulo infecta ómnia excluduntur, penetrent?

Et quoniam a vero non abhorret, ipfarum prolem in mufcas matribus aequales transmutatum iri, cujus corpora chryfalidibus fuis longe fint pellucidiora; exinde facile intelligi poteft, qui fiat, ut magnum interdum infuforiarum beftiolarum agmen fubito evanefcat.

6. XXXVIII. Licet interim natura in proferendis animantibus tam foecunda fit, tanique diverfa ipforum gignendorum ratione utatur, ut ejus ubertas nec exhauriri, nee mente comprehendi queat; nunquam támen neque animo concipere, nec perfuaderi posfum, ex diffolutis in aqua plantarum particulis, corpora unquam organica confectum iri, feu, quod fere per-: inde eft, partes aliquas cafu fortuito combinatas animal quoddam effecturas effe. Ponamus interea, verum effe, quod omnium hominum fidem excedit, Needhamii virtutem plafticam ex plantarum atomis animalcula compofuiffe, ipfe tamen eadem, quoniam pro lubitu locum mutant, utque jam dictum 


\section{P.R O L U S I O.}

eft, fenfu aliquo praedita videntur, animalium claffi accenfet.

§. XXXIX. Ut breviter omnia ftrietinque dicam, ille, qui fubftantiam recte difpofitis artubus caeterisque omnibus, quae animanti propria fcimus, ornatam ideo de animali régno dimovet ac depellit, quod ortus ejus rationem nefcit; idem mihi facere videtur, ac fi gravitatem, quoniam naturam ejus animo affequi non poteft, negare velit.

Q. XI. Nunc ad propofitum revertens, has quoque beftiolas infuforias, quod ex adductis jam rationibus jure fieri poteft, animalibus adnumeramus. Sed quam immenfis, quam inenarrabilibus hoc ipfo claffis eorum incrementis augebitur? Haec enim acceffio, quae vix percenferi poteft, tanta eft, ut plantarum numerum mirifice vincat. Singulis quidem \& plantis \& animantibus fingula jam animalia, quibus infeftentur, conceliimus : horum vero fummam debito longe citeriorem affumi, experientia docet.

๑. XLI. Qua duce in plerisque infurionibus tria, fex, imo viginti animalium genera deprehendi. difcimus. Sex genera Foblotus $(f)$ in aqua foeno fuperfufa; tria Spallanzanius in ea, qua triticum turcicuin

ma-

(f) Joblot Obfervat. d'itit. Nat. faites avec le Microsc. I 6 . D. 38 \& $39:$ 


\section{P. R O L U S I O.}

maceravit $(g)$; rex Joblotus in alia, cui oftrea innatat (b) ; viginti \& amplius idem in aqua quercus: cortici quam affuderat, confpexit (i). Iteratis infuper obfervationious cognitum eft, ex vetere foeno. \&s quercus cortice longe alias prodire fpecies, quam: ex gramine corticeque recentius delibrato: $(k)$. Itaque hac etiam in parte, velut ubique locorum, natura, communis omnium parens, tam variam in proferendis.rebus creatis, tamque multiplicem fe exhibet, ut nec animo comprehendi, nec fufpicione immenfus. earum numerus attingi queat.

Ø. XLII. Des itaque quibuscunque \& plantis \& animantibus duas tantum beftiolarum iftarum fpecies, quam innumerabiles catervas, quam incredibiles greges inde coacervabis? Sexies centum millibus adde tria \& quadraginta millia; quae fi duplicaveris, I286000 animalcula numerabis infuforia; quibus fi: reliquorum etiam animalium copiam adjeceris, erant autem numero 600000 , fumma propemodum ad duos, milliones adfurget.

f. XLIII. Sed cave, tibi perfuadeas, omnes nunc fontes, ex quibus novae acceffiones redundent, exhau-

(8.) Spallanzani l. c.

(h) Joblot 1. c. p. 20.

(i) Joblot 1. c. p. 76 .

(k) Micrographia illuftrata, by G. Adams London $\times$ I77r. 8vo.. P. 347: 


\section{P R O. L U S I O. 29}

hauftos exaruiffe. Scaturiginis enim loco vaftum fe. tibi mare aperit, quod animalium vi, quam continet, ita terreftrium copiam vincit, lenta velut viburna cupreffi. Maris ambitum fi computaveris, illud duas circiter orbis noftri partes occupaffe, continenti unam tantum reliquiffe, ideoque propemodum terra duplo majus effe invenies. Quum vero, quod admodum veri eft finile, fic fe animantium genera, uti domicilii fui magnitudo, habeant: eo ipfo probabili fatis ratione, quantus fit maris incolarum numerus, colligi poteft.

6. XLIV. Multo major illorum, qui in terris, quam qui in mari aluntur, animantium copia nobis innoteficit. Conftat enim, omnem quadrupedum cohortem, totam alitum fpeciem, pleraque infectorum ac vermium genera, nec exiguum pifcium, qui nobis cogniti funt, numerum, fluviorum \& dulcis aquae lacuum habitatorum, eorumque omnium animantium, quos novimus, perpaucos effe, qui mari nutriantur. Quas folo microscopiorum beneficio beftiolas cernimus, quarumque fummam jam ante dedimus, nonne omnes in plantis, in animantibus terreftribus, $\&$ in aqua, corporibus in terra nais affufa, vivunt?

0. XLV. Subductis igitur aliquot maris animalium millibus $a b$ I 886000 fumma, pelagicorum gregum numerus hoc fatis probabili, ut mihi quidem. videtur, modo erui porfet ac definiri : animantium 
'terreftrium genera, demtis 86000 , quae mari innatare concedamus, fint I 800000 : quia vero fpatium, quod mare occupavit, terra continenti duplo majus eft, ejus etiam incolarum numerus duplicetur, qui 3600000 genera conficit. Maxima itaque cum veritatis pecie omnium animalium fummam in quinque millionibus $6^{\circ}$ quadringentis millibus confiftere autumo.

6. XLVI. Hanc autem rationem nec verbis exaggeratam, nec plus jufto elatam effe, obfervationes conteftantur, quae fatis evincunt, pelagum eadem animantium ubertate oppletum effe, ac terra, in qua nihil nudum, nihil inane a natura relictum videmus. Si quae Hillius jam fupra laudatus crebra animadverfione perfpexit, confulueris, ftatim conviEtus fatebere, interiores etiam algae, plantarumque marinarum partes animalculis fcatere. In fuci enim gelatinofi foliis infecta vir acutiffmus microscopii beneficio, roftrum in imam folii medullam inferentia, vidit, ulteriusque inquirendo, alia minoris fpeciei in mediis iftis foliis habitantia deprehendit animalcula, guorum rapinis illa pafcebantur; eoque fine ex latebris fuis eruebantur.

Sic aqua oftreae tergis inclufa beftiolis mirum quantum redundat; fic infectorum \& praecipue onifcorum marinorum aginina, ut mare colluceat, efficiunt.

6. XLVII. Et qui praeftantiffima Baferi, Donati, Marfiglii, Ellifizque opera infpicit, inexhauftos hac in re mavis thefauros obftupefactus demirabi- 


\section{P R O L U S I O.}

tur. Baftero una aquae marinae guttula tres lucentium animalium fpecies exhibebat $(l) ; \&$ in nominati opufculi fui tabula quarta duodecim infectorum genera in fertulariis quibusdam marinis ipf obvia depicta dedit, \& pag. 32. teftatur, fi cunctas, quas oculo armato invenerit, maris beftiolas effingendas curare voluiffet, harum copiam, numerum a fobloto allatum pleno modio fuperaturam fuiffe. ,, Mare enim, פ, addit vir clariffimus, prae aqua dulcirlonge majori , animalium multitudine effluere, obfervando didi$\Rightarrow$ ci $(m)$."

ઈ. XLVIII. Pifcium, quos cognitos habemus, fe* re omnes e profunditatibus nando ad fummum maris fefe extollunt. Sed quis eorum multitudinem percenfere fuftinet, qui vel veficis deftituti, vel aliis ex rationibusfundo adhaerentes; noftrum oculorum fenfum penitus effugiunt, \& nifi forte fortuna interdum fub hominum afpectum veniunt? \& quis unquam fperare poterit, fore, ut infinita illa belluarum infectorumque in maris imo viventium, nec unquam fortafre $e$ voraginibus fuis affurgentium, turba aut nofcitari aut dinumerari queat; quam natura; quanta quanta fit , perpetuis quafi vinculis maris profundo adftrinxiffe videtur? :

\section{XIMX.}

(l) Bafteri Opufc. fubfeciva. T. r. p. -32 :

(m) De collucente aqua marina conferatur etiam Frifflini- deferiprioth centis onifici marini, quae in allgemn Magazin Tom. V. germanice vers fa legitur ; \& Adanison. Voyage au Sénégal p. I5. 
1. XLIX. Nunc explicatu facile erit, unde tot tam inufitatae minusque interdum notae figurae ftructuraeque corpora, in montibus aliisque locis nonnunquam obvia; lapidibus expreffa \& obdueta, ortum trahant, quorum archetypa nemo adhue viva unquam vidit ; quae tamen $V$ oltairius a ludibunda natura effe progenita temere fatis \& ridicule tradidit.

Quis enim dubitat, ex illorum ea animantium clasfe effe, quae maris caeteroquin abyffo: adfixa, vel fluctibus vel terrae motibus, vel alio quodam cafu in terram ejecta, lapidum fenfim duritiem induerint? Beftiarum fic pelagicarum, licet maxima ipfarum pars nos lateat, rationes tamen fat probabiles nunc fubduci poffe, crediderim.

ø. L. Univerfum maris fundum corallia partim, partim plantas aliaque organica proferre corpora, Marfiglius ( $n$ ) extra aleam pofuit. Thefauros igitur naturae parens in oceano adaperit, qui innumerabilia animantium genera continent, quae, mea quidem fententia, caeteras propemodum omnes res conditas \& mirabili copia, \& infinita varietate immenfum quantum antecellunt. Quam exiguus fit belluarum marinarum numerus, quae certis tantum temporibus ad pelagi fuperficiem fe attollunt; quam raro Microcosmus (o), multaeque conchyliorum

(n) Hirt. Phyr. de la Mer.

(o) Pontoppidan 'Naturl, Hift. van Norwegen T. 2. pag. I394. 


\section{P R O L U S I O.}

fpecies in fummo maris fe confpiciendas praebeant, nemo phyficorum ignorat. Quibus omnibus ad unam fummam relatis, calculos paulo ante adduetos debito juftoque longe citeriores confectos efle, cuivis apparebit. Animalia illa, quae breviter quidem jam perftrinxi, quorum tamen nihilo fecius copia vix comprehendi poterat, vel terrae tantum plantarumque e terra natarum incolae funt, vel in aqua vivunt, quae innumerabilibus non animantibus, fed animantium generibus undique expleta eft.

ઈ. LI. Ex quo perfpicuum exploratumque fit, fummum fummi creatoris finem effe vitam, aut uti Bonne-" tus recte indicat, naturam omnia fua confilia, omnem.curam eo contuliffe, ut animantibus cuncta referciret. Quibus quum terra, quum aqua fcateat: nec ipforum opinio a fide abliorret, qui reliquis etiam elementis, aëri nimirum \& igni, fuos habitatores tribuere audent. Ardua quidem fibi fumere videntur, qui ignem etiam animantibus habitabilem ftatuunt; quum nulla pene res viva innotescat, quae omnium illi rerum confectori confumtorique refiftere, aut fine maximo faltem dispofitionis, internaeque conftitutionis fuae detrimento, penetrabilem ejus vim perdurare polleat.

0. LII. Vero autem plus quam fimile eft, tenuisfimis corporibus infecta, quae propter fuam ipforum aërisque pelluciditatem oculorum fenfum fubterfugiunt, in atmosphaerae noftrae regionibus domicilia fua habere. Nonne formidolofus ille vermiculus, quem Linnaus furia infernalis nomine infigniE 
vit, $(p)$ quique homines, intra horae quadrantis $\mathrm{pas}^{\mathrm{s}}$ tium, enecare fertur, ex aëre decidit? Nonne alia animalcula, quae tot plantarum fpecies rubigine \& vulnerant. $\&$ exedunt, auras.incolunt? Quin, quod farris etiam fegetes tam luctifera interdum clade pervaftare \& exinanire folent infecta, atmosphaerae noftrae cives effe, ex: iteratis praeftantiffmi naturae fpeculatoris obfervationibus novimus, qui nobilitatem non tam, qua ortuseft, generis profapia, qua multas infignes familias complectitur, quam affiduo patriae humanique generis commodis \& utilitatibus \& ratione \& experimentis ferviendi fludio metitur (q). Cujus utinam praeclarum exemplum omnes ejusdem generis viros ad humanitatem humanioresque artes excolendas exftimularet!

0. LIII. Non itaque opus eft, ut ad aniles de ranarum, pifciculorum, infectorumque imbribus fabulas. confugiamus. Animantibus enim, quorum multitudo humanam pene fidem excedit, atmosphaeram jam: featere, exinde etiam colligi poteft, quod aër tam terrae marisque, quam omnium, quae in utrisque reperiuntur, rerum exhalationibus alitur, quae commixtae acervatim confufaeque omnis generis animantibus \& receptaculum \& victum praebere facillimepoifunt. Quis praeterea in animum unquam inducet, mundi opificem, cui vel fexagies centenis millibus. $a^{-}$ nimantium generibus orbem hunc oppleviffe placuit fpatium reliquiffe vacuum, quod vel centies mille cu-

bicas

(p) Amoenit. Academ. T. 3.p. 322.

(2.) De Munchlhaufen, vide ejus Houssyater. T. 1. kom Mehlthave; 


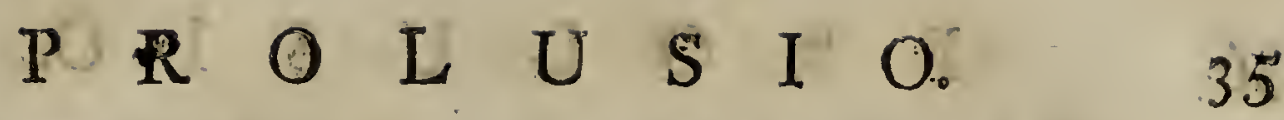

bica milliaria fuperat? Nonne hoc ipfo fecum pugnaviffe, a fuisque confiliis in difponendo rerum or dine difcrepuiffe videretur? cui tamen rei experientia refragatur. Num ergo, huic etiam elemento parem corporum motu fenfuque praeditorum copiam, aequali fpatiorum proportione adfignaturus, probabilitatis me fines ac terminos egredi, jure argui potero?

§. LIV. Ex quibus omnibus neceffaria confecutione conficitur, primo, naturam, quantum fieri potuit, omnia corporibus organicis expleviffe; deinde, vita motuque carentium acervos iis multo inferiores effe, qui fenfu motuve gaudent; quippe qui, ex Phyficorum rationibus, multis illos millionibus vincunt; \& adhuc fub judice lis eft, an dinumerari certisque unquam limitibus definiri poffint?

0. LV. Quot ergo funt illorum, quae nobis innotescunt? Quousque in immenfae hanc profunditatis voraginem cognitione noftra penetramus? In duodecima Linnaei naturae fyftematis editione 5998 animantium genera, quibus nomina impofuimus, percènfentur. Quibus fi illa, quae Buffonius, Pallas; Muellerus, Goezius, aliique naturae venatores celeberrimi poftea defcripferunt, addideris, numerum iftum aliquot centuriarum acceffione augere poteris, \& haec tota illorum fumma erit, in quibus contemplandis defcribendisque hiftoria noftra naturalis nunc occupatur. Immenfam itaque regni animalis regionem, quae nobis.nicog. nita eft, cum tantillo, quod adhuc perveftigavimus, spatio confer, \& quantum fit , quod nefciamus $(r)$, 


\section{6 \\ $P \quad R \quad O \quad L \quad U \quad S \quad I \quad O$.}

delibera : annon minima interdum aquae gutta omnem, qua fuperbimus, fapientiam profternit? Tamlento tardoque gradu noftra rerum cognitio procedit, ut vix primo paffu facto, nobis addubitantibus retrogrediendi magis, quam progrediendi fit animus. Nihilo tamen fecius. erecto animo confidentique pectore eruditum orbem peragrantes, qui ultimis duobus. in feculis hac in naturae fcientia progreffus faeti fint, nobifcum reputemus : annon aliquot millena animantium antea nobis minus cognitorum genera in iisdem detecta novimus? Nonne certiffima nobis exinde fpes injicitur, fi naturae interpretes eximia regum principumque liberalitate adjuti incenfique fic perrexerint; fore, ut fequenti forte feculo plures ex latebris fuis beftiarum fpecies in lucem protrahantur, quam per quinquies. mille, qui jam praeterlapfi funt, annos, factum eft?-

6. LVI. Et cur huic naturalis fcientiae parti inveftigandae, quae tamen maximi momenti eft, non accuratiffima diligentia exquifitiffinaque cura impenditur? quum in corporum verfetur comtemplatione, quorum ftructura \& dispofitio quam proxime ad homines accedit, \& ex ipfis, quos hucusque inveftigavimus, animantibus, non exigua in nos commoda redundent?

Q. LVII: Illae autem, quas fola microscopiorum ope. contemplari licet, beftiolae, nonne certius longe meliusque innumerabilibus aliis, quae tam calamo, quam. viva voce adhuc propofita funt, argumentis. ac demon, ftrationibus probant, rerum effectorem effe, qui ex nihilo cuncta produxit, ejusque fapientiam aeque ac potentiam nullis unquam cancellis circumfcribi poffe? 


\section{S P E C I M E N \\ ZOOLOGIAE GEOGRAPHICAE, QUADR UPEDUM}

DOMICILIA ET MIGRATIONES:

\section{SIS TEN S.}

\section{A P U T I:}

De animalibus per totum pene terrarum orbem diperfis, corumque degenerationibus.

$$
\text { S E. C T I O I. }
$$

2. I. I.

Si a feptentrione ad aequatorem, \& hinc ad regio $D$ nes, auftrum verfus jacentes, necdum fatis nobis cognitas, quousque licuerit, progredieris : unum femper idemque animal, hominem puta, obvium. habebis; donec intolérabile octuagefimi: fecundi, tertii, reliquorumque graduun frigus. fanguinis circulum fpiritumque ipfi penitus intercludat. Qui licet rationis auxilio reliquas propemodum res creatas omnes ditioni fuae fubjecerit; hanc tamen tam mirificam enormemque praerogativam nulla fibi arte acquirere poterat; féd uni rerum omnium effectori acceptam referre debet; utpote qui naturam ejụs fic formavit ac dispofuit, ut conceffa fibi liac facultate uti recte fungique poffet. 


\section{SPECIMEN ZOOLOGIAE}

6. II. Quod quaefo quadrupedum, quod animantium genus, licet caeteroqui prope fatis ad hominem accefferit, invenies, quod pari ratione dictis in regionibus duret, \& ubique locorum tam fibi fimile maneat, ut eam femper formam eamque fpeciem, quae ab aliis omnibus fecerni internoscique poffit, referat? Annon incredibile portentique fimile videtur, idem corpus, eundem fanguinem tam aeftui, qui ad Senegalli ripas vini fpiritum bullientem reddit, quam frigori, quod fpiritum vini rectificatiffimum, quin ipfum fere hydrargyrum gelu conftringit, quale circa Hudfonis Davidisque freta, quale in Kamfchadalorum oris, Afraeque boreralis finibus faevire conftat, refiftere, motumque fuum cum ipfa vita fervare polfe? Quis quaefo tam distantes inter fe caloris frigorisque gradus, quos intra tamen homo vitan fpiritumque ducere poteft, ad thermometri fcalas dimetiens, eorum differentiam inufitatam, imo ftupendam effe, inficiabitur?

5. III. Extrema, quae nobis ex Gmelini obfervatione ac dimenfione, algoris vehementia conftat, in qua homo tamen communi vita frui poterat, anno I 735. Jenifeae, quae urbs fub quinquagefimo octavo latitudinis, \&, fi a Ferri infula computandi initium feceris, fub centefimo decimo longitudinis gradu jacet; dominabatur. Pawizus quidem in disquifitionum de Americae incolis factarum capite, (a) quod de Esquimaviis agit, argentum vivum jam in fexagefimo octavo ejusdem latitudinis gradu, perfaepe gelu concrescere

per-

(a) Recherches philorophiques fur les Americains par Mr. de P. i Berlin 17.72 . 


\section{G E O G R A P H I C A E.}

perhibet: unde vero id hauferit, cujusque auctoritate hanc opinionem fulciat, ficco pede praeterit. Cranzius id quidem de fpiritu vini, minime vero de hydrargyro adfirmat: hoc enim quoties frigore durescit, Fahrenheithiana thermometra ad trecentefimum usque trigefimum, ulterioresque gradus fubfidere confueverunt; quod ex Bramnii obfervatione, (b) cui fub hoc demum algoris gradu argenti. vivi congelatio fucceffit, discimus. Tantae eruditionis, tantique ingenii viro, qualem Pawius fe praettitit, qui res obvias ad fanioris philofophiae regulas acutiffime perpendit, refragari quidem non audeo: interim tamen, quorum teftimonio fretus ea fcripferit, addere debuiffet. Haud itaque vitio mihi vertet, fide rei veritate, donec eam probaverit, fubdubito; quum in tanti momenti rebus vel ip-fum Newtonum, ut exactam orbi litterario rationem: reddat, obftrictum effe crediderim, nifi contradictionis, vel denegatae faltem affenfionis periculum adire velit; quo tamen confilio nemo commentarios fuos conficere, lucique publicae credere folet.

0. IV. Interim Boerbavium (c), frigoris gradus hominibus mortem adferentes longe minores, quam par erat, determinantem Pawizis merito carpit. Quod-r fi enim alcohol, quoties frigore ad fexagefimum usque Farenheithiani thermometri gradum compreffum fuerit, durari concedimus; attamen algor qui Jenifeae in colas ambuffit, altero tanto intenfius faeviit, nihilo tamen fecius hominum vitae pepercit ..... o vo

(b) Braun Diff. de admirando frigore artificiali, quo mercurius congela tius eft. Petrop. $17,60$.

(c) Vide Boerhav, Chemo. 


\section{0 SPECIMEN ZOOLOGIAE}

ఏ. V. Algor hic (d) in ipfum Januarii menfem incidebat, \& hydrargyrum a thermometri dicti puncto, qui ‘ali ammoniaco cum glacie permixto tribui folet, ad centefimum vigefimum fextum usque frigoris gradum depreffit, ejusque vehementiae fuit \& asperitatis, ut pafferes graculosque in ipfo volatu enecatos dejiceret, \& quicquid liberiori in aura gelu conftringi poterat, in glaciem converteret. Concedo quidem, durante acriori hoc rigore, homines fuis fe domibus continuiffe: interim tamen nemo negaverit, eosdem interdum, negotiorum peragendorum gratia, ut foris \& fub dio verfarentur, coactos fuiffe, tamque immoderatas hiemes fine noxa toleraviffe.

f. VI. Non poffum quin hoc loco adferam, quod experientia áliis etiam in oris faepe teftatur, caloris nimirum frigorisque temperiem e graduum latitudine, fub qua regiones fitae funt, dijudicandam non effe, quum jenifeorum urbs, licet duobus gradibus a feptentrione, quam Petropolis, fit remotior, hanc tamen centum ferme fcalae Farenheithianae gradus algore eoque intenfiffimo fuperet: Middletomus autem in Hudfonis freto, terras Euronotum verfus jacentes mira interdum hiemis clementia frui, obfervavit; quae omnia in mappae zoologicae descriptione \& illuftratione, ubi modum etiam, quo Hallejus in dimetiendo calore ufus eft, addere mecum conftitui, fufius explicabuntur.

○. VII. Memoratu interim dignum videtur, hos frigoris impetus adeo intolerabiles avibus fuiffe, ut iis? etiam

(d) Gmelin Flor, Sibiric. in praefatione. 


\section{G E O G R A P H I'C A E.}

etiam volantibus repentinam mortem conciverint; quae tamen, quod Braunius annotavit (e), tam calidioris prae homine indolis funt, ut, quum horum nativus calor vix nonagefimum octavum gradum affequatur, illarum ad centefimum octavum, quin undecimum efcendat. Tota igitur via errant, qui animantia majoris aeftus patientia, majorem etiam algoris vim fine damno perpeti poffe autumant: quum ratio potius in robuftiore corporum ftructura \& difpofitione quaerenda fit. Ne quis opponat: homines, tam enormi frigore faeviente, libero fe aëri fubtrahere, vitamque fuam domuum veftiumque praefidio defendere: id enim rerum naturae \& experientiae repugnare videtur. Certum enim eft, tam afperas praegelidasque hiemes iftis in regionibus haud raro aliquot hebdomadas furere: nonne interea omne commercium, omnis hominum focietas negotiorumque ad vitae ufum neceffariorum curatio interpellaretur?

0. IX. Dolemus quidem, Gmelinum lectores fuos in incerto reliquiffe, quid noxae reliquis animalibus algor ifte attulerit: quod fi tamen fingularem quandam hominibus calamitatem contraxiffet, quin ejus mentionem fuiffet facturus, dubium non eft. Dantur quidem, quod facile largimur, exempla, homines in remiffioribus tonge frigoribus, fpiritu fuffocato, obriguife: fed quum hi vel fedentes ac dormientes, vel alia ratione otiofi a laboribus quiefcentes occubuerint, hoc ipfo meam fententiam non infirmari crediderim.

0. $\mathrm{X}$.

(e) Nov. Comment. Petrop. 'T. XIII. Braunius de Calore animalium. 


\section{SPECIMEN ZOOLOGIAE}

6. X. Quodfi nunc ex altera parte ad extremos, quos homo fine vitae jactura perferre poteft, aeftus gradus. tranfieris: intervallum tantae magnitudinis reperies, quae humanam propemodum fidem excedere videtur. Adanfonius $(f)$ ad Seriegalli, fub decimo feptimo latitudinis gradu occidentem verfus profluentis ripas, arenae calorem, fecundum Realinurii fealas, ad fexagefimum, $\&$, fecundum Farenbeitbii menfuram, ad centefimum fexagefimum feptimum gradum adfcendiffe; in umbra vero collocato thernometro, ad tricefimum quartum, juxta Farenbeitium ad centefimum octavum gradum cum dimidio elatum. effe, teftatur.. Muscenbrokius ( $g$ ) Batavos fuffocatum iri confirmat, fi ipforum aura eo usque incaluerit, ut Farenbeitbii Thermometra in umbris pofita nonagefimum fextum ardoris gradum affequantur, qui ad: Pring lii fimul exemplum provocat, teftantis, Anglos: milites fubs centefimo duodecimo ardoris gradu vix ac: ne vix quidem mortem effugiffe.. Qua ex.re clare fatis. elucet, confuetudinem, quae altera quafi natura eft, in caufa effe, ut alia natio in majore, alia in minore aeftus: vi. Spiritum ducere, ideoque ab hac vel illa gente nunquam tuto.ad univerfum genus hominum concludi pofiit.

0. XI. Quae res. eo nos attentiores reddit, quum: aeftum, quem finguli ejusdem climatis: homines fufferunt, ac perpetiuntur, parum inter fe, \& fecundum multiplices crebriusque iteratas: Brauniz: obfervationes,

vix:

( $f$ ) Hifroire Naturelle di Sénégal po $27 \&$ I 31 : Büfonius obfervationem citat, ex qua adparet, prope Senegalli ripas, Realmurii Thermometrum:

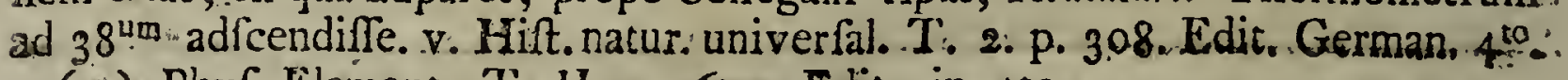

(6.) Phyf. Elemento. T. II. p. 674. Edit. in 410. 


\section{G E O G R A P H I C A E. 43}

vix unum cum dimidio gradum diftare, doceamur. Extremus igitur, in quo homines, quantum quidem conftat, fine mortis metu vivere poffunt, caloris fervor is effet, qui Farenbeitbii Thermometrum ad centefimum usque gradum extollit.

0. XII. Quum autem Brannius de Richmann, Profes-

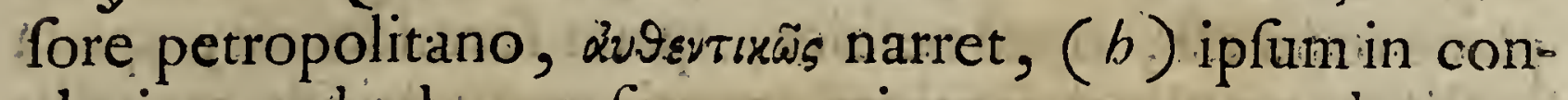
clavi, quod ad centefrmum quintum usque gradum calefactum fuerat, fine incommodo effe, vitaque frui potuiffe; aeftus vero vel igni, vel alio quodam artificio factus intolerabilior femper hominibus effe foleat illo, qui in liberiori aura candet: rem non exaggeratum iricrediderim, fi aethiopes fub ardore ad centefimum thermometri gradum fublato vitam agere, fir nesque temperiei, quae hominibus non plane mortalis eft, inter centefimum trigefimum caloris \& centefimum vicefimum fexturn gradum, quem Farenbettbuns fub zero annotavit, ftatuo: licet uis non contradixerim, qui utrumque ulterius extenfum velint:

ఏ. XIII. Experimenta, quae Brawnius omni cura fummaque circumfpectione fecit $\&$ confignavit, in fuo genere quidem eximia omnique laude digna exittimo; quivis tamen, qui ad naturae contemplationem fe confert, facile perfpicit, calorem arte \& induftria excitatum toti animantium ftatui habituique femper officere; ideoque nunquam cum folis igne $\&$ radiis conferendum esfe,

(h) Novor. Comment. Petropol. T. XIIJ. 1. c. ubi Braunius ufitatum calefactorum in Ruffia hypocauftorum calorem, $112^{\text {mo }}$ quin $116^{\text {to }}$ gradui Farenheitiani thermometri aequaten effe ftatuit. 


\section{SPECIMEN ZOOLOGIAE}

$\mathrm{fe}$, qui per purum liquidumque aëra diffufus corpora fovet atque reficit: Nulla opera, nulla diligentia effciet, ut in capiendis ejusmodi experimentis animantium, prunarum, aliaeque exhalatioṇes penitus fecludantur.

f. XIV. Quicunque vero phyfices cognitionis non plane rudis eft, haud nefciet, quam formidolofa, quam peftifera omni animantium generiaura fit ftrictis cancellis inclufa, igne fervefacta, vaporibusque praegnans: quod Mufcbenbrokius non folum experiundo cognovit, fed etiam in phyfica fua majore (i) bene explicuit: hine nullus dubito; quin canes, quos fupra centefimum decimus quintus caloris gradus jam fuffocaverat, eundem in aprico fine vitae difcrimine pertuliffent. Eadem ardoris magnitudo \& noftris in regionibus non inufitata eft: vix tamen quisquam exemplum proferet, unum alterumque animal eadem enecatum effe, nifi forte vehementiori fimul motu actum propulfumque fuerit, quod autem, fi fieret, tunc cafus ifte huc referri plane non poffet. Quemadmodum enim is acerrimos frigoris impetus longe facilius tolerabit, qui artus movet, quam qui fine motu quiefcit : fic in aeftu omnia plane diverfa \& contraria deprehendimus. Ex quibus conjunetim fumtishominis naturam ita difpofitam effe conftat, ut omnes athmósphaerae noftrae, tam caloris, quam frigoris gradus, qui cogniti nobis perfpectique funt, ferre \& fuftinere queat.

ઈ. XV. Priusquam naturae doctrina, obfervationum $\&$

(i) T. Ii. p. 825. 


\section{G E O G R A P H I C A E.}

\& mathefeos auxilio, a praejudiciorum fraude, praeftigiatorum nugis $\&$ anili fuperftitione purgabatur.; quivis propemodum, obefae cui nares erant, negavit ac pernegavit, fieri poffe, ut homo in loco, qui aliquot millia pedum eminebat, conftitutus, fpiritum ducat. Sed Bouguerio, ejusque in dimetienda terra comitibus acceptum ferimus, praejudicatam hanc opinionem fractam, ejusque contrarii nos convictos effe: quippe qui eos montes confcenderunt; quorum altitudo ad tria fere orgyarum millia adfurgebat $(k)$.

0. XVI. Urinatores ex adverfa parte exemplis fuis teftantur, aëra pulmones quidem magnopere, non itä tamen comprimere, ut firatio penitus intercludatur, fi modo quis fenfim \& pedetentim, non autem fubito ejusmodi viciffitudines fubierit. Aër, quem urinator fpiritu ducit, ex Defaguillierii menfura, decuplo craffior graviorque eft folito, quoties in barometro hydrargyrum ad tricefimum usque pollicem elevatur.

6. XVII. Hominis fuperficiem in quindecim pedes quadratos extendi fupponimus: quumque finguli ejusdem menfurae pedes $a b$ aëre 2148 librarum pondere aggravarigeometrárum filii ftatuant: fequitur, hominem 32235 librarum onere, urinatorem vero, aut quemvis alium in aquam merfum decuplo, quod $32235^{\circ}$ pondo efficit, compreffum iri. Nunc, quaefo, virum in montibus altiffimis vérfantem, tamque tenues auras haurientem, cum illo confer, qui fub aquis in praegravi craffiffimoque aëre aliquandiu faltem vivere poteft: nonne enormis haec differentia tibi incredibilis videbitur?

num

(k) Voyage au Perou. 


\section{SPECIMEN ZOOLOGIAE}

num fieri poffe tibi perfuadebis, ut homo in viciffitudine tam fibi oppofita \& contraria durare ac perdurare queat?

§. XVIII. Bouguerius per integras tres hebdomadas in montibus degebat, ubi argentum vivum ad I5 pollices undecimque lineas, aut fi numerum rotundum, haud multum ab illo differentem, malueris, ad fedecinum usque barometri pollicem fubfidebat. Perexiguo igitur 17 160 librarum pondere urgebatur; hinc differentia, qua ab urinatore, maris aquas qui fubiit, diftabat. fummam $305: 20$ pondo conficiet.

6. XIX. Ut ftatim refellam, quae heic loci obmoveri poffunt; haud ab re fuerit, quae Bouguerius recte provideque admonet, addere: morbos nimirum, quibus illi, qui Pinchincae montem confcenderunt, derepente opprimebantur, magis ab inufitato, qui ibidem faeviit, algore, quam a nimia aëris tenuitate originem traxiffe; licet, uti Scheuchzerus judicat, (l) repente mutata aèris preffio, humana corpora mirifice interdum adficiat; corumque robur partim convellat, partim reftituat.

0. XX. Sed praeter hanc, quam naturae opifex \& moderator hominibus tribuit, corporis praeftantiam, qua extremo, qui his in terris fentitur, tam algori, quam aedui fuftinendo $\&$ in altiffmis aeque montibus atque inis profunditatibus vitae agendae par eft, alia aeque miranda magnique momenti ratio accedit, quam propter homo, ubicunque locorum velit, effe commo-

rari-

(l) Scheuchzeri Aerographia helvet. P. I. 5. I7. de quibus plura in fectione, guae de capris agit. 


\section{G E O G RAPA $\mathrm{A} A \mathrm{C}$.}

rarique valeat. Ubique enim invenit ex quo vivat \& nutriatur. Caeterorum animantium nullus eft, qui, quibushomo vefcitur ac fruitur, eadem cibiloco comedere concoquere poffit. Adfeverent alii, quacunque probabilitatis fpecie velint, totum, quod ita vocant, vegetabilium regnum a natura hominibus vi\&tui alimentoque defignatum effe: nihilo tamen fecius quotidiana partim experientia, partim interna corporum noftrorum ftruetura cominonftrat animalia uno tantúm ftomacho brevioribusque inteftinis praedita, quibus \& homo adnumerari debet, ad carnes etiam vefcendas ita natos effe, ut, earum efuinterdicto, bene commodeque vitam ducere nequeant.

6. XXI. Tot nationes carnis potius quam herbarum fructuumque ufu aluntur, ut nulla propemodum gens nobis innotelcat, quae folo plantarum olerumque nutritu vitam fuftinet. Albinus wiv svi parapirals, noftri aevi: phyfiologorum facile princeps, de rei veritate convietus, adfirmabat; carnem vel crudam, vel leviter tantum \& modice coctam, cibil loco funtam, robur ho: minibus audaciamque addere. Gens Tartarorum, belli: gloria infignis, quae omnis fere orientis terras olim in ditionem fuam redegerat, fola fere carne eaque cruda nutriebatur. Patagones, vaftorum corporum mole: celebres, eodem carnis efu ad immanem membrorum, qua pollent, magnitudinem excrefcere dicuntur.:

0. XXII. Non equidem homines in carnivororum: claffem rejectos volo, quin potius contendo, ipfortm: machinam tam fingulari fapientia \& artificio perfectam effe, ut cum omnibus eduliis, quae vitam naturamque: ipforum non penitus deftruunt, contenti effe poffint: 
Sic integrae nationes folis pifcibus, aliae carne elixa, aliae cruda vefcuntur. Sic Sinenfes ac'Turcae oryza quam maxime vitam tolerant, quum Europae incolae onnia ciborum genera inter fe commifcere \& confumere fóleant, quibus in hos robuftos artus, in haec procera corpora excrefcunt.

6. XXIII. Lybiae nationes quaedam toftis vitam lo. cuftis fuftentant $(m)$; \& Groenlandorim ftomachi vel bataenarum pinguedinem digerunt, quarum carnem, duram quidem \& craffan, quiae bubulae tamen propemodum faporem refert, frufta praecipue ex caudis refecta

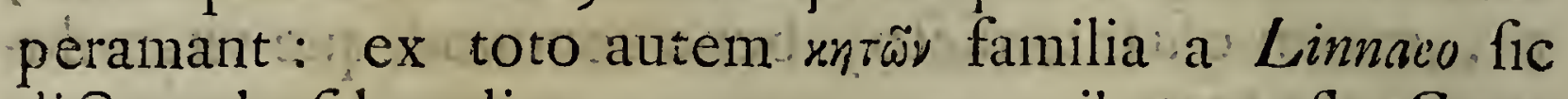
diatos phyfalos eligunt, quorum carnibus, tefte Cranzio, adimodum delectantur (iv).

0. XXIV. Unam caeteroquin eandem nationem in neceffitatis cafu omnibus, quarum partes jam enumeravi, fpeciebus, ad vitam tolerandam frui poffe, variis certiffimisque docunientis probare licet. Siamorum regis legatus, qui Occum Chamnam appellabatur, in Africa fcarabaeis \& locuftis famem explebat (o). Munckii, Danorum claffi praefecti, comites, quos intenfiffimus Groenlandiae algor ipfi vivos reliquerat, balaenarum frufta, $a b$ aliis nautis ante abjecta \& relicta, avidiffime devorabant; quod ex Barrowii itinerariorum collectione perdifci poteft $(p)$, ubi alium ejusdem fortis cafum fide dignus hic teftis adduxit.

0. XXV.

(m) Adanfon Hift. du Sénégal. p. 88. \& Nieburhtii Defcript. Arabiae. Hafnire I 772. 40. p. I 7 I.

(n) Hiftor. Groenlandiae p. 144. (o) Collect. itiner. univ. Germ. T. 10. (p) Edic. german T. r. p. 37 1. \& p. 39. 


\section{G E O G R A P H I C A E.}

6. XXV. Cui fi triftia eorum exempla partim noftris in regionibus, partim noftro aevo pervulgata, adjunxeris, qui "fame domati, quicquid obvium \& vefcendum füit, mandendo confumferunt; nec Americae habitatores filentio praetermiferis, qui ex folofere maniocco, cui tamen radici vim quam maxime virulentam inesre conftat, vitam fuftentant: vel plane nihil, vel parum faltem in orbe hoc fupereffe videbis, ex quo hominum ftomachus neceffaria fibi alimenta non extrahere, quove ad vitam confervandam non uti valeat; fi modo citam praefentaneamve mortem contrahentia, nec ante praeparata venena exceperis. Quis tam coecus eft animi, ut neget, hanc etiam in praerogativis, quibus homo inter omnia omnis generis animalia eminet, numerandam effe?

Ø. XXVI. Dantur quidem, quod lubens concedo, nonnullae quadrupedum fpecies, quae peregrinum ipfis infolitumque victum aliquando non detrectant, quod deinceps, quando ex inftituti mei ratione de bove caneque erit agendum, patebit : at quodnam illorum immenam illam, qua homo cibi loco uti poteft, carnium, pifcium, vegetabilium, quin folfilium farraginem fumit ac digerit?

0. XXVII. Majorem adhuc fententiae meae lucem affúfum iri perfuafus fum, $f 1$, quae de potionum varietate \& vicilfitudine, homini nec ingrata nec inconveniente, memorantur, adjecero: quippe qui cujusvis generis aquas, puras, medicatas, calidas, dulces, falfas, praeterea lac, oleum, vinum, vini fpiritum, fuccos herbis, plantis, fructibus expreflos, \& quicquid potui aptum eft, tuto, \& nifi immodice ea fumderit, fine ullo intertrimento haurit. Navis, quae in ma- 


\section{0 \\ SPECIMEN Z OOLOGIAE}

ri pacifico incognitas adhuc infülas regionesque detectum exierat, non mediocrem omnis aetatis fexusque incolarum copiam offendebat, qui fitim aqua marina reftinxerunt $(q)$. Groenlandi liquentem balaenarúm adipen avide lingunt. Europaei uno eodemque in prandio vel: feptem pluribusque diverfis potionum generibus fe deleetant, quibus omnibus ac fingulis concoquendis perferendisque nulla quadrupedum fecies unquan par eft.

6. XXVIII. De Patagonibus, quos robuftis quidem ordinariamque magnitudinem excedentibus hominibús, minime vero gigantibus, adnumerandos cenfeo, Bougainvillius, teft is oculatus, adfirmat, equorum ip fos canumque fuorum fitim aqua marina fedavifle, quam lubenter biberunt $(r)$; an vero haec eadem animalia vel oleum, vel: vinum aduftum fuerint abforptura, vehementer dubito.

6. XXIX. Equos non nulli fine fanitatis detrimento -in hanc confuetudinem adducunt, ut vinum quidem aduftum, red parce admodun, minime vero alios inufitatos ipfis potus bibant. Elephas quidem integras interdum vini oryzaeque pirita, quin fervidioribus adhuc: potulentis repletas fitulas fine noxa exficcat; quod ta. men immanem corporis ful molem contemplanti, hominumque membris conferentimiraculo efre non poterit. Interim belluan hanc caeteros, quibus homines utuntur? praeter aquam, potus omnes refpuere certum eft.

6. XXX. En novam rationem, cur homo in om

(9) Aliud quoddam exemplum, homines aqua marina fitim fedare, $V$. in Algem. Reizen T. 12.Ip. $2 \mathbf{2} 6$ :

(r) Bougainville Voyage autour du monde p. $13 I_{4}$ 


\section{GE O G R A P H I CA E.}

nibus terrae hujus locis habitare, en novum characterem, quo ab omnibus mundi hujus quadrupedibus discerni poteft. Ex omnibus enim, quae animantis naturam non plane fubvertunt, victitat, feu, quod idem eft, quaevis propemodum res creata, alimenta ipfi ad vitam confervandam neceffaria praeftat. Unde. quaefo haec omnia, nifi ex perfectiore naturae noftrae conftitutione, praeftantiorique corporis humani fabrica nascuntur? Hanc fupremus rerum conditor fporite, conftitutaque opera fic difpofuit, ut prae omnibus animalibus excelleremus.

6. XXXI. Ponamus, nec tot pariter, nec tam varia cibi potionisque genera, quae utilitati falutique eorum ferviunt, hominibus conceffa fuiffe: quo jure, qua arte, quibusque viribus hoc totius terrae dominium, quod natura fautrice ipfis datum videmus, vindicare fibi potuiffent? fi etiam, quod jam aliquoties ex dentium ordine $\&$ aequalitate tentatum effe conftat, fieri poffet, ut animantes propter exteriorem corporun fructuraeque fimilitudinem homini quam proxime jungerentur, quin eidem fubmitterentur claff: haec tamen infallibilis, nec inficianda, nec unquam intermoritura, quae utrosque disjungit, differentia perftat femperque durabit, homnis nempe machinam tanta arte \& fapientia exftructam effe, ut in regionibus \& coeli varietate \& difparili terrarum habitu disjunctiffimis vivere, omnia, licet quam maxime inter fe diverfa fint, efculenta \& potulenta in fuccum \& languinem vertere, omnes ferme viciffitudines ità ferre poffit, ut naturae fuae nihil damni exinde adtrahatur, a feipfo nunquam degeneret, \& nunquam fui diffimilis evadat.

$$
\text { G } 2 \text { f. XXXI! }
$$


52. SPECIMEN ZOOLOGIAL

g. XXXII. Quac hoc loco nor fine probabili fpecie: obmoveri poffent, haud praetereunda cenfeos. Quun enim hominem corporis praecipue perféctionibus adjutum fe longe lateque propagaffe, harumque potiffinum viribus terram imperio ditionique fuae fubjeciffe dixerim, requiri poffet: an non rationis, qua praeditus eft 5 auxilio quaim maxime effecerit, uttam diverfas a fe invicem coeli plagas, tamque multiplices \& haud raro inter fe pugnantes cibos digerat? Quibus facile lubensque concedo \& largior, fanam rationem, cujuś homo particeps eft, omnino fua conferre, ut ignis veftiumque beneficio, frigoris impetus', quo minus noceant, frangere, difcoquendoque cibos, digeftionem maturare valeat. $\mathrm{Nec}$ enim, fi prope axem nudus incederet Esquimavius, igne deftitutus, algorem fuftentaturus effetet, nec nos ipfi, quibus alimur eduliis fine foco tam facile, : quam nunc fieri folet, effémus concocturi.:

0.: XXXIII: Aequa igitur mente perpendamus, natturam nos non ita pilofos; quam plerasque animalium fpecies procreavifie, ideoque illorum quodlibet; fi par iisdem corporis habitus datus fuiffet, inftinetu fuo naturali concitatum, ut fe quovis modo contra nimiam algoris vehiementiaum defenderet; omnem operam, omnem diligentiam fuiffe navaturum. Sic mus tam alpium, quam avellanarum, fic alia quaedam, ut a frigore tuta-fe.praeftent, fcrobes, quibus calide fatis hibernent, fodiunt. Sic aves nidos plumis miniunt mollioribus, pullos:fuos protecturae; fic -erucae, quo propius mutationis fuae tempus accedere fentiunt, eo majori cura vel filis : circumductis, vel alia ratione fibi profpiciunt, ut nec a 


\section{GE $\odot$ G R A P I C A E.}

frigoris, nec ab alia quadam vi laedantur. Volucres, quae more fuo certis ftatisque temporibus ad remotas regiones migrant, quod idem pifcium genera faciunt, fedes fuas cum aliis, quibus commodius tutiusque vietitent; permutare folent.

6. XXXIV. Illos interea homines, qui ab' aquilone proximi funt, natura ipfa a perpetua, quae ibi dominatur, hieme; tam prudenter tutata eft, . ut. (quod Cranzius de Groenlandis narrat $(s))$ carnofa ipfis \& obefa corpora multo fanguine abundantia tribuerit, quae leviter tantum veftita, licet caput \& collum nudatum fit, quamlibet frigoris vim fuftinere poffunt! In tuguriis fuis plerumque folis fe femoralibus muniunt.. Ipforuni exhalationibus tantum caloris ineft, ut Europae advenae, prope fedentes, eas haud diu tolerare valeant; praecipue quoties celebrandorum facrorum caufa acervatin conveniunt, ubi tam calidos vapores exfpirant, quin evomunt, ut vicinis pene fpiritus intercludatur, \& fudores non mediocres eliciantur.

6. XXXV. Eadem fere Pantoppidanas de Norvegiae rufticis enarrat, (.t) quibus brumali tempore, haud raro pectore nudato, (qui mos eorum effe-folet) progredientibus pectoris villi gelu concrefcunt.. Tam fingulari artificio natura, quae animantes. contra algorem pellibus armaverat, homines, pellium loco, ferventioribus, craffis \& pinguibus fuccis inftruxit, ut tam terribili, frigoris vi, pari., quin majori facilitate refiftere polfint...

6.) XXXYI.

(s), Hiftorie van Groenland. Barby. 1765. p. 179. (t). Hift. Nurvege G. 3. 


\section{SPECIMEN Z OOLOGIAE}

6. XXXVI. Quis non haec omnia folis corporibus tribuit? Num rebus ita difpofitis homini plus rationis, plus fapientiae opus eft, quam animanti? Nonne utrique, folo naturali inftinctu adacti, fe in terrae fpeluncas abdere, vitamque fic tueri poterant? fic nec igne quidem, quo tamen praecipue ratio nobis hoc in cafu fuccurrere poterat, indigemus.

ઈ. XXXVII. Deinde \& ratio humana fat multis animantibus fuppetias ferre, eorumque vitam ac falutem, aut veftium an domiciliorum beneficio, confervare tentavit: quos tamen praematura morte exftinctos enectosque fuiffe didicimus. Elephas Petropoli non mediocri cura nutriebatur. Multas Simiarum fpecies Europaei modo erioxylo involutas, modo amiculis velatas, vivas quidem, fed fruftra confervare ftuduerunt. Ourang Outang, qui caeteroquin hominis fimillimus eft; Brafilienfium Viverra, quam Suricate vocitant, fumma licet cum diligentia tepide fatis haberentur, brevi perierunt: \& quis omnes ejusdem generis beftias numerando percenfebit, quae pari quidem ftudio eademque opera cultae \& nutritae, omnes tamen, vix una alteraque excepta, vitam immatura morte finierunt? procreandorum, autem edendorumque foetuum fpes omnis decollata fuit.

ઈ. XXXVIII. Non exiguus animalium numerus ita fuo naturali folo adftrictus videtur, ut, licet in alio quodam loco, eidem caloris gradui expofitus, permodicam aëris mutationem, ab illo, cui adfuetus erat, recedentem patiatur, omnem nihilominus propágationis fpem adimat. Nec Camelum in Brafilianorum terras tranflatum, nec Elephantem extra Afiam pultos produ- 


\section{GE O G R P H I A E.}

cere $\&$ educare novimus; quum e contrario Aethiopes, in Madagafcaris infula \& in Guineae regno oriundi, tanta ftirpem fuam copia propagent, ut Surinamae babitatores permulta ejus gentis mancipia alere poffint. Quot hominum millia interpofitis temporum quorundam intervallis, nunc aequatoris aeftum, nunc, quifub feptentrionis coelo regnat, algorem, pari incolumitate fuftinent?

6. XXXIX. Tertio homines fub omnibus mundi plagis, tam veftibus induti, quam nudi corporibus, auras fine vitae fanitatisque metu hauriunt. Canes ex Europa in American delati, non crines tantum, fed vocem quoque amittunt; quum homo, fi modo regiones quasdam minus falubres, peftilentesque evitaverit, eandem fere valetudinis profperitatem corporisque robur: \& vigorem fervet.

0. XL. Quarto ad Bonguerium ejusque focios iterum provoco, qui multo leviori, quam cui adfueti erant, aëris pondere preff, vix notabilem fanitatis fuáe imminutionem fentiebant. Urinator licet primo, quod facit, aquas fubeundi periculo fanguinem exfcreet, pau latim tamen, confuetudine magiftra, ita obdurefcit, ut ingens compreffi aëris onus fine incommodo ferat: quum? e contrario permulta quadrupedum fub vitrea campana, antliae applicata, fimulac hydrargyrum adfcendere coepit, vita priventur; perpauca vero, quod 's Gravefandius? aeque ac Mufcbenbrokius teftati funt 2 nec mediocriter condenfatum aëra fuftineant $(a)$.

0: XIL.

(u). Vid. 's. Gravefandii P.hỵ.. Elem. 1. 618'. 
56 SPECIMEN ZOOLOGIAE

0. XLI. Huc merito \& illos referimus, qui atrum, argentum caeteraque metalla ex imis terrae medullis elicientes, noxios quidem, quin terribiles vapores aëri intermixtos hauruunt, nihilo tamen minus ad fatis maturam usque aetatem progrediuntur: quod tam Hercyniae incolae \& qui in Potofianis aurifodinis vivere coguntur, quam Chemicorum filii exemplo fuo confirmant. Quibus in cafibus caetera animalia cuncta, homine longe funt inferiora; quippe quae, quod Mufchenbrokius experiundo didicit, "fi in craffioribus aquae exhalationibus vivere coguntur, fubitariae mortifuccumbunt.

6. XLII. Quod alimentorum refpectu opponi poteft, nullius eft momenti; fiquidem multae nominantur nationes, quae, beftiarum more, quicquid ipfas pafcit, nec arte praeparatum, nec coctum devorant : quod adductis jam e teftimoniis patet, \& Cranzius comprobat $(v)$. qui de Groenlandis refert, eos phocarum capita lumbosque per aeftatem gramine, per hiemem vero nive contecto, adfervare; hisque carnibus, quas lingua fua Matiac appellant, vel gelu maceratis, vel aeftu putrefactis, eadem cum voluptate., qua nos pernis fumo praeparatis, vefci. Addit tepentem ipfos phocarum fanguinem avide bibere, balaenarum pinguedinem cum ficcatis halecibus non invitos mandere, quin (quo fingulari exemplo edocemur, quid hominis ftomachus concoquere valeat) quoties circa veris, \& praeprimis Martii Maiique tempora, phocae demigrant, aut vehementiores venti adverfaeque tempeftates eos pifcatu prohibent, ipfos con

chis

(v) L. c. p. 190 . 


\section{G E O G R A P H I C A E.}

chis, alga, corio ex detritis tentoriis, vetulisque foleis collecto., fi modo balaenarum adipe difcoquantur, famem, quam aliquot dies ferre poffunt, fedare $(w)$.

0. XLIII. Quis unquam, licet omnes rationis intelligentiaeque vires adhibuerit, vel boum, vel leonum ftomachos adfuefaciet, ut tam varia tamque varie inter fe comifta efculenta, quibus nos ad famem explendam vitamque fuftentandam, non minori cum voluptate, quam fructu, uti folemus, concoquant? Certum quidem eft, mentem qua gaudemus, ficut aliis in rebus magno, $\mathrm{i}$ ta in hac faltem, aliquo nobis adjumento effe: non tamen negari poteft, fine hac ad omnes coeli terraeque plag as facta \& accommodata corporis machina, nunquam effici potuiffe, ut humanum genus tam late vagaretur $\&$ per tot orbis noftri partes diffunderetur.

§. XLIV. Ratio itaque hoc dominium univerfale, cujus ope in omnibus omnis generis qualitatisve locis commorari poffumus, corpori, cujus donum eft, acceptum refert. Ratio auxiliatrices manus porrexit, ut, quod corporis naturae jam datum tributumque fuerat, eo felicius perficeretur. Tandem \& ex eo naturae noftrae dignitas clare fatis elucet, quod in omnibus, quae occurrere poffunt, temporum, locorum, rerumque mutationibus eadem femper $\&$ a cunctis aliis animantium fpeciebus quam maxime difpar $\&$ diverfa fit maneatque; cujus rei veritatem deinceps, de canibus fe poft hominem quam latiffime extendentibus acturus, quibusdam teftimoniis planam faciam.

Quam- 


\section{8 SPECIMEN Z,OOLOGIAE}

Quamvis enim hominum aeque atque aliorum animalium cutis crinesque immutentur; tota tamen illorum natura \& habitudo cum prototy'po fuo magis congruit, quam canum, boum, ovium, aliorumque animantiuṇ per orbem late difperforum dif́pofitio \& forma; de quibus ipfis eorumque diverfitate infra dicendi locus eft.

Ø. XLV. Homo itaque, guod abunde demonftratum effe autumo, per corporis, qua pollet, firmitatem, ubique terrarum vivere ac fpirare poteft; hinc nulla propemodum telluris pars reliqua eft, quam non fibi vindicaverit \& incolat. Veri enim eft fimillimum, tam Groenlandos, quam Efcumavios, unius ejusdemque nationis populos, perpaucis exceptis gradibus, ad polum usque borealem progredi: quum, qui fub longe mitiori coelo natus eft, Danus in Noogfackii vico fub feptuagefimo fecundo latitudinis gradu durare inoffenfaque valetudine frui queat $(x)$. De Africae, aliisque locis, quae recto folis appulfu ardefcunt, fatis conftat, ea non folum coli, fed frequentiffime etiam habitari.

0. XLVI. Nunc ad mutationes, quas climatum, nutrimentorum, quin \& morum vitaeque ratio in hominibus produxit, tranfiens, non quidem ad fingulares quasvis eorum degenerationes attendam; quippe quas IBuffonizus, Pawius in obfervationibus philofophicis, quas de Americae incolis in lucem emifit, Hallenius in naturali animantium hiftoria, multique alii clariffimi fcriptores tam exacte collectas defcripferunt, ut nihil propemodum addi queat. Interim tamen, qua in re quam maxi-

(x) Vide Lorenzens Charte von Groenland. 


\section{G E O G R A P H I C A E.}

maxime ab archetypo fuo labantur, paucis difpiciam, hominisque naturam ubique fibi fimilem femper eandem efre, quam breviffme curatiffmeque pofium, commonftrabo.

6. XLVII. Duo pôtiffimum funt, quibus homines a fe invicem dignoscimus; quorum alterum ftaturae proceritas, alterum color eft, quo tota ipforum fuperficies, feu cutis tincta confpicitur. Faciei enim orisque habitus $\&$ forma non in fingularibus modo familiis, fed in fingulis ëtian hominibus adeo a fe difcrepat, uit ad eorum fpecies diftinguendas nec fufficiat, nec certam diftinctionis notam fuppeditet. Dictam itaque magnitudinis colorisque differentiam hac tantum de caufa fundamenti loco pofui, ut partim hominem, prae omnibus quadrupedibus, aut nihil aut adimodum patlulum a prototypo fuo difceffife, nec coeli, neque aëris temperiem ipfum magnopere immutare, naturaeque fuae vim reliquis animantium corporibus firmiorem longe durabilioremque effe, commonftrem; partim ut colorum diverfitates non ejus momenti effe comprobem, ut idcirco homines difcolores a diverfis generis fui auctoribus oriundos ftatuendum fit.

6. XLVIII. Ufitatum adolefcendi humani corporis modum quinque pedes, quatuor, fex pluresque pollices, minimum ftatum quatuor, maximum vero fex pedes, parifienfis menfurae, effe fcimus; nec nationes quadrupedali minores, nec vaftioris molis gigantes his in terris reperiri, certum. eft. De intêgris autem gentibus, non autem de fingulis quibusdam hominibus mihi fermonem effe, lectorem benevolum heic loci monitum volo. Brebeum itaque Gallum, qui vix tres pedes fupra terram exftitife fertur, 


\section{0 \\ SPECIMEN ZOOLOGIAE}

\& quoscunque natura (Statii verbis uti liceat), brevi ftar tu peracto nodofum. femel in globum ligavit, aeque ac Gillisn, Italum natione, in quo enormis octo pedum proceritas erat Teutobocbiumque, quem fuper romana tropaea eminuiffe, Florus tradit, quosve alios, a fabulofa antiquitate pro temporum, fuorum ingenio ad immanem vaftamque magnitudinem fietos, Calmetus magno. ftudio fingularique cura conquifivit, ficco pede omnes: praeterea:

0. XLIX: Minimae ftaturae, quos novimus, populi Esquimavii funt, Groenlandi Lappiique. Hi enim: propemodum omnes vix. fupra quartum altitudinis pedem excrefcunt : quum acrior frigoris: vis, quae regiones, fub aquilone fitas, vehementius adflare confuevit, perpaucis tantunz quadrupedibus, rarisque admodum, nec ad juftam magnitudinem adfurgentibus arboribus, vitam: \& incrementum permittat, ideoque humani quoque corporis partes comprimat, nervos gelu: perpetuo conftringat, \&, quo minus artus ad decoram fuetamque longitudinem extendantur, impediat. Nemini ergo, jufto breviora hominum corpora ibidem eva-dere, mirum videri poteft.

0. L. Ex luculentiniimis quorundảm peregrinatorum teftimoniis, quibus fides, negari nequit, in terris etiam graviori aeftu aduftis pygmaeos.inveniri difcimus,; in quibus: Matimbaenfes. interiorisque Madagascaris cultores., Quimos appellatos, numerant. Commerfonius: in epiftola, quam ad de la Lande dedit (y), fe ipfum di--

eti:

(y) Vide Journal Encyclop, 1772 . vel Supplement au. Voyage de Bouo:gainville. Paris 177 ?: 
eti jam populi feminam, tres pedes \& octo pollices altam, vidiffe ait. In eo autem per errorem vir praeftantiffimus lapfus videtur, quod gentis iftius exiguitatem, quam vix ad quartum pedem: extendi adferit, montibus, quos incolunt, ad mille ducentas orgyias fublatis tribuit: Sic 'enim fieri neceffe effet, ut elatiorum longe montium: \& Quitonis habitatores, quorum urbs: mille fexcentas orgyias fuper mare eminet, in aretiorem corporis ftaturam comprimerentur.: Magis itaque, ut in illorum fententiam difcedam, commoveor, qui ex quodam Nanorum pari hanc nationem olim oriundam effe tradunt, quae nullis: deinceps juftae magnitudinis hominibus admixta ejusdem femper ftaturae pumilos procreaverit; quo factum fit, ut ipforum progenies adhuc vegeta duret, \& immutata perennet. Vix enim intenfum aëris calorem homines pufillos reddere perfuaderi poffum.

ઈ. LI. Forfitan appones extremi fub zona, quam torridam nuncupant, aeftus; maximique fub polofrigoriseosdem: faepiffime effectus effe. Sed nonne fic hoc ipfo homines fub meridiana coeliplaga calentes, aeque ac fub aquilone algentes, contractum : iri evinces? Nonne fic aethiopes, quad tamen procul vero eit, in pygmaeos transformabis; quum rerum ordo, \& experientia, optima rei magiftra, evidentiffime doceat, folas vehementiori gelu rigentes terras minoris ftaturae homines producere. Si cuiquam olim tam felici effe licuerit, ut ad eosdem poli auftralis gradus progrediatur, ad quos feptentrionem verfus hucusque penetratum eft, nullum eft dubium, quin utrobique ejusdem magnitudinis ac ftaturae homines fit detecturus.

$$
\mathrm{H}_{3} \text { (IIL. }
$$




\section{SPECIMEN ZOOLOGIAE}

0. LII. Nunc ad Esquimavios Groenlandosque a quibus paulo longius digreffus eram, revertor. Hi feptentrionis pygmaei fatis pingues \& corpulenti funt. Ipfórum venae craffo \& glutinofo fanguine, qualis ex pifcibus vitulisque marinis, quibus quam maxime aluntur, exfpectandus erat, tument, qui tamen, quod jam fupra adductum eft, folus efficit, ut formidolofa, quibus ipforum patria infamis eit, frigora perferre queant: qua de re praeftantiffma de Esquimaviis disquifitio, quatm Pawius in faepius citato de Americae incolis libro dedit, confulatur.

6. LIII. Caeterum tetro quiden horridoque vultu funt, non tamen ad quorundam tartarorum aethiopumque faciei deformitatein accedunt. Subfufco quidem illos, nunquam tamen nigro colore infectos deprehendeș; quum exactiffimis crebrisque obfervationibus perfpectum fit, gelidiffimam feptentrionis plagan atri coloris homines nullos progignere. Ellifus in itineris ad Hudfonis orain faoti defcriptione, \& Pater Lafiteniu, qui de Americanis eorumque religione librum multae quidem lectionis, fed multæ quoque fuperftitionis in lùcem emifit, qui a Baumgarteno in germanicum fermonem converfus fub Hiftoriae Americanae titulo, aliquot abhinc annis , prodiit, Esquimaviorum ; Cranzius vero Groentandorum imagines fatis curite diligenterque pictas dederunt.

6. LIV. Inter naximae proceritatis nationés ex autralis latitudinis terris nobis cognitas y Patagoneś; in aisdem vero noftrae latitudinis gradibus, Hiberni, Norvagii, Danique celebrantur. His omnibus \& Suecorum nonnullis, fub quinquâgefmo fexto gràdu habitantibus, nemo eximian -deč oranieğte proce- 


\section{G E O G R A P H I C A E.}

ritatis fpeciem denegabit, qui non ignorat, eos non folum eorum, qui fub quadragefimo gradu vivunt, altitudinem aequiparare; fed robuftioribus infuper artibus, lationibus humeris, \& firmioris ftaturae habitusque corporibus inftructos effe: licet, qui fub mitiori coelo morantur, Circaffi, Mingrelii cum Georgianis Hungarisque, faciei formaeque dignitate eos aliquantum fuperent.

6. LV. Quaecunque in Norvagiis, Hibernis, Danis, \& aliquibus Sueciae populis, eximia \& praeftantia funt, $P_{a}$ wius in faepe laudatis obfervationibus fuis breviter quidem, fed luculenter fatis hifce verbis comprehendit: qui, inquiens, extremos mitioriş zonae cis polarem circulum fines colunt, eos albo maximam parten crine, coeruleis oculis , candidoque faciei colore, robufto proceroque corpore, forti animo, promta audacia pracditos ftrenuosque bellatores effe ficimus.

6. LVI. Nonne ad memoriam infigne eft, quod fatis vehemens frigoris gradus, quo Hibernia Daniaque fubrigefcit, ampliffima aeque ac fortiffima hominum corpora profert, fibrasque firmas quidem, non tamen rigidas nec inflexibiles reddit, nec membra cutemque, quod propius a polo habitantibus accidere folet, contrahit corrugatque? Heic itaque loci moderata frigoris ratio non tantum permittit, ut homines crescant; fed magno etiam roboris incremento augeantur: quum e contrario Georgiani Graecique fuis in terrae tractibus ad juftam quidem extendantur faturam, nunquam tamen idem robur, eandem humerorum amplitudinem adfequantur.

J. LVII. Nonne probabilis hinc ratio reddi potefir, cur 


\section{SPECIMEN ZOOLOGIAE}

cur Germani, qui Caefaris Tacitique aetate, ejusden cum Danis \& Patagonibus proceritatis, fuere, nunc in breviora corpora tenuioresque artus correpti, quafi coaluerint? hoc alii quidem inde factum effe contendunt, quod frugalius olim fimpliciusque vixerint, efculentis, potulentisque multa arte \& aromatum farragine apparatis abftinuerint, corpora venatu, bellis aliisque magni laboris \& operae exercitationibus induraverint, mentes ab acutioribus, quae vires attenuant., contemplationibus avocaverint, \&., in quo rei quafi caput eft, magis quam ipforum pofteri, caftitati \& pudicitiae ftuduerint.

6. LVIl. Q Quibus rationibus fimul fumtis multum ponderis inefre, \& praefertim mature nimis \& immodice veneri litando corporis wires smirum quantum infringi, fobolisque procreandae poteftatem eripi, non quidem inficior: fed tamen frigoris deminutio, quae in Germanorum agris facta eft, non omitti debuerat; quippe quae procul dubio fua quoque contulit, ut a patrum virtute filii deflectentes in deteriora tranfierint. Perfuafiffomum enim mihi eft, in regione, cujus agri nec arati ante, nec fati tandem coluntur, cujus lacus exficcantur, filvae nimis olim diffufae fenfim excifae coarctantur, incolarumque numerus augefcit, frigoris incommoda admodum extenuari.

6. LIX. Terra enin crebrius fabacta, quas fixas tenebat, falis particulas, frigus, experientia tefte, partim excitantes, partim intendentes, dimittit, quae auris calidioribus receptae mitefcunt; vacuum fuccifis arboribus, folum apricum tolisque radiis pervium incalefcit, vapores $\mathrm{e}$ fruticetis agrisque tepentibus expelluntur, aër, quem firitu ducimus, modico tepore 


\section{G E O G R A P H I C A E. $\sigma_{j}$}

completur, quove major fit incolarum frequentia, eo plus, quatenus regionis fitus id permiferit, frigoris asperitati detrahi folet.

9. LX. Quis itaque dubitaverit, quin Germania olim majore, quam hodie, frigoris vi inhorruerit? quum infignia id documenta commonftrent. Quoties enım, prifcis Remanorum feculis, Rhenus, quod nunc perraro accidit, adeo glacie durabatur, ut ingentibus tergo oneribus, tranfportandis fufficeret? Fruetus praeterea ex arboribus exigui, fruges praegelidis ex arvis pau-. ciffimae colligebantur. Machlides denique \& alces, quae frigidas tantum regiones deamant, ibique fedes fibi deligunt, Caefaris adhuc aevo, per Galliae Germaniaeque filvas errabant, ita difparuerunt, ut nulla penitus fui veftigia reliquerint, poftquam calore, quem tolerare nequeunt, coactae propioribus a polo plagis fpeluncas fibi \& habitacula condiderunt $(z)$. Ex quibus, non exigua probabilitatis fpecie, colligere poffumus, alios etiam temporis fucceffu frigidiores adhuc terrae tractus cultura manfuefactum refotumque iri.

J. LXI. Celebris (a) itaque viy gy ärorors Kruegeri opinio, terrarum hunc orbem, incendio quondam hauftum, etiamnum pedetentim defrigefcere, tradentis, tam a ratione \& veritate averfa videtur, ut longe, majori cum verifimilitudine, multas adhuc nive pruinaque rigentes, eoque ipfo inhabitabiles nunc terras, vomere aliquando profciffas cultasque calidiores fieri poife, credam.

J. LXII.

.. (z) v. Buffon Hift. d. Anim. T. 6 . vol, 2.

(a) Krugers Gefchichre der Erde in den aller alteflen ziiten, 
66. SPECIMEN ZOOLOGIAE

6. LXII. Quum igitur ex jam dietis, maximae robuftiffmaeque ftaturae orbis noftri nationes fub praegelida coeli plaga \& nafci \& durare, liqueat; \& exinde non mediocrem frigoris gradum ad tantae magnitudinis: tantique roboris corpora producenda requiri eluceat : opinio (quam tamen pro inquifita compertaque allatam nolim ) admodum mihi probabilis videtur, frigoris deminutionem in Germaniae populis effeciffe, ut eorum etiam proceritas viresque, quibus olim excelluerunt, deminutae fint.

0. LXIII. Priusquan nunc ad validiffimos auftralisi Hemifpaerii homines contemplandos progredior, operae pretium erit, cujusdam Americae feptentrionalis populi, olim copiofiffimi, nunc vero tenuis admodum rarique meminiffe, qui Pawio tefte $(b)$, Acanfas nominatus, Sub quadragefimo fecundo vel tertio latitudinis. gradu habitavit, Danisque noftris \& Suecis tam corporis praeftantia \& magnitudine, quam caeruleis oculis, flavo promiffoque capillo, alboque cutis colore fimillimus, \& ideo pulcbra natio appellata fuiffe perhibetur.

0. LXIV. Fortaffe quifpiam, meis me ipfus verbis: reclamitare, objiciet, qui fub frigidiori tantun coelo amplorum corporum nationes generarj, A canfantes tamen fub. quadragefimo gradu prognatos effe, \& eximie adolefcere: dixerim. Hunc ipfum tamen, utconfideret, rogatum volo, ex unanimi illorum confenfu, qui tempeftatis frigorisque: viciffitudines obfervarunt, longe vehementiorem frigoris. afperitatem Americae Hemifpaerium prae eo, quod nos. inco-

(b) Rtcherch s philofophiques.fir les. Américainns T. I. p. 155. 


\section{G E O G R A P H I C A E. 6}

incolimus, premere, eandemque, quam novus orbis fub quadragefimo latitudinis gradu fentit, orbem antiquum fub quinquagefimo quarto \& amplius demum vexare: ex quibus optime omnia inter fe confpirare, cuivis facile patebit.

0. LXV. Hos igitur Acanfantes, Americae Danos, feu quod idem mihi fit, tales effe exiftimo, qui fub gelida quidem, pura tamen, ideoque perfalubri coeli temperie ad maximos robuftiffimosque artus excrevere. Quid ? fi ipfos primorum Americae habitatorum reliquias effe ftatuero?

ઈ. LXVI. Sed miffis hifce parum adhuc exploratis, ad eam gentem pergo, quae tot fabulis \& mendaciis, quin contentionibus locum aperuit, Patagones puta, qui Magellanico interdum in freto, interdum, aliis in locis vifi funt. Sic Bironius eos in virginum finu, (Cap de Vierges) navis, ftellae cui nomen erat, (l'Etoile) vectores in Boucoltii finu (Baye de Boucault) \& Boug ainvillius haud procul a poffeffionis terra, quae fingula tamen loca intra quinquagefimum fecundum ac tertium latitudinis auftralis gradum jacent, vixque uno longitudinis gradu a fe invicem diffident, confpexere. In more iftis hominibus pofitum videtur, ut haud diu eo$\operatorname{dem}$ fe loco teneant, eamque maxime ob caufam proximos fines pererrent, quoniani ille Americae tractus fterilis admodum \& macer eft.

ઈ. LXVII. Peregrinantium alii mediocris tantum magnitudinis corpora ipfis tribuunt, quorum alii contra eosdem in vaftiffimorum fere colofforum modum farmant:: quas tamen fictiones, praeter Pawium, cujus 


\section{SPECIMEN ZOOLOGI E}

jam crebra mentio facta eft, nemo certioribus argumer: tis majorique reicognitione, nemo etiam (quod quidem dolendum eft, quum veritas fine contumelia \& infectatione defendi potuiffet) mordaciori dente fregit. Vix crediderim, quemquam fapientum effe, qui I Pawio, gigantes illos ad nonum, decimum, quin duodecimum pedem effictos, fabulis adnumeranti, affènfum-deneget.

ઈ. LXVIII. Interim tamen a veri tramite aberrafe vir magni judicii videtur, quando vagos illos palantesque populos cum aliis illius regionis hominibus, longe breviore ftatura praeditis, confundit. Dantur enim inter diverfas unius ejusclemque loci nationes duae notatu digniffimae, quarum altera vicinos femper fines peragrando huc illuc volitat; altera vero certa fibi domicilia, quae nunquam deferit, certasque fedes, in quibus eo iter $\mathrm{fa}^{-}$ cientibus femper obvia eft, collocavit. In hanc Bougainvillizs fub quadragefimo quinquagefimi gradus latitudinis auftralis minuto, quum Galandi portum teneret, incidit; cuive, quod ipfum advenientem vocula pecherais exceperat, Pecherafiorum nomen impofuit.

6: LXIX. Vir egregius coloribus minus jucundis hunc nobis populum depingit $(c)$; quippe quem exiguo, deformi, macrove corporis orisque habitu, foetore intolerabili effe, conchis quam maxime marinis vefci, (quem folum victum orae hujus fterilitas fuppeditat) phocarum coriis plerosque, pauciffimos autem Guanakarum (fic oves peruvianas vocitant) pellibus veftiri, caeterarum-

que

(c.) Voyage autour du Monde $4^{\text {tn }}$ - p. I54. 


\section{G E O G R A P H I C A E.}

que pene omnium rerum ad vitam neceffariarum penuria premi adfeverat; quos ipfos etiam. Narborougbius iisdem. in regionibus codemque habitu vidiffe adfirmat:

ઈ. LXX. Alteram autem patagonum nationem, quae potiffimum utmemoriae prodatur, digna eft, nec certam patriam nec fixam fedem habere, ex co conftat, quod folis Guanakarum, nullis phocarum exuviis veftita incedit: quum tamen primo fterile iftud littus nec Vicunnae (fic aliam ovium fpeciem appellant) frequentent; deinceps equis vehantur, qui tamen in fuperioribus tantum amplorum fatis camporum fpatiis", Hifpanorum territorium pene attingentibus aluntur; denique conchis abftinentes folis carnibus pafcantur.

Nemini ergo miraculo fit, non omnibus fingulisque, qui naves eo appulerunt, magnos iftos homines videndi copiam factam effe.

6. LXXI. Bironem cos jufto majores fèciffe, dubium non habet, quod Pawius quidem aperte ac dilucide indicare, non idcirco tamen magni. nominis virum contumeliarum aculeis configere potuiffet, qui difertis addiderat verbis, fe folo ipfos adfpectu, nec adhibita quadam menfura, fed quafi in tranfitu, tantae procerit tatis aeftimafre.

6. LXXII. Ut autem veram ipforum magnitudinent curatius indagemus, ipfa magni cujusdam navarchi, qui in geometria etiam verfatiffimus erat, cximioque aftrorum cultore, rerumque naturalium indagatore itineris comite utebatur, verba addam. Bougainvillius eft, quii in curfus fui, quo terrarum orbem circumnavigavit, defcriptione patagones, quos in Boucoltii littore fab, 


\section{$7^{\circ}$

tricefimo quinquagefimi tertii auftralis latitudinis gradus minuto obfervaverat, eximiae magnitudinis homines fuiffe teftatur, $(d)$ quorum nullus quinque pedibus, fex digitis minor, nullus autem quinque pedibus, undecimque digitis major fuerit. Qui navi, cui ftellae nomen impofuerant ( $\left({ }^{\top}\right.$ Etoile) ante ipfum eo transvecti erant, illorum longitudinem ad fex pedes extenderant $(e)$. Latiffimi eorum humeri, ingentia capita, rudes \& inconditi artus, robuftiffima carnofaque corpora, tendines craffae firmaeque, carnes fpiffae \& compactae quam maxime effecerunt, ut eos gigantum filios haberent. Caeterum naturam ducem magiftram que fecuti, fuccisque nutribilibus relieti ad validiffimam illam ftaturam excreverunt, quam hominibus usquam affequi licuerit. Fortha funt nec afpera, nec ingrata, quin potius in aliquibus ad pulchritudinem dignitatemque compofita erat. Facie rotunda, paululum tamen plana \& aequabili, oculis vivido igne flagrantibus, dentibus latis \& candidis, nigro denique promiffoque capillo nitent.

ઈ. LXXIII. Quosdam myftace fat quidem prolixo, raripilo tamen praeditos vidit; cutis eorum, ficuti plerorumque Americae populorum, e nigro rubri, aerique fimilis, coloris erat. Paulo poft pergit: cultris in Anglia fabricatis, quos Bironiuls fine dubio ipfis donaverat,

ute-

(d) Commerfonius eorum altiflinos quos if fe dimenfus fuerat, fex pedum, quatuor digi orum deprel endi ; quae magnitudo fane inufitata fuit. Et Carteret, I atag nes ejusdem magnitudinis efie confirmat. v. Philofoph. Transact. t. 60. 177 .

(e) l. c. p. 126 . 132 . 


\section{G E O G R A P H I C A E;}

atebantur. Equos quibus vehebantur, ad eorum morem, qui ad Platae ripas habitant, ftraverant; \& probabile erat, populum bunc, Tartarorum ritu, circumvagari. Patentia enim auftralis Americae camporum aequora pererrant, \& cum uxoribus liberisque eo advecti, feras aliaque pecora, quibus planities illae refertiffimae funt, venando profequuntur. Ipfis praecipue Guanakas. \& Vicunnas cibi loco \& voluptati effe, exinde fufpicabatur, quod armos lumbosque illarum clitellis fufpenfos: fecum ferebant, quos crudos devorant. Sola pelle pudenda tecti, ceterum ( fic fe confuetudine contra frigoris vim indurarunt) propemodum nudi incedunt. $\mathrm{Li}$ cet enim aeftatis tempore, quae ibidem in Decembrem incidit, eosdem inviferet, thermometrum tamen Realmurii nunquam decimum gradum (qui fecundum Farenbeitbii dimenfionem quinquagefimus fecundus cum dimidio eft) tranfcendit.

0: LXXIV. Hos autem eosdem effe homines, quos: Bironius paulo ante offenderat, hinc elucet, quod iisdem cultris, quos in Anglia confectos Biromius inde advexerat, iisque dono dederat, adhuc utebantur; praetereaque (quod tam Bironius quam Bougrainvillius animadverterat, ) minorum modo gracilentorumque equorum feffores erant. Ejusdem eos etiam ftirpis effe credo, quos Giraldefus in. Gregorii littore vidit. Nec hunc: valde a vero deflectere crediderim, qui eosdem ipfos. effe gigantes contenderit, quos Chili incolae (qui. Chonos vocantur) lingua fua Chaucahues, appellant:: quum: Bougainvillius, navi ad. Poffeffionis finum appulfus a Patagonibus, iterata: vocis Chacua a qua forte to Chaucahues deflectitur, conclamatione exciperetur.

$$
\text { D. LXXV: }
$$




\section{SPECIMEN ZOOLOGIAE}

९. LXXV. Utcunque interim fe res habet, dietas regiones a proceri magnique corporis, amplorum humerorum, \&, ratione totius ftructurae \& habitus, extremae in terrartum orbe, quatenus nobis cognitus eft, magnitudinis gente habitari, certiffmum eft $(f)$. Quod fi coeli plagam aërisque temperiem, fub qua in tantam corporum membrorumque amplitudinem crefcere \& profilire potuerit, exquirere quis velit; is procul dubio eandem fub quadragefimo fecundo auftralis latitudinis gradu, fub quo infula etiam Chiloe fita eft, quive ea jpfa, qua Dania Norvegiaque frigoris afperitate adflatur, oriundam effe largietur: quod iis exacte refpondet quae de Acanfanum coeli, fub quo vixerint, climate adferui, ideoque lectorem eodem remiffum volo.

ઈ. LXXVI. Bougainvillius in Taiti infula, quae proprio nomine Utahiti appellanda erat, \& fub tricefimo decimi-noni latitudinis auftralis gradus minuto jacet, aliam vidit nationem, cujus quidem corpora fuper fex pedes eminuife, neutiquam tamen ad firmos denfosque Patagonum humeros artusque acceffife tradit: praecipue ipfis proceritatis \& pulchritudinis fpeciem tribuit. Interim unam eandemque hanc infulam duas easque diverfas hominum fpecies, quorum altera alteri eximia corporum magnitudine multum praeftiterit, aluifie, no-

tatu

( $f$ ) Dom Pernetty quidem in copiofo, quem Examen des Recherches Plilofopl. de Mr. de P. inferipfit, libro T. 2. p. 305. anglorum cum gallico, aliorumque populorum conferens modulum, Gigantes novem pedes al. tos defendere ftudet: fed quum parifienfium pes cum londinenfi comparatus, fefe habeat ut I35. ad 144 , inde cogitur, ut novem pedes londin. femper octo pedes parif. fuperent. Nulli, crgo hoc aufugium ipfi effe poteft ufus, cum patagonum neminem ad feptem pedes excrefere conftet. 


\section{G E O G R A P H I C A E.}

tatu fatis dignum eft. Ex quo fimul patere videtur, quantum fit, quod de populorum migratione, quae forfitan arctius, quam quis fibi perfuaferit, cum globi noftri converfione \& immutatione conjuneta fuit, nefciamus. Nationem interim, quam propter tenuia exiguaque, quibus vehitur, navigia vix undecim milliaribus in mari fuperandis parem judicamus, vel forte fortuna, vel nimio fui incremento coactam, vaftiffima remotiffimaque maria trajeciffe, ex obfervationibus a Solandro $\&$ Bankio in itineris, quod circa terrarum orbem viri praeftantiffmi fecerunt, defcriptione, collectis videre licet $(g)$.

6. LXXVII. Quicunque ergo homines generalite: confiderat, eos magnitudinis ratione duorum tantum pedum menfura a fe invicem diftare, nec altiffmos unquam minimis altero tanto majores effe inveniet: quum e contrario canum maximi eorum minimcs bis, fexies, quin decies interdum magnitudine formaque antecellant; quam ipfam proportionem deinceps in boum ctiam genere inter Zebu \& Tauroelephantem deprehendemus. Ex quibus conficitur, ftructuram humani corporis, quod caeteris omnibus animantibus multo majores notabilioresque regionum, aeftus, frigeris, alimento:. rumque varietates \& mutationes tolerat, nec tamen ad duplam vel extenditur, vel imminuitur ftaturae fuae amplitudinem, reliquorum omnium, \& illorum etiam animalium corporis difpofitioni, longe praeftare, quae, relicta patria fua, quaslibet viciffitudines poft hominem optime perferre valent.

๑. LXXVIII.

(g) Vide Journal des Schiffes the Endeavour $8 v_{n}$. $177^{2}$ 
74 SPECIMEN ZOOLOGIAE

6. LXXVIII. Pofţ̧uam, quantopere homines ra tione corporum magnitudinis a fe invicem differant, perfcrutati fumus: nunc, quas colorum varietates coeli plagae in ipforum fuperficie feu cute producant, contemplemur $(b)$. Duos praecipue in univerfum colores, album videlicet nigrumque in ipfis praevalere, conftat. Quumque utrorumque diftantia una folis radiorum efficacia determinetur, nec zona tantum, quae propiore folis appulfu exardet, quaeve longinquo ejusdem abfceffu nive pruinaque obriget, fed mediae ctiam inter utrasque moderati frigoris calorisque regiones frequentiffime habitentur: non miraculo effe poteft, fi homines omnibus colorum diverfitatibus ac declinationibus, quae ab albore ad nigredinem tranfeunt, tinctos ideoque albas, fubluteas, fufcas, aquilas \& nigras tandem nationes confpicimus.

ఏ. LXXIX. Ut autem Aethiopes folo coeli ardore nigrefcere eo certius commonitretur, obfervationes quasdam a fide digniffimis auctoribus hac fuper re fa$\mathcal{E}$ tas adferre, \& fundamenti loco ponere liceat (i).

I. Saracenorum Maurorumque populus, qui feptimo poft C. N. feculo Africae partem, quae orientem fpectat, fuae ditionis fecerunt, \& tunc temporis, quod citra controverfiam eft, aut albi aut ad fummum fub:

fu-

(h) De Aethiopum colore ejusque cauffa, praecipue conferantur I. Recherches ana comiques fur la nature de i’Epiderme, \& la Couleur de la fubftance médullaire dans les négres par Meckel in 'T. IX. Hilt. Acad. Berolin. 2. Buffon Allgem. Hift. der Natuur T. III. 3. Demanet Diff. fur la Coujeur des Négres, Hiftoire de l'Afrique françoife Paris 1767.4 . Mitchells. Abhandlung uber die Negern. Hamburger Magazin Tom.

"(i) Recherches Philofoph. fur les Améric, p. Mr. d. Po 


\section{G E O G R A P H I C A E. ?}

fufci coloris fuerunt; eadem, qua primi Africa, indi genae, nigredine funt infecti. Lingua quidem, moribus, \& religione fua, quod Abbas Demanetus tefta! $\operatorname{tur}(k)$, quam regionem occupaverant, mirum quan; tum immutaverunt, fed illi ipfi poltea, nimium ardente coeli aeftu, viciffim magnopere commutati funt. Quod idem Lufitanis, qui decimo quarto aerae Chriftianae feculo domicilium fibi in Africa conftituerunt, ac: cidit, qui nihil minus, quam nigri fuerunt, jam vero ita nigrefcunt, ut a primis ejus terrae incolis haud dignofci queant, nec ipfe t.)emanetus ipforum liberos, qui eidem baptizandi adferebantur, ab Aethiopum Sobole dignofcere potuerit $(i)$.

2. Nigritiei gradum aeftus gradui exacte convenire, experientia docet. Sic ad Senegalii ripas inque Guineae oris, ubi Hydrargyrum in Realmurii Thermometro ad tricefimum quartum, quin, Buffonio auctore $(m)$, fi etiam in opaco loco pofitum fuerit, ad tricefimum octavum gradum attollitur, homines quam maxime denigrantur; quum Hottentotae, qui fub moderatiore coeli temperie habitant, longe minori nigredine, \& Barbariae habitatores, quorum regio, tam maris mediterranei, quam nivium beneficio, quibus perpetuis Atlantis juga oppleta funt, refrigeratur, fufco tantum colore tineti cernantur.

3. Nihil planius, nihil apertius comprobat, ( $B u f f o-$ nii verbis utor $(n)$ ) hominum colores a coeli quam ma-

(k) Hiltoire de l'Afrique françoire T. 2. 222.

(l) L. c. T. 2. p. 224 .

(iil) Hift. der Natuur T. 3. p. 308.

(n) L. c.
$\mathrm{K} 2$ 


\section{SPECIMEN ZOOLOGIAE}

xime plagis oriri, praeter id, quod in terris, fub eo: dem tractu pofitis, quamvis mille pluraque milliaria a fe invicem diftent, aequalis femper coloris populos invenire licet, exempli loco Senegalli accolae Nubiorum: que gentes effe poffunt. Hottentotae quidem a nigri coloris patribus orti funt; nihilo tamen fecius, quoniam eam Africae regionem tenent, quae plurimum frigoris habet, omnes hujus mundi partis colonos albore facile vincunt. Quod \& Demanetus ex magna obfervationum copia in Aethiopum, quam dedit, defcriptione, teftatur: quo longius, inquiens, ab aequatore recefferis, eo ma: gis populorum colorem gradatim inalbefcere videbis, qui prope tropicos adhuc fufcus, \& in temperata dcmum zona albus apparebit, cujus fub finibus candidiffimos hominum invenies. Tandem Aethiops albus nar fcitur, \& ex:folis pudendis lineolaque nigra fub unguium radicibus, fimulac in lucem editus eft, confpicienda, ipfum nigrum futurum, colligi poteft (0). Albor itar que primarius ejus color eft, nigrities.folaribus poftea radiis ipfi inuritur.

6. LXXX. Quibus fuppofitis, novum quendam aethiopicae ftimis anctorem comminici, aut notam; quae a rerum conditore Cažno appofita fuit, nigri coloris: originen conftituere, fupervacaneum eft: quum omnes ejusmodi fictiones, fumulac naturam aequalibus ubi-

(o) Des linfans blanes dans leur naifince, au milieu des peuples noirs, ne peut-on pas cunclare, que le blanc eft I couleur primitive des hommes, \& que le noir n'elt qu'une variété héréditaire par accident depuis plufieurs fiècles, car on ne voit point arriver le phénomène oppofé. Demanet lo c. p. 217 . 


\section{G E O G R P H C A E.}

ubique viribus operantem contemplabinur, evanefcant. Animantium degenerationes non a diverfis cujusque fpeciei parentibus, fed a fola coeli plagarum diftantia facili modo naturalique ordine derivári folent. Simulac vero de hominibus fermo eft, plerumque ad res prodigii miraculique fimiles, quarum naturam rationesque cogitatione comprehendi poffe negant, confugiunt: quum taimen facile perfpectu fit, coeli regiones omnibus, quasin homine obfervarelicet, varietatibus, aeque ac illis, quae in animalibus apparent, explicandisfufficere.

6. LXXXI. Aethiopum nigrorem in mucofo imprimis corpore fedem habere, jampridem pervulgatum fuit; at ipforum etiam cerebrum fubnigrum effe, praeftantiffimi Mcckelii ftudio folertiaeque acceptum referimus $(p)$; quin \& fubfufci quid, quod caeteris hominibus deeft, Nigritarum fanguini ac femini inefre, experientia docuit. Cujus rei idcirco mentionem facio, ut, cur primae aethiopum. in frigidiores tractus tranfpofitorum generationes non. ftatim albefcere poffint, eo clarius appareat; quoniam nimirum praecipui, corum fucci nigrore quodam tincti fint.

6. LXXXII. Ne quis opponat; quum cuticula quan Malphigii rete, foli magis fit expolita; eo ipfo cogi, ut illa majori nigrore inficiatur, quae tamen fubfulca tantum, illudautem penitus.nigrum reperiatur: ex Meckelii enim obfervationibus certo liquet (q), epidermida mucofi

cor-

(p) V. Recherches Anaion. \&c. in Tom. IX. Hift. Acad. Berolin.

(q) Hift. de l'Acad.' de Berlin T. 9. p. 95. Comme P'Spiderme eft plis noir ou plus clair, felon qu'il y a plus de la membrane muqueufe fois elle; on peut fûrement conclure, que l'Epiderme nieft que la Croube déda Mu cofité du Rete Maiphizigii endurcie. 


\section{8

corporis corticulam effe, quae ab aura tantopere exficcetur, ut extremum nigroris gradum continere nequeat.

0. LXXXIII. Ex tribus ergo his obfervationibus meridiano fole clarius elucet, coloris in humano corpore varietates eadem ratione, ac in caeteris per terrarum orbem diffipatis animalium generibus, a fola coeli temperie proficifci, naturamque hoc etiam in cafu ordinem fuum fine miraculi fpecie fervare. Qui ad refellendam hanc fententiam Americae populos, nec fub ipfo aequatore nigrefcentes, fed aeris tantum colore tinctos obmoverit ; is eo ipfo, folis aeftum aethiopes infufcare, novo quafi argumento firmabit; quum fupra jam comprobaverim, eum caloris gradum, quo Nubiae \& Guineae regiones torrentur, nusquam Americae gentes infeftare. In urbe Quito enim, quae $a b$ aequatore quam proxime abeft, Realmurii Thermometrum, quod Lutetiae tricefimum faepe gradum fuperat, vix ad vicefimum quintum adfurgit: licet lubens concedam, vehementiffmam caloris vim non in urbe Quito, quippe quae in excelfis montium jugis pofita eft, fed in Guiana quaerendam effe, cujus etiam incolae prope fatis ad nigredinem accedunt, fuisque exemplis, qua ratione viaque aethiopes exiftant, planiffime docent.

6. LXXXIV., Veri praeterea aethiopes crine breviori \& lanuginofo ab omnibus caeteris albi, fufci, aerique fimilis coloris hominibus dignofcuntur; cujus rei praeter Pawizm, quantum mihi quidem conftat, nemo fpeciofiorem caufam attulit. Quia Nigritarum crinibus, inquit, glutinofior denfiorque mucofi corporis fubftantia perforanda eft : hoc ipfo nifu ut incurvati crispintur oportet, \& quia cutis textura \& integumen- 


\section{GE O G R A P H C A E.}

tum capillis parum alimenti fubminitrare poteft, eo contractiores manere folent. Inufitatum itaque $\&$ portenti fimile foret, in Africae medio homines albos promifîisque crinibus ornatos oftendiffe, quorum quidem exempla in Albinis, feu albis aethiopibus deprehendi videntur; Qui tamen, quum perrari \& diuturno miferoque morbo intabefcentes, amiffo nigrore, pallidi faEti fint, ordinem legemque naturae non invertunt.

6. LXXXV. Nihilo tamen fecius Bougainvillius teftatur, Batavos anno p. C. N. 1763 , excurfione ex bonae fpei capite interiores in Africae partes facta, genti, flavo colore fubmiffoque crine praeditae, moribusque efferatioribus afperae, occurriffe: quod quidem, ut vera fatear, incredibile mihi \& a veritate averfum videtur. Si tamen res ita, uti narratur, fe habuerit, homines iftos, ex alba progenie ortos, \& paulo ante peregre eo profectos, eam, qua inveniebantur, regionem occupaffe, credere malim.

ঠ. LXXXVI. Sic me notatu digniffimas, quibus homines tam naturae, quam coloris ratione a fe differunt, notas fummatim attigiffe; minimos a maximis duos tantum pedes proceritate inter fe diftare; colorem ipforum ab albo cunctos fere gradus, rubrum nempe, flavum, fufcum \& nigrum denique affumere; omnia haec ex variato coeli traetu originem diccere, \& ita, fi modo fine praejudiciis fingula perpendantur, nec miraculis, nec novis ftirpium auctoribus opus effe, fafis expofuiffe mihi perfuadeo $(r)$. $0 . L X X X V I I$.

( $r$ ) Stralenbergius quidem, \& poft hun Pawius, verícolorum crizm quorundam hominum mentionem fecerunt: quos taineil, quum perpauci numero \& fuiffe, \& adhuc fupereffe, fub eodemque cum tartaris, hominibusque ufitati coloris coeli tractu comtnorari dicantur, nec ad intlituti mei ra- 
0. LXXXVII. Corpus auten humanum infigni robore cunctis quadrupedibus longe praeftare, ex hoc etiam convinci poteft, quod nulla, nec fub gelidiffima feptentrionis plage datur natio, quae hispida totoque corpore pilis tecta fit. Canis in regionibus gelu rigentibus fpiffa pelle veftitus, fub aequatore vero depilatus \& glaber incedit: homo autem, caeterorum animantium robuftiffmus, ubique terrarum fui femper fimilis, fibi femper aequalis per univerftum orbem difpergitur, totamque propemodum naturam fubigit. Praecipua tam diffur imperii ratio corporis fui, quod nulla nec frigoris, nec aeftus vis deftruit, ftructura \& firmitate nititur; cujus beneficio quamlibet coeli temperiem tolerat, quodvis alibilium genus, fine memorabili fui damno, aequi bonique facit, Rullibi gentium magnam (quod reliquis tamen animantibus accidere cernimus) praeftantiae fuae jacturam accipit, \& quovis in loco tantum roboris obtinet, ut, rationis ope \& auxilio, altiorique mentis inftinctu, cuncta ditioni fuae fubmittere poffit. Nihil itaque certius, nihil exploratius effe crediderim, quam corporis humani machinam, quam fumma cum arte effetam tantoque robore \& firmitate inftructam eique ufui efie miranur, qui in omnes partes valet, hunc in finem aretioribus vinculis cum praeftantiffima intelligentiae vi \& facultate conjunctam effe \& copulatam, ut omnium animalium totiusque terrarum orbis princeps ac dominus inde nafceretur.

SECTIO

tionem pertineant, filentio praetereundos putavi. Et quoniam ita propoGto. meo, aethiopes fola ferventiuri coeli plaga nigrefcere, fatis fecifle cre. do: ulterius in iplan nigroris caufam \& originem inquirere fuperfedeo. 


\section{SE C T I O I I.}

0. I. Quamquam homo varias animantium fpecies facile domare jugoque fuo fubdere poterat : attamen fanae rationis auxilio illas tantum elegit, ex quibus praecipue fructum commodaque certa fperare poterat. Has in omnes fecum regiones abduxit; has, quoad ipfarum ftatus habitusque permittebat, coëgit, ut diverfis illis \& aëris \& victus mutationibus fe fubmitterent, quas locorum ratio pofcebat. Quo ipfo autem naturam earum fic commutavit, ut nunc alia plane videatur, \& vix amplius, qualis ab initio fuerit nofci queat.

ઈ. II. Ordinem enim rerum geftarum fic animo meo repraefento: hominum genus paulatim tantis augebatur incrementis, ut pernulti patrias fedes relinquere, ulterius progredi, aliasque terras, victum ipfis caeteraque ad vitam neceffaria fuppeditantes occupare impulfi fuerint; nec dubium eft, quin omnia fecum animalia fumferint, ex quibus eadem commoda fibi promittere poterant, quae in natali utrorumque folo ab iffis perceperant. - Hinc domefticorum animalium nomen \& originem natam effe credo. Quumque homo terrarum partes, quibus nunc alitur, non repente, fed temporis progreffu colendas fibi vindicaverit: eo ipfo pecu-, des fecum abductae alium quidem corporis habitum, aliam ingenii vim induerunt, quod tamen, quum fpiffé tardeque fieret, citra fingularem naturae fuae imminu tionem fieri poterat.

ઈ. III. Si vero quis bubalum derepente in Groenlan- 
diam delaturus effet, vix illum: aliquot menfes hanc: tam adverfam ingenio fuo plagam toleraturum, de ipfius, autem propagatione plane defperandum effe, certo perfuafus fum. Quum interim pecora haec domeftica in omnibus ferme orbis hujus regionibus obvia fint, novum ea nobis argumentum dare videntur, primum hominem non per fe, fed creatoris arbitrio exftitiffe: cui tamen: rei ulterius explicandae quum vires meas minus: fufficere fentiam, ejusdemque demonftratio me jufto longius. a praefixo mihi fcopo deductura effet, eam philofophis fubtiliori mentis acumine inftructis totam derelinquo.

5. IV. Hoc autem loco quaeftio moveri poffet, annon reliqua etiam animantium genera, fi páríratione: fenfim pedetentimque in alias regiones traducta fuisfent, ejusdem mutationis ulteriorisque dilatationis capacia reddi potuerint? cui tamen opinioni, quia minus: mihi probabilis \& refpectu quarundam fpecierum plane impoffibilis videtur, quin adfenfum meum denegem, non poffun. Quomodo enim leo, tigris aliique inmanes \& fer Afiae, Africaeque incolae, in aeterna. circa aquilonem glacie, aquas ad fitim reftinguendam: invenire, \& animantia ad voracitatem fuam explendam: jugulare potuiffent?

5. V. Natura hac in re fines caute curateque determinatos \& propemodun fupputandos pofuit, quos:ultro citroque progredi ipfis non licet, quosque dein-ceps, quando in terrarum tractus his animantibus adfignatos inquiram, clariori luci exponere conabor.

5. VI. Nec etiam utilia nobis animalia, quae in patria fua domeftica fuerant, animantia huic aeris terraeque mutationi diu ferendae paria effe, experientia te- 


\section{$G \mathrm{G}, G R A P H I C A$ E.}

ftatur. Camelus enim in Brafiliam delatus haud ita multo poft interiit. Elephas in Neapolitanorum regno haud diu vixit. Et Tarandus, qui domino fuo non exiguo folet ufui effe, vix fine vitae periculo fexagefimum gradum fupergredi audet. Et haec nunc teftimonia fufficiant, quibus animantium \& propagationem \& extenfionem terminis fuis circumfcriptam, eaque hac in parte longe hominibus inferiora effe probem, quorum plurium proferendorum poftea locus \& occafio dabitur.

\section{$S E C T I O \quad I I I$}

5. I. Quod fine ulla dubitatione proximum homini locum occupat, ipfum ubique propemodum comitatur, \& itidem cum eo formidolofiffimis in terrae climatibus durare poteft animal, lupus five canis eft.

J. II Prius vero quam ulterius progredior, rationem me reddere oportebit, quam propter a fententia magni acutiffimique naturae fpeculatoris Buffonii difcedens, duos hofce animantes lupum \& canem, pro uno co demque habeam. Vix crediderim, illum Galliae Pliminn, quem quivis nàturalis cognitionis ftudiofus debita mecum veneratione profequitur, vitio verfurum esfe, me opinionen fuam ad veritatis amuffin excutientem diffentire. Ut autem eo finceriori fide agan, ipfis Philofophi verbis adlatis, diffenfionis meae rationes adjiciam, lectorisque aequitati decidendi poteftatem ifficiam

0. III. Primo: canis, inquit (a), cum lupo nec un-

(a) Hift. der natur 3. Th. I. D. p. II 6 \& praecipue in T. 4. x. D. p. 24 . 


\section{SPECIMEN-ZOOLOGIAE}

unquam cö̈re, nec foetus progenerare poteft; qua tamen in re ipfe fibi aliqua ratione contradixiffe videtur. In canis enim defcriptione lupum, ait, aut vulpem nunquam cum cane coilfe, fe nec fimpliciter, nec fine contradictionis metu affumare velle. Nonne his verbis: concedere videtur, fieri poffe, ut dicta animalia, generandi caufa, conjungantur? Nonne, nifi me omnia fallunt, aliquo faltem modo nunc ait, quod antea negaverat? Rationis loco, cur canem a lupo patre procreatum effe inficiatur, unum, quod male cecidit, experimentum adfert: Si vero, quae: fpem non fruftra: ta funt, exempla aeque certa \& indubitata, quam quo ipfe nifus eft, illi opponuntur; nonne victas manus dare vel invitus cogetur? Quum Galli nec tam frequenter, nec tam cupide litteras Germanorum, quam hi. gallicas difcant, Buffonio dari vitio nequit, quod, quem: Docbelius, vir magno ufu \& exercitatione praeditus, de venatione librum confcripferat, ignoravit, in quo teftimoniis, quibus reclamari non poteft, lupae canisquecoïtum extra omnem dubitationem collocat. Lupae, quae Deffaviae canem venaticum admiferat, fex quidem catulos in utero geffife narrat $(b)$; qui tamen, quum mater in ipro partu periit, omnes mortui proftracti: funt. Aliud exemplum a tefte oculari, coque fide digniffimo, nobili viro de S'cbauroth, qui rebus venationum adminiftrandis a Duce Brunfvicenfi impofitus fuit, didici, qui lupam olim, Friderici Byruthenfrum Marchionis juffu, cani venatorio confociatam, \& ex illa

coi-

(4) Doebels volftiendige Jaeger-practic p. 35 . 


\section{G E O G R A P H I C A E. 8 :}

coitione gemellos, matri fimillimos, in lucem editos vidiffe ajebat, quorum feritas, quum nec altoribus fuis cicures fe manfuetosque praeftiterint, catenis domari debuerit. Plura ejús generis exempla facile colligere poffem: quum vero ex adverfa parte unum tantum adlatum fit; haec nunc fufficiant; praecipue cum Ariftotelem, aliosque magnae famae doctrinaeque auctores, caufae meae duces \& figniferos habeam.

๑. IV. Altera, quam propter Buffonius lupum a cane feparat, ratio eft: quod lupae per tres dimidiumque menfem uterum ferant (c); quum autem canibus triginta dies non amplius ventrem geftent; id certiffmo effe indicio putat, luporum canumque naturam toto inter fe coelo differre: Non iniquo accipiet vir doetiffimus animo, fi auctoritati Doebelii $(d)$, viri in re venatoria litterate periti, majus ineffe pondus credo, qui lupam. aeque atque canem novem hebdomadas gravidas effe difertis verbis adfirmat. Accedit, quod Brookius (e) in naturae hiftoria, quam anglico idiomate contexuit, idem, idque iisdem propemodum verbis, adferit; ; licet Docbelii librum nec legiffe, nec vidife unquam videatur.

6. V. Tertio, lupum cane diutius vivere, Buffonius adfirmat; ad quae vel binis tantum refpondeo: hupum etiam exacto vicefimo vitue fuae anno hebefcere; nec miraculo effe, fi idem animal in ftatu fuo libero \& naturali robuftioris eft corporis, eo: quod diuturnam fervitutem perpeffum magnopere degeneravit.

\section{VI.}

(c) Secund: du Fouilloux. Traité de venerie.

(d) Duebel. 1. c.

(e) Brooks new Syftem of natural Hiftory: 'T. I. p. 200. the Scher. wolf goes nine weeks with young. 
0. VI. Quarto Gallus addit, lupam toto anno femel tantum catulos edere, quum bis canes, quin ter nonnunquam uterum gerant. Quae quidem differentia notatu digna videtur, fed tamen, quasdam etiam catulas, luparum more fingulis tantum annis maribus mifceri conftat; deinde ftupendas mutationes in animum revocemus, quae modo per diverfas, in quas demigrare coguntur, coeliaërisque regiones, modo ex mutatis alimentis, quibus adfuefiunt; modo ex eorum varietate, quibufcum coëunt, originem trahere folent. Quis itaque negare audebit, has aliasque plures caufas poft tot exacta fecula hanc in canibus differentiam produxiffe? Nonne exempla funt in promtu, tam uriginis guam partus tempora in beftiis eo ipfo, quod ab infita feritate mitigatae fuerunt, jam fuiffe contracta, jam prorogata? Una quidem obfervatio ad objectionem hanc repellendam, meamque opinionem confirmandam, fufficere mihi videtur. Conftat nimirum, aprum foeminam anno vertente femel tantum foetus edere, dum fcrofa interim bis parere folet $(f)$. Quum autem Buffonius ipfe porcum domefticum ejusdem cum apro ftirpis effe ftatuat; ex ipfo quaerimus, quam propter caufam haec unius fobolis animalia in edendis pullis tantopere a fe invicem recedant, fusque cicur feram foecunditate fuperet? Id largiori, quo nunc alitur, victui, domiturae, \& quibuscunque libuerit rationibus tribuat; femper ipfifatendum erit: quod in apro \& fcrofa fieri potuit, \& reapfe factum eft; codem modo eademque ratio-

( $f)$ Buffon Hilt dłr natur 3 . T. I. D. p. 64. \& Hállens natur, hift. T. 1. p. 352 . 
tione in lupa \& cane, \& fieri potuiffe, \&, experientia tefte, factum erfe.

6. VII. Quinto, fi quis, inquit, omnia quam diligentiffume exquiret, in externo etiam canum luporumque habitu magnam fatis differentiam deprehendet. Sed cui, quaefo, qui vel in tranfitu ad utraque animalia attendit, non miranda intervalla ftatim in oculos cadunt, quibus ratione exterioris faciei canis calabricus, meli fimilis, moloffus, \& bononienfis minor, interfe diftant. Sed quum externae formae ac figurae mentionem feci, ab inítituto meo non alienum putavi, hoc loco addere: neminem, nifi celeberrimi Bufforii opinione praeoccupatum, inficiari poffe, fimilitudinem, quam lupi cum certis canum, verbi gratia, lupinorum, villaticorum $(g)$; aliorumque plurium fpeciebus habent, tantam tamque notabilem effe, ut vix interdum a fe invicem. dignofci queant. Parum abfuit, quin Astontonizs hoc -ipfo adductus utrasque beftias, lupum foilicet canemque, pro una eademque habuerit: quod his propemodum. verbis clare fatis indicavit (b). Quo majori mentis attentione canes \& lupos, eorumque interiorem non minus quam exteriorem ftructuram contemplor, quove: curatius utrorumque mares $\&$ femellas inter fe comparavi; eo magis inclinabat animus, ut uni cosdem fpeciei adnumerarem, nifi Buffonius lupam cum cane conjugarenequicquam tentaviffet. Quem fcrupulum quum jam evulferim, fuum nobis affenfum denegare non ulterius. poterit.

6. VIII.

(a) Chien-loup,

(i.). Allgem. Hift der nat. 4. T. I. p: 29 , 


\section{SPECIMEN ZOOLOGIAE}

๑. VIII. Si tanden eximius ille naturae fcrutator feroces luporum fpiritus unquam penitus frangi poffe negat; expreffis altem verbis adferit, eos ita ad folitam ferocitatem fuam redire, uti annis viriumque incrementis augefcunt : eo ipfo experientiae, uni hujus rei magiftrae, refragari videtur, quae Americae feptentrionalis habitatores, canum loco, lupis eorum domitu manfuefactis uti docet. Praeterea Doebelius loco jam laudato de nigra, cujus jam fupra meminimus, lupa teftatur, illam manfuetiffimorum canum inftar cicurem fuiffe. Quin \& Buffonius, quum in luporum perficorum, qui auctore Chardinio.(i) faltare didicerant, mentionem incidit, hoc exemplo convinci poterat, infitam eorum rabiem frenari mitigarique poffe. Sed quid? fi nec canes quidem, tam cicures alioqui tamque fociales homini, omnem deponere immanitaten, carniumque interdum humanarum paftu delectari audimus? Quem enim triftia illa exempla fugiunt, eos notos ipfis venatores ftabulum, ubi adfervabantur, illorum cibandorum gratia ingreffos, ultro arripuiffe dilaniatosque devoraffe teftantia?

б. IX. Accedit, quod ipfe Buffonius confitetur, nullam dari animantium fpeciem, quam plene planeque homines jugo poteftatique fuae fubmiferint. Quodfi de imbecillioribus, verbi gratia de ovibus concefferit, multo minus de robuftioribus, quibus canes jure adnumeramus, negare audebit. Verbo: quum nullibi gentium locorumque nec feros nec cicures inter animan-

tes

(i) Voyages de Charein, 
tes tam pares, tamque ftructura $\&$ indole inter fe congruentes, praeter lupum \& canem, invenire liceat: nullo modo perduci porfum, ut eos disjungan.

J. X. Objectiones : alteram, canum nempe fpeciem omnem, alteram vero, luporum fcilicet minus hucusque domitam effe; item, lupas canes admittere, feque illis mifcere noluiffe, eo ipfo jam fublatas effe credo, quod hic coïtus aliis in locis aliquoties ex voto fucceffit. Hinc illas ad reliquam utrarumque beftiarum aequalitatem evertendam minus fufficientes exiftimo. Sit igitur maneatque mihi lupus \& canis idem animal, eadem beftia; ad quam nunc progredior.

0. XI. Lupum, feu quod idem eft, canem ferum, necdum cicurem factum, longe lateque fatis difperfum diffeminatumque reperimus. Nullas enim, nec, quae fub aquilone tam antiqui, quam novi orbis jacent regiones, nec aeftuofiffimas Africae plagas, nec Perfiae terras, nec orientem verfus extenfas Afiae partes abhorret. Dampierius ipfum in decimo octavo latitudinis auftralis gradu $(k)$, \& qui Evangelii praecones ad exteras gentes miffi erant, in Congi regno obvium habuere ( $l), \& \mathrm{fi}$, quod fatis probabile eft, quam be-

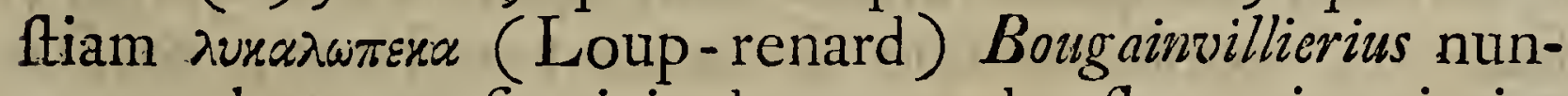
cupat, luporum (peciei adnumeranda eft; etiam in infullis Falklandi habitat $(m)$ : ex quo manifefte lucet, eum in ftatu fuo naturali fub omnibus propemodum coeli climatibus durare poffe. Non tamen a veritate deflectere is videtur, qui primam hujus animalis pa-

(k) Allgem. Reifen T. 12. p. 229. (l) Allgem. Reifen T. 5. p. 88.

(m) Bougainville Voyage auteur du Monde. p. 64 : 


\section{SPECIMEN ZOOLOGIAE}

triam fedemque fub aquilone quaerendam effe contendit; quia iftae regiones non folum magnum eorum: proventum, fed magnam quoque diverfitatem adferunt.

ઈ. XIL. Priusquam ad manfuetudinem dómantur, jam corporum magnitudine, jam ingeniorum ferocitate, quin \& colorum differentia, multum inter fe diftant. Lupus Senegallenfis feritate caeteros fuperat (n); Aegyptiacus minoris quidem ftaturae, fed longe manfuetioris eft indolis: : alios nigro, alios albo, grifeo, luteo, ftriato pelle indutos tam in feptentrionali, quam: in auftrali orbis noftri fuperficie offendes. Illam ipfam: itaque facultatem, cujus ope canis quamlibet coeli aërisque regionem tolerat, jam in lupo, ad quem fui originem refert, quaeras oportet.

ઈ. XIII. Quicunque igitur, quantum domitus alimentorumque diverfitas ad degenerationem iftam tam: notatu dignam adtulerit, certa mentis attentione ponderat; eo facilius concedet, canem a lupo nec differre, nec fejungi, fed potius ad unam eandemque clas fem revocari debere. Diu eft, quod beftia haec hominum nutui paret. Aliquot jam annorum millia praeterierunt, ex quibus ut fine interruptione morigeram fäcilem, manfuetamque fe nobis praeftaret, coacta fuit. Vix dici poteft, quantum haec omnia ad immutandam corporis, ingeniique temperaturam, praeprimis, fi coeli etiam ciborumque varietas accefferit, conferant.

0. XIV. Hinc non modo ad fufpicandum, fed ad: gredendum etiam ducor, antiqui orbis colonos hujus:

ani-

(n) Allgem. Reizen T. 3* P. 3.13\%. 


\section{G E O G R A P H I C A E.}

animantis ufum longe diutius meliusque in rem fuam convertiffe, quam Americani, quorum lupi adhuc tam fibi fimiles erant, quum Europaei advenirent, ut eos nondum canum, fed cicurum luporum nomine appellarent (o). Nonne novo quafi argumento hoc demonftrari poffet, neque Americam ipfam, neque ejus habitatores, qui tam utilem ipfis beftiam nondum manfuefecerant, tam antiquos effe, ut a plerisque perhibentur? quam tamen quaeftionem disquifitioni philofophorum, qui majori otio rem hanc cognitione fua non indignam contemplentur, relinquo.

0. XV. Lupus hic, poftquam hominum imperio fubjectus \& canis nomine infignitus eft, multo fe latius, quam in ftatu fuo naturali extendit. Islandiae, Groenlandiaeque habitatores, itidem ac Guineenfes, canes alunt. Patagones aeque ac Europaei eos inter pecora vernacula referunt. Nihilo tamen fecius ubique tam mirandum in modum degenerant, ut primo obtutu vix eos pro unius ejusdemque fpeciei animalibus fis habiturus. Aliis locis pufilli admodum, aliis fine pilo cernuntur: Qui ex Europa in oram auream deportantur, trium vel quatuor annorum fpatio tetre deformantur, $\&$ poft totidem generationes natura eos nuda crinibus cute, quae vel glabra vel maculata effe folet, veftit. Sub aequatore $\&$ in humidioribus Americae partibus vocem amittunt. In ora aurea nec latrant, nec mordent $(p)$ : ex Europa eo delati brevi tempore tantum baubantur,

mu-

(0) Aufzug befanderer Naturgeíchichte von Carolina, vide Hamburger Magazin 'T. II. p. 59 r.

(p) Allgem. Reizen T. 4. p. $25 \mathrm{I}$. 


\section{2

mutiunt \& ululant; quod; quum Cranzius etiam de Groenlandiae canibus affirmet $(q)$, inde, ficut ex permultis aliis cafibus, colligere licet, eandem interdum $\&$ nimii algoris \& vehementiffmi aeftus vim effe $\&$ efficaciam. Si, qui canes antea nullos vidiffet, Bononienfes cum Danicis majoribus, \& meliteos cum anglicis eximia corporum magnitudine validis; contendere vellet, eos certe ad genera longe a fe invicem diftantia relaturus effet. Hominem e contrario contemplare; hic non folum, quibuscunque terrarum orbis in locis quidquam animalium fpiritu vitaque frui poteft, habitat, fed ubique etiam tam fibi aequalis, tamque nofcitatu facilis eft, ut nemo, nifi qui de omnibus dubitat, omnia fufpecta habet, quin foli radios abnegat, nomen ipfi genusque fuum fit abjudicaturus.

Equidem iargior, Georgianos inter \& Esquimavios, Hibernos inter \& Matimbaenfes pumilos, vel Madagafcaris interioris pygmaeos, de quibus parvulae ftaturae hominibus nos Commerfonitss, qui cum Bougainvillierio terrarum orbem circumnavigavit, certiores fecit, tantam effe differentiam, quanta maxima effe poteft. Hanc tamen, quae ex fola regionum aërisque diverfitate oritur, degenerationem, nunquam tam enormem ac fingularem effe animadvertes, qualis in canibus usquequaque hominem comitantibus obfervatur. Ex ea interim praerogativa, qua unum hocce animal juxta cum homine gaudet, quod nempe propemodum ubique terrarum effe \& durare valet, ratio fortaffe petenda eft,

cur

(9) Cranzens Hift, van Groenland. 
cui homini quam maxime addictum fit, ejusque lateri omnibus locis adhaereat. Et pone, hanc mean conjecturam a vero aberrare; non tamen negabis, eximiam hanc praeftantemque ejus difpofitionem, ut tanta \& docilitate \& obfequio nos ubivis comitetur, naximo nobis ufui effe \& commodo. Bovés quidem ovesque, quod deinceps commonftrabitur, admọdum per orbem diffipatos videmus; quot vero regiones numerantur, in quibus canes folos invenire licet?

6. XVI. Groenlandia cum Kamt chatka nec boves quidem nec equos, canes tamen alit, qui in hac fub. Euronoto fita regione omnium fere domefticarum pecudum partibus officiisque funguntur. Viventes equorum loco adhibentur: mortuorum pellibus quorum villi denfiores effe folent, fe Kamfchadalius veftit. Quoniam natura in diftribuendis eduliis ibidem fe parcam admodum exhibuit, folis propemodum pifcibus nutriuntur." Per aeftatem libere difcurrentes fe in littoribus ripisque faginant; circa autumnum denuo collecti, equorum inftar trahis junguntur. Abfoluto demum diurno labore, ipfos maffa ex acidis picibus confecta, quae Opana ab incolis appellatur, circa vefperam eorum dominus altorque faturat $(r)$.

6. XVII. Alia praeter hanc hominum canumque fimilitudo accedit. Facile nimirum diverfiffmis alimentis adfuefcunt. Alii enim herbis, alii carne, alii pifcibus, alii aliis rebus vefcuntur; \& quis potulentorum fpecies - numerabit, quas varie interdum inter fe commixtas cupide

(r) Allg. Reis. T. 20. p. 26,3. 


\section{SPECIMEN ZOOLOGIAE}

pide bibunt? Qua quidem in re hominibus, qui mulıo majoribus pluribusque commutationibus delectantur, longe funt inferiores; caêtera tamen animalia longis intervallis poft fe relinquunt. Hoc ipfum, quod beftiae huic a natura praecipuum datume eft, permulta contuliffe, ut eo latius per terran diffipetur $(s)$, quilibet vel hebetioris ingenii intelliget.

f. XVIII. In tranfitu hic addere placuit, quod mihi notatu dignum vifum eft, Daniam nempe \& Hiberniam maximas fere canum hominuinque fpecies procreare ; \& qui circa polum areticum nafcuntur, ficut pleraque ejusdem plagae animalia, pelle tectos effe quam pilofiffima: cujus loco, tefte Crainzio, fufficiens cutis obefitas depiles homines a frigoris vehementia tutos reddit. In Calabriae, Perfáe, Afaceque tractibus, qui mediocri tantum folis aeftu torrentur, pulchri quidem homines gracilesque canes nafcuntur, quibus tamen praeter pulchritudinem grăcilitatemque nihil feparatim natura tribuit; quum utrique magnam fatis partem firmi illius roboris, quod Daniae Hiberniaeque tolerabile frigus illis concefferat, $(t)$ amififfe videantur; quod tamen de toto ipforum genere, non vero de fingulis quibusdam intellectum volo, quippe qui tanti non funt, ut exceptioni locus dari poffit. Quum fuper haec homo climatum viciffitudines multo melius faciliusque canibus per-

(s) Et in Otahiti nec non in Nova Zeelandia, maris pacifici infulis, canes exiftere Bougainyillius 1. G. p. 2 I2. \& Cookius in Hawke wortliii itinerum nova collestione $T .3 . p .433$. docent.

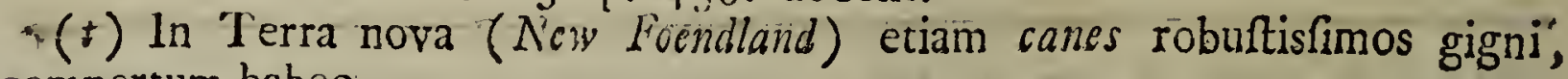
compertum habeo. 


\section{G E O G R A P H C A E.}

ferat: horum dilatatio longe aretioribus finibus reftringatur oportet.

ర. XIX. Interim tamen hoc animantium genus ad: huc alia, quam praetermittere nefas effet, ratione propius ad homines accedit : infinita nimirum $\&$ innumerabili, qua praeditum eft, temperamentorum variatione, quae quidem tam difpar tamque multiplex eft, ut animantes poft hominemnullos, nec illos, qui a phyficis in multas fpecies difpefci folent, nec quos inftinctu naturae, five animali intelligentia, canes anteire cernimus, tam multiformi ingeniorum temperie donatos invenire liceat. Fideles, callidos, malitiofos, fubdolos, timidos, audaces, aváros, invidos $\&$ homines $\&$ canes ubique gentium obvios habebis. Quainvis coeli inclinationem, aërisque difparem conditionem ad tantam difcrepantiam multa conferre concedam; praecipuam tamen ejusdem caufam in ipfa corporis difpofitione animantis quaerendam effe, jure ftatuo: quum in reliquis, quos aeque propemodum per terram difperfos fcimus, hujus temperamentorum differentiae veftigia nulla reperiantur. Affectio interim, qua maxime concitantur, \& a qua, quia ipfis innata videtur, deduci nequeunt, invidia eft.

0. XX. Praeterea hac etiam in re homini non abfimiles fe monftrant, ut ad conjunctionem congregationemque, quin ad naturalem communitatem nati videantur, quod $\&$ in lupis aliisque canibus feris ( $u$ ) haud raro obfervari poteft.

o. XXI.

(u) De canibus fic dictis feris $\Lambda$ fricae, vide Kolbens Befchreibung des Vorge. a. guf. Hofn. p. I53. ed. germ. in ful. \& Allg. Reifen T. 5. p. 
๑. XXI. Si quis omnes, quas diverfae coeli regiones, varius victus, difcrepantesque commixtiones proferunt, mutationes animo oculisque fuis percenfere voluerit; istantum inter canum corpora, externamque faciem, confpiciet diftantiam ac diverfitatem, quanta maxima effe \& excogitari poteft. Adeat, qui evidentia hujuśs rei teftimonia quaerit, exactiffimam, quam Buffonius dedit, canis defcriptionem, tabulamque, quam adjunxit, genealogicam percurrat.

0. XXII. Opponi fortaffe poffet: quodvis animalium genus, fi pedetentim etiam in alias regiones translocatum fuiffet, easdem cum cane fpecierum diverfitates producturum fuiffe, cui refpondeo : hoc idem in folo cane fingulare \& eximium effe, ut omnes propemodum coeli plagas perdurare, \& ubique terrarum, fi modo aeftuofiliimas Africae partes, \& extremum feptemtrionis algorem exceperis, hominis comes \& fectator effe queat. Reliqui enim animantes extra patriam fuam in alias regiones deducti, aut ftatim pereunt, aut fenfim delentur, quod Elepbas, de quo jam dixi, comprobat.

0. XXIII. Leo in temperatioris, quam cui adfuetus eft, caloris terras delatus, non amplius crefcit, quin ipfam vitam praematura morte finit; licet utraeque beftiae admodum robuftae fint indolis. Quae fub frigidiori zona nafcuntur animalia, longe mollioris prae canibus naturae effe, experientia difcimus. Macblis fi

ex

88. Porro de canibus feris Americae, Allg. Reifen T. 13. p. 671. nec non Anfons Reife um,die Weft, in Defcript. infulae Juan Fernandez: de lupo ve. ro mexicano, vide Hernandez. Thefaurum rerum medic. nov. Hifpan. p. 479. 


\section{G E O G R A P H I C A E.}

ex Lapponia in Danian deportatur, paulo polt moritur; \& Caflores e Germania in aliquanto frigidiores regiones, exempli gratia, in Borufjiam tranfpofiti, ut ibidem propagarentur, perpaucis exceptis, difperierunt.

6. XXIV. Itaque nemo ex robuftiori corporum membrorumque ftructura colligat: idcirco fore, ut diutius perennent; id potius animalium genus pro durabiliori habeat, quod quamcunque coeli aërisque temperiem perfert, cum quibuscunque cibariis, quae modo digerere poteft, contentum eft, fibique femper aequale, corporis faltem habitu minus difpar permanet.

ઈ. XXV. Quid quaefo, his fuppofitis, praeter canem, homini proximum cenferi debet? licet eundem caeteroqui, propter nimiam, cui fubjectus eft, degenerationem, homine longe inferiorem, habendum efre concedam. Non autem, ut expromam quid fentiam, in ea fum opinione, ac fi omnia haec animalia; quae tam multis tamque diverfis in locis nunc vivunt ac propagantur, in iisdem etiam ab initio rerum fuerint $\&$ habitaverint.

f. XXVI. Haec potius fententia mihi ad veritatem multo propenfior videtur: quamcunque eorum fpeciem ibi natam effe, ibi patriam fuam habuiffe, ubi optimo formofiffimoque incremento provenit, quam diutiffime vita fruitur, \& fingularem quandam, ut ita loquar, intelligentiam, feu quod idem effe puto, fagaciorem, inftinctus fui naturalis folertiam exferit. Haec norma mihi quidem cum praeftantiffima naturae difpofitione magis convenire videtur, quam quae a quibusdam phi:lofophis fundamenti loco ponitur: creatorem fcilicet a rerum primordio quibusdam animantibus minus commodas adfignáviffe regiones, ut homo co facilius ea fecum inde abducere, illasque in terras deponere poffit, 
quae ipfis aeque ac hominibus majores ingeniorum vitaeque commoditatum acceffiones adferant.

6. XXVII. Nonne hoc ipfum tunc etiam fieri poterat, quando Deus optimam iisdem, naturaeque fuae convenientiffimam adfignaverat patriam? Nonne equus, licet ex Arabia originem ftirpemque fuam trahat, idcirco tamen per varias terrarum orbis regiones disperfus confpicitur?

0. XXVIII. Unde, quacfo, hypothefis ifta, quae totius naturae dispofitioni tam diffentanea, tam contraria videtur, defumta eft? Fortaffe a quibusdam plantis. paucisque pecudibus, quae aliorfum transpofitae in majorem amplitudinem excreverant. Sed quum terrae noftrae globus, quod ex multiplicibus nec incertis documentis elucet, tot ftatus fui converfiones, totque: fuperficiei commutationes perpeffus fit; nemo pro certo affirmare poterit, an non exiguus ille plantarum: pecudumque numerus e folo fuo patrio abreptus, \& cafu vel neceffitate adactus, terras regionesque naturae fuae minus convenientes accupare debuerit: quod etfi nec perfpicue nec plene explicari poffit, naturae: tamen ordine, ejusque fapientiffimo moderatore, longe: dignius mihi videtur, quam ff quis ftatuat; animantibus plantisque magis perficienais hominumi fuppetias exípectandas fuiffe. lllum, qui eadem facultate \&. potentia rem aliquam longe perfectiorem durabilioremque condere poterat, accufare quafi hanc eandem mancam, inchoatam, ftupidamque produxiffet, idem. eft, ac cafui fortuito, ejusque propugnatoribus, qui Deum tollunt ac negant, novum quoddam quo nos ag: grediantur, telun fuppeditare. 


\section{G E O G R A P H C A E.}

\section{S E C T I O I V.}

0. I. $S$ i quis ex me quaefiverit, quod animaliunt $S$ genus poft canem quam latiffime per orbem extendatur? pecudibus domeficis fine controverfia proximiorem locum tribuendum effe, refpondeo. Licet enim vulpes, lepus \& alia quaedam quadrupeda ex naturae fuae dispofitione omnibus totius terrae vicifftudinibus tolerandis paria fint: nunquam tamen per omnes ejusdem plagas tantopere disperfa inveniuntur, quam pecudes; quippe quas, propter corporis fui robur ingeniique docilitatem, homines fingulari quadam induftria curaque in eam confuetudinem adduxerunt, ut hos ipfos paffim comitentur.

6. II. Haec procul dubio ratio eft, cur vulpes, quae cane, bove, oveque, longe minora hominibus commoda praeftat, non omnibus iisdem locis, quibus illa animalia domeftica aluntur, inveniatur: etfi, quod poftea commonftrabo, fi niodo per homines, ut ulterius propagaretur; ipfi liceret, ubique gentium vitam fpiritumque ducere poffet.

0. III. Merito itaque bovi proximum a cane locum adfignamus: quum ipfe Buffonius teftetur, eundem propter eximias, quas hominibus commoditates adfert, per omnes propemodum regiones dilatatum propagatumque efre.

0. IV. Omnes fere Europae partes eundem fovent ac nutriunt. Afia \& Africa jam per aliquot annorum millia ejusdem opera utitur; $\&$ qui Americae novum orbem detexerunt, bovem gibberum, quem a regione, ubi primus confpiciebatur, ferim novae Franciae bovem denominabant, obvium habuere, quem portea in 
hemifphaerio feptentrionali usque ad, circulum ferme polarem progredi ( $v)$, Lybiae aeftum perferre (w), $\&$ ex altera aequatoris parte ad Hottentoltas $(x)$, quim ad Magellani fretum propemodum adfcendere, naturae fcrutatores \& peregrinatores obfervarunt. Reverendus pater del. Tecbo narrat $(y)$ : in (patiofa planicie, quae: ab urbe, a bono aëre denominata, (Buenos Ayres), usque ad Cbilienfan Auftrique regiones extenditur, innumerabilium \& equorum \& boum copiam vagari, \& octogies interdum mille \& amplius, ut pellibus eorum. potirentur, captos, enecatosque fuiiffe.

Ø. V. Eos autem non idcirco folum canibus poftponendos effe judico, quod hi propius a feptentrione vita frui, majoremque frigoris vim tolerare valent, quod deinceps planum faciam; fed etiam, quod pecora cornubus armata, pro pabulorum conditione partim cre: fcunt, partim decrefcunt.

6. VI. Hac de caufa in regionibus modicum inter fe Spatium diftantibus, tam diverfae a fe invicem diffimilesque pecudum fpecies offenduntur. Perfar pufillos. alit boves $(z)$, qui in Ukraina, praecipue vero in Cal. muccenff. Tartaria ad tam inufitatam magnitudinem excrefcunt, ut vix majores uf piam invenire liceat (a). De Helvetia, cujus montium cacumina herbefcente viriditate floribusque amoeniffimis affatim contecta cernuntur, Buffonius affirmat $(b)$, boves ibidem duplo majores illis effe, qui in Gallia nafcuntur, ubi pecudes

cras:-

(v) Hogftrcems tefehrybung von Lapland. p. 282. \& fecundum Ceder. hioelm bovem ad 64 . gradum latitudinis borealis offenditur. Allg. Reif. T. IO (w) Leo Afric, Defcript. Afric. p. 752.

(y) Allg. Reifen. T. 16. p. 124 .

(a) Alls. Keif. T. 7. P. $9 \mathrm{I}$.

(x) Kolbe, lo c.

(b) L. $c$. 


\section{G E O G R A P H I C A E. FOI}

craffiori tantum gramine pafci confueverunt. Et quis noftrum adeo hofpes eft in patria, qui miras hujus pecoris diverfitates, quae fingulis propemodum in territoriis deprehenduntur, nefeiat? Quod idem \& Thevenotus de Indiae bobus teftatur (c), quos inter tam pumiliones, quam gigantes, illos vix trium, hos fex pedum altos, praetereaque. at multos mediae ftaturae numeravit.

0. VII. Quum itaque pafcua non ubivis aequalia, quibusdam potius in locis abundantia, in aliis vero plane nulla fint; miraculo non effe poteft, boum genus, etiamfi canum inftar omnes coeli aërisque viciffitudines fine damno perferre poffet, nan tam late tamen per orbem diffundi. Canis enim cicur omnibus propemodum cibis, quos digerere poteft, vefcitur; ferus autem venando fibi victum quaerit; accedit, quod omnes coeli ftatus ac tempeftates tolerat.

6. VIII. Non quidem inficias eo, quod infra confirmabitur, bovem quoque multis variisque paftus genenibus faturari; fed ipfum hac in re cum cane comparari poffe, nego ac pernego. Conftat enim, carnivoros animantes multo plura concoquere efculenta poffe, quam ruminantes; quippe qui, quod experientia docet, ex ftomachi difpofitione graminibus tantum, herbis, fruticibus frugibusque aliis e terra prognatis aluntur.:

ઈ. IX Si quis heic loci, an omnes. \& fingulae boum fpecies, an Urus etiam, Bifon, Zebu, feu bubulus Indiae parvus, ad unum idemque genus referri queant interrogaverit, illi refpondeo: Buffonium id jam ex parte certo fatis confirmaviffe (d), qui urum

(c) Thevenots Reifen T. 3. p. 252 .

(d) Buffon Hift. der nat. V1 Thisil, I. band.

$\mathrm{N} 3:$ 
ferum totius generis caput, bovem vero gibberum, bonafum, bubulum parvum indicum, aliosque ejusdem fpecies effe perhibet.

0. X. Quod ut probetur, ad duo praecipue momenta attendamus, oportet. Primo anquiramus, an haec animalia cum noftris bobus coëant; deinde, an, quibus a fe invicem diftant, diverfitates ita fint comparatae, ut regionum permutationibus abfcribi poffint.

§. XI. Quod ad prius attinet, de la Nux jampridem Gallos docuit $(e)$, \& Indiae \& Americae Bifontes cum Europearum bobus corpora mifcere, vitulosque progenerare: gibbum vero adventitium quid effe, quod poft primam generationem minuatur, poft fecundam vero \& tertiam penitus evanefcat, experientia fe didiciffe adfirmavit. Praeterea Kalmius $(f)$ in itineris per Americam Septentrionalem facti defcriptione, expreffis adftruit verbis: Bifontes Americanos cum vaccis cicuribus ex Europa eo delatis conjugari.

V. XII. Notas potiores, quibus peregrini boves ab Europaeis dignofcuntur, in cornibus praecipue $\&$ gibbo quaerendas effe puto; fiquidem coloris, magnitudinis, pilorumque varietates, nec ipfam eorum naturam, nec hujus vim \& conftitutionem efficiunt. Quis enim nefcit, cicura etiam animalia tam coloris, quam magnitudinis habitu mirum quantum inter fe differre; crines autem ad amuffim caloris ac frigoris Zonarum, quibus fubfunt, modo augeri \& condenfari, modo decrefcere $\&$ attenuari. Cornuum vel praefentian vel defectum a folis nutrimentis dependere, exemplo deinceps nota-

(e) Buffon l. c. p. 178 .

(f) Kalmis Reire nach Nord-Amerika. T: 2. p. 350 \% 


\section{G E O G R A H I C A E. 103}

tu digniffimo evincetur. Gibbum autem in cafu fitum, nec boum naturae neceffitudine quadam additum effe, $\&$ hanc idcirco deformitatem poft fecundam tertiamque propagationem difparere, jam de la $N u x$ probavit:

6. XIIt. Interim bovem folis, quibus largiffime fruitur, alibilibus nutrimentis tam infolenter immutari, bifontisque gibbum ex una victus, quem abundanter fumit, copia \& adfluentia magis, quam ex onerum, quibus ferendis fubmittatur, preffione ortum effe, vero. quam fimillimum mihi videtur. Quis enim fibi perfuaferit, hanc tantam carnis molem, quinquaginta \& interdum fexaginta libros excedentem $(g)$, ex folo, quem patiatur, farcinarum preffu excretam fuiffe? nonne potius, quod in compreffis hominum partibus fieri cernimus, callum eo, quem nunc immenfa carnis maffa ve ftit, loco duxiffet? Victum autem affatim fumtum modo ad has, modo: ad illas corporis partes augendas a natura deftinari, ex quibusdam ovibus confpicere licet, quarum caudae tam incredibili adipis pondere aggravantur, cui ferendo ipfarum vires vix fufficiunt.

0. XIV. Bos frigoris vehementiain non tanta facilitate, qua canis, tolerare ex eo perfpectum eft, quod nec Kamijcbadales nec Grocnlandi (b) pecudes cornutas educare poffunt. Intenfus calor autem ipfis tum quam maxime nocet, quando folis aeftus pafcua aduffit. Boves in ora murea tam exilis effe faturae, Artus tefta$\operatorname{tur}(i)$, ut vitulis vix rumen praebere valeant; \& e

(f.) Flacourt Rélation de l'Ine dé Màdagafcar p. 20.5.

(b) Egeile in Defeript. Groenlandiae expreffis verbis afferit, in Groentandia nullum, praeter canem, animal cicur vivete poffe; id quod etian

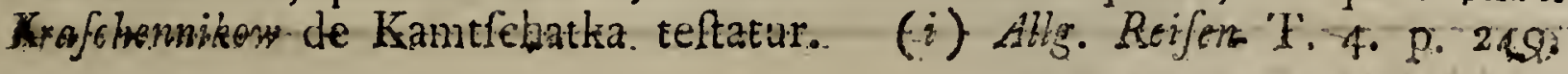




\section{4 \\ SPECIMEN ZOOLOGIAE}

viginti vel triginta vaccis vix tantum lactis colligi poffe addit, quantum uni directoris, qui in arce $S$. Georgii del Mina fedem ac domicilium habet, prandio fufficiat; eas praeterea, licet ejusdem loci caloren longe melius. cane furtinere queant, tam tenues tamen effe affirmat, ut maximae pinguilfimaeque vix ducentas quinquaginta libras efficiant. Cujus rei hanc rationem adfert, quia folis aeftus pabulum hanc circa regionem vehementer amburit; hinc fieri, ut aliis locis, qui eadem fere aeftus gravitate torrentur, fi modo pafcua paulo laetius virefcunt, majores tauri pinguioresque vaccae inveniantur.

0. XV. Futii, Mandingoenfes, reliquique fere omnes, qui prope Gambiam Senegalamque populi habitant, quin infularum oras illas adjacentium incolae magnam boum eximiae magnitudinis copiam numerant $(k)$. Tauros ibi robuftos $\&$ pingues eorumque carnes fapidas admodum effe, vaccas vero affatim lactis praebere, omnes, qui eas terras peragraverunt, uno ore fatentur. Ex quo clare fatis colligi poffe autumo, primum horum animantium domicilium, primamque originem in calidioribus terrac regionibus, praecipue vero in Afra temperatiori quaerendam effe, ubi aptiores, perfectiores, omnibusque fuis \& corporum \& ingeniorum partibus expletiores, \& nafci \& educari perfpicimus.

0. XVI. Quamquam bos Europaeis jam diu maximo fuerit ufui: neutiquam tamen tot \& tanta, quot Indi Cafrique, ex eo commoda adipifcuntur. His non modo easdem, quas nobis, utilitates praeftat ; fed canum etiam, equorumque, quin cuftodum muniis fungitur. 


\section{$G E O G R A P H A C A E$.}

Modo enim reliquum gregem praefidio cuftodiaque fua tegit, modo dominis bella gerentibus auxilio eft, modo terga fefforifuo praebet, modo carpentis junctus, modo pofita fibi onera patienter ferens, ductori fuo obtemperat.

f. XVII. Quod idem \& Kolbius his prope verbis comprobat (l). Hottentotae bove, quem Bakkaleyorem appellant, eadem ratione eodemque fine, ac Magores elephante, in bello utuntur: eum fic erudierunt, ut ad minimum heri fui nutum attendat, \& modo divagantes a grege pecudes reducat, modo gregem ipfum a belluis rapinam minantibus defendat. Ipfe omnes ac fingulos pagi ejusdem incolas exacte novit, \& quosvis peregrinos furibundo impetu adgreditur, ideoque latronibus etiam non exiguum injicit metum terroremque; finguli pagi fex ad minimum, pluresque interdum Bakkaleyores nutriunt, quos viri, foeminae ac liberi pari Itudio \& attentione, ac canes noftri dominos fuos, colunt. Plerique Indiae habitatores eadem commoditate, qua nos equis, bobus vehuntur.

J. XVIII. Et Thevenotus cum Oleario, bovem indicum curfus celeritate equos aequiparare, difertis verbis adftruunt; quod etiam itinerum collectores varie confirmant, bovem teftantes in India equi loco effe ; \& licet nec frena gerat, nec admittat, pari tamen facilitate regi poffe. Continuum fexaginta dierum iter fine remiffione ipfum conficere, fingulisque diebus quindecim miliaria gallica fine damno emetiri poffe; prandii loco eundem farina triticea, butyro faccharoque nigro com-

(l) Kolbe Befchreibung des Vorgeb. ed. in fol. p. 470. 


\section{SPECIMEN ZOOLOGIAE}

commifta, pafci, circa vefperam vero pifis comminutis cibari; trium \& dimidii centenariorum pondere, quod commode perfert, onerari perhibent. Unus alterve quingentarum interdum rupiarum pretio vendi folet $(m)$. $\mathrm{Si}$ praeterea manfuetudinem $\&$ docilitatem, quam iis in regionibus animal iftud commonftrat, exacta mentis acie difpicio, haud improbabilibus rationibus adduetus colligo, Afiam " \& Indiam inprimis, ubi natura ipfum omnibus e partibus expolivit, veram ejusdem patriame effe.

6. XIX. Satis quidem nota mithi experientia eft, quae non fine aliqua probabilitatis fpecie mihi opponi poffet. -Conftat nimirum Swes, quos inter domeifticos animantes Europa numerat, in America, ut primum detegebatur, nullos fuiffe; quos tamen, poitquam ex veteri orbe noftro eo deducti funt, non folum optime ibi provenife, fed eo etiam incremento fuiffe auctos, ut kuropaeos longe fuperaverint. Tantum itaque abfait, ut extra patriam pofiti decrefcerent, ut potius multo majores pinguioresque evaderent. Nonne exinde conjectura mea, qua animantis patriam eam effe ftatuo, ubi quam optime glifcit, infirmari convellique poffet?

6. XX. Equidem lubens concedo, corpora inufitatam ibi in magnitudinem excreviffe, quoniam largiorem, naturaeque fuae magis, quam alibi, convenientem victum illa terrae pars fuppeditat; fed ingenii etiam vim, vigorem, docilitatemque ipfius in novo orbe fic augeri, uti in bove afiatico obfervamus, praecife nego:

(m) Allgem.Reijein T. I2. p. 706 


\section{G E O G R A P I C A E.}

go: quum experientia difcamus, nec manfuetiorem a: gilioremque, nec fagaciorem ibi locorum porcum unquam factum effe. Accedit unanimis vetuftiffimorum frriptorum confenfus, bovem bifontemque poft hominum memoriam Afiae fuiffe incolam conteftans.

j. XXI. Quum ex obfervationibus hinc inde jan adductis conftet, coloris \& cornuum aeque ac corporum magnitudinis diverfitates partim ex coeli, fub quo animal hoc vivit, partim ex victus, quo alitur, difpofitione oriri : ad majorem rei evidentiam quaedam adhuc notatu digna addere placet; quorum primum eft; colorem in bobus mirum quantum variare \& mütari: Nonne fub eadem cóeli regione alii rufo, alii fufco, alii nigro, grifeoque, alii multis fingulari modo inter fe commixtis, alii aliis haud multưm a fe invicem diftantibus infecti coloribus confpiciuntur? Nonne exinde colligi poffet, nullum dari colorem, qui unius ejusdemque loci bubus proprius fit $\&$ adjunctus?

0.XXII. Nihilo tamen fecius experientia docet: certos colores certis terrae aërisque plagis quafi adftrictos \& peculiares videri. Sic Italorumi aeque ac Polonorum boves propemoduin omnes vel grife i vel albi effe folent - (n); qui tamen in India candidi $(0)$, in Africae oris albi quidem, fed nigrore nulto admixti $(p)$, in Germania Galliaque rufi plerumque funt, qui rubor in aliis pailidior, in aliis fulvior ad nigredinem tranfit. Sic \& pellis eorum pro aẹris conftitutione varius eft, quippe qui ad Hudfonis

orani

(n) Voyage de Burnet. Rotterdam 168. T. 2. p. 12.

(o) Grolf. Voy. to the Katt. Indies Lond. 1753. p. 253 .

(p) Allgem. Reizen T. 2. p. 87. 
TO8 SPECIMEN ZOOLOGIAE

oram $(q)$ \& in nova Gallia denfiori longiorique, in Mexicorum regione, rariori, in noftris vero terris breviori pilo tectus invenitur. Quasdam Africae partes, quae flagrantiffimo folis aeftu. torrentur, boves aeque raripilos, quam bubalus eft, proferre, deinceps ex quodam Pbiloftorgii loco demonftrabitur.

ర. XXIII. Si vero ad pilorum praeftantiam re fpexeris, illos, quibus bos gibbofus \& bifon veftitur, omnibus, quos ex bubus nullo gibbere tumentibus collegeris, longe anteponas oportet. Quoscunque enim: bifontes tam vetus, quam novus terrarum orbis alit, pilo \& longo \& bombyci perquam fimili: praeditos fcimus ; quod: Buffonius etiam affirmat $(r)$.. tam boves gibbofos inquiens, quam bifontes, a quibus illi orti funt, longe molliori nitidiorique pilo prae noftris gaudere, quos urorum in modum afperiori rariorique veftitos videmus. Quod memoratu eo dignius eft, quum temperatior alias: Syriae \& reliquae circumjacentis Afiae calor animantium: pilos ferici fimiles reddat, cujus: rei.veritatem Angorae: pecora domeftica comprobant.

6. XXIV.. Ex qua re patet, in natura incompre-henfibiles perfaepe a regula exceptiones occurrere, ideoque in univerfalibus formandis. propofitionibus: omnem cautionem. adhibendam effe.. Quando, ut exemplum: adferam, Buffonius in bifontis: defcriptione annotavit ipfum aliosque boves gibbofos regionum meridiem verfus fitarum quam maxime feffores effe, id in orbe quidem antiquo veritate fuia nititur. Sed quum America, lios:
(q) lbid. T. 17. p. 229.
(r) : L. .. p. 183 s. 
hos animantes fine gibberis fui detrimento molliorumque crinium degeneratione, extremo poli feptentrionalis frigori perpetiendo pares effe, teftetur; ( $(s)$ generalem illam enunciationem arctis admodum limitibus circumfcribendam effe cernimus.

ઈ. XXV... Quum jam ante dictum fit, una eademque in regione boves \&.corporum magnitudine eximios, \& parvitate fua notabiles inveniri; idem huic animalium fpeciei, quod canibus, accidere certum eft: idcirco tamen corpora colofforum, pygmaeorum, \& quae in utrorumque confinio pofita funt, non fingularia genera conftituunt; fiquidem has omnes, quantaecunque fint, diverfitates tam coeli aërisque diverfae temperiei, quam cultus victusque, quo nutriuntur, varietati attribuendas effe credo. Et qui modo, quid coeli ftatus", aëris efficacia, terraeque vis \& conftitutio poffit, curate introfpexerit, omnes tantopere a fe invicem diftantes fpecies, facile ad unam originem eundemque generis auctorem referet.

0. XXVI. Qui extremos.inter maximum minimum. que bovem limites conftituunt, funt $T$ auroelephas $\&: Z e-$ bu. Ille bove noftro duplo major eft; ex Pbiloftorgii relatione pari, cum elephante, pelle veftitur, \& ejus. dem prope magnitudinis eft: quod ex ipfis auctoris verbis eo magis patebit; hoc belluarum genus, aientis., (quas Tauroelepbantos in antecedentibus nominaverat) caetera quidem bos maximus eft, corio autem \& cutis colo-

(s) Bifon freti Hudfonis , Bos cornibus divaricatis, juba longiflina, dorfo gibbofo Linn. Syft. ed. ẊII. Catesby-Carol.'3. p. 20. \& Hernanidez Mex. in Fab. Lyncei Expor. p. $58 \%$. 


\section{IIO \\ SPECIMEN ZOOLOGIAE}

colore \& magnitudine ferme elephas. Hoc animal ipfe vidi, quum ad Romanos delatum effet, idque, quod vidi, fcribo $(t)$ :

0. XXVII. Marmolius in Africae defcriptione adferit (u), vaccas AEthiopiae fuperioris camelos magnitudine aequiparare: \& Pater Liobos (v), cornua bovis Aby/finenfoum tanta effe, adfirmat, ut quodvis eorum viginti \& amplius menfurae anglicae pintas cà iat: Bernierius fe ejusdem capacitatis cornua, quae Habeffinicus Legatus in India feptentrionali intra Gangem fita posfederit, vidiffe teftatur ( $v$ ).

6. XXVIII. Cum hifce, quaefo, bubus illos compares pumiliones, qui, quod $T$ bevenotus, quem jam adduxi, adfirmat, tres pedes alti funt: cum his conferas Bellonii pufillum bovem, quem Zebu nuncupant $(x)$; nonne obftupefces, ejusdem fpeciei pecora fub climatibus parum a fe invicem diftantibus, partim pabulo, partim aliis exigui momenti caufis, exempli caufa, corporum commixtione, tantopere de priftino roboris magnitudinisque fuae gradu, delabi potuiffe?

§. XXIX. Africa itidem patria eft bovis exigui $Z_{e}$ bu diç, $(y)$, qui, vitulorum noftrorum fextam nondum hebdomada egrefforum inftar, duos pedes feptem-

que

(t) Philoftorgii hiftor. ecclef. Lib. 3. Cap. 2.

(u) Vid. etiam Ludolfii Hift. Aethiop. T. 3. p. I57.

(v) Lobos Voyage Hiftorique d' Abiffinie. 'T. I. p. 57.

(w) Voyage à l'Etat du grand Mogol.

(x) Bos indicus. Bos cornibus anre brevioribus, dorfo giblo, . juba-nulla. Linn. Syft. ed. XII. Plura de illo apud Buffonium 1. c. ubi etiam omnes propemodum boum varietates invenies.

(y) Leo Afric. 1. c. p. 751 . 


\section{G E O G R A P H I C A E.}

que digitos altus, manfuetudine fe fua commendat, quique olim fub Danti nomine, quod tamen alius cujusdam Americae pecoris, ab hoc diverfiffimi proprium eft, innotuit. Hoc enim animal, Dant nimirum, nec illud effe, cujus itinerariorum collectione fub Tapiri appellatione mentio facta eft, ex eo conftat, quod iter, in quo ejus mentio fit, jam anno I455., ideoque ante novum orbem detectum, factum eft \& abfolutum: infuper accedit, quod Tapirus cornubus caret. Ex antedictis itaque elucet, boum aeque ac canum magnitudinem mirum quantum inter fe difcrepare.

6. XXX. De cornuum degeneratione, licet in prioribus jam quaedam attulerim, hoc tamen loco non praetermittendum eft, in eadem interdum regione boves. tam cornubus armatos, quam viduos nafci. Qui Islandiam defcribunt, hoc inter alia múlta commemorabilia adferunt, vaccas, quae in auftrali infulae parte aluntur, cornibus deftitutas; boves vero reliquarum ejusdem partium, cornutos effe. Cujus rei rationem addunt: quoniam auftralis partis incolae, deficientibus pafcuis, pecudes fuas pulte, ex pifcibus putrefactis confecta, nutrire coguntur; quum e contrario caeterarum hujus infulae regionum habitatores meliori pabulo boves fuos faturent; hine fieri, ut cornibus ornentur $(z)$. Neminem tam iniquum fore crediderim, quin tam perfpicuo convictus exemplo cornuum tam defectum, quam différentiam alímentorum vel inopiae, vel ubertati fit adferipturus.

SECTIO

(z) Allg. Reif. T. 19. p. 20. 


\section{SPECIMEN ZOOLOGIAE}

\section{S E C T I O V.}

5. I. A d duo nunc animalium genera transgredior,

A quae tam propinqua fe invicem cognatione contingunt, ut haud facile, quid inter utraque interfit, dignofcere poffim: Ovem nimirum \& capram, quae itidem totam fere nobis cogniti orbis fuperficiem occupant; quae quim tam fibi fimilia, tamque confinia fint, ut magni naturae fcrutatores, Buffonius \& Linnaeus, ea vix disjunxerint; nec mihi vitio vertendum erit, fi eorum hac in re veftigia profequar, \& quam longe lateque extendantur, quid coeli aërisque ratio, quid alimentorum varietas, quid domiturae vis in utrisque efficiat, fub uno eodemque adfpectu ponam.

J. II. Ovis licet exigua admodum folertia ingeniique alacritate gaudeat, donum tamen tam eximium rerum conditoris eft, quod nunquam grata fatis mente agnofci, nunquam digne aeftimari poteft: ex quo fimul perfpicitur, ingenii vim facultatemque pecudibus innatam, non femper ad eum frußtum noftrum redundare, qui fperari poterat. Ovis hạec \& capra, quam paulo majori tantum, prae ove, alacritate, praeditam cernimus, tam frigori feptentrionis, quam Guineae calori perferendo fufficiunt: quod eo magis notandum eft, quum utrarumque corpora tam debilia fint, ut nec cum canibus, nec cum bobus unquam comparari queant.

5. HI. Islandia, quae ad fexagefimum fextum latitudinis gradum ulteriusque extenfa eft, oves aeque ac canes alit, quod Horrebowius (a) teftis ocularis, quam-

vis

(a) Horrebow in Allg. Reif. T, Ig. p. 20 \& 21. 
vis Anderfonius id olim negaverit $(b)$, perfpicuis verbis confirmat; caprae, inquiens, ovesque ibi degentes noftris \& magnitudine \& bonitate propemodum aequales funt. Groenlandi vero perpaucas oves, $\&$ excepto cane, nullum cicur animal nutriunt. $\mathrm{Cu}-$ jus rei caufam Cranzius adfert ( $c$ ); hiemis nimirum diutius ibidem faevientis incommoditates inhibere, adftruit, quo minus numerofi earum greges haberi posfint: quuin, quae ad novi Herrenbutbii pagum deductae fint, fatis ex voto proveniant.

0. IV. Ad Senegalli ripas $(d)$, ad aureum litus, \& in Guineae promontorio $(e)$, utrarumque pecudum magna copia oberrat. Caprae in eo tantum ab europaeis differunt, ut minores quidem, fed ovibus longe fint pinguiores. A promontorio, quod Blancum vel album appellant, ad Sierram Leonam inulta \& ovium millia numerantur; caprae in primis ad meridiem fenegae acervatim difcurrunt $(f)$. Ultra aequatorem utraeque fpecies conjunctim progrediuntur. Hinc alii in Congi regno $(g)$, in bonae fpei promontorio $(b)$, in Brafilia $(i)$, in Chako $(k)$, quin \& Dampierius, in novae Guineae regionibus, in Infula $S_{a v u}(l)$, capras obvias habebant $(m)$. Alii ad Janeiri ripas multos vervecum gre-

(b) Anderjons Nachrichten von 1sland. p. 37.

(c) Crans. Allg. Reir. T. 20. p. 40. (d) Allg. Reif. T. 2. p. 87.

(e) Bosmans Befcirreibung von Guinea, Hamburg 1708. p. 278 \& 279.

(f) Allg. Reif: T. 4. p. 250.

(g) Pigafettae Defcript. regni Afric. quod Congus appellatur. p. 83.

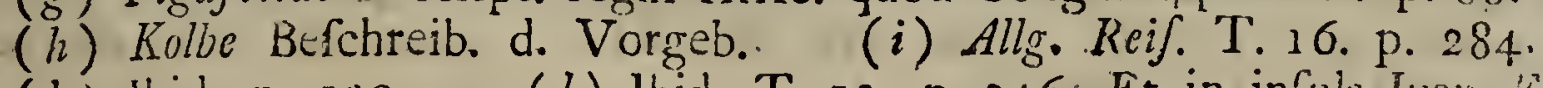

(k) Ibid. p. r29. (l) lbid. T. 12. p. 246. Et in infula Juan fiernandez capræ inveniuntur. ibid. (m) Cooks Voyage in Haw Kesworth's Collection. T. 3. p. $6 \$ 3$. 


\section{II4 SPE CIMEN ZOOLOGIAE}

greges, capras tamen non pari fertỉitate auctas deprehenderunt: quae vero difficultates harum incremento obftiterunt, poftea fublatae funt.

ઈ. V. Ex tot teftimoniis facile patebit, utraque pecora jure merito iis adnumeranda effe, quae quam latisfime per orbem diffeminata fcimus. De ipforum degeneratione deinceps acturus, multas alias, quas nunc inhabitent fedes, prius percenfebo.

6. VI. Coeli auraeque temperies, nutrimentorum diverfitas \& fervitus, in quam ab homine redaeti funt, in his animantibus pari ratione, ac in bove $\&$ cane, quid valeant, commonftravere. Hinc enim effectum eft, ut robore \& alacritate fua privati omnis auxilii inopes evaferint, \&, fibimet ipfis relicti, nullo pacto fubfiftere poffint.

Q. VII. Buffonius capram ammonis vel mufimonem (n), quem etiam Argalin, vel Muflonem vocitant; generis hujus auctorem effe, \& ab ibice (0) feu birco fero capras originem ducere, fumma cum probabilitate ftatuit. Rationes addit, quod in tota rerum natura, praeter argulin, fera inveniatur nulla, quae \& ratione interiorum \& exteriorum partium tam exacte noftrae ovi refpondeat. Solis enim pilis \& cornibus a noftris differt, quae tamen, quod poftea commonftrabo, nec vim nec naturam anithantis efficiunt: praeterea compertum effe ait, arga. lin cum ave noftra cöre, agnosque progenerare. I6icein

(12) Capra comilus arcuatis femicircularibus, jubtus planiufoutrs, palearibus lanis, gula imberbi. Linn. Sylt. Ed. Xll. de Ammone vide Bufforn. l. c. p. 204 \& 216 . Tab. 29.

(0) Cafra cornibur fupra nodofis, in dorfum reclinatis; gula berbato. Lima. Sylt. LC. XII. \& Buffon. 6. Land. 2. Th. p. 81. \& 97. 12ib. 13. 
cem vero eundem effe, atque bircum, ex infigni utriusque \& corporis \& ingenii, quin totius ftrueturae fimilitudine, \& ex eo etiam colligit, quod ferus ille bircus in infula Creta facile manfuefcat. Utraeque ferae juga montium incolunt, deferta loca pererrant, fublimia faxa praeruptasque rupes mira celeritate adfcendunt, aggrefforum vim animofe repellunt, in ardore fortioribus beftiis audacter refriftunt.

0. VIII. Argalis, quod Gmelinas in itineris fibirici defcriptione teftatur $(p)$, in montibus fabiriae auftralis ab Irtifchii fluvio usque ad Kamtschatkam habitat, fingularique fagacitate gaudet. Quem.ipfe confpexit, vix triennium fuperaffe vifus eft: interim tamen nec decem homines ipfum adgredi \& coërcere aufi funt. Tantae cornua molis \& amplitudinis gerit, ut orificia illorum, quae in defertis, Steppen vulgo dictis, interdum reperiuntur, eo loco, quo capiti adfixa fuerunt, vulpeculis abfcondendis fpeluncae loco infervierint. Ingens eorum, quo valent, robur in cornubus horumque ufu confiftere, \& haec ipfa quadraginta librarum pondus interdum excedere perhibent. Hactenus Gmelinus.

0. IX. Tanto igitur intervallo Ammon a noftris domefticis ovibus diftat, ut plerique naturae indagatores eundem ab his fegregantes caprarum claffi adnumeraverint ; licet nota hircorum characteriftica, qua caprae ovesque quam maxime disjunguntur, barba nimirum deftitutus fit. Corporis itaque vires, nervorum firmitatem, ingenii alacritatem, membrorum pernicitatem, ani-

(p) Gmelins (fenioris) Reif. durch Siberi: Goettingnen I 75 I. T. r. p 368. 


\section{SPECIMEN ZOOLOGIAE}

mique audaciam, verbo omnia in fervitute fua ovis perdidit, quibus antea in libertate eminebat; \& tantopere a priftina fua felicitate dejecta eft, ut probabile fit, eam fine domini fui praefidio penitus deletum iri.

6. X. Si quis itaque Buffonii fententiam repudiare, nec ammonom ovium, nec ibicem caprarum patrem adoptare voluerit, is eo ipfo lupum a cane, urumque a bove, diffociaturus effet. Quemadmodum enim ovis \& capra, quod ad naturalem corporis fui ftructuram, cane ac bove longe funt inferiores; fic etiam poft do: mituram in ftatu fuo domeftico, pro utriusque facultate eo majorem fecere jacturam, eoque deteriores illis discefferunt. Ammonis ab ove noftra differentia \& diftantia inter hircum ferum minimamque Africae capram, quam Linnaeus reverfam vocitat, (q) non major eft illa, quam inter Urum \& Zebum, inter lupum canemque melitaeum deprehendimus.

0. XI. . Si aryalian cum ibice comparaveris, tunc in ovium caprarumque genitoribus maxima tibi fimilitudo, \& hoc etiam in oculos incurret, ibicem eadem alacritate argalim, qua hircus arietem, fuperare. lbex, qui in Vallefiae, Salisburgi, Pyrenaeisque montibus, in aliquot arcbipclagi infulis $(r)$, quin tefte Brownio $(s)$, in famaica reperitur, eadem facilitate, qua ammon montium ardua incolit, ad longe tamen praeruptiores fcopulos prae illo ungulis fuis enititur, \& immenfae profunditatis voragines faliendo transvolat. Tam enim robuftae eft naturae, ut decem orgyarum

(q) Capra cornibus creetis apuce recurvis Linn. syit. Lc. XIL.

(r) Hatien Nat. Hit. I. I. p. 3 I3. \& Buffon. 1. c.

(s) Brow'ns civil and natual Hiltory of Janaica Cap. 5. 


\section{G E O G R A P H I C A E.}

altitudinem uno faltu fuperet, \& quoties inevitabile periculum praefentit, furibundustanto fe in venatorem impetu immittit, ut hic exanimis corruat. Adverfariorum quos medio capite petit, offa confringit, \& licet nulla corpori vulnera inferat, id tamen vel arboribus, vel faxis illifum, enecat $(t)$.

0. XII. Aeque inufitatis cornubus, atque ille, armatus eft, \& in defertis rupibusque domicilium quaerit: hac una in re ab argali discriminatur, quod, omnium caprarum more, prolixa barba infignitur, qua ammon omnesque pofteri ejus, oves puta, carent. Caeterum haec fera eadcm propemodum fata, quain argalis, experta eft: manfuefacta enim peraequa proportione tantundem folertiae detrimentum in progenie fua fecit, quam ammon in ovibus. Quum enim ille in ftatu fuo naturali hoc longe alacrior effet; hircis caprisque cicuribus plus etiam nunc ferociae ac vigoris, quam ovibus, relietum efle, ex eo videmus, quod ardua montium filvarumque adhuc fatis audacter ultroque pererrent; quod tamen imbecilliori ovidenegatum, codemque gradu oves nunc capris inferiores elfe, quam hirco fero ammon erat, abunde conftat.

6. XIII. Interim animalibus his eo ipfo, quod e montibus in planum fe demiferunt, magnam pernicitatis, roboris, audaciaeque, quibus pollebant, partem adem tam efle, his palam erit, qui confiderant, in montibus ea multis millibus libris minori aëris onere, quam, nunc prefla, puriores nullisque vaporibus commiltas auras hau-

(1) Gafton Phocbus Vcnerie de Dufoulloux p. 68. v. etiam de Ibice Gesnat. 


\section{IIP SPECIMEN ZOOLOGIAE}

haufiffe, fucculentis iisque nutrita herbis fuiffe, quae vitalem fanguinis calorem partim confervabant, partim augebant. Tantis hifce tamque praeclaris praedita emolumentis mirandum non eft, fi noftras pecudes domefticas jan longe antecellunt.

0. XlV. Quodfi praeterea penfitemus, quid manfuefactio, quid neceffitas effecerit, qua montes cum vallibus, ardua cum planis commutare adactae fint: co facilius comprehendemus, qua ratione ipfarum corpora-imbecilliera, ipfarum natura defidior, ingeniumque hebetius factum fit. Hi animantes eidem legi fubjecti funt, qua reliqui omnes devincti tenentur, ut nimirum, quamdiu montes incolunt, multo fint faniores, alacriores hilarioresque, quam fi ex illis in plana defcendunt.

J. XV. Quam eandem veritatem Hallenius (u) ex multis obfervationibus contemplationibusque generis humani naturae collectam, his verbis conteftatus eft: in regionibus montofis nati homines, corporis pulchritudine \& ingenio multis eos parafangis poft fe relinequunt, qui in planitie vivunt: quod idem in animalia etiam convenire certum eft. Sic elephas montanus majoribus, quam reliqui fui generis, viribus majorique gåudet vivacitate $(v)$. Sic capreoli cervique in collibus nutriti multum illis praeftant, qui in vallium latebris commorantur $(w)$. Sic lepores in montium jugis degentes magnitudine, pinguedine, gratiorique carnium fapore, caeteros fuperare dicuntur $(x)$. Quae omnia

(u) Natur. Hift. T. I. p. 147. (v) Buffon 6. Th. I. Band. p. 23. (wi) Doebels Jagerbuch p. 4. (x) Buffon 3. 1h. 2. Band. p. 144. 


\section{G E O G R A P H I C A E.}

omnia nec admirationem habent; quum propter adductas jam non exigui momenti rationes, aëris fcilicet preflionem, nutrimentorum diverfitatem, \& purioris: aurae fpirationem fieri nequeat, quin animantium natura immenfum in modum varietur.

6. XVI. Scbeucbzerus alpium editiffimos in $95 \mathrm{SO}$ pedum altitudinem eminere contendit $(y)$, quorum cacumina quum aeterna nive contecta fint, capricornus autem \& rupicapra in fertilioribus ipforum regionibus haereant: utrosque faltim ad fexies vel fepties millefimum pedem efcendere, ibique cubilia fibi componere crediderim. Quoties autem barometrum in locum fexies: mille pedes a mari elevatum effertur, argentum vivum, Daniele Bernouillio tefte ( $z$ ), ad vicefimum primúm usque pollicem decidit: aër igitur, qui, hydrargyro ad vicefimum oetavum pollicem fublato, corpora bis mille: quinque \& femiffis librarum pondere aggravat; hoc ipfo in loco pedem quadratum mille quingentis quatuor tantum libris \& octante oneraturus, eoque ipfo fingulis pedibus quadratis quingentarum unius librarum triumque octantium fumma deceffura effet.

0 XVII. Nemini praeterea dubium erit, quin ibicis fuperficies, humana paululum fit inferior: quunque huic quindecim pedes quadrati tribui foleant, iliduodecim demus; quo facto, differentia qua aërarietem in vallibus degravat, in montibus veroallevat, ad rexies mille centum \& octoginta pondo adfurget. Quodf ejus fuperficies jufto major adumta cuiquam videbitur, ipfan tamen differentiam idcirco femper eandęm habere proportionem certum eft. $\quad$ X. XVII

(y) Comment. Bonon. '1.1. 309. (zi) Hydrodynath: Sedt 10. 


\section{I20

6. XVIII. Ponderis interim, quo aër pulmones urget, nullam in hac fupputatione rationem habitam effe, cuivis liquet. Ponamus itaque, quod nonnuli naturae interpretes adftruunt (a), eorundem fuperficiem in decem quadratos pedes extendi : annon eo ipfo aëris efficientia infigniter partim increfcens, partim decrefcens, in montium valliumque habitatoribus mirandam diverfitatem producet? Fac, animal, cujus pulmo, fibrae \& vafa in montium jugis leviori aurae adfueta funt, in imas valles detrudi, ibique ut manfionem habeat, \& nutrimenta fua quaerat, cogi ; quam incredibiles fubire commutationes, quam enormem naturae ftatusque fui converfionem ex immani, quae tunc venas, arterias, quin fingulas ipfius partes comprimit, aëris mole potietur: nonne fanguinis circulatio fufflaminabitur? cor non exiguo cum dolore conftringetur? membrorum incrementum impedietur? corporis robur, ingeniique viresimminuentur, \& paulatim in aliam quafi fpeciem, quae ex aliis quafi parentibus orta fit, converfum videbitur?

f. XIX. Nec omittendum eft, aëra, qui in montibus fpiratur, non modo perfe leviorem, fed hanc etiam propter levitatem, gravioribus particulis adfumendis ferendisque imparem, ideoque peftiferisvaporibus, imas qui valles plerumque inficiunt, minus oneratum effe. Corporum igitur ingeniorumque vires, nullis infalubribus terrae exhalationibus hebetatae, aeque integrae fint, aeque validae maneant oportet, atque ipfe, quem hauriunt, aër ut plurimum eft. Quum enim exfpirationes noxiae, quas folis calor ex agris aquisque tepe-

(a) V. Mu/chicnbr. Philofop. Natural. 


\section{G E O G R A P H I C A E? I2E}

factis excitat, quibusve ingentem morborum vim medicorum filii jure adfcribunt, in montibus vel nullae plane, vel faltem tenuiffmae fint: peftilentia, febres that lignae, aliaque estohima ibidem vel penitus exfulabunt, vel minus periculi damnique adferent: quod Heloetia, Quito, aliaque editioris fitus loca evidentiffimis exemplis comprobant.

0. XX. Sic abbas Ricbardus in aëris, quam verbofam nimis edidit, hiftoria naturali $(b)$, luem, quae aliats regiones infeftas facere, crebroque populos contagio conficere foleat, in Helveiia minus notam, ejusque potius incolas plerosque fanis robuftisque corporibus praeditos effe confirmat. Quod idem Ulloa (c) \& Boitguerius de Quito, Americae urbe non ignobili, mille propemodum \& fexcentas orgyias fupra mare edita, iisdem fere verbis teftantur: morbos, ajentes, qui urbes internecino contactu depopulantur; ibidem ignorari, aëraque puriorem malignis humoribus adeo refiftere, ut nec ipfa lues venerea homineslecto adfixos teneat.

ర. XXI. Si levior, quo excelfae regiones circumfunduntur, aêr vapores ex depreffioribus locis adfcendentes nec: fufcipere nec retinere poteft; ipfe vero generatim aliorum corpufculorum admiftione, eorumque vel incremento, vel decremento, modo gravior, modo. levior fieri folet; eaque de caufa, quod barometrum, ejus index, confirmat, tot tantisque viciffitudinibus obnoxius eft: prono inde, quod ajunt, alveo fluit, ela tiores regiones multo ftabiliori, nec tot immutationibus

ex:

(b) Richard Hiftoire naturclie de P'Arr 1:4. P. 382.

(c) Ulloa Voyage Lib. V. Cap. 6. p. 24 I. 


\section{SPECIMEN ZOOLOGIAE}

expofito pondere, quam valles, uti \& adfici. Quod experientia, optima hujus etiam rei magiftra, extra dubium collocatur. Demiffiori enim in noftra regione hydrargyrum a vicefimo feptimo ad vicefimum nonum pollicem tresque lineas elevari, \& hinc differentiam vìginti unius linearum fubnafci iteratis obfervationibus cognovi. Mufchenbroekius Lugduni Batavortun argentum vivum in barometro tres digitos. $(d)$, Scbeucbzerus in Saneti Gotbardi cacumine decem lineas $(e)$, Bougrierius autem in celebri Americae urbe Quito $(f)$, unam. tantum lineam jam adfcendifie, jam defcendiffe, obfervando didicerunt. Ex quibus effici cogique videmus, in montibus aliquot millia pedum editis, animarlium corpora uno femper eodemque propemodum aëris onere premi; - vallium vero habitatores paucarum interdum horarum intervallo, amplius mille librarum pondere urgeri : ecquis tam fubitas mutationes animantium naturae \& conftitutioni maxima importare damna negaverit?

j. XXII. Duplex praeterea caufa fubeft, quarn propter major frigoris vis in montium excelfitatibus, quam in depreffioribus locis dominetur: primo enini. fubtiliores aëris particulae, ob infignem tenuitatem fuam, exiguum - nodo caloris, gradum admittunt; deinde folis radii, quos aprica terrae planities reffeetit, eousque penetrare nequeunt, ut caloris quidquam in montibus excitare, aut in eorum, vertices. deferre va-

leanr.

(d) MufJchendroek 1. c. T. 2. in Capite de Aëre.

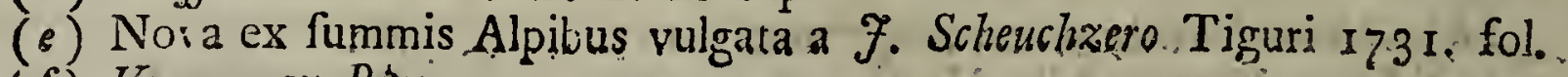

(f) Voyage alt Perou. 


\section{GE O G R A P H I C A E.}

leant. Frigoris igitur perennitas \& aptus \& integra corpora comprimendo corroborat, efficitque, ut naturam longe firmiorem valentioremque induant.

6. XXIII. Ut omnem denique, qua montium incolae prae caeteris animantibus pollent, praeftantiam recte dijudicare valeas; victum etiam, quo pafcuntur, adfpice: qui: ex herbis in puriori aura progerninantibus, \& idcirco caeteris, quae demiffioriun loco nafcuntur, longe falubrioribus efficacioribusque confiftit. Nonne fic eo certius tibi conviEtofatendum erit, fieri non poffe, quin fola tam ingentium fingulariumque commutationum congeries, beftiae e montis cacumine in imas valles depulfae, corpus animumque mirifice invertat, \& in aliam quar transfiguret? Herbae, quae alpes proferunt, aromaticae, tam in capricorno, quam in rupicapra, quae inferiori paululum in loco latitare folet, fuccos generant validiffmos: hinc utrorumque fanguini medendi quandam vim ineffe, non exiguae famae viri multiplici ufu variisque cxperimentis cognoviffe teftantur $(g)$, qui cicurum quoque hircorum, fi aromaticis herbis faturati fuerint, cruorem eadem pollere facultate contendunt $(b)$. Ex quibus fingulis cuique, vel mediocris excelfitatis montes falubritate multum vallibus praeftare, facile patebit.

6. XXIV. Non igitur opus eft, ut alias noftalgiae, quam nominant, caufas exquiramus: quum fola melio-

( $g)$ De vi medica fanguinis rupicaprae \& ibicis, vide Gesneri Hift. Quadrup. P. 322. \& 333.

(b) Hift. naturelle des Animaux par Mrs. Arnault de Nobleville \& Salerne. Paris I 756. T. 4. p. 244 .

Q 2 


\section{SPECIMEN ZOOLOGIAE}

lioris victus abfentia, folus puri tenuisque aẹris defeStus efficere queat, ut quis patriae defiderio mirum quantum urgeatur.

0. XXV Nec dubitandum eft, fat multas alias, quae in humano genere, ejusque natura paffim obfervantur, yariationes ex illo aëris difcrimine derivandas effe. Valde enim probabile eft, hinc fieri, ut vallium montiumque habitatores tam mirabili faepe opinionum fenfumque difcrepantia inter fe differant (i).

6. XXVI. Hippocrates fane longe majori mentis. acumine, quam permulti eorum qui fuam nunc artem profitentur, ad efficaciam refpicere folebat, quam aurae in hominum corporibus exercent $(k)$ : quod idem quoque fectatorem ejus, Arbutbnotium, magnae doctrinae magnique judicii virum, fecife, ex disqui-fitione patet, quam de aëris in corpora humana vi, litteris mandavit praeftantiffimam (l); in qua, praemiffis aliis, , quando, inquit, rationes expendimus 2, quas propter Hippocrates remotarum a fe invicem 2. regionum incolis disjunctas disparesque animi adfec. 2) tiones facultatesque tribuerit; facile perfpiciemus, 2) caufas inter earumque efficientiam, juitam fem;s per aeguamque proportionem effe. In terris feptentrionem verfus pofitis, ubi ex adfcendente in 2\% tention , barometris hydrargyro pondus aëris majus graviusפ, que effe difcimus, humanorum corporum fibrae, 2. quac ex temporum viciffitudine plus minusve mille $\Rightarrow$ du-

(i) De his plara de Montesquieu in libro de l'E/prit des Lair live 14a

(k) Hippocratos de aëre, locis \& aquis.

(l) Hamburg. Magazin. I. $2,3,4,5,6$ 


\section{G E O G R A P H I C A E. I2}

\%) ducentis, mille octingentis, atque adeo ter mille

29

9

99

99

9

9

9

92

9)

99

9 fexcentis interdum libris ab aëre comprimuntur, perpetuo oscillant: quod quidem onus, quum tenues liquidaeque fint aurae, nec fenfus noltros adficit, nec dolorem moleftiasque adfert. Interim tamen clandeftina quadam preffione homines incommodat: cujus omnes alii regionum incolae immunes funt, ubi Mercurii altitudo vel parum vel nihil plane immutatur. Quodfi autem fibrae varie intenduntur, tota etiam nervorum compages, cunctique fpiritus animales fimul adficiantur, oportet. 6. XXVII. Idem de montibus:: mihi quidem in: quit, fatis probabile videtur, variantem nimis \& regionum \& aëris altitudinem efficere, ut eorum conftitutio, qui e terrae fodinis metalla eliciunt, magnam admodum cum montiam incolis diffimilitudinem, noftra inquifitione atque inveftigatione non indignam, habeat. Quum enim montani minus gravi aëris preffu urgeantur: cogitur, ut, qui avium more in tenui puroque coelo moventur, majori mufculorum lacertorumque robore praediti, plus virium partim in praeruptorum collium faxorumque adfenfudefcenfuque, partim in continuo diverfoque corporis motu commonftent. Quantumcungue enim ponderis aëri, quem hauriunt, leviori decedit; tantundem frigus, certa quadam ratione fupplet \& efficit, ut in gravitatis libramine perftent : hinc corporis vires augefcant, animique vigor \& ingenii folertia excitetur neceffe eft. Haec ipfa caufa efle videtur, quam propter Hippoirates animali, in montium jugis commorant, ferocians 


\section{SPECIMEN ZOOLOGIAE}

"ritatemque adfcripferit". Håtenus Arbutbnotius; ex cujus dictis apparet, meteorologiam fingularum regionum non in una mentis agitatione \& contemplatione occupari, quin potius ad vitam confervandam falubriterque tranfigendam, plus commodi, quam quis fibi perfuaferit, conferre, ideoque aevi noftri medicorum officium poftulare, ut Hippocratis, Arbutbrotii. \& Ramazzini veftigia prementes majore, quam plerumque fieri fuevit, hanc fcientiam cura diligentiaque complectantur.

6. XXVIII. Et fi longius, quam par erat, a propofito digreffus videor, hoc ipfo tamen effeciffe crediderim, ut eo dilucidius pateat, nec ibicis folum caprive, fed argali etiam \& arietis difcrepantiam ex fola propemodum domiciliorum, quae fibi elegerunt, diverfitate, originem traxiffe. Quodfi praeterea ad fervitudinis etiam jugum, quod ovi capraeque homines impofuerunt, refpexeris: facile tibi conjectu erit, unde factum fit, ut tam debiles nunc $\&$ inermes utraeque pecudes appareant. Buffonium itaque fecuti, bircum nunc cicurem, quamdiu olim in naturali ftatu fuo vixit, cunden fuiffe, atque ibicem, conftituamus.

6. XXIX. Sed quid de rupicapra? nonne \& hanc nominati jam viri auEtoritate commoti eandem cum noftra capra effe concedemus? Lubens equidem fateor, hanc disquifitionem in propofiti mei rationem proprie non cadere. Quum enim rupicapram juxta cum zbice iisdem fere in regionibus locisque commorari conftet : mihi ex folius ibicis exemplo commonftraviffe fufficit, quo usque caprarum fpecies fefe per orbem diffundat. Interim tamen, $f i$, quid hac de re fentiam, di- 


\section{G E O GR A P H I C A E.}

cendum eft, Buffonii rationes non ejus momenti deprehendiffe videor, quae, ut opinioni fuae fubfribam, pervicerint.

5. XXX. Praecipuum, quo retrahor, dubium eft, quod rupicapra nunquam cum ibice, feu fero birco coïre foleat. Vir quidem celeberrimus huic quam maxime fundamento fententiam fuam fuperftruere annifus eft ( $m)$, quod rupicapra, quum arunco deftituta fit, eo ipfo certiflimum fexui femineo naturaliter infitum characterem confervaverit.. Sed quandiu ipfa. dictorum animalium coïtio nec accefferit, nec aliunde certo fuerit comprobata ; vir praeftantiffmus vitio mihi. ne vertat, fi affenfum meum eo usque differo, donec: contrarium experimentis, quae dubitationem non habent, frimatum fuerit; praecipue quum ibicis etiam. ftructura aliquanto propius ad caprae cicuris, quam ad rupicaprae indolem ac dispofitionem accedere videatur.

0. XXXI. Quoniam reliquae ovium caprarumque fpecies propemodum omnes cum noftris domefticis fe conjungunt; rei ratio poftulat, ut praecipuas, quas diverfis fub.cocli climatibus patiuntur, variationes fummatim percurram.

ઈ. XXXII. Quinque notatu digniores Buffonius ovium? degenerationes percenfet, quarum primum locum aqui... lonalibus tribuit (n): quae plaribus quidem cornubus: praedira, caeteroqui tamen noftris magnitudine pares funt. Cornumin, quibus tam arietes \& verveces, quam; ores

(min) Buffon. 6. Th. 2. band.

(i.) Hiltor: Natur. univerf. Part. VI. Tom. 2. p. 2.082. 


\section{$\$ 28$

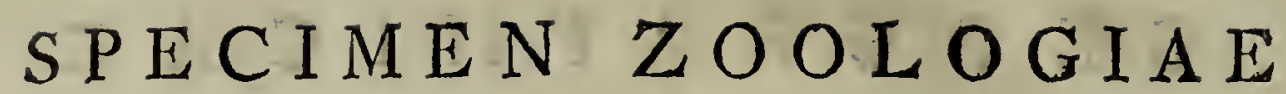

oves armatae funt, \& ampla fpecie \& firmitate atque numero noftrates longe fuperant. Quasdam natura tribus, nonnullas quatuor, quinque \& pluribus interdum cornubus armavit; quod tamen perpaucis $\&$ in grege, e quingentis pluribusque conftante, vix tribus vel quatuor contigit, quae quafi monftruofae raritates $H a f-$ niam miffae prodigii fimiles numerantur $(0)$. Hanc vero discrepantiam ab uno, quo aluntur, victu pronafci, jam fupra, ubi de Islandiace cornutis pecoribus agebatur, exemplo quodam comprobatum feci. Lana, qua vefliuntur, afpera tactu folitoque craffior eft, cujus duritiem ex folo frigore oriri Blancbevillius $(p)$ hac fatis probabili ratione commonftravit: frigus, inquit, craffiores fanguinis particulas, quas animantium pori exhalaturi erant, condenfat, eoque ipfo, ne evaporent, cohibet: hinc fanguis eas motu fuo fecum abreptas in canaliculos, qui fuccos tenuiffrmos crinibus procreandis adaptatos continent, defert. Fieri itaque non poteft, quin lana nimiis craffioribusque alimentis nutrita fpiffior rigidiorque proveniat.

6. XXXIII. Ad fecundam fipeciem nofrates Buffonius oves rejicit, quae in afperis incultisque Hispaniae \& Perfane regionibus tenuiffimas bombycisque propemodum fimiles, in terris vero, graviori aeftu ardefcentibus, hirtas fragilesque lanas ferre folent (q). Tanto interdum \& magnitudinis \& vellerum difcrimine inter fe dittant, ut in terris haud ita longe a fe invicem remotis

(o) Allgm. Reifen Tom. XIX. p. 2 I.

(p) Schreber Samlung von Cameral Schriften T. 5. p. 85. \& feq.

(q) Plura de his apud Schreberum 1. c. 


\section{GE O G R A P I I A E.}

duo, tria \& plura fui diffimillima numerentur genera; quam tamen diverfitatem regionum femper, quas incolunt, paftui exacte refpondere videmus. Sic Oroniae provincia oves alit, quae corporum quidem mole afinos aequiparant; dura tamen hirtaque lana veftitae, cornubusque maximam partem viduae confpiciuntur ; quum e contrario, quas Herfordia profert, minores quidem, fed cornubus armatae fint, fubfericaque lana fuperbiant $(r)$. Et in Galline gregibus lanae mollitiem praeftantiamque pabuli, quo nutriuntur, maximam habere cognationem, Blancbevillius 1. c. teftatur: in Gallia, inquit, ficut omnibus fere locis, lanae qualitas pafcuis ita respondet, ut oves in arenofis pastae regionibus multo teneriorem mollioremque lanam, quam quae in vallibus; pinguioribusque pratis pabulantur, proferant.

S. XXXIV. 3. Ovis, quam laticaudatam Limnacis nominat, in temperatioribus Perfae, Syriae, Aesypii. que terris egregiam itidem lanam alit, quae tamen, fi pecus hoc in calidiores tractus transpofueris, plus minus hirta fieri fuevit $(s)$. Haec ovium fpecies per $(t)$ Tartariam, Perfiam (ul), Africam (v) cunctasque propemodum calidiores plagas diffipata cernitur $(w), \&$ caudis quam maxime, quae tam immodica pinguedine luxuriant exuberantque, ut triginta: $(x)$, interdum quadra-

(r) Schreber. T.XI. Ellis von der Schaafzuscht. (s) Tonu Voyage a Surate.

(t) Pallas Reifen T. x. p. 325 . Olearius Reife-Befchrib. '1. I. P. 32x.

(u) 7 hevenot Reifen Tom. II. P. 379 . Chardin T. It. p. 28.

(v) Allgm. Reife-befch. Tom. VIII. p. I4.

(w) ibid T.: V: p. '313. \& Leo Afric. Defer. Africae.

$(x)$ Kolbe vorgeburge der guten Huffin. Tom. II. p. 67 Ed. $4^{\text {to }}$. 


\section{30 SPECIMEN ZOOLOGIAE}

draginta $(y)$ quin etiam oetoginta (z) librarum pon dus excedant, memorabilis eft.

6. XXXV. Hae ex adipe conftant, quae linguae admota non foluin liquatur, fed jucundiffinum quoque faporem relinquit (a). Monftrofam illam adipis molem foli regionis naturae attribuendam effe, argumentum ex itinerario, cui fides negari nequit, defumtum fatis fuperque comprobat (b).- Mateliefus enim anno p. C. N. I 608. in exigua admodum infula, haud procul a finu Tabulae prope bonae fpei promontorium diffita, ovem ab.Anglis ex Europa eo delatam ibique reli: ctam offendebat, quam coeli temperies pabulique ubertas fic immutaverat, ut cauda in viginti.quinque pollicum craffitudinem excreta, novendecim librarum pondus., \& adeps renibus \& inteftinis adnata, triginta quatuor pondo fuperaret, decemque, quin duodecim pinguedinislibrae refcindi prius tollique deberent, quam carnes, quibus famem toleraturus erat, apparerent: quam in rem Prevo: ftius, coeli temperiem in oves ex Europa in Afram delatas mirandam vim quandam exercere commonftraturus, uberrime inquifivit.(c). Quis ergo eandem in bove etiamgibbofo commutationem factam effe, naturamque, quam adipis abundantiam ovis caudae appendit, bovis dorfo ap: pofuiffe ulterius dubitabit? Tantum enim abeft, uo utraeque pecudes nova quaedam genera conftituant, ut: eas potius, fola aërisalimentorumque, quibus utuntur,

(y) Hallen. Hift. natural. T. I. p. 30 r.

(z) Blancheyille apud Schreber. I. c. (a) Flacourt defcript. Madagafcar.

(b) Allgem. Reife befchr. Tom. Vill. p. 3.12. (c). Allg. Reif. T. V.III. 1.ci. 


\section{G E O G R A P H I C A E.}

efficacia, ab originis fuae patribus paulum degeneraviffe, certo ftatuendum fit.

0. XXXVI. Ovis cretenfis, quae frep/icori nomen tenet, quartumque locum occupat, lanam ejusdem, ac noftrates, bonitatis gerit, \& hac una in re differt, ut cornubus erectis tortilibusque armata fit $(d)$, caeteroqui, tefte Bellonio (e), utraque, tam ftrepficori quam noftratis fpecies pari frequentia Cretae campos pererrat, \&, fi modo cornuum formas exemeris, fibi eft fimillima.

0. XXXVII. Ordine nunc fequitur ovis, quam Linnaeus Guineenfem, Buffonius vero Adimainam appellat, cujusque hic in undecima hiftoriae nateralis parte duas inter fe difcrepantes imagines dedit $(f)$. Haec hactenus enumeratis major, caprinis pilis tecta, duabusque fub collo mamillis praedita eft ; aures demittit, calidiffimas Lybiae ( $g$ ), Congi (b) Senegalliasque ( $i)$ regiones incolit, \&, fi Leoni Africano fides habenda eft, ejus eft magnitudinis, ut, fi cuiquam libuerit, equitari queat. Natura, ex Adanfonii opinione fat probabili, ipfarum lanam, quae in locis vehementiori aeftu calentibus nimio ipfis oneri effe debeat, cum raris admodum levibusque pilis permutavit, \& hac in re femper fibi confimilis eft: in Africa enim graviori ardore ardefcente, canes depilat, ovesque velleribus, quae calorem ipfis intolerabilem redderent, exuit: fub aquilone utrasque pecudes

(d) Gesner icon. 37. \& Ruyfchii Theatr. Animal.

(c) Bcllon. oblervat. p. 15. (f) Buffon 6t. Th. It. Band.

(g) Leon. African. defeript. Afric. Vol. 11. p. 753 .

(h) Allgm. Reifo.bcfch, T. V.p. 86. (i) Adanfon Hilt. du Sénégal p. \$T.

R 2 


\section{2

des villofis pellibus contra frigoris vehementiam munit; $\&$ in Syriae, Perfiae, aliisque terris modice calentibus, nonnulla domeftica animalia pilo bombycis fimili, oves vero tenuiffima molliffimaque lana veftit. Nec hoc loco omittendum eft, negotiatores in nobili Perfiae civitate Mefched dicta, magnam vellerum agnis tenellis detractorum mercaturam facere, quorum lana fubcrifpa argentique alborem referens, ferica mollitie vincit $(k)$.

6 XXXVIII. Quamvis autem Guinem/num oves inufitata corporum magnitudine antecedant: nihilo tamen fecius laticaudatarum quaedam iis forma partim aequiparant, partim anteltant. Sic Pallas $(l)$ de $\mathbb{K} \mathrm{rg}$ iffenfaum ovibus teftatur, eas non deformitate folum, fed magnitudine quoque reliquis omnibus lanigeris pecudibus anteïre; quippe quae vitulo recens nato altiores ejusque roboris fint, $\&$ ponderis ut adultae centum fexaginta, quin etiam ducentas interdum libras excedant (IV. aut V. Pud.): caeterum eas indicis arietibus haud abfimiles effe putat. Capita ipfis curvata tribuit, in quibus labrum inferius promineat, aures demiffae pendeant, colla vero carunculis faepius obfita cernantur. Caudarum loco enormibus; eas adipum maffis oneratas vidit, quae globorum fpeciem referentes, inferiore parte glabrae fuerint, e quious quadraginta circiter libras habentibus, triginta fere febi pondo colligi poffint. Et hac una in re quam maxime illas a Guineerigizum ovibus differre autumat. Por-

ro.

(k) Rélation de la grande Tartarie p. 187: \& Olearius 1. c. Tom.l.p. 5s7\%

(l) Ballas Reife durch Rulland 1'. 1. p. 398. 
ro arietes, omnes cornutos, \& aliquos, Iflandicorum more, quatuor vel quinque cornubus armatos effe refert.

5. XXXIX. Ex qua narratione, quae magni quidem momenti eft, fole clarius elucet, non Indiae folum, fed Islandiae etiam oves cum laticaudatis ejusdem fpeciei effe \& originis, ipfarumque degenerationes non ejus effe indolis, ut idcirco alii diverfique generis parentes iis tribui debeant. Jure igitur in Bufforizi fententiam difcedo, nec omnes folum a Linnaco percenfitas ovium fpecies, fed Ammonem etiam Adimainam, Cretaeque habitatorem, unam eandemque pecudem $a b$ uno quondam patre ortam, locorum modo pabulorumque diverfitate paulum immutatam effe ftatuo.

0. XL. Quodfi nunc minimi corporis tenuiffimaeque ftaturae ovem, qualis quae in Oxonine agris nafcitur effe videtur $(m)$, cum maximis, quae vel ibidem, vel in Kirgifenfium campis pafcuntur, comparaveris; has illa triplo, imo quadruplo, majores gravioresque invenies. Quum enim aries minor circa fexaginta, major autem ducentas fere libras ponderet, hanc, quam attuli, proportionem inde oriri videbis.

0. XLI. Quod ad colorem attinet, oves quidem albis, canis, fuscis, nigris, maculofisque velleribus veftitas, ubique fere locorum invenire licet. Sed tamen unus interdum alterque color huic vel illi regioni magis proprius effe videtur. Sic Turcarum oves, tigridum plerumque more maculis variantur $(n)$. Quas autem Quiloce ager nutrit, nigris capitibus, verficolo-

(m) Ellis apud Schreberum.. 1. c.

(n) Ellis apud Schreb. 'T. X1. p. бo. 


\section{SPECIMEN ZOOLOGIAE}

ribusque corporibus, natura diftinxit (o). Verum \& hac in parte pecudes iftae tantopere a fe invicem discrepant, ut nec locus, nec grex detur, in quo non varie notatae numerentur.

6. XLII. Quum fupra, capram ove robuftiorem effe, jam monuerim: facile inde collectu erat, illius degenerationem minus. quam in ove notabilem fore; cujus etiam rei veritatem experientia fatis fuperque comprobat. Ovinn enim nullis, düobus, pluribusque cornubus armatarum mentio facta eft: capraram vero perpaucae, caprorum autem rariffimi, quibus gloria frontis nulla fit, deprehenduntur; quippe qui plerumque duobus, nunquam autem, quantum quidem conftat, pluribus praediti effe folent.: Deinde magnitudinis ratione caprae non tantopere, quam oves, inter fe differunt. Denique oves quibusdam in terris, lanae loco, pilis amictae, caprae vero nullibi lana, fed ubique locorum pilis tećtae inveniuntur, qui aliis in regionibus tenuiffimi, fericoque frimillimi, in aliis autem craffiores funt.

0. XLIII. Sic feptentrio, a.periores fragilioresque, catidi vero Syriae, Angorae ( $p)$, Heracleae (q), Perfrae, minorisque Afrae, Turciaeque tractus $(r)$ caprinos optimae notae crines fubminiftrant, ex quibus fila, quae quafi ex camelinis confecta pilis plerumque veneunt, ducuntur. Angorae praecipue campis id proprium eft, ut capras non pilis folum promifflis, bombycumque fere mol-

(o) Allgm. Reife.befchr. T. VHit. p. 19.

(q) Valmont de Bomare Dict. Article Bouc.

(p) Buffon Hift. Nat. T. V:

(r) Hallen Hift. animal. T. I. p. $3 I$ I. 


\section{G E O G R A P H I C A E. I 35}

mollitien referentibus ornent, fed cornua etiam cochlearum in modum torqueant $(s)$. Utrumque, ut mihi quidem perfuadeo, partim ex falubri coeli temperie, partim: e fertili herbarum luxurie oritur, quae opima pecoribus, ipforumque naturae quam maxime convenientia fuppeditat alimenta, quorum ubertas, ficut in ovibus vel plura porrectaque cornua, vel ingentes adipis maffas profert, ita in capris fe per omnem velleris fetarumque fuperficiem diffundit, easque longe perfectiores tractabilioresque reddit.

6. XLIV. Res interim haec eo usque explicatu difficillima erit, donec curatiori tam aëris, quam telluris circa. Angoram inveftigatione \& perfcrutatione facta, felicius enodari queat. Et aërem quidem hac in re plus: pabulo conferre, ex eo patet, quod felis etiam, carnivora caeteroqui beftia, longiorem. mollioremque folíto pilum alat.

0. XLV Addendum eft, temperatiores has oras capram perinde atque ovem, ratione memoratu digniffma, transfigurare. Quum enim alteram immáni cauda: onerent., alteram vero enormibus infignire foleant auribus : utraque pecus fola illa corporis fui partelocoque, in quem alimentorum abundantia quam maxime tranfit, variatur. Caprae enim, quam Linnaeus mambricam ap. pellat, aures ejus funt longitudinis (quas tamen peraequa etiam proportione natura dilatavit) $(t)$, ut faepiffime ad terram usque propendeant ( 1 ). Haec ca-

pra-

(s ) Caprae angorens. optim. figuram vide apud Buffon. 1. c,

(t) Ruftels Natural Hintory of Aleppo.

(ul.) Prosp. Alpin. Hif. IEgypt. Lib. IV. p. 229 


\section{SPECIMEN ZOOLOGIAE}

prarùm fpecies, Buffonio tefte, tam laté diffipata cernitur (v), ukt non Syriae folum, fed orientalis etiám Indiae, quin Aegypti campos pererret: aeque igitur, atque ovis, in mitioribus coeli plagis optime provenit: corporum taimen mole \& magnitudine non eo inter fe difcrimine, quo oves, diftat. 2 Licet enim ibex corporis fpecie reliquis praeftet, Limnaei véro depreffa Americae ciopra minimae prae caeteris ftaturae fit : multum tamen aibeft, ut tantum, quantum $\mathrm{Kirg} z / \mathrm{sen} / \mathrm{hum}$ ovis a mini$m a$, quam. Europa gignit, inter fe differant. Cujus: enim caprae Kolbuius (w) \& poft eum Hallenius fub coerulei, difcoloris, Atriatique capri afficani nomine meminerunt; eam Gazellarum, haud quaquam vero caprarum gregibus adnumerandam effe cenfeo.

0. XLVI. A Buffonio interim decem diverfae fpecies, quae ab uno patre, ibice nimirum, ortae fint, commemorantur. I. Ibex, caeterorum parens, 2. capricornus, quem Limnaeus oinifit, folusque Buffonius adduxit (x), 3. bircus nofer cicur, 4. rupicapra, 5 . capra deprefJa Linnaei, 6. ejusdem capra reversa, 7 . capra juiden/is, 8. Angoren/is, 9. mambrica, 10. bircus minor africanus. Quumque harum omnium pleraeque, excepta rupicapra, inter fe coëant, reliquae vero, de quibus id minus adhuc conftat, fibi fimillimae fint, Buffonio non affentire non poffum ; praefertim quum illae fpecies, quae maxime a fe invicem diffidere videntur , verbi gratia, Linnaci capra deprefja \&.véverja,

(v) Buffon Hift. Nat. 'Tom. VI: pars II. p. 89.

(w) Kolbe 1. c. p. p. 14 I..ed. fol.

(x) Buffun 1. c. p. 86 . le Capricorne Tab. 15. fceleti 


\section{G E O G R A P H I C A E.}

fe procreandi caufa conjugare foleant: licet non negem, fatis probabile dubium moveri poffe, an rupicapra, quod Buffonius pro explorato habet, ab ibice oriunda fit; quum barba careat, nec utrasque fpecies, quamquam ferae, fibique ipfis relictae, iisdem fere locis confociatae vivunt, unquam inter fe coilife conftet.

Ø. XLVII. Linnaeus quidem Gazellas (y) etiam caprarum generi adnumerat, quae tamen, quum externo corporis habitu a capris multum differant, nec nifi calidiffimas orbis antiqui terras inhabitent, caprae e contrario, quod hactenus planum facere ftudui, ubique pene locorum degant: non poffum, quin, Gazellas omnesque ipfarum fpecies, feparatim, quod medium inter capras capreasque locum occupet, genus conftituere mihi perfuadeam $(z)$.

6. XLVIII. Quicunque nunc omnia, quae hactenus de capris congefta funt, junctim percurrere voluerit, eas itidem fere, atque oves, per omnem terrarum orbem difperfas effe, eodemque modo coeli aërisque temperie ita immutari, ut a prototypo fuo paulum recedant, facile deprehendet.

\section{SECTIO}

(y) Ex Buffonii fententia Gazellae a capra capreoloque annulis praecipue transverfis colliciisque in cornuum fuperficie; fetis praeterea, quae anterioribus in pedibus confpiciuntur, fasciis deinceps ex denfis machlini-co loris crinibus ilia tegentibus, \& tribus denique ftriis fubalbidis, quibus aures notatae funt, internofcuntur:

(z) Plura de Gazellis in Cap. 3 . \& praecipue apud Pallas Spicileg. zoo. log. T. I. 


\section{SPECIMEN ZOOLOGIAE}

\section{SECTIO VI. \\ De Equo छั Afuro.}

0. I. Tquum poft ovem inter pecora domeftica quam latiffime diffundi, exitinerariis compertum habemus. Et quamvis proximus ei agnatus, iners nimirum $a$ /mus, illi hac in re omnino poftponi debeat: utrosque tamen, quia propter fingularem, quae pluribus ex. rebus appâret, fimilitudinem nonnulli naturae contemplatores unam eandemque ipfos animantis fpeciem putant, feparare non fuftineo.

5. II. Equus haudlongius, quam ovis, a feptentrione difcedit. Islindia enim alacres robuftosque alit equos $(a)$; \& Outbierius (b) fub fexagefimo fexto ulteriorique latitudinis gradu prope Cainunkylam parvulos quidem, fed acres fatis equos, quiaeftate durante congregatim filvas. pererrent, locosque ubi pabulentur, pro lubitu, pafcuorumque cauffa, permutent, ingruente vero hiemis. alperitate ad ftabuilà fua cuncti remeent, vidiffe teftatur. Nullum itaque dubium eft, \& Groenlandos, dummodo pari circumfectione, qua cum ovibus fieri fuevit, periculum facerent, equos effe educaturos.

6. III. Si ab aquilone meridiem verfus difcefferis, in omnibus quas peragraveris, regionibus, fub circulis. etiam tropicis $(c)$ \& fub ipfo aequatore $(d)$ equos of-

(a) Alnderfons defcript. llandiae p. 3o. \& Horrebow in Aligem. Reijen Tom. XIX. p. 20. (b) Journal d'un Vöyage au Nord par Outhier. p.I00.

(c) Adanfon Hift. du Sénégal p. 160. Alligem. Reijen T. V. p. 250.885i.

(d) Bouguer: Voyage au Pérou. 


\section{G EO G R A P I C A E.}

offendes, qui, etfi calor eorum rationi, quod deinceps de illorum degenerationibus acturus fufius explicábo, minus conducit, nihilo tamen fecius fatis agiles hábilesque videntur. Ultra aequatorem progreffus tam in Afiae $(e)$ \& Africae $(f)$; quam in Americae regionibus $(g)$, quousque terrae continentes extenduntur, equos invenies.

0. IV. Tantum abeft, ut afinus tam remotas inter fe coeli plagas toleret, ut Linnaeus (b) potius eum in suecia perrarum effe, adfirmet. In Groenlandiae autem, Islandiae Lapponiaeque finibus, eum penitus ignorari, certum eft. E Succia vero ad temperatiores terras iter facturus ad magellanicum usque fretum, in quo nec nomen quidem eorum innotefcit, non ubivis afinos videbis. Ex innumera peregrinatorum turba nemo, qui Cbilienfrum, Patagoniae, ulterioresque terras perluftravit, afini ibidem obvii mentionem fecit, licet uno quafi ore adfirment, incredibiles boum equorumque ferorum greges, vaftis poft Buenos Ayres campis vagari (i), Paiagonumque gentem equis, quos venatu ceperit, ad magellanicum usque fretum $(k)$ vectam defcendere. Multae infuper tam Afiae quam Europae partes equos quidem, afinorum autem vel nullos plane, vel paucos admodum nutriunt, quamvis utrobique commode fatis vivere auge-

rique

(e) Cooks Voyage in Hawkesworths Account T. 3. p. 683. The tame animals of the Ifland of Savu are Scheeps, goats, hogs, affes, horfes \&c.

$(f)$ Kolbe befclireibung des Vorgeburges der gulen Hoffn. p. 325. Fd. in $4^{\text {to }}$. (g) Bougainville Voyage autour du Monde p. 127. \& feq. Allgem. Reifen T. 16.

(i) Allgem. Reifen T. 16. p. 124.

(k) Birons Reife p. $3 \%$. 


\section{SPECIMEN ZOOLOGIAE}

rique poffent. Qua ex re patet, afinum inulto arctioribus equo finibus contineri.

0. V. Magnos interim \& afinorim \& equorum fevorum greges, qui hominis dominium effugcrunt, \& a quibus cicures noftri dubio procul genus fuum ducunt, relietos videre licet. Equum enim. ferum in Arabiae defertis $(l)$, in Sinenfum provincia $X_{e n /} / \mathrm{dicta}(m)$, in Infula fava $(n)$, in Hungariae, Poloniae ( 0 ) \& quibusdam Ruffiae regionibus etiamnum circumvagari, ex adductis infra $(p)$ auctoribus palam fit.

ઈ. VI. Quos Gmelinus junior $(q)$ in Woronen/s territorio infra quinquagefimum fecundum tertiumque latitudinis gradum, feros ridit equos, his propemodum. verbis delineavit: "Ferorum inquit, equorum maxi" mi vix illorum aequiparant magnitudinem, quos „ manfuetos Ruffi minimis adnumerant Ipforum capi$\Rightarrow$ ta cum reliquis corporum partibus collata jüfto cras" fiora videntur : aures peracutas praelongasque vel , cicurum ritu arrigunt, vel afinorum more demit, tunt: oculis lucidis \& fere flagrantibus, jubis bre"vioribus, fed fubcrispis, caudis plus minus quidem " fetofis, iis tamen femper brevioribus quas cicur 2. equus gerit, inftructi cernuntur. Murinus color - „feris omnibus ejusdem regionis equis proprius eft. , $\mathrm{Pi}$ -

(l). Ieo Afric. T. II. p. $7.5 \mathrm{I}$.

(m) Neuhuf. gefandichaft nach China p. 369 ,

(n) Cooks Voyage in Hawkefworch Account T. 3. . p. 745 .

(o) Hallen Hirt. Natur. anim. part. I. p. 230.

(p) Pallas Reifen durch Rufland P. 2 II.

(q) Sam. Georg. Gmelin Reife Durch Rufland. I. Theill Reife von Peterburg bis nach ' 1 'erkafk in den Jahren $\mathbf{1} 768$. und $1769 \%$ p. $145 \%$ \& 4.6 . 


\section{G E O G R A P H I C A E.}

"Pilis tam longis denfisque veftiuntur, ut ipforum.

, terga tangens non equorum fed vulpium pelles teti-

"g giffe videare. Tanta cum pernicitate currunt, ut

$;$ eodem temporis momento alterum tantum viae fpa-

g) tium, quam optimae notae cicures, emetiantur. Vel minimus enim ftrepitus illos ita terret, ut ftatim

„) fe in fugam conjiciant. Certo certius eft, fingu-

" los greges quendam fibi admiffarium, qui ducis loco

" praegrediatur, eligere, quem equae omnes fequan-

"tur, quove proftrato ita dispergantur, ut, quia,

" ubi tutae confiftere poffint, nesciant, plerumque

, venatorum praeda fiant. Quum libenter apud rufti-

, corum horrea pabularia commorantur, non exiguum

" illis detrimentum adferre folent. Equus admifforius

" domitas Rufforum equas tanto inhiat fervore, ut,

" quas adfequi poteft, certo fecum abducat. Is, cicu:

g. re aliquando, quem magna equarum cohors comita-

", batur, confpecto, harum defiderio, quas ditioni

", fuae fubigere cupiebat, inflammatus, ductorem ip-

" fum maxima extemplo vi \& contentione adgreffus.

„2 eft; \& quum uterque diu fatis, ferus dentibus, ci-

\% cur pedibus, luctati effent; hic tandem, quamvis

, fortiffime reftitifet, fuccumbere, dentiumque morfu

; laceratus perire debuit: quo facto, quarum cupidi-

, ne flagrabat, equarum gregem fecum abduxit.

2, Quoties ferus cum equa cicure coit, media quaedam.

\% beftia inde pronafci folet, quae citriusque parentis

"fimile quidquam habet. Feri ejusmodi equi vivi

\& capti, quod non nifi laqueo effici poteft, quam:

" difficillime a feritate infita mitigari, laborique ad-

g. fuefieri poffunt: Quod utrum ex naturali quadam.

$$
\text { S } 3, \quad \text {, ani- }
$$


, animantis hebetudine pravaque indole, an e rufti, corum nec fite nec prudenter fatis hac in re agen" tium ignorantia oriatur, dijudicare nequeo. Mihi 2) autem de feris tantum hujus regionis equis fermois nem effe, addendum cenfeo. Caeterum omnes ho\& mines in eo confentiunt, feras hafce beftias nulla "arte, nulloque labore ephippiis geftandis adfuefieri is poffe, \& cicuribus etiam junctas ea cum difficultais te \& moleftia procurrere, ut altero ftatim, poft " amifam libertatem fuam anno plerumque pereant".

f. VII. Ipfa auctoris verba memorata digninitima ideo adponere lubuit, partim, quia Gmelini liber nuperrime demum prodiit, tamque novus eft, ut nemo. hucusque, quantum quidem conftat, tam bene feras hafce defcripferit, partim, quia nec Buffonius feros adhuc equos dari convictus videtur $(r)$. Auctor igitur egregius his ipfis verbis non perficue folum probavit, equorum agmina in ftatu fuo naturali multa fupereffe; fed eo etiam confidentiae progreffus eft, ut equum afinumque idem ejusdemque originis animal effe, fuspicetur. Pergit enim pag. 47. "Quum ferus equus. „, femipene equus femique afinus fit, nonne in eam " tranfiri poffet opinionem : feros quosdam equos fen3. fim degeneraviffe, qui hominum poteftati \& difci" fim degeneravilfe, qui hominum poteftati \& difcio plinae poftea fubjecti paulatim in afinos mutati fint, ideoque tam equam cicurem छo ferum, quam affmum iisdem parentibus oriundos effe?

§. VIII. Non equidem nefcio, Buffonium in equi, quam

(r) Imaginem etiam - equitiferi fatis elegantem Gmolinus deferiptioni fuae addidit. 


\section{G E O G R A P H I C A E.}

quam edidit, afinique defcriptione, huic fententiae, ea quam maxime de caufa, refragari, quia mulas unquam. foetus edidiffe, nondum certo conftat. Sed tamen in praeftanti, de animantium degeneratione quam confcripfit $(s)$, disquifitione fua (quae, quod doleo, abfolutis demum iis, quae de homine, cane \& bove collegeram, in manus meas pervenit) ad amplectendam hanc opinionem idcirco propenfior videtur, quod, quae huc usque in mulabus tentata experimentisque cognita funt, rei veritati patefaciendae nondum fuffciant, crebriorique ufu \& confuetudine inveftiganda fint $(t)$. Quum interim naturae fpeculatores certent, $\&$ lis adhuc fub judice fit: ego utramque animantium fpeciem ufitatis hucusque nominibus appellabo, \& unicuique in adjuncta mappa geographica certos fuos fines: terminosque conftituam.

0. IX. Si animantis patria eft, ubi maximo \& corporis \& ingenii vigore gaudet: Bufforio, equis domefticam fedem in Arabiae terris tribuenti, contradicere nequimus ; licet eos imprudentia labi credidering, qui: Arabian nitidiffimos formofiffimosque proferre caballos: autumant: qua in re Niebubrius in praeftanti, quam nuperrime luci publicae expofuit, Arabiac defcriptione (u). optime nos erudivit: Arabes, inquit, equos fuos per-

ma-

-(s.) Ailgem. Hift. der natur T. XIV. (t) Vid. Spallanzani Phyfical. Abhandlungen, \& Bonnet Confiderations fur les corps Organifés.

(u) P. I 6I, i 62. Multis verbis Niebuhrius morem, quem in vendendis eqtis intis celeberrimis Arabes obfervant, tradit, ipfosque in equis maximam majorum, a quibus orti fint, rationem habcre, \& e Koechlani clatr: unum, mille interdum philippicis mercari adfert. 
I4.4 SPECIMEN ZOOLOGIAE

magni faciunt; quos bifariam difpertientes, alteri claffi ita dictos Kadi/cbi, id eft, vulgaris originis adnumerant, quos eodem promemodum pretio, quo Europaei: fuos, habent; alteri vero Koecblani nomine infignitos: tribuunt, quorum profapia jam duobus millibus abhinc: annis obfervata, litteris confignata $\&$ a Salomonis, regum fapientiffimi, equaria genus trahere dicitur. PoIterioris praecipue claffis equi maximis laboribus perferendis, famique per aliquot dies, fine ulla recreatione tolerandae pares habentur. Belli tempore ferociter in hoftes incurrere \& in acie vulnerati gradum referre, fifforesque fuos in tuto collocare, equitem delapfum adftantes cuftodire, \& eo usque hinnire perhibentur, donec ipfi fubveniatur. Quoties propter dominos fuos, in libero campo cubantes e longinquo praedones fentiunt, fremitu hinnituque fublato heros fuos expergefaciunt. Nec magnitudine, nec elegantia, fed eximia, qua ad curfum valent, velocitate infignes, non adeo propter externam corporis membroramque formam, quam fola generis virtutumque praeftantia apud Arabes in pretio funt $(v)$. Quibus \& illa, quae in itinerariorum collectionibus $(w)$ de hoc equorum genere hunc: fere in modum leguntur, exacte refpondent. Arabum equi nec magni, nec pingues, fed pedibus pernices funt: Poffefforum antiquiffima cura eft, ut, qua origine, quo genere nati fint, nulla oblivione deleatur. Magni cumprimis illos aeftimant, qui citato curfu ftruthocamelum confecuti pedibus contriverunt. Sui amantes op-

time

(y) Niebuhr Befchre.bung von Arabien, p. I6I. \& feq. (w) T. Il. p. 288. 


\section{G E O G A P H C A E.}

time norunt, eorumque ofculis ora libenter praebent.

0. X. E quibus conjunctim fumtis fatis fuperque patet, Arabiae equos \& pernicitate, \&, quod majus eft, ingenio prudentiaque reliquis omnibus anteftare; eaque de caufa non inepte colligi, regionem hanc germanam quafi illorum effe patriam; quod Marmolius etiam Leoque Africanus, cicures Arabiae equos a feris, defertam Arabiam pervagantibus, originem duxiffe conteftantes, adfeverarunt:

6. XI. Ex Buffonii fententia ab Arabia in Aegyptum, hinc in Italiam, poft in Galliam, ex hac in Germaniam \& Angliam, tandem in Sueciam delati, ad coeli aërisque temperiem frigorisque menfuram, corporistam robore, quam magnitudine jufta proportione, decreverunt.

6. XII. Ajinus caeteroqui cunctis in calidioribus terrae tractibus optime propagatur. Et licet aliquot Afrae populi, verbi caufa, Calmucci, $T$ artari $\&$ alii nonnulli eum necdum educent: idcirco tamen non dubitandum eft, ipfum ibidem etiam profpero fucceffu laetoque incremento auctum iri; quia camelus, qui minus late per orbem difperfus arctioribus longe finibus coërcet, fat commode ibi provenit.

6. XIII. Quid quod a mmus Afiae Africaeque aeftum facilius equo feliciusque perferre videtur. In aurea enim ora majori longe ftatura \& meliori equis conftitutione effe folet $(x)$; quin \& a Madourae incolis ea in dignitate \& honore habetur $(y)$, ut folas nobilium vita defunctorum, nullas autem plebeiorum hominum

ani-

(x) Allgem. Keifen Tom. IV. p. 250.

(y) Leturés édifiantes. Dixième collection p. 106 . 


\section{SPECIMEN ZOOLOGIAE}

animas in ipfum transferri, $\&$ ab his animari credatur. Afnos itaque pulchritudine, vigore \& magnitudine infignes, in terra non exiguo folis ardori fuppofita, parvos autem, tardos, hebetesque fub frigidioribus coeli plagis invenies. Noftra aetate tam equis quam afinus per plerasque noti nobis terrarum orbis partes diffipatus cernitur: \& quamvis America olim neutros aluerit, nunc tamen eo perducti miro, in meridionalibus quam maxime partibus, fuccelfu profeminantur $(z)$.

J. XIV. Et equumiab-initio \& afinum cinereo infectos colore fuiffe, exinde colligo, quod fera utraque animalia eodem adhuc colore tincta confpiciuntur (a); equum tamen multo longius a priftino illo colore, quam afinum, deflexum diverfos alios duxiffe, experientia comprobat: Ferus autem a/mus hac una re a cicure difcedit, quiod fafcia faepius dilute lutea a capite ad caudam usque ornatus fit (b); \&, fi, quam quintus univerfalis itinerum collectionis tomus hujus animantis imaginem exhibet, typo fuo refpondet, ftriatus fit oportet.

5. XV. Equus. contra, omnibus, quos crinibus natura dare folet, coloribus veftitus reperitur, \&abalbo ad fufcum nigrumque progrediens, cunctas variationes admixtionesque ubique fere locorum monftrat. Cum reliquis quadrupedibus hoc ipfi commune eft, ut albentes imbecilliore, nigrantes firmiore fint natura \& dura-

- (z) Bancroftius in hictoria Guianae p. 7r. Mexicanum regnum, Antillas infulas, Guianam \& Brafiliam, afinos alere-adfirmat; confer. \& Ellü in Peruviae Defcriptione.

(a) Gmelin 1. c. (b) Voyages de Pietro della Valle Ton. VII. p. iq 


\section{G E O GR A P H I CA E. 14\%}

bliiori corpore: quod, quum contemplatione \& inquifitione non indignum fit, deinceps curatius inveftigabo.

0. XVI. De pili indole Buffonius narrat, equos in calidis moderatisque terris breviori fruticantiorique, in iis autem regionibus, quae ad feptentrionis axem fpeEtant, longiori molliorique teçtos effe pilo; cujus tamen: differentiam nec tantam nec tam infolitam, quam in boum, canum oviumque crinibus, deprehendes.

Ø. XVII. Unum fupereft aninial, cưjus Flacourtius fub Mangarfabockis appellatione meminit, quod, licet minus adhuc cognitum fit, tamen, portquaun a/mi feri mentio illata eft, praetermitti non debeat. Dapperus (c) in fua Africae defcriptione pauciffima de ipfo attulit: Buffonium vero id plane omiffife miror. Si certa funt, quae Flacourtius de illo refert, Madagafcar is infulam patriam habet (d), auriculisque fat longis praeditum eft, utpote quae fupra oculos dependent, eosque contegunt: caeterum quoad formam, vocem, ungulasque: afino equalis videtur. Si Commerronius, qui aliquamdiu in Madagafcaris regione commoratus eft, \& hujus etian animantis naturam, more fuo, diligenter procul dubio exquifivit, ante reditum non obiiffet, an \& quibus in rebus ab afino differat, ab eo didisciffemus; nunc vero affnorum generi annumerandum erit, donec de ipfo major lux affulgeat.

6. XVIII. Quis ergo mirabitur, equum, quem terra non mediocri tepore calens genuit, in calidioribus locis op-

(c) Dapper Defcription de l'Afr. p. 457

(i) Flacourt Rélation de p'lle de Madagafcar. Paris I $66 \mathrm{r}$. 


\section{SPECIMEN ZOOLOGIAE}

optime glifcere \& augeri; ideoque Barbariae (e), Turciae $(f)$, Aegypti $(g)$, Perfaee (b), Neapolis (i), Hijpaniae $(k)$, ; aliaque ejusdem fitus \& climatis regna optimae indolis equis fuperbire $(l)$ ?

6. XIX. Nihilo tamen fecius nec mediae Africae (m), nec orientalis Indiae, nec qui in magni Mogolis ditione furit $(n)$, aeftus, animantis hujus caeteroqui praeftantiffimi rationibus conducit: Ipfumque in Nigritia au-: renque ora proventu felici carere, nimius fine dubio, qui medias Africae partes adurit, folis ardor in culpa eft. Quod tamen in orientali India fecus fe habere videtur. Senegalliam enim equos non ignobiles atere fcimus (o), licet fervor, quo regio haec ardefcit, longe: vehementior illo fit, quo Surata torretur, Alia itaque caufa accedat oportet, quae efficiat, ut Afiae hic traEtus equis plus detrimenti adferat; parumque exploratum eft, anid pabulo, an aẹri, an utrique vel praecipue atmof phaerae humiditati imputandun, fit. De Bengalae.

(e) Shawr Reifen nach der Barbarei p. 14?.

(f) Toumrnefort Voyage du Levant Vol. Il. p. 28.

(g:) Pokok Befchreibung dér Morgenlandes T. I. p: 3:24:

(i h) Voyage de Chardin T. II. p. 25

(i) Valinont de Bomare Diction. d'Hift. natur. Tom. HI. p. $9 \%$

(k) Hallen Natur gefch. T. I. p. 229

(b) Quum Butfonius \& Valm. de Bomare omnes propemodum equorum varietates fufe defcripferint: ijs emumerandis fuperfedere poffum.

(m) Itinerar. univerf, collectiones T. IV. p. p. $25^{\circ}$. equos ad auream: oram exigui pretii, \& ajinis tardiores effe adfirmant, \&. p. 385. Philippus, equos ad Nigritiae oras tam parvas effe adfert, ut ad folos aethiopes cibandos adhiberi poffint.

(n): Voyages de Tayernier T: $_{3}$. p. 334. Et in Infula favu fub calidiffimo Afrae coelo fita, equos minoris ttaturae, exiftere, Cookius. in Hawnesworth Account P. 3. p. 683. docet. De Infulae Favae equis idem compro. bat Cook. 1. c. p. 744: \& (.o) dilanfon Hift. du Sénégal: p. I 6 I. 
faltem ora, interiorisque Indiae parte conftat, utramque hominibus etiam noxiam effe.

6. XX. Fines itaque, quos intra pulcherrimi optimaeque notae \& alacritatis equi gignuntur, decimo quinto \& quinquagefimo quinto feptentrionis gradu, exclufa tamen, uti jam dictum eft, inferioris Afiae parte aliqua, terminemus. Dania quidem aliaeque regiones aquilonem verfus ulterius progredientes, \& magnos \& alacres equos proferunt $(p)$, fed quo propius ad poli arctici circulum accefferis, eo contractiores dominisque fuis fimiliores ipfos deprehendes. Islandin enim Lapponumque regio durabiles quidem \& fubcraffos, fedminutos etiam brevesque equos nutrit $(q)$, quod idem in oppofita poli antaretici plaga, in freto nimirum Magellanico, ufu venit $(r)$, ubi equi, quamvis ex Hifpania eo devecti fint, parvi quidem \& gracilenti; caeterum. umnibus oneribus laboribusque ferendis pares, patagonibus, ingentis ftaturae hominibus, impigre alacriterque ferviun*. Equis igitur aequalis ac hominibus fors obtigit, qui eadem ratione a quibusdam coeli plagis tantopere immutantur, ut fub quinquagefimo quinto fextoque gradu, quem acrior jam vis frigoris adflat, magni fatis \& robufti, in ulterioribus vero, qui gelu intenfiori rigent, parvi brevioresque fint; fub temperatiori vero coelo, in procera corpora, decorasque fpecies excrefcant.

§. XXI. Inter maximae interim minimaeque ftaturae

(p) Hallen Nat. gefchichte T. I. p: 230 . \& praecipue Pantoppitan Dae: nifches Atlas.

(q.) Allgem: Rtifon T. XIX: p. 20: Outhier p. roo:

(r) Bougainville Voyage autour du Monde p. 1.3 I. \& Byrons Voyage in Hawkes:sorthis Account T. I. P. 32 : 


\section{ro SPECIMEN ZOOLOGIAE}

equos non tanta, quanta inter canes, differentia deprehenditur. Unum enim tantummodo equum Tavermiervius vidit $(s)$, quem venatico cane haud majorem fuiffe teftatur: quod tamen exemplum fingulare monitrique fimile novum genus nunquam efficiet. Quos itaque Aetbiopia, Neapolis, quaedam Germaniae regiones, Dania inprimis, equos profert, corporum-magnitudine reliquos antecedere! qui vero in Norvegia, Islandia, infullis Feroenfibus ( $t)$, \& Oelandin praecipue; nafcuntur $(u)$, minimos illorum effe, quos adhuc novimus, ufu \& experientia docemur.

5. XXII. Quamvis a/mus, quod jam narravimus, frigori tolerando, minus equo, fufficiat: idcirco tamen e:idem cum equo patria editus eft. Arabia enim non praeftantiffimis modo equis, fed optimae etiam fortis afinis abundat. Ex Niebutbrii enim (v) \& Cbardenii (w) teftimoniis, Arabiae afini feroces, magni, audacesque, \& in itineribus praecipue magno effe ufui folent, eaque de caufa magno fatis pretio veneunt. Originem fuam fine ulla dubitatione $\mathrm{ab}$ illis ducunt, qui in Lybiae $\mathrm{N}_{\mathrm{c} \text { - }}$ vidiaeque defertis vagantur $(x)$, \& Barbariae equos celeritate aequiparant, quorumve carnibus incolae deleEtantur $(y)$. Ferus infuper afmuis in quibusdam Archipelagi infulis adhuc obvius eft, nullaque propemodum in

re

( s)Voyage de Tavernier Tom. III. p. 334.

(t) Debar natuerliche und politifche Gefchichte de inful Feroe Kopenhag. 1757. p. I 10. (u) Linné Reife nach Oeland p. 1z6. (v) Befchreibung von Arabien p. I64. (w) Voyage de Charlin T. II. p, 26.

(x) Leon. Afric. defcript. Afric. 'T. 11. p. 752.

( $y$ ) Buffonius exemplo, quod ex Olearii itinere in Perfiam defumtum eft, quam fapidae afinorum carnes fint, comprobat. 


\section{G E O G R A P H I C A E. $1_{5} \mathrm{I}$}

re a cicure differt, nifi quod robuftioris ferociorisque fit indolis.

$$
\text { SE C T I O V I I. }
$$

\section{De Sue.}

๑. I. Ne illa animantium genera, quae tam auftraI lem, quam feptentrionalem aequatoris latitudinem inhabitant, hominumque auxilio \& curatura, propter eximia, quae nobis praeftant commoda, in maximos auctus diffunduntur, a fe invicem divellam, nunc ad fucm progredior: qui nec tot nec tantas quidem, quantasque equus, canis \& ovis, utilitates nobis adferre folet $(a)$ : multo minus cum bove, qui maximarum commoditatum copia fe opportunum hominibus praebet, comparandus eft; nihilo tamen fecius multa hominum millia carnis fuae alimento fuftentat. Sic, exempli gratia, Cbinae regno, quod innumerabili prope incolarum multitudine reliqua omnia tantopere fuperat, ut aliquot millena millia plus, quam ipfa Europa, numeret, nifi porcorum caterva aleret, magna victus penuria laborandum foret.

D. II. Regionem autem non modico teporé calentem fium effe patriam, vel exinde patere autumo, quia Afrae Africaeque terrae, graviori aeftu ardefcentes, aprorum, a quo porci dubio procul originem fuam di-

(a) Varii calidioris terrae incolae equorum, canuin, afinorumque carnibus famem tolkrant \& \& Lappones interdum, teilues illos egentesque homi nes, equorum curne vefei, Hogftroemius adfirmat. It Othaiti incolas caues in eduiuis habere Cookius 1 . c. docet. 


\section{SPECIMEN ZOOLOGIAE}

ducunt, copias nutriunt $(b)$; quorum tamen nulli in tractibus aquilonem verfus pofitis inveniuntur : cosque regis demum Friderici primi tempore in Sueciam deportatos effe, ex Linnaeo conftat (c). Porcos deinde meliori longe laetiorique ubertate in terris, quas major teporis vis calefacit, quam quae acriori algore aduruntur, glifcere \& augeri, experientia docet. In his enim carne fpiffrori $(d)$, corporis habitu pinguiori $(e)$, ingenioque folertiori $(f)$ praediti, permundi, \& generatim reliquis reliquarum terrarum praeftantiores deprehenduntur.

0. III. Denique omnes, qui ad porci naturam \& fimilitudinem quam proxime accedunt animantes, fus nimirum aroinaticus, qui Pecari nomine infignis, \& in, Americae parte meridionali obvius eft. 2. Babiroefa, Javae, Sumatrae aliarumque ejus tractus infularum ha-: bitator, dentium ex ore prominentium, longitudine confpicuus, fub torrida, quam dicunt, Zona, luftra fe-: desque fuas habent.

6. IV. Si ab antiqui orbis aequatore vel Boream vel auftrum verfus procelferis, omnibus in terrae partibus, quas mitior coeli temperies adflat, porcos habebis. Conftat enim inter omnes peregrinantes, non in cunctis tantum Europae, fed in Afiae $(g)$ quoque

(b) Buffon Part. III. vol. I. p. 67.

(c) Limné Fauna Suecic. p. 15. (d) Brook Natur. Hift. T. I. p. 76.

(e.) Mandelloh in $F a v a e$ infula tantae pinguedinis fues vidiffe teftatur, quorum fumina ad terram usque propenderint.

(f) Hallen Naturgefchichte T. 1. p. 363. ac 'Pallas Spicileg. zoolog. Fafcic: 2 .

(g) Afia cuncta porcorum genera nutrit; ea tantum loca excipias oportet, ubi Muhamedis religio ipforum ufum interdicit. Faiki ripae, quousque 


\section{G E O G R A P H I C A E.}

Africaeque (b) partibus tam apros, quain porcos offendi: quod deinceps, ipforum degenerationes percenfurus, variorum teftimoniis confirmabo.

0. V. Sus quidem nofker novo orbi minus fuit cognitus; eo autem delatus tam felici proventu áuetus eft, ut, qui in Canadam ( $i)$, Antillas ( $k$ ) infulas, Guia nam (l) Brafiliamque $(m)$ coloni mittebantur, ipforum carne vitam percommode fuftentarent... Non qui-. dem eousque ad feptentrionem, quain reliqua, quale animalia dicunt domeftica, penetrat : interim tamen eorum nonnulli algori fatis vehementi tolerando parés fưte.

0. VI. Nec Sueciae enim, quod jam monui, inec Nordlandiae \& Norwegiae, quae ad fexagefimum tertium quartumque usque gradum protenduntur, porci defunt, quod viri, quibus fides negari nequit, lúculenter adftruunt $(n)$. Groenlandia vero, Islandia, Lapponia, \& Sibiria, quae fub eodem cum illis latitudinis gradu jacet, propter nimiam, quae iftis in regionibus furit,

procurrunt, fues nutriunt (I). Clineinfes animal hoc, caeteris omnibus pofthabitis, magni faciunt (2), magnoque ftudio, ut cumuletur, curant. Gaponia ( 3 ), Ceylanum (4), Philippinaeque infulae (5), Regnum Calecut ( 6 ), tam feris, quam cicuribus porcis fcatent.

(h) Schaw Reis. in der Barbar. p. i57.. Buffon Defcript. Apri promont. virid. Pallas Spicileg. Zoolog. Fafcic. 2. Adtanfon Hift. du Sénégal. p. 76. \& Kolbe 1. c. p. 165 .

(i) Ehrenmalm Tom: XX. Allgem, Reifen p. 593. (k) Allg. Reif. T. \%ั.

(l) Rochefort Hift. des Antilles. p. 445.

(iin) Banccoffs Güiana p. 74. \& Fermin Surinam p. II.

(n) Allg. Reifen T. XVI. p. 284.

(1) Palles Reifen durch Rusland p. 428 . (2) Du Halde Befchreibung ven Cht4a.T. II. p. 163. ( 3 ) Kaempfer Tom. XI. der Allgem, Reifën p. 690. (4) Aligem. Regen Tom. XI. p. 427 . (5) Ibid. T. VIII. p. 51I. (6) Vogage de Fr. Pyrard. Paris 1679. 1. P. p. 287. 


\section{T54 SPECIMENTZOOLOGIAE}

frigoxisvehementian, nulla hucusque fum veftigia monftraverunt ; alioquin enim a pşregrinantibus contum mentio facta fuiflet.

Q. VII. Quum vero, quae nobis in auftrali latitudine terrae cognitae funt, non ad eosdem gradus procurrant; prono inde alveo fluit," nec frigoris vimi ribidem tantopere, quam in feptentrionis extremitatibus faevire: fuesque idcirco ad ultimos propernodum auftri fines pro: dire poffe. Numerantur autem non tantum in bonae fpei capite foecundi fuum greges; fed Chiloe etiam, quae a freto magellanico haud multum abeft, novique orbis continentes terras fere claudit, eorun copia abundat $(0)$.

0. VIll Merito itaque fuibus eas inter pecudes, quae per utramque latitudinem fefe extendunity \& in plerisque regionibus nobis adhuc cognitis bene proveniunt, locum adfignamus: licet non eo usque, quo equus, aquilonem verfus procedant; quod etiam per naturae fuae difpofitionem facere nequeunt, quae, quia minus flexilis, tantae coeli aërisque mutationi pers ferendae non eft. Perexigua enim caloris frigorisque differentia ad eorum ftatum non mediocriter variandum fufficit; fic Buffonio tefte $(p)$, vel unus latitudinis gradus colorem ipforum tantopere immutat, ut in Galliae pro: vinciis, quae aquilonem fpeetant, verbi cauffa

(0) Byronius calamitates, quas ad Patagonum oram in prino fuo itinere perpeffus eft, enumerans, addit: (videatur p. 152. germanicae libri ejus verfionis, quae 1769: Norimbergae in lucem prodiit) Chiloenfium incolas tot tantosque fuum greges alere, ut Chilienfibus \& Peruvianis, quidquid: pernarum utrisque opus eft, impertiri queant.

(p) Hift. der Natur. Pars III. Vol. I. 


\section{GE O GR A P H I C A E $\quad \mathbf{5 5}$}

Vivarienfi, fues plerumque albi fint, quum in Delphit natu, gui modicum tantummodo fpatium ab illa diftat; nigro plerumque colore infecti confpiciantur.

6. IX. Non eit itaque, quod miremur, hos quadrupedes plus equis degeneraviffe. . Tam yarie enim a Te invicem diffidentes numeramus porcorum fpecies, quas vix ac ne vix quidem ab uno eodemque generis auctore deducere quis audeat.

5. X. Quos interim Zoologorum communis fenteng tia ejusdem generis effe ftatuit, fumimatini perftringam. Sunt nimirum I. aper; 2. fus noffer cicur; 3. Jamenjuinil ; 4. Finenfrum, \& 5 . denique jnomen /umm porci, qui omnes non folum procreandi caufa fe copulant, fed fibi etiam quod ad interiores exterioresque partes, frmillimi funt. Quamvis enim framenfium fues caeteris paulo minores, Finenfium autem fumine ad terram usque demiffo, rarogue pilo veftiti fint, \& javanenfunls pinguedo minus fpiffa, ideoque minus grati faporis fit; thae tamen vas rietates non ejus funt momenti, ut earum ratio haberi debeat: fi quidem quos Europa porcos alit, gravioribus longe commutationibus expofitos videmus.

5. XI. Sic Linnaeus inter illos, qui prope Upfaliam educantur, multos dari narrat $(q)$, quicaeteris quidem formae corporisque habitu aequales, minime verobifulci, fed, equorum more, folidis armati funt ungulis. Viro celeberrimo Arifotelis verba, quibus idem fe in Illyrice, Paeoniaeque /ublibus obferyafe teftaturis non in mentem veniffe, inde fit veri fimile, quia, utrum quis

(q) Amioenitat. Acádem. Vol. V. p. 401. \& feq. 


\section{SPECIMEN ZOOLOGIAE}

in aliis idem fuibus extra Sueciam animadverterit, interrogat. Arifloteles autem, quoniam quadrupedes ex ungularum ratione módoque certas in claffes redigere conffituerat, incertus fuit, ad quamnam illarum porcos hofce referret $(r)$... Hinc patet, rem interdum levis admoduim ponderis illorum circulos vehementer turbare poffe, qui omnia ad certain methodum difpertiri, nimisque fpeciales diftinctionis notas fundamenti loco ponere conantur.

0. XII. Magnitudinis etiam refpectu tanta inter quinque jam allatas fpecies, quin \& noftros inter Europaè porcos diftantiä reperitur, quanta poteft effe maxiina. Nonnulli enim ad quinque \& feptuaginta \& quingenta pondo excrêfcunt ( $(s)$; quum tamen Siamenfes vix nonaginta quatuor librarum $(t)$, ideoque fexies \& amplius sillis fint-minores. De Hippanine juibus Linnaeus traditi (4i) oos cos perfaepe fex inenfium vitulis majores

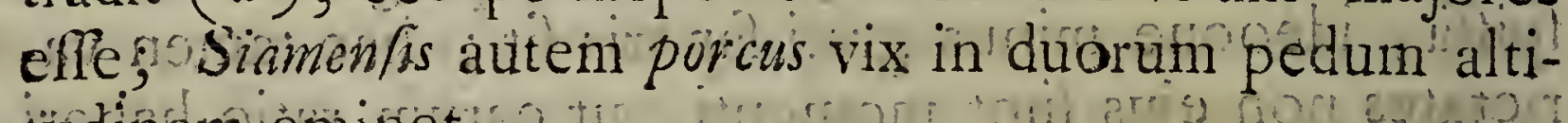
tưdinem eninet:

6. XIII Quodad ipform - colores attinet, vel albi plerumque vel niǵri, vel ex utroque mixti confpiciuntiur: If Ferus enim porcus utplurimum niger vel faltim fufcus eft, quim e contrario cicur, aut albus, aut nigro tantum variegatus \& virgatus fit: Interimi ex apri cun cécure fue coitu difcolores plerumque vel albo nigroque tincetos porculos pronafci, experientia docet.

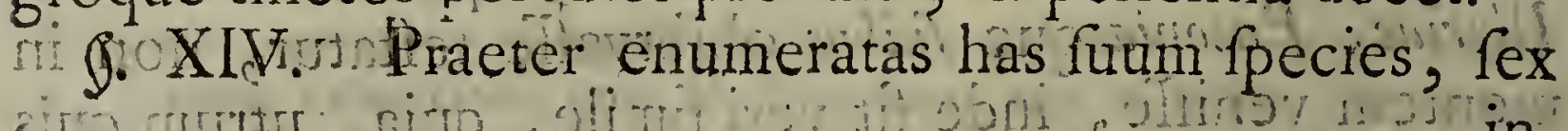

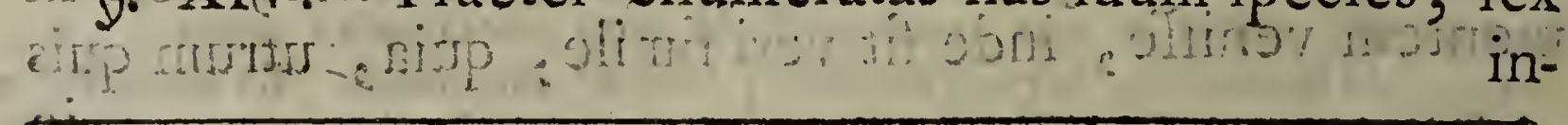

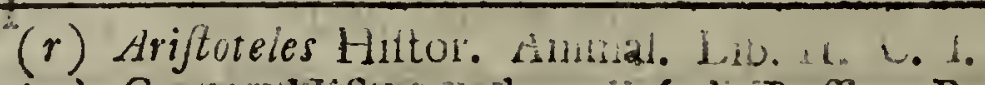

(s) Gesner Hift. quadrup. (t) Buffon. Parr. III. Vol. I. p. 75 .

(u) Amoenitat. Acad.r. Vol. Vi 


\section{G E O G R A P H I C A E.}

inveniuntur, quibus nemo quidem porcorum nomen denegabit: de quibus tamen naturae indagatores certant, \& lis adhuc fub judice eft, utrum apro patre oriundi \& cum reliquis ejusdem fint generis nec ne. Quorum fpeciei tribuunt I. Guincenfem; 2. in Madaga/care (v) $6^{\circ}$ 3. viridi Capite viventem (w); 4. aetbiopicum, 5. TaiajJum, qui etiam Pecari nomine infignitur, \& 6 : Babirocfain, five aprum cervimum. Tria priorum nomina locos ftatim, quibus \& nafcantur \& parcantur, oftendunt. $P$ cari Americae auftralis incola ad Mexicanae usque fines progreditur: Babiroefa autem in aliquibus tantum fer ventiffmo folis ardore aduitis orbis antiqui partibus, verbi gratia, in Moluccis Sundaicisque infulis commoratur.

ઈ. XV. Difcrimen, quo porci Madagafaris \& Gui neae inter fe diftant, tantulum eft, ut neminem, utrosque curatius contemplantem, dubitaturum effe, perfuadear, quin eos communi patre, apro, fatos efre confiteatur. Ipfos itaque hanc folam ob caufam illo; rum fpeciei fubjeci, quorum origo adhuc pro incerto habetur, quia indubitatis rem documentis ad liquidam perducendi occafio hucusque defuit. Duo funt dentes molares, quibus pluribus natura aprum prae Madogajcaris fue armavit, \& hi totam differentiam conftituunt. Sed quoties porci uno alteroque dentium \& quidem primo rum deftituti cernuntur!

Q. XVI. Qui Dambentoniz, quam de fuum dentibus defcriptionem dedit $(x)$, perluftrayerit, facile con vin-

(v) Flacourt Hitt. de Madagafce p. I52. \& Buffor 7. T. 2. p. ${ }^{2} 3^{2}$.

(y) Buffon l. c. p. 243 .

(x) Buffon Part. IIt. Vol. I. p. 9o. fq. \& p. Is8. fq. 
$75^{8}$ S PECIMEN ZOOLOGAE

vincetur, naturam non una femper eadenque ratione ac lege fic agere, ut nunquam aberret. Eam enim pluribus perfaepe dentibus molaribus mares quam femellas inftruere, eorumque interdum ordinem fic turbare, ut fparfim \& incondite pofiti videantur, experiendo difcimus. Sic Pallas $(y)$ in fum noftrorum maxillis inferioribus octo perfaepe dentes incifores, in fuperioribus autem quatuor reperiri obfervavit. Ex quo lucidum omnibus \& manifeftum eft, characterem in ordinandis quadrupedum generibus a folis dentibus defumtum, minime fufficientem nec tam certum efle, uti permulti fibi perfuadent. Duorum itaque molarium defectus, in Madagafcaris porcis notatus, nunquam efficiet, ut idcirco alius cujusdam generis originisque fues habeantur. Eosdem ergo fine ulla dubitatione $a b$ afro deducendos effe credo.

0. XVII. Sus autem Guineen/zs, quem HalleniusexaEte fatis expofuit $(z)$, auribus quam maxime demiffis crinibusve, quibus fetarum loco veftitus incedit, a noftro difcrepat: \& vix quemquam, qui, quae de cane, bove, oveque jam attuli, rite penfitaverit, aufurum efle crediderim, ut beftiam hanc cui idem cum apro, \& corporis \& morum habitus eft, tam levidenfem propter differentiam ad aliud genus remittat, aliique cuidam patri tribuat.

5. XVIII. Sus interim actbiopicus, quique in viridi Capite domi eft, caeteris paulo magis a noftrate difta-

re

(y) Spicileg. Zoologic. Fafcic. II. p. 9.

(z) Natur. Gefchichte T.I. p. 360. 


\section{G E O G R A P H I C A E. 559}

re videtur, praecipue fi ex folis dentibus utrumque dijudicaveris. Noffratem porcum perinde atque aprum, quadraginta quatuor dentibus armatum effe, in omnium fere cognitione verfatur. Nihilo tamen minus quosdam etiam in nonnullis eorum interdum defiderari, nunerumque iftum perfaepe diminutum reperiri, res pervulgata eft. Nunquam enim natura nec in his, nec in aliis animantibus, eundem morem fervare folet.

5. XIX. Qui in viridi Capite porcus vivit, Daubentonio auetore $(a)$, qui ejusdem caput quoddam exfcriptum dedit, viginti modo quatuorque dentibus inffruetus effe dicitur $(b)$. Et cui phyficorum tam no-

(a) Buffon Part. VIi. Vol. II. p. 243.

(b) Uc, quibus quotve dentibus porci armati fint, uno quafi obtutu perfpiciatur, eorum numerum, optimorum anctorum ductu, adponam:

1. Apri porcigue noftri cicuris utraque maxilla fenis inciforibus, caninis binis. \& quatuordecim molaribus armata eft. Duo interdum minoris formae dentés, pone prominentes caninos confpiciuntur. His omiffis, fummam habebis quadraginta quatuor dentium; qui numerus \& Guineenf $f u m$, Favanenfum Sinenfiumque fuibus communis eft.

2. Quaevis porci Madagafcaris maxilla fuperior totidem inciforibus caninisque, inferior autem non quatuordecim, fed decem modo molaribus, quinque nimirum in utroque latere, inftructa eft ; itaque quadraginta tantun dentes eidem adfunt.

3. Capitis xiridis funm inferior maxilla fex incifores, duos caninos, fex molares, in utroque nimirum latere tres, continet; maxilla vero fuperior duos incifores totidemque caninos, \&, quod fatis probabile videtur, fex. molares, tres nempe in utroque lacere monftrat, qui fummam viginti quatuor conficiunt.

4. In Pecari fuperiori maxilla quatuor incifores, duo canini, duodecim molares: in inferiori autem fex incifores, canini duo, duodecimque molares numerantur: quorum fumma triginta octo eft.

5. Barbiroefat fuperior maxilla quatuor inciforibus, duobus caninis, cecemque molaribus; inferior autem totid m caninis \& molaribus, \& fex inciforibus prazdita elt. Sumna igitur triginta quatuor dentibus conftat. 


\section{SPECIMEN-ZOOLOGIAE}

tabilis differentia non addmirationem movebit? Sed quunz calput, in quo dentes numerando percenfuit, integrum non effet; facile fieri potuit, ut quidam dentium jam defecerint, ideogue omitti debuerint, quod ex praeftantiffimi-viri verbis fufpicari licet, qui nec ipfe numerum hunc pro certo exploratoque habet: quid? Si caput fuilfet, in quo natura a ritu fuo aberraffet? Quoniam praeterea hucusque alia nulla in animantis hujus dëntes inquirendi data eft facultas; certi quidquam de itlo vel adfirmare, vel negare temerarium effet: etfi reliquae, quas cum noftris fuibus gerit, fimilitudines, $\&$ praecipue prominentes canini, quos toti fuum generi a natura tributos effe conftat, quive in capite etiam ifto apparuerant, me commovent, uit viridis fic dieti Capitis porcos ab apro, communi fuum patre, ortos, fatis probabiliter credam, quos coeli \& aëris temperies pabulique ratio paulum immutavit.

0. XX. Aetbiopunis fus, qui paucis demum abhinc annis indefeffa celeberrimi naturae fectatoris, Pallafii, amici digniffimi, opera \& defcriptione innotuit $(c)$, majori adhuc intervallo ab apro diduci videtur. Quadrupes hic in Africae interioris regione, quae ducenta milliaria a bonae fpei Capite diffidet, captus, $\mathrm{Ha}^{-}$ gam delatus aliquamdiu vixit, primoque ftatim adfpeEtu, quan enormi capitis \& magnitudine \& craffitudine noltratibus porcis antecellat, commonftravit. Oculi in fummi capitis parte pofiti a crinibus circuncirca

ex-.

6. Suis aethiopici utraque maxilla primores nullos, duos caninos habet; de molarium vero dentium numero, hucusque nihil certi adferri poteft.

(c) Spicileg. Zoologic. Fafcicul. 11. 


\section{G E O G R A P H I C A E. I6I}

exftantibus $\&$ umbellae quafi formam referentibus, ab imminentis folis ardore obumbrantur. Canini inufitatae magnitudinis dentes, qui longiuscule prominent, timoris quidquam adferunt. Cutem raro pilo obfitam fetarum fafciculi, quafi penicilli more difpofiti, vestiunt. Labium fuperius, quousque dentibus circumjectum eft, craffum quidem durumque, flexile tamen eft, \& utrumque roftri angulum mollioris carnis lobus femiovalis operit. Dentes incifores nullos habet, quorum loco gingiva, quae praedura laevisque eft, utitur. Odore etiam a noftris fuibus recedit: cafeum enim Helvetiae viridem, quem Scbabzieger vocitant, redolet. Mirae celeritatis callidique eft ingenii, quo noftrates longe poft fe relinquit.

0. XXI. Et haec eft africani illius incolae imago, qui caeteroqui roftro terram fodere, grunnire, corpus lapidibus crebro atterere, \& reliquos omnes porcorum noftrorum mores imitari folet. Num igitur folus primorum dentium defectus fufficiat, cur ad aliud quoddam animantium genus referatur, nec ne, aliis dijudicandum relinquo. Si cornutas cuidam beftias ex cornuum ratione modoque in certas claffes difpertire libuerit, ad quamnam illarum, oves, quibus cornua defunt, quarumque fupra mentio facta eft, relaturus esfet? Quod fi cuncti quadrupedes fecundum ungulas in quasdam fpecies diftribuendi effent, cui earum Sueciae, Illyrii, Paeoniaeque fues adfcribendi forent? Quis oves cornubus vacuas, quae cum reliquis omnia communia habent, ovium claffi, fuesque folidis ungulis inftructos, omnique ex parte caeteris fimiles, fuum generi adnumerare dubitabit? Nonne natura in 


\section{t62 SPECIMEN ZOOLOGIAE}

augendis minuendisque dentibus, aeque ác in formandis ungulis cornubusque, pro arbitrio libertateque fua agere poteft? Integra animantium indoles \& difpofitio, for-ma nimirum, vitae genus moresque, non autem fingulae quaedam partes, quae falva incolumique illortum fubftantia abeffe vel adeffe, multifariamque mutariposfunt, ipforum genera conftituat difcriminetve oportet. (d).

Q. XXII. Sed aliud dubium, idque majori probabilitatis fpecie, Pállafuris movet: an nimirum aetbiopicum porcus idem fit cum noftrate? quoniam, licet mas effet, nec cum cicure fue noftra, nec cum indica, quum ad illum admitterentur, coire voluit, quas potius caninorum dentium ope, qui inufitata magnitudine prominuerunt,' tam infefte excepit, ut prior ftatim enecaretur, altera, ne pari modo interfecta fuccumberet, removeri debuerit.

f. XXIII: Si, quod a Bufforio in cane, lupoque factum effe diximus, ex una ftatim obfervatione ress omnis decidi dirimique poffet : controverfia jam transacta, porcoque huic non aper, fed longe alius gene-

ris

(d) Ablit fufpicio, me celeberrimorum in republica litteraria virorum aufus eximios improbare velle, qui omnes res creatas certa quadam methodo difponere tentaverunt. Ingratiffimo enim is animo foret, qui de Kleinii, Brisfonit, Linnaeique, (quos omnes honoris caufa nomino) infignibus meritis detracturus effet, quorum Ingulorum, \& praecipui hujus opera, quem ultimo loco nominavi, hiftoriae naturali tantalux affufa eft, tantumque commodum acceffit, ut perpaucis nune in plagulis omnia perfpici queant, quae multo quondam ftudio \& labore e variis anctoribus conquirenda erant. Ordo enim, qualis qualis fit, confufioni femper praeferri debet: modo ne anxie nimis notis inhaerens, quas fpeciales fundamenti loco femel pofueris, fed naturae potius, communi rerum parenti, obfequaris. 


\section{G E O G R A P H I C A E. I . I}

ris fui auctor dandus effet. Magnam vero his in cafibus cautionem adhibendam efre, unamque $\&$ alteram naturae notationem \& animadverfionem ad rem dilucide expediendam, minus fufficere, in Sectione, qua de cane actum eft, comprobaviffe videor. Quid autem obftat, quo minus, quod ibi, heic etiam locum inveniat? Num res ideo certa eft \& expedita, quia femel aut bis minus profpere fucceffit? Quemadmodum itaque unum, quod Buffonius attulit, exemplum, a cane lupum disjungere nequit; fic nec hoc experimentum aethiopiae porcum a noftro divellet: quivis potius fapientum largietur, faepius ante periculum effe faciendum, quam lis haec plane componi pleneque perfici poffit.

0. XXIV. Tandem odor etiam, huic animanti proprius, opponi poffet: nonne autem ferus Americae feptentrionalis taurus mofchum redolet; unde bovis mofchi nomen ei datum effe conftat? Nihilo tamen fecius ip. fum cum domeftico noftro corpus mifcere, nec novum genus conftituere Kalmius teftatur. Tamdiu itaque, non exigua cum probabilitate, hunc ab apro, communi fuum ftirpe, primam fuam duxiffe originem credo; donec contrarium novis iisque certiflimis data occafio. ne documentis probatum fuerit.

O. XXV. Species haec, ut Pallafus opinatur, (e) interiorem fe in Africam usque extendit. Veri enim fimillimum eft, ferum, quem Adanfonius ad Senegalli ripas Jutm vidit, $(f)$ non, quod ipfe credidit, $B a$ -

(e) I. c. (f) Hiftoire du Sénégal p. $7_{\mathrm{X}}^{6 .}$ 


\section{I64 SPECIMEN ZOOLOGIAE}

biroefJam, fed aetbiopicum fuiffe, qui propter caput informe, immanesque, qui ex ore prominent, caninos, adfpectu torvus eft.

j. XXVI. Duo adhuc animalia fuperfunt, quae an aprum patrem olim habuerint, nec ne, haud facile probatu eft. Taiaf $/ u(g)$ \& Babiroeffa, (b) quorum prius Linnaeus breviter quidem, fed tam lucide depinxit, ut cum aliis haud facile permutari poffit. Suem ipfum dorfo cy/ifforo, cauda nulla praeditum, nominat; \& quia duabus praecipue notis, quod cauda caret, glandulamque humore femper odorifero refertam in tergo habet, a reliquis omnibus difcrepat; omnino fingulare quoddam genus conftituere videtur. In auftrali inprimis Americae tractibus commorans, ad Mexicanam usque regionem progreditur. Nomine plerumque mexicani apri infignitur (i); iisdem cum noftro moribus, codem eft ingenio: gregatim enim femper ingreditur; terram roftro: fuffodit, frugibus, radicibus, herbisque agreftibus, quin \& ferpentibus, lacertis, aliisque ejus generis vermibus, vitam propagat; ex fero mitigatus, domeflicus fit, fed nullis cum aliis, nec cum illis, qui ex Europa in Americam transvecti \& ibidem efferati, nomen ingroram porcoram (cocbon marron) adepti funt, procreandi causa copulatur. Ex quo, \& quain maxime e caudae defectu, glandulaeque praefentia, beftiam hanc

(g) Buffon Part. V. Vol. II. p. I3. (h) Id. Hart. VL Vol. II. Linn. Sylt. Sus dentibus duobus caninis fronti innatis $\mathrm{Ed}$. I2.

(i) Apud mexicanos vocitur, Quapizotl vel Quauhtla coymatl. v. Hermandez 'thefaur. rerum medic. nov. Hifpan. Recrhi de animalib. p. 637 . 


\section{G E O G R A P H I C A E. I 65}

hanc ab apro minime genus fuum trahere, Buffonius cum aliis naturae inveftigatoribus colligit.

6. XXVII. Quum vero jam commonftraverim, noftros etiam fues per omnes Americae meridionalis partes difperfos reperiri : ne operae quidem pretium erat, quousque haec $\tau \tilde{\delta}$ Taiaffu fpecies fe extendat, disquirere. Interim illum nec abfona, nec naturae disfentanea fingere crediderim, qui differentiam, qua beftia haec a noftris fuibus diftat, morbo cuidam tribuere velit.. Quum enim omnes, iftique inprimis porci, qui terras vehementiori aeftu ardefcentes inhabitant, graviorem femper aliquem odorem efflare foleant: cur fieri non potuit, ut graveolentes illae partes, quae per totam fuis cutem diffurae erant, in terris aeque magno humore atque calore redundantibus, qualis America auftralis eft, tandem in ulcus quoddam feu fonticulum coaluerint, qui dorfo affixus, fanieque perpetuo fluens, temporis fucceffu tergi glandulas ita immutaverit, ut omnem, quam caudae augmento natura deftinaverat, materiam abforbens, animanti \& debilitatem \& corporis deformitatem contraheret $(k)$ : quae quidem, licet minime ut ex tripode dicta, pro inquifitis \& compertis adferam, eandem tamen probabilitatis fpeciem prae fe ferre mihi videntur, quam illorum opinio habet, qui breviorum tibiarum canes ex rachitide ortum traxiffe tradunt.

๑. XXVIII.

( $k$ ) Cutis norbos haereditario quafi jure a patre ad liberos nepotesque interdum tranfire, fingulari exemplo Edwardi Gleanings, \& transactiones phi6ofoph. No: 422. confirmant. Pater enim quidain hirfute, feu spinis potius hirfutis obfita cuce, ejusdem cucis aliquot liberos, feu integram fotius. Samiliam, produxit. 
$166^{2}$ S PEC MEN ZOOLOGIAE

6. XXVIII. Bábiroefja denique eximia, qua pollet, magnitudine $(l)$, duobusque dentibus caninis infignis: eft, qui e fuperiori maxilla prodeuntes, ab imis ftatim radicibus furfún vergunt, $\&$ cornuum nnore, (licet révera dentes, non autem cornua fint) porrecti adfurgunt $(m)$. Molliori praeterea quam aper, pilo veftitus, nunquam cum fribus foris, qui ipfum tamen pafcentem faepius comitantur, coit. A canibus venatoribusque agitatus,' hoftes fuos exploraturus ad arbores $\mathrm{fe}$ reclinans fublime fe tollit, caeteroquin arborum foliis \& gramine vivit $(n)$.

0. XXIX. Sat multa, forfitan inquies, quibus ab apró diftat, difcrimina! fed fi tecum reputaveris; primo, corporis inagnitudinem nunquaim ad novum quoddam genus conftituendum fufficere; dein dentes ejus caninos prominentes illis aequales effe, quibus porci noftrates armati funt; porro, eadem grunnientium voce, fubtiliori olfactu ingenioque, \& fummatim iisdem-moribus ipfum cum noftris conficuum; poftremo beftiam hanc nec düm fatis cognitam, nec recte curateque adhuc defcriptam effe : facile conjeeturam capies, eam propinqua fatis apruin communem funn patrem cognatione contingere.

0. XXX. Hactenus animantium nobis utiliffimorum genera, quos homo ditioni fuae fubjecit, \& nunc ubi-

que

(l) Linne Babyrulta magnitudine cervi.

(mi) Briffon Allgem. Hilt. der Natur. Part. VI. Vol. II. pag. 253. quo loco Daubertonius evincit, hos dentes apri caninis effe fimillimos.

(n) Figuram Babiroeffae jnvenies I. apud Pifonem in Bointii Tract. de Animal. Ind. Orient. p. 61 . \& in Siba Thefaur. T. I. Tab. 50. Tig. 2. A 


\section{G E O G R A P H C A E 16 ?}

que terrarum comites habet. Sed pedem paulisper fit ganus, \& quid exinde generatim effici cogique poffit, paucis contemplemur.

0. XXXI. Qui ad ea, quae de patria quadrupedum, tam mirandos hominibus fructus praebęntium, dicta funt, mentem adhibuerit; is dubio procul inde colliget, natale folum, quod bovem, equum, afinum, ovem, capramque a rerum initio genuit aluitque, 2 fian mediam partem, feu regionem modico fatis tepore calentem fuiffe: praecipue fi attenta contemplatione didicerit, ipforum indolem \& difpofitionem omnibus partibus fuis expletiorem ibi perfectioremque fieri.

6. XXXII. Sed haec ipfa Afa hominis etiam prima fuit patria Ut enim incertam exiguaeque utilitatis, de paradifi fitu, theologorum difceptationem omilttamus; hoc faltem exploratum cognitumque eft, Afine quasdam partes, exempli gratia, Natoliam, Mingrelinm \& alias aequabili modicoque aeftu calentes, hominis naturae conftitutioni quam maxime idoneas, ejusque animi vigori augendo, ingenioque exacuendo, convenientiffmas, praeterea \& agrorum ubertate fructuumque varietate tam opimas, tam fertiles effe, ut \& pecora \& hominem conmodiffime alere poffint. In fequenti autem libri hujus capite ea percurfurus animantium genera, qui certas tantum orbis noftri zonas occupant; quorundam aliorum, cameli nempe \& dromadis, mentionem faciam, qui Afram perinde incolunt, permagnoque hominibus ufui effe folent.

6.XXXIII. Negentalii ac pernegent, univerfum hoc, ordine admirabili difpofitum effe, fapientiaque exquifitiffima adminiftrari; \& in alia omnia difcedant: nonne haec 
haec ordinatio memoratu digniffima ipforum refellit, redarguitque errorem, quod inter res creatas, homo, puta, qui magna quidem rerum ad commoditatem felicitatemque fuam neceffariarum penuria laborat, ea tamen mente, eoque confilio praeditus eft, ut obvia omnia in ufum fuum conferre polleat, cum omnibus, quae ipfi opus funt, commodoque fuo fervire poffunt, ne multum diuque iis conquirendis diftineretur, in una eademque regione fit oriundus?

5. XXXIV. Objicient fortaffe: quoniam omnes ferme quadrupedes in iisdem terrae tractibus optime proveniunt, ideoque maxima ipforum copia in terris, modico calore tepentibus, optime $\&$ commodiffime vivere poteft; homini, praeftantiori ingenii acie ornato, nihil aliud factu opus fuiffe, quam ut ex ingenti eorum numero eos tantum eligeret, quos maximum fibi fructum laturos effe praeviderit.

6. XXXV. Sed ad aequatorem propius accedant illi Pyrrhonis fliii ; nonne in Africa, quae folis ardore torretur; nonne in Afiae partibus, graviori aeftu ardefcentibus, eandem quidem animantium copiam, minime vero tantas utilitates adferentium, offendent? nonne ibi, loco bovis, leonem; loco equi, caracalem; ovis, byaenam; caprae, pantberum; \& cameli, tigridem regiam obvios habebunt? Omnium tam éxitialium naturae monftrorum patria in aeftuofinitimis tantum plagis reperitur, quas quidem domefica etiam pecora tolerare poffunt; quis autem eas ipfas communem utrorumque fedem fuiffe fibi perfuaferit? quippe quae partim peffime ibi $\&$ vivunt $\&$ proveniunt, partim maturius, quam aliis in locis, pereunt.

ઈ. XXXVI. 
0. XXXVI. Tota itaque via errant, qui fub catidiffimo coelo maximos quadrupeduni greges nutriri autumant. Quo ipfo, quae ratione ferventiffinarum regionum obmoveri poffent $f_{g}$ infirmantur! guod vero ad terras minus tolerabili frigore horrentes attinet; ficco pede praetereo quim quasdam folumnodo pecudes ibi vix ac ne vix quidem educi, vivasque confervari $;$, experiundodifcamus:- qua de caufa alio quodam inodonatura ipfis profpiciens hune defectum compenfaviffe videtur.

S: XXXVII. Hominem itaque cum tot quadrupedum, quibus nec igne, nec aqua magis utitur, generibus, eadem in patria fatum creatumque effe, ei fummopere, lus crofum erat \& opportunum: quo tanquam novo argu: mento doceri exiftimo; mundum, eumgue animalem praecipue non initium modo fuum habuiffe, fed a fapiente etiam benignoque creatore conditum effe: fi quidem aliarum quaevis belluarum vicinitas, hominem aut plane deftruxiffet, aut maximam faltem rerum ipfi utilium inopiam attraxiffet.

0. XXXVIII. Aeque memoratu digna eft, quae ad hominem inde redundat; commoditas, quod pecudes illae tam flexibili ingenio, robuftaque tiatura funt, ut hominem quoquoverfum comitari, omnés coeli plagas cum ipfo tolerare, \& easdem ubique ipfi utilitates praebere valeant. Fac; bovem, equum, ovem \& reliqua pecora uni eidemque coeli plagae fic adftricta effe, ut patriam fine vitae periculo permutare nequirent; quod rhinoceroti s elephanti g, leoni, aliisque immanibus beftis accidit nonne longe minora, longe arctioribüs limitibus circumfrripta forent commoda, quae ex illis Y 


\section{0 \\ SPECTMEN Z OOL OG I AE}

percipimus? Quot orbis noftri trâctus vafti incolisque \& cultoribus nudi jacerent, nif his, qui nobis adjutofes: funt, animantibus, ut fe comites etiam darent, liceret? Q Qtis, haec omnia cafu \& fortuito accidiffe, fibi: perfuaferit?

J. XXXIX Cur non ex altera párte quadrupedes: morum diritate ingeniique immanitate deterrimi, itidem:

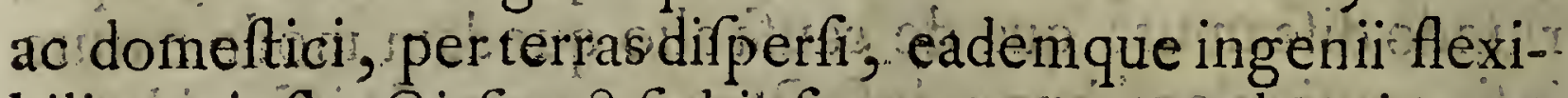
bilitate inftrueti funt? fed 'úfortunatuin tunc hominem, cui ubivis gentium cum belluis, ipfuir ïnfefte aggredientibus, conflictandum fuiffet Nullibi pecorumgregibus, ex quibus.fructum percipere poterat, ftipatus, per totum orbem hoftibus cinctus: Fevifflimis; ; cửnetis contra; quae ex domefticorum grege àdipfum redundante, emolumentis: I Poliatus, nullo usquaim loco fine folicitudine? quiefcere, fine metu refpirare pôtuiffet.

Q. XL. Is ftatus, ea generis humani conditio fuisfet, ni:fingularis fumini rerum arbitri providentia do mefticis pecudibus eam corporis habilitatem addidiffet, qua fe per omnem terrarum orbem, quousque habitabilis eft, diffundere valent: nifi eandem plerisque feris: beftiis denegaffet , hasque loce fuo natali ific alligaviffet, ut fine vitae difcrimine procul inde difcedere nequeant.

$$
\text { S E C T I O V I I I. }
$$

Praeter enumerata hactenus, alia quaedám animaliums fuperfunt genera, quae nee tante hominibus funt: ufuig nec fic frangi domariqge potuerunt, ut eorum jugo fe penitus fubmitterent folo tamen naturae fuae 


\section{G EOGRAPH $\mathrm{CA}$.}

robore \& ftruetura cum percenfitis totum pene orbem pererrant, \& ubigue locorum, minori tamen numero, homini occurrunt. Talia funt 1. felis, 2. valper, 3. lepus, 4 cervis, 5. ghs cam mire, 6. Jciurus \& 7 muftela: reliqua quae omnia per ütramque globi noftri terreftris latitudinem diffipata cernimus, licet vel hominis nulla ipforum educandorum cura accefferit; vel, fi qua acceffit, trifti tantúm cafui cuidam, qui ea hominum "poteftati" fubjecit, adfcribenda eft. Quae breviter quidem perftringam, eorum tamen degenerationes, quoad ejus, propter perturbatam adhuc, necdum fatis explicitam animalium cognitionem, fieri po: teft, perluftrabo.

\section{Felis.}

6. I. Felis, cane minus manfuetus, minusque caeteris beftiis ferus \& immanis, medius, \& in confinio cicurum ferorumque animantium effe videtur. Quumque venandorum murium caufa ab homine nutriatur; hinc forte factum eft, ut ex parte tantum domefticis pecoribus annumeretur; praecipua tamen ratio in ejusdem natura magis ad feritatem, quam manfuetudinem, proclivi, quaeratur oportet. Interim fat multis in terrae tractibus reperitur, quam tamen generis fui dilatationem fibi magis ipfe quam homini debet."

0. Il. Ferus, qui cum cicure noftro coïre fuevit, unius ejusdem generis eft, \& uterque tam feptentrionis frigora, quam Africae aeftum fuftinet; interim tamen nec Kamjcbatka, nec Lappia cum Groenlandia Islandiaque feles nutrit." In Samojitiae quidem defcriptione, 


\section{$17^{2}$ SPECIMEN ZOOLOGIAE}

quae decimo nono collectionis itinerum univerfalis tomo inferta eft $(n)$, feles etiam in regionibus iftis; $\mathrm{EH}_{-}$ ronotum verfus fitis, commorari legimus an id autem certa explorataque rei veritate auctor fripferit, \& ad feles noftros refpexerit, yalde dubito; quum naturae fcrutatorum, quantum mihi quidem conftat, nemo beftiam hanc in circuli polaris vicinia viderit, Limneusque in Fauna Succica de fele domedtico (b) , cajus unius mentionem facit, teftetur, eum novum Sueciae incolam, ex aliis terris advectum effe. Et Ponsappidanus, Norvegiam. \& feros \& cicures feles alere, adfirmans (c) de inferioribus procul dubio ejusdem regni partibus id intellectum voluit. Quum enim illud ad feptuagefimum primum dimidiumque poli gradum extendatur, miraculo foret, qui fiat, ut Lappiae quae Norvegiam attingit, feles defint: cui accedit, quod frigoris etiam vim abhorreant.

6. III. Quae conjunctim fumta denuo evinçunt, fines huic animanti praefcriptos non ultra fexagefumum tertium aut quartum latitudinis gradum extendendos efre. $A$ quo fi per utriusque hemisphaerii continentes terras progredieris, feles tam cicures, quam feros, feros nimirum in Canadenfrum, Illinefum (d), Mexicanorum, totiusque Americae feptentrionalis regionibus (e), quin etiam in plerisque orbis antiqui filvis invenies: Cicures non in omnibus folum totius Europae domibus locum fedemque habere, fed Natoliam quoque $(f), P$ erjam,

(a) Pag. 494. (b) Pag. 3 .

(c) Naturliche Gefchichte von Norwegen T. II. p. 18.

(d) Charleyoix Hift. de la nouv. France T. Ill. p.4.7\%

(e) Acofta Hift. Nat. des Indes Lib. 4. Cap. 33.

(f) Voyag. de Pietro della Valle T. V. p. 98. 
Magni Mogolis imperium (g), Cbinam, Tartarihm magnam, caeterasque Afiae partes $(b)$, eos copiofe fatis alere, peregrinatores confirmant.

Q.IV. Aeftus vehementiam, quae fub tropicis iproque aequatore furit, domefticis pecudibus melius faciliusque feles perferunt : hinc tam feri, quam cicures Guineae (i), Madagafcaris (k), Congi (b), Regni Tunkin (m), Infulae Javae (n), Panamae \& Guianae (o), Peruviae, Cbilienfunn (p), Braflienfunm regionis, \& P Patagonica $(q)$, incolae funt, \& fic genus hoc a exagefimo tertio latitudinis aquilonaris gradu omnes propemodum cognitas nobis terras peragrat, nec, quod notatu adhuc eft dignius, tantum, quantum bos, canisque degenerat.

6. V. Longe minoribus itaque \& corporis \& magnitudinis fuae mutationibus eft obnoxius; quodfi firmiori ejus naturae quis tribuerit, ipfum a vero minus aberrare crediderim. Canum boumque fpecies dantur, quae octuplo, quin duodecuplo \& amplius, vel majores. vel minores funt; quum feles feri vix dimidio cicures. fuperent. Chincn/fum felis unus eft, qui, quod, Buffosius recte annotavit $(\boldsymbol{r})$, propter molles, demiffasque

aur-

(g) Du Halde Berchr. von China T. I.

(i) Gmelini (Sonior.) Reifen T. I. p. 315.

(i) Allg. Reif. 1. IV. p.' $25 \mathrm{E}$ \& Bosmans Guinea p. $28: 2$.

(k) Flacourt Hift. de Madagafe. p. I5.2. (l) Osilby"s Africa p. 52 r.

(m) Baron Defcript. of Tunkin p. 5 .

(n) Cook's Voyage p. 745. in Hawkesworth' Account. T. 3.

(o) Fermin Hift. de la Hollande équinox. p. 7 .

(p) Allg.. Reij: 'T. XVI. p. 272.

(q) Narborough. Voyage dans le 3 me Tom. des Voy. de Coreal. p. $\sigma_{3}$.

( $r$ ) Vir. Buffonii Tom. III. pars 2. ubi Dalıbentonius fingulas fulium dimentiones appofuit. 


\section{4 \\ SPECIMEN ZOOLOGIAE}

aures longius a caeteris fui generis differt: ipfaque ex perientia praeftantiffimi viri fententiam, animantes tam feros, quam cicures, flaccis quos natura auribus inftruxit, quam maxime a generis fui auctore degeneraviffe, fatis fuperque comprobare videtur.

0. VI. Caeteroqui beftiam hanc cane melius faci- Tiusque aeftui refiftere, exinde difcimus, quod, quum Guinea canes depilet, felis ibidem femper fibi finilis fit maneatque (s). Quod fi cunctos, quos Europa feles nutrit, inter fe comparaveris, nusquam eos tanto a fe invicem intervallo diftare cernes, quanto brevioribus tibiis caneś a vénaticis anglicisque. Non mirum eft, Syriae, Natoliae, \& quam maxime Angorae terras, quae fálubriori coeli temperie gaudent, tam caprarum aliarumque pecudum, quam felium etiam pilos in meliores transducere fubtilioresque $(t)$; utpote quos natura ibidém pellibus tam denfis mollibusque veftivit, ut bombycem imitari videantur. In Hifpaniae jant Perfiaeque regionibus, ubi mitiori fub aëre vivunt, multo teneriori crine, quam in aquilonaribus regionibus tecti, \& praeterea quibuscunque colorum varietatibus-tineti comparent. Nigri enim, albi rutili, maculati, quin etiam coerulei $(u), \&$ feri \& cicures feles paffim oculis fubjiciuntur.

0. VII. Americanum interea cattum montanum a Seba deficriptum(v), \& a Meiero in animalium collectione

vi-

(s) Allgem. Reifcn. T. IV. p. $25 \mathrm{I}$.

(t) Videacur felis angorenfis imago, quam Buffonius cielit Part. 2. Vol. III. I'ab. V. Allgem. Natur. Hifl.

(16) Kolve Befcribung der Vorgeb. der G. H. p. 153. in fol.

(v) Quanhpecofi. Vicle Stbe Thef. T. I. Meiers Thiere 3 Theil \& Fir. 


\section{GE O G R A P H I C A E.}

vivis coloribus depictum, ferum cattum effe cenfeo; quia nec ejus color, ut tigrinis ipfe felibus annumeretur, efficit, nec externus ejus habitus \& forma a fero magnopere deflectit:

6. VIII. A fero igitur, qui grifeo colore, fubfúca per dorfum fafcia, annulataque cauda fuperbit, quinque fpecies, quas ordine percenfebo, difcedunt. I. Felis nimirum nofter, qui omnés propemodum colores recipit; 2. bifpanicus molliori crine ornatus; 3 perficus denfiori pelle indutus, glaucique grifeo intermift coloris, \& a Buffjonio Curtbufien/is (chat chartreux) nomimine infignitus eft; 4. Angorac felis crebra denfaque juba, fubtiliffimo pilo, qui fericum fere aequiparat, crafraque fatis cauda notabilis; \& 5 denique, qui pen dulas aures demittit: \& haec de felibus.

$$
\begin{gathered}
\text { S. C. T I O IX. } \\
\text { Dilpes. }
\end{gathered}
$$

Q. I. Vulpem, quae lupun feu canem proxima cogna tione attingere videtur, pari ratione per easdem terrae partes diffipari, \& a feptentrione ad auftum usque dilatari, poffea demonftrabo, fi notae prius ratio nesque allatae fuerint, quibus tam a lupo, quan cane diftinguatur.

0. I1. Primo quidem adhuc nullo, quod omni dubio \& exceptione majus fit, exemplo comprobatum eft,

Fernandez Hit. Quiadrup. nov. Tilip. p. 6. Gap. 17. in fine Thefaur. rer. medic, nov. Hifp. Hermandsaiti. 


\section{SPECIMEN ZOOLOGIAE}

eft, vulpes fe cum canibus, procreandi caufa, conjunxiffe (a): quod Doebelius quidem adfirmat, non tam exquifito tamen certoque documento comprobat, quo lupi canisque coitum planum fecit; animalium for: taffe analogia inductus, rem, nullis rationibus convictam, generatim fic tradidit, uti incerto rumore percrebuerat. Buffonii ergo fententia, qua vulpem canemque diverfas diverfique generis beftias effe docuit, inconcuffa adhuc ftat ac perftat.

ర. III. Deinde vulpes Specus cuniculosque agit, quod vel a cane unquam aut lupo tentatum quisquam nec viderit nec legerit. Lupum, fortaffe oppones, corporis fui robore confifum talibus latebris haud egere? fed eo ipfo utrosque \& natura \& genere disjunctos effe, concedes. Accedit, quod nec canis nofter in America efferatus fe fcrobibus factis unquam in terram defodiat. Hanc itaque terrae fubfoffionem notabile difcriminis fignum effe, mihi perfuadeo.

6. IV. Praeterea, nec canem, nec lupum, fed utroque multo intolerabilius, nec, uti lupus, carnes morticinas, quibus hic vefcitur, olet. Quodfi canum nonnullos multum diuque carne faturaveris, foetorem quidem graveolentem efflant, qui e carnibus, \& animantium praecipue cadaveribus, quae devoraverunt, oritur: fed oulpes, cui cádaverum carne famem fedare non opus eft, quia prae lupo pluribus longe \& gratioribus cibis vitam fuftentare poteft, foetorem nihilominus teterrimum Spirat; qui adeo ipfi proprius eft, ut nulla arte, nullo

(a) Doebol. neueroefhere jaeger practic. P.38. 


\section{GE OGR A P H I C A E.}

Pudio depelli queat; licet variis \& bene alentibus etiam eduliis mundiffime puriffimeque nutriatur: qua in re pitorio potius, quam lupo fimilis effe videtur.

6. V. Porro, pluribus longe vulpes, quam canis lupúsque, alimentorum generibus comedendis concoquendisve par eft. Cancros, bufones, fcarabaeos, locuftas, nel, uvas, \& multa alia, quae cupediorum loco habet, fumit; quae canis aeque aclupus non modo intactá relinquint, fed naufeantes etiam adfpernantur.

6. VI. Tandem, vülpes longe difficilius lupo mitigatur : quippe quáe ad certam usque aetatem naturae quidem fua feritatem deponere videtur; túnc vero ad priftinos mores ingeniumque fuum redit: ficatenis vinctus fuerit, aegritudine conficitur. Nec fando quidem auditum eft, gentem aliquam manfuefactis vulpibus, canum loco, ufam fuife: licet intolerabilis, quem perpetuo exhalat, foetor etiam in culpa elfe potuerit, quo minus id usquam tentatum fit:

0. VII. Quum denique \& lupus \& vulpes ejusdem fint feritatis, faepiusque alter ab altero quam proxime habitet: praeterlapfa tot fecula unum tandem aliquando alterumque exemplum, has beftias coilfe, fuppeditatura fuiffent. Corporum enim horumque ftructurae diverfitas, quam in canibus longe majorem evidentioremque confpicimus, non tanta eft, ut id impedire potuiffet. Ambos igitur, quia promifcua venere abftinent, non unius ejusdemque generis quadrupedes effe, donec contrarium meliús probetur, jure meritoque ftatuö.

0. VIII. Poftquam, lupum canemque nulla prorfus cum vulpe cognatione conjunctos effe, fatis probabili- 


\section{$17^{8}$ SPECIMEN ZOOLOGIAE}

ter commonftratum dedimus: nunc etiam, quousque beftia haec per terrarum orbem diffundatur, inveftigemus. Mirabundi vulpem prae caeteris omnibus animantibus quam proxime ad polos utrosque accedere videmus. Omnium enim colorum vulpes in Spizbergae regionibus, quae a feptuagefimo fexto ad octuagefimum usque gradum extenduntur, reperiri, certum eft $(b)$ : Nova Zembla (c), Groenlandia (d), Islandia (e) \& qui Sibiriae tractus fub iisdem latitudinis gradibus fiti funt $(f)$, magnas earum catervas alunt. Lappra. $(g)$ Norvagiaque (b) omnes itidem earum (pecies nutrit, 85 in novi orbis barealibus terris, verbi gratia, in Hudjowis freto (i) \& Canada $(k)$ paffim oberrant.

J. IX. A pola arctico digreffáe temperatas utriusque hemisphaerii plagas occupant. Europam enim, Afiam minorem, Perfiae ( 1$)$, Tartariae magnae $(m)$, Japoniae ( $(n)$, mexicanosque $(0)$ agros $\&$ filvas incolunt; nec plagas fub aequatore jacentes, etfi propiori folis appulfu caleant, penitus abhorrent. Hinc Aegyptus $(p)$, Barbaria $(q)$ aureaque ora $(r)$, vulpium quidem,

fed

(b.) Vuyage de la comp. des Indes Urient. Kuuen 1721. 1. 1. p. 98. On voit outre cela, fur ces côtes des renards blancs, gris, \& même des noirs. (c) Allgem. Reifen T. XIX. p. 68. (d) Ibid. T. XX. p. 38

(e) Anderfons Befchreibung von Ifland.

(f) Gmeiins Reifen. Tom. XIX. Allgen. Reifen. p. $342 . \& 407$.

(8) Linnaei Fauna Suec. p. 6. \& Oeuvres de Regnard T. 1. p. I7.5.

(b) Pontoppidan Natur. Gefchichte von Norwegen T. II. p. 42.

(i) Allg. Reif T. I7. p. 23c. (k) Vayage de la Hontan T. LI. p. 42

(1) Voy. de Chardin. (m) Allg. Keif. T. VII. p. 2x.

(n) Kaempfer Befchreibung v. Japan in du Halde T. IV. p. I39.

(o) A Colta Hift. Naturelle des Indes Livr. 1. Chap. 20.

(p) Grangers Reir, durch Egypten in d. Goetting Reir. T. III. p. 410

(1) Sharileilen p. I57. ed. germ. (r) Avtus in Allgem.Reifen T.IV.p.257: 
fed per exiguum duntaxat numerum poffidere dicuntur. Non enim fatis adhuc evidens \& perfpicuum eft, annon peregrinantes, in Congo aliisque regnis, quae folis igni torrentur, Fakbalem, quem aureum lupum nominant, viderint, ipfumque vilpem effe crediderint.

6. X. Si capricorni tropicum transgreffus fueris, terras auftrum verfus fitas, magna rurfus earum copia redundantes videbis, quove propius ad polum antarcticum accefferis, eo frequentius tibi occurrent. Paragayenfium enim regiones catervatim peragrant $(s)$; \&. Narborougbius eas in Defideradi promontorio $(t)$, in Magellan freto, in infula Maire \& Fuliani linu, obvias habuife teftatur.

0. XI. Ex quo patet, vulpem plagarum frigore inhorrentium potiffimum incolam effe, \& forte a feptentrione progreffum, inde generis fui dilatandi initium feciffe: quod idem ex mira ejus foecunditate, abundanti multitudine \& varietate, quae in borealibus praecipue terris obfervatur, dijudicari poteft (ii). Datur enim ibidem magna albarum, grifearum, rufarum, nigrarimque vulpium copia. Albae, quae IJatidum nomine (v) innotéfcunt, \& a Linnaeo canes cauda recta, apice concolore vocatae funt, frigidiffimarum tantum coeli plagarum feffores funt, Novae tamen Zemblae, Spizbergae, Groenlandiaeque limites \& Afiae regiones, quas mare glaciale alluit, non excedunt; \& inde vix ad fexagefi-

mum

(s) Alig. Reifen 'T. XVI. p. 127.

(t) Allgem. Reifen. T. XII. p. 34. 35. 39. vel Voy. de Narborough; dans le 3 me 'rome des Voy. de Coreal. p. O3. \& 55.

(u) A fola Bergen $\sqrt{2}$ Norvagiae provincia quatuor millia quotannis pe:liom vulpinarum in Daniam deportati fama fert. Pontoppidan.

(y) Aq. Pesrop. T: V. p. 356. 
num usque octavum latitudinis gradum defcendunt. Aliis itaque earundem regionum animantibus, quin \& urfis, melius longe fortiusque frigus intenfiffimum tolerant. Heemskerkius enim (w), quum in Nova Zembla, non fine ingenti vitae fuae periculo, hiemare cogeretur, per menfes hibernos, qui Batavis adfpectum folis penitus eripuerant, intenfiffimamque frigoris vehementiam attulerant, albos etiam urfos a feptentrione meridiem verfus progreffos effe, $\&$, nocte illa trimeftri durante, folas vulpes albas, oras maritimas occupaffe, animadvertit, quas tamen, urfis cum fole redeunte revertentibus, denuo concefferint.

f. XII. Haec albarum vulpiam feecies minoris quidem prae noftratibus altitudinis eft; interim tamen, noftrarum more, cuniculos agit, eodem vietu páfcitur, \&, ratione habitus externi, noftris eft fimillima $(x)$. Quum itaque beftias feptentrionem inhabitantes vulgo albefcere experientia difcamus, quod in urfo, lepore aliisque jampridem obfervatum fcimus: nulla fane mihi dippicienti ratio occurrit, quam propter Buffonius IJatidema álius cujusdam generis animantem effé ftatuerit. Majori jure Hallenius a meis partibus ftare videtur, quia llfatis ejusdem cum noftratibus vocis, ejusdem odoris, ejusque ftructurae ac difpofitionis, \& idcirco eadem. beftia eft, cujus pellem fola frigorisvis canam reddidit $(y)$.

0. XIII. Sed in terris borealibus, praeter albas, glaucae etiam, fubgrifeaeque vulpes offenduntur, quae aèris.

(3v) Voyage de la Comp. des Ind. T. I. p. 127.

(x) Quod eo confidentius adfirmare poffum, cum tres Ifatides Petropo: ii vivas videre mihi.licuerit. $\quad\left(y_{i}\right)$, Hallens Nałurgefch. $I_{i}$. I. 


\section{G EO GR A P HICA E. I I I}

aëris tempeftatumque viciffitudine modo decuffatim, variisque maculis notatae, modo unicolores funt. America feptentrionalis albas itidem \& colore quidem argenteo ornatas alit, quae ad $M i\left(\int_{i} / 2 p\right.$ pi quam maxime littora inveniuntur $(z)$ : canadenfes enim grifeis jam pellibus tectae funt. Simulac vero hoc animal regiones temperatiores attingit, pellis ejus fufco, fubrufo nigroque colore tingitur; ruber tamen rufo commixtus proprius ipfi \& communis effe videtur. Longe alia ratione a venatoribus vulpes in Brand-\& Birken-fuchfe difpefci folent, quarum illas Linnaeus canum cauda refta, apice nigro, has canum casda recta, apice albo, nomine defignat. Quum autem totum, quo difcernuntur, difcrimen in eo quaerant, ut, quarum caudae apex, aures, pedesque infufci funt, ad priorem claffem referant; quarum vero pedum, aurium caudarumque extremitates albo diftinctae comparent, pofteriori claffi adtribuant; tam exigui momenti diffinctionis notas naturae indagator niliil morabitur:

0. XIV. Cur Linnoeus, qui canes, licet diverfiffmis diftinguantur coloribus, non disjunxerat; vulpes tamen, ex colorum difcrimine, in certas fpecies diftribuerit, animo comprehendere non poffum. Hanc enim viam fecuturo, feles etiam feri, pro colorum varietate in: fuas fpecies diftribuendi fuiffent:

0. XV. Vulpes nigra, quan itidem vivam vidi, minus adhuc, quam alba lfatidis nomine vulgata, a noftrate differt. Si pilorum enim nigritiem exceperis;

ejus-

(z) Alig, Reif, T. XVII. pi. 230 . 


\section{SPECIMEN ZOOLOGIAE}

ejusdem illam formae, magnitudinis, vocis \& odoris effe perfpexi. Quinque hae beftiae, quarum contemplandarum mihi Petropolis copiam fecit, in Tartariae regionibus, quae Chinam attingunt, captae erant, úbi nigrarum vulpium domicilium efre \& patriam $(a)$, ex Gmelino \& Marco Polo difcimus, qui eas in Kublaykbani terris eximiae magnitudinis vidit: easdemque in auftralis Tartariae regione ad Cbirici ripas inveniri, ab aliis peregrinantibus relatum legimus. Nigrarum interim vulpium pelles magno in pretio haberi, \& propter raritatem martis interdum fcyticae peliibus praeferri notum eft.

§. XVI. Corporum magnitudine parum inter fe vulpes differunt, \& fortaffe, quas Pallafus in Kirgejenfum ruribus confpexit, ubi montuofa loca inhabitare folent, minimae funt ftaturae $(b)$ : quod tamen, quum certam menfuram nullam addiderit, nec, qua cum fpecie illas collatas velit, indicaverit, generatim modo dicere potui. Etfi vulpes caeteroqui cunctis fere coloribus tinctas invenias; figurae tamen habitusque ratione, parum a fe invicem diftantes obfervabis.

\section{$\begin{array}{llllllll}S & E & C & T & I & O & X\end{array}$ \\ De Lepore छ Cuniculo}

5. I. Leporem flexilis quidem, tam robuftae tamen naturae effe, ut per omnes fere tam antiqui, quam novi orbis partes difperfus inveniatur, \&

per-

(a) Allgem. Reiferi T. VII. p. 21. \& 474. \& Gmelini (fenioris) Reife durch Siberien T. I. p. 40I.

(b) Pallas Reifen durch Rusland T. I. p. 234: Korfak. Canis cauda fulsya bafi apicegue nigra Linn. App. p. 223. 


\section{G E O G R A P H I C A E $\quad 183$}

perpaucis tantum, iisque nullius fere momenti rebus exceptis, ubique unum eundemque effe $\&$ manere; $\boldsymbol{B}_{\text {nifforius }}$ teftis eft graviffimus. Ex unanimi propemodum peregrinantium relatione lepus easdem, cum vulpe, poli arctici plagas incolit. Groenlandia (c) enim, Lappia (d), Norvagia (c), Hudfonis orae $(f)$, aliaeque ejusdem tractus terrae, lepores alunt.

f. II. Quam vero in Nôva Zeimbla, Spizberga, aliisque regionibus nimia frigoris vi infamibus nullos deprehendere liceat : exinde vulpem vehementiori aëris rigori tolerando aptiorem effe liquet. Hinc termini, ad quos usque utrumque animal progreditur, paululum inter fe difcrepant.

ఏ. III. Ad leporum autem tam dilatationem, quam degenerationem commonftrandam, ipfa Buffonii verba adpofuiffe fufficiet $(g)$., Variae orbis noftri difpofitio" nes, inquit vir celeberrimus, aequas in hoc animan\% te, atque in aliis omnibus, mutationes proferunt. "Lepores enim, in montibus degentes, iis multo " majores crafiiioresque funt, qui in aequali agrorum " planitie nutriuntur; quin utrorumque color etiam " diverfus eff. Montium enim incolae furco magis in" feetifunt, qui fub collo in album commutatur; quum \% agrorum feffores pelle propemodum fubrubro tegan22 tur. Editioribus qui in montibus, terrisque aquilo22. naribus commorantur, per hiemem albefcunt; aeftate

(c) Cranzens Groenland in Alig. R. A.-XX. p. 37 .

(d) Hegftroeins Befchr. v. Lappland. p. 22.

(e) Pontoppi an Befchr. v. Norweg. T.II. p. 19.

(f) Ellis i eife nach Hudfons Meerbufen p. 181. \& 84.

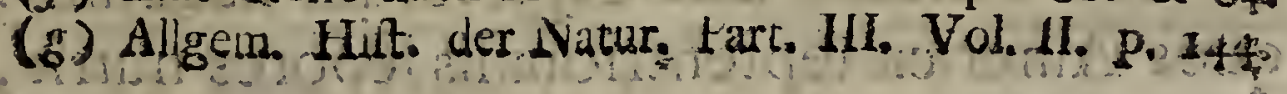




\section{SPECIMEN ZOOLOGIAE}

\% te autem regrediente, proprium colorem denuo in„) düunt: perpaucos, \& forfan aetate majorés tantum \#, albore feimper notatos invenies. Senectus enim „ provectior in univerfum omnes plus minusve canos "s reddit. Notata dignum eft, calidiorum terrarum, "Italiae nimirum, Hifpaniae, Barbariaeque lepores

"longe iis minores effe, quos Gallia, reğionesque " feptemtrionem propius accedentes alunt. Sic Grae\%. ciạe quoque lepores, aegyptiacos corporum magni-

" tudine fuperaviffe, ex Ariflotele difcinus. Per om\# nes coeli plagas aeque diffipati offenduntur. Magna

" enim eorum cópia Steciae, Daniae, Poloniae, Rus\# fraeque regna; magna vi Gallia, Anglia, Germa" nia; magnis acervis Barbaria, Aegyptius, Archipe"lagi infulae, inprimisque Delos, redundat, quae " nunc Idilis, olim, propter'ingentes, quos habuit, " leporum greges, Eagia fuit appellata.. Tandem \&

"Lappia non exiguum eorum exhibet numerum, ubi „per decen menfes albi, per duos autem reliquos, " qui aeftatis calorem referunt, fubgrifei comparent.

"Non iminerito itaque quaslibet fere coeli terrarum-

" que partes oräsque gratas ipfis \& commodas effe col-

" ligimus. Interim tanien certiffimae obfervationes do-

" cent, in terris orienten verfus pofitis, minorem lon$\%$ ge ipforum copiam, quam in Europa exiftere, \& inf 2. America meridionáli vel paucos admodum, vel nul22. los plane reperiri; quamvis in Virginia \& Canada, " quin etiam in regionibus, quae ab Hudfonis ora " propius abfunt, magellanicoque in freto frequentes $\Rightarrow$ occurrant $\Rightarrow$ annon, quos Atherica feptentrionalis lepores thutrit, 


\section{GE O G R A P H C A E 285}

„) diverf cujusdam a noftratibus generis fint : quim

„, peregrinatorum nonnulli eos non folum réliquis mul-

„2 to majores, fed ipforum etiam carnes albi coloris, \&

2) diverfi a noftris faporis effe teftentur. Quibus ad-

„ dunt : eorum pilos nec unquám defluere, nec muta-

", ri, pellesque.ipforum hac de caufa aliis longe effe

„ praeftantiores. In regionibus, ardentiffimo folis aeftu

, calentibus, ut in Senegallia, Gambia, Guinea \&

2 praecipue in Fidae, Apamae, Acrae \& quibusdam

" fub torrida Zona jacentibus tam Africae quam Ame-

"ricae territoriis, in nova, verbi gratia, Hollandia \&

9. Panamae freto, quorundam itidem animantium pe-

3) regrinatores mentionem faciunt, quos lepores qui-

و dem vocitant, qui tamen cuniculorum potius generi

g adfcribendi effent. Hi enim in calidioribus terris

" exorti natique, nusquam ad frigidiores coeli plagas

" tranfeunt; quum lupus e contrario, quo frigidioribus

, in coeli aërisque tractibus habitat, eo major eoque

"robuftior evadat".

6. IV. Apertae huic leporis defcriptioni, quam vir praeftantiffmus ex optimis fideque digniffimis auctoribus, quos fingulos in margine daudat, collegit, perpaitca quaedam addere mihi liceat. Quum feptentrionis lepores per hiemem albefcere, aeftate vero redeunte, priftinum colorem refumere adftruat: Cranzius: ( $b)$ de Groenlandiae leporibus contrarium, eos nimirum albos lifemper manere, teftatur. Tain aeftatis in quit, quam hiemist tempore, albi funt, ideogue ab iis, quos Norvagia nutrit, , qui gr aeftate ingruentse,

(h) Allgen. Kreilen T. XX. p. 37 . 


\section{SPECIMEN ZOOLOGIAE}

pilos ex cinereo rufos recuperant, diverfae videntur fpeciei. Non itaque foli, qui annofiores funt, fed. fingularis quaedam eorum fpecies, quovis anni tempore candida permanet. Qui Norvagiam incolunt, quod e Pontoppidani hiftoria natúrali ejusdem regni fcimus (i), muribus etiam vefcuntur.

0. V. Interim Buffonius erraffe videtur, qui.cuniculos iis annumeravit animantibus, qui nunquam in aquilonaribus, fed in calidioribus tantum plagis habitent. Pontoppidanis enim, loco jam dicto, tam lefores, quam cuniculos Norvagiae feffores effe adferit: \& Ellif fuss. in itineris, ad Hudfonis oram quod fusceperat; defcriptione, non leporum folum, fed etiam cuniculorum mentionem fecit. Sic pag. 18r. cuniculos, lepores, \& perdices nominat, quorum colores ufitatos immutari ait; \& pag. 184. ur $/ 0$, cuniculos \& lepores diffinetememorat Ex quibus quidem, cuniculos feptentrioñis etiàn frigora perferre poffe, discimus; licet longe minori quam lepores numero ibidem disperfi reperianturi.

5. VI. Qui vero in aurea ora ad Senegalli ripas lepores degunt, minime cuniculorum, quod tamen Buffonius autumat, fed leporum generi adfribendos: effe, partim Desmarchafous teftatur $(k)$, qui tam cuniculorum, quam leporum carnes in aurea ora minus fapidas effe fcribit, partim Adanfonius docet (1), qui in Senegalli hiftoria leporum carnes cuniculorum carnibus guftu quidem haud abfimiles effe adfirmat: cos autem, querum carnes guftaverit, revera lepo-

(i) p. 19. T. II. (k) Allgem. Reifen Tom. IV. p. 385 .

(l) Huift. du Sénégal. p. 25 . 


\section{GE O G R A PHICA E. $18 \%$}

res, non cuniculos fuiffe, ex eo palam fit, quod fcrobes ipfos nullas effodere addiderit; qua tamen in re lepores quam maxime a cuniculis diftare conftat.

〕. VII. Praeter fuscos, cinereos, albos candidosque, quorum jam meminimus, lepores, etiam nigri interdum inveniuntur, quorum Hallenisis $(m)$ duos, álterum ex Wormio, alterum ex magno, qui Dresdae colligitur, rerum naturalium thefauro attulit; quibus tertius, qui Brunfuigae $\mathrm{S}^{\text {mi }}$. Ducis collectione adfervatur, annumerari poteft. Sic etiam cornutos nonnul, los in fuperiori faxonia inventos effe, ex Kleinio $(n)$, \& Meiero (o), difcimus, qui cos depictos exhibuerunt.' Omnes hi autem fingulitantum obvii fuerunt, nec certas quasdam fpecies, nec integras conflituunt familias,

5. VIII. Cunicuhlis, quil fpecuum magis fodiendorum focietatisque \& congregationis colendae inftinctu, quam externa quadam internaque naturae conftitutione, a lepore diffidet, pari quidem cum illo paffu in auftrali \& aquilonari orbis noftri hemisphaerio progreditur; non tamen idcirco ubique tam frequens eft, quam, quem proxima cognatione contingit, lepus. Nullos itaque, aquilonem verfus, certos ipfi in mappa, quam appofui, geographica, fines conftituere potui : praecipue quum longe majori infrequentia circa feptentrionem obvius fit; quamvis jam commonftraverim, animal hoc, fi fides Ellifiso habenda eft, in Hudfonis etiam ora fcrobes fuas agere.

§. IX. Sed, ut verum fatear, vix mihi perfuadere pos-

(m) Natur. Gerchichte Tom, I. p. 4 I2. (n) Quadrup. Difpof. Tab. LI. (e) Meiers Shiere Nuurnb.rg I748. fol. T. II. "Tab. XXX1H...", 


\section{SPECIMEN ZOOLOGIAE}

poffum, iftud, quod in moderationibus quidem terris: cubilia fua effodiendo, commode poteft, in agris etiam perpetuo gelu glacieque conftrictis idem facere, \& ibidem habitare ac provenire poffe. Hoc faltem certum eft, Sueciam, aliasque ad gelidiffmum eptentrionis axem fpectantes regiones, quales Lappia, Groenlandia, Afia orientalis \& Kamfchatka funt, aut ejusdem fpeciei animalcula nulla, aut quaedam tantummodo eo perducta, fingulari arte \& induftria educare Ipfe enim Pontoppidanas, cujus jam verba attuli, Norvagiae quidem cuniculos, fed perraros tribuit. Ip forum itaque patriam non in feptentrione, fed temperatiori in climate calidioribusque plagis g ob optime nutrit. augeantur, quaerendam effe exiftimo.

O. X. Magna fatis eorum multitudo Portugalliae, Hispaniae, Galliae, Bataviae, Angliae, Italiae, to tius etiam Europae campos inundat, ubi plerumque cibi loco adhibentur. Afia quoque aliquot eorum (pecies profert, folaque tam dilute cinereos (les riches) quam angorenfes gignit alitque $(P)$. Buffonius etiam locum auetoris cujusdam allegat, qui finum perficum cuniculos nutrire comprobat Cbardinius $(q)$ vero per omnem Perfiam cuniculos offendi teftatur. Barbaria $(r)$, Lybia (s), Guinea, \& Kolbio auctore ( $t$ ), Saldanae finus qui haud procul a bonae fpei capite abeft, magnos eorum acervos pafcit. Dampierius (u) eos in nova Hollandia

fub

(p) Buffon. I Jit: d. Nat. p. 3: Vol. II.

(q) Chardin Voyages T.IV. p. 82. Dans tout le Royaume, dit-i], on trouve des lapins \& des liévres. (r) Shaw Reifen. p. 57.

(s) Leon. Africon. defcript. Afric. Part. 11. p. 727. (t) Kolbe I. c. p. I5.3.

(u) Allgem. Reijen T. XI.. p. 26. 
fub vicefimo primo latitudinis auftralis gradu vidit; quive illorum ex Europa in Antillas infulas delati funt, miro ibidem augeri incremento feruntur $(v)$. Alia plura teftimonia, ipfos omnibus in utroque aequatoris latere terris calidioribus optime provenire, quum res omni dubio careat, adferre fuperfedeo.

๖. XI. Nec tamen nego, ipfos longe majori, quam lepores, difficultate frigori refiftere. Eos vero imbecilliores effe leporibus, eo ipfo commonftravi, quod respectu colorum, plures prae illis, mutationes fubeant. Una enim interdum cuniculorum familia omnibus propemodum, quos per pilorum naturam poteft, coloribus fuperbit. Dantur albi, qui rubris ut plurimum oculis praediti funt; dantur difcolores, nigri \& cinerei, quorum quidem plurimos numeraveris.

0. XII. Pilorum quoque varietate magis, quam lepores, inter fe diftant. Quosdam enim rari, quosdam denfi, nonnullos promiffi crines veftiunt. Domefticus nofter cuniculus, qui a fero, cujus pili ex fufco cinerei effe folent, originem habet, confuetis tantummodo pilis tectus comparet; quum contra ea dilute cinereus (le riche $(w)$ ) dupliciter, lana nimirum breviori, quae cutem tegit, \& longiori pilo, qui prominet, lanamque operit, ornetur. Hinc quafi revictus colligo, hanc fpeciem aeque, atque cartbufiannum felem, vel in Perfia, vel in aliis ejusdem caloris regionibus oriundam effe; quum utrique hi animantes pro indole conftitutioneque fua uno eodemque, cui fubfunt,

(y) Du Tertre Hift. des Antilles.

(w.) Vide imaginem hujus varietatis apud Buffon. 1. c. 


\section{I9O SPECIMEN ZOOLOGIAE}

climate coacti pari intervallo a prototypo fuo digredi videantur.

0. XIII. Cuniculus Angoren is, ficut capra felisque ejusdem regionis, optimis tenuiffimisque pilis praeditus eft, qui non folum denfi, fed tres etiam plerumque digitos longi undatim \& lanae inftar crispi funt; caeteroquin autem intra domos educatus, noftratium more, diverfis coloribus ornatur.

0. XIV. Sunt praeter haec alia quaedam animalia, quale praeteriiffe vitio mihi verti poffet; praecipue quum leporibus cuniculisque tam fint aequales, ut fortaffe unius cum ipfis originis haberi queant. Quorum primum lepus eft Javanen/ss, cujus imaginem $\mathrm{Ca}$ tesby depictam dedit $(x)$, qui noftri leporis naturam, mores vitamque refert, \& in eo tantum diffidere videtur, quod anterioribus in pedibus quatuor, in posterioribus tres digitos numeret; quum noftratium tam leporum, quam cuniculorum, anteriores pedes quinque, pofteriores autem quatuor digitis praediti fint. $\mathrm{Au}$ ribus praeterea brevioribus, nec acuminatis, fed paulo rotundioribus gaudet; pofterioremque corporis partem priori craffiorem habet, \& cauda breviffima inftructus eft. Color ipfius fufco paululum admixto rufescit, \& Javam, Sumatram aliasque illius regionis infulas colit. Buffonium in ultima operis fui parte, in quam animalia ftrictim tantum defcripta congeffit, hanc beftiam praeiermifife miror.

ఏ. XV.

(x) Catesby Hift. de la Carol. \& Seligmans Vogel T. IV. Tab. CXIII. Leporem capenfem cauda lengitudine capitis, pedibus rubris, Linnaei, cuniculi tantum varietatem effe aliquum exiltimo. 


\section{G E O G R A P H I C A E. I9I}

6. XV. Altera, cujus hoc loco mentio facienda erat, Gmelini Tolai eft, quem cuniculum in/ggniter caudatum leporini coloris nuncupat $(y)$; qui in Tartaria trans Baikali lacum reperitur, \& externi habitus, vitae generis, fubrufi coloris, foraminum effodiendorum ratione, quam proxime ad noftrates cuniculos accedit, folaque cauda longiori diftat; cujus extremitas, tefte Rubriquifio $(z)$, in parte fupina, nigra, in prona vero, alba eft: quem, quum Buffonius a noftratibus ortum \& paulisper modo variatum effe ftatuat, quia tam morum, quam ftructurae, totiusque dispofitionis maxima inter utrosque fimilitudo intercedit, quin ipfi adfentiam non poffum.

6. XVI. Duo quaedam Americae animalia accedunt, quibus Tapeti ( $a$ ) \& Apareae (b) nomina funt indita; quorum illud ab Europaeorun cuniculo parum differre, color \& aures leporini, nigri oculi, caudaeque defectus comprobat. Quum autem fcrobes nullas effodiat; Buffonitus hanc beftiam eandem effe exiftimat, quam Fornandez fub Citli nomine defcripfit (c), novaeque Hispaniae leporem vocitavit. Et quoniam ejusdem cum lepore noftro formae fit, iisdemque moribus ac cibis utatur, ideoque vix ac ne vix quidem ab eo difcedat, varietatem tantummodo noftratis aliquam. effe, fumma cum probabilitate credit. Americam: praecipue meridionalem incolit; licetque fatis foecun-

da:

(y) Noy. Commentár. Petrop. '1. V. Tab. XI.

(z). Rélation des Voyages en Tartarie par Rubriquis p. 25. Hoc \& precedens animal a Linnaeo omiffum eft. (a) Pifo de Indiae utriusque re maturali. p. I02: (b) Ibid. p. 103. (c) Fernandezii Hift. animal. nov: Hifp. p. 2. in Hernandczii Thefaur; rer. medic. nov. Hif. 


\section{SPECIMEN ZOOLOGIAE}

da fit, nihilo tamen fecius, quia beftiae aliquot carnivorae ejusdem rapina vivunt, perraro peregrinantibus obviam eft.

0. XVII. Et Aparea (d) in Brafilia habitat. Quod fi Tapeti originem a leporibus traxeris, hanc Apaream pari jure cuniculi noftri varietatem appellare poteris; quippe cui \& corporis habitu \& moribus eft fimillima. Ejusdem propemodum cum noftratibus cuniculis magnitudinis, ejusdem cum leporibus noftris coloris eft. Quum animal hoc nec notum fatis, nec a multis defcriptum, mihi vero illius contemplandi in praeftan-

\section{(d) Aparea,}

Integra corporis longitudo eft Altitudo antica Poftica

Longitudo capitis

Maximus ejus ambitus Ambitus roftri

Spatium, quo nares inter fe diftant Aures longae funt Crurum longitudo eft "Totius corporis ambitus

Pedes antici longi funt

Pedes poftici in tres digitos exeunt, maximus. que longifimi digiti unguis longus eft . . Anteriores pedes quatuor digitis inftructi funt, maximus unguis longus eft

Cauda caret,

Caput, anterioris corporis dorfique pars maxima leporini, pofterioris zutem fublutei eft coloris. Gula pilis ex albo cinereis obfita; pedes autem fufcis teeti funt. Dentes incifores glirium dentibus, fimillimi videntur. Quum reliquos contemplari non licuerit; eorum nee formam nec figuram dare poffum. Caput leporum capitibus magis inflexum eft. Cutem animalis, quod nee maximis nec minimis fui generis adnumerandum cenfeo, ita infarferunt, ut inufitatam corporis pofitionem referat. 
tiffimo hiftoriae naturalis mufeo, quod Brunfuigae adfervatur, facultas data fit: haud ingratum fore lectoribus putavi, fi ejus imaginem in fubjecta notula, quantum fieri poteft, depictam darem.

0. XVIII. Si Apaream cum Lepore Favanen/a, cujus jam mentio facta eft, comparaveris, perfimiles utrosque animantes invenies. Et nifi Catesbyus memoratum a fe leporem Sundaïcarum infularum fefforem effe, expreffis verbis dixiffet, facile in eam adduci me opinionem paterer, ut utrosque unius effe generis ftatuerem. Sundaïcas infulas fub eodem cum Apareae patria latitudinis gradu jacere conftat: nonne hinc fieri poterat, ut Brafiliae \& Indiae orientalis clima pares in cuniculo mutationes produceret? quod faltem in his animantibus, qui tam in antiquo, quam novo orbe haud procul ab aequatore vivunt, accidiffe mihi videtur. Quam opinionem, etfi non exigua animum meum probabilitate percutiat; idcirco tamen minime pro inquifita \& comperta adfero: praecipue quum nedum fatis fpectatum fit, Catesbyo veram leporis Javanenfis patriam innotuiffe.

0. XIX. Quamvis interea quatuor hi, quos hactenus percenfui animantes, Tolaus nimirum, Lepus javanen/is, Tapetus \& Aparea permagnam noftratium \& leporum \& cuniculorum fimilitudinem gerant: ipfis tamen in mappa, quam adjeci, geographica, communem cum his locum adfignare dubitavi, \& Tolaum potius in Tartariam, Leporem a Catesbyo depictum in $\mathcal{F} a$ vae infulam, Tapetum \& Apaream in Americam feptentrionalem \& Brafiliam eo usque relegavi, donec, an revera ejusdem cum noftris fint generis, nec ne, 


\section{SPECIMEN ZOO LOGIAE}

tempus \& occafio docuerit. Hoc tamen certum eft, naturam, quae nuspiam adfultim, fed ubique pedetenitim progreditur, ab his ad Agousium, hinc ad $\mathrm{C}_{6}$ viarum, \& fic porro ad murem alpinum progredi.

\section{SE C T I O X I. \\ Cervus $\xi^{9}$ Caprea.}

6. 1. T icet cervorum non ita numerofa fit copia: regiones tamen maximo intervallo a fe invicem disjunctas pererrant ; totúmque aquilonare terrarum orbis hemisphaerium, quod ex deinceps dicendis patebit, frequentiffime habitant. Nifi duo tresve aútores eosdem in Peruvianorúm Brafilienfrumque tèrris etiam obvios habuiffent; eos fine ulla dubitatione illorum numero excerperem, qui per utraque aequatoris latera diffipati cernuntur. In cunetis feptentrionis partibus paulo temperatis beftias has videre licet. Cerulus enim caradenlis, cujus nitidiffimam imaginem academia parifienfis exhibet $(n)$, elegantioribus : \& unajoribus tantum cornubus fuis a noftrate differt.

j. II. Omnis propemodum Europa ipfum indigenam fuum agnofcit fovetque. Quotve Afiae regiones, quot ejtis regna numerantur, quae cervos pascunt? Sic Cbona (b), Tartaria (c), Mongalenfumm terrae $(d)$,

(a) Vid. Mém. de I'Acad. des Sciences T. I. à la Haye 73 I. p.265.

(b) Neuhofs Gefandfchaft der Ooftind, Comp. p. 370.

(c) Ailg. Reis. T. 7. p.041. (di) 1bid, p. 77: 


\section{G E O G R A P H I C A E. I95}

Perfia (e), Siam $(f), \mathcal{F a v a}(g)$, Sumatra $(b)$, $\&$ reliquae hujus antiqui orbis partes cervos nutriunt.

ঠ. III. Nec Africae intenfus folis ardor eos penitus expulit: quippe qui in aurea ora frequentes confpici capique folent $(i) ; \&$ Labatus: Senegalliae aethiopes magnam quotannis cervorum ftragem edere teftatur $k$ ). Barbaria cervorum aliquan fpeciem noftratibus quiden paulo minorem, caeteroqui tamen iis perfimilem alit, quae ab habitatoribus Bekker $\xi^{\circ}$ W $a j b$ (l) appellata gregatim femper ingreditur. Notatu vero non indignum videtur, Kolbium in bonae fpei promontorio cervos nullos habuiffe obvios. Animal enim, cajus fub cervi appellatione meminit, quodve tam animantium dictionarii auctor $(m)$, quam Hallenius (n) promon' torii feu capenfem cervum nominavit, fine dubio $G a z e l-$ larum fpecies eft. Kolbius enim iple ejusdem cornua ramis deftituta recta adfcendere $\&$ annulata in fubulam exire teftatur $(0)$.

J. IV. Americae etiam, nec tamen folius Canadae

(e) Chardin T. 4. p. 82, Salmon und Goch Staat v. Perfien p. 66.

(f) Hirt. du Roy. de Siam par, Turpin 1.I. p. 30.. \& Diction. des Anim, au mot Cerf.

(g) Cooks Voyage in Havpkesyorti's Account. T. III. p. 746. \& Allg. Reif. T. VIII. (h) Allg. Reif. T. X. p. $35^{\circ}$.

(i) Bosmans Guinea p. 204. (k) Voy. de Labat. T. II. p. 32.

(1) Siaw Reir. p. r5 r. (m) Dict. des Animaux au mot Cerf.

(iv) Hallens Nat. Hitt. T. I. P. 334 .

(o) Kolbius p. 335. promontorii, inquit, bonae fpei cervorum cornua pedem alta, ramos nullos habent, a vercicibus ad radices taevia, terecia, fubfufca, angufte annulata, acuminata \& ad medium usque recta funt, ubi pantulum incurvantur, poftea vero reeta iterum fic progrediuntur, uc extremitates ter quatergue amplius, quam eorum radices diftare videantur. 


\section{SPECIMEN ZOOLOGIAE}

dae incola cervus eft $(p)$, auctore potius $E$ Ellifio $(q)$, Hudfonis promontorium tot tamque numerofis gregibus pererrat, ut freto Deerbound nomen dederit. Nec mirandum eft, eousque ipfum progredi, quum, quod Pontoppidanus affirmat $(r)$, in Dronthemenfium quoque agris, fub fexagefimo quarto borealis latitudinis gradu inveniatur, quin, Linnaeo tefte $(s)$, nec vehemens Sueciae frigus averfatur. Hic ultimus tamen $\&$ algoris \& feptentrionis gradus, quem perferre valet, effe videtur. Nec enim Islandia, nec, quae ulterius procurrit, Groenlandia, nec Afia orientalis, nec Spizberga cervos habet.

0.V. Et quamvis Anderfonius cujusdam cervorum fpeciei, quae Groenlandiae frigora fuftineat, meminerit $(t)$, Kleiniusque hanc eandem effe putaverit (u), quam Edwardus fub Groenlandicae Dorcadis nomine depictam dedit (v): priorem tamen ea tantum collegiffe \& confcripfiffe dicunt, quae a nautis relata audiverat, quaeve, quum nec ab Eggedefio nec a Cranzio, quibus tamen oculatis teftibus fides quam maxime adjungenda eft, minima cervorum Groenlandicorum mentio facta fit, nec vera neque explorata haberi poffunt. Quicunque infuper quam Edwardus cervi in Hudfonis.

pro-

(p) Ellis 1. c. p. 88. Cervum hunc potius rangiferis adnumerarem, nifi Ellifins in itineris fui defcriptione toties fub cervi appellatione ipfius meminiffet.

(q) Aligem: Reifen Tom. XVII. p. 8\%. la Hontan ibidem greges triginta $\&$ amplius cervorum vidiffe teftatur.

(r) Hift. v. Norweg. T. II. p. 18: (s) Faun. Suec.

(t) Anderfons Island p.. I7 I. (u) Quadrup. Difpor. J. 9..

(vi) Edivard. Avr. I. Tab, LI. \& Seligmans Vogel T. II. 
promontorio inventi imaginem curatius contemplatus fuerit, facile obfervabit, junioris eam Rangiferi figuram effe, cujus cornua, quod reliquis ejusdem generis omnibus commune eft, antrorfum flexa fint. "Accedit, quod Edwardus, fe macblidis cujusdam natu majoris cornua, hifce fimillima, praeterquam quod in extremitatibus palmata fuerint, vidiffe teftetur. Et quum Anderfonius ipfe cervo fuo nomen Reensdyr, id eft, Rangiferi impofuerit, exinde fatis fuperque patere arbitror, quicquid de cervo fuo confcripfit, de Rangiferis intelligendum effe.

0. VI. Quoniam vero cervus in frigidioribus Americae tractibus fedem fixit, \& quod e jam adductis elucet, contra Plinii fententiam ( $w$ ), nec Africae calorem abhorret; nemini miraculo effe poteft, ipfum in novo etiam orbe perinde atque in veteri a borea usque ad auftrum progredi, \& in calidiffimis fub aequatore pofitis coeli plagis, verbi caufa, in Peruvia Brafiliaque; reperiri. A canadenfi nimirum in mexicanas regiones tranfiit. Hernandezius enim vel potius Reccbi non candidos folum, fed fuscos etiam noftrates cervos in Mexicanorum terris vivere teftatur $(x)$. In Panamae ihft-

(w) In Africa nec apros, nec cervos, nec capreas, nec urfos Plin. Hift. Nat. Lib. VIII. Cap. 58.

$(x)$ Inter cervorum genera, quae apud novam hanc Hifpaniam adhue mihi videre licuit, (praeter candidos totos, quos reges cervorum effe Indi fibi perfiafere, nuncupantque a colore, Yztac mazame) primi funt, quos vocant Aculliame, Hifpanicis omnino fimiles forma, magnitudine ac reliqua natura. Minores his apparent Quauhtmazame, fed usque adeo a caeterorum timiditate alieni, ut vulnerati homines ipfos adoriantur; ac faepenumero interimant. Hos fequuntur magnitudine Tlallhuicamazame, qui forma effent omnino eis fimiles, ac timidiores viderentur. Minimi $\mathrm{Bb} 3$ omniuma 
199 S PECIMEN ZOOLOGIAE

ifthmo $(y)$ etiam cervos commorari peregrinatores adfirmant, quos hinc in Peruviam Brafiliamque progresfos effe, nemo, rem attenta mente penfitans, in dubium vocabit.

0. VII. In univerfalibus itinerum collectionibus ( $z$ ) tres Peruviae Paraquariaeque cervorum /pecies numerantur, quarum primia boum magnitudinem, cornuaque ramofa habeat, quae paluftria praefertim loca peramet; fecunda capris noftris paulo major in camporum planitie vivat; tertia vero femeftris juvenci formam \& magnitudinem ferat. Primae fpeciei nofter procul dubio cervus adnumerandus eft. Licet enim poftea commonftrandi locus fuerit, pabuli differentiam in cervo mirum quantum valere: idcirco tamen minus probabile eft, cibaria, quibus in duabus hifce regionibus pascuntur, tantopere inter fe differre, ut ftupendas, quae in triplici hac fpecie animadvertere licet, ftaturae amplitudinis varietates producere potuerint.

0. VHI. Interim hos ipfos cervos effe crediderim, quorum venatum Ulloa defcripfit, quorumve in nova Andalufia, exiguo temporis intervallo, quingenti interdum venando dejici feruntur, (a), \& quorum propter abundantiam Chaconis regioni id ipfum Cbaconis nomen, quod, loci habitatorum lingua, a ferina carne originem trahit, impofitum fit. Horum rero majoris ftaturae animantium minus frequentem in Brafilia

cmnium funt Temamazame. Recchi apud Hernandezium in 'Thefau. rerum med. nov. Hifp. p. 324 \& 25. (y) Allg. Reif. T. XVI. p. I, 5.

(z) T. XVI. P. I 27

(a) Magni cervi.in Braflia nulli funt, fi fancti Vincentiil praefecturam exceperis. Allg. Reif. T. XVI, p. 269. 


\section{GE $O G$ R A P H C A E.}

filia numerum dari, exinde manifeftum eft, quod in fola ii fancti Vincentii praefectura confpiciuntur ( $b$ ). Nulla interim cura, nulloque ftudio expiscari mihi licuit, utrum cervi ad Chilen usque, ulteriusque progrediantur, nec ullam indagare rationem potui, cur Chili, quae tamen Peruviae confinis eft, cervos nullos nutriat, quos tamen propter camporum ubertatem alere poterat.

0. IX. Ipforum magnitudo ex pabuli , quo pafcuntur, varietate, in una interdum eademque, regione diverfiffima eft, quod Buffonius experimento memoratu digniffimo obfervavit., ", Corporis, inquit (c), formam , $\&$ amplitudinem a fola alimentorum copia \& qua" litate dependere, hoc documento convictus novi.

, Cervus, quem per quatuor annos domi meae large g. fatis copiofeque eduxi, tam corporis magnitudine ;\& robore, quam carnis copia \& pinguedine, reliquos "s omnes natu longe majores, qui in filvis meis pabu" lantur, \& opimo fatis corporum habitu funt, mirung "quantum fuperabat."

0. X. Cervos interim in frugali foecundaque planis tie commorantes, corpore quidem majores, iis vero, qui in faxofis montium regionibus nutriuntur, minus durabiles effe, experientia doceinur. Minimae inter omnes' ftaturae corficus eft, qui, quim, ex Buffonii relatione, noftris dimidio minor fit, ipfius cervorum generis pumilia jure haberi debet (d). Fufco crine

(b) Alls. Reif. T. XVI. p. 378 .

(c) Buffoin Hifft: d. Nat. 1. 3. Vol. II. p. 53 .

(d) Vid. Buffonii locum jam citatum, ubi corficus etiam cervus hie depictus cernitur. 


\section{0

veftitus, fat corpulentus pedibusque brevioribus praeditus incedit. Hanc autem corporis exiguitatem petrofae fterilique patriae fuae tribuendam effe, ex equis, mulis, afinis, vaccis, qui ex Boswellii teftimonio per totam infulam omnes ejusdem ftaturae funt, dijudicari poteft $(e)$.

ऽ. XI. Haec maxima notatuque digniflima cervi a prototypo fuo, magnitudinis refpectu, deflexio eft; quae fine ullo dubio ex locorum, in quibus habitat, diverfitate - originem traxit; praeter quam tamen aliae dantur, quas vel climatis, fub quo vivit, vel alimentorum, quibus fruitur, ratio produxit: quod in animantibus, qui per totum pene orbem diffeminantur, auras tam diverfas trahunt redduntque, $\&$ modo pingui, modo tenui pabulo utuntur, minus mirandum eft. Summa cum probabilitatis fpecie Buffonius fcribit, bippelapbum tragelapbumque, quorum antiqui auctores faepius meminerunt, $(f)$ eundem effe, cui Germani $\tau \tilde{\omega}$ Brandbirfch, Galli autem cervo arduennen/s. nomen indidere, qui, quod Fabricius $(g)$, Misniae olim rector, Gesnero perfcripfit, aquilini \& atri propemodum coloris crine veftitur, caeteris fui generis robuftior eft, \& Bohemiae, quam maxime filvas inhabitat $(b)$. Jubae ab humeris, gula, pronaque colli parte de miffae aliqualem ipfi equi formam fpeciemque

prae-

(e) Boswells Befchr. von Corlica. p. $4 \mathrm{I}$.

(f) Gesn. Hirt. Quadrup. pag. I I 0 I.

( $g$ ) Olim, quod Ariftoteles teftatur, apud Arachotas Indiae populos, inventus eft. Arift. Hift. animal. Lib. II. Cap. I. vid. etiam de Tragela. tho Plin. Hift. Nat. Lib. VIII. Cap. 33.

(b) Vide Wald-Forjt und Faeger Lexicon Prag. 1.76\$. pag. 145. 


\section{G E O G R A P H I C A E.}

praebent, qua a reliquis fui generis potiffimum diftinguitur.

6. XII. Coloris etiam varietate admodum inter fe cervi differunt, (i) qui perfaepe a fufco, quem ipfis natura tribuiffe videtur, valde recedit. Sic ille, cujus modo mentio facta fuit, fubniger eft. Doebe: lius fe albi argenteique pili multos vidiffe teftatur $(d)$; $\&$ nomenclatoris in venatorum gratiam collecti auctor plerosque albos rofeis oculis praeditos effe adferit (l).

f. XIII. Multos praeterea diverfis notatos variegatosque effe coloribus, non alii folum auctores, fed Ridingerus etiam confirmat, qui aliquot ipforum imagines magno ftudio elegantiffimeque exfculptas dedit. Hinc parum abeft, quin credam, quadrupedem, quem Buffonius, (m) Plinium (n) fecutus, Axin vel Gangis. cervum appellat, noftratem efre, cui caeteroqui fimillimus eft, quive folius climatis, fub quo vivit, effectu colorum, quibus nunc fuperbit, diverfitatem induit. Corporis enim formam habitumque intuens medium ipfi inter cervos damasque vulgares (Dambir/cb) locum tribues: cornua vero cornubus cervi noftratis ex-

acte

(i) Doebelius cervi colorem triplicem effe dicit: I. fubrufum, 2. ex fufco rufum, \& 3. ex luteo rufum. v. ejus voll komne Faeger - practic.

(k) Ibid. pag. 2. In Mexicana regione candidos pafci cervos, ex Hornandezio deinceps probabitur.

(b) "In noftris (Bohemiae) filvis candidi offenduntur cervi, quorum "oculi \& labia rofeo colore funt infecti ". De candidis cervis praeter "Ariftoselem Plinius etiam videndus eft. Wald Forft und Gaeger - Lexicon Prag. 1768. pag. 144. Utrum vero, quod Buffonius opinatur, cervi domatu album colorem induerint, aliis dijudicandum relinquo.

(m) Buffon P. 6. Vol. I. \& Mém. de l'Acad. des Scien. T. I. p. 265.

(n) Plin. Hift. Nat. Lib. VHI. Cap. 2 I. edit Gronov. T. I. p.5I4. 


\section{SPECIMEN ZOOLOGIAE}

acte refpondere cernes. Idem calidiorum Africae ( 0 , Afiae \& illarum quam maxime regionum, quas Ganges alluit, Bengalae $(p)$ nimirum \&. Golcondae ( $q$ ) feffor eft. Buffonius quidem a dama patre ipfius originem derivare non dubitat: fed fi a tanti viri fententia difcedere licet, ipfum a noftro cervo deducere malim, partim quod fimillima huic cornua gerit, partim quod inter noftrates etiam verficolores máculofique cervi permulti inveniuntur. Praeterea in flagrantiffimis terrae tractibus fedem fixit, in quibus, quod poftea pluribus commonftratum dabo, pleraque animalia diverfis coloribus maculisque diftineta confpiciuntur: Cervum hunc tam parifienfis academia in praeftanti, quam in lucem emifit, animantium collectione fub cervi Sardinien/is appellatione, quam Buffonius in faepius laudata hiftoria fua naturali optime defcriptum depictumque exhibuerunt.

0. XIV. Hic idem, quetn jam nominavi, vir celeberrimus Axin quidem eundem cum dama difcolori effe autumat, qui ex fua opinione in bonae fpei pro: montorio comparet. Quum vero Kolbius, qui multos annos ibidem commoratus fatis amplam ejusdem quadrupedis contemplandi poteftatem habuit, unus hac in re judex \& arbiter effe poffit: primam quaefo operis fui, quod promontorii hiftoriam naturalem continet, editionem evolvas ( $r$ ), ubi nullam quidem cer-

vo-

(o) Belion. Obfervar. Cap. 2 r. p. 120.

(p) Luilliers Reifen nach Oftind: p. 54 .

(q) Recueil des. Voy. de la Comp. des Ind. T. VII. p. 52 I.

(r) Prodiit Norimbergae anno 17 19. \& p. 390. Kolbius ita feribit: es giebt hier (im Lande der. Namaquas) vieles Wild, auch eine Art bunter. 
GE O G A PH I C A E 203

vorum dámarumque, fed multarum infer Hotentotas, qui Namaquae vocantur, degentium ferarum \& difcolorum inprimis maculoforumque capronitm mentionen invenies, qui quidem apud Namaquas ( $s$ ), non autem in promontorii finibus, numerofifimis gregibus \& milleni interdum obvii, albis luteisque maculis permixte diftineti noftratium hircorum magnitudinem non attingant; campos autem celerrimo curfu pererrent, quorum carnes, quoniam feras, non vero bircos fapiunt, efu jucundiffimae fint. Quivis fine dubio exinde colliget, beftias hafce Gazellarum, minime vero cervorum damarumque generi adfcribendas effe.

0. XV. Potiffimis cèrvi varietatibus, terrisque, per quas dilatatus reperitur, diftinete percenfitis, nunc ad caprcolum, quirmaximis propinquitatis vinculis cun cer-5 vo conjungitur, transeo. Hic pari quidem ratione per utramque tam novi, quam antiqui orbis latitudinem,

cer-

odér getleckter böcke, welchéman an dem yorgebuirge und deflen bexirk nie mals frchet. Die haben nemlich weisfe und gelbe flecken durcheinainder. Die find an grösfe den Europaîfen böcken kaum gleich, aber überaus inell. Man trift fie bey taufenden beifammen an. Ihr fleisch if nicht unange. nehm zu effen, und hat den wenigten gefmack nach Bockfeifh, fondern gleichet dem Wildpret Qum Gallus quidam libri hujus fatis ampli epitomèn lingua fua ediderit, quae poftea in germanicum quoque idioma translata ent, \& capri.(Bock) voculam damam (Daim) reddiderit: ńn dubito, quin Buffonius, hoc vocabulo feductus, in hune errorem inciderit, ut caprum pro dama vulgari habuerit. Eadem imprudentia germanicus etiam hujus epitomes interpres lapfus vocem gallicam Daim per rupicaprain (gems ) expreflit; qui omnes errores ; prima libri edicione infpect ; fa. cile concidunt \& folvuntur.

(s) Namaquajenfium Hotentotarum regio ex Folbii computatione iub tricefimo circiter latitudinis auftralis gradu jacet, ideoque quinque prope. modum gradus a promontorio diffidet. Delilius vero, qui in mappa fua geographica cos ad vicefimum fecundum usque gradum grógredi affirmar, eosdem adhuc longius inde removet. 


\section{SPECIMEN ZOOLOGIAE}

cervo tamen infrequentius difperfus offenditur, certasque fibi terrarum oras tractusque delegit, in quibus perpetuas fibi tamque proprias fedes fixit, ut proximos etiam confinesque agros evitare videatur. Hinc faEtum eft, ut certi huic animali fines certaeque finium determinationes in mappa geographica nullae conftitui potuerint, quippe quibus fummatim fumtis aliquas tantummodo regiones, easque magnis disjunctas intervallis inhabitare mos eft.

j. XVI. Genus hoc cum cervo pari fere paffu eousque ad feptentrionem progreditur, ut in Norvagia ( $t$ ) etiam, Sueciaque ( 1 ) inveniatur; boreales tamen Americae terras multo copiofioribus agminibus inundet. Septentrionalis enim Americae defcriptio plane diferteque perhibet, nullam animantium fpeciem praeter capreolos Canadae regionis immenfa pervagari copia, nullamque facilius unquam meliusque cicurari poffe; ideoque miraculo effe, qui fiat, ut Galiorum domibus agrisque nulli eorum greges impascantur $(v)$. A feptentrione plurimas Europae regiones cum cervo pererrat. In Tartariae $(w)$, Chinae $(x)$, Sibirix $(y)$, Java (z), aliisque Afiae regnis \& tractibus reperitur; in Africa bonae fpei promontorium incolit $(a), \&$ permultas Americae plagas, auftrum verfus fpectantes

oc-

(t) Pontoppidan Hift. v. Norweg. T. II. p. I9. (u) Fauna Suec. p. I4.

(y) Allg. Reif. T. XVII. p. 229. \& Dumont Mém. fur la Louifiane T. I. p. 75 , (w) Allg. Reif. T. VII. p. 64I.

(x) Neuhofs Gezandfchaft p. 370

(y) Gmelin (Jenior.) Reif. durch Siberien T. I. p. 232. \& paffim

(z) Cooks Voyage in Hawkesworth's Account. T. III. p. 746.

(a) Kolke l. c. p. $33^{2}$, ed. in 4 to. 
occupat. In Peruviae enim hiftoria naturali de capreo$h s$ dicitur $(b)$, eos nulla propemodum in re a noftratibus differre, \& ibidem etiam gregatim ingredi. Americam autem auftralem quasdam ipforum varietates alere, deinceps probabitur.

0. XVII. Ex quibus omnibus manifeftum eft, capreolum, qui per utramque \& veteris \& novi orbis latitudinem extentus confpicitur, primi capitis animalibus jure adnumerandum effe: quamvis non in omnibus, quas cervi occupant, regionibus inveniatur. Non enim pari cum illis paffu ad feptentrionis oras progreditur; deinceps peregrinantes ampliorem in Africa cervorum, quam capreolorum numerum obviun habuerunt.

0. XVIII. Plures interim prae cervo capreolus varietates numerat, quarum noftris in terris duas tantum novimus, Jubrufam fcilicet atque fuscam. Haec alba quadam in tergo macula notata eft; fubrufa autem, ficuti collium montiumque incolae, quibus haec aggregari debet, aequatae camporum planitiei incolis univerfim praeftantiores funt \& robuftiores, fic majoris etiam eft incrementi.

ઈ. XIX. Afiam quoque duplicem illorum fpeciem nutrire, fide digniffimi docent fcriptores. Communis enim, nobisque vulgatus, ex Gmelini (c) aliorumque peregrinatorum relatione, Siberiam incolit; praeter quem in eadem regione, ad fuperiores Irtijcbi flu-

mi-

(b) Allg. Reif. T.XVI. p. I 28.

(c) Gmelin. (fen.) Reir. T. I. p. 239 \& 296. 


\section{SPECIMEN ZOOLOGIAE}

minis ripas (d), \& in Cafanenfín provincia (e), animal quoddan', cui nohen faig ae eft, reperitur, quod capreolis accenfendum effe non dubito. Gmelimus qui-den fenior in itinerum fuorum per Siberiam factorum enarratione paffrm cjus meminit; fed Pallafurus in praeftantiffimo opere, quo fum per easdem regiones iter confeetum explicuit, hanc riobis beftiam fufius longe curatiuşque delcriptam dedit $(f)$. Quicunque viri celéberrimi verba, quae fubtus adjunxi, fine praejudicio animaliumque genera multiplicandi prurigine legerit, dubio procul non poterit, quin faigam hanc capreoli noftri varietatem ftatuat. Cauda enim cum papilla cuticulari commutata, \& tubercula, quae verrucis fimilia in cornum bafi exftant, aeque minus, atque paulo

ma-

(d) Ibicl. T. I. p. 213 :

(c) Pallas Reif. durch Rusland T. I. p. 198. 2 Ir. 400.

(f) Fallas $1 . c$. in defriptionibus animalium fugitivis quas operi laudato -fubnexuit, cervus, inquit, Pygargus Saiga: Magnitudo fupra damam; color fere : capreoli. Cornua triturca, ut in capreolo, bafi tuberculis multifórmibus muricata, vernanti gemma pilis arrectis undiquie hirfutifima \& Barbata." Autress intus àlbo villoriffimaé; oculi ciliis, pilisque circa orbitam fparfis, longis, nigris. Cauda nulla, tantum papilla cutacea, craffa fupra anun; clunes area magna nivea ad dorfum tisque adfcendente. Vellus altifimutim, fíbtus artubusque lutefcens; ambitus näfi \& latera labii inf riorisis nigra, ipjo tanenen apice kabii albo. Obfervatur in campeftribus \& montanis. fruticofis elltra Volgam.

Eodem in libro f. 2 I1. addit : has Saigaki eum in modum manfuefcere, ut dominum fum undique; quin etiam per aquas comitentur; amararum eas \& aromaticarum quam maxime herbarum efu delectari, \& hinc effici, ut carnes fingularifi quidem, minus tamen ingrato fapore inficiantur. Pag. 400. hoc iptis proprium effe tradit, ut oculorun pupulae fpongiofis quatuor excrefeentijis-circumdatae fint, quas ideirco iffis additas cenfet, ut nivium, quibus ingentes patriae fuae campi contegl folent, fplendureni eo melius \& citra aciei liebetationem perferre valeant. 


\section{G E O G R A P H I C A E. $20 \%$}

major corporis amplitudo, fufficiet, ut eandem a capreolis noftris fegregemus, quum cornua, colorem, formam, mores, carnis faporem \& omnia cum noftro communia habeat.

6. XX. Africae capreolos a generis fui patre $\&$ indole digredi, notorum mihi peregrinantium neminem tradidiffe, recordor. Quos enim bonae fpei promontorium pafcit, Kolbio, rei hujus tefte locupletiffimo, noftratibus funt fimillimi $(g)$ : quum e contrario America, quod Buffonius adftrtit, plures eorum fpecies alat. Animantes enim, quos Reccbius fub Mazamaie \& Temamazamae nominibus defcriptos dedit, capreolos effe Buffonius fupponit, quod quidem de Mazama \& quam maxime de Teutblamuzame fatis probabiliter fecisfe videtur, utpote qui non ejusdem folum magnitudinis, fed quod primum fummumque habeo, minoribus etiam cornubus in ramulos exeuntibus armatus eft $(b)$.

(g) Kolbe l. c.

(h) De novae Hifpaniae cervis capreolisque Recchius ex Hernandezii relatione p. 324. Feribit: inter cervorum genera, quae apud novam hanc Hifpaniam adhue mihi videre licuit (praeter candicios totos, quos reges cervorum effe Indi fibi perfuafere, nuncupantque a colore Iżtacmacame) primi funt, quos vocant Aculliame, Hifpanicis omnino fimiles furma, matgnitudine ac reliqua natura. Minores his apparent Quauhbtama ame; fed usque adeo a caeterorum timiditate alieni, ut vulnerati homines adoriantur, ac faepenumero interimant. Hos feg inuntur magnicudine Tlallhuica. mazame, qui forma \& moribus effent omnino fimiles cis, ni timidiores vide. rentur. Minimi funt Temamazame, fed hos ac reliqua genera, inter quae numerantur Trutbolalmazame, Temamazame \& hujnsmodi alia pernulta, ego potius computaverim inter capreos. El ibidem: Teuthtlalhiazame, quie capraram mediocrium paulove majori conftant magnitudine, P1o teguntur cano, \& qui facile avellatur, fulvoque, fed lateribus \& ventre candentibus. Cornua gettant juxta exortum. lata ac in paueos parvosque teretes \& praeacutos ramos divifa. Thefaur. rer, med. nov. Hifp. p. 324 . 


\section{8

Temamazame vero \& longe minor capreolo, \& corniculis praeditus eft, quae tubulonum inftar fimplicia funt, nec ramos habent. Mihi quidem explicatu difficile videtur, qui fiat, ut eadem in regione eadem ferarum fpecies nunc fimplicibus, nunc ramofis corniculis inftructa nafcatur. Quodfi vero Temamazamae ratione, fcrupulus quidam nobis refederit; foli animantis ignorationi, in qua adhuc verfamur, tribuatur, \& donec experientia plus lucis affuderit, excufetur.

ర. XXI. Idem Buffonius iterum iterumque mihi laudandus, Guianenfium Brafilianorumque Cuguacu-aparam fub Mazamae \& Cuguacueten fub Temamazamac appellationibus latere, \& utrasque feras unum effe capreolum noftratem exiftimat ( $i)$. Cujus rei inveftigandae caufa, ipfi auctores, Forminius nimirum \& Bancroftius, qui earum meminerunt, easque nobis defcriptas dederunt, confulendi effent. Sed utinam ipforum verba tam clara effent \& luculenta, ut res ex ipfis confici plane decidique poffet! Ferminius eft, qui in Hollandiae aequinoEtia-

(i) Si Pifonem confulueris, facile deprehendes, ejus Cuguacuetae defcriptionem ab icone, quam hujus beftiae exhibuit, toto coelo differre. In hiftoria enim naturali \& med. utriusque Indiae p. 97. fcribit: " praeter "dorcades Europaeas Brafilienfibus non multum diffimiles, capreae, indi" genae cuguacuetae non cornutae \& Cuguacu-aparae cornutac praecedenti"bus minores exiftunt. Imago autem, quam pag. 98. addidit, \& cui nomen Cugacuete praefixit, cornibus armata cernitur. Sphalma itaque typographi fuboleo, qui nomina permutavit \& cuguacu aparae nomen imagini apponere voluit : alioquin enim auetor ipfe fibi concradixiffet. Quum vero effigies illa capreolum noftrum exacte referat, exinde colligo Cuguacu aparam, cui auctor cornua, mediocria tribus ramufculis villofis ornata, quae, quotannis amittat, cineritiumque colorem tribuit, capreolum noftrum effe. Quid, fi Cuguacuete, quod Buffonio probabile videtur, femella Cuiguacu aparac effet? 


\section{G E O G R A P H I C A E.}

ctialis hiftoria $(k)$ cervum illarum regionum capreolum effe contendit, qui in magnis denfisque filvis habitet, fubrufi coloris fit, cornuaque brevifima gerat, \& idcirco cervus corniculis breviflimis vocitari queat.

6. XXII. Haec ipfa igitur fera eft, cui Barrerius( $l$ ) cervi majoris corniculis breviffimis, \& Bancroftius $(m)$ t8 Bajeus nomen addiderunt, \&, cujus ultimo loco mentionem feci, Bancroftius adjungit : eam ipfam quam proxime ad capreoli noftri formam ftaturamque accedere. Ex quibus omnibus minus quidem evidenter patefeit, utrum hoc animal Bajew Tamazame an Mazame, aut, ex Buffonii fententia, Cuguacu-apara fit; interim tamen fub una dictarum Guianae beftiarum capreolum noftrum latere, magna cum probabilitatis fpecie colligo; \& $\tau$ B Bajeudefcriptio eo fere me perducit, ut, propter cornua, quorum acumina incurvata funt, ipfum pro Tamamazame habeam. Si, quid fentiam, adponere licet, Cuguacu-aparam, noftratem capreolusw \& Cuguacucten,

(k) Hift. Nat. de la Hollande équinoct: p. $\sigma$. Le cerf de ce païs elt plutôt une biche des bois, qu'un véritable cerf. Il fe tient dans les grands bois; fa couleur eft rouffatre; fes cornes font fort petites; auffi peut-on l'appeller: cervus corniculis breviffinis.

(l) Effai d'Hiftoire naturelle de la France équinoet. Paris r $74 \mathrm{r}$. p. I7 1 . Vix comprehendere poffum, cur nec Bancroftius nec Ferminius expreffe addiderint, utrum beftiarum cornua ramofa lint, nec ne? Ex utrorumque defcriptione ramis ipfas nullis praeditas fuife, elucere videtur, \& tunc Temainazamarum fpeciei effent adfcribendae.

(m) In Hift. Natur. Guianae p. 73. Guiana, inquit, duas cervorun fpecies alit, quorum altera, altera major eft. Majorem tam regionis incolae, quam Europaei Bajeu, minorem vero. Wirrebocerram nuncupant. Bajeu europaei capreoli magnitudinem habet, qui majori capite, breviffmis cornibus, quorum acumina paulo inflexa funt, magnis demiffisque auribus, oculis vegetis \& flagrantibus, collo caudaque brevi. quidem, fed craiffa praeditus eft. 


\section{IO SPECIMEN ZOOLOGIAE}

femellam ejusdem; Temamazamem vero, cujus imaginem Reccbius pag. $3250^{\circ}$ dedit, feram adhuc minus cognitam effe, credo, quae caprarim fortaffe generi attribui debebat. Caprcolus itaque in Brafiliae montibus fub Scoafju $(n)$ \& Cuguacu-aparae appellatione, in Mexicorum regno fub Teutblamazamae denominatione redit, in Paragoyae agris noftrati ex amuffi refpondet (o), nullusque dubito, quin $\tau$ Cariacu, cujus dimenfionem Daubentonius nobis exhibuit, noftri capreoli aut Cuguacu-aparae mas fit $(p)$.

J. XXIII. Quantacunque interim fit obfcuritas, quae in beftiarum hactenus enumeratarum defcriptione deprehenditur: hoc tamen exinde lucidum fit manifeftumque, capreolum per omnes. Americae meridionalis plagas, quae flagrantiflumo fole torrentur, dilatatum effe. Quoniam vero peregrinatores, qui Patagonenfes, Magellanicas, quin \& Chilienfium oras peragrarunt, mentionem ejus nullam plane fecerunt; ipfum in auftralibus novi orbis tractibus vel nunquam vel perraro reperiri, inde fatis probabiliter colligo.

Ø. XXIV.

(n) Ex Lery relacione ampliffimae poft Tapiriffam magnitudinis animal, quod in Brafilienfium campis pafcitur, cervorum aliqua pecies eft, quae ab indigenis Scoalus: nominata, noftris cervis minor, cornua multo breviora, crines vero ejusdem longitudinis cum noftratium caprarum crinious alic. Aligem. Reifen T. XVI. p. 269. (0) Ibidem p. I 28.

(p) Quid? Ii dies tempusque doceret, Recchii Temamazamen Antilopam, \& hane ipfam ferarum fpeciem non antiqui folum, quod Buffonio placet, fed novi etiam orbis incolam effe, illamque viri celeberrimi opinionem in hoc etiam animante fic convelli, velue in Opa!jo, quod poftea boco fuo commonftrabitur, fracta eft? Interim Temamazamen minus adhuc cognitis e caprarum forte genere animantibus adfcribi, quam Buffonii de Gazellis opinionem rejici mallem. Num forcaffe data a Recchio figura Subulunem refert? 


\section{G IE O G R A P H I C A TE.}

0. XXIV. Hoc etiam loco dama vulgaris commemorandus effet; qui tamen quum fatis notabili differentia a cervo diftet, multo praeterea cervis capreolisque rarior occurrat, \& idcirco animantibus adnumerari debeat; qui certas tantummodo Europae Afraeque regiones incolunt: non mirabere, fr folis ipfum in mappae geographicae locis, ubi fedem fibi domiciliumque collocavit, annotatum, \& deinceps in capite tertio, quod animalia in aliquibus tantummodo terris obvia continet, defcriptun confpexeris.

\section{SE T I O X I I.}

6. I. F xiguus adhuc minoris ftaturae quadrupedum numerus fupereft, quorum corpora facultate tam praeftanti natura donavit, ut commode \& fine ullo incolumitatis fuae detrimento in omnibus mundi plagis $\&$ vivere poffint, \& revera vivant, quorum tamen nonnullos tam dubiis fibique interdum contradicentibus indiciis depictos legimus, ut, utrum ejusdem, an diverfi generis fint, dijudicatu fit difficillimum.

0. II. Nifi Buffonio crebra iftos contemplandi occafio fuifet oblata; ipforum permulti is adhuc tenebris circumfufi jacerent, ut vix ac ne vix quidem in lucem extrahi, \& quales fint, certo dijudicari poffent. . Viri celeberrimi munus eft, quod illorum non paucos, qui diverfiffinis antea fub nominibus circumferebantar, unius nunc generis ejusdemque fpeciei effe fcimus; ipfius cura elfectum eft, ut confufio illa perturbatioque, quam antiqui in iis definiendis admiferant, quam: 
que nulla hucusque diligentia explicare poterat, nunc fublata fit $\&$ in ordinem redacta. Magnam illorum turbam filentio premo, qui olim vel penitus ignorabantur, vel minus nobis innotuerunt, quales foetentes (die Muff: feten) aliique plures fuerunt, quos fola viri acerrimi perveftigatione nunc cognofcimus, fuisque claffibus fubmittere valemus.

0. III. Non equidem inficior, ipfum animalium genera, demtis refiffisque fat multis, admodum contraxiffe: nihilo tamen fecius jam fupra, ubi de lupo fermo erat, dilucide commonftraviffe autumo, ipfum quoque animalia ab uno patre oriunda aliis generibus minus provide affignando diffociaviffe, quod jiciuri, cujus nunc fpecies percenfebo, exemplum evidenter confirmabit.

0. IV. Sciurus hic cum glire \& mure eft, quem per univerfum etiam pene terrarum orbem difperfum offendimus. Tria haec genera tam certis indubitatisque Natura characteribus inter fe diftinxit \& feparavit, ut citra erroris periculum dignofci veftigiaque, quibus $\mathrm{ex}$ una regione in proximam tranfiverint, indagari queant. Lubens equidem concedo, praeter tres hafce beftiolas in utrisque $a b$ aequatore tam feptentrionalis, quam auftralis latitudinis gradibus, alias etiam nonnullas of fendi, quae ad eandem fpeciem referri debeant; qualestalpae, muftelae \& reliquae plures funt, quas, quantum pracfixus mihi fcopus permiferit, huic capiti adjunEtas dabo. Quia vero fcriptorum nemo certis dilucidisque verbis tradidit, an omnes etiam regiones illas inhabitent, quae gradus iftos interjacent: aequum judicem nihil amplius a me poftulaturum confido, quam 


\section{G E O G R A P H I C A E. 2I}

ut, quae auctores fide digni de illis commemorant, quaeve ipfe diligenti perfcrutatione indagare potui, fuppeditem percenfeamque.

\section{Sciurus.}

0. V. Sciurum tenui quidem gracilique, fed robufto tamen corpore alacrique ingenio natura donavit, effecitque, ut pari cum enumeratis jam quadrupedibus robore tam zonam glacialem, quam quae folis appulfu ardefcit, tolerare valeat. A feptentrione, qui ejus potiffimum patria effe videtur, eum profequar, partimque illius varietates, partim, quousque fe extendat, breviter perftringam.

0. VI. Ut autem aquilonaris latitudinis gradus ad quos usque adfcendit, eo certius definiam, antea Buffonii fententia, luculentiffimi cujusdam fcriptoris auctoritate infirmanda, \& demonftrandum eft, cinerei coloris fciurum feptentrionalem \& virginianum, quem Galli le petit gris vocitant, cum noftrate, qui rufis grifeisque interdum admixtis veftitus eft crinibus, eundem effe.

0. VII. Solertiffimus naturae venator Gmelimus junior, qui colorum diverfitates in fiisris obvias fumma cum mentis attentione obfervavit confignavitque, fequentia in itineris fui defcriptione narrat $(a)$. , Sciurus 2 (prope vicum $K_{a} /$ tirskoi haud procul ab urbe $W$ ora: 2, nesh jacentem ) in novembri jam colorem fuum, qui ex $\Rightarrow$ rufo fufcus effe fuevit, mutare coepit, quod in ter-

ga

(a) Gmelini (jun.) Reif, durch Rusinn T. I. p. 35. 


\section{SPLCIMENZOOLOGIAE}

"s. primum \& quidem cito fatis, deinceps in alvo $\Rightarrow$ factum effe vidi, quam poftea pedes \& tandem ca" put fequebantur. Superior corporis pars femper ci„ nerea, magis tamen minusve fufca eft.

"L Linnaeus itaque beftiolam hanc convenientiffime

" ex coerulefecenti cincream appellivit. Pars autem in-

" ferior femper albefcit; quam ob caufam vir idem in

2. natura perfcrutanda folertiffimus alio quodaim loco

os foimuan per hiemem fupra.cinereum, infrá vero canum

¿s efie recte adfirmavit. Buffonii opinionem infirma-

$\Rightarrow$ turus \& cinereum riffumque fciurum idem effe animal,

\% quod nec vitae, nec morum habitu differat, fuffi-

" cienter comprobaturus, varias pilorum mutationes

" tabula feptima \& octava curáte exprimendas curavi.

\% Scruri pilis ad aures elongatis nullis, aliquoties con-

„ templandi copia mihi facta eft, quen quidem a cae-

" teris paululum, non ita tamen diftantem inveni,

g, ut fingularem quandam fpeciem conftituat; quin po-

\% tiusipfum varietatem tantum aliquam effe, convietus

„, compertusque autumo; quum per aeftatem reliquorum

\% omnium more ex rufo flavefcat. Medias etiam varieta-

" tes quasdam obfervavi, quarum circa aures pili minus

\% longi, imo breviffimi exftabant. Tandem tales etiam vi-

\% dere mihi licuit, qui pilis iftis penitus caruerunt. Ex

"quibus omnibus elucet, Buffoniii fic dietum pesit gris,

"cum fciuro vulgari unius ejusdemque generis effe $(b)$ ".

0. VIII. Hactenus Ginelinus: ex cujus obfervationibus ea cum animi attentione, quae peritum naturae

(r) Fufcum fciurum, ingiediente hieme, albefcere Pontoppidanis in Norvagiae Hift. Natur. T. H. p. 46. etiam teftatur. 
indagatorem decet, factis manifeftum eft, fciurum noftratem \& vulgarem cinereum (le petit gris) eunden: effe, qui, quoniam cum cinereo etiam, quem Virginia nutrit, exacte congruit, nos certiores reddit, tres iftos, nempe fufcum, Ruffiae Lappiaeque cinereum (petit gris); \& Virginianum unius effe fpeciei fciuros, qui multo propius ad feptentrionem progrediantur, quam quis ante hanc a Gmelino datam relationem fibi perfuadere potuifiet.

6. IX. Ipforum itaque limites, qui pilis ex fufco rufis veftiti, vix ad Sueciam usque extendi videbantur, nunc ipfo polari circula definiendi funt, a quo fe per veterem aeque ac novum orbem difilipant. Per totam enim Europam undique difreminati reperiuntur. America feptentrionalis fat multas ejus varietates alit (c); in Canada enim valgares rufa, in Virginia $(d)$ \& nigri \& majores cinerci (le petit gris), in Mexico (e) aliis: forte praeter nigrum coloribus praediti inveniuntur. Afia varias ejusdem fpecies numerat.: Sic Ruffia cinereas multas fovet, quae in Siberia, ficut plerique ejusdem regionis animantes, albefcunt, quarum exemplar ex Realmurii mufeo Briffonius attulit $(f)$. Id tamen mirum fortaffe quibusdam accidet, hanc candem regionem nigros etiam alere $(g)$

Q. $X$

(c) Allg. Reif. T.XVII. p. 23 (di) Brifon Rogn. animale

(e) Rechii Sciurus Méxicanus in Hornand Mliefar rer. med nov. Hip. p. 582. vide etiam Dejcript. des Ind.par Jean de Lact p. \&. \&. charlevoix Hitt. de la nouv. Franee $T$. p 273 .

(f) Brifon regn. anim. Sciurus albus Sibericiss.

(g) De Siberiae fciuris Gmelinus fenior in prafatione fecindas parti

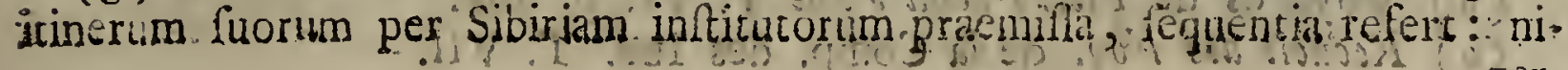




\section{SFECIMEN ZOOLOGIAE}

6. X. Nec Africae calorem fciuri abhorrent. Barbaria enim quosdam nutrit, quos ftriae in lateribus albae alternatim fufcae aut nigrae a noftratibus difcriminant (b). Gmelini junioris enim obfervationibus crudimur, auriculas breves \& orbiculares pilis deftitutas varietatem quidem, non autem fpeciem aliquam fingularem efficere. Striatus ille fciurus, paulisper tamen immutatus, novam quoque Hifpaniam incolit $(i)$, quem eundem cum Buffonii palmarum $(k)$, hosque omnes \& fingulos cum vulgari nótro effe exiftimo, quem, poftquam patriam fedem reliquit, coeli aërisque temperies leviter transformavit.

6. XI. Nec novi, nec antiqui orbis zonae calidioris aeftum fciuros repellere, experientia docemur. In Madagafcaris enim filvis, quod Flacourtius confirmat, fub T/ht/ibi nomine, cinereo colore infectus vivit (l). In Siamae regno fecundum Tacbardii relationem, albus incedit ( $m$ ); in Cambaya ex candido cinereus (12), \& in Bengala (0) maculis fparfus confpicitur.

6. XII. Et meridionalis America diverfas ejusdem varietates pafcit. Ferminius eum in Surinamo, nigro

gerrimi colorss feiuri, qui tamen omnium etiam minutiffimi func, in $\Im$ akeska \& Nert/ctinska nafcuntur. Newrfowifchaenfes quidem iis majores, fed cinerei funt. Theleutenfum feiurorum eximiam corporum magnitudinem tota fere Sibiria admiratur, quos argenteo colore infignes permulti nigris longe anteponunt. (h) Sciurus getulus. Sciurus fufcus friis quatuor albidis longitudinalibus.- Linnæi Syft. Ed. XII. \& Jllward. av. tab. 198. vel Seirgmains Vogel T: 4. (i) 'Seba Thefaur. Vol. I.' p. 76.

(k) Seiurus palmaruin. 1.e Palmilte.

(l) Flacourt Hift. Nat. de Madagafc. p. I 5 I.

(in) Tachards Zweite Reife nach Siam Hamburg I 708.

(n) Voya: es de Pietro della Valle T. VI. p. 368.

(o) Recucil des Voy. de la Comp. des Ind. T. VII. 
tantum colore tinctum, cauda praeditum prolixa, quae longis denfisque pilis veftita erat, vidit, quem europaeus magnitudine multum fuperet $(p)$. Bancroftitrs $\mathrm{e}$ contrario Guianenfem cum noftrate pari corporis fpecie, ventre $\&$ pectore album, reliquisque partibus pallidum, \& ex flavo fufcum, in utroque vero latere ftriis albis anguftioribus \& oblongis notatum effe adfirmat $(\eta)$. Quum hi viri tam idonei fint teftes, ut eorum verbis fides haberi debeat, nos inde, Americam meridionalem duas varietates alere docemur, quarum ultima a Bancroftio memorata tamen eadem illa, cujus Marcgravius in hiftoria Brafilienfi mentionem fecit $(r)$, quippe cui exacte refpondet, effe videtur, fi unguen parvulum fubnigrum exceperis, quem Marcgravius in pedibus anticis, pollicis loco, qui Brafilienfi deërat, obfervavit.

0. XIII. Sciurum itaque plerasque per notas nobis \& habitabiles orbis partes difperfun reperimus; licet non negem, eum climatum viciffitudinibus multas pasfum effe mutationes. Idcirco illorum methodum minus probandam effe exiftimo, qui ipfum ex colorum diverfitate in fuas fpecies diftinguere tentaverunt; quum omnes, \& rufi, \& cinerei, \& nigri, \& albi, \& ftriati, \& cujuscunque alius coloris, iisdem moribus, eadem corporis ftructura utantur. Virginiae fciurus (le petit gris) decem pollices fexque lineas, nofter autem vulgaris octo tantum digitos, fex lineas longus eft. Qui vero

in

(p) Fermin Hift. de la Hollande équinox. Artic. Ecureuil.

(q) Natuerl. Hift. v. Guiana p. 85. (r) Marcgrav. Hift. Brafil. p. 230 $\mathrm{E} \mathrm{e}^{-}$ 


\section{SPECIMEN ZOOLOGIAE}

in Barbaria habitat, quem getulum vocant, vix quinque pollicum longitudinem excedit. Univerfum itaque genus hoc, quamvis per omnes propemodum mundi regiones diffeminatum cernatur, minime tantum, quantum pecudes domefticae, a fefe difceffit; quin \& ipfa naturae, corporis morumque indoles \& habitus ubique fibi fimilis, abique aequalis eft.

0. XIV. Praeter recenfitas hactenus fciuri varietates, alios quosdam animantes partim Linnaeus, partim Hallenius ipfis adnumerarunt. Sic Linnaeus (s) $A_{a-}$ vum Ariis quinque fufcis longitudinalibus, ab aliis Helvetium (le SuifJe) nuncupatum, huc referre non dubitat, qui tamen Barbariae jciuro longe minor eft, muris figuram habet, \& cauda (quam in omnibus fiuris tam longis denfisque ornatam pilis deprehendimus, ut ea fupra dorfum reflexa fe tegat inumbretque) raris tantum $\&$ tenuioribus pilis veftita terram verrit. Quum denique fciuri in arboribus locisque aliis elatioribus commorentur, \& interdum quidem, raro tamen defcendant: huic Helvetio, quam Virginiae fciurum appellant, ea de caufa terreftris nomen datum eft, quod humi tantum repit, \&, cuniculorum inftar, fcrobes, ubi latitet, effodit; quibus de caufis longius a fiiuro, quam lepus a cuniculo diffidet.

f. XV. Quamlibet animalia, quorum natura moresque aliqua ratione congruunt, invitus divellere $\&$ fegregare aufim: nunquam tamen concedi poffe crediderim, ut, quae toto coelo differunt, uni claffi fub-

mit-

(s) Sciurus Striatus. Roeffelvigha Syft. Ed. XII, 


\section{GEOGRA P H I A E.}

mittantur, musque fciurorum generi adfcribatur. Hanc itaque beftiolam Helvetii (le fuiffe) nomine adjecta mappa geographica in Carolinae regione ita notatam exhibebit, ut cum fciuris non confundatur.

0. XVI. Denique glirem veterum vel endymionem (den Siebenfchlaefer:) quem Linnaeus $(t)$ fciurum casum, fublus albefcentem nominat, quin \& murem avellanarum fciurorum claffi additum invenio; quanquam utrisque nihil plane, praeterquam quod in arboribus plerumque vivunt, cum fciuris commune fit; utpote qui, quod avellanarum muri $\xi^{2}$ gliri accidit, per hiemes nunquam obrigefcunt. Utrosque itaque a fciuris jure diftinguendos autumo.

6. XVII. Si autem quaefiveris, an non foiuri etiam volantes reliquis adfcribendi fint: id quidem, non ea tamen confidentia nego, qua endymionem maremque avellanarum fegregavi. Et quoniam certum eft, hos petauriftas (u) (quod nomen ipfis Kleinius Halleniusque indiderunt) fingulare quoddam genus conftituere, praecipue quum reliquis fciuris intermixti, uno quidem eodemque loco vivant, nunquam tamen procreandi caufa inter fe commifceri compertum fit; ipfos potius ad ultimum libelli hujus caput, quod animantes fingulis quibusdam locis proprios continebit, rejiciam.

SeCTIO

(i) Glis Linn.

(u) Sciur: hypochondriis prolixis volitans, carda rotundata Linn. Synt. Ed. XII. le Polatuche. Buffion.

Ee? 


\section{SPECIMEN ZOOLOGIAE

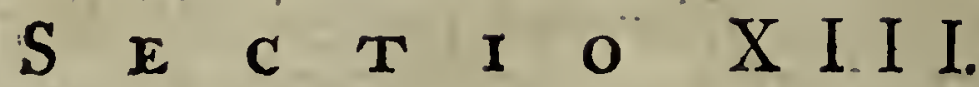

\section{De glire $\xi^{2}$ mare.}

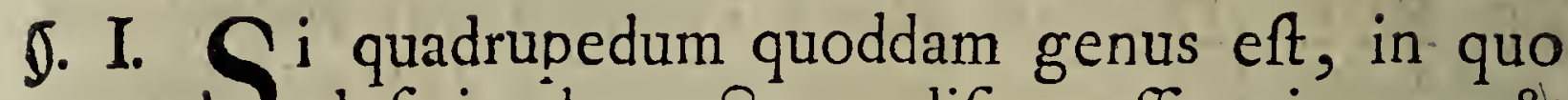
$S$ definiendo auctores difcrepaffe, incerta \& male cohaerentia pro certis verisque arripuiffe, \& fpecies varietatesque parum curate diftinxiffe videntur: id glirium fane muriumque \& illorum quidem potiffimum eft, qui codem, quod nobiscum incolunt, folo funt innati. Quicunque manibus rem tenere voluerit, BrisSonii regnum animale evolvat, idque cum duodecima Linnaci fyftematis editione conferat; nonne beftiolas, modo ab altero laudatorum virorum murium albo perperam infertas inveniet, modo ab altero neglectas defiderabit? Sic, ut rei exemplum proferam, firmulotum (a) a Linnaeo praetermiffum, a Briffonio muribus. afrociatum, deprehendet. Sic animalcula murium generi adjuncta leget, quibus praeter duos incifores nihil plane cum illis commune eft. Exempli loco Paca (b) fit, indicusve porcellus (c), quem cuniculum Brifjonius nuncupavit.

6. II. In quot infuper quantasque falebras incidit glirium muriumque hiftoriam disquifiturus, eorumque ftirpes, ftirpium auctores \& varietates indagaturus!

Utros-

(a) Le Surmulot Buffon. P. 4. Vol. II. Rat de Bois. Mus cauda lon. geffima, fupra gilute fulvus infra albicans. Brilfon regn. anim. p. I70. Ed. in 4 to. (b) Paca. Mus cauda abbreviata pedibus pentadaciylis lateribus flavefcenti lineatis. Linn. Syft. Ed XII:

(f) Caria Cobaya. Marcgr. Hitt, Brafil. 224. Porcelles Linn. 


\section{G E O G R A P H I C A E. 22r.}

Utrosque enim ab hominum olim contubernio \& focietate remotos vixiffe, nemo prudentum inficiabitur. Quo enim tempore homines nec fementa faciebant; nec de domibus \& horreis, quibus fruges demeffas fubveherent \& affervarent, exftruendis cogitabant; dictos animantes jam exftitiffe, cubiliaque fua habuiffe oportet. Quis vero, an tunc ejusdem atque nunc indolis, coloris, magnitudinisque fuerint, an poft fuam in aedes noftras transmigrationem, qua ipfa non exigua nobis detrimenta contraxerunt, mutationes, qualesve induérint; quis, quo ingenio, quibus moribus, qua forma vitaeque ratione tunc fint ufi, exponere ac determinare audebit?

ઈ. III. Ex quibus omnibus patet, quot \& quanta fint, quae de animantibus, qui in dies nobis ante oculos verfantur, in dies nos damnis afficiunt, nefciamus? Utrosque interim filvarum olim incolas fuiffe, terraeque $\&$ arborum fructibus paftos vitam propagaviffe, ex corporum ftruetura, ex cubilibus quibus habitant, exaliorum, qui proxima ipfos cognatione attingunt, agreftium fcilicet, majorum minorumque avellanarum reliquorumque murium moribus ac ritu, quo fe nutriunt, difcimus.

Ø. IV. Si; quae fatis mihi probabilia videntur, dicenda funt, Brij]onii furmulotus (d) genuinum glirium. caput, musque major campeftris $(\dot{e})$, muris noftratis

pater

(d) Mus cauda longifima Jupra dilute fulvus, infra a!bicans. Rat des bois. Briffonius. Non equidem ignoro, furmulotum glires noftros minus benigne excipere; fed canis etjain lupum infefte profequitur, licet ejus* dem lint ftirpis, nec non glires inter fe facpiffime bella gerunt.

(e) Mus cauda longifima fufous, ad latera rufus.: Mus campeftris ma. jor. Brifonius. 
pater eft, totumque hoc animalculorum genus ad tres quam maxime fpecies revocari poteft, quarum prima imures avellanarum majores minoresque continet, qui, quod per hiemem frigore rigefcunt, a relquis omnibus fatis fuperque diftinguuntur. Secundae glires adfigno, a quorum parente furmuloto \& glires ipfi \& omnes eorum varietates originem ducunt. Tertia mures, \& majorom praecipue campeftrem tanquam generis hujus auctorem cum minoribus agreftibus domefticis omnibusque reliquis ipforum varietatibus complectitur. Quae fingula, fi locus propofitique mei ratio permitteret, fufius dilucidiusque enodari explicarique poffent. $(f)$.

Ne itaque longius a fcopo meo aberrem, donec res ipfa decidatur ac tranfigatur, verae gliris $(g)$ murisque $(b)$ noftri patriae expifcandae finibusque, quousque extenduntur, \& varietatibus pro virili exquirendis me accingo.

§. V. Glires muresque proprios antiqui orbis indigenas fuiffe, femper mihi ad fidem pronum fuit, donec duodecima fyftematis Linnaei editio, glirem noftrum ex America in Europam navi transportatum effe, expreffis verbis teftabatur $(i)$. Vir hic omni liberali doetrina politiffimus jure poftulat, ut fuae opinioni affenfum ne denegemus; praecipue quum maxima hiftoria naturalis

(f) Tunc autem glis, quem Linnaeus foiurum canum, fubtus albidum, Germani endymionem nuncupant, fingularem mihi fpeciem confitueret, qua mediante fciuri ad glires transirent; quam tamen opinionem nemini ut fyftema quoddam novum obtrufam volo. $(g)$ Mus rattus. Linnaeus.

(b) Mus Mufculus. Linnaeus.

(i) Ex America navi quadam Antwerpiana primum in Europam pervesiffe refert Popping orb. illuftrat. Linn. Syft. Natur. Ed. XII:' P. 83: 
fcientiaeque animalis pars ipfi accepta referenda fit. Sed haec ipfa etiam illius auctoritas, cui fides $\&$ habetur $\&$ habenda eft, efficit, ut quos imprudens invitusque admiferit errores, eo majoris fint ponderis. Itaque non teftibus folum locupletiffimis evincam, glires muresque ex Europa in Americam transportatos effe; fed ipfa etiam a Linnaeo allegata Poppingii verba, quibus fretus vir praeftantiffimus hallucinatus eft, adjungam, erroris fui fontem $\&$ aperturus $\&$ elifurus.

ఏ. VI. Pawius $(k)$. Americae incolas perquirens, fequentia a Zarate mutuatus eft $(1)$ : navis quaedam claffis, a Placentiae Epifcopo ad detegendas meridionales Americae terras miffae, fretum magellanicum tranfiens portum de los Reis cepit, primosque, quos unquam Peruvia vidit, glires eo detulit, qui poftea immenfo aucti funt incremento. Famam effe, Pawius adfirmat, in mercium colligatarum fafciis ciftisque glirium pullos eo deportatos fuiffe, quibus Indi deinceps $\tau \overline{8} \mathrm{O} c 0-$ cba nomen impofuerint, quod rem e mari vel ortam vel advectam defignet. Glires navi in Bermudenfesinfulas transportatos ibique mirandum in modum maximisque auctibus creviffe, in univerfali itinerum collectione narratur $(m)$. Et Rocbefortius, glires Caraïbis antea penitus incognitos, navibus eodem perlatos, \& per ipforum terras diffeminatos planiffime teftatur $(n)$. Ex quibus multisque aliis fole clarius elucet, perniciofam

hanc

(k) Recherches fur les Américains. (l) Zarate Conq. du Pérou.

(m) Alls. Reifen T. XVII. p. $\sigma_{3} 8$.

(n) Hift. Narur. \& Morale des Aatilles. Rotterdam 1659. p. 265; Les rars, qui étoient autrefois inconulus aux carailies on gagné la terre. 


\section{4 \\ S P E C I M E N \\ $\mathrm{ZOO}$ \\ O L O G I A E}

hanc beftiam hinc eo perduetam noxas, quas ab Americanis accepimus, talionis quali jure ipfis compenfaviffe.

6. VII. Nec folis Indiae occidentalis populis, fed Africae etiam meridionalis fefforibus glires muresque impertivimus; qui, fi Kolbii teftimonio fides tribuenda eft, antequam Europaeorum naves eo appulerunt, nec his innotuerunt. Glires enim eorum animalium numero accenfendos effe, Kolbius ait (0), qui non ab initio ibrdem habitaverint, fed navibus demum eo fint dedacti.

0. VIII. Quodf praeterea nobifcum reputaverimus, glires in Europa prius \& vulgatos \& decantatos fuiffe, quam de novo orbe detegendo Europaei vel fomniarent, nec ulli unquam naturae interpreti, quantum mihi quidem conftat, glirium ex America arceffendarum fubiisfe cogitationem : eo majori miraculo eft, qui fieri potuierit, ut vir perfpicaciffimus huic errori implicaretur; quumque in decima fyftematis fui editione rei hujus ne verbulo quidem meminiffet, Poppingii poftea verbis perperam intellectis inductus, novam hanc opinionem ultimae laudati libri editioni infereret; quum tamen ipfe Poppingius, minimae caeteroquin auctoritatis fcriptor ( $p)$; non, quod Linnaeus, fed contra putaverit, quod

(o) - Kolbe Edit, in fol. p. 16.3 .

(p) Libro ipli (qui hoc ticulo fuperbit: orbis illuftratus, feu nova hiftorico politico seographica inperionum rerumque publicarum per totum orben defcriptio auttore F. F. Popping. F. V. L. Ratzeburgi i 669. I 2mo:-) omnis fere ficles deroganda eft, qujppe quem auctor nimia fuperftitione \& credulitate abreptus confcriplat, fabulis manifeftị̂mis mendaciisque in:pudentiffmis explevit. Pagina enim 14. Electoris moguntini palatium ti- 


\section{G E O R A P H I C A E. 225}

quod ejus verba, quae ipfa apponere lubet, perfpicue confirmant., Animalia, inquit, nobis incognita ge„ nerat (America): - mures gliresque ex Antwerpiana " quadam nave primam $i b i$ originem traxere, qui poftea " magno numero aueti magno incolas damno affece"runt; equis etiam antehac deftituti fuerunt Ameri" cani $(q)$.

6. IX. Quantacunque \& oculorum \& mentis acie verba ipfa contemplor, femper hoc mihi dicere videntur : glires muresque navi quadam Antwerpienfi in Americam perlatos effe. Fac ita interpungantur: animalis nobis incognita gencrat glires muresque: nonne tunc vocula $i b i$ novum tibi negotium faceffet? quam, quoniam fermo de America eft, nulla arte ad Europam retraxeris; \& fequentia : equis ctiam antebac déflituti fuerunt Americani, totam litem diriment; nifi enim tò etinm ad ante nominatos glires muresque retuleris, fenfum auctoris verborum nullum habebis. Accedit, quod so generat: - majori intếrpunétionis nota, colo nimirum, a fequentibus disjunitum fit, quod nec gravi, nec magna fine ratione factum fit oportet. Glires ergo, quorum patriam in antiquo orbe quaerendam effe cenfeo, ex America ad nos perveniffe, omni veritati repugnat, $\&$ praecipitanter le $\mathcal{E}$ ta Poppingii verba virum celeberrimum, ut contrarium iis fenfum elicueris, induxiffe furpicor.

\section{0. $\mathrm{X}$.}

ginta auri millionibus conftitiff; pag. 568: virginem ab urfo vitiatam; pag. 518. puerum oculis igneis cornibusque bovinis in hecem editum narrat, qui, licet quatuor santum horas vixerit, haec tamen yerba $J_{i t}$ prolositus: vigilate, dominus vefter advenit. Praeter alia ejus generis multa p. 285. inferialis etian yenatoris mentionem fecit. (q) Popping. l. c. p. 196. 


\section{SIPECIM LN Z OOLOGI AE}

0. X. Glirem interim primam domefticanque fedem in moderatio tibus habuiffe regionibus, exinde colligere licet, quod, Pantoppidinno tefte $(r)$, non ultra Helgelardiae fines progrediuntur, mnec iftius frigori fatis - refifterenvalents Cranzius autem in Groenlandiae defriptione ullam nec glirim nec inurium (utrosque enim intolerabilis vis frigoris repellit) mentionem facit. - 0. XI.n In Kamt.jobatka vero quaedan animalia fub glirium muriunique nuncupatione reperiria Krajabenninikonio (s difcimus, glirem ibidem vivere \& paffin occurrere tradenti, qui tamen in territorio tam inholpitali vix exfpectandus erat. Tres ibidemillius fpecies reperiri addit, quarum prima brevioiri cauda ritilóque pelle ornata g eandem cum iftis, quos Europa nutrit, -magnitudinem habet, clamore vero, quem edit, quo porcellas noftros imitatur, quam maxime diftat: caeterum vero cum muftelarum quarundam fpecie, quae tamen glivibus, iisque forte minoribus, vefcitur, cognationem aliquan habet Hos glires Kamfolodalium contubernales effe feribit, quorum penu, liberrime \& rèmoto omni timore utuntur, ad quam confidentiam inedia excitantur. Tertiam fpeciem, quae campos \& fruticeta inhabitat, ex co vivere refert quod primae clam furripiti Majores glires guos l cgulifcbit/cb nuncupant, quos in cellulas quasdam diftinguunt, quae totidem penuarias fubterraneas conficiunt. Quae deinceps de mo-

ri-

(r) Natur. hift. von Norwegen P. II. p. 56

(s) Allgem. Reifen T, XX p. 866 


\section{G E OG R P P I CDA E}

ribus, quibus utuntur, de crebriori ex Kainfchadalium finibus, quos interdum penitus deferunt, difceffu, aliaque ejus generis multa retulit, quae jufto longius a fcopo meo recedunt, nunc omitterns, folum addam, fub una trium iftarum fpecierum noftrates etiam glirès; quod mihi quidem videtur, comprehendi.

J. XII. Auctor interim nec extremis quidem, quod ajunt, digitis rem attigit; fiquidem ipfe anibigit, utrun gliribus an muftelis quadrupedia ifta fint adnumeranda; quum tamen diverfiffimis muftelas dentibus inftructás effe, fcire debuiffet. Interim in eam propemodum opinionem perducor, fub maximo Kamtfcbatkie glire noftrum latere cricetum, ad cujus fimilitudinem proptér breviorem caudarn, qua priaeditus éf, rutilam pellem, qua veftitur, cellasque, quas in terra fibic fodit penuarias, potiffimum accedit. Tertia fpeciés murem forte campeftrem noftrum, vel quem agrarium Pallafus nuncupat ( $t$ ), ; fub fe continet; quod tamen, an certum fit, an minus? diligentior inveftigatio in pofterum inftituenda commonftrabit. Caeterum beftias hafce frigorum rigoris impatientes effe, ex Linnaei etiam relatione colligere licet, qui glires, quod de his folis, non autem de muribus adftruit, in Suecia quidem, non autem in Lappia vivere teftatur $(u)$.

○. XIII. Europam mira utrorumque animantium copia urgeri, neminem latet. Archipelagi infulae, in quas navibus noftris transvectos autumo, iftis adfluunt $(v)$.

(t) Pallas Reir. d. Rusland in append.

(u) Fauna Suec. P. II. habitat ubique in Suecia, excepta Lapponia,

(y) Lettres édifiant. Rec. i 8. p. 201. 


\section{SPECIMEN ZOOLOGIAE}

Ruffi \& Sibiriae incolae (w) ipfos velut domefticos inviti nutrire coguntur. Regni Cafani incolas furmuloti vexant $(x)$. Ambos interiores etiam in Afiae regiones penetraffe, ex Chinae $(y)$, Perfiae, Japoniae $(z)$ hiftoria naturali perfpicimus, ubi non maximis folum incrementis augefcunt, fed etiam faltare docentur. Nec Javam Indiamque $(a)$ occidentalem proprie fic dictam, infulasque maris pacifici $(b)$, novamque Zelan$\operatorname{diam}(c)$ iis vacuas effe conftat; quas in regiones fine dubio Europaearum navium ope pervenerunt. Africam quoque \& auream praecipue aetbiopumque oras, incredibili glirium muriumque multitudine, quae non exigua habitatoribus detrimenta inferat, laborare, peregrinantes uno quafi ore fatentur $(d)$. Quod de bonae fpei promontorio Kolbius etiam, quem jam fupra citavi, confirmat (e), qui eos non ibi natos ex Europa potius eo devectos opinatur.

6. XIV. In coloniis, quas angli in Anerica feptentrionali conftituerunt $(f)$, magno fefforum damno praevalefcunt. Et Americam quoque auftralem miram eorum vim alere Bancroftii $(g)$, Ferminizque (b) Guianae defcriptio comprobat, \& qui pofteriori loco nominatus eft, noftris ipfos gliribus muribusque tam fimi-

les

(w) Gmelin (fen) Reif. T. 1. p. 315. In Tomsk. find eine erftaunliche nenge mause ( $x$ ) Pallas 1. c. p. 304. (y) Neulnaf l. c. p. 263.

(z) Kampfers Jap. du Halde 4 Th. p. I38. (a) Allg. Reif. T. 10. p. 3 I6.

(b) Wallis Voyage in Hawkefworths Account Tom. 1. p. 483 .

(c) Cook Voyage in Hawkefw. T.3. p. 438 .

(a) Bollinans Guinsa p. 299. (e) Kolbe l. c. p. 163.

(f) Hilt. de la Jamaïque traiuite de l'Anglois par M * Lond. I752. \& praecipue Allg. Reif. T.17. p. 638. (g) Het. V. Guia p. 85.

(h) Hollande équinox. p.25\&44. 


\section{G E O G R A P H I C A E.}

les effe, ut iisdem defcribendis fuperfedere potuerit, expreffe addidit. Quis dubitaverit, eos non mediocri quidem colonis calamitati ex Europa iftuc etiam transportatos effe?

6. XV. Ex quibus omnibus confici crediderim, diEtorum animalium fedem patriam Europam fuiffe. Quo autem tempore, qua ratione exinde in omnes totius orbis partes transmigraverint, ex navigationis hiftoria, fi operae pretium effet, commonftratu foret facillimum.

ஞ. XVI. Rattus tamen longius progredi videtur. Narborougbio enim prope Lemairii infula, in freto magellanico $(i)$, \& Cookio in Otabeita $(k)$, quae in auftrali mari jacet, quin \& in Novae Zelandiae (l) terris ab ipfo demum penitus detectis obvius fuit. Qua ratione has in oras pervenire potuerit, aliqua probabilitatis fpecie in altera disquifitione, opellae huic addita, explicuiffe puto. Haec itaque beftia in omnibus fere mediocri frigore expofitis regionibus commoratur, eamque, ficut aliae omnes, quas latius per orbem diffufas fcimus, multis varietatibus diftingui, facili conjectura profpicere póffurinus.

D. XVII. Magnitudinis quidem ratione a gliribus $\&$ muribus parum diftat $(m)$. Colorum vero diverfitate majori intervallo diftinguitur. A fubnigro enim, qui proprius ipfis communisque color eft, ratti rúfescere, canefcere $\&$ albefcere folent, muresque a mu-

rino

(i) Voyage de Narborough, dans les Voy. de Coreal T. IIl. p. 64.

(k) Cook Voy. in Hawkesworth's kccount T. II. p. 187.

(l) Ibid. T. III. p. 438.

(in) Rattus enim maximus in feptem circiter, mus varo, fi caudam exceperis, vix in tres dimidiumque pollicem pórigitur. 


\section{SPECIMEN ZOOLOGIAE}

rino in furcum, fubalbidum \& album denique colorem transeunt. Nec omnes unius ejusdemque aetatis (Daubentonii verba funt $(n)$ ) cinereis fubluteisque circulis. diftinctos confpiciuntur. Cinereus enim color, quo horreorum incolae imbuti funt, in domuum fefforibus paulisper in canum deflectit; quae variatio partim ab alimentorum, partim ab aëris qualitate dependere videtur. Hinc tamen, ex mea quidem opinione, maxima illa notatuque digniffima degeneratio, quae quam longiffime a naturali fuo colore difcedit, albor nimirum, quo glires aeque atque mures quidam infigniuntur, ortunin trahere nullo modo poteft. Quoties enim eodem in loco, quid quod? eodem interdum in nido albos nigris cineritiisque pullis intermiftos offendimus, qui, frmulac lucem confpexerunt, difparilem ftatim a caeteris colorem produnt, licet eodem fub coelo, eademque matre nati fint \& eodem victu alantur.

6. XVIII. Nonne albitudo ifta, animal, cui ineft, vitio potius \& infirmitate quadam laborare, portendit? Mihi quidem haec animalia per magnam aliorum eodem albore fplendentium fimilitudinem gerere videntur. Pafferes enim candidis interdum pennis tectos cernimus, qui perinde atque albi mures gliresque (horum autem oculi fubrufi, naresque \& pedes ruffei funt) ftirpem ejusdem coloris nullam propagant. Certa phyficorum filiis pervulgataque opinio eft, animantes albis pilis veftitos majori prae illis, qui nigra fufcaque pelle teguntur, corporum infirmitate viriumque imbe-

cil-

(n) Hitt. der.Natur. P. IV. Vol. I. p. 177. 


\section{G E O G R A P H I C A E. 23 I}

cillitate urgeri, quod in hominibus, equis, bubusque accidere, experiundo didicerunt: ex quibus colligere licet, in aliis etiam animalibus eandem alborum effe pilorum rationem, quam canorum in fenibus capillorum fufpicamur. Totius feilicet corporis imbecillitas, pill ut cani penitus arefcant, non quidem permittit; pertenues tamen, quibus alantur, fuccos ipfis porrigit, quos corpus ipfum, cui ad fui confervationem in fenectute parum nutribile relinquitur, fine fui detrimento fuppeditare yalet. Non autem de copia, fed aquofa potius tenuitate fuccorum, feu, quod idem eft, de exili, qua praediti funt, virtute \& efficacia mihi hoc loco fermonem effe, lectorem monitum volo (o).

S. XIX. Nusquam hanc alborum animantium infirmitatem melius certiusque, quam in homuncionibusillis, obfervamus, qui fub \& prope aequatorem vivunt, \& Kakerlakennorum Albinorumque nominibus innotefcunt, quorum rationem in glires muresque candentes melius quadrare puto, quam, quod ab aliis prolatum legimus, qui ab albis parentibus albam progeniem hanc fic ortam effe, ftatuunt, velut equi candidi candidos progenerare folent. Meo quidem judicio nemo hac de re folidius acutiusque $P$ navio in fua de Americae incolis difquifitione differuit $(p)$. " Semen enim aethio"s. pis, qui cum aethiopiffa albinum gignit, vitio quo" dam adfectum effe credit": quod veri quidem fimil-

(o) Hanc ego rationis, qua crines pilique per hienem albefcant, animo meo fpeciem repraefento: Frigus quod utrorumque tubulos comprimit viam humori nutribili, colores crinium efficienti, quo minus intrare queat, praecludit. ( $p$ ) Recherches Philofoph. fur les Blafards. 


\section{SPECIMEN ZOOLOGIAE}

limum eft. Qưm enim fanum aethiopis femen natura fubfufcum fit, id vario, licet adhuc incognito nobis, modo depravari corrumpive poffe, nemo emunctiorum narium dubitabit. Et cur idem non in aliis etiam animalibus evenire poteft?

ऽ. XX. Haud equidem nefcio, quia monftrofi ifti Albini haud procul ab aequatore nafcuntur, omnem alboris frui caufam in nimium, cui fubfunt, folis ardorem conferri. Sed quis idcirco inficias ibit, morbos, quibus mares murium gliriumque corripiuntur, etiam in culpa effe, ut ipforum femen parili ratione vel corrumpatur, vel ita immutetur, ut candidos femellae pariant, quos fpeciei fuae albinos nominare poffes. In generationis enim doetrina tot adhuc dubia, tot obfcura occurrunt, ut praeter hypothefes nihil hucusque certi proditum fit. Effectus ipfi quidem certiffmi funt, quorum tamen caufae noete adhuc nubibusque obfcuratae latent. Hinc nec mihi clariorem rei lucem adferre, fed, quid de ea fentiam, quidve probabile mihi videatur, ex hypothefi tantum explicuiffe liceat.

\section{SECTIO XIV.}

6. I. Perpauca fuperfunt quadrupedum genera, 1 quae, hactenus percenfitorum inftar, in utroque aequatoris latere magnas easque cohaerentes orbis partes occupant. Dantur fortaffis \& alia, quae aliquas cis ultraque circulum aequinoctialem jacentes terras incolunt; quas tamen vel permodicas, aretioribusque finibus circumfcriptas, vel aliorum tractuum, quos animalia ifta intactos relinquunt, interpofitu di- 


\section{G E O G R A P H I C A E.}

remtas effe oportet: mihi faltem, quod lubens fateor, funt ignotiffima. Quorum hoc adhuc in capite mentio facienda eft, talpa funt $\&$ muftela; quibus beftias quasdam marinas, phocas filicet, manatum \& lutram marinnm, amphibia a Buffonio nuncupatas, addere placet. His omnibus expofitis capiti huic, quadrupedes per plerasque notas nobis regiones difperfos comprehencienti, finis imponi poterit.

ઈ. II. Per omnem fere Europam taipa dilatatur; quumque nemo fere hominum fit, a quo propter varia, quae ipfi propemodum innocenti damna campis hortisque illata, imputari foleant, ignoretur: ejus definitionem addere, noctuam Athenas effet. Quia per omnem propemodum antiquum orbem diffufa invenitur; infuper exiguo eft corpore, \& plerumque fub terra latet: inde faetum effe puto, ut peregrinantes eam altiffimo faepe filentio praeteriverint. Afiae ipfam effe indigenam, certa reperire indicia minus mihi contigit. Ex uno Seba (a) qui variegatae dedit imaginem, didici, in Sibiria ejusdem aliquam offendi fpeciem, quae tamen, quoniam cauda caret, duos digitos reliquis fui generis pauciores habet, breviori roftro inftructa eft, \& pelle tandem ex rufo, fufco, flavoque coloribus variegata veftitur, utrum ad talpae noftrae varietates revocari queat, nec ne; incerti adhuc animi fluctuor.

0. III. Africam tam orientalem, quam occidentalem talpas alere, ex eo certiffime conftat, quod Schawius in

Bar-

(a) V. Thefaurus T. I. p. 52. tab. 32. Talpa ecaulata palmis tridary. lis. Linn. Taupe doré. Buffon. Talpa ecaudata, ex yiridi aurea, pedibus sn. ticis tridactylis, pofticis tetradactylis. Briffonii regn. anim. 
234 SPECIMEN ZOOLOGIAE

Barbaria, quae Africae caput eft, candem paffim occurrere (b); Kolbiasque ipfam in bonae fpei promontorio, quod ingentem hanc terrae partem claudit, vidiffe teftantur $(c)$. Quidni eam in medio etiam Africae gremio reperiri credamus? Nonne miraculo.fimile. foret, animal, quod navibus transportari nullis potuit, in extremis quidem regionis finibus vivere, in medis autem illius vifceribus defiderari? Peregrinatores itaque aut minus animos ad hanc beftiolam advertifle, aut conditorem ejusdem, quae tam lento gradu procedit, in tocis tamen immenfo intervallo diffitis vivit, fpatiumque interjacens intactum vacuumque relinquit, plures fimul easque diverfiffimis inlocis ita produxiffe ftatuendum eft, ut. non ab uno, fed a multis generisfui auctoribus defcendant.

6. IV. Duas America talpae fpecies habet; prior: Briffonii talpa caudata cx dilute cinereo ruf $a$, pedilurs anticis tridactylis, pofticis tetradaclylis eft. Haec mihi eadem videtur; quae, Ferminio tefte $(d)$, in Surname habitat, foloque colore rufo anoftra differt. Pofteriorem Virginia nutrit, quae ex Brifonii defcriptione $t a k$ : pa caudata nigricans ex faturate purpureo mixia, pedibus anticis ¿' poficis pontadaciylis eft, \& a Kleinio Virginiana nigra vocatur: Quam in Guiana etiam inveniri ex Ferminio colligere licet, qui talpaim nigram (e) (fic ipfanin nominat) ibidem confpexit. Binae hae varietates folae novi orbis incolae funt $(f)$,

(b) Schiaw: in itiner. p. I57. talpam, cuniculum, leporem, aprum ma. gnis gregibus in Barbaria obvios effe tradit. (c) Kolbe l. c. p. I:58. Ed. in fol.

(d). Holland. équinox. p. 45. (c) L. c.

(fi) Fr. Fernande (ius in hiftoria quadrupedum novae Hifpaniae p. 7. 


\section{G EO G R A P H I C A E. 235}

\& quemadmodum in calidioribus ejusdem regionibus cuniculos fuos fuffodiunt, ita nec frigidiores plagas adfpernantur. Nam in his etiam nidos fibi conftruunt, vitamque tolerant.

6. V. Et Europa nonnullas varietates, difcolorem nimiruin \& albam nutrit. Haec non in Polonia folum, fed, quod Limnaeus confirmat, in Suecia quoque obvia eft $(g)$. Difcolorem $(b)$, quam albis nigrisque maculis diftinetam Seba defcripfit, ex Frifia orientali acceperat. Suecia vero \& Norvagiae pars auftralis (i) ultimi fines funt, ad quos usque progreditur. Ulteriores enim terras polum verfus procurrentes, quae nimio frigore torpent, abhorrere videtur, quia in mollibus tantum fubactisque agris nidos quam maxime condere victumque conquirere folet.

Haec etiamfi pauca funt, quae de quadrupede ifto colligere licuit; manifefte tamen commonftrant, ipfum late

aliam, prater has, talpae 1peciem, quae Tucan nuncupecur, commenorat. Tucan, inquit, talpae, ut videcur, fpecies eft, dodrantem aequans longitudine \& latitudine humerum humanum; carnofa pinguisque atqueadeo brevibus cruribus infiftens, ut ventre pene terram attingat. Fulvo pilo, brevi cauda, uncis unguibus, longisque, roftro murino, parvis \& orbicularibus amriculis, -binisque fuperna parte totidemque inferna dentibus primoribus longis exfertis \& incurvis, non fine aliis, qui licet longe minores, funt tamen firmiffimi. Edulis eft caro, pinguis ac jucundo guftu, fed ftuporem incutit dentibus rodentium ofla. Hebeti eft vifu, ac fub lucem prorfus nullo; fubterraneis cavitatibus vivit. Quum antro egredi contingit, repetere illud nefcit, atque ita alterum de novo excavat, quo fe condat. Pafcitur omnium radicum genere. In Hernand. Thefauro.

(g) Faun. Suec. p. 7 .

(b) Seba in Thefauro. Vol. I. Tab. XLI. Cur Linaaeus in duodecim Syftem, naturae editione has talpae varietates omiferit, comprehendere nequeo. Eit in Helvetia albas reperiri talpas Brookfas in Hir. Natur. rradidit. (i) Pontoppidan Hift. v. Norw. T. I. p. 55 .

$$
\text { Gg } 2
$$




\section{SPECIMEN ZOOLOGIAE}

late fatis per terrarum orbem diffundi, ac dignum fuisfe, qui capiti huic primo adnecteretur.

\section{$\begin{array}{lllllllll}S & E & C & T & I & O & X & V\end{array}$ \\ De Muffela.}

5. I. $M^{u f f c l a e}(a)$ pari cum talpis ratione in utrarumque orbis noftri latitudinum plagis tanı frigidioribus, quam calidioribus vivunt, traetibusque multis interjacentibus penitus ignorantur. Patriam ejus feptentrionem fuiffe, exinde colligere licet, quod omnes fere, quae illi fubfunt, provinciae muftelas fovent - earumque varietates proferunt. In antiquo orbe Suecia (b) eft, Lappia (c), Norvagia (d), dein pleraeque Rufficae tam Europaeae, quam Afiaticae regiones $(e)$; in America aquilenari vero Hudfonis fretuin $(f)$, quae muftelas alunt. Eas autem nec Groenlandiae nec Islandiae habitatoribus notas effe, exinde conjicio, quod Cranzius, Horrebovius Anderfoniusque alto eas filentio praetermiferunt. Si tamen, quae fuspicor, vera funt, una Kamtfchadalienfium murium fpecies $(g)$ nuuftelis adnumerari debet, \& tunc hae quoque regiones muftelas alerent.

б. II. Ex enumeratis jam regais ipfas in Daniae,

Ger-

(a) Muftela vulgaris. (b) Linn. Fau. Suec. p. 3 .

(c) Oeuvres de Regnard T. I. p. I78. (d) Pontoppidan 1. c. p. 48.

(c) Allg. Reif. T. XVII. p. 273.

(f) Pallas \& Gmelin (Jen.) palfim: \& Allg. Reif. T. VII. P 2 I.

(g) Allgem Reifen T. XX. 


\section{G E O G R A PH I C A E 237.}

Germaniae, Poloniae, Galliae, Itahiaeque fines transiiffe exiftimo, ubi nunc paffim fub Hermelinorum appellatione non exiguo in pretio habentur. Hcrmelimum yero muftelae vulgaris varietatem effe, conjectu cuivis crit facillimum, fi animo fuo reputaverit, primo, utrasque beftiolas corporum magnitudine parum inter fe differre $(b)$; deinde utrarumque ftrueturam mirum quantum convenire; poftea, utrasque fubfufcum colorem, quo plerumque teetae funt, cum albo permutare. In hicmelino enim anguftioribus cancellis inclufo Daubentonius mutationis hujus initiun obfervavit (i); \& Pallafus expreffis teftatur verbis $(k)$, bermelinum perinde atque muftelas vulgares, prope Simbirskii campos, per aeftatem fordido fubnigro colore veftitas effe; quum tamen eo ipfo aeftatis tempore illae, quae in Europa meridionali confpiciuntur, pilis ex rutilo croceis fplendeant. Accedit, quod utrumque animal eadem indole, iisdem fit moribus, nunquam domari queat $(l)$, eodem victu, carnibus nimirum vivat, melle fumto pereat. Quis itaque unius illud ftirpis effe ultra dubitabit?

6. III. Cur autem Buffonius folo caudae apice, qui bormelini femper, mufclae nunquam niger effe confuevit, commotus fit, ut utraque animalia diffociaverit, comprehendere non poffum. Cur non eadem de caufa vulpes etiam, iisdem nigris caudarum apicibus inter

fe

(h) Muftelam enim feptem pollices \& amplius, hermelinum vero vix no. vem longun deprehendes.

(i) V. Daubentonius Defcript. Hermelliani ap. Buffon T. IV. Vol. I.

(k) Pallas ikeif. d. Rusl. 'J. I. p. 129.

(l) Quae forfan caufa cft, cur, quamdiu inclura affervantur, nungquam inter fe cuëunt.

$$
\mathrm{Gg} 3
$$




\section{SPECIMEN ZOOLOGIAE}

fe difretas, in duas fpecies diftinxit? Sed vir celeberrimus ad magnitudinis etiam patriaeque diverfitatem provocat. Quum vero corporis anplitudo nullius fere hac in re momenti, patria vero utrisque communis fit, (Sibirskii enim caniipi tot mu/felarim, quot bermelinoram greges nutriunt) quin Linnacum fequar non posfum, qui in duodecima naturae fyftematis editione bermiclinum vúlgarenique muftelan ejusdem fpeciei animalia, illudque -hujus varietatén effe adfeveravit. Eodem loco Linnaeus muftelae cujusdam perexiguae meminit, quam muffelam pedibus fiflis, corpore albo, calbdae apice vix pilis ullis nigris, muflelan nivalens vocavit, quae in INeffrobotbnia habitet, \& bermineo fimillima, dimidio autem minor fit; quae forte minima fpecies, aut muftelarum tantum varietas effet.

S. IV. Quibus praemiffis, utrum in calidioribus etiam muftela regionibus commoretur, circumfpiciamus. Ultra Italiam eandem progredi conftat. In fuperioribus enim Africae partibus, in Barbaria nimirum fub fersel-Haile appellatione, fi Shawio fides habenda eft, occurrit $(m)$. In Cayenna, Americae meridionalis tractu, Barrerius duas animantium fpecies, quibus muftelarum nomina impofuit, obvias habuiffe, in Francia fua aequinoctiali teftatur $(n)$, quarum altera, quam muftelam minorem rufan fubtus albam definivit, vulgaris noftra effe videtur. Quo minus vero alteram, quam maximam atram effe, mofchumque redolere tradidit, huc referamus, magnitudo, color odorque ani-

man-

(m) Shaw 1.c. 1. 157. (n) irance équinox. p. I56. 
mantis impedit: hic enin nec in miuftela vulgari, nec in hermelino tam fuavis \& jucundus eft, ut nares delectet.

S. $\mathrm{V}:$ Quóniam in reliquis auftralis Americae. partibus ulla muftelarum veftigia indagare nequiveram; berimelinum autem in noninullis tantum Africae provincis, \& quidem in Congo, fub In/aris nomine \& in Bauboinco (o) vivere, hoc a Compagnono (p.), illud a Dappero didiceram: parum aberat, quin horum omnium teftimoniis rejectis, Buffonii, muttelas cum berimelinis in Zona, quam torridam vocant, nullas vivere, tradentis opinioni, toto capite adnuisfem: nifi locupletior teftis, Pallafusus, me revocaffet, qui hermelina in moluccenfibus infulis nata, ipfe vidisfe confirmat (q). Hujus igitur auctoritas, ut cum Buffonio diffentiam, non fuadet, fed imperat. Muftelam itaque in folis feptentrionis regionibus degere, quamque Seba javancenfem nuncupat (r), Vam/irarum generi fubjiciendam effe, vir praeftantiffimus nulla nunc probabilitatis fpecie evincere audebit : quin potius, quum hermelina in Moluccae infulis confpecta fint; muftelàs ctiam, quae ejusdem cum illis fpeciei funt, in Java provenire convietus concedat.

S. VI. Hae funt terrae, quas in plagis ferventiori fole calentibus quadrupedes ifti inhabitant, Cayenna. nimirum, Java \& moluccenfes infulae. Alias enim nul:

(o) Allgem. Reifen T. II. p. 502. (p) Ibid. 'T. V. p. 89:

(q) Pallafus l. c. p. 129: in adjecta nota: hermelina, inquit, ex moluccenfibus infulis allata vidi, quorum pili, more muftelarum; quae Euro: a auftralis habet, nunquam defluunt: $(r)$ Sebo in Thefauro Vol. I: 


\section{SPECIMEN ZOOLOGIAE}

nullas expifcari mihi licuit. Idcirco tamen fieri poffe non nego, ut in multis, praeter has, aliis calidioris Zonae regionibus, quae forte oculis non fatis attentis .fe fubtraxerunt, muffelae habitent. Muftelam itaque meruiffe, quae capiti huic addatur, exinde quidem, fed hoc etiam fimul patefcit, immenfi fpatii intervalla porrigi, quae niuftela vel nunquam tetigerit, vel fattem, tanquam vitae fuae noxia, deferuerit. Ab Hudfonis enim fretơ ad Cayennae fines quantum interjacet quod intactum reliquit! Nemo interim beftiam, cujus Pifo meminit, Maricacaramque appellari (s). \& in Mexicoruin agris commorari tradidit, muftelae noftrae Speciem effe objiciat. Tam mores enim, quam magnitudo refragatur. In orbe antiquo aequalis prope a Barbaria Tartariaque ad Javam infulasque moluccenfes diftantia fupereft, quae, quantum quidem conftat, animalia muttelis noftris accenfenda nulla plane nutrit. 6. VII. Terreftres hi quadrupedes funt, de quibus certo adfirmari poteft, eos per amplas fatis in utroque aequatoris latere terras diffundi. Dantur, quidem alii duo, ur/us nimirum, martesque, quos cis etiam transque acquatorem reperiri, auctores nonnulli teftantur; quorum tamen teftimonium non adeo planum eft \& comprobatum, ut fides ipfis ex toto haberi queat; quippe quos aliquas tantummodo easque arctiores terrae plagas incolere, neque, inftar hactenus enumeratorum, plerasque orbis noftri partes occupare, poftea demonftratum ibo.

S E-

(s.) Pifo 1. c. p. 324 . qui ipfam quoque animantis imaginem addidit. 


\section{G E O G R A P H I C A E.

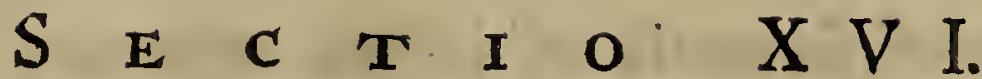

§. 1. Nunc itaque ad illos transgredior, qui fedes 1 in continenti terra fixas quidem nullas habent, in illa tamen faepe \& confpiciuntur \& commorantur; licet proprios fibi penates in mari collocaverint, in quod, data quavis occafione, defcendunt. Septem illorum fpecies hucusque notae funt; praeter duas enim pbocarum /pecies, urfus, equus. leoque marimus, dugon \& manatus eft; quorum tria tantum, caris fcilicet leoque marinus cum manato aliquem fibi hoc in capite locum vindicare poffunt; quia, quod ftatim probabimus, tam in aquilonari, quam auftrali orbis hemisphaerio deprehenduntur; quum e contrario rofmarus urfusque marinus cum dugone in aliquibus tantum oceani partibus luftra fua condiderint.

6. II. A pbocis proprie fic dictis (a) itaque initium mihi facturo in genere notandum eft, iftarum belluarum hiftoriam naturalem tam adhuc mancam effe, ut, fi eam partibus fuis expletiorem velimus, multa, quae adhuc deficiunt, addenda fint. Alii enim naturae fpeculatores, quos inter Linnaeus, BrifJonius eft \& Kleinius, unam folummodo ipfarum fpeciem; alii vero, exempli gratia Buffonius, quique cum eo ftant, duas; alii plures conftituerunt. Linnaeus in Fauna, quam edidit, Suecica (b). duarum olim varietatum meminerat, quarum alteram nigram, alteram grifeam effe, alteran gregatim, alteram fingulatim incedere dixerat. Decima vero ac duodecima

(a) Phoca vitulina. Vitulus marinus. (b) P. 4. 


\section{SPECIMEN ZOOLOGIAE}

cima naturae fyftematis editio 'unius tantum phocarum vitulinarum fpeciei mentionem facit, licet, fi ad corporum magnitudinem refpexeris, minimum duae fatis inter fe difcretae numerari queant. Buffonius leonem quoque marinum phocarum generi fubjecit; quem tamen partim infolitam propter corporis amplitudinem, partim infignem, quae marem inter feminamque interlucet, propter differentiam, fingulare quoddam genus conftituere mihi videtur. Hallenius (c) cum Parfonio (d), pbocas in quatuor (pecies diftinxit, quas quidem, $f_{1}$ varietates a peregrinantibus memoratas collegeris, fa- cile confici poffe autumo.

0. III. Priusquam vero, per quae oceani freta disperfae inveniantur, commonftro, ipfarum fpecies varietatesque perfcrutabor, in quo, ut eo felicius tutiusque progrediar, auctores confulam, qui naturalem feptentrionalium regionum hiftoriam nobis confcriptam dederunt. Etfi enim pbocae, quod poftea confirmabo, ubique fere gentium occurrunt, nullibi tamen tot earum $\&$ greges $\&$ fpecies, quam in oceano aquilonari deprehendes.

V. IV. Pontoppidanus quatuor ipfarum fpecies in medium attulit $(e)$, quarum prima communes phocas, fex circiter pedes longas, continet; Jectundae alias his aliquanto minores tribuit, quas germanico nomine Steinfeebund infignivit. Tertiae eas fubdidit, quae equorum magnitudinem referunt, quas Norvagiae fefrores Hav - Ercen vocitant. Quartat tandem illas adfignat;

qua-

(c) Nat. Hift. T. I. p. 579. (d) Pliliojoph. Transact. nr. 469. p. 383. \&6.

(c) Pontopidan Hift. v. Norweg. T. II. p. $23 \%$. 
quarum capita cute laxiori tecta confpiciuntur, qua oculos, quoties libet, obvelant; \& idcirco mitratae (Klappmiitzen) appellantur.

J.V. Cranzii vero Groenlandiae defcriptio $(f)$ quinque nobis Species tam coloribus, quam magnitudine inter fe diftantes exhibet, quarum minimae fex pedes longae, natu grandiores maculofis veftitae funt pellibus. Has duae fequuntur fpecies, quas, quia ejusdem funt magnitudinis, \& folo colore paululum differunt, uni foli recte fubmittendas effe exiftimo. Ulterius enim adultae jam corpora in octo fere pedes extendi, \& pro aetatis fuae ratione variis notari coloribus confueverunt. Crefcere deficientes, canae, ipfarumque terga clypeo quafi nigro duabus lunis dimidiatis fimili picta cernuntur. Altera fpecies, quae Cranzii tertia eft, crinibus fub fufcis cuti minus adjacentibus, fed fetarum more erectis, a priori difcedit. Quum utraeque hae fpecies $\&$ paulo acuminatis, quibus praeditae funt, capitibus, \& ampliori longe, qua pollent, corporum forma, una eademque ratione, abilla difcernantur, quam Cranzius primo loco pofuerat, quin unam tantum fpeciem efficiant, nullus dubito. Quarta, cujus Cranzius meminit, fpecies tertiam magnitudine aliquantum fuperat, Haec illa ipfa eft, quam Pontuppidsnus mitratam nuncupavit (Kluppmutze) de qua hic etiam adftruit, frontem ejus craffa rugofaque pelle ita effe armatam, ut tempeftatibus exortis eam oculis inducere, hosque contra arenarum fluctuumque vim tueri, ac tutos praeftare

pos-

(f) Cranzens Groenland Allg. Reir. T. YX, p. 62.

Hh 2 


\section{SPECIMEN ZOOLOGIAE}

poffit. Spiffam brevemque nigri coloris lanam albos fubter pilos nutrit, quae interlucens procul fpectantibus fuf $c i$ coloris fpeciem praebet. Hiaec dubio procul fingulare quoddam genus conftituit, de quo praeter rerum feptentrionalium fcriptores neno certiores nos reddit. Ultima denique fpecies, cui Groenlandi $\tau \tilde{\varepsilon} U k / u k$ nomen impofuerunt, omnium eft ampliffima. Decem enim pedes longa, pelle denfa, pilisque fubnigris veftita eft $(g)$.

ઈ. VI. Si duos itaque hos, qui hiftoriam feptentrionis naturalem exactiilime omnium illuftrarunt, auctores, inter fe contuleris, oceanum aquilonarem tres; quod minimum fit, phocarum fpecies nutrire, difces; parvulam filicet, cujus longitudo quinque vel fex pedes conficit; majorem, cujus menfura decem pedes excedit, \& mitratam $(b)$, quae majoris quidem magnitudinem aequat, fed cute fronti adnata notabilis eft.

6. VII. Utrique vero auctores, pbocam minutifimam duos tantummodo pedes longam, cujus imaginem, praeter Buffonium (i), Academia etiam parifren/ls (k) dedit, alto filentio praetermiferunt, quam antiquormm, feu, quod perinde eft, maris mediterranei phocam effe, Buffonius, \& mea quidem ex opinione, veriffime judicat. Praeterea nondum fatis exploratum eft, annon phoca,

(g) Krafchonnikovius, in fua Kamtfchatkae defcriptione quatuor etiam phocarum fo.cies numeravit. Allgem. Reifen T. XX. p. 268.

(b) Phocam hanc mitratam Egedefus quidem in Grocniandia fua, red minus curate \& eleganter depictam exhibet; meliorem ejus icona Ellifus in itineris ad Hudfonis fretum fucti defcriptione reddit.

(i) Buffon T.VII. Yars I. (k) Mém. de l'Acal. des Scien. T. I. p. I I9. 


\section{G E O G R A P I C A E.}

cujus fub vituli marini nomine defcriptionem, tabulave XLV. effigiem dedit Buffonius, fpeciem quandam novam conftituat. Licet enim admodum illi refpondeat, cujus naturam formamque Albinus expreffit (1), hac tamen, quae duos tantum pedes octoque digitos longa erat, triplo fere \& amplius major eft, quippe quae in fex dimidiumque peden extenditur.

0. VIII. Praeter illas itaque jam nominatas tres fpecies, duae forfan accedunt aliae; quid quod Parfonius vitulorum marinorum mentionem fecit, qui adulti vix pedales funt. Coeli autem climatibus hanc tantam tamque fingularem degenerationem tribuendam effe, exinde minus mihi probabile eft, quod feptentrionem tres inter fe diverfiffimas fpecies alere, jam fupra commonftravimus. Permulta igitur fupereffe, quae de phocis ignorentur, jure Buffonius queftus eft: his tamen querelis fola peregrinantium, quibus naturae inveftigatio curae cordique eft, induftria modum dare poterit. Mei interea officii efie putavi, fingulas faltem notas hucusque fpecies enumerariffe.

6. IX. Quum vero cardo rei in eo mihi vertatur, ut, quae phocarum fpecies fub frigidiffimo, quae fub temperatiori, quae fub calidiffimo coelo habitet, indicem; iis me laqueis implicatum fentio, ut, qua me ratione expediam, propemodum ignorem. Ltineraria quidem fi confulo, uno quafi ore mihi occinunt, phocas per omnes fere oceani partes difperfas reperiri. Dampie-

(l) Majores feptentrionis phocas Academiae Leidentis olim decus $B$. S. Albinus in Annotationibus Academicis Lib. III. Tab. VI. \& Parforius in Transaction. L'Hilor. num. 400. depingendas curaverunt, 


\section{SPECIMEN ZOOLOGIAE}

pierius $(m)$, navigatorum facile princeps, in feptentrionalibus tam Europae, quam Americae regionibus, in auttalibus Africae terris, ut in bonae fpei capite, quin magellanico etiam in freto immenfos phocarum greges reperiri docet. Et quamvis in occidentali India, fi Campecbii frctum exceperis, viderit nullas, eas tamen ipfi in omnibus fere meridionalis Africae littoribus, ab ig mis terra ad aequatorem usque, frequentes occurriffe; in feptentrionali vero aequatoris latere illas fub vicefimo demum primo latitudinis gradu denuo comparuiffe tradit. In orientali tamen India fruftra phocas quaefivit,

6. X. Equibus, beftias hafce per omnia fere oceani littora diffundi, fatis quidem evidenter pater; idcirco tamen, quae ipfarum fpecies, an major an minor tam late vagetur, nondum conftat. Ampliori praecipue corporum mole confpicuas totum pene oceanum peragrare, ex Narborugbio difcimus $(n)$, qui in itineris, quo orbem circumnavigavit, relatione haud obfcure adftruit, phocas, a quibus infulae magellanico freto conterminae, quam ingenti agmine frequentant, nomen impofitum fit ( Seal's Island, Seckalber in/ul) ' quinque pedum longitudinem fupergredi. Hoc idem \& Byron docet. Hic enim iisdem fere in oris in $D_{e} /$ fiderii (o) nimirum portu ( $D$ e/ire ) phocas juvencorum magnitudinis confpexit. Nonne ex his, phocas majores utraque aequatoris littora inhabitare, clare fatis elucet? Sed quid de minoribus, quae in duos tantum pedes por-

(m) Voy. de Dampier T. I. p. 118.

(n) Voy. de Narhornugli dans le Tom. III. des Voy. de Coreal p. 5 x.

(0) Eyron's Voy. in Hawkesw. Account T. I. p. 16. 


\section{G E O G R A P H I C. A E.}

riguntur, ftatuemus? Nemo quidem memoratorum haetenus peregrinantium earum meminit: quibus tamer nihilo fecius accidere potuit, ut exiles hafce beftias, propter formae tenuitatem, vel neglexerint, vel minus dignas habuerint, quarum mentionem facerent.

0. XI. Licet amplioris ftaturae phocis hoc in capite locum fuum merito dandum fuiffe generatim demonftraverim, aliis tamen achuc fcriptorum teftimoniis comprobandum effe duxi, eas omnia fere marium freta occupare. Dampierius ipfas in Timoris infula, quam ferventior coeli plaga torret, invenit $(p)$. In bonae fpei promontorio infula quaedam (Robben-Eiland.) nomen ab ingenti, quae ibi congregatur, copia, nacta eft $(q)$. Novae Zeelandiae littora vitulis marinis adfluere, Cookius $(r)$ obfervavit. Novae Hollandiae finui cuidam, fub vicefimo fexto latitudinis gradu jacenti, ab innumerabili horum quadrupedum copia, quam congregatam ibidem perfpexerat Dampierinas, phocis nomen indidit, $S e a l ' s b a y(s)$. Haud procul a Maara Fuero Byronius $(t)$ \& prope luan Fernandezii infulam Anfonius (u) eas offendit: \& fic non modo totum fere mare pacificum earum multitudine redundat, fed ipfas nec auftralibus nec ad caurum fitis Americae littoribus deeffe, Pater de $A$ fcenfione docet $(v)$, qui magnos illarum greges in Sancii Lucae finu propter Californiae peninfulam invenit, quae omnes oceani orae nexae inter fe \& quafi conjugatae funt.

J. XII.

(p) Allg. Reif. T. XII. p. 26 I. (q) Kolbe. p. 208.

(r) Cook's Voyage in Hawkesworht's Account T. III. p. 420.

(s) Allg. Reif. T. XII. (t) Byron's Voyage in Hawk. Acc. T. I. p. 86.

(u) Anfons Reife um die Welt. p. II5.

(v) Gefchichte yon Californien T. I, p. I. 


\section{SPECIMEN ZOOLOGIAE}

f. XII. Sed quid? fi lacus etiam, qui terris cinguntur, nec cum oceano cohaerent, phocas alunt? De mari enim Cajpio Pallufus adfirmat (w), fe multas easque grifei coloris, quo maris baltici phocae infectae fint, tantaeque obefitatis vidiffe, ut non animantes, fed utres pinguedine refertas vidiffe crediderit, in quibus prae adipe capita \& brachia difcerni nulla potuerint.

6. XIII. Cujus autem auxilio \& qua via eo pervencrint, altioris indaginis quaeftio eft. Volgam, Jaikum aliosque fluvios iftud in mare influere conftat; fed hoc etian certum eft, illud, quantum quidem adfpectu percipimus, nec cum nigro, nec cum perfico finu connexum effe colligatumque. Quum interea naturae fcrutatores probabilibus nonnullis rationibus, quas infra adjunctás leges $(x)$, probare conati fint, Carpium mare

cer-

(w) Pallas Reife durch Rufland T. I. p. 428.

(x) Prius, quod adferri folet, argumentum eft: quoties mare Caspium Euro moveatur, nigrum quoque fluctibus jactari; quod vicilfim \& Caspio accidat, quoties nigrum Zephyris agitetur. Deinde Kircherus varia tam algae, quam arborum genera, quae in Cafpii tantum littoribus pronafci conftet, in nigro natantia reperiri, in mundo Subterraneo perhibet. Prior quidem ratio magni, fateor, ponderis, majoris tamen mihi, aquarum vim, quam Volga \& reliqui amnes in Caspium mare transfundunt, computanti, effe videtur; quod, quum illa aquarum moles, quantum adfpectus judicio fentitur, nusquam defluat, eam canalibus fub terra latentibus in alia quaedam loca exonerari neceffe eft. Fac enim, triginta per annum cubicos aquarum pollices evaporationibus maris fuperficiei fubtrahi ; vix tunc quindecin pedum cubicorum billiones mari demtas reperies. Volga vero fulus plus novem billinnes anno vertente immittit; Jaikum autem cum Embáa, Kuma, Terka, Kuraque jundim fumtos alterum tantum aquae advehere; facile conjectu eft. Nonne plana regionum circumjacentium inundentur oportet, nifi alia ei maria fubterreftri meatu connexa effe ftatuas, quidus, quae fuperani aquae exceptae abforbeantur. De quibus Luloffi Geographiam alioramque audturum opera huc pertinentia confulas, 


\section{GE O GR A P I I C A E.}

certis fub terra cuniculis in mare nigrum effundi; \& ex: auctorum quorundam relatione patefcat, mediterraneum $(y)$ etiam mare phocas majores nutrire; fubterraneis illas meatibus hinc in nigrum, \& ex hoc in Caspium tranfiiffe, \& adhuc tranfire, a fide non abhorret. Accedit, Cafpii maris aquas falfas etiam, caeterisque marinis effe quam fimillimas.

0. XIV. Sed alius quidam fcrupulus objicitur, quem non tam facile evulferis: Sibiriae videlicet lacus, Baiknb dictus, qui fub quinquagefimo fecundo latitudinis, \&rcentefimo vicefimo quinto longitudinis gradu in Irkutskien/s provincia fitus, in octoginta milliaria germanica extenditur, aquamque dulcem \& liquidam continet, magno non tantum pifcium, fed, quod caput rei eft, phocarum etiam numeroabundat; licet certo fit certius, ipfum nec cum oceano, nec, quantum explorari hucusque potuit, aliis cum maribus copulari.

0. XV. Langius $(z)$, teftis divtortns phocarum quidem in eodem degentium meminit, ipfarum vero colorem filentio preflit; 1 sbrandus tamen 1 de/fus nigro easdem tinctas tradidit. Gmelino autem Jeniori, viro caeteroqui diligentifimo, qui, quum naturae inveftigandae caufa iter per Sibiriam inftitueret, lacum hunc transvectus eft, vix ignofci poteft, exim ad rem hanc notatu digniffimam vel minus attendiffe, vel faltem filentio ipfam praeteriifie. Parum igitur aberat, quin

tan-

(y) In'dem neveften Zuftande der Africanifchen Reiche Tripolis, Tu-, nis und Algier. Hamb. 1708 . 3. p. 5.

(z) Langens Reife nach China in Webers verænderten Runand. T. I. p. 80 . 
tanti viri filentio inductus, tam Langii, quam Isbrandi Ide/zi , \& qui utrosque fecuti funt, teftimonia, quafi fidem nullam merentia, rejeciffem. Quoniam vero $A n$. derfonium eodem mecum dubio circumactum, a tefte, cui fides negari nequit, Hicidentrictbin nimirum, quem fupremum, quod metalli fodinis Petropoli praeeft, concilium ad mineras in illis regionibus rimandas detegendasque miferat, edoctum effe legebam, phocas, quas Heidenreicbius ipfe viderat, in Baikulis lacu \& vivere $\&$ augeri $(a)$, hujus effato fidenter acquiefco. Hic autem illas tam coloris ratione, quam corporum mole Baltici maris habitatoribus fimillimas effe, \& a Tartaris circumhabitantibus jaculo tricuspide hamato configi narravit.

5. XVI. Anderfanius ipfas e mari glaciali in fenifei (b) amnem, \& hinc per Tunguskae flumen in Bai. kalis lacum defcendiffe conjicit; per Angarae flumen viro clariffimo dicendum erat; hoc enim a Fenifeo in lacum iftum profluit. Tinnguska vero multis ultra Baikalem parafangis feptentrionem verfus fcaturiens in Fenifeum quidem, non autem in lacum ipfum, quocum nullis aliis meatibus conjunetus videtur, aquas fuas effundit $(c)$.

6. XVII. Quamvis de caetero Ahderfonius aliquam phocarum e mari glaciali per fonifei Angoracque fluvios viam, qua in Baikalem transmigraverint, exputavifre

vi-

(a) Anderfons Nachricht von Island. p. 23.5

(b) Anderfonii liber fluvium Denifeum noninat, fed procul dubio error operarum eff.

(c) Vid. Mappam Mucoviae generalem, quae primum in Atlante Rusfico locum cccupat. 


\section{G E O R A P H I C A E. 25I}

videatur: nihilo tamen fecius nodum hinc expeditu fere difficiliorem reddit. Cur enim haec ipfa animalia, quae in aqua dulci, cui femel adfueta funt, optime proveniunt, nec in Fenifeo, nec in Angora, nec in aliis Sibiriae amnibus, per quos in lacum ipfas defcendiffe dixit, confpiciuntur? Equidem phocas interdum in fluviis adfcendere, eo tutius concedo, quum Pallafus eas hiemis tempore e mari Cafpio in faiko ad Guriefii agros usque progredi narret $(d)$. Quia vero Guriefum, haud procul a Faiki oftio pofitum, Caspii fere maris littora attingit; Baikal e contrario ducentis quinquaginta milliaribus germanicis, fi recta via ad glaciale mare perrexeris, remotus eft: tanto tamen in itinere nec phocam vifurus unquam, nec, nifi in fluminum oftiis, prope maris littora capturus es. Utraque, quaefo, intervalla compares; ingens, quo inter fe diftant, fpatium computes, \& utrum illud cum hujus vel minima parte aequari conferrique poffit, dijudices. Hac itaque $A$ Anderfonii opinione difficultates, quibus res obftructa eft, minime tolli, patefcet. Hinc eam univerfali potius cuidam orbis noftri commutationi converfionique tribuendam effe, autumo. Quod quum in altera opufculo huic adjuncta disquifitione, ubi de animalium etiam migratione quaedam adferuntur, fufius tractaverim, nodumque hunc aliqua faltem ratione folvendum tenta: verim: Lectores illuc remiffos volo.

0. XVIII. Praeter has, quae in aqua dulci commorantur, pbocas novi nullas. Ubi vero Stellerus (c) \& polt

(d) Pallas 1. c. p. 430 . (e) Steller Befcirreib. fonderb. Seethiere in Introductione, \& Hallen Natur. Hift. T. I. p 582. 


\section{SPECIMEN ZOOLOGIAE}

poft hunc Hallenius ejusdem fpeciei beftias, argentei coloris, aquam dulcem incolentes invenerit; fcio cum ignorantiffimis ; \& unde pofterior, quae de phocis viginti pedes longis narravit, hauferit, aeque mihi ignotum eft. Fortaffe de leonibus marinis ea intellecta voluit, de quibus ftatim acturus füm. Confentiunt interim laudati hątenus auctores, pilorum colores in phocis mirum in modum variare. Alias enim nigris, alias fufcis, maculofis, fubrufis, canis, albis aliisque pellibus indutas effe, perhibent.

J. XIX. Minimi corporis phocam, quam Academia parifienfis diffectam depictamque exhibuit, fingularem aliquam fpeciem conftituere, inon exigua tantum forma, fed externa etiam, quae in ejus capite deprehenduntur, \& in aliis. propemodum omnibus deficiunt, aurium veftigia fatis evincunit. Neminem itaque confilium meum improbaturum puto, quo beftiolam hanc a majoris ftaturae phocis, quas latius per orbem dilatatas fcimus, penitus fejunxi. Et quoniam. Buffonius argumentis graviffimis planum fecit, eam folam eife, quam antiquiffini orbis cultioris populi cognitam habuerint; in adjuneta mappa Geographica in illo tantum mari, mediterranieo puta, ejusdem mentionem feci, quod prifcorum feculorum homines optime noverunt, in quove folo phocas iftas parvulas offenderunt $(f)$.

§. XX. Nunc ad alium transeamus animantem, quem

(f) Uc, quae fentian, tatear, minus comprehendere pollum, qua va $\&$ ratione parvula haec phoca e mari mediterraneo in Indiam tranare pocuerit. Illa enim, cujus imaginem, Buffonius dedit, a poffeffore fuo, qui, foluto certo pretio, ipfam fpcetandam pratbuit, indici maris incola ferebacur. 


\section{$G E O G \cap A P H I C A E$.}

quem Linnaeus Buffoniusque phocis quidem adnumera verunt, inufitata tamen amplitudine fua a phoca vitulina fegregandum exiftino, leonem foilicet marinum $(g)$ :

0. XXI. Si ąuctores, qui animalia quaedam fub. leonis marini appellatione defcripferunt, in tranfitu \& quafi per nebulam infpexeris; fortaflis omnia ejusdemque fpeciei effe, arbitrabere. Quodfi vero datas ab ipfis defcriptiones curatius examinaveris; iisdem fere, quibus in phocarum enarratione, difficultatibus implicabere. Interim tamen huic beftiae locum hoc in capite dandum effe credidi; etfi nondum convictus fim, Kamtjcbadalienfum marisque auftralis leones marinos, feu, quod idem eft, illos, de quibus Stellerus Anfoniusque nos certiores fecerunt, ejusdem effe peciei; fed partim, quoniam fub judice adhuc lis eft, an ad eandem fpeciem referri debeant, nec ne, partim quod phocis generatim fumtis accenferi \& foleant \& jure poffint

6. XXII. Ut eo compofitius procedam, quibus in rebus fic dicti ifti leones inter fe congruant, quibus difcrepent, ex ipfis andorum verbis cognofcamus. Primum itaque stellerum audiamus (b). " Altero tanto " inquit, haec beftia urfo marino gravior eft." Summae magnitudinis mares mille propemodum fexcenta pondo (40. Pud.) fuperant (i). Femella brevioris

gra-

(g) Phoca leonina Phoca capite antice criflato. Linn Syft. Ed. XII. Dampierii L.eo marinus. Nov. Comnient. Pêtrop. T. HI. p. 360.

(b) Stellers' ausfuhrl. befchreib." von Sonderbaren i Meerthieren. Halle 1753.8. p. 152 \& Novil Comment Petrop. 1. c.

(i) Quum nrfusmarinus novem circíér menfurae anglicae pedes longus fit; leo oEtedecim habeat oportet. 


\section{SPECIMEN ZOOLOGIAE}

graciliorisque corporis, nudatique pilis colli eft. Erecti enim crispique pili, quibüs mares quafi jubis fuperbiunt, his defunt. Catuli ftatim a nativitate, urforum pullis, altero tanto funt majores. Leo marinus prae craffa cute, quam erecti denfeque pofiti pili tegunt, veftitur; pilique ipfi, vaccarum velut crines, ignei funt coloris, catulorumi phoenicei \& feminarum quafi minio vel ochra acriori tincti, recens nati badii effe folent: 5. XXIII: Capita capitibus urfinis majora $(k)$, nali porrétiores, \& furfum paulisper recurvati, dentes permagni, urfinisque $(l)$, quibus caeterum \& ordine \& forma fimillini, quadruplo longiores funt, latioresque $(m)$. In oculorum praegrandium amplorumque canthis majoribus caruncula prominet, quae cinnabaris ruborem refert. P Pupula fnaragdi more fcintillat, tunica cornea eboris politi inftar fulget. Oculi ciliis muniti canthique majores panniculo carnofo, quo oculos contegant, armati funt (n). Aures, coni peciem habentes, fesquidigitales \& arrectae ftant. Marium colla erectis denfe excretis crifpisque pilis, jubae loco, ornantur, quibus feminae carent.

ఠ. XXIV.

(k) Capitis ur/2ni ambitum fi pone aures dimetieris, triginta anglicorum pollicum menfuram habebis.

(l) Urfi marini dentes canini maximi octo lineas longi, in maxilla autem inferiore nonnulli pollicem fuperant.

(iil) E Stelleri dimenfione urfi marini dentes in fuperiore maxilla funt quatuor incifores, qui bifulci, feu duplici acie inftructi; totidem canini, quorum duo caeteris majores; omnes vero incurvati; molarium loco duodecim canini alii, peracuti; in maxilla inferiori: quatuor incifores; duo ejusdem generis alii, qui pollice longiores, introrfum acuti; decem canini crecti mo: larium loco: qui omnes fumman XXXVI dentium, efficiunc.

(n) Idem efie videtur cum nembrana nistitante in volucribus. 


\section{- G E O G R A P H I C A E. ${ }_{2}^{2} 55$}

0. XXIV:- Quum Stellerus pedes omiferit, antea tamen, fe illas praecipue partes notaturum effe, pollicituls fit, quibus lio ab urfo marino, quocum caeteroqui fatis congruit, digrediatur; inde leonum pedes pedibus urforuin non abfimiles effe colligo, quibus, phocarum ritu, quatuor incedunt. Anterióres pilis obdueti penitus exferuntur, nec quod in phocis ufu venit, fub cute claufi latitant. Metacarpium, carpum, digitosque pili nulli, fed nigra cutis fupra laevis, infra fulcata veftit. Manus \& digiti unain in maffam coalescentes fpathae aut vomeris formam exhibent. Quinque digitis utuntur, quorum pollex reliquis, qui, ficut in hominis pede, fenfim decrescunt, longior eft. Nec fuperiore neque inferiore in pedum parte ulla articulorum veftigia animádvertuntur, pes integer ex uno potius offe carnisque frufto confiftere, fingulisque digitis unguiculorum quaedam rudinenta appofita videntur. Pedes pofteriores in extima corporis parte.prope anum adnatifunt, \& tain arcte inter fe connectuntur, ut in terris progredientes illos tanquam inutile fibi pondus poft fe trahant, fulcosque in arenis ducant; quae omnia phocis vitulinis etiam communia esfe fcimus.

0. XXV. Abfolutahac Stelleri defcriptione, quam, quantum fieri potuit, contractam dedi, nunc Anjonii vel potius $I J$ ilteri, quoque relationem leonis marini, in mari auftrali viventis, apponamus, eamque cum antecedente conferamus, ut ex utraque animantium iftorum vel fimilitudine vel diffimilitudine, utrum iidem fint, nec ne? co certius colligere-valeamus.

ઈ. XXVI. 


\section{SPECIMEN ZOOLOGIAE}

6.XXVI. , Leonis marini, Whalteri verbả funt (0), \# fi plene adolevit, , tongitudo a duodecimo ad „ vicefimum, craffitudo ab octavo ad decimum quin", tum usque pedein extenditur. Pinguiffimus idem ", tamque fanguinofus eft, üt unus interdum fex \& " quod excurrit amphorarun ( 2 Oxhoefte) menfu" ram effundat. Pelle fubfusci coloris, brevioribus pi\% lis obfita tegitur, cauda vero pinnaeque fubnigrae " funt; quae ipfae, quas pedes potius nominaverim, " in extremitatibus fuis in digitos difeetae videntur. "Cutis enim digitos connectens ipforum apices non \% attingit; ; quodvis digitorum acurnen ungue tenuiffi" mo munitur. Licet leo hic phocarum majorum ", fimulacrum \& effigies quaedam effe videatur; non„2 nullis tamen in rebus manifefto inter fe discrepant; " quod in? maribus quam maxime apparet. Hi enim , ingenti roftro feu proboscide, quinque pollices \& " amplius fubter fuperioris maxillae extremitatem de" pendente, praediti funt Feminae, quibus haec „, rietus appendicula deeft, partim hac ipfa, partim " etiam ideo a maribus facile diftinguuntur, quod iis " longe funt minores.

†. XXVII. Utrisque nunc auctorum verbis inter fe collatis, certó quidèm patefcit, leones hofce nec externa fpecie, nec corporis habitu fibi dispares effe. Primo enim ejusdem fere funt amplitudinis ; utrorumque deinde pedes anteriores, quos Anfonii in imagine depictos videmus, admodum conveniunt. Pollex enim: di-

(0) In defcriptinne infulae $\tilde{f}$, van Fernandez. Anfons Reife um die Welt 1749.4 to P. 115. 


\section{G E O G R A P H I C A E. 25 ?}

digitorum eft longiffimus, caeterique, quod Stelleris retulit, paulatim decrescunt; licet pictor in eo erravife videatur, quod leoni digitos humanis prope pares finxerit, quod tamen nec $\boldsymbol{W}$ altcri, nec Sicelleri defcriptioni respondet. Tum eadem icon oculos etian aeque grandes eminentesque exprimit, ac Stellerus eos defcriplit: praeterea utrorumque feminae maribus fuis multo exhibentur minores $(p)$. Porro colore pilisque parum a fe invicem diftant. Uterque enim fcriptor breves ipfis pilos colore fubfusco tinctos tribuit. Tandem \& Stellerus \& Walterus utriusque leonis carnes optimi effe faporis, refert. His omnibus morum etiam, quibus inter fe conveniunt, aequalitas quaedam addi poteft. Belluas enim hasce admodum fomnolentas effe, nec exiguos uxorum greges, de quibus atrocisfime mares inter fe dimicare loleant, fecum habere auctores laudati teftantur.

ఏ. XXVIII. Nihilo tamen fecitrs multa etiam, quibus perquam disjunctos disparesque ipfos cernimus, invenies. Walterus enim roftrum feu proboscidem maribus, quos vidit, addidit, quae a fronte pendens nares operiat, quamque fi ex imagine adjecta dijudicare velis, criftam potius appellaveris; hanc tamen ficco pede Stcllerus praeteriit. Quodfi tecum reputaveris, criftam hanc notatu fuiffe digniffimam, utpote qua leo non folum ab urfo marino infigniter dignofcatur, fed animantis etiam forma faciesque mire varietur, non

po-

(p) Vid. Figuram in Anfonii itinere decimam tertiam, quam unam hujus leonis habemus. Stellerus enim non leonem, fed urfum marinum depingi curavit. 


\section{SPECIMEN ZOOLOGIAE}

poteris non colligere, ipfam Stelleri leoni defuife. Cur enim vir, qui quam diligentiffme omnia conquifiverat, criftae mentionem non fecerit, ratio probabilis dari poteft nulla, nifi quod nullam viderit.

§. XXIX. Hac crifta Linnaeum inductum effe, ut phocam mitratam, (Klappmutze (q)) de qua fupra locuti fumus, cum leone marino Anfonii confuderit, $\&$ utrasque belluas pro una eademque habuerit, ex duodecima fyftematis fui editione difcimus; in qua leonem marinum defcripturus mitratae ad phocae effigiem ex Ellifii itinerario mutuatam, provocavit $(r)$. Hunc autem Anfonii criftatum leonem eundem effe cum pboca milrata, perfuaderi nequeo; quum ex rerum eptentrionalium fcriptoribus pateat, mitram phocae fronti minus firme affixam, tam folute potius capiti adhaerere, tamque mobilem effe, ut a phoca pro lubitu rejici \&, neceflitate flagitante, umbellae loco, fuper oculos expandi queat; cujus tamen rei admodum memorabilis II alterus, nec omnino quidem meminit. Deinde mitram hanc mares a feminis ita difcernere, uti crifta lcones in oceano auftrali a leaenis diftinguit, nec Egredefus nec Cranzius docent. Phocarum denique mitratarum longitudinem, quae decempedalis eft, leonum amplitudo alterum tantum antecellit.

6. XXX. Ut autem ad leones marinos revertar, in crilta hac fronti adnata neque unam nec maximam

quae-

(q) Mitratae hujus Phocae imaginem, a nullo auetorum hucusque curase fatis depictam, ex mufeo Brunsvicenfi, ubi affervatur, cum ejusdem menfura, propediem, exactins defcriptam exhibebo.

(3) Euffenium mitratam hanc phocam plane omifife, dolendum eft. 


\section{G E O G R A:P H I C A}

quaeras discretionis notam. Dantur enim aliae ejusdem fere ponderis. Ex W alteri relatione leones prope Juanis Fernandezii infulam graminibus herbisque victitant, quibus purae limpidaeque aquae rivorum ripas veftiri dixit; quum Stellerus, Kurilienfium infularum leones piscium phocarumque carnibus vefci, expreffis verbis confirmet.

๑. XXXI. Si ex beftiarum dentibus judicare licet, carnivororum animantium claffi leones omnino accenfendi videntur: nec in illam facile deduci poffum opinionem, quam P'arfonius propofuit, marinos nempe leones dari boum ventriculis inftructos. Leones hos phocarum fpecies, easque mole maximas effe, lubens equidem largior; quumque phocae, ex Stelleri obfervatione, ventriculo duplici praeditae fint; non video, quid obftet, quo minus leonem hac etiam in parte phocis fimilem effe, fimilique ratione herbis \& graminibus e terra natis pafci concedamus, inprimis quum, codem Stellero tefte, mirae longitudinis inteftina habeant. Interim tamen tam ex phocarum omnium, quam leonum marinorum dispofitione interna ftructuraque confici autumo, \& carnibus eos $\&$ herbis nutriri.

0. XXXII. Tertia, quam propter leones hos dis junctos velim, ratio, iconum eft diverfitas. Quam enim WValterus in Anfonii itinerario aeri incifam dedit, nec volam externae cujusdam auris, nec veftigium monftrat, quod majoribus cum phocis leones commune habent, nec laudatus auctor in eorum defcriptione auribus ipfis uti vel verbulo indicavit: quum tamen Stellerus plane \& diferte addiderit, Kamfchat$\mathrm{Kk} 2$

ken- 
kenfium littorum leonem auribus effe inftructum,

- gquae in fesquidigitalis coni modum ftent erectae.

0. XXXIII. Quod discrimen fi cum caeteris hactenus memoratis conjunges, nonne ad credendum in-. clinabit animum, diverfas illas feparatasque effe leonis marini fpecies? Certiffime enim perfuafus fum, Stellerum, fi ab Anfonio datam imaginem vidiffet, minime gentium in eam tranfiiffe opinionem, ut, quem Dampierius defcripfit, qui oceani quoque auftralis indigena eft, \& ab Anfonii beftia nulla in re discrepat, unius ejusdemque fpeciei effe, contenderit. Ut autem climatum diftantiae tanta haec degeneratio accenfeatur, phocae vitulinae majoris qualitas prohibet, quae fub frigidiffmis, temperatioribus, majorique aeftu torrentibus coeli tractibus omnibus, \& augefcit \& femper fibi fimilis permanet. Accedit, quod caloris frigorisque diftantia \& mutatio in oceano, ubi patria quafi ipiorum fedes eft, exigui modo \& neutiquam tanti fit momenti, quam in terris.

6. XXXIV. Ex quibus junetim fumtis patefcit, leonem criftatum maris auftralis incolam nullo jure folam illius varietatem appellari poffe, qui in Kurilienfium littoribus vivit. Ne vero confufioni cuidam anfa praebeatur, in mappa geographica tam prope Kamtfchatkae littora, quam in auftralis oceani locis, ubi leones marinos obvios effe, auctores tradiderunt, pbocae leoninae vel leonis marini voculas apponendas curabo, iperans, lectores, quam ejus fpeciem intellectam ve$\mathrm{lim}$, nunc facile agnituros effe. Anfonii itaque leonem praecipue in freto magellanico, prope malovini- 


\section{G E O G R A P H I C A E. 26r}

cas (s), Juanisque Fernandezii ( $t$ ) infulas, prope novam Zelandiam $(u)$ in oceano auftrali invenient. His enim quam maxime in regionibus eum habitare, ex auctoribus in margine laudatis discimus; quum e contrario in Kamtfchadalenfium littoribus, Kurilienfibusque infulis, quam Stelleris expreffit beftiam eadem fub nomine fint quaefituri.

0. XXXV. Utrum autem, qui prope Californiam $(v)$ bonaeque fpei promontorium $(w)$ deprehen duntur, priori an pofteriori fpeciei adjudicari debeant, nec ne? tempus docebit; quamquam, fi conjecturam adferre licet, Californiae leonem, ob regionum vicinitatem, Kurilienfibus adnumerare malim. Stellerum Kamt fchatkae leonem marinum cum auftralis oceani habitatore, quem Dampierius defcripfit, perperam confudiffe \& utrasque beftias fecus pro una eademque habuiffe, hactenus fatis probabiliter demonftratum credo.

0. XXXVI. Utrum autem cum urfo etiam marino $(x)$ idem ipfi acciderit, minus explicare valeo. Praeter illa enim, quae vir hic diligentiffimus de animante hoc marino $(y)$, qui cum leone ejusdem eft patriae, fcripfit, pauciffima ab aliis auctoribus relata leguntur. Spielbergius urfi quidem fub nomine, mari-

nae

(s) Borgainville Voy. p. 64. \& Byron Voy. in Hawkesw. Account. T. I. p. 49 .

(i) Anjon l. c.

(ii) Cook Voyage round the World in Hawkesw. T. IIT. p. 438.

(y) Gefchichte von Californien '. I. . p.42. ('y) Kolbe l.c.

(x) Phoca urlina, phoca capite anriculato: Limacus.

(y) Stcller von Merliwurdigen Seethieren. und Nov. Commentar. PCurop. T. Il. 


\section{SPECIMEN ZOOLOGIAE}

nae cujusdan belluac mentionem fecit $(z)$, quae propter fanetae Elifabethae infulam haud procul a bonae rpei promontorio, intra trigefimum quadragefimumque auftralis latitudinis gradum, acervatim conficiatur; \&, quod ad forman faciemque, cum urfo terreftir ad pedes usque pofticos, quos pho-: carum inftar poft fe trahat, admodimm conveniat, ro: ftro acuto fuscoque colore praedita fit; quam tamien Buffonius ( $a$ ), fine ulla ratione probabili, $D u$ gonum numero, qui cum equis marinis congruunt, ad-. numerandam putat; quamvis Spielbergius ne verbulo quidem nos certiores reddiderit, an dentibus etiam caninis prominentibus, quibus dugones inftrueti effe folent, armetur ; qui, fi adeffent, ipfam ab urfo, quocuin a Spielbergio comparatur, quam longiffime discernerent. Hanc potius beftiam, a folo Stcllero optime defcriptam, verum urfum marinum effe fuspicor: Quodfi laudati viri defcriptionem actis petropolitanis infertam Buffonius infpexiffet, quam tamen aeque atque auctorem plane ignoraffe videtur, etfi, quem novisfet, digniffimus erat; fine dubio in eandem mecum fententiam transgreffus; $u$ rom hunc non in dugonem transformaffet.

5. XXXVII. Fortaffis fecunda etiam marinorum illa luporum fpecies, quam Ulloa (b) prope Juanis Fer-

ñan-

(z) Aligem. Reifen 'T. VIII. p. 227. it. Voyages des Hollandois T. IV. p. 20. Rouen 1725. 8vo. (a) Buffon T. VII. P. I. le Dugon.

(b) Allgem. Reifen T. IX. p. 516 . Ulloa tres phocarum fpecies ad Juanis Fernandezii infulam vifas fub luporum marinorum denominatione commemorat, quarum prima fublutei coloris tres dimidiumque; altera grifei, 


\section{G E O G R A P H I C A E $\quad 263$}

nandezii infulam acuto itidem roftro inftruetam obfervavit, huc referri poffet, nifi aurium vix in octo lineas extenfarum brevitas id prohiberet. Haec quidem ws 'sy $\pi x x_{0} 0$ y $y$ ideo tamen addere libuit, quia nondum fatis demonftratum eft, annon urfils etiam marimus, .qui propter Kamtfchatkam obvius eft, tam late, quam caeterae phocae, diffufus inveniatur; q quod pro certo expeditoque affirmaffe nolim. In mappa caeterum geographica ad Elifabetbae infullam nomen urfâ marini; ad Juanis Fernandezii vero littora lupi marini voculam (fic enim Ulloa ipfum nuncupat) appofitam invenies.

f. XXXYIII. His miffis nunc ad beftiam tranfeo, quae prae hactenus enumeratis multo propius ad pisces accedit, licet ex plerisque naturae venatoribus quadrupedum ordini inferta fit, \& pari cum phocis majoribus ratione per utrumque aequatoris latus diffipata cernatur, quaim Manatum (lamantin) (c) appellant.

f. XXXIX. Belluae huic, cui Stellerus, qui itidem formam ejus omnium optime expofuit $(d)$, vaccas marinae, nomen dedit, cum reliquis phocis, quas inter \& balaenas medium quafi locum occupat, hoc eft commune, ut a feptentrione meridiem verfus progredia: tur, $\&$ in plagis tam frigore, quam calore graviori aduftis commoretur. Hoc loco repetendum duco, quod

novem; tertia, quae Anfonii leonem marinum continet, duodecim pedes longa eft.

(c) Manatus trichechus dentibus laniariis inchifis. Linn. le Lamantin.

(d) Steller von Merkwardigen Thieren p. 48. \& Noy. Comment. Pstres, T. 11. Bufforb. Lib. VII. P. I. p. 213. 


\section{SPECIMEN ZOOLOGIAE}

quod jam ante notavi, frigus nimirum aeftumque no eas vires in maria, quas in terram continentem, exercere $(c)$, \& hinc fieri, ut marium animantes, :qui late per orbem diffunduntur, prae quadrupedibus terreftribus minus varientur, quod tam in phocis majoribus quam in manato evidentiffime perfpici poteft. Licet enim totum fere oceanum pervagetur: idcirco tamen eandem femper formam faciemque immutatam retinet $(f)$.

ઈ. XL. Quicunque auctores horum animantium meminerunt, etfi in corporis ejus amplitudine definienda in omnia alia discedant $(g)$, unanu tamen iftos eandemque femper formam \& habitum referre, uno quafi ore fatentur. Qua de caufa tantummodo commonftretur neceffe eft, eos in omnibus fere latitudinis gradi-

(e) Vide disquifitionem meam alteram.

(f) Si formas habitusque manatorum prope Kamtfchatkam, Guianam; Antillasque infulas habitantium inter fe comparaveris, femper ipfos fimiles fibi deprehendes; licet corporum magnitudine mirum quantum inter fe varient. Stellerus iis, quos deferiptos dedit, oeto millia pondo \& viginti novem longitudinis pedes tribuit, quum Gumilla (dans l'Hiftoire de l'Orénoque ) eidem feptingenta quinquaginta, Adanfonius aliique, octingenta tantum pondo dederint. Adanfonius \& Condaminius, hic in itineris fuper Amazonum flumen facti, ille in Seriegalli defcriptione, fecundum Buffonii relationcm, octo tantum pedes beftiam hanc longam effe, dixerunt. Rochefortius vero (dans l Hiftoire des Antilles $p$. 178.) eam propter Antillas infulas octodecim longitudinis pedes crefcendo fuperare, adfirmavit. Eam vero, quod Linnaeus in duodecima fyftematis fui editione, \& Aiuellerus in commentario in Linnaeum confcripto tradidit, centum tantummodo aut ad fummum ducenta pondo habere, menda fcribentium effe videtur. Forte librarum loco centenarios viri celeberrimi fcripturi erant.

(s) Quid? fi tanta haec magnitudinis differentia melioribus, quibus utuntur, nutrimentis adfcriberetur? Conftat enim, \& balaenas fub polo anftrali commorantes, iis etiam, quae fub polo arctico vivunt, longe mizores effe. 


\section{G E O G R A P H I C A E. $=265$}

bus occurrerc. Ne autem fenfum verbis meis alienum sector tribuat, ipfum praemonituin volo, beftiam hanc nunquam in alto, fed aut in ejus littoribus, aut majorum in fluminum oftiis commorari.

6. XLI. Extremi verfus feptentrionem fines, quos occupat, Kamtfchatkae littora funt, infulaeque Aliam inter \& Americam jacentes. Quam enim Cranzius vaccam marinam circa Groenlandiam obfervari narrat, non manatus, fed equus marinus vel ros/marus, eft. Accedit, quod, praeter Stellerwm, rerum feptentrionalium feriptor nullus de manato quidquam in medium attulit. Deinde ad Senegallae Gambiaeque ripas (b), prope Congi Loangique regna \& penes Zairam (i), ubi porci marini (Scbrveinefijch) nomine infignis eft, confpicitur. Porro manatum efle, qui in Congi regionibus virgo marina ab Europaeis vocitatur, ex eo perspectum eft, quod, quicquid de illo refertur, in hane ad amuffim quadrare perfpicimus. Concedamus, qui in Angolae lacubus habitat, paulo reliquis minoren effe, \& Dapperum aliquos, qui octo tantuin pedes longi fuérint, vidiffe. Concedamus, aliis tertibus fide digniffimis manatos fub adfpectum veniffe, qui viginti pedum longitudinem fuperaverint, \& aliquot millia librarum graves fuerint: utrosque tamen caeteroquin

(h) Oexmelin . Hirt. des Avantur. T. II. p. I15. \& Kilanforii Deferiptio, Buffoni: P’ati VII. inferta.

(i) Allgem. Raifen T. V. p. 24. Figura acri incifa, quae Manati fpeciem repraefentare debcbat, e Earboto defunta ab animaite valde ab. horret. Confer Dapperi quoque Africann. Aethiopes ipfum Noulla-u-mafata id eft, forcum marinum ; Lufitani usoven narrinam; allique Luropaei yir. gincm marinam nuncupant. 


\section{SPECIMEN Z OOLOGIAE}

habitu formaque fibi fimillimos effe, gramine herbisque ad fluvios natis pafci, carnibusque eorum accolas mirabiliter delectari, onnium, quide ipfis foripferunt, confenfu comprobatur.

§. XLII. Ipfos in mari quoque Indico \& quidem ad Celebis infulam habitare, Sirenasque appellari, quem in margine citatum vides $(k)$, locus confirmat. Mucllerus illos in Maldiviae infulis \& in Madagafcaris fretis vivere, adftruit (l). In America eos tam ( $m)$ Antillis in infulis, Nicaraguae lacu (II) \& Mexici regio- ne (o); quam in Guianae (p) \& Orenoki (q) oris, quin $\&$ in Amazonii fluvii ripis inveniri, Condamisius $(r)$ aliique teftes locupletiffimi probant. Monftrum practerea marinum a Brafilienfibus 2 pupiapra diEtum, $\&$ a Lufitanis pro bomine marino habitum $(s)$, quod flumina plerumque incolere fertur, Manatum effe, perfuafiffimus fum. Ex quibus omnibus liquet, manatum in plerisque oceani littoribus reperiri, ideoque dignum fuife, qui, licet $\psi s v d \partial r \varepsilon \tau p a \pi s s ~ f i t, ~ a n i m a n t i-$. bus primi capitis infereretur.

Ø. XLiII.

(k) Ailgem. Reifen T. XI. p. 483 .

(l) Limnes volftaendig. Naturfy ftem T. I. p. I75.

(in) Rochefort hift. des Antilles p. 178. \& Nouveau Voyage aux Inles de l'Amérique T. II. p. 200.

(n) Hemandezius feu Recchins pocius, in thefauro rer. medic. nov. Hisp. p. 323. imaginem animantis dedit, quae magnorum quidem ocuIorum, manuum in pedibus anticis, roftrique acutioris intuitu a vero. aberrat, aliqua tamen ratione beftiam repracfentat. Optimam cjus icona Buffonius, fed ab embryone tantum depingendam curavit: \& Roche fortius aliquam exhibuit. (o) Vuygage de Coreal T. I. p. 91.

(p) Bancrofts Guiana p. i 13. (q) Gimilla Hift. de l'Orcnoque.

(r) Condamins Reife, in den 2. T. Goeiting lieif. p. 226.

(s) Aligem, Reif. T. XVI. p. 28 r. 


\section{G E O G A P H I C A E. 26 ?}

f. XLIII. Hi funt quadrupedes, quos a gravinii-. mis auctoribus edoctus, nifi per univerfum terrarum orbem, per plerosque faltim in utrovis aequatoris latere tam antiqui, quam novi orbis gradus, diffufos novi. Kölbius quidem putoriwn quoque noftrum in bonae fpei promontorio confpici $(t)$, \& Stellorus (u) lutranis Kamtfchadalenfium littorum fefforem, cum Brafilienfi eandem effe, perhibuit: quoniam vero praeter hos peregrinantium nemo iftorum animalium meminit, dietaeque regiones. immenfo a fe invicem intervallo disjunguntur; ea in fequens potius caput rejicienda credidi, ideoque lutrae Brafilienfi in patria fua locus datus nomenque adfcriptum eit.

f. XLIV. Singulos auctores, quorum teftimoniis nitor, quoad fieri potuit, adlegavi, quod tamen iis in quadrupedibus folis omiffum eft, de quibus aliinnde jam certe conftabat, eos per plerasque terrae nosftrae regiones dilatari, quod in cane aliisque nonnullis factum videbis.

ऽ. XLV. Antequam fumma capiti huic manus imponatur, duo, quae neceffaria ex ante dietis confecutione fluunt, addere libet. Alterum eft, ex omnibus quam latiffme per orbem disperfis animantibus, praeter lupum, nullos dari, qui fingulari fint magnitudine, $\&$ praedas faciendo hominibus noceant. Alterum: pauciffimos quadrupedum, de quibus hactenus expofitum eft, reperiri, qui nullum plane hominibus fruetum adferant. Glis, muls, vulpes \& talpa foli funt, quibus .

fine

(t) Kolbe l. c. (u) Stellers Seethiere. 


\section{SPECIMEN ZOOLOGIAE}

fine fingulari incommodo carere poffumus. Illorum itaque plurimos ubique difipatos invenimus, qui no-bis funt utiliffimi. Erunt forfan, qui cafui rerumque fortuitarum concurfui id tributum velint, \& providentiam e mundi lujus conftitutione ac directione profcripturi, omnia ex aeternitate fataliter fic definita. effe, autument: multos tamen, quibus de meliore luto praecordia, quod ajunt, fieta funt, fingulari fummi conditoris fapientiae, quam venerabundi demircmur. oportet, mecum adfcripturos effe confido, rerum ordinem fic, nec alio quodam modo 2 dispofitum effe \& confervari.

ఏ. XLVI. Qua interim ratione factum fit, ut quadrupedes e patriis. fedibus fuis in alia quondam loca demigraverint, folumque vertentes nunc per omnes fere terras difieminati confoiciantur; \& quo pacto in infulas longiffimo faepe fpatio a terra continenti remotas pervenerint, perardum eft demonfirare. In altera quidem libello huic adjecta disquifitione, nonnulla , quibus res haec obfeura dilucidari poffit, attuli; interim tamen tot tantaeque adhuc difficultates fuperfunt, ut haud facile quenquam rem expediturum $\dot{\alpha}$ omnibus, quae opponi poffunt, dubiis fatisfacturum crediderim. Quis enim nefcit, demigrationes iftas ex prima demum orbis noftri hiftoria., varisque, quas ab initio perpesfus eft, inverfonibus \& permutationibus tartum explanari poffe? Quascum ignoremus, guid mirum, fitam abftrufis in rebus aquam haerere confitendum eft? Acquun itaque lectorem, ubi magnis me aufibus excidiffe fenferit, veniam daturum elle, certiffme fpero... 


\section{G E O G R A P H I C A E. 269}

\section{A P U T SECUN D U M.}

\section{Introchutio.}

๑. I. Confideratis quadrupedibus, qui ab utroque aequatoris tam veteris, quam novi orbis latere, vel ad feptentrionem $\&$ auftrum usque progrediuntur, vel maximas faltim telluris oras occupant; ad.illos nunc tranfeo, quos natura nec tam robuftos quidem, nee tain fiexiles condidit, ut aeque magnas orbis noftri regiones fub diftantiffimis inter fe coeli climatibus jacentes, tolerare polleant; quibus tamen nonnullos intermifcuit, qui, etfin non tam late, quam primo in capite enumerati per orbem diffundantur, nihilo tamen fecius amplos fatis ejusdem traetus fibi vindicant, quum c contrario permultos aliós perexiguis tantum terrae patiis inclufos adftrictosque videamus. Priorum in numeromachlidem, caftorem, clopbantem, aliosque ponendos cxiftimo, qui aut in antiquo pariter novoque orbe, aut in quibusdam faltim quatuor iftarum partium, in quas tellurem noftram geographis defcribere mos cft, deprehenduntur: pofteriori vero ordini plerasque fimiarum f́pecies, makines, ploblidotos caeterosque ejus generis tribuendos cenfeo, qui aretioribus circumferipti limitibus permodhca tantummodo vel novi vel veteris orbis loca inhabitant.

l. II. Omnium igitur, de quibus adhuc fermo inftituendus eft, quadrupedum divifio in duo capita diftri. buatur oportet, quorum altcrum illos continelit, qui mag-

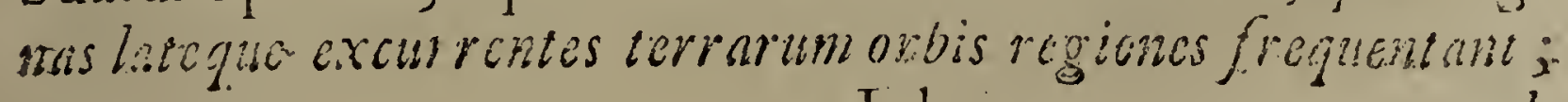


alterum vero reliquos exhibebit, qui fingúlares unius $a \%$ terinsque telluris partis regiones incolunt.

0. III. Sic uno quafi obtutu lector benevolus perfpicere poterit, quid in fequentibus duobus capitibus exfpectare queat; ne tamen animantium fedes, in quibus vivunt ac propagantur, tam certis limitibus circumfcriptas exfpectet, quibus regum principumque ditiones geographi determinare folent. Aethiopem enim loturum crediderim, qui milliaribus quadratis terras computare volucrit, quas intra quadrupedes ifti commorentur; quippe qui modo huc, modo illuc difcurrere finesque folitos tranfilire amant. Patrias igitur corum fedes coeli tantum gradibus dimetiri fufficiat; licet ultra hos ctiam faepiffme evagentur. Pari ratione quosdam vel in Afia vel in Africa fola inveniri, certo fatis nemo adfirmaverit; quum facillime fieri poffit, ut ex una dictarum orbis partium in alteram transgrediantur.

6. IV. De quadrupedibus quidem, qui torridae utriusque hemisphaerii Zonae fubfunt, magna cum probabilitate, utrum veteris, an novi orbis feffores fint, ftatuere naturae interpres \& judicare volucrit: de Africae vero Afiaeque \& Europae incolis, qui per magnos terrae tractus diflipantur, fidem nemo interponere poterit, annon ultra gradus proprios ipfis ufitatosque procurrerint; quod in Europae inprimis Afraeque finibus locum habet, utpote quas minus a natura, quam a politicis dijunctas videmus $(a)$.

๑. V.

(a) Afiam Europamque natura jpfa montibus aptifime, disjunxiffe videeur, çuan fequerenulur oportebat. 
0. V. Quoties igitur animantes hoc in libello occurrent, quibus domeflica fedes in Europa fuerit adfignata, qui tamen fub eadem etiam Afrae latitudine inveniuntur; hoc aeque minus cuiquam fit miraculo, ac fi quis hominem fub eadem coeli plaga tam in Europae, quam Afrae regionibus laete florentem, feliciter adolefcentem, fuaviffmamque maturitatem affequentem, audiverit. Nemo itaque vel in tabula, quae addita eft; geographica, vel in hac illius dilucidatione anxie nimis.poftulet, ut animalium patria ea determinetur accuratione, qua geographici fcriptores urbium vicorumque fines defcribere folent: adquiefcat potius, fi folis illud coeli gradibus, nullis autem milliaribus circumfcriptum confpexerit.

6. VI. Altera, quam opufculo huic adjunxi, disquifitio, multa, quae huc facient, remque iftam copiofius explanabunt, fuppeditabit; ad quam humanum lectorem remiffum, monitumque volo, doetifimum quoque Buffonium in praettantifimis, quas de animantibus edidit, differtationibus, qui illorum in alterutro, qui in utrisque telluris hemisphaeriis quaerendi fint, ftrietim quaedam attuliffe.

0. VII. De beftiis interea quae fecundo hoc in capite recenfebuntur, monendum eft, ipfarum quasdam, quae ampliores. telluris tracus babeni, aeque in antiquo, quan novo orbe commorari; aliquas autem antigui tantun e/Je indigenas; quod ipfum novam capitis hujus fibdividendi anfam praebet.

0. VIII. Quas in utroque mundi hemisphaerio obvias habemus, feptentrionis fub regionibus fua plerumque luftra condunt, ubi nafcuntur, ubi propagantui; qui- 


\section{$27^{2}$ SPECIMEN ZOOLOGIAE}

bus urfun, maciblidem, alcin \& alios nonnullos jure tribuimus: iis vero, qui folius orbis antiqui funt habitatores, elephantem, camelum, dronedarium leonenque cum quibusdam aliis adnumeramus.

0. IX. In quibus tamen omnibus percenfendis minime tann prolixo mihi effe licebit, quam in primo capite neceffe fuit. Quum enim hi animantes minus late prae ill lis per terrarum orbein difpergantur, ideoque minusa prototypo fuo degeneraviffe admodum probabiliter colligendum fit ; quum praeterea degenerationes varietatesque, quod fupra jam fufius commonftratum dedi, a domitu quam maxime \& fervitudinis jugo, füb quod ab hominibus rediguntur, dependeant, quod domefticis plerumque animantibus accidere folet; - domeftici vero perpauci tantum hoc in capite occurrant: quae nunc de refiduo animalium grege dicenda funt, in pauciora poterunt verba conferri.

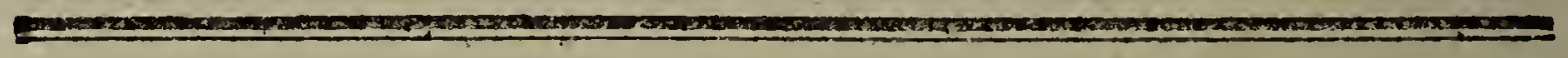 \\ SE C U N D I C A P I TIS \\ \begin{tabular}{lllllllllllllllll}
\hline & $A$ & $R$ & $S$ & $P$ & $R$ & $I$ & $O$ & $R$.
\end{tabular}}

De quadrupedibus magnos, tam autiqui quan novi orbis, tractus tencntibus.

\section{SEC TIO I.}

5. I. d fecundum itaque caput progrediens prioA rem ejus fectionem cum quadrupede exorsilar, cui, quum late fatis per orbem diffipatus inveniarur, 


\section{G E O G R A P H I C A E.}

tur, locus propemodum in primo jam capite dari potuiffet.

Ursus is eft, cujus domicilium in feptentrione praefertim quaerendum effe, exinde colligo, quia illis in tractibus non plurimi folum fui generis, fed maximi etiam atque robuftiffimi habitant, nullisque aliis in terrae plagis tot ipfus varietates numerari poffunt. LVormius $(b)$ quatuor ejus in Norvagiae regno fpecies reperiri teftatur, quarum tres in continenti, una vero prope oceanum glacialem vivunt..Pontoppidanus (c) eidem regioni duas tantumimodo, alteram majoris, alteram minoris ftaturae adfribit.

0. II. Buffonius (d), Pratzenium (e) fectutus, alteram herbis \& graminibus, alteram carnibus folis nutriri, afferit; eaque de caufa, utrasque ut diffociet, animum inclinat, \& Wormio, qui carnivoras cum illis coïre dixerat $(f)$, qui gramine vefcuntur, fidem abrogavit. Sed quoniam omnis tam interna, quam externa corporis ejusque partium ftructura in utrisque fic congruit, ut una eademque effe videatur; \& Ponioppidanus praeterea, Norvagiae urfos tam gramine herbisque, quam carne famem tolerare, adfirmat $(g)$, haec Buffonii diftinctio concidit, quam \& ipfe in ultima nunquam fatis laudandi operis fui parte miffam feciffe videtur.

O. III.

(b) Mufeum Wormianum p. 3 I8.

(c) Hift. v. Norweg. T. 2. p. 24. \& feqa.

(d) Allg. Hift. der Nat. 4. Th. 2. band.

(e) Hift. de la Louifiane par le P'age du Pratz. p. 77. (f) Mur. Worm. 1.c.

(g) Qui l. c. p. 28. urfum neceffitate coactum radicibus, gramine, herbis \& maxime angelica, quac laeto ibidem incremento provenit, itemque rubis, \& baccis forbi, ufitate tamen ovium caprarumque rapinis vivere fcribit, quarum cibus ipfi gratiffimus fit. 


\section{SPECIMEN Z OOLOGIA E}

6. III. Urfi varietates tam coloribus, quibus infectae funt, quam corporum amplitudine, inter fe differunt. Maximus corpore, quem Norvagia urfum equinuing nuncupat, fubnigro; minoris formae autem fubrufo tinctus eft. Ponioppidanus urfos omnium fere obfcuriorum, paullo colorum dari confirmat. Pili aquilonalitum, inquit, urforum, aut fufci aut fubfufci, interdum fubcani, eorumque extremitates albae funt $\&$ argenteae, qui omnium pulcherrimi habentur. $U_{r} / \mathrm{j}$ etian terreAtres toti albicantes dantur, qui Tartariae funt indigenae $(b), \&$ fine ullo dubio a reliquis fufco notatis originem duxere. Difpariles igitur \& verficolores urfos effe, non inficior. Velut autem glaucae, canae, rufae albaeque vulpes unius ejusdemque fpeciei effe, nec quae pircibus, baccis, uvis, ovis, aliisque ejus generis eduliis pafcuntur, a fe invicem feparari, diverfisque generis auctoribus attribui poffe, commonftratum eft: lic Urfos rufi, fursi, cani albique coloris diverlis flitipibus addicere nefas duco.

g. IV. Sed, quod majoris momenti effe videtur, urforum alba quaedam fpecies occurrit, quae maria accolit, ibique victum fibi quaerere folet, \& cum ijaride feu vulpe alba, quacum confociationem aliquan colit, circa extima glacialis maris, Spizbergat (i) fcilicet, Novae Zemblae (k), Hud/onis freti (l), Groenlardiae

(b) Rélation de la grande Tartarje Amlterd. 1737. p. 8. \& sligenl. Reifen I. VII. P. 474. Ex Marci Poli relatione in regno Kublai Cunni albi urfi viginti fpithamas longi inveniuntur.

(i) Martens in Allg. Reif. T. XVII. p. 287.

(k) Voyage de la Compagnie des Indes Orient. Rouen I725. T. I. p. I24:

(l) Ellis Hudfonsb. in Goetting. Reif. T. I. p. 39. 


\section{GE O G R A P H I C A E:}

diae. (m) Islandiaeque (n) littora haeret, quae ftatura caeteris multo ampliori, proceriori collo, grandiori capite, pilisque candidis longioribus praedita, canis rauci more latrat, \& modo in terris, modo horrendis in infulis, quas ex immenfis glaciei fruftis congeftas novimus, fe tenet, Ex partin quidem phocis, partim vivis mortuisque piscibus vitam ducir; cui tamen quodvis etiam efculentorum genus acceptum eft, utplurimum vero carnibus avidilime inhiat. Nulla juris fpecie effera hacc \& immanis bellua amphibiis phocarumque gerieriaddi poteft, quippe quae vix aliquot temporis momenta aquis fubmerfa vita frui firitumque ducere pollet $(0)$.

Q. V. Et Buffonius Urfum hune, qui vulgo fecus marimus vocitari fuevit, \& ab illo, cujus in phocarum defriptione jam mentio faeta eft, nimiam \& corporis \& morum propter diffimilitudinem plane disjungi debet, unum eundemque cum reliquis fui nominis generisque quadrupedibus effe, bene recteque contendit.

0. VI. Nec opponatur, ipfum pifcibus ali? Quibus enim aliis rebus animal carnivortum e terra ad maris glacialis littora transpofitum, nifi pifcibus aliisque beftiis mari innatantibus famen toleraturum effet? Nec externa ejus fpecies a reliquis urfis adeo difcrepat, ut ejus diverfitatem a fola climatis aërisque natura ortam effe, negare quis valeat? Quum enim canibus polari fub circulo latrandi ufum eripi conftet: quidni urforum murmura in raucos debilesque latratus ibidem converti poffe,

con-

(m) Egedes Groenland p. 84. (n) Allg. Reif. T. XIX. p. 20.

(o) Voyage de la Comp. des Indes Orient. T. I. p. 6o. \& pafima. $\mathrm{Mm} 2$ 


\section{SPECIMEN ZOOLOGIAE}

concedamus? Quin itaque album hunc amplioris.corporis urfum, maris glacialis accolam, caeterortum al:quam tântum várietatem effe ftatuam, non pofium ; \& qua ratione viag̨ue a feptentrione progrediens per reliquas orbis terraruin regiones diffipetur, paucis nunc exquiram.

j. VII. Urfum e patria fua egreffum totan fere Europam permagnasque A/iae partes pervagari, ex eo liquet, quod non totius. folum Europae, Poloniae ni- mirum, Galliae, Helvetiae, Sabaudiae, Graeciae, Pyrenesque vaftos montes filvasque denfiores pererrat; quod, quia cognitum fatis pervulgatumque eft, ulteriori probatione nulla indigebit; fed, quod jann commonftratum dedi, Afrae etiam regiones immenfas occupat. Sic albus, qui marini nomine infignis eft, in omnibus propemodum oceani glacialis littoribus occurrit.

Q. VIII. Urfus vulgaris prope Tomskum $(p)$, Ilims: kium que $(q)$, Sibiriae urbes vivit, \& haud procul a $\mathcal{f}_{a-}$ cutis, qui perinde atque Americae feptentrionalis incolae, carnibus ejus mirifice delectantur, luftra fua con: $\operatorname{dit}(r)$. Duas praeterea ejus varietates Cafani regnum nutrit $(s)$, quae ad $W^{\prime}$ olgae ripas ulteriusque meridiem verfus, defcendunt $(t)$. Et quoniam auctorum infrix laudatorum teftimonia comprobant, urfum in P' aleffimae (u) etiam, Chincufum (v), Siamacque regnis $(w)$,

(p) Gmelin (fenioris) Reif. durch Siber. T. I. p. 322.

(q) Ibid T. II. p. 20\%. (r) Ibid. 1. c. p. 470 .

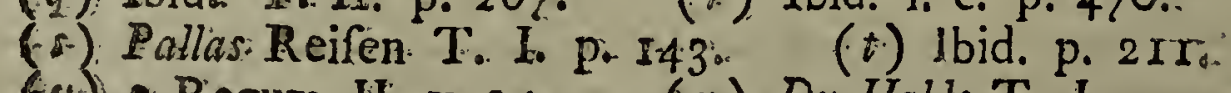

(vi) 2. Regum II. vi: 24 (v) Du Halde T. $I_{0}$.

(ar) Turpix Hift. de Siam T. Io p. 5050 


\section{GE O G A P I CA E.}

in faponis $(x)$, infuper favae $(y)$ Ceylonisque $(z)$ infulis reperiri ; in aperto pofitum effe credo, Urfum plerasque propemodum $A /$ /na terras inhabitare: licet, quod lubens fateor, fidem pro iis, quae Turpiniuts Gentilisque nairant, nullam interponere audean; quum ille, hiftoriae naturatis pene rudis, incerta multa collegiffe, hic autem, quae de favae urfis relata audiverat, temere confcripfiffe videatur. Bontius enim, Cookins aliique frriptores fide digniffrmi, qui dictae jam infulae defcriptiones ediderunt, quadrupedem hunc, quem ifti ibidem: commorari dixerant, taciti praetereunt.

C.IX. In Africae vero terris mimus frequens eft, quamlibet Plisius qui nullos ibi urfos ali adfeverat (a) erraverit; atpote quem Barbaria (b) fub Dabbi nomine fovet, Prosper Alpimus in Aegypzo (c) \& Dapperus in Congi regno $(d)$; vidiffe teftantur. Quoniam autem qui fenc$\mathrm{gam}$, auream oram, bonaeque $/ p$ ei promontorium peragraverunt, nullam urforum ibi viforum mentionem fecerunt, Dapperi teftimonium de ur.jo in Congi finibus degente, erroris fufpicionem mihi movere, non nego, ipfumque potius generatim calidioris hujus terrarum partis plagas reformidare autumo.

6. X. Caeterum omnes, qui Americae feptentrionalis oras peregrinando adierunt, uno quafi ore fatentur, urforum ibidem., ficut in veteris orbis ejusdem latis

(x) Katmpfers Japan. du Halde T. IV. p.

(y) Iue Gentil. Voy, autour du Monde T. III. p. 85.

(ङ) Knox in Allg. Reiren T. VHII. p. $5 \mathrm{Ir}$.

(a) Plin. Hift. Nat. I. 8. Cap. 36 . In Africa urfos non gigni conftat:

(b) Schaw Barb. p. I 57. (c) Hift. Nat. Aegypti Lugd. Batav. p. 233 -

(d) Altg. Reif.T.V. p.89.

\section{$\mathrm{Mm} 3$}




\section{SPECIMEN-ZOOLOGIAE}

titudinis regionibus, magnos greges reperiri $(e)$. Eosque hinc etiam fatis longe meridiem verfus digrefros, ex eo manifeftum eft, quod non in Mexici folum $(f)$, fed in Peruviae $(g)$ etiam regno \& ad omnes fere $M a$ ranonis ripas (b) inveniuntur. Nullos autem nec in Cbili, nec in freti magellanici terris fedes fibi fixiffe, ex eo probabiliffime conficitur, quod peregrinatorum nemo, quantum quidem invertigare potui, fe urfos ibidem vidiffe, nos certiores reddit.

6. XI. Quia illorum, qui per meridionales Africac regiones itinera fecerunt, nullus urformin ibidem obviorum mentionem fecit, ipfos aequatorem vel minime vel faltim perexiguos ejusdem gradus tranfiffe colligo. Anguftius igitur prae antecedentibus, laxins autem prae fubfequentibus in terrarum orbe fpatium fibi vindicat.

0. XII. Colores, quibus infectus comparet, il confideraveris, nigros, fufcos, fubrufos, albosque numerabis, quorum ultimi duplicis funt fpeciei. Alii, qui montes filvasque incolunt, quos Daubentonius depingendos curavit ( $i)$, canis; alii, qui maris glacialis in littoribus vitam agunt, rufis praediti funt oculis. Quantum colore, tantundem \& magnitudine inter fe diftant. Dantur enim minores vix quatuor pedes longi: dantur, ex Batavorum relationibus inter marnos albi, quorum proceritas ad duodecimum usque pedem extenfa admirationem movet $(k)$.

0. XIII.

(e) Voyage de la Hontals \& Allg: Reif. T. XVII.

(f) Befechrcibung von Neufpaunen in Allg. Keif. T. XIII. p. 672.

(g) Ulloa in Allg. Reir. T. IX. P. 3 II.

(h) Conidaimine Reif in Goetting. Sammlung T. II. p. 302 .

(i) Buffor l. c. . (k) Voyage de ia Comp. des lindes T. I. p. gr. 


\section{G EOG G APH I C H ES}

๑. XIII. Buäbus igitur rationibus adductusi prinum Urfo capitis hujus fecundi locuin dedi, quarum altera: eft, quod in extremis feptentrionis, quae nobis cognitae funtregionibus, prima lufftra fua condere coepit; altera, quod unus omnium quadrupedum, qui hoc in capite percenfebuntur, quam latiffime per utrosqué orbes diffufitis invenitur.

0. XIV. Si folius traetuum, per quos dilatentur animalia, magnitudinis ratio habenda effet, urfum martes, cafor hutraque ex caufis deinceps adferendis, fequi deberent. Quum vero hortim quadrupedum nullus prae tarando propius ad polum, a quo tamen exordium cepi, accedat, \& ipfe hinc in utrumque orbein digrediatur, cundem cum alce, quae proxima illi cognatione conjuncta videtur, urfo fubjicere pofteaque caeteros anit mantes addere, fatius reique convenientius effe duxi:

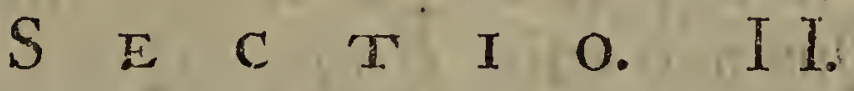 \\ Tharandus (a) \& Alce (b).}

0. I. $B$ ina haec animalia non ideo conjunxi, quod B unius ea fpeciei effe crediderin ; id enim nemo unquan mili perfuaferit; fed quoniann ab omnibus fere Naturae fpeculatoribus ea tanquan ejusdem ge-neris combinari video; \&. quam maxime, quod utraeque eosdiem propemodum terrae tractus inhabitant : licet, quod

(a) Tarandis. Cervus cornibus ramofis recurvatis teretibus; fummitatibus palmatis. Rangifer. Linnaei Syft. Ed. XII.

(b) Alces. Cervus cornibus acaulibus paimatis, caruncula gutturali Linnei Edit. XII. 


\section{SPECIMEN ZOOLOGIAE}

quod deinceps demonftratum dabo, hac etiam in re paululum a fe invicem difcedant.

6. II. Rangiferum in feptentrionis extremitatibus fedem fuam fixiffe, ex eo clarum eft, quod fub octogefimo prope longitudinis gradu in Spitzbergae oris vivit $(c)$, faeviffimumque hiemis gelu perfert ; ex quo id folum incommodi patitur, ut propter pabuli uberioris defectum parumper emarcefcat. In omnibus idcirco \& novi \& antiqui orbis polo vicinis, Groenlandiae nimirum (d) Lappiaeque terris, ubi domitus, folus habitatorum divitias efficit $(e)$, in Norvagiae porro $(f)$, Ofinkorum $(g)$, Tungufenjüun (b) \& plerisque Sibiriae Euronotum verfus pofitae plagis $(i)$ invenitur.

6. III. Ipfumque in Americae etiam, eorundem graduum regionibus effe, exinde jam certo colligitur, quod iis in antiqui orbis finibus, qui novo contermini funt, commoratur; in hoc autem rov Karibu nuncupationem nactus eft. Quamvis enim Briffonius ( $k$ ) caribuem hunc, cujus caput quoddam infpexiffe, capitique quadrupedis, quem fub cervi burgundici appellatione fonfonus defripferat $(l)$, fimillimum deprehendiffe teftatur, a Tarando diftinguat: nihilo tamen fecius vir naturae pe-

(c) Martens Spitsbergen in Allg. Reif. T. XVII. p. 287.

(d) Egedes Groenland p. 84. \& Cranz

(e) Hoftgroems Lappland p. 87. \& feq. Regnard Oeuvres T. I. p. 105. \& palfim. $(f)$ Pontoppidan 1. c. p. 21 .

(g) Nouveau Mémoire fur la grande Ruffe T. II. p. I8r.

(b) Gmelin (fenior.) 1. c. T. Il. p. 143. (i) Ibid. 1. c. p. 207: \& 275. \& 542. (k) Le Regne Animal. 4 to p. 9I.

(l) Fonft. Quadrup. T. XXXV. vel Ruyfci. Theatrum Animal. T. II. 'T́ab. XXXV. 


\section{G E O G R P I C A E. 28R}

ritiffimus in ipfa capitis dieti definitione, ramo illud unico antrorsum verso donatum. fuif]e fatetur, qui ramus in fonfoni etiam cervo, quem burgundicum dixit, confpicitur; certamque cervorum inter \& rangiferiormm cornia difcretionis notam conftituere folet.

f. IV. Concedo quidem, cornuum faftigia in ramgifero palmata effe, quarum tamen palmarum in ifto rov Caribu capité nulla fuerunt veftigia. Quodfi tamen cervorum etiam cornua varia interdum effe \& multiformia, tecum reputaveris, praetereaque fieri potuiffe, ut caputhoc, cujus Rrifonius mentionem fecit, Tarandi cujusdam junioris fuerit : dubium omne facile concidet. Ramus igitur ille antrorfum verfus, quo ipforangifer tam a cervo, quam ab alce diftingui folet, cetor mihi evidentique indicio eft, Tarandi cujusdam caput illud fuiffe $(m)$.

0. V. Rangiferum infuper Americae etiam fefforem effe debere, certiffima inde confecutione efficitur, quonian Groenlandia, quam Americae feptentrionali conjunctamque fcimus, eandem beftiam alit. Quumque Caribu Canradenfunm, ad quos a Grocnlandis.defcendere commode poterat, fola magnitudine praecipue a Tarando differat $(n)$; nullus dubito, quin utraque beftia una fit eademque ; raraque tantummodo \& tenuia, quae $\mathrm{Ca}$ nadae campi fuppeditant, nutrimenta impedire, quo $\mathrm{mi}-$

(m) Pernegare quidem non aufim, fieri potuife, ut caput cervi cujusdam inufitatis admodum cornibus armatum fuerit. Quot enim \& quantas mutationes cervorum comua induant, nemo nefcit.

(ii) Vid. Buffon T. VI. P. II. p. 56. item Brooks natural Hiftory T. I, p. O8. ubi Caribuis etiam icona dedit. 


\subsection{SPECIMEN ZOOLOGIAE}

minus cornua in folitam proceritatem excrefcere poffint, mihi probabile videtur $(0)$.

6. VI. Alterum, quo convietus caribuem \& inrandim idem animal habeo, argumentum hoc eft, quod utrumque haud procul a feptentrionis traetibus recedit. Quum enim caribunn greges Hudfonis fretum, quae germana ipforum patria effe videtur, copiofiffime pervagentur: minus tamen frequentes ad Canadae campos defcendant $(p)$, Mexicornmque regio fat multos quidem cervos, caribus tamen nullos numeret : pari fere ratione tarandi vel nunquam, vel rariffime faltem, terrarum frigoribus intenffimis infamium fines tranfire, temperatioresque plagas invifere fueverunt.

6. VII. Haec itaque rangiferi varietas, Cnribu, calidiores paulo Amcricue feptentrionalis partes abhorret, $\&$ in Canada quidem fub quadragefimo jam latitudinis. gradu occurrit; quum Tarandus in orbe antiquo fub quinquagefimo demum feptimo oetavoque reperiatur. Outhicmio fub fexagefimo fecundo gradu (q) rangiferi ocourrebant. In Siberia vero prope Ochozki oppidum $(r)$, qrod fub quinquagefimo octavo gradu fitum eft, confpici folent. Gmelinus eos in 'Tungufenfrum regione, quac Bratskoy Ofroy nominatur $(s)$, fub quinquagefino fexto jann obvios habuit.

0. VIII.

(o) Haec fortafis ratio eft, cur Americae rangiferi iis minores fint, quos orbis antiquus nutrit; licet ree in Buffonii nec in Pawii fententian ciftedere pofin, " qui omnes Americae quadrupedes minori caeteris ftatura: effe putant: quum Hudfonis fretum bifontes, habeat, qui orbis antigui boves, fi tauro-elephantem exceperis, mirum quantum antecellunt.

(p) Allg. Reif. '1.XVI1. p. 85 \%

(q) Entre Weifta \& Hermonger. Voyage d'Outhier.

(r) Gmelin (fen.) T. II. p. 542. (s) ibid. p. $1933^{\circ}$ 


\section{GE O G R A P H I C A E. z $z$ X}

5. VIII. Nonne hinc fole clarius elucet, tam Amori. cae, quam A/ae terras feptentrionales \& ad euronotum jacentes, longe vehementiori frigoris vi präe illis afflari, quae iisdem poli gradibus fubfunt? Nec enim Suleciae, Trinniae, Livoniaeque, nec Rulfiac curopaeac proprie fic dietae, Cafanique regna, rangiferos alunt. Interim experientia docet, nullum beftiarum genus majori cum difficultate vitaeque periculo ex patria fede, \& crimate, cui adfuetum eft, in alias easque calidiores terras. transponi poffe; quod faepe quidem tentatum eft, nuinquam tamen fortuna voto conatuique fubfcripit. Bartholino tefte, Daniam rangiferi plene deferuerunt, nec amplins ibidem ut olim proveniunt $(i)$. Et Ponnoppidamus (u), Regnardusque (v), tentatas corum educationes propagationesque fecusibi cecidiffe, omnesque periiffe, confirmant. In theriotrophio, quod Cafellis floret, 'Tarandos vivos nutriri, confitat; eos vero bene ibidem lubenterque vivere, \& fobolem propagare, nemo prudentum adfirmavcrit. Nec enim Dania, Borulfiaque eos commode educare valent, nec, ex Limnaei teftimonio (w), Sueciae regiones, quae Latpial confines funt, cosdem fovent.

0.IX.'Non poffum, quin heic loci novo quodam argumento Gormaniane Galliaeque regiones folis apricatione magis incaluiffe, commonftrem. Rangiferi enim, qui olim utrarumque filvas incoluerunt $(x)$, aliquot $\mathrm{ab}=$

(t) AEta Hafnens. 167 t. (2) Pontopp. Norweg. T. II. p. 2 I.

(y) Oeuvres de Regrand. Paris 1750 . I. I. (iv) Lini Faun. Suec.

(x) Jul. Caefar. de Bello Gall. Lib. VI. Cap. XVII. \& la Vezerie de 7. Dufouilloux. Paris I614. 27. 


\section{SPECIMEN ZOOLOGIAE}

abhinc feculis penitus inde difeffife novimus. $B u f f a-$ nius quidem, Gallian calidiore nunc coeli temperie, quam olim frui, ex futiani imperatoris epiftolis comprobat $(y)$, qui fuo tempore regni hujus agros acriori gelu riguiffe fcripfrt ; fed recentiori documento res ex: Serrefio probari potef, qui, Francifco primo imperante, anno I543, milites diftributas fibi vini portiones congelatas dolabris concidiffe, corbibusque domum fuam detuliffe narrat $(z)$. Qua relatione, vinum gelu intenfiori penitus concretum fuife, eainque hiemis magnitudinem, quod inde fequitur, diu fatis perfeveraffe docemur; cujus rei exempium noftris diebus praeter Lappiam, Norvarian aliasque fub eodien coelo pofitas regiones, alia nulla praebet. Ex quo fimul evidentiffime patefcit, quantopere exficcatis paludibus, excifis filvis, novalibus profciffis, auctoque hominum numero terae mitigentur, climatis afperitas emendetur, vis frigoris frangatur, atque diminuatur; cujus tamin rei ampliorem expofitionem commodiori \& loco \& tempori refervaturus, ad Tarandum regredior:

10. X. Fines itaque, quos rangifer antiqui in orbis. regionibus \& in Afra quidem orientalióccupat, a quin: quagefimo fexto latitudinis gradu ad oceanum usque. glacialem extenduntur. In Europa in fexagefimo demum, aut quinquagefimo nono confpici folet. In

(y) Buffon T. VI. 2 B. . p. 52.

(z) Lé fecond Volume de l'Inventaire -général de l'Hiftoire deFrance par Fean de Serres à Cologn. 1615. p. 231: On départort le Vin de munición à coups de cognces, \& fe débitoit au poids, puis les Soldats ¿emportèrent en des paniers. 


\section{GEOG R A P I C A E. $285^{\circ}$}

America vero, quae acriori frigore horret, jam a quadragefimo fecundo ad feptentrionis extrema, ficut $\mathrm{E} u$. ropae rangifer, progreditur. Nimis itaque anguftis eos terminis Buffonins circumfcripfit, qui illos in $A / 2 n \&$ Europa polarem duntaxat intra circulum commorari tradidit; quum tamen Hardangenfes perpetua nive contectos montes provinciae Bergen/is, fub fexagefimo gra: du jacentes, numerofiffmis gregibus pérerrent $(a)$.

\section{Alces.}

6: XI. Beftia haec partim fingulari, qua fuperbit, magnitudine, partim cornibus ab imo ad fummum palmatis, a rangifero quidem diftat; interim tamen latam fatis cum illo tam veteris, quam novi orbis fafciam feptentrionem verfus occupat. Bufforius animal hoc circulum polarem, quem intra habitat, transgredi negat; \& peregrinantes, in Groenlandia, Spitzberga, Nova: Zcmbla, Hudfonisque finu, ubi rangiferi frequentes inveniuntur, nulla plane alcium veftigia deprehendi, uno: quafi ore teftantur.

6. XlI. Caeterum aretioris tantummodo latitudinis: gradibus defcribuntur, quos nunquam fere tranfeunt. Buruffin, Polonia, Livonia, Cumlandia $(b)$, Iiminaque $(c)$. obis antiqui regiones funt, quas etiamnum tenent, $\mathrm{cx}$. qui-

(a) Pontoppid. 1. c. p. 22.

(b) Tenent alces praegrandes albae Ruffiae filvae, fovent patátinatutus varii, Novogrodenfis, Brescianenfis, Kiovienfis, Volhynienfis circa 4 Stepaw, Sendomirenfis, Livonienfis \&c. Rzaczynski Auctarium P. $3 \mathbf{z}_{52}$.

(6.) Oeuvres de Regnard T. I. p. 65. Ed. 1750 . I2mo. 


\subsection{SPECIMEN ZOOLOGIAE}

quibus in Sueciam, Norvagiam, Lappiamque ( $d$ ) ad fexagefimum terium \& quartum usque gradum proccdunt.

0. XIII. In Cafanen/a Afiae regno fub quinquagefimo fecundo aut tertio gradu primum confpiciuntur (e), $8 z$ in variis Sibiriae tractibus, verbi caufa, in $U_{h}-K a$. sieno gorskaja-Krefofliae $(f)$, Kusnezi $(g)$, Irkuzkizque (b) terris, item in Tartariae magnae, Kalkaemenhum, Molnhfumque filvis in quadragefimo quinto latitudinis gradu fub rov Hon-ta-ban appellatione, obriae funt ( $i)$; \& hinc, tefte Gmelino (k), ad Ilimski oppidum, quod fub quinquagefimo octavo gradu pofitum eft, ad fexagefimum usque, $\&$, quod veri quidem fimillimum eft, amplius progrediuntur.

6. XIV. In Americae Canadenfibus praccipue terris vivit. Multo enim certioribus comprobari rationibus poteft, Gallorum Orignalem, Anglorumque Moo/e-decr veram alcem efre, quam ante, fub Caribu nomine rangiferum latitare, commonftratum eft.

6. XV. Quum aliguot abhinc annis mas cum feminahujus animantis (Moofe-deer) una cum variis aliorum quorundam ejusdem fpeciei cornubus ex America feptentrionali in Angliam delati effent, Pennantus (l),

(a) Lappiam perpaucas alcium ex Lithuania interdum eo transgredientium alere Scliefferus in Lappiac defcriftione p. 310. adfirmat.

(e) Pallas Reifen T. 1. p. 198. \& p. 21 I.

(f) Gmolin (fen.) I. c. I. I. p. 230 (g) Ibid p. 206.

(h) Ibid. 'T. Il. p. I65. (i) Allg. Reil. T. VII. p. 76.

(k) L. c. T. II. p. 207 .

(l) Sgnopfis of Quadrupeds. Chefter 177 I. Vehementer doleo, eximil in hune praeftantemque librum nuper demum \& tam fero quidem ex Arghia mihi transmiffum efle, ut eoden prius, quam nunc, uti minus licuerit. 


\section{G E O GR A P H I C A E. 287}

licet pro fingulari, qua poillet, quadrupedun cognitione diligentiffme omnia perforutatus fuiffet, cos ne minima tamen in re a noftris alcibus fecerni potuiffe, confirmavit. Ex cujus unius teftimonio, quod inftar plurium efre poteft, certiffime, Canodain alces alere, conficitur: earum tamen aliquas caeteris magnitudine

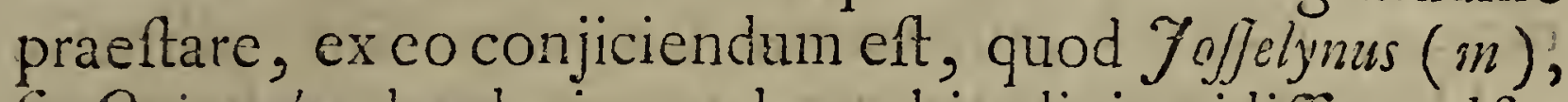
fe Orignales duodecim pedum altitudinis vidiffe, adfirmat, quorum cornua trecentarum, quin quadringentarum librarum fuerint. Ipfum tamen hac in re modum exceffife fufpicor, quia reliqui auctores omnes, \& ipfe Labontanus (" Americae alcibus equorum duntaxat magnitudinem tribuit.

0. XVI. Nihilo interea fecius in Hiberniae quibusdam regionibus cornua, quac non nifi alcium effe posfunt, effodiuntur, quorum Pennantus teflis avtortys fequentem dedit deferiptionem: ", Cornua, inquit (o), , in Hibernia effoffa, ab origine, qua capiti affixa „, funt, quinque pedum totidemque digitorum altitu2 dinem habent; ramus, quem frontis vel oculi nomi-

"nant, undecim pollices longus, \& maxima palmac " latitudo oftodecim digitorum eft. Si ab extremo " dextri cornu acumine ad finiftri faftigium diftantiam " dimetieris, feptem pedes novemque pollices nume2) rabis, quibus tamen adhue majora quaedam reperiri 2, dicuntur. Caeterum hac etiam in re a reliquis alcium " cornubus diftinguuntur, quod ab imo, ubi capiti gad-

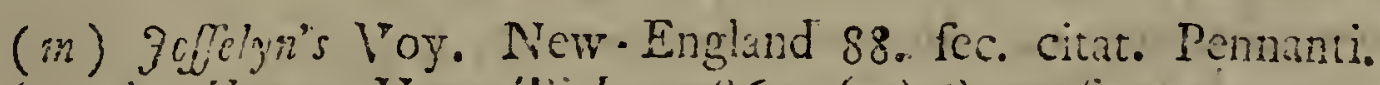

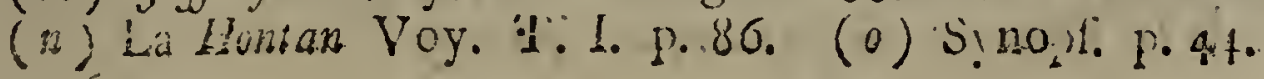




\section{SPECIMEN ZQOLOGIAE}

\% adnata funt, loco, ad palmas usque proceriori trun" co fulciuntur". Sibi ab aliis relatum effe, vir egregius tradit, oetingenta circiter poft Eboraci caftellunz in America milliaria quadrupedes mirandae magnitudinis dari, quos indigenae, feri homines, lingua fua $W$ askeffe vocitent, qui, quod veri fimillimum fit, tantis hifce tamque infignis proceritatis cornubus fint inftrueti. "2 Quomodocunque interim, pergit, res fe habeat, al" ceni noftram in America commorari, ipfamque unana " eandemque atque Orignalem ab Ang lis Moofe-decr $"$ nuncupatam effe, omni dubio caret. Hactenus Pon"nanutus". Alcium tamen novi orbis aliquas diverfi etiann coloris diverfaeque ftaturae effe, Dudleyus ( $p$ ) auctor eft, qui minores, $a b$ incolis IV ampoofes dietas, cana vel grifea, majores vero fufca pelle veftiri, commemoravit. 5. XVII. Canadac igitur feffor eft alce (q), eandem vero Hud, onis etiam fretum incolere, vehementer ambigo, quia Ellifus eam tacitus praeterit; cujus tamen, fi illam obviam habuiffet, certe mentionem fcciffet. Praeter Canadann Britonum quoque Caput (Cap Breton ( $r 3)$ Nova Anglia $(s)$, Virginiaque ( $t$ ) alces alit; \& quum, quam poftremo loco provinciam nominavi, ad tricefimum fextum gradum porrigatur; exinde docemur, alcein aequa cum tarando proportione propius in America, quam in veteri orbe ab aequatore abeffe.

5. XVIII.

(p) Philofoph. Transact. Abridg. VII. 447.

(q) Allg. Reif. T. XVII. p. 84. \& p. 227.

(r) Wichtigkeit von Cap Breton 1747. 8vo. p. 7 1.

(s) Denys Defcript. de l'Amérique Septentr. T. 1. p. 27.

(t) Hiftoire de la Virginie. Orléans $1707 \cdot \mathrm{p}: 213$. 
6. XVIII. Notatu praeterea dignum en, hunc eliam quadrupedem aeque ac rangiferos in Europae quondam regionibus meridiem verfus ad Germanian usque Gabliamque, quod auctores fide digniffmi comprobarunt, proceffiffe $(u)$; decrefente autem frigore, pedem referentes Galliam penitus réliquifie. In Germania, in uno adhuc Borulfiae regno, locum conftitutioni fuae convenientem nactus videtur, ubi commode adhuc habitare poffit. Pari ergo cum tarandis ratione beftia haec thermometri vivi loco effe poterit: aliasque plures ejus na: turae atque indolis reperiri, quae fola coeli aërisque temperie coactae, fedes fuas relinquant, \& in alias ftructurae fuae magis conducentes migrent, e quarum habitaculis deinceps regionum, in quibus confident, coeli etiam aërisque qualitas dijudicari queat, non mediocri cum probabilitate autumo; quam tamen rem ulteriori disquifitioni refervatam volo.

$$
\begin{gathered}
\text { SE C T I O III. } \\
\text { Martes (a). }
\end{gathered}
$$

๑. I. mnium quadrupedum, quibus hoc in capite locus dari debet, poft urfum nullus eft, qui fufius per orbem difperfus reperiatur, quam martes. Quoniam vero tarnalus propius ad polum adfcendit; ipfum urfo ftatim adjungendum effe, credidi. Quod fi

ta-

(u) Ful. Caefar de Bello Gall. Lib. VI. vide de his etiam Buffon. T. XII. p. 51 \& 52 .

(a) Martes. Muftela pedibus fiffis, corpore fulvo-nigricante, gula pallida. Linnaei Syft. Ed. XII. 
tamen terrarum, perquas difperguntur, regionumque, quas pererrant animalia, refpectus habendus eflet, \& marles \& intra tarando ubique anteponi debuillent. MIartem a feptentrione ad aequatorem fere defcendere, poftea commonftrabo, fi antea, quid de varietatibus fuis mihi videatur, expofuero. Sic enim deinceps in enumerandis terrae, quas occupat, partibus eo facilius progredi licebit.

6. II. Noftris in regionibus duae vivunt beftiolac, quibus martium nomen imponi folet; quarum altera campeftris, arborum, abietumque, altera vero domeftica, faxorum fagorumque martes appeilatur $(b)$, quae omnes nec dentium numero, nec colore pilorumque natura, nec corporis forma, nec interna externaque partium ftruetura, nec moribus nec excrementis, moschum firantibus, nec ulla propemodum alia in re a fe invicem difcedunt. Cur itaque a Naturae indagatoribus in duas diftribuantur fpecies: haec una forfitan ratio reddi poreft, quod albo altera, altera flavo gutture infigniatur, altera fedem fibi, domibus noftris propinquiorem, altera remotiorem fixerit.

6. III. Daubentonius, qui cum Bufjonio campefrem. a domefitca disjunxit (c), praecipuan diftineionis notam in colore, quo guttura difcrepant, quaerendam effe, ipfemet fatetur: nec tamen vulpes, licet diverfiffmis inter fe coloribus, albo nimirum, nigro rufoque difcernantur, feparat, cunctas potius unius ejusdemque fpeciei varietates effe ftatuit. . Vir clariffmus Ges:

(b) Varietas duplex rufticis: fagorum, gucture albo; abictun gutture 甘avo. Linnaeus l. c. (c) Bufforn '1. VIl. p. I08. 


\section{GE O G R A P H I C A E 29:}

Gosnerain, qui fecundain Albertum magnum, campofrein cum domefica ñante coîre dixerat (d), refutaturus; neceffum fore contendit, ut ex utrarumquie con ${ }^{2}$ junctione catulorum prognatorum guttura tam flavo, quo campeftris, quam albo, quo doméftica infignis fit, colore fimul notata conficiciantur. Sed quid obflat, quo minus catulus vel matris vel patris folius naturani coloremque referat? \& gutture vel fubalbido tantum aut fubflavo fignetur? Nonne fieri potuit, ut mertitum par quoddam, necefîtudine, aliisque caufis adactuni rus relinquens, in aedificia fe receperit? \& quoniam victus ibidem catulis fuis aptior magisque fufficiens in promtu erat, patriam fedem, filvam puta, cum áedibus noftris permutaverit?

0. IV. Quum praeterea \& venatores utrasque unius ejusdemque fpeciei effe, uno ore adfirment $(e)$; qui quis ratione ipfas tam fibi aequales divellere audeat, penitus ignoro. Parum abeft, quin perfuadear, Buffos nium Daubentoniumque, Linnaco, qui in Fauma fuccica abietum fagorumque martem unam eandemque effe, dixerat, contradicturos hanc diftinctionem excogitaffe; quorum tamen fententiae vix curatiorum naturae contemplatorum quisquam acceflerit.

6. V. Dantur praeter hos alii duo animantes, quos fine ulla dubitatione martis varietatibus accenfendos au-

tu-

(d) Gesner Quadrup. p. 867 .

(c) Docbelius in practica venatorum p. A. Saxorum, inquit, arborumque inartes omnibus in rebus fibi funt finillimae, if unum hoc exceperis, quod illae pellibus dilute fufcis tectae, alboque gurture notatae fint, \& $\ddot{\alpha}$ muris disjectis aedibusque ruinofis donicilia fibi condant. 


\section{SPECIMEN ZOOLOGIAE}

tumo; Pekanus nempe \& Wifonus, utrique Amcricue feptentrionalis feffores, quos Buffonius primus omnium eleganter curateque fatis depictos exhibuit $(/)$; licet per alios jam naturae ferutatores $(g)$ \& illos etiam, qui pellium mercaturam faciunt, antea innotuerint.

0. VI. Pekanus, Daubentonio tefte, fajortmin marti caeteroqui fimillimus, pedibus paullo craftioribus utitur, nec macula fub gutture tam lucide allba ornatus eft. Wifono, qui proceriori collo gandet, album fub gula deeft. Quum interim utrique hi quadrupedes, qui $\mathrm{Ca}$ nadan incolunt, caetera omnia cum marte communia habeant, utrosque martium noftratium fpeciei fubmittere non dubito. Buffonius l'ekanam a faxatili feu domeftica oriundum, Wifónumque campeftris varietatem effe putat; qui autem pelle tantum ipeciofiore tecti, noftratibus eadem ratione praeftent, qua cufforum liutrarumque. America feptentrionalis indigenarum pelles reliquas omnes fuperant, quibus veteris orbis caffores lutrasque veftitas videmins.

0. VII. Adduetis itaque rationibus lectorem convietum iri, (pero, martem campeffrem, dome/itcam, Pekanam IV ifonumique tantummodo varietates effe, quae a communi quodam generis fui patre originem traxerint. Nunc quas etiam terrae plagas pervagentur, confiderantes, ipfris antiquo in orbe minime gentium eo latitudinis, quo ur/us \& tarandus, adfcendere obferva-

mus

(f) Buffon $\mathrm{l}$. Xul. le Pekan Iab. Xlil. le Wifon Tab. XLIII. pag. I0). Pennintus Pekanum \& Wifontm minme incer fe differre, adferit.

ig) Brifjun. p. $2+6$. Lid. Hard. mutala pilis coloris lacurare caftanei in toto corpore. Le Vifon. 


\section{G E O G R A P H I C A E. 293}

mus. Spitzberga enim, Nova Zembla, Afaeque regiones polarem ultra circulum pofitae, martes nullas alunt. In Lappia (b) autem, Norvagia( $i)$ Sueciaque ( $k$ ) frequentes fatis occurrunt, $\&$ hinc ad Daniam, Poloniam, Grmaniam, Gallum, lialiam ( $l$ ), Gracicingue usque defcendunt ( $(m)$. In Alia varias Sibiriae $(n)$ regiones, Coffanenfurm (o) praeterea, Chinenfunn, Thibetbani regnif $p), T$ imkznenfown $(q)$ illvas, quin \& Muldivas $(r)$ infulas occupant.

0. VIII. Airicam naturae martis ac rationibus minus conducere, ex eofufpicor, quod Sbawizs, Bosmannus, Kolbius \& multi, qui de Africae hiftoria naturali confcripferunt, nullam ejus mentionem faciunt. Nihilo tamen fecius Anzikorum regio, quae Conyi (s) regno confinis eft, murtes alere fertur; \& Bufjonius eas Madagafcaris etiam felfores effe, e Siruy/io probat $(t)$; illasque dumefticas, non autem campeftres effe, idcirco autumat, quia domefticae calidiores tantum, nunquam vero frigidasfeptentrionis regiones tenere foleant: quam tamen viri celeuerrimi fententiam nul'a probabilitatis fpe-

cie

(h) Hugftroems Lapptand. p. 22.

(i) Pranteppic T. II. p. 46 . ( $k$ ) Limn. Faun. Suec.

(i) Saggio J'Offervazioni fopra P'lifold di Cherfo ed Ofero d'Alberto Fortis Venczis 777 I. pag. 73. (m) Bulfon T VII.

(i) Graclin (fen.) l. c. T. 1. p. 296.

(o) Pallas Reifen T. I. p. I43. ¿ Rytechkow Orenburgiche Topo. graphie in Bufchings Magazin T. VII. p. 44. (p) Aligem. Reil. T. VII. p. 210. (q) Voyages di Tavernier. Rouen 17 13. T.IV. P. 183.

$(r)$ Voyages de Pyrard T. 1. p. 87. On voit aux Maldives beaucoup de Fouines.

(s) Relacione del Reame di Congo per F. Pigafetta. Roma r 59 r. pas. 32. Inverfo gl' Anzichi pigliano anco de martori

(i) Struys Voyages. Ruuen 1719 . T. I. p. 30. 
cie fundari, e Pontoppidani relatione diccimus (u), qui Norvagiam \& domeficas \& campefles martes nutrire, expofite \& aperte confirmat. Non tamen milit temperare poffum, quin ipfus in fententiam, quam in alio quodam incomparabilis operis fui tomo propofuit, tranfeam: Africae nimirum iftas, de quibus jam locuti fumus, beftiolas, non martes, fed $V$ an/rras potius, aut, quod idem eft, Infras effe, quarum figura, quam fatis eleganter depictam dedit, proxime ad mirtem accedit $(v)$; praecipue, quum nemini adhuc, martium veftigia in Africae terris reperire contigerit.

0. IX. Americam martes nutrire, tam Hudfonis finus, quam Canadae ( $w)$ filvae, quae illarum multitudine abundant, quin varietates etiam comprobant, quas in hac orbis parte obfervaviffe licuit; quibus Pekamum, ID J Jonum illamque beftiolam adnumero, quae ab Huromibus Ottay vocitata $(x), \&$ a Buffonio martis Speciebus adfcripta eft.

0. X. In auftrali etiam America animal quoddam marti perfimile reperitur, quod muftelarum generi omnino fubjiciendum efre cenfeo. Indigenae illud Tayram, Barrerus vero muftelam maximan moschum redolentem appellat $(y)$; Limnaeus ( $z$ ) autem \& Buffonius (a) iftud Brownii Galeram (b) effe putant, quam Linnaeus muftelam pedibus fiffis atram, collo fubtus nacula alba trilobam definit. Ex quibus quidem omni-

bus

(ii) Pontoppil. I. c.

(v) Buffon T. XIIr. p. 9r. (w) Allg. Reir. T. XVII. p. $23 \mathrm{r}$.

(x) Theodat. Voyage au Pays des Hurons p. 308.

(y) Bartcre Hift. Naturelle de la France Equinox. p. 155.

(2) Sylt. Nat, Ed. Xli. (a) Buffon T. XV. p. 10 .

(b) Bioina IIftory of Jamaica Cap. V. p. 4.85 . 


\section{G E O G R A P H I C A E. 295}

bus Tayram martis imaginem referre intelligimus, praecipue quum moschi etiam odor accedat. Quoniam interim res nondum fatis explorata $\&$ in fola adhuc conjectura pofita eft, nec Ferminius Bnncroftiusque fe martes in America anfrali obvias habuiffe dicunt: res, donec dies \& peregrinantium induftria meliora docuerint, in incerto relinquenda eit $(c)$. Ex hactenus tamen dictis evidenter fatis elucet, martes noti nobis cis aequatorem orbis plerasque regiones occupaviffe.

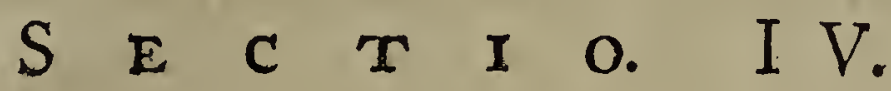 \\ Cafor (a) E Lutra.}

f. I. unim cafor \& lutra ninus longe, quam urfus \& martes a patria fia, feptentrione, meridiem verfus digrediantur, ut befliae hac illas ftatim. fubfequantur, ordo rei poftulare videtur. A caforibus capiamus exordium, qui maris nigri littora. (b) olim tenuerunt, \& Buffoisio tefte (c), in Gallia, Italia, Hispania, quin etiam in Agypto Perfanque interdum, rari tamen \& finguli modo confpecti funt. Uirum autem dietis in locis adhuc confpiciantur, vehementer dubito, quum ab omnibus, qui Perfiam nuper Aegyptumque itineribus fuis peragraverunt, nulla eorum mentio agi-

te-

(c) Pennantus in Synopfe of Quadrup. p. 225. Tayranz a Galera fegregat, alteramque in Guinea vivere adfltruic, quam cum bettia a Bosmanno in Guineae delcriptione Kokcboen nuncupata, eandem effe putat; a alcerans autem Guiat nam incolere adfirtoat, quod, utrum ita fe habeat, teinpus dissque docebit.

(a) Caftor cauda ovata plana. Fiber. Li,menei sytt. Nat. Ed. XIt.

(b) Plin. Hirt. Nat. Lib. Vill. Cap. XXX. (c) Buffon T. VIII. p. 17r. 


\section{SPECIMEN ZOOLOGIAE}

tetur. In Danubii etiam ripis, Helketiae, Italiale, $G$ allincque fluminibus $(d)$, unus nonnunquam caftor alterque reperitur; eademque ratione Gormaniae etiam flumina invifit $(e)$.

5. II. Gregatim vero \& fociati frigidiores tantummodo tam novi, quam antiqui orbis plagas frequentat. Quoniam ergo Americam modo borcalem $(f)$, Lappian dehinc, Norvagiam ( $g$ ), aliosque corundem graduum tractus magna copia multisque agminibus incolit; optime ibidem provenit; fplendidiffimo pellium nitore induitur; habitacula fua mirabili artificio magnaque dexteritate exftruit ; \& majorem quam in reliquis terris, folertiam commonftrat : neceffiria inde confecutione colligimus, commune ibidem patriae fuae folum effe, in quo natus olim \& propagatus eft.

() III. Vix interea crediderim, eo quemquam fubtilitatis proceffurum effe, ut caftores in duas fpecies diftinguat, quarum altera magnis gregibus incedens domicilia fibi condat, altera vero de exftruendis acdificiïs minus follicita relictis gregibus folivaga oberret. Unum enim omnes illos eundemque caftorem efre, nemo non perficiet, qui attentioribus paullum oculis ipforum naturam indagaverit. Et fi morum quandam in ipfis difparitatem obfervaveris, eam vel corporum cuidam de-

(d) Reperiuntur Caftores, apud Burgundiones, circa Matronam fluvium, Sequanos in agro Cabillonenfi, Locharingos, Auftrios, circa Dallubiun, ubi Biferi appellanur, in Helvecia circa Arulam, Ruím \& Lomageni fluvium. Ruycch. Theatr. Animal. T. 11. o. 10..

(e) Doebels Jeser Practic. Artic. Dieber. (f) Ailg. Reir. T. XVII.

(g) Pontoppid. T. II. p. 5 I. 


\section{G E O G R A P H I C A E. 297}

feetui, vel climatis, cui fubfunt, vitio, vel hominum, quos verentur, propinquitati tribuas. His enim necesfitatibus adacti animos despondere, irrequieti trementesque de urbibus vicisque condendis, vel ne cogitare quidem, vel artes fuas penitus dedifcere videntur.

0. IV. Fridericus fecundus, Boruffiae Rex, fat magnam caftorum turbam multo labore congregavife ajunt, ut eundem ex illis fructum caperet, quem Americae feptentrionalis indigenae percipere fueverunt; fed operam oleumque perdidit. Difcurrentes enim focietateque diffoluta ita disperfi funt, ut in Brandenburgenfum finibus vix unus hinc inde alterque interdum inveniatur; qui, quoniam domiciliis, quibus commode vivant, nullis, fed fcrobibus tantum, quas, huino egefta, fodiunt, fe tegere \& fuftentare folent; omni, quo caeteroqui nitent, decore deftituti, macie fordidi detritis pellibus fqualent.

J. V. In Sibiria nunc partim finguli partim congregati prope Sarapuli (b) oppidum fub quinquagefimo feptimo latitudinis gradu, per fuperiores fenifei regiones $\&$ ad $O b b i$ ripas ( $i$ ), longe tamen infrequentius quam olim, reperiuntur. Quum enim, ex Gmelini relatione, Siberia quondam magnos caftorum greges aluerit, a regionis incolis, quorum numerus crevit, fe-. de fua depulfi, eum in modum exftirpati funt, ut jam. non nifi rariffime occurrant. Gimelinus itaque multa \& jure quidem de furore queritur, quo innocentes utilesque iftae animantes nunc exfcindantur. In Cafani qui-, dem

(b) Gmelin. (fenior.) 1. c. T. I. p. 1or. (i) Ibid. T. III. p.487. 
298 SPECIMEN ZOOLOGIAE

dem regno paffin, fingulares tamen ad $\mathcal{F}$ aiki ripas $(k)$ \& prope Berskii campos (1) difcurrunt.

J. VI. Utrum in Afac regionibus ab axe meridiem verfus procefferint; recentiora itineraria nulla docent: nec Tartariae Cbinneque defcriptiones ullam caftorum ibi degentium mentionem jaciunt. $\mathrm{Si}$, quod Plinitus teftatur $(m)$, quem Buffonints etiann fecutus eft, caftor nigri olim maris accola Perrâtaeque feffor fuit; procul dubio hinc pedem nunc retulit, easque tantum Afrae partes, quae in feptentrionem vergunt, fibi vindicavit: Non equidem nefcio, dietionarii animalium audorem $(n)$ fub caftoris voce beftian hanc Indiac quoque oricntalis Africneque habitatorem effe adfeverare: ipfum autent hac in re fecus imbutum ac deceptum fuiffe furpicor. Quum enim Indin a primis quondain feculis urbium, vicorum, hominum, pecortm, quin omnium etian rerum copia fertilis \& opulcnta fuerit, \& plus quam modico tepore caleat: quilibet, aequa ren indiciil lance ponderans, facillime colliget, fieri nequivifte, quin animal fub borca natum, frrigoribusque adfuetum, inufitato folis calore, hominumque fibi noxiorum frequentia adactum, terras illas vel penitus evitarerit, vel cito fatis deferuerit.

9. VII. Caftorum interim copiam \& numerum decrefcere ac minui, caufa duplex adferri poteft. Partim enim climatis coelique temperies, quod in Germa-

mia

(k) Pallas Reif. T. I. p. 283 .

(l) Ibid. p. I98. vide etian Ryftcovii Orenburg. Topographie in Bufching Magazin 'T. VII. ( $m)$ Plinius l.c.

(8) Dictionaire des Animarx. Paris I7.59. T. I. p. 444. 


\section{G E O G R A P H I C A E. 299}

nii Gallinque factum effe jam commonftravimus, ita mutari potuit, ut eam caftor amplius tolerare nequiverit; partim nimia hominum appropinquatio effecit, ut quadrupes, qui hominum commercium fibi inimicilamum effugit, é longiffime inde amoverit. Quo faEtum eft, ut in remotioribus nunc a focietate noftra locis, \& in feptentrionis praecipue terris, quas homines rariffme invifunt, quaeri debeat, ubi omnes a natura conceffis fibi tam corporis, quam ingenii dotes, optime liberrimeque oftendere \& exercere valet.

(1. VIll. Quod ipfum etiam experientia fatis fuperque comprobat. In ipfis enim Cinadae \& Carolinae tractibus, ubi germana ipforum patria effe videtur, multo minores nunc caftorum urbes pagosque, quam olim, offendes (o). Poftquam enim Europaei per iftas nunc regiones diffufi propius illis acceferunt, avaritiaque ducti fcopletis fuis aliisque methodis beftiam hanc commodius, quam Americae olim indigenae interficere aufi funt: nemo mirabitur, fi latiora fibi profugia quaerentes illis etiam in locis rarefcunt $(p)$. Columbus itaque Americam detegendo non hominibus folum, fed animantibus etiam iniocentibus ejusdem incolis tot tantasque clades \& miferias intulit, ut haud vitio ipfis verti poffit, fi quassvis diras ipfi imprecentur.

J. IX. Limites, quos intra caftor americanus, qui cum noftrate unus \& idem eft, commoretur, Buffonius

(o) Allg. Reif. T. XVll. p. 8 I.

(p) Silentio praemittere nequeo, collegium, quod in Hudfonis freto merculuram facit, anno $I_{7} \sigma .3$. numerum $5+60^{\circ}$ pellium caltoribus detractarum vendidifle. Penmant.

$$
\mathrm{PP} 2
$$




\section{SPECIMEN Z OOLOGIAE}

a tricefimo ad fexagefimum latitudinis gradum extendit. Sat multi ergo feptentrionis animantes, qui latius ad polum adfcendunt, ipfum poft fe relinquunt. Groenlandia enim, Nova Zemblia, Spitzberga aliaeque ejusdem la. titudinis regiones, caftorem ignorant, cujus patriae praecipua fedes Canada effe videtur. Solum fere antiqui orbis. Norvagiae regnum eft, quod inhabitet, \& ubi domos urbesque fuas adhuc exftruat. Hinc certi fines, quos intra verfetur, nulli conftitui poffunt; nec iftorum, qui difperfi hinc inde in cubilibus effoffis delitescunt, ultra quadragefimum quartum vel quintum latitudinis gradum quenquam amplius reperies. Nemo peregrinantium nos certiores reddidit, bettias hafee vel in Africa, vel in America auftrali unquam vifas $\ddot{\alpha}$ inventas effe.

6. X. Magnitudine quidem parum inter fe differre videntur $(q)$; coloribus autem eo magis disjunguntur; quum alii, qui propius ab axe ablunt, nigra pelle, quae pulcherrima efre, maxinoque in pretio thaberi folet, veftiti compareant; pilis alii cafaneis, alii fubflovis quales Illmon/zimn regio nutrit $(r)$, ornati; alii car nis qui vulgaris communisque ipforum color ch, tecti inveniantur: albis autem rufo paululum intermixtis inftrueti rariffimi habentur $(s)$. Quo latiius a polo difcedunt, eo-magis pellium natura degenerat, \& e nigritia caneicit.

I. $2-$

(q) Corporum longitudo vulgaris a roftri extremitate ad caudae initium. pedum duorum dimidiquire effe folet.

(r) Charlevoix. Hift. de la Nouvelle France T.II. F. 94.

(s) Brifon Regne Animal. Edit. 4to. p. I35. 
GEOGRA PHI C A E. 30I

\section{Lutra $(t)$.}

0. XI. Etfi caftor longe fatis $a b$ aquilone meridiem verus difcedit: lutra tamen, quae, fi diverfam dentiuin qualitatem ordinemque exceperis, propinqua caftorem cognatione contingit, propius ipfo ad aequatorem defendit. Longius illam a polo fedes \& domicilium fibi collocare, exinde colligo, quod in Hudfonis freto, quod castoris patria eft, lutra fub adfpectum nulla cadit, nec in fuperioribus Jenifei Obbique ripis, quas caftor occupat, confpicitur: paucorum tamen duntaxat graduum intervallo inter fe diftant. Canadae enim indigenae lutram aeque atque caftorem venando agitant $(u), \&$ utrisque plagas infidiasque tendunt. Norvagia $(v)$, Lappia (w) \& llginskoia ( $x$ ), Siberiae provincia fub quinquagefimo feptimo latitudimis gradu pofita, lutras alit.

.0. XII. Canadenfem vero cum noftrate ejusdem fpeciei effe, is tantum inficiabitur, cui utriusque naturam formanque inter fe conferendi vel occafio defuerit vel voluntas. Qunum enim Daubentonius unum, quo ambae diftingui poffint, momentum effe adfluat $(y)$, quod illa caftaneis atrisque maculis, quae noftrati defunt, variegata fit, vix quemquam fore puto, qui tantilla diverfitate ductus duas hinc lutrarum fpecies conftituere andeat. Caizaden/is quidem amplioris \& ftata-

$\mathrm{rae}_{2}$

(i) Lutra. Murtela plantis pulmatis nudis, cauda corpore dimidio breviore. Limnaei Sylt. Lid. XIL. La Loutre Buffon T. Vil.

(u) La Hontan in Alig. Reif. T.XVII. p. 87. (v) Pontoppiar. 1. c. p. 54

(v). Hogfroem. 1. c. p. 22 . (x) Gmelin (fen.) T. 2. pag. 232.

(\%) Daubentons Befchreibung der Canad. Otter. in Buffon: T. XuL..

$$
\text { P } 3
$$




\section{SPECIMEN ZOOLOGIAG}

rae, interim tamen, BrifJonio auctore $(z)$, noftratem vix duobus digitis fuperat.

6. XIII. E nominatis jam Europae regionibus in Succiam, cujus incolae magna ipfam cum dexteritate manfuefactam pifcibus capiendis adfuefaciunt $(a)$, in Poloniae, RuJfiae, Livonias (b), Germailae, Galliae, Neapolis, Sarmatiae (c) Graeciaeque (d) terras digreditur. In Afin Ilginskoi Kirenskoique (e) Siberiae regiones, itemque Samaiae $(f) \& \mathcal{Z} a i k i(g)$, qui Cafani fluvii funt, ripas Tartariaeque Mongulenis (b) traetus tenet. Quando autem Turpinus aliique, Siamae graviori aeftu calefcentis fluvios magna lutrarini copia abundare, tradunt $(i)$, id incertum adhuc \& ferutandum effe autumo. Quum enim peregrinantium hucusque nullus certalutrae veftigia in Africa reperire potuerit, nec cam Indiae fefforem effe dixerit; quin Buffonii, beftiain hanc calidioribus coeli climatibus tolerandis minus parem judicantis, opinioni fubrcribam non dubito.

0. XIV. In America ipfam Canadae, Acadiae $(k)$, Novae Scotiae (l), Penfluaniae (n) aliarumque corum graduum provinciarum habitatorem effe, laudati in

mar-

(z) Le Regne Animal. 4 to p. 273.

(a) Vid. Law de Lutra in Schwed. Abhandl. der Acad. d. Wifenfeh. T. XIV..p. I47. (b) Rzacynisiki l. c. p. 221.

(c) Dict. des Anim. '1. 2. p. 718. (d) Ariftot. Hir. Anim. lib. 8. cap. 5.

(e) Gmelin. (fen ) 1. c. ( $f$ ) Fallas Reil. T. I. p. 199.

(s) Pallas l. c. p. 429 . (h) Neahof Gelandfoh. n. Chn p. 393.

(i) Turpin Hift. du Roy. Sian 1. 1. p. p. 3i6. On trouve des Louires dans toutes les rivières de Siam.

(k) Diercville Reife nach Acadien in Goetting. Reif. T. III. p. 252.

(l) Befchreibung von neu Schottand Leipzig 1750. 8ro. p. 7 I.

(m) Kalms Reife nach Amer. 'T.'Il.' p. 35 I. 


\section{G E O GR A P H I C A E ? 3०3.}

margine auctores comprobant; nullum vero teftem, fide dignum, lutram in'Mexici etiam Peruviaeque regnis nutrini adfirmantem, reperire mihi licuit.

0. XV. In Brafilia quoque fpeciem aliquam lutramin vivere, ex Burrcro (in) conftat, qui nigricantem ipfam cauda deprefia \& glabra praeditam effe fcribit. Marchrivius (o) eain Jiyam five Carigieibeium appellat, \& Buffonizis cjus fub Surcoviennae nomine $(p)$ meminit, qui cum Brifjonio (q) Thevetum $(r)$ fecutus, beftiam hanc cum noftrate admodum congrue. re adfirmat. Stellerus vero Carigueibeium iftum eundem" effe quadrupedem tradit, quem fub Kaintfcbadalenjas lutrae marinae nuncupatione more fuo, id eft, optime defcripfit $(s)$. Varia tamen funt, quáe his omnibus obmoveri polunt. Lutram enim, quam Thevetus \& Marcgravius in America auftrali invenerunt, illa, cujus Stelleris 'mentionem fecit, multo minoren efre, ex eo patet, quod hanc tres pedes parifienfis menfurae longam effe, nominatus jam auctor dixit; Tbevetus vero Sarcoviomae, felis tantum longitudinem, \& Marcgravius, canis mediocris proceritatem tribuit; canis autem venatici majoris paene nullius longitudo tres pedes explet, canisque mediocris vix ad duos pedes extendi folet. Deinde lutram braflilienfem lutea gula infignitam Thevetus vidit, quam

(n) Hift. Nat. de la France équinox. p. I55.

(o) Hift. Brafil. p. 234. ( $p$ ) Buffon T. XIII. p. Iz6.

(q) Le Regne Animal 4to. p. 278. la Loutre du Brefil.

(r) Singularités de la France Antaretique p. 107.

(s) Stcliers Seethiere. Halle I753. p. I6I \& I64. 


\section{SPECIMEN ZOOLOGIAE}

in Kamt chbadalenfz vel nunquam vel faltim rariffime Stel. Lerus obfervavit. Tum Brafolienfis lutra caudam Marcgravius ejusdem cum ipfus pedibus longitudinis effe adfirmat; Stellerus e contrario de Kamtfobadalenfiz caudam ejus tres dimidiumque pollicem pedibus longiorem efie teftatur. Accedit tandem, quod haec mare tantum prope Kamfchatkam, minime vero flumina lacusque aquae dulcis frequentat; quum Sarcoviermanon in 1 Brat faliae folum fluviis, fed in Orenoqua ctiam Platnque fe contineat, ibique victum fuum quaerat. : Si derique miras Braflienjis Kambscbadalen/isquè climatis varietates inter fe comparaveris; vix poteris, quin, utrum pares hae lutrae \& aequales fint, nec ne, ambigas. Utramvis itaque beftiam in fúa, quam incolit, regione ad, notatam mappa geographica tibi exhibet. Interea tamen fieri polfe, -ut braflien/is a noftrate genus fuum ducat, non inficior. Utraŕumque faltem definitiones inter fe collatae fatis probabiliter docent ; unum idemque animal in iis defcriptum effe, quod exiguis tantum fortuitisque in rebus varietur.

6. XVI. Lutra igitur noftra, quod ex hacenus dictis patebit, per utrumque orbem late fatis dispergitur. Interim alia quaedan f́pecies reperitur, quae, etfi. noftrati non exacte respondeat, hoc tamen cum illa commune habet, ut in antiquo pariter atque novo orbe, minus tamen diffufa inveniatur. Minor haec eft, quae paludes inhabitat, quanque Limnacus multe: lam lutreolam plantis palmatis bois jutis ore allo definit $(t)$.

$R z a-$

( $t$ ) Muftela Lutreola Lini. Syft. Ed. XII. Leffer Octer Pemnant Synopr. p. 239 . 


\section{G E O G R A H I C A 305}

Rzacinskisus quadrupedem hunc Poloniae, Lituaniae Rus fiacque propriam \& fub Nurcki \& Nurtzii appellatione notum effe tradit (u). Finni illum Tricburtum \& Sueci Maenkium nuncupant (v).

6. XVII. Sueciae, Finniae, finitimarumque regionum paludes incolit, \& inde in Afram tranfit. P'allajius enim ipfum fub Norkae nomine in Cajanenji regno ad Faiki ripas obvium habuit (w), cui prae majoribus lutris hoc praecipuum \& fingulare effe obfervavit, ut venando agitatus intolerabili odoris foeditate, quam emittit, perfequentes ipfum depellat: qua animantis proprietate docemur, eum Americae quoque borealis incolam effe. Kalmizus enim teftis auiotins Minkium quadrupedem martium generis effe, confirmat, qui in novac Cacfureae (Nenjerfey) aquis reperiatur $(x)$, vitamque pifcium, animalium terreftrium minorum, aviumque captura propaget, \& haud raro foetorem teterrimum efflet. Haec confiderans \& nomen, quod Sueci ipfi impofuere (Maenk) illi, quod Sueci Americae feptentrionalis feffores eidem fecerunt (Mink) admodum congruere mecum reputans, Minkium hunc lutram effe palu/lrem jam perfuadebar. Poftquam vero Pennanti Zoologian infpexeram, \& a Bartranno (y), Minkium, cujus contemplandi crebriorem in Amserica feptentrionali occafionem habuerat, evidentiffimis e rationibus lutrarum minorum fpeciei adnumeratum effe legeram, animal hoc eo confidentius Jutreolis adjudicare potui, quae in utrovis orbe ali-

(u) Rzacynski Hift. Pol. p. 2. 8. (v) Fauna Suecica.

(w) Pallas Reir. T. I. p. 9б. ( $x$ ) Kalms Reife T. $3 \cdot$ p. 30

(i) Synopf. of Quadrup. p. 2qc.

Q q 


\section{SPECIMEN ZOOLOGIAE}

aliquot latitudinis gradus occupat; licet in America p:opius ad acquatorem, quam in Europae Afraeque terris progrediatur. In illa enim ad $P$ enflivaniom confinesque ei regiones fub tricefimo fere octavo gradu fitas defcendit; in Afa illam in Cafani regno fub quinquagefimo fere gradu offendinus. In Europa fub eodem gradu, \& quidem in Polonia vivit; in Suecia vero \& Fimnia aliઘuanto propius ad polum adfcendit.

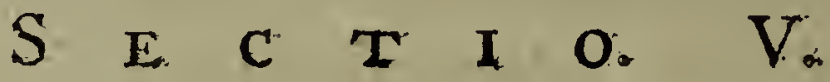

$$
\begin{aligned}
& \operatorname{Lynx}(a)
\end{aligned}
$$

1. I. T nus fere quadrupedum tigrinis maculis, variegatus., quem aquilonalis terrae tractus. nutrit, quive per antiquum aeque atque novum orbem difperfus reperitur, lyns eft. Quum reliqui omnes, qui. lyncem aliqua conjunetione \& fumilitudine tangunt, animantes, pantberae nimirum, leopardi, oncae, fervali, lupi tigrini \& his fimiles in oris acriori folis aeftui expofitis domicilia fua habeant: in una lynce natura exceptionem feciffe videtur ( $b$. . Quod fi in Africae etiam Indiaeque regionibus lynces proprie fic dictae obviae: unquam fuiffent; vera tamen certaque ratio, cur coeli, fub quo natae effent, patriaeque fuae calorem cum fri-

gi-

(a) Folis cauda abbreviata apice atra, auriculis apice barbatis. Linnaei Syft.

(b) Memoratu dignum eft, omnes tigrinos aut fafciis variegatis notatos quadrupedes vel fub corrida zona, rel in terris eidem conterminis vivere, quod ex zebrae', ciraffac, tigridis regiae, pantiorac, leopardi, forvali, margayae, exeloti, civetce, genettae, follarace, aliquot muffetorum \& alio: mum quorundam exemplis difcimus. 


\section{G E O G R A P H I C A E. 307}

gidioribus plagis commutaverint, adferri nulla poffet. Experientia enim docemur, carnivoras beftias ea potiffimum de caufa calidiores tractus caeteris praeferre, quia plura in illis, quam alibi, animalia, quorum carnibus famem propulfent, habeant.

ठ. II. Kleinius quidem (c), fe Dresdae lyncem ex Africa eo delatam vidiffe, perhibet. Quum vero peregrinantium nemo lyncium in terris nimio folis igne calentibus vifarum mentionem faciat, \& illi, qui vel peregrinorum animantium commercium faciunt, vel iffa argento foluto fpectanda exhibent, ea vel in $A$ frica vel India orta effe, mentiantur: argumenta, quae Buffowizls lynci huic africanae oppofuit, tanti mihi ponderis effe videntur, ut, quin iis affentiar, non poffim.

ఏ. III. Quantum e teftibus fide dignis conjectare licet, lynx in Europa Norvagiam (d) Sheciamque (c) inhabitat, ubi duplex ejus varietas, alba nimirum nigris maculis diftineta, quam indigenae Kattlo denominant, \& fubrufa nigro variegata, quam $W$ arglo vocitant, invenitur. Finnia porro, Livonia, Curlandia, Litbuania $(f)$, Pomerania, \& omnis Germania feptentrionalis lynces nutrit $(g)$, easque Galliae etiam incolas quondam fuiffe ferunt $(b)$. Et quis unquam, earum aliquas alpium adhuc pyrenaeorumque montium ferfores effe, praefracte negaverit? licet expreffis Buffonius ( $i$ ) verbis nullas Galliam lynces alerre teftetur.

ठ. IV.

(c) Quadrup. Difpolit. p. 77. vide polfea de Lynce Kolbii.

(d) Pontoppid. 1. c. p. 40. (e) Fauna Suec. p. 2.

(f) Rzacynski Auctar. Hit. Nac. Polon.

(s) Hallens Naturgifch. T. I. p. 524 . \&c. \& Dobel. J. c.

(h) Plin. Hift. Nat. Lib. VIII. Cap. XIX. (i) T. IX. p. Iz6.

Qq2 


\section{SPECIMEN ZOOLOGIAE}

ఏ. IV. In temperatioribus Afia borealis regionibus lynces commorari, ex ea patet, quod in Sibiriae $(k)$, Cafanenfum (l), Arenburgenfum (m.) Cabardeique (n): terris occurrant, \& ad: quinquagefimum usque latitudinis gradum, qui in Europa etiam ultimus ipfarum terminus eft., defcendant. Americam autem aquilonarem. lynces habere, inde conftat, quod in Gaspefrae finibus ad. Laurentii ripas ( 0 ) in Huronenfum terris $(P), \&$ per omnes Canadae (q) \& Carolinae $(r)$ regiones ad trigefimum quintum usque gradum obviae fint.

6. V.. Novus hic etiam orbis duas earum varietates: fovet, quarum altera albida nigris maculis notata noftrati perfimilis eft; alteram, quae novi Eboraci (Neu-Pork) feffor eft, natura pelle ex fufco rufa, fufcis quidem, minus tamen diftincte expreffis maculis veftivit, pilis: mollioribus inftruxit, caudamque atris ftriis infignivit; quam Pennantws in praeftantidiimo opere fuo fub Baylyncis appellatione, propter infignem, quo ornata eft, colorem, fufius defcripfit $(s)$. Et ex imagine eleganti, quam adjecit, manifefte fatis apparet, beftiam hanc lyncis varietatibus omnino accenfendam effe.

6. VI. Hoc itaque etiam animal, Aincricac terras Europae regionibus multo frigidiores effe, nos ccrtiffi:

mos:

(k) Nouveaux Mémoires fur la grande Ruffie 'T. II. p. 73 .

(l) Pallas. Reir: 'T. I: p. 143 .

(in) Ryt fchkov Orenburg. Topographie in Bufchings Magaz. T. V.II. p. 40.

(.n) Staehelins Nachrichten von der Cabardei in Bufchings Magaz. T. V.1. p. 46\%: (a) Nouvelle Rélation de Gâfpefie par lo Clercq. Paris. $169 \mathrm{f}_{0}$ p. 483. ( $p$ ) Voyage de Theodat. p. 307 .

(q) Allg. Reir. T. XVII. p. $229 . \quad(r)$ Lanjon's Carolina p. . I \&

(s.) Synopf. p. 188. Tab. XIX. 


\section{G E O G R A P I C A E}

mos reddit. Attamen feptentrionis traetus intenfiori frigore horrentes nullos occupat. Groznlandia enim, Spitzberga, Nova Zembla, \& alia eorundem graduum loca lynces ignorant. Quam autem Kolbius in bonae fpei promontorio offendilfe adfirmat: (ti), aut Servalus aut Guepardus, quem Buffonius nobis defcriptum dedit, efre videtur; quippe qui lyncibus, fi fafciculos e pilis longiffimis conftantes auricularum apicibus adnatos exceperis, fimillimus eft. Accedit, quod praeter Kolbiun auctor fide dignus, qui Africaim, quantum peregrinantibus pervia eft, peragravit, nullus lyncium ibi abviarum mentionem ullam fecerit.

$$
\begin{gathered}
\text { S. E C T I o. V I } \\
\text { Gulo (a) }
\end{gathered}
$$

5. I. I yncem beftia fequatur, quae diverfffimi qu:dem generis eft, fed tamen easdem fere cum illa terras incolit, parique in feptentrionis oris crudelitate furit: gulo eft, quem nefcio, quo fato naturae fcrutatores modo cum byaena, modo cum wolverena five quikbatcbio (b) permutaverunt. Ab byaena ipfüm differre, certum jam expeditumque eft; eundem vero a wolverena etiam diftare eo exactius disquiramus; quoniam viri ab animalium cognitione inftructiffimi, Buffonius nimirum Pennantusque Linnaei, dictas hafe be.

(t) Kolbe 1. c. p. I57.

(a) Gulo. Muftela pedibus fiffis corpore rufo fufco medio dorfi ni ro. Iinnaci Syft. Ed. XiI. le Gloutton Buffon. T. XUII. p. I55:

(b.) Urfus. luscus. Urfus cauda elongata, corpore ferrugineo; roftso fusfo, fronte plagaque laterali. Linnaci Ed. XII..

Q. $3:$ 


\section{0 \\ SPECIMEN ZOOLOGIAE}

beftias, gulonem fcilicet $\&$ wolverenam dirimentis, fententiam refutaturi, unam eandenque effe autumant.

V. II. Utrorumque animalium defcriptionem quum laudati jam viri omnes dederint, \& illa, quae margini adpofui fupplementi loco effe poffint (c): eam praetermiffurus, praecipua tantum momenta, quibus inter fe diftinguantur, adferam: quorum unum ad totum $\mathrm{ex}^{-}$ ternum beftiaruni habitum fpectat, eft, quod wolverena melis admodum perfimilis eft; gulo e contrario ad canis villofi, brevioribus pedibus pilisque minus crispatis praediti effigiem accedit, cui aúres refectae viden-

tur

(c)

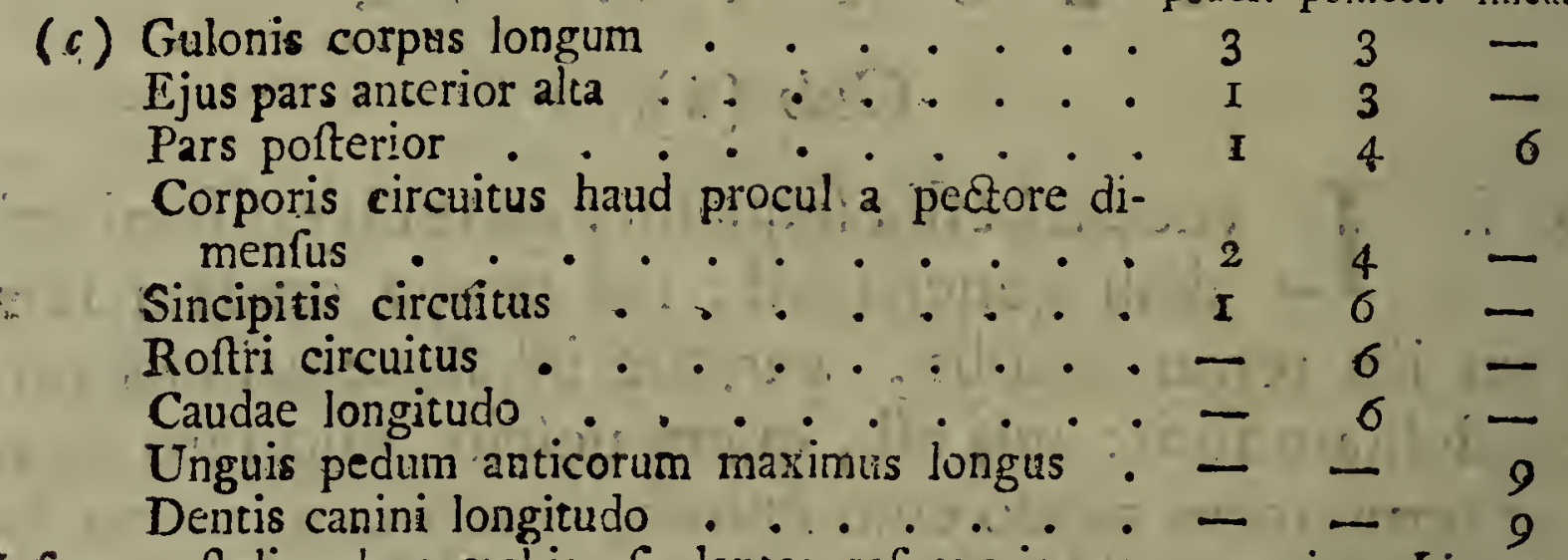

Ipfum muftelis adnumerabis, fi dentes refpexeris, quos optime Linnaeus deferipfit; licet hoc in uno difeeflerit, quod ultimam inolarium minorem prioribus fecit, quum jufto tamen ordine gradátim fic promineant, ut ultimus omnium maximus altiffimusque effe videatur. Totius corporis color niger; line inde grifeo admifcetur; pedes admodum villof toti funt cinervi. Fafcia fulva per dorfum procurrit. Pellis inftar panni damafceni diverfis figuris ornata eft. Pili perasperi martis crinibus bonitate cedunt. Roftrum brevioresque aures nigri funt coloris; oculis fat magnis praeditus efle videtur; quamvis illi, quos in pelle effarcta confpexi, nimis protrufi effent. Tam in anticis, quam polticis pedibus quatuor digiti numerantur. Quod Kleinius ipfutn pentadactylis adnumeravit, id foli, quod vidit, exemplo proprium fuiffe fufpicor. Quadrupes hic haud procul Helmfadi, plumbea confixus eft glandula, cujus cadaver pollinctum in ducali rerum naturalium thefauro Brinsvigae adfervatur, quod imagini, quam folus Klci. sius optiman dedit, exacte refpondet. 


\section{GE $\odot$ G R A P H I C A E. 3RT}

tur $(d)$. Hac in comparatione optime utrorungue animantium icones, quas Kleinnus de gulone $(e) \& t$ \& $d$ wardits de wolverena $(f)$ dederunt, ob oculos milhi verfantur. Roftro deinde inter fe difcrepant, quod wolverena mucronatum, gulo autem craffum habet \& obtufum; poftea gulonis caput globi fpeciem refert, quod in walverena productius eft. Haec porro laevibus, nec, uti gulo, villofis pilis tecta incedit. Tum gulo nec ex fulco rufi, quod Limnceus adfirmat, nec inftar volverenae ab Eidwar do depietae lucidi coloriș eft, nec albicantibus lunatis in pectore maculis, quibus quickbatcbium ornatum Pennantus tradit, infignitur : verbo, nec color, nec pili inter fe conveniunt.

J. III. $G$ $\sharp l o$ adhaec caudae loco fafciculo villofo. denfoque -utitur; quam wolverenze cauda peraequa proportione \&x longior \& laevior, \&, ubi corpori adhaeret, tenuior effe foleat. Tandem gulo pelle penitus undulata, quicḱbatcbius contra laevi tectus cernitur. Quas omnes diverfitates non e contradicendi pruritu, fed partim ex ipfis animalium imaginibus, quas laudati fupra auctores exhibuerunt, partim ex ipfo, quod: effarctuin Brmasvigae adfervatur, exemplari collegimus,

de

(d) Pontoppidanus in Hift. Norugg. T. II. p. 45. admodum congruenter: gulonis facies, inquit, \& magnitudo: eadem fere eft, quae canis; oblongi; craffioribus autem pedibus acutisque $\&$ unguibus $\&$ dentibus in ftructus eft. (e) Kleinii difpofitio quadrup. Tab. V.

(f) Edwardi avium Tom. IV. Tab. 103. Pennantus in Synops: of Qua. erup. p. Iو6. elegantem etiam beftiae figuram dedit; fed quum Ediyardus: eam vivarn vivisque coloribus depingi curaverit, Pennantus vero pellem. tantum delineaverit; illius pitius imaginem, in qua dorfum beftiae conve. xum. apparet, eligendam effe putavi.: 
de quibus, cuicunque omnia contemplari libuerit, facile convincetur $(g)$.

0. IV. Si wolverenam, cujus iconem Edwardus aut $P$ emnanutus delineandam curaverunt, attento perluftraveris animo, facile ipfi pone Racoon aut urfam toiorem $(b)_{3}$ guod Linnaeus fecit, optime locum tribuendum effe concedes. Gulo autem, cujus corpus corpori canum perfimile eft, quique muftelarum dentes habet, fingutare diverfumque genus quoddam conftituere mihi videtur. Fortaffis natura ipfum in confinio utrarumque bestiarum medium pofuit, illasque ejus interjectu copulare voluit.

Q. V. Si vero, cur Buffonius utrasque unam eandemque effe ftatuerit, rogitaveris; refponfum feres: quia utrarumque feptentrio patria eft, ex qua in vicinas continentes terras tranfire potuerunt; nec aliae ullae tam fimiles fibi beftiae reperiri poffint. Hanc normam, lianc naturae regulam effe concedamus, feptentrionis aninalia utrique orbi effe communia. Non itaque nego, mirandan videri exceptionem, quam natura hane in regulam adfcripfiffet; mox tamen auctorem laudabo, qui gulonem in America etiam reperiri, luculenter teftasur. Quaeres fortaffe: qui fiat, ut wolverena antiquum orbem hucusque minus inviferit? Sed pari etiam tatione requiram, cur tigris regin Afram quidem, nec

(g) Praecife interim negare noluerim, coeli aërisque temperiem regiozumque dittantias e gulone wolverenam formare potuife; quod autem, an revera factum fit, adhuc dubito; praecipue quum tam gulo, quam wolvoscrac Americae fint feffores.

(z) Urfus lotor. Linnaews. le Raton Buffon. Racoon. Falms America. 
tamen Africam, cur profimiae Africam, nunquam vero Afam inhabitent? Etfi ad quaeftiones hafee nec certa fatis, nec evidens refponfio reddi queat; idcirco tamen rationes, quibus wolvercnam gulonemque diverfas plane beftias effe, demonftravi, minime gentium evertentur.

ঠ: VI. Donec itaque utrasque nec varias inter fe nec difpares effe convictus fuero, eas ut disjungam, quos terrae tractus gulo folus pervagetur, disquiram oportet. Lappin (i), Norvagia $(k)$, Suecia $(l)$, $\boldsymbol{R} u \int$ fia, Litbuaniaque $(m)$, praecipuae funt antiqui orbis regiones, in quibus vivit. Interdum ad Germaniann usque procedit. In Saxonia enim quendam olim captum effe, Kleinius teftatur (n); \& alius, cujus fupra jam in margine mentio facta eft, in agro Brunfuicens $/$ prope Helmfladium confixus eft; qui tamen infmi forte extremique commorationis fuae in Europa termini funt. In auftralis enim Germaniae ignoratione verfatur; folumque natale fuum feptentrio eft, ubi in ufitatorum pervulgatorumque animalium numero haberi folet. In omnibus propemodum $A$ /zae borealis partibus obvius eft. Sibiria enim Burattorum (o) Tunguforumque terrae, Cafani regnum ( $p)$, Elutborum (q.) fines, naultique alii majoris Tirtariae tractus $(r)$, quin Kamt chatki etiam ipfum alunt; \& hac in regione aliquam ipfius va-

rie-

(i) Scheffers Lappland \& Hogfiroem l. c. p. 22.

(k) Pontoppid. l. c. p. 45 . (i) Fauna Suec. p. 2.

(m) Rzacynski l. c. p. 218. (n) Ktein l. c.

(o) Emclin (fen.) T. 1I. p. 203. \& p. 470. \& T. III. p. 492.

(p) R $t$ t flkkov Orenburg. Topograph. in Bufching Magaz. T. vIT. p. 4 G.

(i) Alg. Reil. T. li1. p. 8\$, (r) Tsbrand Tides Reife nach China R 


\section{SPECIMEN ZOOLOGIAE}

rietatem reperiri, ex Krascbenninikovii verbis colligo('s), qui fubalbidi gulonis meminit.

6. VII. Nec Americam gulonibus vacare, duobus modo teftimoniis comprobare poffum. Quodfi vero wolverenam, gulonem etiam effe dixeris, plura guionis veftigia in novo hoc orbe habebis. Cranzius ( $t$ ), ipfum fub Amanki nomine in Groenlandia, raro tamen inveniri, adfirmat. Vir diligentiffimus in prima hiftoriae Groenlandicae editione beftiam hanc de folo nomine cognoverat; poftea vero accuratius omnia exquirens, eandem terrae hujus indigenis voracitate fua formidolofam effe infamemque, ad canis majoris magnitudinem accedere, \& pelle ex nigro canefcente veitiri, audivit (u); quae omnia in folum gulonem quadrare, nemo non inteiliget. Ipfum autem inter Esquimavios etiam in Labradoris terra haberi, difertis verbis aditruit $(v)$; an $\&$ aliae Americae regiones ipfum foveant, certi quidquam nec habeo, nec reperire potui. Ex quibus omnibus manifeftum eft, gulonem per utriusque \& novi \& veteris orbis borealis regiones diffipatum effe; Gmelinum tamen, qui animantem hanc pari cum homine paffu per omnem terrae fuperficiem diffurum ftatuit, magnopere falli ( $w)$ : quum nec Africam, nec Ainm auftralem, nec Americam meridianam gulones unquain nutriviffe, conftet.

SECTIO

(s) Allg. Reir. T. XX. p. 265. (t) Ibid. p. 39.

(u) Cramz. Fortfetzung der Hiftorie von Groenland Barby 1770. pag. 237. (y) Ibid. pag. 308.

(अ) Gmelin Reifen T. III. p. 495. Buffonii opinioni alfentio, qui, Grnelinum nac in re errafe, \& hyaenam cum gulons permutavife, putat. 


\section{GEOGR A P.H I C A E. $3 I_{5}$}

\section{$S$ E C T I O VII.}

0. I. $\mathbf{P}$ auci fuperfunt quadrupedes, qui quantum. Pqidem certo conftat, in utroque orbe obvii funt. Quum iis folis, qui feptentrionem incolunt, ex Europa in Americam migrare liceat: exiguus, fi eos, quorum jam mentio facta eft, exceperis, illorum numerus reitabit, de quibus hoc in fecundo capite dicendum eft: quorum tamen nonnulli, exemplum fit mus lemnus aliique, certis tantum locis quafi affixi videntur. Praeter jam percenfitos itaque feptem adhuc capitis hujus parti priori, Jciurum volantem puta, mamnotam, melem, murem ampbibium, murem terreftrem, mufelam zibellinam, murem porcellunn \& rofmarum adneOti poffe, exiftimo.

\section{Sciurus volans ( $a$ ).}

0. II. Beftiolam hanc volantem tam fub veteris, quam novi orbis axe boreali, fedes domiciliaque fua conItituiffe, e documentis deinceps producendis manifefte apparebit. Interim filentio non praetereundum eft, $\mathrm{Lin}$ naeun duos ejusdem feceiei animantes, quorum alter Scinrus hic, alter ex murium genere eft $(b)$, cui fuum etiam fubdidit, recenfuiffe; pofteriorem folus Seba \& vidit $\&$ depictum dedit $(c)$, qui a priori, qui grifeus $\&$

fub-

(a) Sciuriis yolans. Sciurus hypochondriis prolixis volitans, cauda rotundata. Linnaei Edit. XII. le Polatoubize. Buffon T. X.

(b) Mus volans. Mus cauda elongata, villofa palmis teiradactylis, plantis pentadactylis, hypociondris extenfis volitans. Limmaei Edit. XII.

(c) Seba 'Thefaur. T. I. p. 72. Tab. XLIV.

$$
\operatorname{Rr} 2
$$




\section{SPECIMEN ZOOLOGIAE}

fribflavus eft, partim rufo fufcoque colore, partim eo diftat, quod membrana, cujus ope \& falit \& volat, jam capiti adnata confpicitur, quod in priori fecus habet: partim, quod anticis in pedibus quatuor, in pofticis quinque digitis utitur. Sed quod primo: ad colorem attinet, hunc in fingulis fere fciurorum fpeciebus immur tari, neminem fugir; deinde pedum digiti in foiuro volante (Polatouche) fere iidem funt, qui in anterioribus, quod Daubentonius teftatur $(d \cdot)$, quatuor quidem digitos, fed aliquod etiam pollicis veftigium, in pofterioribus totidem cum pollice exferto habet. Nonne fieri poterat, ut Seba ad pollicis illud veftigium in animante. jam mortuo \& exficcato minus attenderit? Membranan denique fuperiori paulum loco, quam in Sciuro volante, acapite nimirum occipere, non tanti res.momenti videturr, ut idcirco nova, cuibeftiolam hanc fubmittamus, fpecies conftituatur.- Quum praeterea mus his volans. Sizuro generatim quam. fimillimus fit,, ex eadem, in: qua ille commorari folet, regione, e Virginiae fcilicet \&. Mexici. oris allatus, \&, quod praecipuum eft, aeque ac fciurus pernox vivere \& circumvolitare confueverit; quin murem hunc, vel ipfum.fciurum, vèl. faltim ejus varietatem effe ftatuam non poffum.. Quod eo me confidentins. facere poffe autumo, quia Linnaeuss, dum animantis hujus meminit, ad Edwwrdum provocat; Edrwardus autem follum. coilurun volantem (e), murem vero nullim defcripfit.

§. III. " Multo autem certius eft \& exploratius, Bris. Soniz:

(d.), Buffon 1. c..p. s9. (e) Edwarlis Rirds T. I. p. Igr. . 


\section{G E O GR A P H I C A E 317}

fonii fciurum $(f)$, quem Ecureuil volant de Sibérie nominavit, pro fciuri. volantis varietate effe habenduin; quippe cui fimillimus eft, cum quo eandem patriam incolit, \& in hoc uno differt, qquod totus canus \& proceriori eft corpore.

0. IV. Quibus praemiffis, locanune, in quibus habitat, determinatu erunt facillima. In Siberia Gmelinus (g.) fenior eum tam in U/t-Iginskoi terris, quam prope Mofcoviac urbem, frequentem fatis vidit. Kleinio (b) aliquot ejus exemplaria ex.Kriczowien/i praefectura, quae in . Wobilavien/s regione in $R$ ulfiae confiniis jacet, transmittebantur, \&, Linnaeo tefte, Lappian Finniamque incolit (i). Ipfum per Americam feptentrionalem late fatis difpergi, Canada (k), Hurones (b), Carolina (m), Penfyluania (k),

- Virginiaque (o) docent, quibus omnibus notiffimus eft, $\&$, auctore Fernandezio, hinc ad Mexicun ( $p$ ) usque difceffit... Quum beftia haec in antiquo orbe nuspiam. quinquagefimum quartum longitudinis gradum tranfiliat; Mexicum autem tropicum contingat; novo exinde documento, Americam majori frigoris vi afflari, coarguimur.

(f) Regn. animal. Edit. ato p. 159: fciums dilute cinereus, cute ab anticis cruribus ad poftica, membranae in modum extenfa, volans.

(g) Gmeirn (fen.) l. c. 'T. II' pag. 232 :

(h) Quadr. difpofit. p. 54. 1lli, quos habui, habitame, in flys Capitaneatus Kriczovienfis in confiniis Ruffae.

(i) Fauna Suecica pag. 9. (k) Allg. Reif. T. XVII. p. 23 r.

(l) Voyage de Théodat. p. 3c5. (m) Lawfön Carolina p. 124:

(n) Kalmii itiner. T. II. p. 352. \& 460. qui hos Americae fuuros fio birienfibus exacte refpondere, affirmat.

(o.) Hift. du nouvear nonde par F. de Laet p. 88. \& Seba Thefur. T. I. p. 72 .

(pi) Fernandes Hift. Animal: novae Hifp: p. 9. in Hemanil The auro serum Medic. nov. Hifp. Rumae $16.5 \%$ 


\section{I8 SPECIMEN ZOOLOGIAE}

ఏ. V. Interrogabis fortaffe, quid de Limmaei Sagitta (q) ftatuendum? annon etian ad fciuri volantis'varietatem referri debeat? fi externum ejus habitum formamque confulueris; vel nullo plane, vel exiguo admodum difcrimine utrasque animantes inter fe differre, concedo. Quoniam autem in favae tantummodo aliisque paucis prope adjacentibus infulis commoratur, \& in majoribus feptentrionem inter dietasque infulas pofitis terrae tractibus plane ignoratur: hane Sagittan eo usque fingularem quandam Jciuri fpeciem puto, donec aliquis naturalium fcientia excultus illis in regionibus. ipfam contemplatus, quae \& qualis fit, apertius nos docuerit. In tabula interim geographica tanquam beftiam fingularem eam Yavae adfcriptam invenies $(r)$.

$$
S \text { E } \quad \text { C } \quad T \text { I } O \text { V V I I I. }
$$

\section{Marmota (a).}

5. I. Ut inftitutio noftra de Marmota eo commodius fufcipiatur, quid beftiae huic praecipuum a natura datum fit, ante docebo. Sic enim omnes illius varietates uno quafi obtutu perluftrare, \& quousque dilatentur, (dilatantur autem longe fatis lateque) dijudicare poterimus. Non folum marmotae formam, fed mores etiam, vitae rationem, \& confti-

tu-

(q) Sciurus Sagitta fc. Hypochondriis prolixis volitans, cauda planopinnata lanceolata. Linn. Opcimam ejus defcriptionem \& jinaginem Forzsaantus in Synopfa p. 292. dedit, quam in Pallufii ctiam Mifoellan. Zoolog. p. 54. defcriptam videre bicet. (iv) Vid. Cap. III.

(a) Marnota. Mus canda abbrieviata, fubpilofa, auriculis rotundatis, buccis gibbis. Linnaei Syjt. Ed. XII. Buffon T. VIII. 


\section{G E O G R A P H I C A E.}

tutionem eircumfpiciamus. Differt autem a caeteris fibi haud diffmilibus beftiis, his maxime in rebus, quod primo generatim fua fibi domicilia montanis in tractibus, quin iplis etiam in montibus condat; ideoque non mirandum eft, eam in Helvetia, Sabaudia aliisque ejusdem indolis regionibus inveniri. Deinde vel ipfa fibi fpeluncas effodit, vel jam effoffas \& ante factas occupat; tum fonus, quem edit, tibiae inflatae frmilis aures peracute ferit \& complet. Tandem bruma ingruente, nifi calidioribus in locis affervata fuerit, obrigefcit, \& lethali quafi fomno fopita jacet. Quae figna praemittere placuit, ut, quae animalia marmotae adnumerare poffis, quae minus, eo facilius dignofas: quae tamen omnia de iis duntaxat beftiis intellecta velim, quae externam aliqualem marnotae fpeciem referunt. Quas quum Linnaeus $(b)$, Buffonius \& alii, qui in tradenda animantium natura occupati fuerunt, ample latis defcripferint; hoc negotio fuperfedere poffum.

0. II. Primo itaque in Polonia aliisque regionibus: deinceps nominandis beftiola quaedam occurrit, cui Babako nomen eft, cujusque forma exerior a marmoto nihil fere aut paululum faltim diftat; quare Daubentonius $(c)$ etiam hanc illamque eandem effe ftatuit. Rzacynskius iftam in Carpatbicis montibus habitare $(d)$, acutiffmum fiftulae fonum edere, per hiemem obrigefce-

(b) Iinn. Syft. Ed. XU. Glires. Rius. n. 7, 8, 9.\& Pennant. Synopr. fub titulo Marmot. p. 268.

(c) Dailientonius Bobakum marmotae in omnibus praeter pollicem, qui in illo major duobusque offulis, quae huic defunt, inftructus eft, fimillimun effe adfirmat. Buffon T. XIII. le Bobak.

(di) Razcynski Hilt. Yol. nat. p. 233. 


\section{SPECIMEN ZOOLOGIAE}

fere, fpecus, quos incolat, ipfam fibi apparare, facillimo negotio manfuefcere, canesque perinde atque alpium marmetas odio habere tradit. Ex quibus omnibus recte Buffonius, Bobakun marmotae varietatem effe contendit, cujus grifeus tantummodo color in abbidiorem, flavus in pallidiorem mutatus fit.

0. III. Dein Americae borealis, Canadae nimirum \& Penfyluaniae frigidiores orae monacem nutriunt, quem Catesbyus (e) depingi curavit, $\boldsymbol{P}$ ennantusque propter infignem \& formae \& morum fimilitudinem marmotis adfociat. Licet enim cauda paulo proceriori pilofiorique inftruatus fit; nihilo tamen minus ipfum maimotarum fpeciem effe, his de caufis cenfeo, quod in frobibus etiam habitat, fonum tibiae acutiffimum edit: quapropter ipfam Galli fftulatorem (Jiffenir) nuncupant $(f)$, \& perfacile ad manfuetudinem domatur.

6. IV. Fortaffe quis Jevraschkam a Gmelino $(g)$ defriptam propter morum, quibus utitur, frmilitudinem, narmotarum Speciei adnumerandam effe arbitrabitur; fed quum marnotis longe minor efie foleat, praetereaque easdem cum Bobako terras incolat, \& quod deinceps demonftratum dabo, pro mure potius citello ( $Z$ icfelratte) haberi debeat, jure ipfam hinc amovendam effe putavi; \& quoniam Bobakus eosdem Sibiriae fines, quos Jevrascbka occupat, hac ad terminos, per quos marmota fefe extendat, conftituendos non opus erit.

f. $V$.

(e) Catesby Carolina app. 28. vel Seligmann Vogel T. IV. Tab. CII. Mus monax. Mus cauda mediocri pilofa, corpore cinereo, auriculis fubratundis, palmis tetradaetylis, plantis pentadactylis. Linnaeus.

(f) La Hontan Voy. T. 1. P. 233 :

(s) Gurelin (fen.) Reir. 'T. IL. p. 443 \& 444 . 
0. V. Poftquam igitur mormotam, bobakum, monacen unum idemque animal effe cognovitus; ; nunc. etiam, quousque diffundantur perquiramus. Italiae autem Helvetiaeque alpes acervatim incolunt; hine in $A$ thAriam (b) transgredientes, in Podolia Poloniaque ( $i)$ fub Bubaki appellatione occurrunt. Ab Alpibus itaque per Tirolem ad Carpatbi juga pergunt. Bobakus auten in Urale vicinisque huic montibus \& in $C_{n} \int a n i$ jugis, ubi Suroki nomen accepit, denuo confpicitur $(k)$. Quumque montes hi cuin Carpatbo cohaereant $(l)$, marmota vero montium feffor fit; quin interjacentibus etiam in $R$ uffae regionibus inveniatur, nullus dubito. $\mathrm{Ab} \mathrm{U}^{*}$ ile ad Siberiae montes, ad Jakuzkam (m) Chinenfemque Tattariam $(n)$ usque procedit. Hos omnes autem montes alpium jugis catenae inftar committi, \& per Sibriam in Tattariam usque uno tenore excurrere, e laudati jam Buacbii exactiffma tabula geographica difcimus. Cunctis itaque in montibus, inter quadragefimum tertium ac quartum \& fexagefimum circiter latitudinis gradum orbis antiqui poftis, qui cum alpibus nexi.quafi jugatique funt, marmotam commorari, non exigua cum probabilitatis fpecie autumo.

0. VI. Et hinc ratio patet, cur nec Suecin, nec Lappia Norvagiaque marmotas alere pofft. Quamvis enim nonnullos harum regionum tractus minor frigoris vis afflet: beftiae tamen huic, quae per montium edita

pro-

(h) Kramer Elenchus Vegetabilium \& Animalium per $\Lambda$ uftriam inferio. rem obfervatorum. Viennae 1756.8 vo. p. $317 . \quad$ (i) Rzacynski.l.c.

(k) Pallas Reif. T. I. p. 96. \& p. I29.

(l) Vid. Buache Cartes Phyfiques. (m) Gmelin (fen.) T. II. p. 445 .

(n) Bell's Iravels to China T. I. p. $33 \%$. 


\section{S PECIMEN Z OOLOGIAE}

progredi folet, longo nimis circuitu prius per altiora feptentrionis loca eundum fuiffet, quam dictos montes potuiffet adfequi. Quod ipfa quoque experientia confirmatur, quae nec Sueciam, nec Lappiam Norvagiamque marmotas nutrire docet. In America, cujus indigenae ipfi monacis feu fiftulatoris nomen impofuerunt, in Penfylvaniae, Marilandiae \& Quebecci montibus, quin \& in Babamenfibus (o) infulis vivit, isque extremus domicilii fui terminus eft. Et quoniam, hanc novi orbis partem majori longe frigore prae antiquo urgeri, jam faepius commonftravi; haec procul dubio ratio eft, cur animal hoc a vicefimo tantum fexto ad quadragefmum octavum borealis latitudinis gradum adfcenderit. Ex quibus omnibus apparet, animantem hunc latam fatis utriusque orbis fafciam occupare. In calidis autem $A$. Siae Africatque terris fruftra hucusque quaefitus eft. Qua vero ratione, gua via ex antiquo in novum orbem tranfierit, quidve de tanta ejus migratione cum aliqua probabilitate in medium proferri poffit; in altera, quam adjunxi, disquifitione declarabo.

$$
\begin{gathered}
\text { S E C T I O I X. } \\
\text { Meles }(a) .
\end{gathered}
$$

6. I. ic folitudinis incola etf magnum fatis fepH 1 tentrionalis hemisphaerii tractum occupat, nullibi tamen acervatim confpicitur; nec de illius varie-

ta-

(o) Cateshy 1. c. \& Peinant. 1. c. p. 270.

(a) Melcs. Urfus canda concolore, corpore fupra cinereo, fubtus nigro, farcia longitudinali per oculos auresque nigra. Linnati Ed. XIl. 


\section{G E O G R A P H I C A E. . 323.}

tatibus auetores multa narrare memini. Venatores qui-. dem melein caninam a fuilla fecernere fuftinent (b), fed nec Buffonio, quamvis quoscunque poterat, ad disquifitionem vocaffet, ajroirny quendam expifcari.licuit, qui de hac nullius fere momenti differentia certiorem ipfum redderet; quod idem quum \& mihi acciderit, hanc diftinctionem plane rejiciendam, foliusque varietatis a Briffonio memoratae (c) mentionem faciendam effe, puto: cujus pellis pars fuperior tota albens, inferior flavebat, quin \& ungues albi; corporis autem longitudo, quae in noftratibus duos dinidiumque pedem. efficere folet, unius tantumimado novemque digitorum erat. Qui quadrupes quum ex novo Americae Eboraco, Realmurio dono miflus fuerit, facile ad fufpicandum, Americae meles omnes albere, perducere poffet; quod ipfum tamen a veritate longe averfum effe, novique potius orbis meles noftratibus exacte congruere, deinceps commonftrabo. Haec itaque melis varietas eadem forte ratione, qua rattos muresque candidos a reliquis fui generis prognatòs fupra diximus, a vulgaribus etiam parentibus oriunda eft.

0. II. Quousque meles dilatetur, confideraturus ab Europa ordiar, ubi, Buffonio tefte (d), in Galliae, Germaniae, Angliae, Poloniae, Italine, Hifpaniaeque finibus occurrit, quos ultra tamen in calidiores terras minus progreffa, nec Graecis cognita fuiffe videtur. Sha-

(b) Meles caninus; meles fuillus. Meles canina roftro paulum craffiore prae fuilla praedita dicitur.

(c) Briffon regre animal. p. 255. Ed, Parifienf. Meles fupra alba, infra ex albo tiavicans. (d) Buffon T. VIII 
324 SPECIMEN ZOOLOGIAE

Shawius (e) in Barbarin nullam reperiri planiffme dicit; alique, qui Africam adierunt, ne minimam, quantum mihi quidem innotuit, melis mentionem inferunt. Septentrionales, quas Europae regiones incolit, Suecia funt $(f)$ \& Norragia $(g)$, cujus tamen inferiores moderatioresque tantum oras melem occupaffe crediderim, quia in Lappia, Islandia Siberineque regionibus iisdem cum Norvagìa fub latitudinis gradibus politis, fruftra eam guaefireris.

0.III. Afrae quidem, fed temperatiorum modo tractuum incola eft; quippe quae frigoris vehementiam abhorrere videtur. Sic montuofa Simbrrskii loca(b), $\mathcal{J}_{\text {aiki }}$ ripas $(i)$, Cafanque terras generatim frequentare folet. Et quoniam in Chinenfum regno revifitur $(k)$, ipfam quoque Taltarue Chinam inter Rufflamque jacentis, feflorem effe, conjicio.

6. IV... In America boreali Penfyluaniam (l) inhabitat, \& in Hudfonis etiam freto $(m)$ comparet. Kalmims in ipra America, Pennantus autem Londini melium americanarun pelles illis, quas Śucia alit, fimillimas. viderunt. Melem vero ad Mexici Floridaeque terminos defcendiffe, nec volam, nec veftigium reperire potui. Certos ipfi fines, quos intra contineatmr, nemo facile conftituit ; partim quia folitudines amat, partim quia fub terra plerumque vivere, $\&$ in fpeluncas fe abdere, raroque fub hominum confpectum venire fuevit. Interim.

ex

(e) Shaw Reif. p. i54. (f) Fauna Suec. p. 6 .

(g) Pontoppid. 1. c. p. 5t. (h) Pallas Reif. 1. I. p. I2g.

(i) Ihid. p. 376. (k) Bells Travels T. II. p. 83 ;

(1) Kalms Reif. T. If. p. 332. (m) Pennant. Synóp. p. 20.2. 


\section{G E O G R A P H I C A E. 325}

ex hactenus dictis fatis patet, non injuria melem feptentrionis animantibus accenfendam effe, quae $\&$ novo \& antiquo orbi communis, ad fexagefimum duntaxat longitudinis gradum adfcendat, calidosque nimis Africae, Afrae Americaeque traetus devitet.

$$
\begin{aligned}
& \text { S E C T I O X. } \\
& \text { Mus ampbibius }(a) .
\end{aligned}
$$

D. I. Mus amplibizis \& erre/fris itidem feptentrionis habitatores funt, qui exinde per utrumque orbem difcurrunt. Prió per omnem Europam diffipatus in Italia, Germania, Gallia, Anglia aliisque regionibus reperitur, \& aquilonem verfus haud ultra Sueciam $(b)$ progreditur; fortaffe tamen in quibusdam adhuc Norvagine locis commoratur $(c)$. Ipfum in torrentibus meridiano fole terris vivere, auctorum nemo praeter $B c l$ conem adftruit, qui Aegypti eum incolam effe adfeverat (d). Interim tamen mercator quidam teftis ocularis. fidem, qua dignus erat, mihi fecit, favac infulas magnis glurim amphibiorum alba pelle veftitorum gregibus abundare. Quae relatio fi minus a veritate deflectit, duplici de caufa memoratu effet digniffima; partim, quia frriptorum nullus murium in calidioribus terris obviorum mentionem agitavit, partim quod novo fic argumento $\mathbb{B u f}_{\mathrm{f}}$

(a) Mus amplibius; müs cauda elongata, pilofa, plantis palmatis. Lina naei Ed. XII. Per erroren vir celeberrimus palmatis feripfife videtur. Non enim caftorum inftar membrana, qua natet, inftructa eft, quod tamen Lin. naei vncult innuere videcur. (b) Fauna Succ. p. Io.

(c) Pontopp. l. c. 'J. II, p. 57. (d) Belon. Aquat. 30.

Ss 3 


\section{SPECIMEN ZOOLOGIAE}

Buffonii fententia, Zonam torridam aninalia candida nulla proferre tradentis, frangeretur. Aliud enim, exemplum jam ante, quum de muftelis ageremus, allatum eft.

6. II. America vero, maxime autem Carolinne $(e)$ \&r Perifybaniae $(f)$ agri, glires amphibios tam folito fuo colore infignitos, quam alba fubcanaque pelle vefitos nutriunt. Omnes, quos quidem potui, libros excuffi, ut quousque praeterea animal hoc diffunderetur, exquirerem ; fed operam oleumque periffe fateor: interim tamen quae adduxi, ad comprobandum fufficiunt, iftud eorum numero, quae tam novo, quam antiquo orbi propria funt \& communia, attribuendum effe.

$$
\begin{gathered}
\mathrm{S} \text { E } \mathrm{C} \text { T I } \mathbf{0} . \mathrm{XI} \\
\text { Mus terreftris }(a) .
\end{gathered}
$$

M uri amphibio terreffrem fubnectimus, quippe qui II itidem in utroque jam orbe vivere dicitur, \&z, Buffonio auEtore, non in Germaniae folum \& Galliae, fed in Italiac etiam Helvetiaeque campis occurrit $(b)$. Linnaeus in Suecin (c) \& Pennantus in Anglia (d) ipfum obvium effe, expreffis verbis teftantur. Quum itaque. Europae aquilonale frigus tolerare poffit, ipfum Amevicae etiam feptentrionalis algori fuftinendo parem effe,

(e) Law fon Hitt. Carol. p. I22. (f) Buffon T. XV. p. 9\%.

(a) Mus terreftris. Mus cauda mediocri lubpilofa, palmis fubtetradactylis, planis pentadadylis, auriculis vellere brevioribus: Linnaeus. Le Campagnol. Buffon. T. V1l.

(c) Fau.i. Sicc.

(b) Buffon T. VIl. p. 187 .

(d) Synop!. of Quadrup. p. 305. 


\section{G E O G. R A P H I C A E $\quad 327$}

ne miremur. Pemantus, eum Terram novam (Terre neuve, Newfonndland) magnis jam agminibus frequen: tare, fribit $(e)$. Num autem per alias etiam regiones, \& quam late diffundatur, nihil certi habeo. Utrum navibus noftris eo transportatus, an potius novi etiam orbis indigena fit, \& a rerum principio tam Americae, quam Europae incola fuerit, nec ajere, neque negare poflum.

\section{$\begin{array}{llllllllll}S & \mathbf{E} & \mathrm{C} & \mathbf{T} & \mathbf{I} & \mathbf{O} & \mathrm{X} & \mathrm{I} & \mathrm{I} & \end{array}$ Múfela Zibellina (a).}

ఠ. I. Duplici ratione commotus muftelam hanc $\mathrm{Zi}$ bellinam animalibus, quae utrique orbi communia funt, adnumerare audeo; partim quia omnes fere beftiae, quarum patria antiqui orbis feptentrio eft, etiam in novum tranfiverunt; partim quia $P$ 'ennarltus muftelarum fpeciem aliquam, in America feptentrionali quae reperiatur, attulit (b) , cujus facies, forma \& ftructura, unam fi magnitudinem exceperis, quam proxime ad Zibellinum accedit, quain piccium multelent . (Fissber IV ce/cl (c) nuncupavit. Pedes hirti \& craffrores, crinium radices fubalbae, acumina vero nigra, caput ex

(e) Ibid. (a) Muftela pedibus fifis, corpore obfeure fulvo, fronte exalbida, gutture cinereo. Linn La Zibeline. Buffon T. Xllf. Nov. Commentar. Petropol. T. V. Tab. VI. (b) Synopf. of Quadrup. pag. 223. (c) Cur hoc nomen ipfi impofitum fit, quum pircibus nullis nutriatur, parum conftat. Folfelynus, tefte Pennanto, animal hocce, Sable h. e. muftelam Zilullinam, vocat. v. JoJsilyn Voy. p. 8\%. 


\section{SPECIMEN ZOOLOGI.AE}

albido cinercum, myftax craffiorum \& prominentium pilorum, albi ungues, digiti tam anticis quam pofticis in pedibus quinque, in pofticis interdum quatuor, cauda longiori \& villofa, colorum in variis animantibus crebrae variaeque mutationes, verbo, omnia ipfi cum Zibellino noftra communia funt; fola tamen magnitudine diftat. Noftrae enim corpus fi a nafo ad caudam dimetieris, oftodecim plerumque, fi caudam feorfin, duodecim pollices numerabis. A Pennanto autem memoratae beftiae longitudo ad caudan usque viginti octo, caudae folius feptendecim digitorum eft, quae quidem

- differentia notatu digna. Si tamen illa in animum revocaveris quae hactenus de aliis ejusdem quidem fpeciei, diverfffimae licet magnitudinis animantibus allata funt; fi porro tecum reputaveris, omnes fere antiqui orbis quadrupedes, quorum domicilium feptentrio eft, quive per fpatiofos terrae tractus diffuf vagantur, Amercae etiam borealis incolas effe : tunc facile, hanc etiam, procul dubio, in novum orbem tranfiiffe ad conjiciciendum duceris; alioquin enim folus propemodum foret, quem ab univerfali regula eximeres. Vitio igitur $P$ ennanto minime vertes, qui maxima cum probabilitate beftiam hanc Americae Zibellinam effe dixerit.

0. II. Quodfi ergo in celeberrimi viri fententiam difcefferis, hanc ipfam multo latius prae Sciuro volante diffufarm videbis. In Lappia (d) enim, Ruffia (c) totaque Siberia $(f)$ \& quam maxime \& optime prope Nert-

fchins-

(a) Oeuvres de Réguard '1. 1. \& Schefers Lappland pag. 136.

(c) Mullers Sammlung Rufifciter Gelchente T. 11!. p. 505 .

(f) Ibid. p. $506-50$ \% 


\section{G E O G R A P H I C A E.}

fbinski \& Fakuzki urbes $(g)$, infuper in Tattaria (b), Kamtfcbatka (i), Cbina (k), Kurrlibusque infulis (l), confici capique folet. A Pennanto autem defcripta Zibellina major Americam feptentrionalem acervatim pererrat; in Novo Eboraco \& Penfyluania ( $m$ ) praecipue, fedem fibi fixit, unde per annum aliquot centuriae pel-1 lium in Europam deportari folent.

D. III. In veteri orbe vix ultra quinquagefimum octavum gradum procurrit; in America vero, quae vehementiori frigore uritur, ad quadragefimum usque defcendit. Varietates noftrae ex coloris pilorumque bonitate aeftimantur $(n)$. Dantur enim fufcae, dilute $\&$ obfcure fulvae; poftremae, nigrae \& Kangarienfes (0) appellantur; quas vero plurimi aeftimant, e Nert/cbinski \& Fakuzki provinciis deferuntur ; interdum $\&$ albae totae, raro tamen inventae funt $(p)$. Eadem colorum \& americanae Zibellinae ratio eft; modo enim fufcum, modo dilute, modo oblcure fulvum colorem indue. re fueverunt.

(f) Gmelin. (fen.) 1. c. T. II. in praefat. \& p. 36. \& Muller 1. c. p. 508 :

(h) Allg. Reif. T. VIr. p. I 3. (i) Muller l. c. p. 510.

(k) Allg. Reif. T. VII. p. 474. (l) Pennant. l. c. p. $21 \%$.

(iin) lbid. l. c. p. 223 .

(n) Zibellinae pili tam flexiles funt, ut, quocunque manibis eos detruferis demulferisque, nunquam obnitantur., femper patius \& prompte fequantur. (早) Gmelin. (fen.) l. c. (p) Muller l. c. p.515.

$$
\text { T. }
$$




\section{SPECIMEN LOOLOGIAE \\ S E C. T I O. X I I I. \\ Mus porceilus $(a)$}

T anc beftiolam heic loci adnectamus, quae etfi ex 1 America originem trahat, in Europam tamen translata tot tantisque aucta eft incrementis, ut domefticis pene noftratibus addici queat. In Brafiliae quae ipfam genuit, aliisque calidioribus Americae terris Caviae (Cobayae) nomine appellatur (b). In Europam inde transportata in Lufitaniae, Hispaniae, Galline (c), Germaniaeque locis permultis mirum in modum multiplicata reperitur; a frigore tamen, cujus impatiens eft, tuta praeftetur oportet. In Africam quoque e patria fua eam effe transmiffam, exinde probabile eft, quod $A n-$ gli eandem porcellum Guinenjem ( Guinea - pig) vocitant. Colorem ejus noftris in regionibus admodum variare, exinde difcimus, quod albi, nigri, lutei $\&$ difcolores porcelli mures permulti numerari foleant.

$$
\begin{gathered}
\mathrm{S} \mathbf{E} \mathbf{C} \mathbf{T} \mathbf{I} \text { o } \mathrm{X} I \mathrm{~V} \text {. } \\
\text { Rofmarus }(a) \text {. }
\end{gathered}
$$

arum abfuit quin Zonae frigidae belluam quac hard: 1 quidem continentem utriusque orbis teram, maria tamen, utrumque interfluentia, occupat, omififfem. Ress-

(a) Mus porcellus. Mus canda nulla, palmis tetradactylis, plantis tridactylis. Linnaeus. Le Cochon d'Inde. Buffon T. VIII.

(b) Pito de utriusq. Indiae re natur. \& med. p. 102 .

(c) Buffon T. VIII. pag. I.

(a) Rosmarus. Trichechus dentibus laniariis. fuperioribus exfertis. Lizz maets. Le Morfe. Buffor T. XuII. 


\section{G E O G R P H I C A E. 31}

Rosmarns eft, feu equus marinus, quem olim in quadragefimo quarto vel quinto latitudinis feptentrionalis gradu, commoratum effe, ex eo liquet, quod Galli quondam eundem capturi, navibus ad Sabuli promontorium (Cap Sable) haud procul a Novae. Scotiae finibus, fub quadragefimo quarto latitudinis gradu fitum, profecti funt $(b)$. Nunc autem, quod Busfonius teftatur $(c)$, equos marinos polarem citra circulum nullos vel perpaucos invenire licet; fatisque probabile eft, hominum avaritiam, quae balaenas etiam ulterius propulit, effeciffe, ut equi etiam marini, priftinis fedibus fuis relictis, ad axem propius fint progreffi. Omnia propemodum maria feptentrioni vicina, quae haud longe a polari circulo diftant, \& tam veterem quam novum orbem circumfluunt, Rosmarus occupat. In Huidfonis enim freto (d), Laurentii fuminis oftia $(e), I_{s-}$ landiae $(f)$, Groenlandiae $(g)$, Spitzbergae $(b)$, novae Zembliae \& Samojitiae oras $(i)$, Anadirskoi $(k)$ \& Kamt)chatkae (l) littora, frequentat, \& verbo, a polo ad quinquagefimum fere quintum latitudinis feptentrionalis gradum defcendit, omniaque oceani freta, quae tam antiquum quam novum orbem circumfundunt inhabitat.

SECTIO

(b) Lenis Ueicription de l'Anérique Septentrion. T. 1. p. 66.

(c) Bufion T XIII. .

(d) Ellis Hudfons Meerbufen. In Goett. Reir. T. I. p. 260. \& paffim.

(c) Defcription des Indes Occident. par de Laet. p. 42 .

(f) Anderfons Island p. 105. (g) Cranz in Allg. Reif: T. XX. p. 62.

(h) Martens spitzbergen p. $18 \mathrm{I}$.

(i) Yorgdragers Walfichlfang. Nurnberg. 1750. pag. I94 \& I95.

(k) Muller Saınm. Ruff. Gefch. T. III. p. 564 .

(l) Krafchennikow in Allg. Reif. T. XX. p. $26 \%$. 
332 SPECIMEN ZOOLOGIAE

\section{S E C T I O X V.}

A bfolviffe nunc videor eorum quadrupedum enarraA tionem, qui utriusque orbis Zonam ab axe propemodum boreali ad tricefimum fere latitudinis gradum usque procurrentem, \& ita non regiones modo infefto frigore preffas, fed earum etiam partem occupant, quae moderatiori jam coelo auraque fruuntur. Buffonius quidem erinaceum illis \& vespertilionem addidit; fed licet perquirendo multum laboris exhauferim, exinaceum tamen in America offendere mihi non licuit. Negare non audeo, fieri per naturam poffe, ut vespertilio nofter in Americam transvolarit; necefre tamen foret, ut coeli locique diverfitas habitum ejus moresque ita immutaverit', ut peregrinatorum nemo ipfum nolle quiverit; quippe qui cuncti illum taciti praeterierunt. $\mathrm{Et}$ quanquam qui nzovum Eboracum inhabitat (a), noftratem magnitudine aequiparet; figura tamen differt, dentibusque inciforibus nullis utitur. Hiftoria itaque parvulorum horum quadrupedum tam manca adhuc tan!que incerta eft, ut, quousque diffundantur, quod allis: hactenus in beftilis emolitus fum, nunquăan disquirere aufim. Varias itaque vespertiliomum fpecies caput tertium, \& quamlibet quidem in fua patria fic exhibebit ${ }_{\approx}$ uti in tabula geographica annotata reperitur.

SECTIO:

(m) Pennant. Synops. p. 367. No. 283. Noftris etiam refpertilionibus ex Daubentonii ( $\left.{ }^{*}\right)$ teftinonio dentes incifores deeife, concedo; trabicus tamen \& forma Novi Eboraci vefpertilionum penicus a noftratibus diftat.

$\left({ }^{*}\right)$ Eutfon T. VIII. s. $\mathrm{X}$. 


\section{G E O G R P H I A E. 333}

$S$ E C T I O X V I.

ఏ. I. Unc ad quadrupedes transeundun effet, quí 1 in folo orbe antiquo non exigua fibi fpatia vindicant; ante tamen trium vel quatuor animalium. mentionem faciamus, quorum patria quidem feptentrio non eft, quae tamen nihilo fecius orbis tam antiqui, quam novi, feffores funt. Negare quidem \& pernegare: Buffonius conatur, beftias in regionibus propiore folis: appulfu ardentibus viventes, utroque in orbe reperiri. Et feptentrionis quam maxime quadrupedes e continenti terra in continentem facillime transmigrare potuifie, $\&$ revera tranfiife, ex hactenus dictis fole claritis elucet. Interim tamen veritas, licet omnes contra nitantur, per fe ftat ac perftat. Et quanticunque ponderis. Butfioni fit effatum, id tamen aliquot animantium in-s dole infrrmatur, quos quidem vir eximius unius novi orbis habitatores effe adfirmat $(a)$, quos tamen anti-: quus etiam alit. Eosautem perpaucos effe numero, nec antiquo in orbe late disperfos inveniri, lubentifime largior.

0. 11. Primus illorum mihi Pbilander efto (b), fecundus Targidradus (c) (Unain), tertius Myrmciopbiya', quartus Pbalangero (d) quaedam fimilis befia, quibus: for - :

(a) De rationibus, quas propter Bufonins haec animalia, quae calidioris Amcricae feffores funt, antigito in orbe non reperiri ftatuit, quid-; ve de jpforum migrationibus judicari poffit, lector benevalus, disyuilitio. nem alteram, opufculo hus arncesam, confulat.

(b) Didelphis tnarfupialis. Did. mammis oceo intra abdomen. Limagus:s, Ee Sarigue. Puffon ri. X. (c) Bradypus didaetylus. L'Unau. Buffom I. XuI. (d) Le Phalanger. Buffon. T. XIII. 


\section{SPECIMEN ZOOLOGIAE}

forfan fpecies alia major glirium volantium addi poffeet.

б. III. Pio jam Pbilandrum in Amboinae terris fedem habere patriam me docuerat $(e)$, nec ignorabam, smurem mar/upialen Sebne ex eadem regione ipfi transmiffum fuifre: quo ipfo Pifonis opinio confirmari videtur. Interim Buffonius fpeciofiffimas oppofuit caufas, quibus huic fententiae adverfus ivit. Infuper \& Seba ipfe teftatur, Pbilandrum, quem ex Amboina acceperit, peregre eo fuife transportatum $(f)$; quibus verbis non occulte approbat, quae Buffonius dixit. Vix itaque eo perduci poteram, utbeftiae, quae folis Americae terris ufitata \& pervulgata eft, in orientali etiam India patrium folum darem. Perlectis tamen, quae P'ennantus in Synop/s fua collegit $(g)$, Bankiusque de itineribus fuis confcripfit $(B)$, verifimillima caeteroqui fententia Buffonii : Zonae torridae animantes, quibus \& $P$ Pbilander adnumerandus eft, non utriusque orbis incolas effe, adftruentis, fic animum in deliberando diftraxit, ut, quo me verterem, non haberem. Pemnanus enim Pifonem, Valentynam \& Braynium (1) auctores laudat, qui Pbilandrum Indiam orrentalem inhabitare perhibeant; fed etiam multos magnosque in Batavia rerum naturalium collectores hanc beftian creberrime ex ifta orientem verfus fita regione accerfendam curare, feque eo ipfo quam maxime convictun effe teftatur, Pbilandrum

aeque

(e) Pifo Hitt. Nat. \& Med. Lib. V.Cap. XXIV. pag. 323. De Cariguey'a (1arigue) in Inaiis Orientalibus, idque folum, quantum hactenus con. tat in Amboina fimilis beftia frequens \&c. nomen illi Cous. Cous inditum.

(f) Seba Thef. Vol. 1. p. 64. hocce animal nobis ex Amboina miffum eft fub nomine Coes - Coes, eo quidem delatum ex oris remotioribus.

(g) Pag. 206. (h) Cook's Voyage in Hawkesworth's Collect. T. III. (i) Le Bruyn Voyages T. I. p. 347 . 


\section{G E O G R A P H I C A E. 335}

aeque in continenti Americae terra, atque in orientalibus antiqui orbis infulis optime provenire.

6. IV. Omni interim attentione dignum eft, quod \& Pifo \& Seba narravere: beftiam nimirum hanc non in tota verfus orientem India, fed in una Amboinae regione reperiri. Quid? fi nauta quidam vulgaris lufitanicae vel batavae navis e Braflic exeuntis, fe in Europam trajectum iri credens (nautici enim operarii. facpiffime tunc demum de curfu, quem teneant, maritimo certiores fiunt, quando vela jam in altum data funt) marem feminamque $P$ bilandri tanquam rarioris animan. tis, aut curiofitatis, aut lucri caufa, fecum fumfiffet, \& deinceps invitus praeterque opinionem non Europae, fed orientalis Indiae portum, quo praetor navalis contendit, appulfus utrosque vel pretio redemtos, vel taedio, vel alia quacunque caufa motus, liberos demififfet? Nonne fieri poterat, ut regionis fertilitate, aërisque falabritate adjuti, fobolem propagaverint, quae deinceps aucta eft? Hanc faltim conjecturam accipere, quam Buffonio contradicere, \& Pbilandrum in orientali India domi effe, ftatuere malim. Ipfum interea in Virginia, ¿x infulis Antillis (k) Louifrana (l), Mexici (m), Guimane (n), Brafoline (o) Peruviacque (p) territoriss, fparfimque in orientalis Indiae quibusdam partibus, qualicunque fato eo delatus fit, commorari, nemo nunc inficiabitur.

Q. $\mathrm{V}$.

(k) Rochefort Hift. des Antilles. p. I22.

(l) Du Pratz Louifiana T. 11. p. 65. (m) Rochefort l. c.

(n) Barrere France Equinox, p. 16\%. (o) Pijo. L. c.

(p) Allg. Reir. T. XVI. 
336. SPECIMEN ZOOLOGIAE

6. V. Quemadmodum antem id, quod ad veritatem propenfus videcur, exemplis nifi roborari, faltim illuftrari poteft, alins beftiae mentionem adjiciam, quan pari ratione Antricac terminis Buffonius circumferipferat, \& nihilominus in aliis etiam antiqui orbis regionibus obvia eft, illique admodum congruit, quam fub Pbalangeri appellatione Buffonius defcripit: ", Ani\% mantis, (Caukii verba funt (q)) ex Opofforumn gene$\Rightarrow$ re Bankio heic loci (Novae erat Hollandiue nuperri" me detecta orientem verfus jacens ora) capiendi " copia dabatur : Femella erat, quam duo pulli comi" tabantur. Ex omnibus a apparebat, eam beftiae fimil"Jimam elfe, cui Buffonius Pbalangeri nomen impo" fuit. Vir hic rerun caeteroqui naturalium peritiffi"mus, qui eam folius Americae fefforem effe autumat, " per errorem lapfus effe videtur. Propius enim ve"ro funt, quae P'allafus de P'balangero tradidit, Pha" langerum fcilicet Indiae orientali proprium effe. "Quem enim Bankius nactus eft, uti habitu \& mori"bus, fic potiffmum pedibus, quibus a quovis alio \% animantium genere mirum in modum ablorret, illi "quam fimillimus eft."

"O. VI. -Quodfi ergo, quem Buffonius vidit, Surinamae fuit habitator, hic in nova telluris parte (fic jure novam Hollandiam appellamus) quae centum quadraginta gradus \& amplius, feu, quod codem recidit, ad'minimum mille centunque milliaria germanica a $S_{u-}$ riname diftat, a Bankiv captus, evidentiffime commonftrare

(a) Corks Voyage round the World inHawkesworth's Collection $T$. III. p. si3. 


\section{G E O G R A P H I C A E. 337}

re poterit, eundem in remotiffmis etiam ab Americae terris reperiri. Quodfi vero Buffonius in determinanda illius patria erravit, \&, qui orientalis Indiac indigena erat, Anericae fefforem effe perhibuit: inde pari ratione patefcit, animalia ad Pbilandrorum feu Opofforum genus (nam ipfe difertis verbis Pbalangerum Pbilandro perfimilem effe ait) pertinentia non in folo orbe novo nutriri. Interim tamen aequitate fic poftulante fateamur oportet, fieri potuiffe, ut tam Pbalangerus ille, quam a Bankio vifus animans, novum aliquod genus conftituat, quod in unis Indiae orientalis Vulturnum fpectantis partibus domicilium habeat.

0. VII. Neque iis fides deneganda eft, qui Tardigradum (r) aeque in Cellonis infula, quam in occidentali initia fedem habere tridunt. Bufforizusiisdem de caufis, quibus $P$ bilundrum in folam Americam meridionalem relegaverat, $\&$ hunc iisdem novi orbis cancellis inclufit. Si tamen anceps adhuc \& ambiguum Sebae teftimonium foret $(s)$, quo orientalis Indiae indigenam ipfum nuncupavit, Penmantus accedit $(t)$, qui a viro, cui fides negari non potuit, cuique in orientali India commoranti fatis longum temporis intervallum effluxit, edoctum fe effe, confirmat: Tardigradum in Rengalae montibus Paliacat tcrjibus non infrequentem reperiri.

0. VIII. Idem hic Penmantus animantem a Bosmann:o $(u)$ in Guineae littoribus vifum, \& Pottonis nomine infignem, ad Tardigradorum genus referendum effe au-

tu-

( $r$ ) Bradypus didactylus. Bradypus manibus didactylis, cauda nulla. Limaei Edit. XII. I'I naut. (s) Seba I hefaur. T. I. Tab. XXXIV.

(t) Synopf. p. 321 . (u) Bosmans Guinea p. 296. 


\section{SPECIMEN ZOOLOGIAE}

tumat; \& res ipfa cogit, ut concedamus, Pottoniems hunc iisdem cum Tardigrado moribus effe. Bosmannus enim eum, propter fingularem, qua langueat, focordiam, Igravom feu Luyaerd a Batavis nuncupari teftatur, illum turpem etiam deformemque adfpectu effe addit. Quum autem caput etiam mirae magnitudinis \& anticos pedes ipfi tribuerit, qui manibus humanis fint perfimiles; utrumque vero in Tardigradis nunquam conficiatur: eum vel ex Unavorum genere eximi, vel, fi Tardigradis. nihilo fecius adnumerandus fuerit, eousque plane intactum feponi debere exiftimo, donec temporis fucceffu \& peregrinantium diligentia lumen huic animali affundatur.

6. IX. Vera nihilominus germanaque Tardigradi patria mihi America efie videcur, in qua non unam alteramque infulam aut exiguam folummodo regionem occupat, fed Surinamae Cayennacque (v) terras plerasque, quas Amazonius fluvius regiones alluit (w), Brafilianque $(x)$ tenet; quum e contrario praeter Ceilonis infulam Bengalaeque partem locus antiqui orbis nullus, quem inhabitet, notus fit.

C. X. Myrmecophay arum quandam fpeciem in veteri brbe vivere, licet Buffonius aliter exiftimet, certum: tamen eft. $P^{\prime}$ allufus enim hujus beftiae foetum in bonae. fpei promontorio repertum defcripfit $(y)$, Kobbiusque fe ibidem animal, a Batavis Suem ( $\boldsymbol{z}$ ) terreflem vocitaturn, confpexife, adfirmat, cujus roftro dentes de-

(y) Buffon '1'. Xlll. p. 22. \& 1eq.

(w) Abbeville Mifronau Maranon p. 252. (x) Allg. Reif.T.XVI.p. 273.

(y) Pallas, Mifcellan. Zoolog. p. 64. (z) Kolbenls. Vorgeb: p. 165 . 
defint, quod praelongam linguam formicetis immitters formicis vitam toleret, peracutis unguibus armatum, capite tenuiffimum in roftrum exeunte, pilisque ex fulvo rufis praeditum fit. Quicunque datis ex hifce tam certis perfpicuisque fignis Americae Tamandwam non noverit, ipfam vel penitus ignoraverit, aut ex induftria ignorare velit opus eft. Interim hace ipfa eft beftia, cujus foetum Pallafus delineavit, cujusque anticos pedes quatuor digitis inftructos fuiffe tradidit. Parum abeft, quin perfuadear, Myrmecopbagan, quam Scbadefcripfit, ex Africa ipfi adlatam fuiffe. Strachanus eam Ceilonis quoque incolam effe autumat, ubi fub $T$ algoi nomine innotefcat (a). Quibus omnibus aequa mente ponderatis, annon, ut Pennanto Pallafioque afrenfum. praebeas, \& aliquas horum animantium varietates in orbis etiam antiqui calidioribus terris vivere concedas, perfuadebere $(b)$ ?

6. XI. Recenfiti hucusque pauci quadrupedes priorem inter \& pofteriorem fecundi capitis fectionem medium quafi locum nec injuria fibi vindicant. Quum enim prior eos contineat, qui magnum per utriusque orbis aquilonales regiones fpatium occupant, pofteriori autem illos tributurus fin, qui antiquo tantum in orbe magnos terrae tractus tenent: haud abfonum videbatur, eos, de quibus jam locuti fumus, quibus America

(a) Philofoph. Transaet. Abrid. Vol. V. p. ISo.

(b) Pennantus quidem, Americam quoque pantheres veros alere fufpiextur. Quum vero nullus teftis ciztort:1s \& fide dignus hujus rei nos certiores reddat; viro adfentiri enusque differam; donec meliora certioraque cdoctus fuero, \& pantherem interim anriqui orbis indigenam efie aurumo.

$$
\mathrm{VV} 2
$$




\section{$34^{\circ}$ SPECIMEN ZOOLOGIAE}

rica quidem patria eft, qui tamen in fingulis etiam quibusdam veteris orbis partibus reperiuntur, in utriusque Sectionis medio pofuiffe.

\section{A P I T I S S E C U N D I P A RS POSTERIOR.}

Do animantibus magnos antiqui tantum orbis traElus tenentibus.

$$
\begin{array}{llllllll}
S & E & C & T & I & O & I
\end{array}
$$

merica nunc relicta ad caeteras tres orbis antiqui A partes pergimus, quarum eos tantummodo quadrupedes narrabimus, qui, quod minimum fit, per duas mundi partes late fatis diffufi offenduntur. Eos autem quam maxime, qui per fexaginta longitudinis gradus diffipantur, hic percenfere mecum conftitui; quumque nullus eorum in leptentrione fedem habeat patriam; cuivis illorum longitudinis graduum, quos inhabitant, decem ad minimum milliaria germanica dari volo. Dein regiones, per quas diffeminentur, nifi maribus aut lacubus majoribus nonnullis interfluis dirimantur inter fe cohaerere fuppono. Quemadmodum itaque in priori fectione ab aquilone ad aequatorem usque, quantum licuit, progreffus fum; fic hac etiam in pofteriori, eadem ratione eademque via pergam; \& primo quidem, quinque beftiolas habemus obvias, quae ab naturae indagatorum nonnullis murium generi, $\mathrm{ab}$ aliis vero marmotis adjiciuntur; quales funt Mus citel- 


\section{G E O G R A P H I C A E. 34!}

lus, Cricetus, Glis feu Rattus fomnolentus, Surmulo: tus \& Erinaceus europaeus.

\section{Mus citelliss (a).}

6. I. Animal hoc Buffonius cum Pennanto a Souslika diffociaverunt; utrique iftud vel ex paucis, quae infpicere ipfis licuerat, exemplis, vel ex folis eorundem defcriptionibus procul dubio noverant. P'allafius itaque, cui crebrior magnam eorum viventium copiam fpeculandi contemplandique facultas data fuit, dux nobis \& auctor fit. Praeftantiffimus hic Naturae inveftigator Souslikum Muremque citellum eandem effe beftiam evincit, \& aliquot cjus varietates, quae tam colore, quam magnitudine inter fe differant, reperiri confirmat. , Omnium, inquit vir celeberrimus (b), qui g. vaftitates (Steppen) incolunt, animantium vulga"riffinus eft Mus citellus, quem \& Souslik nominant, " qui varios vaftosque campos omnes, W L olgam inter " \& Tanaim fitos, ad quinquagefimum tertium fere " latitudinis gradum catervatim pervagatur. Pelle ni" tidiffime maculata tegitur, quan propter dignus es" fet, qui acervatim caperetur, quod factu facillimum " eft. Idem vero animans in omnibus tam meridiona"libus, quam ad Volgam auftrum verfus pofitis Sibe, riae regionibus non majori folum corporis amplitudi", ne, fed aliter etiam variegata pelle, quae canis ma", culis ornata efre folet, praeditus confpicitur. Cau, dam

(a) Citellus. Mus cauda abbreviata, corpore cir cres, auriculis nullis. Linnaeus. Le Zifel \& le Souslik. Butfoin T. XV. ,

(b) Pailas Reicrn curch Runand T. I. p. I29.

$\mathrm{V} \vee 3$ 


\section{2 \\ SPECIMEN Z OOLOGIAE}

" dam villofam \& totam Marmetae fpeciem habet, cu"jus etiam mores imitatur." Hactenus Pallafus.

j. II. Haec ea ipfa eft beftiola, quod Pennontus etiam obfervavit, quam Gmelinus fenior haud procul Jakizko, Siberiae urbe, vidit, \& cujus fub Fevra/chkae appellatione mentionem fecit (c). Jevrajcbkam enim, fi magnitudinem exceperis, marmotae tam fimilem effe fribit, ut marmotae pumilio haud injufte dici mereatur. Prioribus Pallafuns addit: T Tcherkajfes, quae Tattarorum natio eft, Muri citello majori, feu, quod idem fit, Sufliko, Awrafcbkae appellationem indidifre. Ex quibus, Murem citellum, Suftikum \& Feoralcbkam diverra quidem nomina eandem vero beftiam effe, apparet; quae quousque fe diffuderit, facili nunc negotio explicari poteft.

0. III. Ex Hungaria (d), quae prima ejus in Europa fedes effe videtur, ad Auftriam (e) Bobemianque pergit; hinc Poloniam $(f)$ Ruffiamque petit, \& Mojcoviae regiones tranfiens Orenburgum usque, quin ad $\mathrm{Ca}$ fani regnum progreditur $(g)$. Hinc ad Siberiam ad Jakuzkii oppidum usque tranfit $(b)$. Tractum itaque percurrit, qui centum longitudinis gradus \& amplius continet \& a quadragefimo quinto ad fexagefimum fecundum latitudinis gradum extenditur.

SECTIO

(c) Cmelin. (fen.) Reif. T. II. p. $443 \& 444$.

(i) Gesner Hiftor. Animal. de Quadrup. p. 836 . (e) Ibid. pag. 835 .

(f) Rzacynski Hift. Natur. Polon. p. 235 .

(g) Rytfchkov Orenburg. Topogr. in Bufchings Magaz. T. VIl. p. 47. \& Fallas. 1. c. (li) Gmelin. (1en.) l. c. 


\section{G E O G R A P H I C A E.}

\section{S E C C T I O. I I:}

Cricétus (a).

0. I. urem citellum beftia fequatur, quae ejusI 1 dem generis, eorundem fere morum eft, \& per aeque magnum propemodum terrae fpatium disperfa reperitur. Criccius is eft, Gormanis, proh dolor! propter damnum, quod illis adfert, notiffimus; in tanta tamen ejus frequentia \& multitudine hucusque varietas nulla obfervari potuit. Quam Linnaeus ejus defcrip. tionem dedit, ea in noftrum quoque Cricetum exaete quadrat, fi cum, qui Cafani regnum incolit, exemeris. $P$ allafus enim praetervilgarem maculofum alius quoque varietatis mentionem fecit, quam totam nigram in omnibus Ruffine campis auftralibus penesque Simbirskii terras maxime commorari, caeterisque ufitatioribus frequentiorem inveniri dixit; coëunt tamen utrique inter fe; unusque puerperarum nidus \& nigros interdum Cricetulos \& maculofos continet $(b)$. Hoc unum Cricetus habet praecipui, quod varietas illa, fi ulterius paulo auftrum verfus procefferis, dispareat; cujus tamen rei culpam nec coeli, nec aëris temperiei tribuere poteris; utpote quae tam exigua in diftantia tanta effe nequit, ut tam repente colorem immutet. Hanc unam varietatem omnia inveftiganti mihi reperire licuit. Quem enim

Gme-

(a) Cricetws. Mus canda mediocri, auriculis rotundatis, corpore fub. tus nigro, lateribus rufefcentibus, maculis tribus albis. Linn. Buffon T. XIII. le Haimflei. Optina ejus imago habetur in Meieirs Thiere. Nurnberg. 1748. fol. 1. II. Tab. LXXXI \& LXXXI. (b) Pallas. Reif. T. I. p. 128. 
Gmelinus Junior orientis Cricetum nominat $(c)$, Suslikum effe, de quo jam diximus, curatior animantis contemplatio docet.

6. II. Quum Cricetus e Germania, ubi patriam ejus fedem efle furpicor, ex altera parte in Auftriam (d), ex altera vero in P'oloniam, Ucraniam (e), \& inde in Ruffiae Cafanique $(f)$ regna tranfeat; cum citello Mure fub eodem propemodum coeli tractu progredi videtur. Utrum vero, veluti Mus ifte in Siberiae quoque interiora penetret; valde dubito. Ipfius contra incunabula veftigiaque illis jan in regionibus reperies, quae magis occidentem fpectant, nec a Citello tanguntur. Germania enim, quae murem iftum adhuc ignorat, Cricetum. agrorum meffisque fuae vaftatorem ingenti fuo damno fatis fuperque cognofcit. Quodfi, per quos longitudinis gradus diffundatur, generatim computaveris, vix illorum fexaginta numerabis.

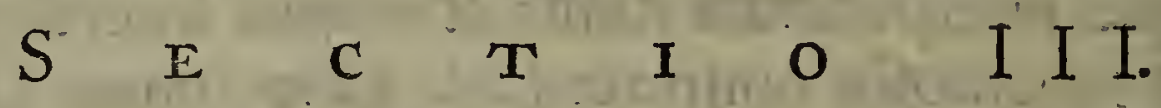

$$
\begin{aligned}
& \text { Glis feu Rattus fomnolentus (a). }
\end{aligned}
$$

Pergimus quadrupedes quosdam e Murium genere illis adjudicandos, qui omnium in hac fecundi capitis fectione memorandorum proxime feptentrionem domicilia fua habent, enumerare. Tales antiquorum glis, quem nunc Lindymonem feu murem Jomnolentum

(c) Gmelin. (jun.) Reife durch Runund. Tom. I. Tab. V. p. 30.

(d) Kramer Elenchus Veyetab. \& Animal. per Auftr. Inferior. obferv.

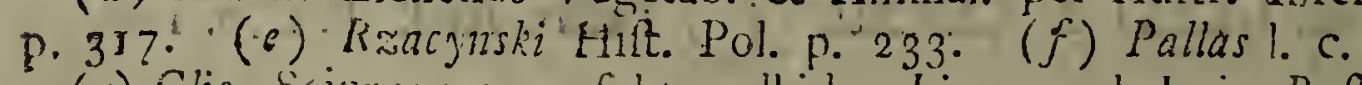

(a) Glis. Sciurus canus, fubtus albidus, Limacus, le Loir. Buffon. T. VII. 


\section{G E O G R P I C A E.}

(felenscblafer) appellant, \& furmulotus funt; quorum prior tamen, glis nempe veterum in Europa non tam feptentrionem, quam potius meridiem verfus progreditur. Hispaniae enim, Galliae, Helvetiae, Aufriae, Italiae $(b)$, cujus indigenae ipfo quondam hilarius avidiusque vefcebantur, Croatiae, quin \& Graeciae (c) incola eft. Porro in Cafani regionibus circa Samaram vivit (d), unde, quod veri eft fimillimum, per Ucraniami \& adjacentes Tattariae terras proceffit. Totus itaque, quem occupaffe videtur, tractus, octoginta circiter longitudinis gradus efficit, \& inter trigefimum quintum \& quinquagefimum quintum latitudinis gradum fitus eft.

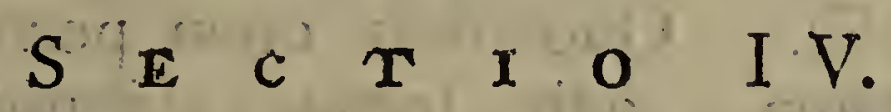

\section{Surmulotus froe rattus migrans (a).}

6. I. $P$ oft rattum muremque vulgarem beftia haec, quae ex murium genere eft, quam latiffime disperfa reperitur; quae etiam, quod admirationem movet, itinera in proximas terras inftituens, magnos faepe curfus abfolvit. Cives parifienfes, tefte Buffonio, ipfam anno feculi hujus quinquagefimo quarto adhuc ignorabant; nec magnae Britanniae feffores ipfam ante tricefimum ejusdem feculi annum noviffe, Pennantus do-

(b) Buffon T.VIIII. p. 93. \& Gesn Hitt. Quadrup. p. 62 r.

(c) Arijlot. Hift. Animal. Lib. ViII. Cap. XVII.

(d) Pallas Reif. T. I. p. 154 .

(a) Mus cauda longiffima, fupra dilute fulvus, infra allbicans. Brilonib Regn. Animal. p. 170. le Surmulot. Buffon.T. Vill. p. I18.

$$
\mathrm{X} \cdot \mathrm{x}
$$




\section{SPECIMEN ZOOLOGIAE}

docet (b), \& Gairkoi Gorodoki urbis in Ufenfi provincia pofitae, habitatores $P$ allafio narraverunt, hanc rattorum fpeciem poft fexagefinum quintum hujus feculi annum fuis demum in finibus vifum effe $(c)$. Quum enim magnis provincia ficcitatibus laboraret, beftiae hujus immenfa copia e vaftis Samarae campis ad urbem confugiens per portam aliquam urbi fe intulit, \& quod memoratt dignius eft, hospites hi perniciofi amplam illawn, qua urbs dirinitur, plateam nondum tranfiverunt, fed in urbis parte, quae orientem fpectat, conftiterunt. Quaecunque rei hujus memorabilis caufa fit, id faltem ex hifce auctorum locupletiffinorum relationibus patet, rattorum migratorum nomen jure ipfis impofitum efre. Quotannis enim porro pergunt: nec eft dubium, quin feculis quibuśdam praeterlapfis omnes telluris noftrae regiones, quarum aditu mari non prohibentur, occupaverint. Nunc eos $A n-$ glia, Gallia \& Germania nutritv Ip fos énin Bruñfugae in domibus, quas Ocrae fluvius adluit, confpiciendi crebrior mihi copia fnit. Utrum vero in terris acriori gelu rigentibus inveniantur, hac ex caufa dubito, quod feptentrionalium rerum naturalium feriptor nullus furmaloti: meminit; temperationes e contrarid regiones ipfis gratiores effe videntur. Eum vero Orenbusgumi usque perrexiffe, jani fupra dixi.

G. II. Surmulotun fub Randicotae nomine in orientali erian India obvium efie, $P$ tmantus teftatur $(d)$,

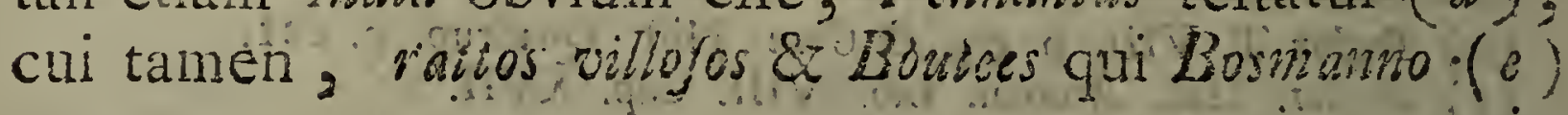

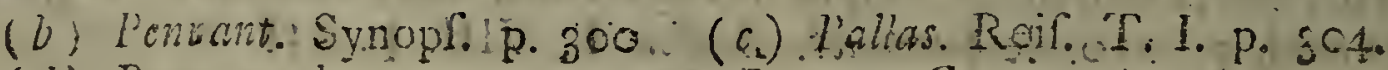

(4) Pcinant. 1. c. p. 300 : (a) Bosmans Gunea p. $29 \%$ 


\section{G. E O G A P II I C A E 3.4}

in Guinea occurrebant, furmulotos effe, adfirmanti affenfum praelere nequeo, quum expreffis verbis addideritl volleos illos felibus noftris majores \& Boutces paulo quidem tébuiores, multo tamen illis longiorcs fuiffe. Quomodocunque interim res fefe habeat, ex hactenus allatis videre licet, furmulotuin mirum in modum per telluris orbem extendi : quumque ingenti indies incremento augeatur; werendum effe, ne cum ratto tandem per moderatiores calidioresque terras omnes diffipetur.

\section{$S E C T I O V$. \\ Erinaceus Eiropaeus (a).}

Q. I. Quanvis adhue ambigan, utrum quadrupes hic tam late diffufus inveniatur, ut hoc in capite locum fibi aliquem vindicare poffit: nihilo tamen minus eundem hac maxime de caufa omittere nolui, quod Pennantis (b) Siberiae Erinaceum, quem Seba defcripfit (c), noftratis yarietatem effe perhibuit. Quodfi vir praeitantiffimus hac in re erraverit, noftratem tamen per quadraginta pluresque longitudinis gradus dilatari, certo conftat. A Port ugallia enim per Hispaniam (d) progreffus, median fere Peloniann penetrat (e). Eum in omnibus etiam interjacentibus terris, in Gallia fcilicet, Germania, Italia \& Graecia fédem habere, tam certuni fpectatumque eft, ut probatione nulla indigere videatur.

\footnotetext{
(a) Erinaceus Europaetis, auriculis rotundatis, naribus criftatis. Linnaeus.

(b) Pennant. Syn. p. 2 16. (c) Seba Thefaur. T. 1. p. 79.

(d) Buffon T. VIII. p. 20. (c) Racynski l. c. p. 233 . $\mathrm{X} \times 2$
} 


\section{SPECIMEN ZOOLOGIAE}

0. II. Ipfum vero moderatiores etiam Rufiae partes incolere, ex eo probabile fit, quod teftes aujtortat narrant, fe in Eftbiae ac Livoniae perinde atque Iing riae regionibus illum obfervaviffe. Si pellibus, ex quibus major ad nos utilitas redundaret, veftitus effet; hoc ipfo homines ad inveftigandum eum curiofiores facti, diligentius fine dubio ad ipfum attendiffent: nunc autem a plerisque peregrinantibus neglectus latet, \& ipfum Rytscbkovium in Orenburgi, quam edidit, defcriptione, beftiam hanc neglexiffe autumo, quoniam erinacoum auritum, qui Pallafio tamen ibidem obvius erat, $\&$ fingularem aliquan fpeciem efficere dicitur, omifit. Idem Pallafus in itineris per $C_{a}$ fani regnum inftituti narratione, praeter confuetudinem fuam, meamque opinionem, ipfum filentio praeteriit, nifi forte iis lub animantibus eum latere credideris, quos nimio gelu expofuit, \& an rigefcant, tentavit ( $f$ ); quod revera factum effe potuit. In dicto enim libro de erinaseo tanquam de beftia loquitur, quae facile obrigefcat; licet, utrum in aurito, an in vulgari erinacso periculum iftud fit factum, non addiderit. Si, cujus Seba mentionem fecit, erinacei noftri varietás eft, Siberiae incola effet; fed Gmelinus fenior ejusdem ne verbulo quidem meminit; cui tamen in magno itinere, quo Siberiam omnem emenfus eft, aliquoties occurrere debuiffet. Minus ipfum in feptentrionis indigenarum ignoratione verfari, ex Ponioppidano $(g)$ difcimus, qui eum in Norvagia vivere teftatur, quod idem \& Linnacus de Suecia confirmat (b). Lappim

(f) Pallas. Reir. T. I. (g) Pontoppid. Norweg. p. 55. (b) Faun. Suec. 


\section{G E O G R A P H I C A E. 349.}

pin vero, Islandia aliaeque iftorum latitudinis graduum: regiones, illum penitus ignorant. In temperatioris autem Zonae terris vix Europae Natoliaeque fines egreffus eft: Flaccurtius ( $i$ ) quidem crinaceum Madagnfcaris etiam in agris inveniri, qui noftrati perfimilis fit, commemorat. Quoniam vero Kolbius in relatione, quam de Africac animantibus dedit, tacitum ipfum praetermifit, prope ad credendum proclivis effem, Flaccurtium by/tricem nominatum intellectumque voluiffe, nifi alio quodam operis fui loco figillatim in animantis hujus mentionem incidiffet.

0. III. Ex iis, quae perfcrutando comperta habeo, certior factus effe videor, erinacetm noftratem nec in A/ra calidiori Africamque, nec in America habitare; quamvis illuftris Buffanius illorum claffi eum inferuerit, qui utriusque orbis regiones incolunt. Ipfum a quadragefimo quinto circiter latitudinis gradu ad fexagefimum usque extendi, fpatiumque intra decimum fexagefimumque latitudinis gradum occupare, nec hos fines facile transgredi, autumo. .

$$
\begin{aligned}
& \begin{array}{llllllll}
S & \mathbf{E} & \mathbf{C} & \mathbf{T} & \mathbf{I} & \mathbf{O} & \mathrm{V} & I .
\end{array} \\
& \text { Hyfrix (a). }
\end{aligned}
$$

Toc animal graviori fole ardefcentes orbis antiqui 1 regiones frequentat, \& nusquam hucusque in feptentrione repertum eft. Hyftrix enim canadenizs to-

(i) Flaccourt Madagafcar-p. I52.

(a) Hyfrix criftata. Hyftrix paimis tetradaetylis plantis pentadad.y. lis, capite criftato, cauda abbreviata Linn. Buffor. T. XII.

$\mathrm{X} \times 3$ 


\section{$35^{\circ}$ \\ SPECIMEN ZOOLOGIAE}

to coelo a noftrate differt. Agricola tefte $(b)$, aliquibus demum feculis praeterlapfis Europae meridionales in terras, ubi antea incognitus erat, fe intulit; \& ex illo tempore lialorim advena eft, qui ipfum in deliciis habentes avide comedunt. Secundum illorum tefimonium, qui ex Compoltella, religionis caufa, itinera fufcipiunt, Itifpaniae quoque \& Lu/staniat feffor eft $(c)$. Minus interim ipfi Europam meridionalem jucundam effe gratamque exiftimo, quam Afia eft \& Africa, quae germąna ipfius forfitan patria eft. Hy/tricom enim Italiae $\mathrm{fi}$ cum ea comparaveris, quam India orientatis nutrit, longe illam minoris ftaturae, pejus figurati corporis, a culeisque confufe pofitis minoribus \& tenuiori-bus armatam invenies (d). In Afia etiam \& Africa latius diffeminata cernitur; ubique enim locorum ferme obvia eft. A Barbaria (e) per Auream Nigritiaeque $(f)$ oras progreditur, \& in Bonae Spei promontorio comparet $(g)$. In Afia Palaefinam (b), Bucbariam, \& quam maxime urbis $S$ cafsemi agros (i), Perfam, porro Cbinam, Indiam (k), Malaccam, favan (l) Sumatramque inhabitat, eamque his ultimo nominatis in regionibus folis lapidem Bezoar proferre Scba adftruit.' Sic omnem propemodum \& Afinm calidiorem \& Africam occupat, nec ultra quadraginta aliquotque latitudinis gradus re-

pe-

(b) Agricola de Animantib. Subterran. Bafileae 156r. p. 486.

(c) Gesner Hift. Quadrup. p. 633.

(d) Buffon T. XIl. Tab. LI \& Li.. (e) Shaw Reif. p. 156.

(f) Bosmans Guinea Hamburg 1708: p. 295. (g) Kolbe p. 166.

(7i) Halfelquift. Reif. nach Palaeftina p. $555^{\circ}$

(i) Marco Polo in Allg. Reif. 'T. VII. p. 435.

(le) Voyage de Tavernier T. II. (l) Seba Ihefaur. T. I. p. 79 \& 8 . 


\section{G E O G R A P H I C A E. 35}

periri folet. Novo autem orbi plane deeft. Quae enim fub Americae byftriciun nomine commemorari folent, alius funt plane generis, quorum deinceps mentio fiet.

\section{$\begin{array}{llllllllll}S & E & C & T & I & O & V & \text { I I. }\end{array}$}

\section{Cervus dama (a).}

5. I. $\mathrm{F}^{\mathrm{x}}$ cervi defcriptione in primo jam capite data patebit, hunc quadrupedem iis omnino adnumerandum effe, qui non in utroque folum orbe habitant, fed utraque etiam aequatoris latera occupant. Longe aliam damae prae cognato fibi cervo naturam, longe aretiores, quibus circumfcribitur, fines efre, experientia docemur. In America enim ejus veftigia nulla invenies; fiquidem Cornua, quorum effigiem $P_{\epsilon n-}$ nantus dedit $(b)$, quaeve damae virginianae effe feruntur, toto coelo ab illis differunt, quibus dama nofras armatur; quippe quae in anteriora flexa, nec in extremitatibus palmata funt, qua tamen fingulari nota damae noftri a cervis, aliisque animantibus cornutis difcriminantur. His Pennantus etiam motus Americae damam a noftratibus diftinxit, cervorumque numero addidit, quorum cornua teretia vel cylindracea, non autem palmata fint.

0. II. Quadrupedem igitur hunc, damam feilicet, orbis tantum antiqui fefforem efle autumo. Quod co ma-

(a) Cervus dama. Cervus comibus ramofis recurvatis compreffis, fummitace palmata. Linnaetis. (b) Synoplo of Q:adrup. p. sI. Iab. IX. 
352 SPECIMEN ZOOLOGIAE

majori cum probabilitatis fpecie ftatuo, quia, quod deinceps commonftrabitur, non eodem cum cervis paffu ad feptentrionem adfcendit, ubi commodiffime ex antiquo orbe in novum tranfire potuiffet. Nec in antiquo orbe aeque late ac cervus diffufus cernitur, nec regiones, in quibus nutritur, arcte fatis cohaerent: variis potius intervallis disjunguntur; nec tot nec tam numerofos damarum quam cervorum greges ullibi locorum hucusque vifos effe conftat.

ঠ. III. In Europa Poloniae (c), Germaniae, Galliae; Italiae, Hispanias (d) Graeciarque (e) incola eft. In Afia Palaefinam $(f)$, \&, Pcnnanto tefte, partes Cbinae feptentrionales occupat $(g)$. Ex quo, ipfum in aliquibus etiam temperatioribus Tattariae partibus haberi fufpicor. Permulti enim peregrinantium, cervorum ibi cervisque fimilium ferarum copiam obviam effe, uno ore confirmant (b). E quibus damam per antiquum orbem admodum quidem dilatari, magnis tamen fpatiis domicilia, in quibus vivit, diremta, nec, ut cervorum habitationes, copulata effe cernimus. Africae vero indigenae ipfum plane ignorare videntur. Beftia enim a Stibb/io prope Barracondam confpecta, \& fub 'Tonkangi nomine $(i)$ defcripta, quam damae perfimilem cffe dixit, \& multo majori corporis ftatura denfaque juba, quae damis tamen deeft, ornata fuit. An interim coeli aërisque temperies \& foli ubertas hujus mutatio-

(c) Rzacynski Hirt. Pol. p. 217 .

(d) Butfon $T$. VI.

(c) Vid. Ariftotelis Hift. Animal. L. II. Cap. XiV. p. fub nomine.

(f) Halfelquift. Palaeftina pag. 342: (g) L. c. p. 50 .

(il) Allg. Reifen T. VL paffim. (i) Alllg. Reif. T. IIL. p. 72. 


\section{G E O G R A P H I C A E. 353}

tionis caufa fuerint, $\&$ an hic quadrupes nihilominus damis noftris adnumerandus fit, tempus docebit. AuEtor autem, qui Kolbii librum in gallicum idioma tranftulit, dubio procul, quod primo jam in capite notavimus, gravi errore lapfus, caprum maculofum, qui forte Gazcllarum fpecies fuit, quem Krolbius inter Hoterntottas Attaquas viderat, per maculosam damain reddidit $(k)$.

0. IV. Quodfi ergo dama Africam nimio folis igne aduftam abhorrere videtur; certo ipfum \& regiones nimio frigore infames evitaturum effe colligamus, fas eft. Linnaeus ipfum in Sueciae quam maxime magnatum theriotrophaeis ali \& reperiri teftatur $(l)$; \& Pontoppidanus cervos quidem capreolosque Norvagiae habitatores effe adftruxit, damam vero alto filentio praetermifit. In aliis autem feptentrionem propius pofitis traetibus, verbi gratia, in Lappiae, Samogitiae, quin etiam in Canadae, aliisque iftorum graduum terris, ubi cervi in magnam fatis ftaturam formamque glifcunt, ullam damae mentionem invenire mihi non licuit. 'Interim nifi plures, faltim totidem, quam cervorum, varietates damarum confpiciuntur. Buffonio enim auetore, Hispaniae damae ejusdem cum cervis noftris funt magnitudinis; quum e contrario noftri damae multo cervis minores effe foleant. Colorum ratione praeter maculofos, variegatos albosque, fufci etiam, e rufo badii, hique omnes in una interdum eademque regione obvii funt.

SECTIO

(k) Vide Cap. primi Section. de Cerrn. (l) Fauna Suec. p. Ito Yy 


\section{SPECIMEN ZOOLOGIAE

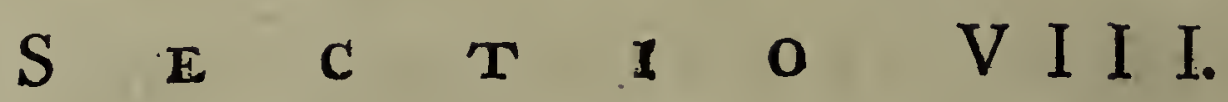 \\ Camelus ( $a$ ) $g^{2}$ Dromedarius (b).}

6. I. Duo animalia domeftica, quae orientis incolis plus fere commodi adferunt, quam boves, de induftria conjungimus, \& quafi unum idemque confideramus; quod domitu \& fluentibus inde tam corporis quam morum mutationibus eam formam, illum ftatum, in quo nunc confpicitur, induit. Nec prototypon nobis fupereft, ex quo camelus olim ferus Sijudicari poffit. Du Haldius quidem ex formularum a Sinenfium medicis praefcriptarum collectione excerpta quacdam attulit, quibus feros camelos in Cbinae regionibus, Tattarian caurum verfus attingentibus, dari, docemur (c); utrum autem haec ad veritatem accedant, nec ne, in medio relinquendum eft. Hoc certo conftat, nullibi adhuc gentium ferum camelum inventun? effe, ex quo ipfum vel a primo ftatim mundi noftri tempore, vel paulo poft manfuefaetum effe, conficitur.

C. II. Cannelum autem duobus dorfi tuberibus praeditum, quem bactrianum nominant, ejusdem cum illo, quem uno tantum gibbere inftructum novimus, \& or:ginis \& generis elie, ex Olenrii relatione difcimus, qui dromedsrium cum camelo non modo coïre, fed foetum etiam proferre fcripfit, qui itidem firpem fuam pro-.

pa-

(a) Camslus Bactrianus. Camelus dorfi tophis duobus. Buffon T. XI.

(b) Camelus dromas. Camelus topho dorfi unico. Linnasus.

(c) Du Halde T. III. p. 5 I 3. Cameli tam feri, quam cicures e Chinae. regionibus feptentrionem fpectantibas a flavo fluvio occidentem verfus jacentibus inveniuntur, 


\section{G E O G R A P H I C A E. 355}

paget $(d)$. "Quodfi hoc tecum reputareris, reliquasque omnes, quibus inter fe camelus ac dromedarius conveniunt, fimilitudines addideris, \& quibus quantisque immutationibus animalia ad manfuetudinem domita fubjiciantur, cujus rei exempla primo jam in capite, quum de animantibus domefticis fermo effet, adlata funt, deliberaveris: facillime eo perduceris, ut Buffonii fententiae, utrosque animantes unam eandemque effe ftatuentis, faveas. Aliis etiam in rebus camelum degenerari cernimus. Sic alios corporum magnitudine, alios currendi velocitate caeteris praeftare relatum legimus; quos tamen omnes pro folis varietatibus habendos crediderim. Oleario auctore, Perfae dromedariorum progeniem in quatuor fpecies dividunt, quarum optimam illam effe tradunt $(e)$, quae ex dromedario mare cum camelo femina pronafci folet.

ઈ. III. Gibbum etiam, qui pro alimentorum ratione increfcere \& decrefcere folet, alios majori, alios minori onerari docemur. Animal a Muellero, qui Linnacum percommode commentatus eft $(f)$, vifum, $\mathrm{cu}-$ jusque gibber vix fub adfpectum venit, ex numero camelorum tenuiffmae ftaturae fuifre, autumo, cujus tuber vel inedia vel tenuiori vietu evanuit. Si vero laudatus hic auctor dorfi quoque fpinam ad gibbum efficiendum fua conferre fibi perfuadet; id quidem in camelorum monftro quodam fieri poffe concedo. Exactiffi-

mis.

(d) Olearii Reifebefchreibungen. Hamburg 1696. pag. 299.

(e) Olearius 1. c. p. 290 \& 300. Leo Africanus in Africae defcript. po 746. feqq. trium tantum fpecierum meminit.

(f) Vollftaendiges NaturfyAtem. Nürnberg I773. T. I. p. 37. I.

$\mathrm{XY} 2$ 


\section{SPECIMEN ZOOLOGIAE}

mis interim ex anatomicis a Drubentonio Buffonioque contrarium difces $(g)$, qui dromedariorum pariter atque camelorum fceleta iis in locis, quibus tuber adhaeret, peraequa, minime vero elata effe adferunt, \& expreflis verbis acutos vertebrarum proceffus, nihil plane ad formanda dromedariorum gibbera conducere confirmant, quippe quae ultimis potius vertebris, iisque omnium breviffimis, fint impofita; quod idem ex cameli fceleto, quo ducis noftri rerum naturalium thefaurus fuperbit, evidentiffime apparet. Minoris adhuc momenti eft colorum difcrimen. Dantur enim cameli ex atro. fufci \& lucide cani ; dantur, qui omnibus inter ja!n nominatos colores pofitis varietatibus ornati funt.

6. IV. Suppofita igitur fententia, dromedarinum \& camelum ejusdem ftirpis, ejusdem effe \& originis, nunc quousque diffundantur, indagemus. In mappa geographica generale cameli nomen lineae, fines terminosque dirimenti, appofitum invenies; iis vero in regionibus, ubi camelus bino tubere fignatus habitat, $\mathrm{ca}^{-}$meli voculam, \& ubi dromedarii vivunt, dromadis nomen adfcriptum habebis; minus enim fpatii dromas prae robuftioris naturae camelo occupat. In Europa folae Turcarum imperio fubjectae provinciae quadrupes iftos alunt, quibus divites tantummodo principesqu e populi uti fueverunt (b). Hinc per Tartariam Crimmeam, $N a$ toliae, Armeniaeque $(i)$ terras ad $\operatorname{Circafjos}(k)$., poft ad Calmucbos Bascbkirosque Tartaros pergit, \& KirginJens.

(g) Buffon T. XI. p. 15r. (h) Leo kffric. p. 746.

(i) Niebuhrs Befchreib. v. Arab. p. 104.

(k) Olearii Réifebefcinr, p. 378. feq. 


\section{G E O G R A F H I C A E. $35 \%$}

Senfum (l) usque regionem tranfit. Omnes hi Tartari, quod Pallafulus confirmat $(m)$, numerofos camelorum bino dorfi gibbere infignium greges nutriunt; quibus non ad onera tantum ferenda utuntur, fed carnibus etiam ipforum \& lacte, five recens ac dulce fit, five acorem traxerit, famem tolerant. Ex lacte ipfo magnam quoque ipfos vini adufti copiam extrahere, \& e crinibus fubcoacta tentoria fua conficere folent.

6. V. In Siberia Tartariaque camelos altius polum verfus progredi, Burcletosque (n) fub quinquagefimo fexto latitudinis gradu eos alere, quin 7 inngufos etiam, qui ulterius procedunt, ingentes ipforum greges pafcere, Gmelinus confirmat $(0)$. Ad fexagefinum itaque gradum extenduntur, quem tamen fine vitae periculo fupergredi nequeunt. Qui enim cameli ad Fakuzki usque fines fub fexagefimo primo latitudinis gradu, orientem verfus pofitos, deducti funt, frigore morbisque correpti moriebantur $(p)$. Ex quibus magna cum probabilitatis fpecie colligo, animantem hunc tam uti$\mathrm{lem}, \mathrm{fi}$ in moderatiores Europae regiones nec inontofas nec paluftres nimis deferretur, haud infelici proventu ibi vivere augerique poffe. Hunc autem. A/ane tra. Etum, qui a Calani regno ad Cbinam porrigitur, vere fic dictos camelos, qui binis tuberibus infigniuntur, fovere, auctores in margine laudati adftruunt. Jam enim Pallafii verba idem de Calmucbis conteftantia adduxi。

(l) Rytchkow Orenb. Topogr. in Bufchings Magaz. T. VIl. p. 4 a. (m) Pallas Reir. T. I. p. 325 .

(n) Leitnitzii Novilima Sinica. I 699. p. 166.

(o) Gmelin (fen.) Reif. d. Siber. T. II. p. 127. (p) Ibid. p. 552: 


\section{$35^{\circ}$ SPECIMEN ZOOLOGIAE}

duxi. Turkeftanos $(q)$ infüper, Elatberos $(r), K a l$. kaenfes, Mongolos $(s)$ \& Cbinenfes $(t)$, Camelorum opera \& auxilio uti, peregrinatores fide dignifimi docent. Cur itaque Linnaeus hos animantes in Africa fola inveniri fcripferit, qui tamen Afiae quoque partium non nimio folis aeftu flagrantium incolae funt, plane nefcio.

J. VI. Poftquam itaque, quas feptentrionis regiones camelus inhabitet, exacte commonftraviffe puto, nunc etiam, quousque tam in $A$ fia, quam Africa aequatorem verfus defcendat, inquiram. In Afin PalacJtinae (u), Perfane (v), fuperiorum Indofani partium (w), $\&$ quam maxime Arabiae ( $x$ ), feffor eft, qua in regio. ne patriam originemque fuam olim habuiffe videtur. Maxima enim ibidem ejus frequentia \& multitudo reperitur, \& invicti fere eft corporis, ad ingentes labores graviffimaque onera quibus Arabes vagi lemperque huc illuc volitantes ipfum \& degravare \& fatigare confueverunt, perferenda. Quadrupes etiam hic Arabian praecipue decere, ejusque folo, quod \& fabulofum $\&$ motu facillimum elt, admodum convenire videtur. In hoc enim molles pedes minus laedit, \& lubricas vias ibi nullas invenit. Niebubrius, Arabiam omnes fere camelorum fpecies, tam majorum, quanin minorum five uno gibbere, five fint binis tuberibus praediti, qui tamen

ibi

(q) Mémoires pour fervir à l'Hift. des Animaux. Pare. I. p. 80.

(r) Eilutherorum Cameli omnes majoris formae duobusque gibbis onuni funt. Allg. Reif. T. VII. p.9I. (s) Allg. Reif. T. VII. p. 76.

(t) Ibib. T. VI. p. 547. vide etiam Neuhofii Icon Cameli in Gefand. fchaft nach China. (u) Voyages de Pietro della Valle T. I. p. 360.

(v) Olear. I. c. (iv) Tavernier Voy. T. I. p. I61.

(x) Niebulirs Arabien p. 164. Profp. Alpin Hift. Aegypt: pi 226. 


\section{G E O G R A P H I C A E.}

ibi rariores funt $(y)$, nutrire, expreffis verbis confirmat. Inferioribus autem in Mogolici regni partibus camelorum veftigia vel nulla vel rariffima tamen invenies, \& in Siamae, Pegu \&.Malaccae campis, in Sundaicis reliquisque aliis eorundem graduum infulis ac regionibus nequidquam quaeruntur. Ex quo colligimus, Afare terras flagrantiffimo aeftui expofitas, quas elephantorum patriam effe conftat, camelis intolerabiles effe, quod etiam a Buffonio fcientiffime obfervatum cernimus.

(5. VII. In Africa illis jam in regionibus, quas mare mediterraneum alluit, confpiciuntur. Barbaria $(z)$ easdem fere, quas Arabia \& Per/ia varietates habet. Hinc in Aegyptum (a) \& ad Aetbiopes (b), Senegae (c), Gambiaeque (d) fluviorum adcolas progreditur. Occidentem verfus Nubiam Abiffiniamque frequentat. Vix tamen crediderim, eos omnes terras Senegam inter $N u$ biamque jacentes occupaffe, quarum interiores partes vehementiori calore prae illis, quas in littoribus fitas venti a mari flantes refrigerant, afficiuntur, quamquam adhuc in Regno Tombut $(e)$ inveniantur. Omnes interim, gui A/ricam inhabitant, uno plerumque gibbere oneratos effe, quos dromedarios vocant, laudati infra auctores finguli teftantur.

0. VIII. Jure igitur Buffonius camelos duplici tubere infuructos terrarum minori calori expofitarum feffores effe

(y) Nibbuir. 1. c. (z) Shaw l. c. p. I43 \& I49.

(a) Prefp. Alpin. 1. c. (b) Ludoff Hift. Aechiop. Lib. I. Cap. X: I. I3

(c) Brie in Allg. Reif. T. 11. p. 492.

(d) Demanet Hift. de i'Afrique françoife. T. II, p. Is so

(e) Leo Afr. p. Z48. 


\section{SPECIMEN ZOOLOGIAE}

effe autumat; quamvis nimis auguftos camelis terminos conftitucrit, dum eos ad cancri tantummodo tropicun defcendere adftruit; qui tamen in Africa ad decimum ferme feptentrionalis latitudinis gradum procedunt. Nunquam autem aequatorem attingere vel tranfire videntur. Nec enim Guineam, nec Auream nec Nigritiae oram camelos nutrire legimus; \& trans aequatorem plane ignorantur. Faria etenim tefte, Caffri Mongalenfes, antequam Barrettum fuderant fugarantque, camelos nullos viderunt $(f)$. Nec Kolbizs in fua, quam de bonae fpei promontorio dedit, defcriptione, ullam cameli mentionem fecit; licet fim perfuafiffimus, eum, $\mathrm{fi}$ iftos in fines delatus fuiffet, optime fuiffe proventurum. E quibus omnibus conjunctim fumtis manifeftum efre credo, camelum, qua fub voce dromedarium etiam comprehenfum volo, fuperiores tantum Africae partes occupare, ejusque domicilium a fexagefimo ad decimum usque latitudinis gradum in Africa aeque atque $A$ /ar diffundi. Quonian autem nulli propemodun, adhuc in Europa cameli vivunt, ficco eam pede praetereamus oportet. Spatium hoc itaque in tabulfa geographica exacte definitum videbis $(g)$. Nec America, quantum quidem conftat, tantae utilitatis animantem adhuc novit. Nonnullis quidem experimentis, an in Famaicae \& Barbadocs infulis vivere ac propagari poffit, tentatum eft $(b)$ : nondum

ta-

(f) Allg. Reif. T. V. p. 220.

$(g)$ Hifpanian quidem, an ibidem cameli bene proveniant, \& augeri poltint, periculum fecifie, fed fucceffum conatui minus refpondilfe dicunt.

(b) Brown's Hift. of Jamaica, London 1750. p. 4.88. 


\section{G E O G R A P H I CA E 36 I}

*amen fortunam roto fubferipfife audimus: Utrum Brafiliae aliaeque meridionalium partium terrae $\&$ a u ae animantis naturae magis conducant, dies docebit.

$$
\begin{gathered}
\text { S E C I I O I X. } \\
\text { Fakkal feu Adize (a). }
\end{gathered}
$$

5. I. uum confure illos agere crediderim, qui in enumerandis animalibus rationem ordinem. que nullum fecuti ea combinant, quae nec ejusdem generis eorundemque morum funt, nec propter externam quandam fimilitudinem conjungi commode poterunt: priusquam Jakkalis feu lupi aurei dilatationi commemorandae manum admoveo, lectorem benevolum admonendum cenfeo, nec confufionis amore, néque infelici illuftris Buffonii imitandi ftudio faetum elfe, ut beItia haec camelum excipiat; perfuafum potius habeo, mihi propter ipfam libelli hujus dispofitionem, nifi ha! hucinari voluerim, hunc ordinem eligendum fuife. Poftquam enim quadrupedes fecundum fua donicilia digerere, \& quam procul vel a feptemtrione vel ab acquatore, vel.ab utrisque habitent, perquirere coeperam: non potui, quin hanc viam ingrederer, ne perplexe \& confufe egiffe viderer. Quanquam interea rem. alio jam loco liquide purgare ftudui (b); heic tamen loci, perfpicuitatis caufa, addere libet: nullum animantium facile inveniri, qui antiquo in orbe camelum, per utrasque aequatoris partes lupo aurco latius diffun$\mathrm{da}-$

(a) Lupus aurcus. Canis, lupus auretis dictus. Limnoci Sygt. Edit. XII. Butforit: XIL, (3) Vid. praefation. 


\section{SPECIMEN ZOOLOGIAE}

datur. Equidem \& bubaluin a patria fede fua, quam fub torrida Zona quaerendam effe credo, pari propemodum paffu tam neridiem, quam aquilonem verfus progredi, \& per naturae fuae conftitutionem, quippe quem herbis etian terraeque frugibus pafci conftat, Jakkale propius ad camelum accedere, lubens largior. Quoniam vero bubalus, quod jam monui, ardentillimo folis aeftui dietis in terris ortus eft, nec unquan in fere. ftatu fwo, fed manfucfactus demum, eo usque feptemtrionem verfus procedere cogitur, quousque lupus aureus, quem \& Adiven vocant, fponte lua perrexit : huic priorem locum concedamus; quem ille poftea fubfequatur, \& cum iis deinceps beftiis commodiffime conjungatur, qui eodem folo patrio orti gramine itidem, frugibusque terra natis victitant; elepbantem puta \& rbinocerotem, qui tunc omnes, quum tam vitae genere, quam infigni corporum immanitate fibi fimiles fint, jufto ordine, quem nec fakkal turbabit, percenferi poterunt.

ఏ. II. Hunc vero \& Adivem unam eandenique beftiam effe, fundamenti loco ponimus. Licet enim Buffonizs hac in re difcrepare videatur; ipfi tamen, utrasque exigua duntaxat corporis magnitudine, \& vel lucidiori paulum vel obfcuriori flavedine inter fe diftare, fatendum eft. Quibus accedit, quod peregrinantium plerique, verbi caufa, Delomius $(c) \&$ Shawius $(d)$ beftiae huic utrique \& Cbakkalis \&. Adivis nomen impohunt. Quodfi etiam notabilis aliqua diverfitas inter-

ces-

(c) Voyage de Delon p. 109

(d) Shaw Barb. p. I 54 \& I 55. Dib. vel Adive vel Chakliah. 


\section{G E O G R A P.H I C A E. $36_{3}$}

cefferit; eam tamen tanti non effe ponderis judico, ut novas fpecies, fed varietates potius quasdam, quarum affatim lupos inter $\&$ vulpes reperiuntur, conftituant.

f. III. Forte interrogabis: annon Fakkalcm vulpis varietatibus annumerare liceat, quacum ex omnium, qui ipfius mentionem fecerunt, teftimoniis, \& corporun forma ftaturaque, \& intolerabili, quem exhalat, foetore, quam maxime convenit? Cui tamen opinioni quio minus adfentiar, Olearii relatio impedit $(e)$, qui iisdem in terris agrisque \& $\mathcal{J}$ fakkales \& vulpes nollirates quidem inveniri, disjunctos tamen fegregatosque vivere, expofite \& aperte adfirmat. Quum praeterea vulpes, in fpecubus fubterraneis luftra fibi fua condant, idem a Fakkalibus nunquam tentatum eft. Denique jam fupra vulpem alte fatis ad feptemtrionis plagas adfcendere commonftravimus; quuin e contrario fakkal calidiores modo regiones frequentare foleat: \& hac ipfa quin majori etiam ratione a lupo diftat. Perfia enim \& $\mathcal{J}_{\text {alk }}$ ales \& lupos alit, utrosque tamen curatiffime diftinguit. Donec itaque beftiae hujus naturam $\&$ indolem melius edoctus ero, $\&$ icon, quae ipfam exactius referat, dabitur, (quod hucusque intermiffum effe admodum miror, praecipue, quum tot praeftantiffmimi viri củsontal ejus mentionem fecerint) eandem ut fingularem aliquam fpeciem feparatim contemplabor, \& quan longe lateque diffundatur, feorfim inquiram. Interim tamen fieri polfe, ut nonnullae ejusdem varietates offendantur, inficiari nolo.

O. IV.

(e) Olcarius Raif. Schleswis 1647. p. 278

\section{$\mathrm{Zz} 2$}


${ }_{3} 64$ SPECIMEN ZOOLOGIAE

j. IV. Fakkal itaque ab Europae partibus mieridiem praccipue fpectantibus, a Turcia $(f)$ nimirum \& Graecia ( $g$ ) ordiri videtur. In illa enim permagnus, corum circa Conftantinopolim numerus confpicitur $(b)$; in hac autem Arifoteli fuo jam aevo fatis noti fuerune. Antiquorum enim Gwa Jakkalem effe, non Buffonius, folum in animantis hujus defcriptione demonftrare ftuduit, fed Bocbartus id jampridem certiflimis argumentis multaque cum eruditione firmavit (i $)$, quem fi $B u f f c-$ r. ius confuluifet, - labori fuo aliqua ex parte iuperfedere potuiffet. Hac tamen in re vir ille praeitantiffmus, $B c$ cbaitus lappus eft, qui papionem (Bavian) Jakkalen \& swo unum idemque animal effe perfuadere nobis voluit. Lupus itaque hic aureus in Natoliant, Syriann $(k), A r_{-}$ mcriam, Perfanm (l), Arabiam (m), Indoftanium \& Bengalam (n) progreflus. omnes ferme Ajiae calidioris partes occupat $(0)$.

0. V. Africae autem regiones, in quibus obvius eft, Barbaria ( $p$ ) funt, Algicria, Aegypus (q); neć dubium eft, quin feri etiam canes, quos Zuctoellius $(r)$ in Congi regno vidit, quorumque fub Mebbiarnm deno; minatione meminit, fakkales fuerint. Dẹin \& Kolbius, ipfos

(f) Belon Obfervat. Lib. II. Cap. CVIII.

(g) Ariftot. Jist. Anim. Lib. 11. C. XVII. (in) Niebulars Arab. p. 166.

(i) Bochart Hierozoicon Lib. III. Cap. XII. (k) Niebuhr. l. c.

(l) Olear. I. c. (m) Niebuhr. l. c.

(n) Voyage d'Olof Toree à Milan 1771. p. 39. Voyage de la Bo:liayebe -Gouz p. 254. Lettres Edif. I 2 me Rec. p. 93. vide Buffon T. XIll. p. I45.

(o) Kaempfer Amoenit. exot. p. 413. Jackal pene onnem orientem in: habitat. (p) Show l. c. (q) Hajelquift. Palaeft. p. 550.

(r) Zuchelli Reife nach Congo p. 293. v. Kolbe. 


\section{G E O G R A P H I C A E。 $36_{5}$}

ipros in bonae fpei promontorio habitare, teftatur $(s)$. Ex his itaque indiciis luce clarioribus, beftiam hanc amplas Europae terras, magnam A hrae partem omnemque Africam incolere patefcit. Ad quadragefimum fecundum aut tertium latitudinis gradum defcendit. Ipfum enim ulterius feptemtrionem verfus pergere, nemo, nifi Buffonius, teftatus eft, qui Caroli noni tempore Galline matronas Jakkalibus, melitacorum canum. loco, ufas efle narrat ( 1 ), quod tamen, utrum auetoribus fide dignis defendi queat, ipfi relinquamus oportet.

$$
\begin{gathered}
S \quad \mathbf{E} \quad \mathbf{T} \text { I O X } \\
\text { Hyana }(a) .
\end{gathered}
$$

ઈ. I. B eftia hace, quae folitudines amat, optimum, 1 poft Jakkalem, locum, fequentes fibi propter rationes, vindicare videtur; partim quia easdem fere, quas ille, regiones occupat; partim, quia Limnatus eandem canum generi fubjectam voluit. Pennantus primus eft, qui praeter hane byaenam, alius adhuc mentionem fecit, quam maculofam nominat $(b)$, quam non capitis folum forma, fed maculis etiam pilae figuram referentibus, jubaque breviori, a noftra, quam ftriatam appellat, difcriminari adferit. Vivae hujus beftiae contemplandae aeque mihiac Pennanto copia: facta eft, quam ex Africa huc delatam effe, poffefior. perhibebat. Moren interim. Pennauto geranus, \& hane

(s) Kolbens Vorgeh. p. I52. (i) Buffon T. X1Ll. p. I43.

(a) Hyaena. Canis canda reet? ann:lata, pilis cervicis ereatis, auricu. lis nudis, palmis tetradaciylis. Limnacus. Buffor T. $\mathrm{X}$.

(b) Synopf. p. I б2. Spotted Ityma.

$$
Z_{2} z_{3}
$$




\section{SPECIMEN ZOOLOGIAE}

hanc ab illa eo usque diffociemus, donec certioribus documentis convicti, an diverfae fpecies, an tantummodo rarietates fint? dijudicare poffimus.

0. II. Striata noftra byaena in Afra Syriae, Turcine njiaticae (c), Perfine (d), Arabiaeque (c) terras inhabitat. Quumque Porphyrias Indiae Crocutam, byaenam effe adftruat $(f)$, hinc eam fatis late ad aequatorem verfus defcendere colligimus. In Africa Barbariae fines tenet $(g)$, ubi Dubbabae nomen ab indigenis nacta eft. Multas dein alias Africae borealis partes occupat (b), \& denuo in Aetbiopine terris ( $i)$, quin etiam in Madagafcare comparet. Si Buffonii opinio a vero minus abhorret, qui quadrupedem ab infulae hujus fefforibus Tara/fen appellatum ( $k$ ) itidem byaenae noftrae adnumerandum effe exiftimat, qua de re Commerconizs nos brevi fortaflis abhinc tempore certiores reddet, beftiam hanc fatis late per orbem diffundi, eo evidentius coarguemur.

Duo quadrupedes raptu viventes byacnam ideo fequentur, quod eadem fere cum illa utuntur patria, \& a naturae indagatoribus felium plerumgue generi attribuuntur, Carakal fcilicet \& Uncia.

(c) Nieremberg Hilt. Nac. Antuerp. 1635. p. IS I.

(d) lacmpf. Amoenit. p. 4 I r. (c) Niebulirs Arab. p. $166 \& 167$.

(f) Torpliyrius de abftinentia ab ufu carnium. (g) Shaw Barb. p. 154 .

(h) Iro Afric. p. 75o. (i) Lzdolf. Hift. Aethiop. Lib. 1. Cap. \$. so. (k) Mémoines pour fervir à l'Hiftoire des Indes Orientales 1702. p. 168. 


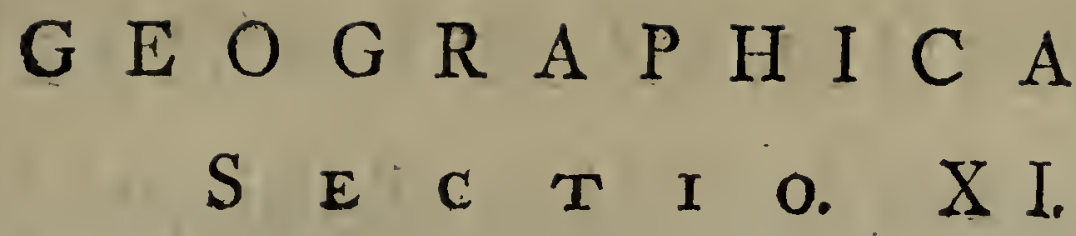 Carakal (a).}

I aec beftia propter fafciculos in auricularum apice, 11 longioribus e pilis conftantes, quam proxime quidem ad lyncis fimilitudinem accedit; fed in eo tamen longe fatis ab ipfa recedit, quod fufea pelle tenuiorique capite praedita eft. Quumque lynx frigidarum tantum regionum incola fit, Carakal, quam Perfae Syab-gufch appellant, ni calidiffimos, calidiores faltem terrae tractus inhabitat, nec usquam feptemtrionem verfus progreditur. Vivit enim in Syriae (b), Barbariae (c), Arabiae, Perface, Indiaeque (d) terris, \& fic per feptuaginta longitudinis gradus \& amplius, per Africam Afam que diffunditur. A trigefimo enim feptimo latitudinis gradu exorfus, cancri quidem tropicum in Afia paulum oppido egreditur, in Africa vero longius ab aequatore disjunctus commorari fuevit.

$$
\begin{gathered}
\text { S E C C T I O. X I I. } \\
\text { Uncia (a). }
\end{gathered}
$$

J. I. Uncia e rapacibus voracibusque tigridum fpeciebus fola tam late, \& in regionibus quidem arcte fatis cohaerentibus, difperfa invenitur, ut huic

(a) Folis auricula atra dicta. Le Caracal Butfon. Syah. gush Shaw. Linnaeus animal hoc praetermifit, quod lic deferibi polfec: fells cauda abbreviata, auriculis nigris apice batbatis, corpore fubfufco concolure, c.lpite attenuaio. Le Caracal. Buffon T. IX.

(b) Voyage d'Orient du Pere Philippe. Lyon I69g. Lib. II. p. 76.

(c) Shaw Reif. p. 155 .

(d) Voyage de Thevenot. Paris 1664. P. II. p. I14.

(a) Uncia. Once Luffon T. 1X. \& Pennant. p. 175. Panticra Plinsia. 
368 SPECIMEN ZOOLOGIAE

huic capitis fecundi foetioni jure adjungi queat. Lin nacus unam hane cum pantbera \& leopardo, eandemque efie beftiam credidife videtur. In duodecima enim $f_{y}$ flematis fui editione mentionem ejus nullarin fecit, quemadmodum alias multas felium fpecies omifit, quarum tamen Bufforizus jam ante meminerat. Sed misfis his, unciam nec pantberis nec leopardis adnumerari porfe, e mox adducendis rationibus certiffme perfuadeor. Longe enim pantbera minor domituque facilior eft; pelle praeterea, non ut illa, lutea, fed alba tegitur. Hinc fit, ut nigrae, quibus infignis eft, maculae co magis eluceant; dein prae pantbcra, quaie acoue ac leopardus, flagrantiffimis tantum Africae partibus inclufa videtur, alias plane, pluresque terras occupat. Porro \&s leopardum a Buffonio P'onnantoque hoc ñomine infignitum ampliori corporis magnitudine fuperat; quumque ille elegantioris lutei coloris pellè fuscis maculis ornata veftitus compareat; albos uncia pilos nigris maculis variegatos habet. Quibus omnibus viri praeftantiffmi commoti hanc uncian Plinii pantheram effe colligunt, qui breves ipfi in candido macularum oculos tribuit $(b)$.

0. II. Poftquam igitur brevibus pro fcopo noftor verbis uncinn ab aliis fimilibus ipfi animantibus fegregavi; nunc etiam, quas regiones occupet, confiderabo. Rarbariae indigenis fub Faedhi nomine nota eft $(c)$. Hinc in Arabian, Perfum (a), Hyrcaninm, aliasque Ajac partes meridiem fpectantes, ad Cbime provinciam

(b) Plint. Hift. Nat. Lib. VIll. Cap. XVII.

(c) Schaw Barb. p. I 53 .

(d) Olarins Rcifebufureibungan. Hanb. 1695, p. 23 I。 


\section{G E O G R A P H I C A E.}

Peking (e), cujus incolae pellium his beftiis detractarum commercia faciunt, progreditur. Omnibus his in terris ipfa ad venatum condocefacta, commonftrat, eam minori longe opera, quam pantberas, manfuetam reddi poffe. Ryt/cbkovius de animante in Orenburgen/z provincia obvio, cui $\mathrm{Babr}$ nomen accolae impofuerunt, commemorat $(f)$, quem unciam effe furpicor, quippe quae omnium tigrinorum majoris ftaturae felium unica eft, quam extra torridae zonae cancellos evagari fcimus. Quum itaque centum pluresque longitudinis gradus occupet, hinc ipfius dilatationem amplae fatis magnitudinis effe, apparet. Africae tamen interiores partes abhorrere videtur; in $A$ fia vero ad quadraginta $\&$ aliquot latitudinis gradus adfcendit.

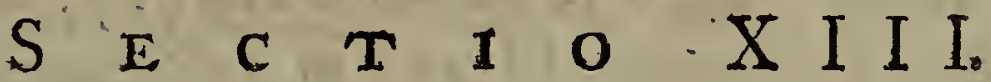

\section{Bubalus (a).}

6. I. A d ea nunc animalia progredimur, quorum A patria fedes zona efre torrida folet, \& quae maxime intra antiqui orbis tropicos, quos rariffme, \& quidem vix ad decimum usque gradum, transcunt, fera, feu, quod perinde mihi efie videtur, in

na-

(e) Thevenot Rélation de la Chine 1696. p. 19. ex Bufon vid. etian Muller Samlung Rufifch. Gefchichte T. III. p. 549 .

(f) Bufchings Magaz. T. VII. p. 39. Bakr ille invenitur praecipue cirea mare Aral.

(a) Bubalis. Bos cornibus refupinatis intortis antice planis. Linnacus. Jure Buffonius hunc a bove vulgari fegregat; nec enim unquam cum bobus noftris coït, nec bubali vaccae noltris, nec noftrae illius vitulis rumen praebent. Le Buffle. Buiffon T. XI. 


\section{SPECIMEN ZOOLOGIAE}

naturali ftato fúo inveniuntur. Duas autem in claffes ea commode difpefcimus, quarum altera terrae frugibus, altera carnibus pafcitur.

6. II. A priori fiat initium, \& a bubalo, qui caeteris longiffime a patria fua recedit, fermonem inftituamus. Extrema, quam cicur ipfe feptentrionem verfus regionem habitat, Italia eft $(b)$, ubi nunc etiam Manfredoniam Barleffamque inter ferus vivit; \& tempore demum regis Agilulfs, qui nonagefmo primo feculi fexti, ad decimum fextum feptimi feculi annum regni habenas tenuit, in Lombardiam translatus effe dicitur $(c)$. In Afra Armeniam, Euphratis Orontisque ripas (d), \& haud procul Derbente Caspii maris littora $(e)$, totius Perfane regiones $(f)$, Indoftaniam, Tigridis ripas, Bombayam ( $g)$, Bengalam (b), Malabariam ( $i)$, Siamae (k), Tunquini $(l)$, Cbinaeque filvas $(m) \&$ campos incolit. Permagnos ejusdem greges infulae pbilippinae $(n)$, quosdam etiam $\mathcal{F}$ ava $(0)$, Celebes $(p)$, \& minor, quae magis Euronotum fpectat, Savu $(q)$, alunt. Sic om. nes ferme Afrae terras modo ne nimis peraruerint, a quadragefimo latitudinis gradu, ad aequatorem \& ultra,

omnes,

(b) Voyage de MifJoen T. III. p. 54 .

(c) Warnefridi de geftis Longobardor. Lib. IV. Cap. II.

(d) Niebulirs Arabien p. 165.

(e) Olcarius Reife. Schleswig 1647. p. 278.

(f) Olearius Reife (Edit. fecunda) 1696. p. 298. (g) Niebulirs. 1. c.

(ih) Luillier in Allg. Reif. T. X. p. 612. Torie Voy. a Surate p. 55 .

(i) Voy. de Deloa p. Iro. (k) Turpin Hift. de Siam T. I. p. 301 .

(l) Rhodes Tunquin p. 5 r. (m) Allg. Reir. T. VI. p. 545.

(n) Allg. Reif. T. XI. p. 427.

(o) Cook's Voyage in Hawkesworth's Account. T. III. p. 745 .

(p) Ibid. p. 683. (q) Allg. Reif. T. XI. p. 482. 


\section{G E O G R A P H I C A E. $37 x$}

omnes, quas A/fae adnumerant, infulas Bubalus inhabitat.

5. III. Nec in Africa regio nobis cognita eft, in qua non bubalus vel ferus vel manfuefactus obvius fit. Argypum (r) enim, Senegae ripas (s) \& Guincam ( $b$ ) frequentare fertur. Nec dubium eft, quin feros etiam inter boves. (1i), quorum in Con$g i$ defcriptione fub Eimpakaffae $(v)$ aut Impanguezzac nomine mentio illata eft, bubalus locum habeat; praecipue quum, Kolbio auctore, in bonae fpei quoque promontorio acervatim occurrat $(w)$. Et quoniam in Aby/finiae finibus confpicitur, maxima probabilitas animum meum percutit, eum in Zanguebaris etiam oris habitare; licet vel nullam vel exiguam faltem Africae hujus Orientem verfus jacentis regionis, cognitionem hucusque habeamus. Quicquid itaque Africae terrarum nobis adhuc innotuit, bubalis . fcatere cernimus. Hinc elucebit, ipfos Zonae quidem torridae feffores, fed tam flexilis quoque indolis effe, ut $\&$ in moderatioribus terris fine detrimento fuo vivere queant. Pellem fuam tunc ad aëris, coeli \& terrae, quam incolit, temperiem accommodari, exinde manifeftum eft, quod quae Indiae in agris prope caluefcat, in temperatioribus autem tractibus pilo \& denfiori \& promisfiori tecta inveniatur. Ex Bulfonoiii relatione, quam ex probatiffimis auctoribus haufit, bubuli, fimulac e calidiffimis in frigidiores paulo regiones tranfierit, docilita-

tem

(r) Haffelduift 1. c. p. 577: Maillet Defcript. de l'Égypte p. \& 7 .

(s) Demanet Afrique françoife T. II. p. I28. (t) Bosman l. $\varepsilon_{0}$

(u) Pigafetta Relatione del Reame di Congo. p. $3 \mathrm{r}$.

(v) Allgem. Reif. T. V. p. 85. (w) Kolbe l. c. p. 143.

Ala $a$ z 


\section{SPECIMEN ZOOLOGIAE}

tem imminui docemur, Qui enim in Italia educatur, illo, quem Aegyptus nutrit, ftupidior, \& hic Indiae fefforibus hebetioris ingenii effe perhibetur. Ex omnibus itaque palam fit, Indiam terrasque eidem folis calori expofitas, modo aquae ipfis ne defint, potiffimum effe locum, ubi natus fit omniumque optime proveniat. Quod eo magis adhuc confirmari cernimus, quia Africae partes maximo folis aeftu calentes, Congo nimirum \& Benguela, aliquot ejus varietates nutrit. Ex Carli enim relationbus pater, rufos ibidem, nigros, variegatosque bubalos inveniri $(x)$.

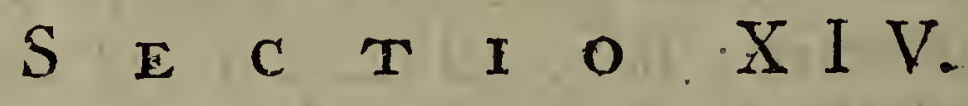 \\ Bos Gnous.}

§. I. Tgnotuin hucusque \& nuper admodum deteetum 1 memoremus animal, quod mea quidem fententia inter Linnaei pecora \& belluns, vel fi malueris, equum inter \& bovem, locum occupare, \& boum quidem generi fubjici, aliqua tamen ratione equis etiam, quibus nonnullis in rebus haud abfimile eft, adnumerari poteft, celeberrimi Allamandi curae ftudioque acceptum referimus, qui in Buffonii, quam edendam curavit, hiftoria naturali Tom. XV. pag. I I 3. Tab. IV. elegantiffinam exactiffimamque beftiae, quam $\tau^{\prime}$ Gnou nomine infignit, tam defcriptioncm, quam imaginem exhibuit. Quod vir praeftantiffimus omnium optime praeftare poterat, utpote cui animantis, quod jam Hugae in theriotropheo Smi. Araufiae Principis vivum ad-

(x) Ailg. Reif. T. V. p. 85. 


\section{G E $O$ G A P H I C E.}

adfervatur, cominus videndi contemplandique copia facta eft. Vir eximius, illud afinum magnitudine aequiparare, fcribit, additque, reliqua ejusdem generis, quae in fede patria naturali fua libertate utuntur, longe majoris corporis alacriorisque effe ingenii. Quam $A l$ lamandus beftiam dimetiendam curavit, tres dimidiumque pedes altam \& quatuor dimidiumque longam invenit.

b. II. Totum corpus, fi partes quasdam mox nominandas exceperis, in cervi morem pilis brevioribus fulvi coloris, quorum apices albefcunt, tegitur. Hinc fit, ut ex albo cinerei coloris effe videatur. Caput bovis capiti, licet craffus fit, non eft abfimile; cujus pars anterior longioribus pilis nigris veftitur, qui fubter oculos defcendunt; \& quia etian candidi ejusdem longitudinis pili, barbam inferiori in labio efficiunt, fingularem id intuentibus inufitatumque adfpectum, praebet; oculos animantis magnos nigrosque cilia alba longiora cingunt, quae ftellae fpeciem referunt, e cujus medio oculus ipfe emicat. Superior frontis pars nigris duobus cornibus novendecim digitos longis armatur, quorumbafis \& ambitus feptendecim digitorum patiun complectitur. Cornua ipfa per fex digitoram longitudinem recte procedentia fe invicem tangunt, polt in altitudinem curvata in cuffidem exeunt. Duos pollices. a cornibus crinis craffior jubae in modum pronafcitur, qui a fuperiori colli parte ad dorfum usque defcendit; cujus radices albae apicem verfus nigrefcunt, aures pone cornua brevioribus pilis nigris tectae prominent. Parum abeft, quin e dorfo, quod aequabile procurrit, e femoribus, pofterioribus corporis partibus \& cauda, quae longioribus crinibus albis ornata eft, equam te juA a a 3 . ve- 


\section{4

venem cernere credas. Colliinferiora breviori crine, caput autem longiori veftitur; pedes tam formam, quam elegantiam, quin \& nigras cervi habent ungulas. Dentes incifores in fuperiori maxilla nulli, in inferiori autem octo numerantur. Ex quibus, licet vir celeberrmus id certo comperire nondum potuerit, fatis tamen probabiliter beftiam hanc earum numero, quae ruminantur, adfrribendam effe, conjicit. Licet primo adfpectu nulla feritatis indicia monftret; contacta tamen, propius accedentes ipfanque demulcentes cornibus petere minatur. Interdum fe in genua demittit, \& fic caput in terram inclinans celeri fatis pafiu progreditur.

6. III. Animalia haec per Africae interiora fatis copiofe dilatari dicuntur. Gordonus, Batavorum centurio, Africae inveftigandae defiderio a bonae fpei capite ad cancri tropicum progrediens, magnos eorum greges obvios habuit, \& Allamandus, illos Africam interiorem, Aethiopiam \& adfines alias regiones pererrare furpicatur.

Nomen Gnous ab Hotentotis a fono, quem edit, accepiffe, probabile eft, licet boum ritu interdum quoque mugiat, \& clamorem, qui ardeae vocem imitatur, edat. Herbis pafcitur. Utrum in Congi regno fub emspakaffae rel empabing ae nominibus lateat, temporis fucceffu demum docebimur.

Nomen Gnou in mappa Zoologica bonae fpei capiti adfcriptum habes.

J. IV. Nunc ad alios duos tranfeamus quadrupedes, qui fub illo ipfo quidem climate orti videntur, quorum tamen naturae indoles ita comparata eft, ut prima fuadomicilia fine vitae periculo relinquere, in aliasque ter- 


\section{G EOGRAPHICA E.}

ras migrare haud polleant; fagax eft elepbas, \& asperioris ingenii rbinioceros.

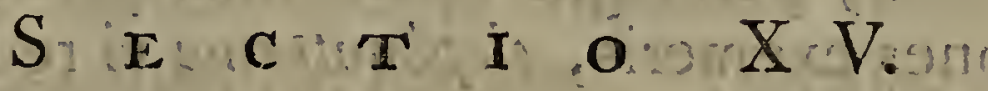

$$
\begin{aligned}
& \text { Elephas }(a)
\end{aligned}
$$

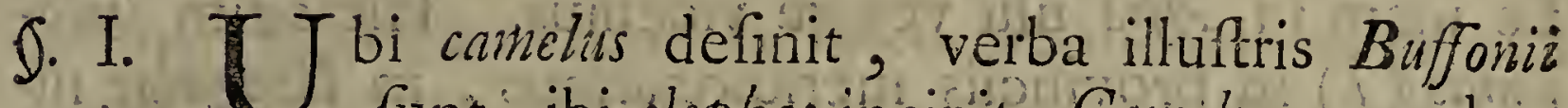
funt, ibi cleplas incipit. Cainelus, quod ex antecedentibus patet, fatis alte feptentrionem verfus progreffus, inde ad decimun quintum latitudinis gradum defcendit. Elepbas autem ad fummun a vicefino latitudinis gradu in Africae oris reperitur, qui interiorès fortaffis nondum notas nobis regiones, fub vicefimo quinto gradu pofitas, majorique aeftu torrentes jam incolit. In Hovalenfuim regno (b) aliquantum cis Senegam fito, quantum mihi quidem innotuit, primum reperitur. Dein Gaimbiae ripas $(c)$, dentium orain $(d)$, quae a dentium eburneorum ibi obviorum multitudine nomen habet, omnem Guineam (e) Congique $(f)$ ad bonae fpei promontorium $(g)$ usque tenet. Aequatorem itaque transgreffus per Natalis terram (b) (Terre di Natal) Manicaim, Mozambicum (i) Mombazam, feu quod idem eft; per onnem Zanguebarcm ad Abyfiniam $(k)$ usque pro-

ce-

(a) Elephas maximus. Linn. Buffon T. XI. (b) Allg. Reif. T. II. p. $33^{2}$

(c) Demanet Afriq. franç. 1.11. p. I20. (d) Allg. Reif. T.IV. p. 385 5

(e) Bosman Guinea. Hamburg 1703. p. 377.

(f) Pigafetta Relatione del Reame di Congo. Roma I591. p. 27. \& feg

(g) Kolbe l. c. p. 148.

(h) Hamilton in Allg. Reir. T. V. p. 209.

(i) Marmol Defcript. de l'Afrique T. I. p. 58.

(k.) Luddolf Hift. Aethiop. Lib. I. Cap. X. S. I8. \& feg. 


\subsection{SPE CIMEN ZOOLOG IAE}

cedit. In omnibus, in quios Europae indigenis hucusque penctrare licuit, interioribus Africae tractibus fedem habet; verbo, permagna haec orbis pars, fi boreales. cjus regiones exemeris, clepbantorum vi redundat.

b. Il. Quemadmodum in Africae terris fub vicefimo, aut vicefimo quinto demum latitudinis gradu, occurrunt; fic idem in $A / f r a$ ufu venire videmus. Hic enim Indoftanis (l) in provinciis meridionalibus, in Bengalae ninimirum (m), Cocbini, Malabariae (n), Carnati, Aracani, Pegui $(o)$ \& Siamme $(p)$, quin etiam in Chinae tractibus (q) quibusdam, elcppantes habitant. Quodfi vero in Afia hinc inde ultra vicefimun quintum latitudinis gradum eos offendi legimus, certi efre poffumus, manfuefactos illos effe, qui arte educati aequales iftis fint, quos Perfane reges $(r)$ alere dicuntur. Praeterea in aliquibus A/cae infulis, verbi gratia, Ceilonen/i $(s)$, funt obvii, ubi maximo \& robore \& animo \& folertia opraediti effe vidéntur. Porr in Sundacis $(t) \&$ Pbilippinis $(u)$, cos hấbitare conftat.

J. III. Quae hucusque ipfius varietates innotuerunt,

(.l) Voyages de Bernier T. II. p. 64. \& Mandeljo Reifen I 696. p. 65.

(in) Pyrard Voyages. Paris I679. p. 237. (n) lbid. p. 287.

(o) Recueil des Yoyages des Hollandois. Rouen $1725 . T$. V. p. 53 .

(p) Tachards Zweite Reife. Hamburg 1709. p. 213.

(q) lraecipue in provincisis Nanking \& Junnan. Vid. Newhofs Gefand: follati nach China. Amfterdam 1060: p. 371 .

(r) Olearizs Perfifche Reife 1606. (Ld. 2da) p. 256.

(s) Iyes Reifen. Leipzig I774. T. I. p. I03. Anderfons Oriental. Reif. I006. p. 04. Tnox Ceilan; \& alii.

(t) Voyages de la Comp. des. Ind. Rouen 1725. p. 77. Sumatra Allg. Reir. 'T. VIll. p. 92. Java.

(i) Vojages de Gemelli Carreri. Paris 17 16. T. V. p.200. Mindanao. 


\section{G E O G R A F H I C A E.}

magnitudine inprimis \& colore inter fe diftant. Africani enim generatim iis minores funt, quos India orientalis fovet; licet Mozamibiquenfes faepiffime Indiae orientalis incolas ftatura fuperare ferantur. Optimae indolis clephantes, quos maximis dentibus natura armavit, monta$n i$ vocantur $(v)$; quia montium maxime feffores effe folent. Color animantis ex fufco plerumque canus eft; nonnulli tamen lucidiori, quin albo penitus notati inveniuntur, qui tamen fingularem fpeciem nullam efficiunt, rarioribus potius funt accenfendi. Hinc fit, uit Indiae reges de elephantium alborum titulo dominioque inter fe conflictentur $(w)$.

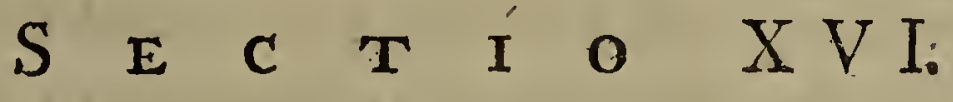 Rbinoceros (a).}

Q. I. $R_{\text {binoceros, qui corporis mole elephanto parum }}$ $\mathbb{R}$ cedit, eas quidem ipfas fere cum illo regiones, non eadem tamen copia, frequentat. Nec ipfum tam alte boream verfus adfcendere inde colligo, quod peregrinantium nullus fe illum in Senegae ripis obvium habuiffe teftatur; nec Bosmanmus in Guineae, quam dedit, defcriptione, rhinocerotis mentionem fecit. Africae regiones, in quibus primo confpicitur, Aebiopia funt \& Aby/finia (b), dein Congi campos, Angolac montes (c), Anzicanam regionem, bonae Jpei (d) pro-

mon-

(y) Buffon T. XI. p. 23 .

(w) Olearrii Anhang und Befchreib. Mandello Reir. 1696. p. I46.

(a) Linn. Sytt. p. 104. Buffor XI. p. 98 . \& feq.

(b) Ludolf Hit. Aethiop. Lib. I. Cap. X. I. 78 .

(c) Pigefetta l.c. p. 29. (d) Kolbe 1. c. p. I590

$\mathrm{Bb}$ b 


\section{SPECIMEN ZOOLOGIAE}

montorium, terramque de Natali dietam pervagari dicitur (c). In Afia Bengalae $(f)$, Siamis' $(g)$, Cocbinchinnae (b), Sinen/sque provinciae Quang- $\int(i)$ ( 2 \& Sucbuen $(k)$ incola eft. In Sundaicis (l) infulis omnibusque propemodum aliis terris, quas elephas inhabitat, rbinoceros etian invenitur. In Africa propemodum nullas carum, quae cis aequatorem fitae funt, terras occupat, illumque vix ad decimum latitudinis gradum \& paulo amplius progredi furpicor, quamvis per naturae fuae conftitutionem altius procedere poffit.

f. II. Nec eandem ipfum cum elephanto foecunditatis vim habere, ex eo liquere autumo, quod hi gregatim, obizocerates vero finguli, raro bini, rariffime. plures in campis difcurrentes obferventur; majoris tamen ponderis aliqua non praetermittenda ipforum varietas occurrit. Quum enim elephanti molis tanturn magnitudine colorisque diverfitate inter fe diffideant: his etiam in rebus rbinocerotes quidem a fe invicem diftantes, aliique majoris, alii minoris formae \& ftrueturae, alii furvo, alii fubfufco folum colore infeeti confpiciuntur. Sed quosdam etiam repertos effe ferunt, qui duobus, quin \& tribus interdum cornibus armati

fue-

(e) Allg. Reif. T. V. p. 2 ro.

(f) Voyage de Pyrard I 670. p. 237.

(g) Turpin Hift. de Siam T. I. p. 29I. Allg. Reif. T. X. p. 315.

(h) Borri Hift. Cochin-China. 797. v. Ponnant. p. 75 .

(i) Allg. Reif. 'T. VI. p. II3.

(k) Neulinfs Gefandfchaft nach China p. 370.

(l) Bontii Hift. Natur. Ind. p. 5 I \& 52 ap. Pifon. (Java) Vide etiam Jurgen Anderfen Oricnt: Reifen Hamb. I696. pag. I I. Olcailus Anheng und Befchreib. Mandelno Reif. p. 144. (Sumatra). 


\section{G E O G R A P I I I C A E. 379}

fuerint. Et Kleinizs ( $m$ ) \& Eberbardus ( $n$ ) in hiftoria naturali varias duplicium iftorum cornuum imagines dederunt, quales in pbilofopbicis quoque transactionibus $(0)$. exhibitas fcimus. Hamiltonius $(p)$ infuper fe in terra Nalali rbinocerotis caput, quod tribus juxta politis cornibus inftructum fuerit, inveniffe confirmat. Ex quo Linnaeus quidem varietates hujus beftiae duobus vel tribus cornibus praeditas dari colligit $(q) ; P_{\text {alla/ous autem, }}$ de effoflis in Siberiae campis animantium fceletis anquirens $(r)$, multiplicata ifta cornua crefcentis tantum fenectae indicia effe ; \& quemvis rbinocerotem, dum actate annisque provehatur, duplici vel triplici cornu armari fatis probabiliter evincere ftuduit. Quam litem nemo, nifi cui animantis hujus hiftoriam naturalem in ejus patria exquirendi facultas data fuerit, dirimere, reique veritatem praefens in lucem proferre poterit. Quicquid interim fit, rbinocerotenn uno, duobus, tribusque cornibus infignem, unum eundem quadrupedem, cornuumque iftam multitudinem minime diverfas fpecies, fed, ad fummum, varietates quasdam efficere, omni dubio caret.

SECTIO

(m) Quadrup. Difpofit. Tab. II. p. 29.

(n) Eberhards Thiergefchichte, 1768 . Tab. II.

(o) Ph. Transąt. Abr. IX. P. roo.

(p) Hamilton's Voy, fo the Eart. Ind. T. I. p. \&.

(q) Limi. Sytt. Ed.XII. p. 104. (r) Nov. Commentar. Petropol. T. XIII. 


\section{SPECIMEN Z OOLOGIAE $S$ E Icbreumon (a).}

Q. I. Dercenfitis nunc animantibus, qui herbis frugibus aliisque terra natis in torrida orbis antiqui parte nafcuntur, ad eos transgrediar, qui carnibus nutriri, eadem cum illis patria uti, \& per $A$ fram Africamque fatis dilatati reperiri folent. Initium ab illa fiat beftiola, quae fub Pbaraonis gliris appellatione nota eft \& pervulgata, quae ab utroque Zonae torridae latere fatis late diffunditur. Frigidiufculas tamen regiones non attingit feptemtrionis autem praegelidos tra. ctus penitus abhorret. Aegyptus (b) praecipue eft, quam inhabitat, quaeve propter fingulares, quas hujus incolis praeftat, utilitates, illam inter numina dicat (c); dein etiam Barbariae (d) feffor eft ; hinc in Arabiam Indiamque tranfit, ubi Kulemplero tefte $(e)$, per omnes calidiores terras ad Gangem pergit. Hic \& terram continentem fub Mangutiae nomine, \& infulas quasdam fub calidiffimo $A$ fiae tractu jacentes, $C e i$ ionem $(f)$ nimirum, Sumatram $(g)$ \& J Jovam occupat.

D. II. Afia domefticis eam quidem animalculis adnumerat; fed externum tamen habitum aliquantisper immutat: Mangrutia enim, quam Icbnewmois corporis

ma-

(a) Viverra Ichneuncis. Viverra cauda e bafi incraffata, fenem attcnuata pollicibus. Limnacus. La Mangoufte Buffon T. XIII.

(b) Hafelquift Reiren p. 275 .

(c) Deteript. de l'Egypte par Maillế 'T. II. p. r29.

(d) Shaw Reir. in d. Barb. p. I57. (e) Kaempfers Amoenitat. p. 57 s.

(f) Sicle Thefaur. T. 1. p. 66. (s) Kampfer: 1. c. 


\section{G E O G R A P H I C A E}

magnitudine multum vincit ; cauda fenfim in acumen definente, praedita eft, quum Icbnewmonis cauda in: pilorum floccum exeat, quod utrumque ex imaginibus ab Echvardo datis \& a Seligmanno transforiptis confpicitur (b). Ambae interim beftiolae ita inter fe conveniunt, ut nec Buffonius, nec Pennantios ( $i$ ) eas diffociare aufi. fint, eas potius unius fpeciei varietates effe dixerint. A Buffonio delineatam vero Ixquipatlam aut Confam Icbneumonis etiam varietatibus adfcribendam effe, quod Muellerus tradidit ( $k$ ), non poffum, quin propter eximiam eorum diffimilitudinem inficias eam.

J. III. Propter climatis aërisque temperiei aequalitatem fufpicandum erat, Icbineumonem Africae quoque terras trans aequatorem pofitas incolere poffe ; idque revera fieri, exinde videmus, quod, Kolbio $(l)$ auctore, in bonae Jpei promontorio obvius eft; an vero medias etiam calidiffimae hujus Zonae regiones habeat, incertiffmus fum. Nullum enim quos inficicere licuit, auctorem, ullam hac de re mentionem facere memini; nifi glivinum majoris formae, quos Bosmannus in Guineae oris obfervaffe frribit, unum alterumque in Ictneumonum numero ponere volueris $(\mathrm{m})$. Mediae fortaflis Africae tractus aefu graviore quam quem Icbnemmon tolerare poteft, torrent. Fortaffe itaque ex Aegypti oris, quae patria ipfis fedes effe videtur, quoniam ibi-

dem

(ii) Seligmans Voegel T. VI. Tab. XCIV. Edwards. p. 199.

(i) Synopf. p. 220 . \& feq. (k) Limnaei Vólftaendig. Naturfyftem. T. I. p. 245. (l) Kolbe l. c. p. 158.

(m) - Bosmannus, in cujus deferiptionibus multa inveniuntur; quae nondum fatis expedia funt. Vid. ejts Guinea p. 299. \& feq.

$\mathrm{Bb} b 3$ 


\section{SPECIMEN ZOOLOGIAE}

dem \& corporibus \& numero optime augentur, digreffus, medias partes fibi perniciofas fenfit, \& in moderatiores paulo terras, torridae nimirum Zonae extremitates, tranfiit, ubi melius vivere $\&$ provenire poterat.

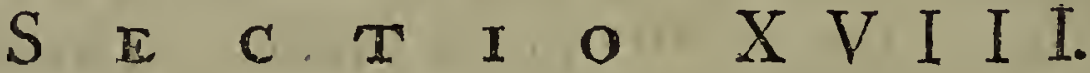

is

Felis Zibetbus (a).

S. I. Ture meritoque celeberrimi Buffonii opinioni fubfcribo, qui hunc quadrupedem orbi tantummodo antiquo originem fuam debere credit; licet alii multi fint, qui ipfum etiam Americae domefticum efle autument. Reccbii praecipue relatio Buffonio contradicere videtur, quia a Gregorio Bolivaren/i, beftiolam hanc novi orbis regionum effe indigenam, audiife teftatur $(b)$. Quum vero Fernandezius in fua, quam de Americae guadrupedibus edidit, defcriptione, expreffis verbis (c): felen hunc, fecundum Hispanorum affertiones ac teftimonia, ex injulis Pbilippicis in Americam delatum effe, adftruat; auctorum praeterea, qui novum orbem peragraverunt, nullus fere hujus be-

(a) Virerra Zibetha. Viverra cauda annulata, dorfo cinereo nigroque undatim ftriato, Linn.

(b) Falri Lyncei Schol. in Anim. Zibethic. Recchiii in Thefauro rerum medic. Hernandizii. Romae 165I. p. 539. ubi tam orbis antiquus quan America pro Parria felis Ziletlii habetur.

(c) Pag. 11. Cap. XXXIV. Non me latet, vulgare effe, hoc felis vocari genus Hifpanis, quamquam advenam, non indigenam verum, qui ex infulis Philippicis coepit, jam in hanc novam Hifpaniam adferri \&c. Fr. Fernandes lift. Quadrup. Nov. Hifp. 


\section{G E O G R A P H I C A E.}

beftiae mentionem faciat; \& denique Zibetbum odoramentum a mercatoribus quam maxime ex Orientis regionibus ad nos deferatur: his rationibus commotus, felem ipfum merito antigui orbis progeniem effe, colligo. Quoniam interim Manillam areto multiplicique cum America nexu copulari, hujus etiam novi orbis tractus meridionales eo tepore calere fcimus, quem beftiae hujus \& proventus poftulat \& incrementum : fieri potuiffe non nego, ut unus alterque iftorum felium; navi e nominata jam infula in aquae pulchrae portum (Acapulco) fint transportati; qui deinde vel manfuefacti aut feri, vel cafu vel confilio aucti, per iftas, vicinasque iis regiones diffeminati fint. Batavi etiam felem iftum, quia magnum illis fructum adferre folet, nutriunt: cur non Mexicorum regnum \& Amorica meridionalis generatim, commodius eum aleret? Acofta interim, Piso, ID aferus, Correalius, Barrerus, Bancrofinus, Ferminus, Condaminus \& Ullon mentionem ejus fecere nullam; ni$\mathrm{fi}_{1}$, quod tamen a ratione \& veritate averfum mihi videtur, fub Muffetorum ipfum nomine latere, quisquam fibi perfuaferit; quum e contrario, quod jamjam demonftratum dabo, peregrinatores, qui in calidiffmas. antiqui orbis regiones excurrerunt, easque defcripferunt, felem hunc domefticum iftarum terrarum animantem effe, confiteantur.

b. II. Felis autem hic ad fummum a tricefimo primo latitudinis feptentrionalis gradu Syriam (a), Inaiam

pro-

(d) Ruyycll. Theatr. Animal T. II. p. I57. 


\section{SPECIMEN ZOOLOGIAE}

proprie fic dictam (c), Mulabariam $(f)$, Siaman $(s)$, Ploilippicas (b) infulas \& omnes ferme calidiffrmos $A$ fane tractus pervagatur. In: Africae partibus quam maxime Guineanir $(i)$, Abyfinian $(k)$, Conguin $(l) \&$ Loing un ad bonae usque Spei promontorizm $(m)$ occupavit; \& hine in alterum latus tranfiit, ubi in Madagafcaris terris fub $T$ alamuci ( $n$ ) nomine paffim occurrit.

J. HII. Buiffonius primus eft, qui variis notabilibusque beftias hafce difcriminibus inter fe diftare, obfervavit $(0)$; varietatesque iftas animalis $Z$ ibetbi nomine (Zibet) infignivit, quas a feli Zibetbo (Civetze) diftinguendas effe autumat. Maximam autem differentiam in eo pofuit, quod feli juba \& annuli defint, quibus animal Zibethi ornatum confpicitur. Quum caeteroquin tam ratione externae formae internarumque partium conftitutionis, quam refpectu bene olentis odoramenti, ejusque fedis; quin etiam pellis variegatae intuitu, exacte fibi refpondeant: utrasque vir ceteberrimus non ut fingulares duas fpecies expreffis a fe invicem verbis difcernere $(p)$ aufus eft. Et Pennantuis etian, eas ut varietates tantummodo inter fe diffa-

(e) Voyages de Pyrard troiième Partie. p. I 4 .

(f) Voy. de Dellon p. I \& \& 8 . (g) Turpin Hif. de Siam T. I. p. 300.

(ii) Alig. Reif. I. XI. p. $427^{\circ}$

(i) Bosmans Guinea p. 2. \& Allg. Reil. T. III p. 275. \& 322 .

(k) I'Afrique de Marmol T. I. p. 57. (l) Pigafetta 1. c. p. 32.

(m) Fabri Lyncei Expoft. ap. Recchi: in Hernandez Thefauro p. 539. ubi dicitur Feles hos in montibus Lunae usque ad promontorium bonae - fpai reperiri. An Kolbens Biefam Katze (p. I.54.) felis Zibethus?

(n) Allg. Reif. T. VIH. p. 574. (o) Buffon T. IX. p. I64.

(i) Ibid. P. I6?. 


\section{G E O G R A P H I C A E.}

re (q), fcripfit. Civettae feu feli Buffonius Africanz patriam, \& Zibetbi animali $R$ fram effe tradit.

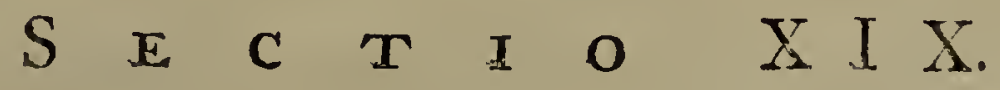

$$
\text { Fofjana (a). }
$$

A nimal fubnectimus, feli Zibetbico, fi odoratam A modo fubftantian \& receptaculum, in quo colligitur, quibus utrisque caret, exceperis, caeteroqui perfimile. Fofjana eft, cui, quoniam itidem zonam torridam incolit, \& pari propemodum cum illo ratione fat multas terrae calidioris regiones, licet minus inter fe cohaerentes, pererrat, locum hic dandum effe cenfeo. Eam fub Berbae denominatione in Guinea (b) reperiri, Buffonius adftruit; cui jure adftipulor. Praeterea in Madagafcaris (c) \& Cocbincbinae (d) finibus, itemque in Pbilippicis ( $e$ ) infulis vivit. An autem in terris etiam reperiatur, quae enumeratas iftas regiones dirimunt; futura demum tempora docebunt.

Sectro

(q) Synopf. p. $235 \cdot$

(a) Viverra Foffana. La Folfane. Buffon. T. XILI.

(b) Bosmans Guinea p. 299 .

(c) Allg. Reif. T. VilI. p. 273. \& praecipue Buffon 1. c. p. 89. Ren cund. de Poirre (d) De Poirre apud Buff. l. c. (e) lbid.

\section{$\mathrm{Ccc}$}


386 SPECIMEN ZOOLOGIAE

$$
\begin{gathered}
S E \text { C T I O X X. } \\
\text { Leo (a). }
\end{gathered}
$$

6. I. Coronidem capiti fecundo nobiliffimus \& pene rapaciffimus quadrupedum, qui zonam folis ardoribus aduftam inhabitant, leo nimirum imponat; quem fatis longe a priftinis fuis fedibus demigraviffe, ex Ariftotele difcimus; quippe qui Europam olim \& inprimis quidem Graecinn leones aluiffe, expreffis verbis adfirmavit (b). Nunc autem nec Actoliam ad Acbeloi, nec Thracian ad Nefli ripas fub quadragefimo ulterioribusque gradibus leones nutrire, omnes, qui iftas regiones peragravere, teftantur. Eos autem non auctis hominum catervis ad hanc difceffionem perductos effe, ex eo patet, quod majori longe hominum multitudine Graccio Arijlotelis aevo frequentata fuit, quam quibus nunc temporibus ipfam frib Turcarum ditione immitique dominio cultam novimus. Extimus, ad quem pertingunt, feptemtrionis gradus tricefimus circiter quartus eft latitudinis borealis. Hand enim procul a Bagdade (c).Eupbratis inter \& Tigridis flumina nonnulli interdum leones confpici folent. Syriae vero $8 \mathrm{r}$ Palefinane fines penitus reliquerunt. Nec Aegyptum amplius, praeter quos ex interiori Africa eo depor-

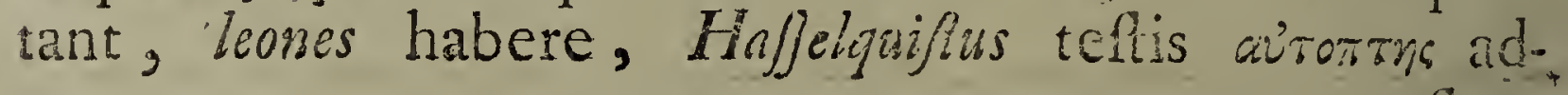
ftru-

(a) Leo. Feliscauda elongata, corpore helvulo. Linracus. Buffon T. IX. (b) Ariftot. Hirt. Animal. Lib. VI. Cap. XXXI. \$. 396. pag. 776. Idit. Scaliger. (c) HaJelauifoto. Palaeftina p. $5 \sigma_{3}$. 


\section{G E O G R A P H I C A E.}

ftruit $(d)$. Sed nec ifta hujus beftiae demigratio aucto ibidem hominum incremento tribui poterit. Quis enim, nifi excors, Aegypti Pale Atuneque feraciffimos quondam laetiffmacque ubertatis agros nunc frequentius, quam fub potentiffimis olim regibus, qui innumerabili fere multitudini imperitabant, habitari dixerit?

J. II: Notabilis itaque illa leomum -imminutio dubio procul vel a Romanis, vel a regionum incolis originem traxit; qui eos tam propter immanitatem, qua faeviunt, quam funeftas clades, quas hominibus inferebant, fic forfam exfcindere tentaverunt, velut Angli lupos, e regno fuo exftirpare conabantur. Quod quidem in terra continenti, quam in infula, qualis Anglia eft, difficilius effectu erat; nihilo tamen fecius id commodi inde acquiri potuit, ut luftris fuis relietis leones in alios fines depelierentur. Nec immutata coeli aërisque temperies, quae feptemtrionis animantes, verbi gratia, tarandos, priorem patriam deferere, ulteriusque boream verfus progredi coëgit, in leonibus locum habet; quum certis nullis rationibus probari poffit, Aegypti Paleftinaeque coeli tractus majori nunc, quam olim, frigori expofitos, ideoque leonibus minus habitabiles effe. Nifi cultas olim, nunc autem hominibus nudatas regiones frigidiores redditas effe ftatuere volueris; quod quidem fieri potuiffe non negaverim, interim tamen hac occafrone longe nimis petitum videri poffet. Solus homo, cui refiftere nihil valet, quod magna me probabilitate

per-

(a) Ibid.

$$
\text { C c c } 2
$$




\section{SPECIMEN ZOOLOGIAE}

percutit, infeftis eas regiones armis perpopulatus, befluas has trifti clade interfecit, reliquasque perpulit, ut relictis, quae hucusque tenuerant, luftris, alia fibi aliis, ubi tutius vivere poffent, in locis quaererent.

6. III. Quod ipfum etiam experientia confirmari deprehendimus. Sulla enim, qui poftea dictator fuit, primus omnium centum jubatorum leonum pugnam Romae dedit; poft cum l'ompejus Magnus in circo quingentos \& in iis jubatorum trecentos quindecim; Caefar autem dictator quadringentos (e); qui omnes intra quadraginta circiter annorum patium occifi funt. Quumque praeterea leones, ficut reliqui omnes corporis magnitudine infignes carnivori animantes, miminime multi fint, illique perpaucos tantum quotannis catulos uno enixu edere foleant: facile conjectu eft, quanta, interfectis, tam exiguo temporis intervallo, mille leonibus, ipforum infrequentia exorta fit. - Et fie aliquam faltim probabilem redditam effe rationem autumo, cur beftiarum harum numerus decrefcere magis, quam increfcere debuerit. Accedit, quod igne vehementiffme terretur, ideoque faepius factum effe ferunt, ut minus cultae nationes folis titionibus leones in fugam verterint: quid igitur obftat, quo minus bombardarum poftea inventarum explofiones illos tremere $\&$ horrere credamus, quae non fragorem tantum, tonitru haud abfimilem, emittunt, fed ignes etiam \& fulmina evomunt, quibus eminus fe feriri \& vulnerari fen-

(e) Plin. Iiift. Nat. Lib. VIII. Cap. XVI. 


\section{G E O G R A P H I C A E 2389}

fentiunt. De induftria verifimillimas has adferre ratio. nes volui, quibus commoti leones vel tutiora in loca fecefferint, vel numero deminuti jam rarius occurrant, ut eo certius commonftraretur, Buffonium erraffe, qui ipforum decrementum humani generis incre. mento attribuerat; quod tamen in aliis forte tam regionibus, quam animantibus locum habere poffe, non negaverim.

0. IV. Quamvis leo Aegyptum reliquerit, Fezae tamen \& Marocci regna $(f)$ tenet, Atlantis juga frequens incolit, Barbariaeque tractus occupat $(g)$. Sub moderatioribus vero climatibus non eodem robore, quo fub calidiori coelo, pollet. Atlantis enim feffor, qui frigidiori paululum aëre utitur, nec tam robuftus effe, nec tanta immanitate faevire folet, quam qui ardentes Lybiae arenas, aut arida Zaarae deferta incolit (b). Ab albo deinceps promontorio (Capo Blanco) ad Tagrini promontorium progreditur (i). Bosmanmus quidem in Guineale, quam dedit, defuriptione, nullam ejus mentionem injecit; non tamen dubitari poteft, quin iftis etiam in terris habeatur, praecipue quum in Congirurfus, Angolae ik), Anzikanisque tractibus ( 1$)$; quin \& in Feggufenfum $(m)$ regionibas, quae tamen longius iftis ad aequatorem extenduntur, inveniatur.

Ex

(f) Leo Afric. Defcript: Afric. p. 754. (g) Shiaw Barbar. p. 152.

(b) Leo Affric. l. c. (i) Allg. Reil. T. III. p. 310 .

(k) Carli in Allg. Reir. T. IV. P. 542 \& 544.

(li) Pigafetta Relatione del Reame di Congo p. 29.

(m) Millg. Reif. T. V. p. 100.

C C 3 


\section{SPECIMEN ZOOLOGIAE}

Ex Kolbii relatione leo omnes Hotentottorum nationes ad bonae fpei usque promontorium comitatur $(n)$. In $\boldsymbol{R}$ fricae partibus, quae orientem fpectant, terrae $\mathrm{Na}$ talis filvas ( Terre di Natal (o)) fibi vindicat. In Nutbiae porro \& Aby/finiae ( $p$ ) montibus luftra fibi condidit, \& fic omnis fere Africae, fi Aegyptum exceperis, habitator eft.

j. V. In Afra praeter illa, quae ante nominavimus loca, meridionales tantum plagas occupat. Arabine (q) enim, Indofanae $(r)$, Malabaris, Ceilonis $(s)$ Sumatraeque $(t), \& \tau$, quod admodum probabile mihi videtur, aliarum quarundam eidem coeli temperiei fubjacentium hujus terrae partis regionum feffor eft. Sed quia nec Siamae nec Cbinae indigenae obvium eum $(u)$ habent: exinde conficitur, eum nec in flagrantiffimis etiam Aface plagis tam copiofe, quam in Africa, dilatatum reperiri. Ex quibus onnibus manifeftum eft, nullam praeter $P$ erf fam in Afra regionem dari, quae cis aequatorem nunc leones alat, qui hoc in regno ad tricefimum usque latitudinis gradum adfcendunt.

\section{Ø: VI.}

(n) Kolbe 1. c. Quod Deslilius in Africae meridionalis, quam dedit, tabula geographica de manfuefactis leonibus tradidit, eos cun Heufaquis, auxiliarium inftar, ad bella proficifei, nec affrmare, nec negare audeo; fit potius fides penes anctorem.

(o) Allg. Reif. T. V. p. 200.

(p) Ludolf Hift. Aethiop. Lib. I. Cap.X. (q) Niebulrs Arabien p. 164.

( $r$ ) Bernier in Allg. Keif. T. XI. p. Io9.

(s) Innox Rélation d'un Voyage de l'Isle de Ceilan. Amfterdam I693. p. 89.

(t) Olearius Anhang in Mandelfo Reif. p. I4t.

(u) Navarette in Allg. Reif. T. VI. 


\section{G E O G R A P H I C A E. 39r}

5. VI. Americam autem leones penitus ignorare ex eo colligimus, quod peregrinantium fide noflra dignoram nemo, fe leones obvios habuiffe, hucusque adftruxit. Quem vero Americae leonem nunncupant, cui novi orbis indigenae Pumae nomen impofuerunt, aut, quod Pennantus autumat, Conguarus ( $v$ ) eft, aut alia quaedam animantium fpecies, quae leonum numero nullo jure, nulla ratione adnumerari poteft; quum nec juba ornetur, nec illa corporis amplitudine audaciaque fuperbiat, quae leones infignire folet; quin potius propter ftaturae exiguitatem timiditatemque fingularem parum curetur: $(w)$.

Arifoteles quidem teonum etiam crispis pilis praeditorum $(x)$, Aelanus $(y)$ autem \& Oppianus $(\boldsymbol{z})$ nigris albisque pellibus tectorum meminit; fed quoniam nec volam eorum nec veftigium in peregrinatorum commentariis, quibus fides haberi poffit, reperire potui: in Buffoni fententiam tranfeo, qui has varietates in rerum natura nullas dari, fibi perfuadere videtur. Quorundam interim pelles fulyo dilutiori, aliorum fubfusco magis infectas effe, aliosque caeteris \& corporum amplitudine \& roboris praeftantia antecedere, lubens largior. Hoc enim aliis eriam omnibus ferme animanti-

bus

(v) Le Couguar Buffon T. IX. Tigris fulva. Brifon Regn. Anim.

(v) Condamine Reilen in Goetting. Reif. T. 11. p. $30 \mathrm{I}$.

(x) Ariftot. Hift. Animal. Lib. IX. Cap. LXIX. pag. I1 54. Edit. Scaliger.

(y) Aelian. de Anim. Lib. XVII. Cap. XXVI. pag. 945. Edit. Gronov. 4 to.

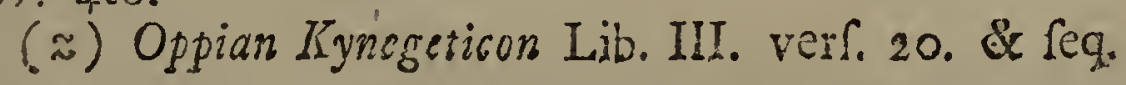


392 SPEC. ZOOLOGIAE GEOGRAPHICAE.

bus commune eft. Generatim vero leo terrarum partis recto folis appulfu ardentis, ad quam homines perraro penetrant, incola \& virium roborc firmiffimus \& animi audacia eft promtiffimus.

Finis Capitis Secundi.

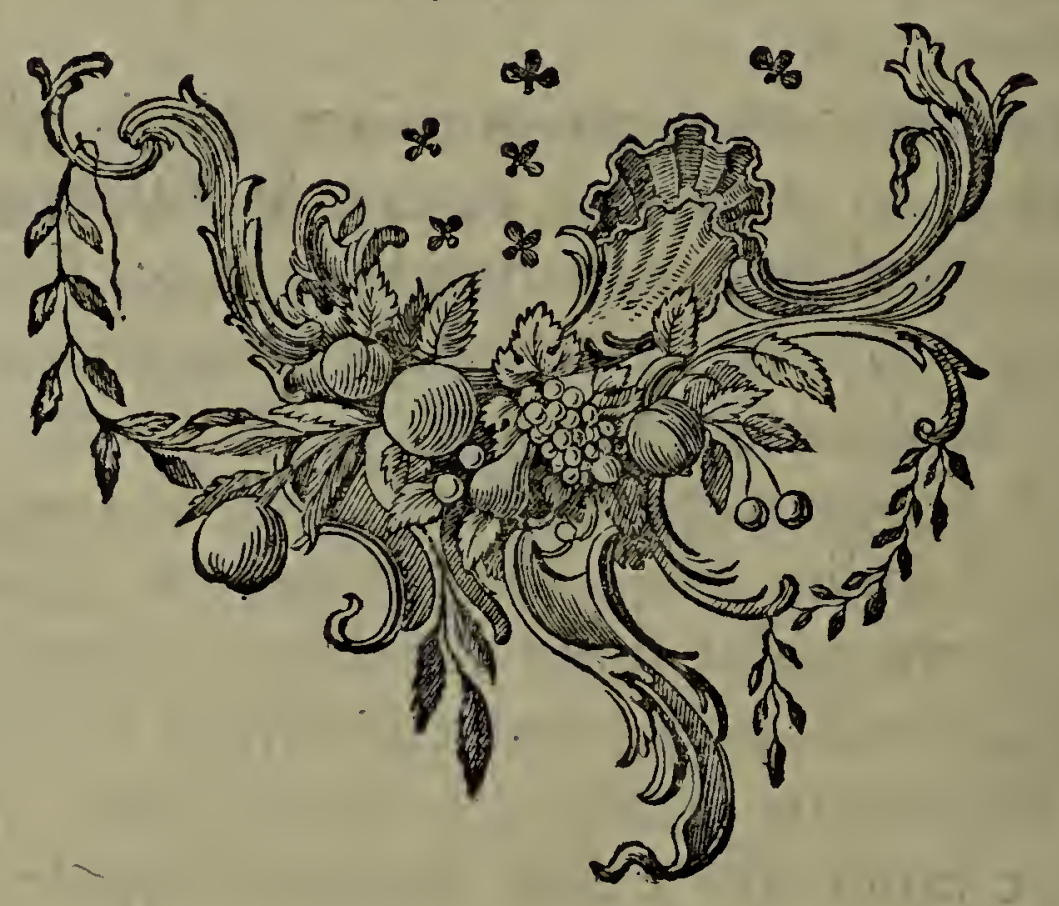




\section{S P E C I M E N \\ ZOOLOGIAE GEOGRAPHICAE, QUADR UPEDUM}

DOMICILIA ET MIGRATIONES $S$ I $S$ T E N S.

\section{CAPUT TER TI U M}

De quadrupedibus arctiorilus plagis novi antiquive mundi alligatis.

i quis animalium in praecedentibus capitibus enumera$\$$ torum fummam fubducere voluerit: partem fere omnim, quae nobis hucusque innotefcunt, dimidiam jam abfolutam effe inveniet. Quum enim omnis eorum grex, fi varietates memoratu digniores iis addideris, tres circiter centurias expleat, \& jam centum triginta \& amplius percenfita fint:centum fere \& quin quaginta fupererunt $(a)$, in quibus commemorandis nunc occupabimur; quae tamen, quia reliquis minus a prototypo fuo degeneraverunt, varietates propemodum nullas habent. Quos quadrupedum aut per totum telluris orbem diffipatos reperimus, aut faltim in utrovis aequatoris, orbis tam veteris quam novi, latere, Zonas permagnas incolere novinus; eos pauciffimos effe, e primo capite didicimus. Majorem illo:

(a) Buffonius iila ad ducenta tantum genera \& amplius coëgit; tunc aub' tem varictates, \& recte quidem, omittendas exiftimat.

Dd d 


\section{S PECIMEN Z O L OGIAE}

lorum copiam, qui latiora tantum telluris patia tenent, capnt fecundam, quod eosdem continet, ob oculos ponit. Omnium autem plurimi, quos nunc ordine fuo perluntrabimus, arctioribus duntaxat terris alligati videntur; quos tamen finibus fuis non ita adftrictos dixerims tut eosdem nunquam egrediantur: Cunctos itaque ad caput hoc tertium rejectos volo, quos rel anguftus feraginta tongitudinis gradibus fpatium occupare, minoribusque tantummodo tractibus inclufos, vel per diffitas minusque inter fe coliaerentes regiones disperfos \& hinc \& inde obvios fcimus.

Nuac codem quidem ordine, quem hactenus fecutus fum, a feptentrione exorfus ad temperatiores terras, \& hinc ad aequatorem progrediendum, \& fingula animalia, fingulas regiones inhabitantia, enumeran. da efient: fed quoniam non exiguus illorum numerus fub eodem interdum cocli climate vivit; fieri non poffet, quin haec dispofitio magnam \& perturbationem \& confufionem adferret. Accedit, quod feptentrio pauciflimos quadrupecum, quorum hoc in capite mentio facienda eft, alit; e contrario fat magna ipforum copia Zona, quam torridam nominant, redundat, cujus aleftum permulta famianum, antiloparim, dafypodumque genera- \& tolerant \& amant, eoque ipfo ibi patriam fuam. effe commonftrant. Poiro monendum eft, in capitis hujus animalibus varietates vel nullas vel pauciffimas in. venifi. Quum enim nulla fere arte perduci hucusque potuerint, ut bominis jugo fe fubmittant, . ipfique doméfticarum inftar pecudum ferviant: inde factum effe. credo, ut nec fedes fuas, nec coeli temperiem mutaverint, nec a prima parentum fuorum forma ingenioque difcefferint; eandem potius naturam conftitution- 


\section{G E O GRA P H I C A D. 395}

nemque retinuerint. Quoniam interim ordo quidam fervandus erat, ad quem contemplandi hujus capitis aninantes difponerentur: Linnaeum ducem prae religquis eligere malui. l'emnantun quidem tutius fequi potnisfen, qui non exiguum eoruin numerum, quos Linneeus praetermifit, convenienti loco inferuit; it ingenue fateor, Angli hujus celeberrimi /ynopfin caeteris omnibus hucusque in lucem emiffs libris multo ploniorem effe exactiorenque. Quia vero Limaci.jy/ann in omnium fere manibus verfatur, virque hic folertifinmus tam paucas numero fubdivifiones addidit, ut uno quafi obtutu perluftrari omnes queant: lectorum comnoditatiinfervire, illudque reliquis anteponere magis placuit: quicquid tamen Linnaeus omifit, partim e Liuffonco, partim e Pemanto, loco fro infertun invenies. Cáput itaque tertium hoc nomenclatoris vice fungerur, \& Guagdrupedum per exiguos modo terrarum tracus difperfom rum patriam brevibus quidem, quacunque tamen fieri potuit, cura, diligentiaque exhibebit. Ceterum non eo procedam audaciae, ut animantes a Limmaso, nefcio, an confulto, an imprudenter neglectos (prits enim fyllema fuum collegerat, \& in lucem emiferat, quan Pemnantus (ynop/s fuae manum admovit) novis Linnaei more formatis effictisque nominibusinfigniam; qua in re naturae ferutatores modum nunc excedere, novisque nominibus nova indies addere non dubitant: 'quoslibet potius perfpicue fatis luculenterque vel fecundun Lunnaeum, vel alium quendan auctorem defnivifie, generi, ad quod pertinent, adjunxife, untm alterunique optimorum fcriptorum, qui eos aut defcriptos aut depictos dedit, laudavife, Ex patriam denique foden illonm,

$$
\text { Dd d } 2
$$




\section{SPECIMEN ZOOLOGIAE}

quocunque ftudio indagare potui, appofuife mihi ful: ficiat.

Unam tamen divifionem mihi aflumendam efle, rei natura 2 fuadet \& praecipit. Quum enim quadrupedes, qui hoc in capite percenfebuntur, in novo partim, partim in veteri orbe reperiantur: ordo perfpicuitasque pofulare videtur, ut illis, quos antiquns orbis nutrit, primum locum tribuam, iftosque ftatim fubnectam, qui ejusden generis Amorica etian habitatores funt. Sic, exempli gratia, veteris orbis Simias jufta ferie enumerabo, quas deinceps novi ftatim orbis beftiae ejusdem. nominis excipient. Sic, guoscunque LANNAEUS uni cuidam generi adjudicavit, leetor benevolus conjunctos quidem offendet, nec tamen antiqui novique orbis. animantes confufe inter fe permixtos effe, aliquan. querendi fpeciem habebit.

$$
\begin{gathered}
\text { S. E C T I O I } \\
\text { De Simiis. }
\end{gathered}
$$

2. I. riusquam fingulas hujus generis fpecies enar- ramus; partim de ipfarum divifionibus, partim de orbis noftri tractibus, quos totum hoc animalium genus quae LIN Nate fub. Simiarm appellatione comprehendit, occupat, nonnulla praenittere liceat. Quod ad prius attinet, Limnaei veftigiis infifere placet, qui Simins in tres clafes dintribuit; quarum prima eas continet, quibus cauda deeft; Secunda papiomes, qui caudas breviores habent; tertin tandem cercopithecos, caudis longioribus praeditos; quos Buffonius de\$uo in duos ordines, \& mea quidem opinione recte. 


\section{G E O.G R A P H I C A E. 397}

diftinxit: quarum priori Simias longioribus caudis, calvis natibus folliculisque in utroque maxillie inferioris latere.inftructas addixit; quae omnes, juxta cum iis, quas roftro nullo \& breviori tantum cauda natura armavit, antiqui orbis indigenae funt. Pofteriori vero eas.fubmifit, quarum caudae longiores, nates pilis tectae, folliculi autem in roftro nulli funt, quaeque cunctae novum orbem inhabitant. Magni omnino ponderis hanc fubdivifionem effe, ex eo patet, quod ea ipfa quadrupedes, 'quos novus orbis fub Simiarum denominatione nutrit, externi habitus cultusque ratione, non folum ab hominibus, fed ab antiqui etiam orbis Simiis curatius penitiusque difcernuntur. Sic, ut cxemplo res illluftretur, Amcricae Simiantin femellae nulla menftrua, quae tamen fat maltis veteris orbis Simiis communia funt, patiuntur: ipfasque praeterea novi orbis Simias de novo Buffonius (b) in eas, quae caudis prehenfilibus (fit venia verbo a naturae indagatoribus recepto) praeditae funt, quibus, (pirae in modum contortis, quamcunque rem apprehendunt, firmiter tenere, illique adhaerere folent, \& in illas difpartitus eft, quibus natura caudas rectas, denfioribus pilis veftitas, dedit; quae, an ulli ipfis fint ufui, adhuc ignoramus. $P$ enwantus etian, quem ad fupplendum Limnaei opus aeque atque Scbrebcrum, praeftantiffmi de animantibus: mammalibus operis $(c)$ auctorem, ducem potiffimum fequemur, hac eadem difinctione ufus eft; quae quum.

$\mathrm{ma-}$

(b) Bufon Hift. der Nat. T. XIV. Edit. Germ. in 4 to.

(c) Die Saengthiere in $\Lambda$ bbildungen nach der Natur mit Befchre: bangen. Erfter Theil. Erlangen 1775 , 4to.

Dd d 3 


\section{SPECIMEN ZOOLOGIAE}

maxime mea referat, quoniam, in quo rei cardo mihi verfatur, patria beftiarum fedes fic facillime innotefcere conftituique poteft, non poffum, quin \& ego eandem fundamenti loco ponam.

5. II. Quod ad alcerum, ad terrae nimirum traetus, quos Simiae incolunt, fpectat, pleraeque exiguas tantummodo regiones occupant; perpaucae tainen, ad quas Ourangus etiam Outang us referri debet, latius disfeminatae reperiuntur; quae quidem, quod lubens $\mathrm{fa}-$ teor, in fecundo an capite fuiffent enumerandae : quia vero numerus ipfarum exiguus eft, ipfaeque per terras, quae vel nusquam, vel rariflime faltem inter $\mathrm{fe}$ cohaerent, diffufae conf́piciuntur; eas a reliquis fuis fpeciebus divellere nolui; praecipue quum lector in patria ipfarum, quan fingulis femper feparatim addidi, haud facile errare poffit.

j. III. Omnium, quae fimiarun generi adfrribi folent, beftiarum domicilia in genere fub Zona pofita videmus torrida; quam tamen nonnullae ipfarum fpecies consque fupergrediuntur, ut quibusdam in regionibus, in Japonis fcilicet infula, fub tricefimo feptimo latitudinis feptentrionalis gradu Simiae jam fint obviae. Hoc tamen excmplum \& rariffimum \& fingulare effe non inficior. In Europa enim fimias nullas habitare, fed cafu quodam eo delatas, \& hinc factum elfe, ut haud procul Gibraltaria occurrant, Pennantus teflatur (i), quum e contrario variae ipfarum fpecies, fere omnes tam Africae, quam Afiac partes calidiores magnis gre- 


\section{G E O G R A P H I C A E. 399}

gibus pervagentur.. In America quadrupedes, quos $/ 2$ miarm nomine indigenae infigniunt, vix a vicefimo primo \& fecundo feptentrionalis latitudinis gradu, \& quidem a Merico haud procul a circulo tropico occipiunt. Florida enim \& regiones ad foptentrionalon fiuvizm (Rio del Norte) fitae, aeque ac California fimiis: funt deftitutae. En novum argumentum, quod Americam antiquo orbe frigidiorem effe comprobat!

6. IV. Generaliter itaque \& univere fimias tractus graviori fole candefcentis incolas appellare poffumus; quarum copiae \& varietates, quod Bosmannus Atkinfuzisque docent $(e)$, iis quam maxime in locis crefcunt, ubi: folis ardor vehementiffime faevit. Et hinc non probabilistantum, fed ad veritatem etiam propenfa mihi $B$ uffomii fententia videtur, qua veteris orbis fmias nullo Amevica loco, novique orbis beftias nusquam gentium in antiquo reperiri, vel faltim olim repertas fuiffe, autumat. Quodfi tamen exceptiunculas quis adduxerit; is vel navibus, vel alio hominum auxilio illas eo traductas, effe, fecum reputet. Suppofitis hifce, quae de omni fimiarum genere dicenda erant, nunc brevioribus nobis, in percenfendis ipfarum fpeciebus effe licebit.

$$
\begin{aligned}
& \text { S IM I A E E.C.A U D E.S ( }) \text {. } \\
& \text { Ourangus Outningus }(g) \text {. }
\end{aligned}
$$

6. V: Nec temere nec immerito animal primum 10 -

(e) Allg. Reir. T. IV. p. 262.

(f) Simiac cauda nulla. Simizae seterum. Linnacus.

$(g)$ Satyruss. Simia ccaulata ferruginea lacertorum pilis reverfis nai-

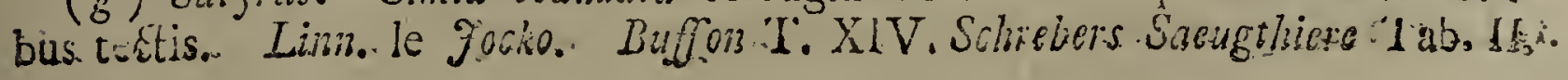




\section{SPECIMEN ZOOLOGIAE}

locum occupet, quod quidem hand ita frequenter, fed fingillatim duntaxat obvium eft; multo tamen latius aliis fpeciebus difperfum offenditur. Homo Jyluefris eft, quem. Buffonius plus jufto ab homine rationali fegregavit, cui vero $P$ awius $(b)$ in praeftantiffma fua disquifitione locum, qui ipfi debebatur, reddidit. Ourangus enim Outangus eft, qui hominem cum fimiis quam proxime conjungit, \& in catena, qua rerum mater, natura, omnia inter fe copulavit, medius quafi annulus eft, cujus ope homines fimiis connectuntur. Certiffime enim mihi perfuadeo, fi paulo elimatiora tantum ipfi organa, politioresque nervi \& fenfus dati fuiffent; infimae fortis facultatisque hominem inde evafurum fuife : Limnacum vero albinos feu allii coloris Acthiopas cum Ourango Outango minus reete permutaviffe, Pawius jure notavit. Homo enim, cujus mentionem fecit, Nocturnus, nifi Ourangus Outangus eft, qualis revera effe debet, in rerum natura nullus eft. Hoc P'awius Limaco opponere \& potuit \& debuit: utinam autem id more qui philofophum magis decet fine afperitate feciffet, nec viri, doetrina incredibilique rerum copia \& varietate abunda nis, quem orbis eruditus jam pridem veneratur, laudibus derogaviffet! Parum enim abeft, quin ad convicia progrediatur.

S. VI. Interim Ourangi Outangi, quod Ruffonius etiam cum Penmanto Scbreberoque annotavit, duae videntur effe fpecies, quarum altera minoris eft ftaturae, quae vix ad trium pedum altitudinem adfurgit; altera autem

pro-

(h) Réfleziuns fur les Àméricains. 'Tom. 11. Chap. 11. 


\section{G E O GR A P H I C A.E. $40 \mathrm{I}$}

proceriori eft corpore, quod quinque pedum menfuranu fupcrat. Qua in re Battelii (i) quam maxime teftimonio nitimur, qui, licet eruditionis expers, rerumque naturalium fcientiae ignarus, itinera fua inftituerit; nihilo tamen minus, cui fidem habeamus, meretur; partim quia probitatis ingenuitatisque famam fert; partim quia caeteris peregrinantibus diutius in $\mathrm{O}:-$ vangorum patria commorari coactus fuit. Hic, giod P'urcbaffus retulit, duas hujus homini perfimilis befliae dari fpecies afferit, quarum altera Pongo vocatur, guae eadem cum hominibus magnitudine eft $\&$ craffitudine; qua tamen altera, quae Liniocko appellatur, longe minor exiftit. Priorem Europa vel nunquam vel faltim nondum adultam vidit. Bu fijonii enim Focko, qui Parifos delatus erat, aeque atque illi, quos Echwardus $(k)$ \& $T y / 0$ mis (l) defcripferunt, quemque anno 1738. ex Angola in Bataviann deportatum fcimus ( $m$ ), trium pedum proceritatem nondum attigerant; omnes autem vel pulli erant, vel tales effe perhibebantur. Nemo itaque, eosdem veros Pongorum filios fuifre, tuto negaverit. Quumque adulti jam magnam intelligentiae ingeniique fiseciem prae fe ferrent: non exigua cum probabilitate hinc confici poterat, eos quam proxime ad hominum fimilitudinem accedere. Quod licet magni fit momenti: a nullo tamen naturae fectatorum obfervatum effe, intelligo.

§. VII. Multis variisque Ourangun Outangum nomi-

(i) Purchafs Pligrims T. II. p. 982. V. p. 623. \& Allg. Reif. T. V. p. 90. (k) Ecinuard av. 213 .

(i) Anatomy of a Pigmy London I699. fol. (m) Allg. Reir. T. IV. Ee e 


\section{SPECIMEN ZOOLOGIAE}

minibus fignatum efre, ex eo patet, quod praeter illa, quae jam adduximus, ab. Anglis Chimpazea, a Guichvenibus, Barlisto auctore (n), Quoias morrou, a Bengalenfibus Golok (o) \& Barris interdum appellatur. Lu. fitani voculas Malayicas Ourang Outang per El Selvago. \&. Bontius ${ }^{\circ}(p)$ ad verbum per bominem jylueftrem interpretati funt. Limnaer conjectura, qua Satyram antiquorum illum effe credit, eumque ipfe fic denominavit, idcirco mihi arridet; quia fatis probabile eft, veteres popúlos vifam hanc beftiam pro Satyra habuis$f e$; licet Ponnantis id ea de caufa neget; quoniam veteres. Satyros cauda inftrietos effe dixerint, quae huic beftiae defit. Quas omnes denominationes hunc in finem collegi, ut, ubicunque animantis hujus, qui poit hominem memoratu digniffmus'eft, fub quocunque nomine mentio fit, is ftatim nofci dignofcique poffit. Smittae tamen nuncupationem, qua Buffonius ipfum defignari opinatur, ex induftria omifi. Bosmannus enim Smittas in. Guinea copiofiffme reperiri teftatur $(q)$. Quum vero certum fit, Onrangos Outangos vel nuspiam, vel faltim non illis in oris, qui, habitatorum copia abundant, gregatim obvios effe, \& Alkin/rus fylveftrem hunc hominem quam rariffme in Guinea confpiciaffimet $(r)$ : fub Smitta hac Ourangus nullus, fed: potius, ex Pemanti opinione, quaedam Simiarum caudis praeditarum fpecies latere poteft.

6. VIIF

(n) Allg. Reif. T. IV. p. $262 \&$ 63. \& ibid. 'Tom. 1ll. p. 321.

(o) De Visme Philofolp. Transact. Vol. XIV. p. 33 .

(p) Hif. Nat. Ind. ajud Hifon. p. 84 .

(q) Allgonkeiro I. IV. p. 2010 (r) 1bid. po. 


\section{G E O G R A P H I C A E. 403.}

0. VIII. Confideratis nunc Ourangi Outangi denominationibus, ad propofitum revertor. - Duplicem ipfrus dari varietaten, alteram majoris, minoris alteram proceritatis, antea dixi; de utrarumque igitur nune patria, quod inftituti mei caput eft, disquiramus. Z Zo. nam fibi terridam proprie fic diezam, quam folam inhabitet, delegit; ideoque cum ultimo praecedentis capitis animante exacte conjungitur. In Africa nec Barbaria, nec Aeryptus albumique promontorium Ourangos nutrit. Cis Gambiam (s) vero Guineae, Loangi, Angotae totiusque Congi $(t)$ eft incola; ulterius tamen meridiem verfus procedere haud videtur. Eun enim in bonae fpei promontorio reperiri, idcirco dubito, quia Kolbius ne verbulo quidem ipfius meminit: In A/ia Coromandelis (u), Bengalac, Bornei(v), Sunatrae $\mathcal{f} a-$ vaeque (w) indigena eft. Quae omnes terrae quum vix ac ne vix quidem ab aequatore difcedant; hinc femi hominis iftius fedem patriam quam prozime fub aequatore antiqui orbis quaerendam efre cognofcimus. Vix enim decem vel ad fummum duodecim latitudinis tam in feptemtrionali, quam auftrali aequatoris latere; longitudinis e contrario centum fere viginti quinquge gradus occupat; quo refpe\&tu quidem in fecundo jam capite commemorandus fuiffet. Quoniam vero ipfum a himia ruin genere divellere nolui, praetereaque omnes, quos in praecedente capite enumeravi, torridae Zonae animantes Ourango multo latius diffunduntur: eun hucus-

- que

(c) Rélation du Voyage de Gennes par Froger. p. 12. (i) Allg. Reifo T. V. p. po. (u) V̈uyage aux Inles Orient. par Grolfe. p. 329.

(v) Becman's Tiavels to Borneo London 1718. p. 37. ("1) Bontius 1.6. Fe e 


\section{SPECIMEN ZOOLOGIAE}

que refervare, novumque caput hoc cum animali inchoare malui; praecipue quun longitudinis ratione non interrupte, fed magis colaeerenter dilatetur, feriemque guadrupedum apte connectat.

Integrum Ournngorann genus, quod Pawius recte annotavit, exiguo tantum numero $\&$ rarenter, nufiam vero, reliquarum fimiarum more, gregatim incedit. Interim Pawius ex Hamonis Cartbaginien/is $(x)$ \& Stritbonis $(y)$ verbis quibusdam, eorum agminum frequentiam olim longe majorem fuiffe, comprobat, \& exinde in homines, qui omnia peffumdare \& difperdere - foleant, culpam confert, cur.magnus quondam flo. rensque Ourangortun numerus parvis nunc exiguusque confpiciatur. Fortaffis interiores in Africae regiones fe reccperunt, ubi magnis nunc agminibus ab hominum . infidiis periculisque tuti vivunt \& augentur.

6. IX. Teftium fide dignorum nullus eft, qui fe Otrangos in America obvios habuiffe dicit. Ex l'aw's quidem relatione Evangelii quidam praecones apud $P_{a-}$ raguayos fimias humana facie formaque praeditas virere tradiderunt $(z)$; fed recke vir praeftantifimints additit, hanc relationem talem effe, qualis ab emiffuris expectari poffit, cuique fides haberi, nifi locupletior teftis accefferit, nulla poffit. Nunquam autem naturae ve. natorum quisquain Ourang zmm hucusque in noro orbe natum vidit. Bancrofizus quidem femihominem iftum Guianae indigenam effe fcribit (a), fed fimul addit;

IL:-

(x) Plin. Hilt. Natur. Lib. VI. Cap. XVIII.

(y) Strabo Geogr. Lib. XV. (z) Rélation des Miffions du P.ragury p. J52. (a) Bancruft's Guiana p. 78. 


\section{G E O G R A P H I C A E. 405}

rumorem eum a regionis tantum incolis inventum effe ac diffipatum; quia peregrinantium nemo, nec auctor ipfe, licet diu fatis ibidem commoratus fit, Ourangum ibi confpexit; qua de re nec ipfe narrationi huic fidem tribuit. Quum itaque \& naturae indagatores \& pere. grinatores omnes de Ourango, Americne habitatore, mentionem faciant nullam: eundem antiqui folius orbis effe incolam, jure adfirmamus.

\section{Gilibon (b).}

f. X. Ab Ourango Outango natura pedetentim ad ea animalia progreditur, quae penitus ab homine disccdunt: hinc fit, ut quam longiffime tandem a ceteris regregetur. Nusquam autem evidentius quam in foniarthin fimilia gradus, quibus natura defcendit, animaliumque copulationem \& confentientem ejus coagmentationem perficere poteris; fi modo tam aequus fueris, ut, quotics hiatus aliquis tibi obvenire videbitur, tecun reputes, multa adhuc animalium genera vel penitus ignota nobis, vel minus curate adhuc defcripta fuperesfe, quibus expleatur. In beftia confideranda nunc occupamur, quae quidem aliquam hominis fpeciem gerit; fed tamen partim propter enormem manuum longitudincm, partim propter nates calvas, quae in homine fylveftri pilis tectae crant, ab illo recedit. $O_{b-}$ rango itaque longius a nobis diftat. Primus, qui eam de-

(b) Homo brachiiis longitudine corporis. Linnaeus. Mantiffa plantar. altera. Le Gibbon Buffinz T. XIV. Tab. II \& 11I. Simia longimana Schriebers Sulugthicere. Toin. I p. 66. Simia long imana ccaudata natibus calvis. 


\section{SPECIMEN ZOOLOGIAE}

deicriphit, illiusque imaginem nobis exhibuit, quum antea plane ignotus fuilfet, linifonius eit. Praeci. purs, quo ab aliis tam fui ggeneris, quam reliquis omnibus notis adhuc animantibus dignofcitur, character, in brachiis confiftit productioribus; quibus, vel pofticis pedibus incedat, vel arrectus lieerit, femper terran attingit. Gibbonis etiam hujus duae numerantur warietates, quarum altera major tres, altera minor vero duos tantum pedes alta eft. Pennantus (c), cui minorem vivam videndi copia data efft, ipfan majori tam fimilem effe adfirmat, ut praeter diverfam magnitudinem nuila re alia inter fe diftingui poffint; \& Daubentonuns utrasque fola proceritate diferetas cifparesque invenit $(d)$.

f. XI. Interim Gibbon folas djune regiones inhabitare videtur; nec enim inter Africae fimias, quas Liosmannus, Battelius, Marmoliuss aliique enumeraverunt, locun habere videtur. Buffonius $(e)$, etfí auctores, e quibus fua hauferit, non nominet, Gibbonem tamen in Coromandelis promontorio, in Malacca, ubi minor ille, qui Angliae nobilis Clivii mancipium erat, oriundus fuifre dicitur, in Moluccisque infulis habere fcribit $(f)$. In Ganinanis etiam regno, quod haud procul a Cbina fub vicefimo primo longitudinis \& centcfimo vicefimo fecundo latitudinis gradibus fitum eft, vivit, cujus incolas ipfi to Fefe $(g)$ nomen dederunt.

(c) Synupf. p. 100. (d) Hin. der Nat. I. XIV. p. 59.

(e) Lift der Nat. 'I'XIV. p. 52 . (f) Pemant 1. c. p. Ico.

(g) Mémoires fur la Chine par le Comte p. 5 10. \& Neuhofus in legationis, quan in Chinam fufceperat, defcriptione p. 373. in Gannanis rezono animal, cujus forma prope fatis al humantrn accedat, longisque bra. chiis infruetum ef, reperiri tradilit. 


\section{G. E O GR A P H I C A E. . $47 \%$}

In Hainamis infula, quae inferiores Chima regiones attingit, ipfum reperiri ex du Holdio difimus (b), qui fimiam ibidem nigri coloris, hominique hand abfnilem confpici teftatur; quam quidem infulan. Pcmanius in. Chinae regionem convertit, eique nomen Mang - $\sqrt{2}$ impofuit, quam tamen nec in Awvillii, nec in du Haldii libris mihi reperire licuit: interim tamen ipfam hane fimiam Gibbonem effe ftatuit ; quod quidem propter animantis nigritudinem \& formam, quae humanae admodum refpondet, ipfumque Hainaris infulae fitum, quae cum beftiae illius patria eodem fere fub coeli climate jacet, vero non abfimile videtur. Quoniam autem. Gibbon prae caeteris omnibus animalibus praelongis, quibus utitur, brachiis, facillime dignofci poteft, quorum tamen du Haldius ne verbulo quidem meminit; meum hac de re judicium, donec clariori omnia luci experientia expofuerit, reprimo. Plura quidem de beftiae hujus rarioris domicilio expiscari mili non contigit; interim tamen ex his liquet, Otrangun ipfo multo latius diffufum offendi, quippe qui omnes ferme antiqui orbis ad aequatorem pofitas regiones occupat; quum Gibbon e contrario, quod tigridi etiam proprium eft, arktis admodum Zonae torridae finibus in $1 / \mathrm{ia} \mathrm{fo}-$ la contineatur.

\section{Pitbeca (i).}

ๆ. XII. Haec fimiarum fpecies ceterarum, quae cau- .

( (i) Du Halle China T. 1. p. 229. Edit. German.

(i) Simia Sylvaluus. Sinia ccaudata natibns calvis, capice fubrotondo,

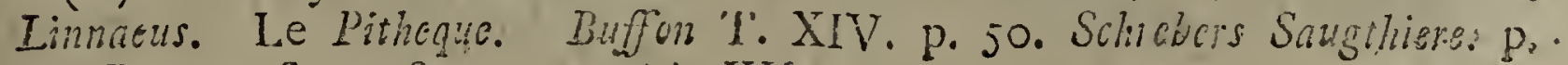
03. Pemnant Synop?. p. 28. Tab. XII。. 


\section{$409^{\circ}$ SPECIMEN ZOOLOGIAE}

caudam nullam habent, facile minima, cum praecedente autem aeque bonae eft indolis. Generatim dignum exiftimo, quod notetur: tres hafce, quas hactenus enumeravi, finians, ficuti formue ratione quam proxime ad hominem accedunt, ita reliquarum etian fui generis manfuetiffimas effe \& moratiflimas; ex quo colligere licet, eas perfectioribus pracftantioribusque ingenii facultatibus pollere. Haec autem pitheca gregatim in Aethiopia $(k)$, Manritania \& Guinea (l) rivit. Bufforius $P$ cmanantusque (n) eam in Afia etiann reperiri putant;

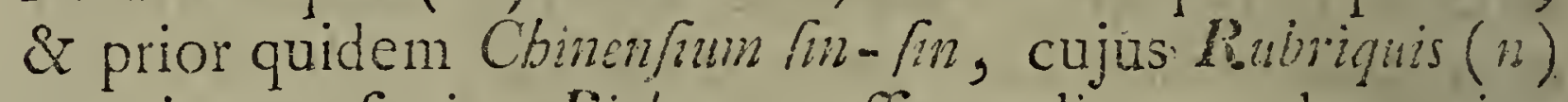
mentionem fecit, Pithocam cffe credit; quod nec improbabile effet, nifi át Haldius exprefis rerbis, / $\min / 2$ nem illam hominis mediocris ftaturam aequiparare $(0)$, feripfiffet, idemque Neulufinus, qui heic loci confulendus eft, teftaretur. Felicius illum conjectare crediderim, qui fub fin-fine Ourangum Outang un laiere exiftimaverit. Quum P'cmmantus pigmaeos, qui, quod Groflits retulit, Carratae filvas incolunt $(P$.$) , pilbccus$ effe antumet; \& Limnacus illas Coilonem incolere adflruat (q), exinde cas non in Africae tantum, fed in Aface quoque calidioribus quibusdam locis habitare, probabiliter confici poteft. Vehementer dolemus, plerosque peregrinantium haud ab illa naturae cognitione inftruetos fuifie, ut certo fatis \& exacte quosvis ob-

vios
(k) Ludolf. Hift. Aethiop. 1.ib. I. Cap. X. \$. 50 \& 57.
(b) Bosmans Guinea. (m) Buffon \& Fennant l. c.
(n) Rubriquis in Aigen. Reifen T. VII. p. 394. haec animalcula in
Cathai vel China occideniali inveniri feribit. (o) Du Halle I. 1. p. 34.
$\begin{array}{llll}\text { (p) Voy. to the Eaft. Ind. p. } 365 . & \text { (q) Sytem. Nat. }\end{array}$ 


\section{G E O GR A P H I C A E。}

vios fibi animantes \& fmias inprimis exprimere ac de* fignare potuerint. Hincid mali exortum eft, ut illarum fpecies \& nomina non modo mifcuerint, fed etiam turbaverint, difficillimumque nunc fit conjectu, de quibus fint locuti. Simiarum plerumque magnum numerum, variasque fpecies unna eademque regio alit, quibus idem vitae genus, eaedem fere praeftigiae communes effe confueverunt. Criteria, quibus inter fe diftingui debebant, non femper tam evidentia funt \& perficua, ut oculus minus exercitatus eas primo obtutu, fine confufione difcernere valeat; cui fingularis quidam nova faepiufcule monftrique fimilia narrandi pruritus accedit, Quanti ergo laboris res, quantaeque moleftiae fit, ex mancis, mutilis, dubiis \& fabulolis nonnunquam relationibus veri certique aliquid elicere, is dijudicandum relinquo, qui manum operi admoverint. Nonne hinc etian factum effe videmus, ut, quod Outnngo proprium erat, Papioni attributum fit? Alios ejus indolis errores multos filentio premo.

\section{Simia Inuus $(r)$.}

0. XIII. Buffonius fimiae huic, cui Magoti nomen impofuit, convenientiffimum locum tribuilfe videtur, dum mediam eandem inter primae claffis fimias papionesque interjecit. Hactenus enim enumeratarum inftar vel

( $r$ ) Simia Inuus, stula ecaudaca, natibus calvis, capite oblongo. Linnacus. Le Magot. Buffon T. XIV. Tab. VII \& VIII. p. G3. Ia Schreberi animalibus fugentibus Tab. V. hujus Invi elegans effigies exhib:tur, quae exiguam, immobilem exoffemque caudam exhibet: \& quae illa differt quam Buffonius dedito 


\section{IO SPECIMEN ZOOLOGIAE}

vel caudam nullam, vel breviffimam \& exoffem habet.

Facies autem, quae in antecedentibus plana magis \& aequabilis, ad humanam prope accedebat, in magoto admodum prominet, caninique roftri fimilitudinem habet: ideoque non hac folum de caufa, fed etiam prop: ter dentes caninos, quos prae jam memoratis fibi adfinibus longe majores infignioresque gerit, cynocepbali nomen jure ipfi datum effe autumo. Et ficut tam $\mathrm{O} u$ rangus Outungus, quam Gibbon \& Pitbeca ingenio mites, moribusque quicti funt; fic Magotum e contrario ejus morum procacitatis asperitatisque effe comperimus $(s)$, ut lolus papio eundem protervia fuperet.

G. XiV. Interim multas Africae partes., verbi gratia, Mauritaniam ( $t)$, Aetbiopian, quodque admodum probabile eft, Guneam quoque occupat. Dolendum autem eft, Bosmannum de plerisque fimiarum fpeciebus in Guinen obviis generatim tantummodo \& fic effe locutum, ut, quas intellectas volucrit, haud ita facile conjici queat. Buffomius etiam fimias, quarum greges non exiguos in bonae fpei promontorio Roberius La dus confpexiffe teftatur, cynocepbalos fuiffe tradit (u); guum autem ea figna easque illarum notas Ladius atiulerit, quae in multas alias $\&$ in ipfos etiam papiones quadrant ; haec viri illuftriffimi opinio adhuc in incerto mihi pofita videtur. Multo certius tutiusque ea, quae Tincitius Maria, itidem a Buffonio laudatus (v), de fimiis cinerei coloris, cauda carentibus, quarum ag-

(s) ld Buffoninus tradidit. Sclirelerus ei mores fatis faciles tribuit. ( $t$, Prof. Alpin. Hit. Nat. Acgypt. T. I. p. $24 \mathrm{I}$.

(u) liob. Lade Voy. T. I. p. 80 . (v) Lufon T. XrV. p. 65. 


\section{G E O G R A P H I C A E.}

minibus Malabariae regio abundat, retulit, de folis magotis dicta effe adfirmare polfumus. Ex cujus narratione certo fatis hanc fimiarum fpeciem nec calidiffmas Afrae partes abhorrefcere difcimus; quod ipfum etiam Pennantus, Dellonizus (w) Roquiusque $(x)$ teftantur, qui eas \& Indine \& Arabiae incolas effe perhibent. Et Scbreberus ipfum Africae fefforem effe dicit; fed quo auctore, non addit. Memoratu autem digna eft $P^{\prime} e n-$ nanti relatio, qui, Gibraltarian quoque cynocephalos quosdam nutrire $(y)$, nos certiores facit, quorum tamen origo non ex Europa, quin potius e cicuribus quibusdam cynocepbalis per peregrinantes eo delatis petenda eft, qui felici deinceps proventu ibidem aucti hanc Europae regionem graviori aeftu calentem occupaverunt, \& adhuc tenere dicuntur. Qui quidem cafus, fimias in Europa etiam fub dio, fine hominum ope, - propagari docet, ita raro tamen exiftit, ut prodigii fere fimilis habendus fit. Magotum itaque plures per terras difperfum videmus, quam alia ulla fui generis animalia; id quod etiam cum naturae conftitutionisque fuae robore exacte congruit: cujus beneficio, Buffonia tefte, in conclavibus non calefactis fine fingulari valetudinis fuae detrimento hiemes in Gallia fuftinere pollet. In tabula geographica fub Inui nomine notatus reperitur.

\section{Man-}

(w) Voyage de Dellon p. 83.

(y) Synopi. p. Iòr.

(x) La Roque Voy. p. 2 Io.

Ff $f_{2}$ 


\section{I2 SPECIMEN ZOOLOGIAE Mantegar $(z)$.}

6. XV. Beftiae hujus, quae itidem cauda caret, ean tantum ob caufam mentionem feci, ne quam fimiarum adhuc nobis notarum lector defideret; licet patria ejus fedes nondum certe innotefcat. Duo autem funt, quibus a cacteris fuae fpeciei optime facillimeque diferni - poteft; quorum alterum cirrus eft cornu in modum furfum erectus, quo fuperior capitis pars infigniri folet, quem propter Pennantus eam cirratum ( $t u f t c d$ ) appellat. Alterum dentes duo funt canini maxillae fuperioris, ita. ex ore prominentes, ut aprorum dentes propemodum. aequent; quibus rebus efficitur, ut tetra admodum fit. adpectu \& horrida. Quodfi hifee anterioris corporis, quod nullis fere pilis tectum apparet, nuditatem addideris; flmiam hanc procul dubio dignam aeftimabis, cujus mentio heic loci fieret; nec Schrebero adentiri porfum, qui beftiam hanc cum fimia Mormone eandem efle ftatuit; cui tamen dentes longius prominentes defunt, cujusque nec pars corporis anterior pilis veftitur. Operae pretium facturus mihi videtur, qui fimiam hanc Pennanti fynopfi in egregiam, quam Scbreberus de animalibus dedit mammalibus collectionem, ubi nunc de. ficit, fupplementi loco transferret. Eam vel $A$ fac vel Africac regionum, flagrantiffmo ole torrentium, habitatorem efle, licet eas fpeciatim denominare adhuc nequeam, omni dubio caret.

SECTIO

(z) Tufied Ape. Penrant. Synopf. p. 102. Tab. XII. fig. 2. 


\section{G E O G R A P H I C A E. 413 $S$ E $C$ C $T$ T I}

Quae fimias brevioribus cautis infructas, five Paprones, continet.

๑. I. fimiis, quibus caudae nullae funt, nune 11 ad eas tranfimus, quae brevioribus praeditae confpicinntur, fub communi papionum nomine comprehendi, \& calidiffimas tantum antiqui orbis regiones inhabitare folent. Bancrofitus quidem papiones in Guinea etiam inveniri ait $(a)$, fed.hac in re eodem errore abreptus eft, quo fimiam Quatonem, quae Buffonii Conita eft, quantumvis cauda fatis longa gaudeat, ecaudem fecit ac defcripfit. Nec a Buffono, nec a Penunto, nec (fi qualecunque meum teftimonium aliquid ponderis habet) a me ipfo in auctoribus fide dignis, qui calidiores novi orbis partes peragrarunt defcriptasgue dederunt, ulla aut vola aut veftigium papionum brevibus caudis praeditorum inventum eft.

Qui fuperfunt, quadrupedes nunc breviter perftringam, quoniam ipforum variationes aut nullae funt, aút minus certe tutoque determinari poffunt. Praeterea contra voluntatem praeterque opinionem meam hoc tanto campo liberius vagatus fum, quam mihi propofueran. Linnaeum igitur \& duodecimam quidem $\sqrt{y}=$. flemalis fri naturae editionem fequar; quae Buffoninus aliique docti naturae indagatores litteris mandarant, quaeve a Linnaeo omilfa invenero, addam; é Sobrelheri egregio, quem de animantibus mammalibus in lucem

emi-

(a) Bancrofts Guinns p. 79. Edit. German.

$$
\text { Ff } f
$$




\section{I4 SPECIMEN ZOOEOGIAE}

emifit, libro, quoties opus effe videbitur, quae defunt, fupplebo, \& patrias denique animalium fedes adjungens ad finem properabo.

\section{Simia Maimon Linnaei.}

๑. II. Simia caudata ( $b$ ), fubbarbata, genis cocruleis ftriatis, natibus calvis. Limn. N. I. Le Mandrill. Buffon. T. XIV. Tab. XVI \& XVII. Ribbed Nore (Baboon) Pernant. Num. 69. Papio hic genis quam maxime violarum colore infectis prope nafum fulcorum more deorfum currentibus, a reliquis omnibus differt. Quibus fignis ductus haud facile perfuadeor, hunc eundem cum mandrillo effe, qui Guineam inhabitat, quod Buffonius quidem ftatuit. Quia vero nec Barbotus nec Bosmannus violacei coloris', quo facies ejus imbuta effe debebat, mentionem fecerunt, quin potius Guineac Mandrillum, hominis inftar, alba facie ornatum effe $(c)$ confirmaverunt; vir praeftantiffimus, me hac in re ab ipfo diffentire, vitio non vertet; praecipue quum Guineênfis beftia quinque pedes, haec vero fimia Maimon duos tantum alta fit. Unum, in quo conveniunt, nafus eft mucofus, qui tamen aliis fortaffe multis conmunis eft. Quoniam Pennantus etiam eum Guineae in- colam effe autumat; ipfum mappa Zoologica in dicta jam regione fub Papionis primi nomine exhibebit.

\section{Simia Mormon.}

๑. III. Simia femicaudata, fubbarbata, nigro-fuscai,

(b) Semicaudata fcribendum erat. (c) Allg. Reif. T. IV. p. 262. 


\section{G E O G R A P H I CA E. 4I5}

ca , malis tumidis, nudis cyaneis, oblique ftriatis, natibus calvis fanguineis. Ex ipfa Altfirgemeri hac definitione (d) apparet, huic papioni, quem nonnulli Chorani nominant $(e)$, cum praecedente permulta, in primis autem genas violacei coloris communes effe. Ipfi quam maxime cirrus in capitis vertice, cujus tamen Allftrosmorus in data fua defcriptione non meminit, proprius eft. Kramerus autem $(f)$ ipfun fimiam nominat fetmicaudatam barbatam, vertice fetis tectis mitram referentibus obfito, unguibus acutis. Quum hoc loco violaceae genae omiffie fint; utrasque definitiones conjungas oportet; ut, qualis beftia fit, recte intelligas. Quam Alt/2roemerus beftiam vidit; ab hominibus, qui ipfam in Ceilone oriundam tradiderant, circumducta fuit, cujus pellis effarta Brunsvigae in ducali rerum naturalium thefauro affervatur; quam vero in collectionibus Vratinavienfibus defcriptam legimus, e Malacca fuife, perhibetur; Ailam ergo maximo aeflu calentem patriam habuit. In tabula Zoologica eam dictis in regionibus fub papionis fecundi appellatione notatam reperies. Quoniam dentes canini prominentes ipfi defunt, Mantegarim quidem generi eam adnumerare non aufim; nec tamen, annon Maimonis aliqua fit varietas, fatis conviEtus fum.

\section{Simia Nemefrina.} Q. IV. Simia femicaudata, fubbarbata, grifea,

(d) Abhandlung der Schwed. Acalem. der Wifenfci. I. XXVIII. p. I +4. Tab. III. (e) Brefauei Samminng is. Verfuch. p. I77.

(f) Kramer Animal. Auftr. p. 310 . 


\section{II SPECIMEN Z,OOLOGIAE}

iridibus brunneis, natibus calvis. Lim. fyftem. Edit. XII. Num. IV. le. Maimon. Buffon. T. XIV. Tab. XIX. pag. 10.5. Pig-twiled Monkey. Edward Gleaning's I. pag. 8. T. 214 . Haec bonae indolis breviorisque caudae $\mathrm{fi}^{-}$ mia, Edwardo tefte, Sumatrae indigena eft. Knempfertus $(g)$ in Faponiae regno fimias badii coloris, facie rutila pilisque nuda, brevioribus caudis praeditas, quae perquam dociles fuerint, fibi obvias fuiffe adfirmat; quae omnia de papione nemefrino dieta effe, Pennantus (b) credit. Ipfum itaque in utrisque his infulis fub papionis tertii nomine mappa Zoologica exhibet. Eum autem continentes etiam Afiae partes fub eodem coeli climate pofitas inhabitare, licet certi adhuc nihil hac de re cognofcere mihi licuerit; vero tamien haud abfimile videtur.

\section{Simin Apedia.}

Ø. V. Simia femicaudata, palmarum pollice approximato unguibus oblongis, pollicum rotundatis, natibus teetis. Limnaei Syft. Edit. XII. Num. V. \&' Amoentat. Academ. T. I. p. 278.

Ne quis mancam nimisque imperfectam hanc quadrupedum enumerationem efiè objiciat; beftiam heic loci adjungere volui, cujus patriam, quam tamen exquifviffe, \& indicaffe noftra maximi intererat, adhuc ignoramus. Necdum, quod ultro fateor, ipfam inter femicaudatas locum habere porfe, convictus fum; partim

(g) Kacmpfers Japan T. I. p. I26. Edit. Angl. fol. \& du Halä Tom. IV. Edit, Germ. (/t) L. c. p. 106. 


\section{GE O G A P H I C A E 4 IIZ}

tim quia Linnaeus eam $\int c i u r i$ tantum magnitudinis effe, ait: tam exiguae autem ftaturae papionam nullus adhuc notus ẹft; partim quia nates ejus tectas effe fcripfit, quod a papionum, breviori cauda inftructorum, natura $\&$ confuetudine abhorret. Eadem dubia Schrebero (i) etiam fuborta effe video, qui beftiolàm Americae fimiis adnumerandam cenfet. Linnaeus eam Indiae habitatorem efre dixit; fed, quia, quam Indiam intellectam voluerit, non addidit; generatim nimis \& ambigue dixiffe videtur; forfan occidentalem nominaturus erat.

\section{Simia Spbinx.}

6. VI. Simia femicaudata, ore vibriffato unguibus acuminátis, natibus calvis. Linn. Edit. XII. Num. 6. le Babortin. Buffon T. III. Tab. 13. 14. pag. 79. Gesneruis $(k$ ) jam hujus papionis proprie fic dicti icona reliquit, in qua tamen brevior tantummodo cauda confpicitur. Buffonius duas Spbinges vivas depingendas curavit, quae itidem brevi cauda ornatae funt. Si tres iftas imagines inter fe contuleris, fatis probabiliter mihi Pennantus erraffe videtur, qui $p p h i n g e m$ hanc bamatryadibus, eoque ipfo fimiis longiori cauda praeditis adnumeravit $(l)$; cujus tamen rei rationem nullam attulit. $S c b r e b e r u s$ etiam $(m)$, quod jam conjectura profpiciebam, beftias hafce itidem diveras effe, autumat.

Kol-

(i) Schrebers Saeugthiere T. I. p. I24.

(k) In qua ipfi barbam fetis horridam appofuit; qua ex ratione Lin: naeus beftiae foritan os vibriffatum tribuit : qua tamen barba-Buffonil imagines carent. Gesn. Hift. Quadrup. p. 802. (l) Synopf. F. 107.

(in). Säeugthiere T. I. p. 80 \& 82 : 


\section{I8 SPECIMEN ZOO LOGIAE}

Kolbii vero papinnem, quen in bonac/pei promontorio obvium habuit, phingem nullam elle, ex co cérto fatis colligo, quod in prima veraque libri fúi editione, quae in forma maxima prodit, expreflis verbis (n) feripfit: , pa29. piones longa cauda infructos effe e plus quam fexcen", tis ipforum hifce oculis meis vidi. Cinereus itaque color \& longior cauda in Kolbii papionibus, eos fphinges nullas, fed hamadryades effe, fatis fuperque demonftrant. Interim fpbingum, de quibus nobis nunc fermo eft, varietates nonnullas dari, non Buffoniimodo Tabula XIV. teitatur, cujus imago reliquis longe minor, caeteroqui vero majoribus fimillima eft, fed Sicbrebcrus etian, papionis figuram, quam Pennantus fub tou Now Baboon (0), feu novi papionis nomine depictan dedit, aliquam spbingis, cui admodum refpondet, varietatem effe adfruit; \& Pennatus Tretretretram $(p)$ huc referendam effe, autumat. Nec quae vera lpbingls patria fit, certo fatis conftat. Ipfam itaque fub papionis quarti nomine, addito interrogationis figno, (quoprohdolor! partim quia certi exploratique nihil apponi poterat, partim ne audaciae ac temeritatis arguerer, faepius utendum fuit) philippinis infulis Guineacque in tabula Zoologica appofitam invenies.

SECTIO

(m) L. c. pag. 138 . quoniam Gallus Kolbii epitomator \& Germanicus hujus epitomes translator haec auctoris verba omiferunt, non mirum eft, ea in Buffonii confpectum non veniffe. Gallicus epitomator multa ejus generis peccata admifit, eoque ipfo multa non ambigua folum, fed incertiora etiam, quam antea fuerunt , redadidit.

(n) Synopf. p. I04. Tab. XIII. (o) Flaccourt Madagafcas: 


\section{GE O GR A PH I C E 4 I}

S E C T I O I I I.

\section{Orbissantiqui-famiace longionibus caudis.}

\section{Hainádrys.}

ঠ. I. Simia caudata cinerea, auribus comofis, un$S$ guibus acutiufculis, natibus calvis. Linn.

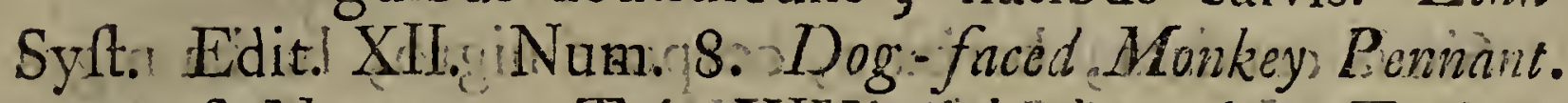
Synopf. Num: 72. Tab. XIV. Sobreberus I. c. Tab.X. Simiae huic cum Pemanto primum inter eas, quae longis praeditae funt caudis, fpbing $i$ verol ultimuin inter papiones locum idcirco attribuendum cenfui, quoniam utraeque beftiae mutiltis adhuc in rebus, fi caudas exceperis, fibi funt fimillimae. Quunin interim inamadryades, quippe quae variis in locis gregatim ingrediuntur, Jphinsilus longe frequentiores lint y mitandum ent, qui factum fit, ut exacta veraque illarum effigies ante Pein nantum nulla edita fit. Quae enim in Kolbii libro exftat, fimiam ecaudem refert; ideoque toto coelo ạts animañ te ipfa aberrat. Pemnantus, quam Bellonius (a) figuram dedit, laudat. Optime vero omnium finiam hanc Edwardus depixit, quam icona non ipfe auctor, fed P'enmantus publici juris fecito Hamadryades fatis late per orben diffundi, ex eo patet, quod ipfun bonae fpei promontorium \& regiones poft illud jacentes in $A$ tbiopiam (b), Arabiam \& praefertin remenfes filyas $(c)$, forfan \& alias Aface partes incolit to Zoologica tabula ipfan fub fimiae primae appellatione monftrabit.

a.)

(a) Belon. Portraits, 10? (b) Haffelquift Reife p. 189.

(c) Niebuhrs Befcreib. v. Arab. P. 167. 


\section{SPECIMEN ZOOLOGIAE \\ a.) Simin $\angle$ eter.}

0. II. Simia caudata, barbata alba, barba nigra. Linnaei Syftem. Edit. XII. Num, 9. Lowandou. Bufffon. Tom. XIV. pag. IO2.

\section{b.) Sinid Silinus.}

Simia caudata, barbata, corpore nigro, barba nigra prolixa." Linnaei Syft. Ed. XII. num. Io. Ouanderou. Buffon. Tom.XIV. Tab. XVIII. p. Io2. Remant: Tab. Xill. A. Fig: I:

\section{c.) Simia Faunts.}

- Simia caudata, barbata, cauda apice floccofa. Linnnei Syft. Edit. XII. Num. I I. Cercopithecús barbatus, fupra ex nigro \& fufco mixtus, infra albus, barba incana, mucronata, cauda in floccum definente. Brijfonii regn. animale Edit. parifienfis p. 209. Pennant. Jynop/is Tab. XIV. fig. 2. Lion tailed Monkey.

Trés hafce beftias merito combinamus. Sibi enim tam funt fimiles, ut Pennantus eas varietates modo effe putaverit ; Buffonius vero ultimum , Faunzm fcilicet, Malbroucium (d), \& floccum, quem in Clu/fi effrgie $(e)$ caudae acumini appofitum cernimus, pictoris commentum effe autumat. Quum autem praeter Clufrum Ponnantus etiam beftiam hanc depictam exhibeat, \& utrorumque imagines hac in re exacte inter fe conveniant; ut cauda in Hoccum definat: hoc ipfo Faumus fileno, cui jam

(d) Malbrouc. Buffon I. c. p. 134. (c) Cluf. exot. p. 37 I. 


\section{G E O G R A P H I C A E.}

jam fatis fimilis erat, eo fimilior redditur; qua de re utrosque disjungere nolui. Veterum filenumque $B u f f o-$ nius papionibus, id eft, fimiis brevi cauda ornatis adnumerat, quia Ouanderonem quem ipfe viderat, breviori tantum cauda inftruetum obfervavit : fed Pennantus utrius . que etiam generis animalia, faumm nempe \& fllenum ipfe confpicatus in ambobus longiores caudas illas animadvertit, quas imaginibus fuis adpingendas curavit. Hunc itaque ducem fecuti fimiam hanc barbatam jure illarum claffi fubjicimus, quas longioribus caudis natura inftruxit. Tres interim hafce fimias in tabula Zoologica feparatim pofitas, primam nimirum fub fimiac Jecundae, fecundam fub tertiae; tertiam fub quartae appellatione iis in locis, ubi nunc reperiri dicuntur, Vetertm. in Ceilonis infula $(f)$ Guineaeque $(g)$ terris, flenum in Ceilone (b) \& Coromaindeline promontorio, Faunum in Ceilone \& Malabaria $(i)$ pofitas invenies. Temporis demum fucceflu, utrum \& qua inter fe propinquitate conjunctae fint, docebimur. Knoxius alius cujusdan majori barba ornatae in Ceilone commorantis fimiae meminit, cujus totum corpus \& barba quoque albeat; quae, quoniam a Ceilonis fefforibus eodem, quo filenus T: fcilicet $W^{\prime}$ anderou nomine infignitur, varietas forfan quaedam priorum eft. Ejusdem coloris fimiae, quae toto nimirum corpore albent, in Macaffare, Celebis regno, degere, parvique \& degeneris canis indolem habere, quales ai W anderou omnes, ferun-

tur.

(f) Knox relat. of Ceilon p. 26. Allg. Reif. T. VHII.

(g) Allg. Reif. T. 1V. p. 205. (h) Knos l. c. (i) Buffon I.co 


\section{SPECIMEN ZOOLOGIAE}

$\operatorname{tur}(k)$. Satis itaque probabile eft, Celebis fimias. (l) raus $W$ anderou adnumerari debere : fed haec omnia minus adhuc explicata funt, nec, nif temporis interjecto quodam intervallo, explicari poterunt; quod idem de fimiis aliquibus albis ftatuamus oportet, quas Pemnantus in Guinea \& Compagnonus in Lanbouco (m), rufis ocutis praeditae fint, habitare dixit $(n)$.

\section{Simia Cynamolgos.}

0. III. Simia caudata imberbis, naribus bifidis elatis, cauda arcuata, natibus calvis. Linn. Ed. XII. Num. 15. Simia cynocepbalus. Simia candata imberbís flavefcens ore producto, cauda recta natibus cálvis. Linn. ibid. Nro. 16 . le Macaque. Buffor. Tom. XIV. Tab. XIV. p. I I4. le Malbrouc ibid. Tab. XIX.

Utrasque fimias, ut varietates tantum inter fe diftingui, Pcrnantus ftatuit (0), \& fr ex ipfarum imainibus, quas Buffonius exhibuit, judicare licet , revera fibi fimillimae funt. Marcgravio tefle $(p)$, Angolam irihabitant. Bufforizus autem eas Aethinpiae cives fecit, quia inmiam aegyptiacam ab Hafjelquilo vifam defcriptamque (q) Makakum effe ftatuit, quae tamen non Makakis, fed Hamadryadzbus potius, feu papionibus fufcis adnumerari de-

(k) Defeript. du Royaume de Macaçar. Paris 1088. p. 50 .

(l) Schreberus in libro de animalibus mammalibus per erroren loco $C_{c}$. Zebis rou Borizo numen feripfit. Allg. Reifen T. XI. p. 483.

(m) Compagnon. Allgem. Reif. I. II. p. 5 I2.

(n) Forfan hue etiam pertinet Simia Siamenfibus Onke dicta, quae toia nigra defcribitur. Turpin Hint. du Roy. de Siam. 'T. I. p. sos.

(o) Synops. p. I.I. (p) Hift. Bralil. p. 22.7. (q) Hafleiquifl Reil. 1. c. 


\section{G E O G R A P H C A E.}

debeat. Malbroucius, quem cuin Makako eundem effe judico, in Bengalia habitare dicitur, ubi ipfum fub Jimine quintae appellatione notatum habebis.

\section{Simia Diana.}

6. IV. Simia caudata barbata, fronte barbaque faftigiata. Linnaei Syft. Edit. XII. Num. I7. Spotted Monkey. Pennant. fynopr. p. I I 2. Simia haec, quam Buffonius novi orbis incolam putat, veteris fefror eft. Limnaeus ipfam in Academiae Suecicae actis optime defcripfit $(r), \&$ e figura, quam adjecit, caudam ejus non prehenfilem effe difcimus; licet Marcgravius facile nos eo perducere poffet, ut contrarium ftatueremus $\left(s_{s}\right)$. Domicilium fuum in Guinea Cong $i q u e$ regno habet $(t)$; in utrisque regionibus fub fimiae fextae nomine pofita reperitur.

\section{Simia Mona.}

6. V: Cercopitbecus pilis ex nigro \& rufo variegatis; pedibus nigris, cauda cinerea. Briffonii rcgn. anim. Mone Buffon. Tom. XIV. Tab. XXXVI. p. I 56. Varied Monkey Peinnant. fynopr. num. 84. Simiae hujus Barbaria (u), Actbiopia (v) \& Congo patria eft. Buffonius eam in $A / \hat{i} a$ quoque habitare, nullo tamen auctore, adftruit. Dictis eam Barbariae \& Aetbiopiae finibus fub fimiae feptimae denominatione inferui...

Si-

(r) Abhandlung der Schwed.- Acad. der Wiffchenfch. I. XVI. p. 215

(s) Marcgray. l. c. ( $t$ ) Marcgr. l. c.

(u) Leo Afric. Defeript. Afric. p. $757^{\circ}$

(v) Pro/p. Alpin. Hift. Nat. Aegypt. Lib. IV. p. 2.t. 


\section{SPECIMEN ZOOLOGIAE}

\section{Simia Patas.}

0. VI. Red Monkey. Pennant. num. 82. Patas. Buffon. Tom. XIV. Tab. XXV \& XXVI. Haec fimia acque ac praecedens a Linnaeo eft omiffa. Patas ex Bruaei relatione (w) in Senegalline terris prope Tubao fub decimo fexto latitudinis gradu vivit, \& pelle fua perquam rubicunda infignis eft. $A b$ aethiopibus ibidem degentibus patas nominari folet. Buffonius Tab. XXVI. aliquam ejus varietatem nigris ftriis diftinetam dedit. In tabula Zoographica Patas fimiae octavae nomen habet.

\section{Simia Talapoin.}

iv. VII. Talapoin. Buffon. Tom. XIV. Tab. XI. p. 173. Hujus fimiae patriam minus recte notam effe, dolemus. Buffonius eam Indiae incolam effe putat. Quia vero ipfum Talapoini nomen Siamici idiomatis effe videtur, in Siamae regno beftiam fub fimiac nonae appellatione cum interrogationis figno notatam invenies.

\section{Simia Cephus.}

0. VIII. Simia caudata, buccis barbatis, vertice flavefcente, pedibus nigris, cauda apice ferruginea. Linnaei Ed. XII. Num. 19. Moufac Buffon. Tom. XIV. Tab. XXXIX. p. 17r. Cercopithecus alius Guineënfis Marcgravii hift. nat. Brafil. p. 228. Hanc fimiam Guineae indigenam effe a Marcgravio docemur. In tabula Zoologica ut fimia decima patriae fuae adfcripta eft. Si-

(w) Brut in Allgem. Reif. T. I. p. 364. 


\section{GE O G R A P H I C A E.}

\section{Simin Nictütans.}

S. IX. Simia caudata imberbis nigra, punetis pallidis adfperfa, nafo albo, pollice palmarum breviffimo, natibus tectis. Linn. Edit. XII. Num. 24. Cercopitbecus angolen is alius, totus niger at infperfo cano, nigredine per totum corpus, nalo albo. MArcgrav. l. c. p. 227. Notatu digna eft Linnaei defcriptio, quae beftiae huic nates tectas tribuit, quod fimiis veteris orbis caudis longioribus inftructis inufitatum effe fcimus. Quoniam autem Linnaeus illam ipfe vidit, de rei veritate dubitari nequit. Hoc auctore, Guineam, Marcgravio autem tefte, Angolam inhabitat. In utrisque igitur regionibus fub fimiae undecima nomine in Zioologica tabula notata reperitur.

б. X. Simia Petaurifta. Scbrelertus de animalibus mammal. Tom. I. Tab. I9. B. Blanc-nez. Allamand Hift. nat. de Mr. de Buffon. T. XIV. Tab. 39. Cognitionem fimiae hujus \& fingulari fua pulchritudine, \& manfucto, quo pollet, ingenio infignis, cujus nafus praecipue macula alba triangulari, facies nigritie barbaque colore albo memorabilis eft, celeberrimi naturae inveftigatoris, Profefforis Allamandi diligentiae debemus, qui teftis $x^{3}$ rortin ejus, \& in cujus aedibus a pluribus annis laete adhucdum vivit, exactam apertamque defcriptionem Buffonii operi Amftelodami impreffo addidit. Hinc Scbreberus illam eximio fuo de animalibus mammalibus libro, qui in hiftoria naturali maximi ponderis eft, inferuit. Petauriftae appellatio idcirco ipfi impofita videtur, quia, quoties vel corpus in altum levat, vel in longum mittit, avium more volaffe, non faliiffe videtur. 


\section{SPECIMEN $Z$ ZOOLOGIAE}

Quoniam ad Allamondum ex Guinen deportata ef, eam in Zoologica mappa eadem in regione fub finine dudccima nomine adnotavi. Una trium harum aut petau. rifa, aut quas huic proxime praemifimus, fimiis procul dubio albo nafo praeditis, quas Artus in Guinea obvias habuit $(x)$, accenfenda eft; quae vero illa fit, haud facile quis dijudicabit.

\section{Simia Sabaea.}

0. XI. Simia caudata imberbis fiavicans, facie atra: cauda cinerea, natibus calvis. Linnaci Sylt. Ed. XII. Num. I8. Callitricbe Buffon. Tom. XIV. Tab. 37. Edwardus quidem (y) hanc a quadam promontorii viridis infula Sancli facobi Siminan (St. Jago-ape) nominat; licet non in fola hac infula, fed in Podoris etiam. ad Schegae ripas jacentis filvis gregatim occurat $(z)$. ubi eam in tabula Zoologica fub limiae decimae tertnae. nomine viciebis.

\section{Simia Aygula:}

Q. XII. Simia caudata fubimberbis grifea, eninenua pilofa verticis reverfa longitudinali. Linnoei Edit. XII. Num. 2. . Aigrette. Buffen. Tom. XIV. Tab. XXI. p. I I.4. Calidiflimas $A$ fane regiones, praecipue Javam incolit, ubi Tiaekko appellatur ( $a$ ); quo ipfo nomine Scbreberus. etiam eam defcripfit. In mappa Zoologica fimine decimas quartae nomen habet.

Si-

(x). Artus Allgem. Reif. T. IV. p. 260.

(y) Edwards Gleanings I. T. $215 . \quad$ (z) Adanfon Voy. au Senegalo.

(a.) Osbers Reife nach Ooftiendien Roftok I765. p. I3०. 


\section{G E O G R A P H I C A E.}

\section{Simia Sinica.}

0. XIII. Simia caudata imberbis, capillitio undique horizontaliter caput obumbrante. Limnaei MantifJa plantar. II. p. $52 \mathrm{I}$. Bonnet Cbinois. Buffon. T. XIV. Tab. XXX. Buffonius fimiam hanc mitra finenfi infignem Bent galiae indigenam effe adftruit, quo tamen auetore nitatur, non addidit. Pemantus $(\dot{b})$ eandem Rillovinuin feu Rillurem effe autumat, quam Knoxius in Ceilonis infula vidit $(c)$, quibus in regionibus fingulis eam tabula Zoographica fub fimiae decimae quintae appellatione exhibet.

\section{Simia Aetbiops.}

0. XIV. Simia caudata imberbis capillitio erecto lanulaque frontis albis. Limnaei Syft. Ed. XII. Num. I9. Mangabey. Ruffon. T. XIV. Tab. XXXII \& XXXIII. Utraeque hae beftiae, quas Buffonizis dicto fub nomine defcripfit, folo colore $\&$ albo margine, qui faciem ambit, inter fe differunt, quas Madagafcarem inhabitáre Buffonius, Haffelquifus autem Aetbiopine, feffores effe contendit $(d)$. Utroque igitur loco fub fmine decimae fextac appellatione adfcripta in Zoologica mappa funt.

\section{Simia Nemaea.}

6. XV. Simia caudata imberbis, buccis barbatis, cauda alba. Liminaci Manti IJ Plantar. UI. pag. 52 I. Douc Buf

(b) Synopr. p. r r7. (c) Know Relat. of Ceylon p. 26.

(d) Haljelguifl Reif. po I90.

Hh th 2 


\section{SPECIMEN ZOOLOGIAE}

Buffon. T. XIV. Tab. XLI. pag. 179. Poivri auxilio factum eft, ut Simia haec, quam-in Cocbincbinae regno invenerat, Buffonio primum innotuerit, qui eam fffacam effe credit, quam Flaccourtius in Madagafcare viderat. Utrisque igitur in regionibus fub decimae Septimae nuncupatione in tabula Zoologica cernitur; licet fortaffe alias etiam: Afine flagrantiffimo aeflu calentis partes \& Zanguebarum incolat.

\section{Simin Rotoway.}

5. XVI. Palatine ou Rolorvay. Allamand hift. natur. de Buffon. T. XV. Tab. XIII. pag. 77. Ut hanc quoque fimiam nofcamus, fingulari praeceptoris mei aeternum colendi Allamandi ftudio meritisque in hiftoriam naturalem eximiis debemus. Quum Buffonii editionem, Amftelodami quae prodiit, ipfe non polfideam, e $S_{c}$ brcberi de animantibus. mammalibus opere praeftanti $(e)$ beftiae hujus mihi cognitio data eft, eanque Palatinae nomen inde accepiffe didici, quod ejusdem caput aliquo quafi focali cinctum fit \& ornatum. Guineae fuit incola, quam Allamandus defcripfit, ideoque ipfam eodem mappae Zioologicae loco fub fimine decimae octavae: nomine pofitam reperies.

\section{Simia Maura.}

Q. XVII. Scbreberus in animalibus mammalibus Tab: XXII. Negro-Monkey. Pennent. p. II5. Eidwardus $(f)$. aeque:

(e) Schrebers Saengthiere T. I. Tab. XV. p. 109.

(f) Middle - Jized Black Monkey. Edwaris glean: 3: p. 22 I. Tab. CCCXI. 


\section{G E O G R A P H I C A E.}

aeque atque $S c b r e b e r u s$ exactas fimiac hujus imagines dederunt; quia, Seba $(g)$ tefte, in Ceilone habitat, \&;, Edwardo auctore, Guineae feffor eft, utrisque in regionibus fub fimine decimae nonae appellatione in tabula Zoologica locum nacta eft.

\section{Simia Syricbta.}

6. XVIII. Simia caudata imberbis, ore ciliisque vibrilfatis. Limnaei Syft. Ed XII. Num. 33. P'ettivernus (b) nobis hanc fimiam, guam cercopithecum luzonicum minimumn appellat, depictam dedit, ejusque patriam in pbilippinis generatim infulis \& praecipue in Luzone quaerendam effe perhibet. Scbreberus vero beft am novi orbis indigenam fecit $(i)$ : Fieri quidem potuiffe non. nego, ut Pettiiverius hac in re erraverit, fimiaque ifta ex America in Manillam deportata fit; fed quibus rationibus inductus Scbreberus, Pbilippinis infulis multas res. naturales alias cum America communes effe ftatuat $(k)$, $\&$ hanc thefin fuam quadrupedum refpectu probare poffit, necdum perficio. Biremes, de Manilla olim in aquae pulcbrae portum (Acapulco)' delatae, animalia quidem antiqui orbis in novum, \& alia novi in antiquum orbem transferre poterant, \& fine dubio etiam transtulerunt, quod ex feli Zibetica dif́cimus; alia tamen nulla innotuere, quae tam Philippinarum infularum, quam Americae figillatim indigenae effent. Donec: itaque Simine hujus hiftoriae naturali plus lucis datum fue-

rit;

(g) Seba Thefâtr. Vol. I. p. 7.7.

(i.h) Petiveri Gazophyl. Nat. \& Art. p. 2I. Tab. XIIL.

(ii) Saeugthiere p. I24. (k) libid. p. 125:

$\mathrm{Hh}_{\mathrm{h}} \mathrm{h}$ 


\section{SPECIMEN ZOOLOGIAE}

rit; fub vicefimae titulo eam nominatis jam infulis in tabula Zoologica adfcripfi.

0. XIX. Praeter viginti has enumeratas hactenus cauda longiori praeditas antiqui orbis Simias, Pennantus. adhuc duarum mentionem injecit; quarum alteram e flavo cineream, (Tawany-Monkey) alteram capris fimilem (Goat-Monkey) effe dixit (l). Prioris figura, quam addidit, felis Speciem habet; pofteriorem ex imagine in mufaeo britannico depieta defrribendam curavit; utrorumque tamen patriam minus curate determinavit; dum priorem Indiae quidem habitatorem appellat; fed cujus ejusdem partis? non addit; pofferioris autem domicilium nec quidem nominarit. Haec caufa eft, cur vetrasque omittere debuerim.

\section{$\begin{array}{llllllll}S & E & C & T & I & O & I\end{array}$.}

\section{Americae Simine.}

5. I. $S$ ub capitis hujus primordio jam dictum eit, $S$ ut veteris novique orbis Simias certa explorataque ratione inter fe dignofcere polleamus, magno naturae interpreti, Buffonio, acceptum referendum effe; quippe qui, quas America etiam nutrit, in eas, quae caudis prehenfilibus, quibus, quoties ufus poftulat, res fibi neceffarias apprehendere poffunt, \& in alias, quae caudis flaccidis, quarum ufum adhuc ignoramus, inftructae funt, jufte fatis \& exacte diffinxit, prioribusque Japaionum, pofterioribus fagoninum nomina im-

(l) Pennant Synopf. p. I20. 


\section{G E O G RAF H I C A E. 43}

impofuit. Nos virum celeberrimuin fecuti omnes hafce beftias fuis, quas incolunt, teryis, quantum fieri potuit, in mappa Zoologica adfcripfimus, \& fapaioncs eadem, qua antiqui orbis Simins ratione numeris adpofitis vocula abbreviata Sap. defignavimus; Jagroumes autem fimili vocis compendio $\xi a g$. indicatas reperies $(a)$.

ఠ. II. Prius vero quam cujusvis Americom inhabitan. tis fimiamque referentis beftiae patriam feparatim enumero: obfervationem, mea quidem fententia, memoratu haud indignam jam in capitis hujus initio allatam quidem, nec tamen certo fatis confirmatam praemittere liceat, quae Americam majori reliquis telluris patriae partibus frigore aflari eo magis convincere videtur. Dum enim de omnium fingulariumque fimiarum domiciliis circumfpexi; ea in orbe antiquo remotiora ab aequatore offendi, quam quae novo in orbe obviae funt. Simiarum enim antiqui orbis regiones ad feptentrionem fpectantes ultimae, in quibus simiae liberiori aura fatis adhuc commode vefcuntur, Barbaria, quin Faponia etiam \& Gibraliaria funt; quod, quum de Inuo \& Simia memefrina ageretur, obfervatum eft. Ex quo elucet, has beftias ad tricefimum usque feptimum latitudinis; gradum progredi, hujusque algoribus adhuc tolerandis: pares effe. Americae autem Simins disquirenti earum nec in Virginia, Novo Mexico \& Carolina, nec in Floridae, Carolinale meridionalis \& Californiae finibus ulla: reperire veftigia mihi licuit. Dampicrius in Campecbi

finusi

(a) Litterain Gallicam ç, quae uti figma pronuncianda eft, eo fine: deleginutis, ne Sag. cum Sap. confufum errores le letori pariat., Accedit, pyud Sagouninum appellatio par $\mathbf{c}$ adjinncto fibilo $\mathrm{s}$ fcribi debebat. 


\section{SPECIMEN ZOOLOGIAE}

finu decimum nonum inter $\&$ vicefimum (b) latitudinis gradum Simias confpexit; \& hi ultimi ad boream qui vergunt, feptentrionis termini funt, quos intra Simiae inveniuntur. Hermandezius aut Reccbitus (c) potius expreffis verbis in calidioribus tantummodo Mexici partibus Simias, quas indigenae Ocumatl'os appellant, commorari teftatur. Quum vero Mexici regiones paululum admodum ultra tricefimum gradum excurrant, earumque fines feptentrionales tricefimum tantummodo in capricorni tropico gradum attingant; partes ejusdem calidiores, quarum Hermandezins meminit, eas effe credo, quas trans cancri tropicum pofitas fcimus, ideoque vel tropico, vel quod funmum eft, vicefimo quinto latitudinis gradu fimiarum Annericam incolentium domicilia circumfcribi perfuadeor (d). Equidem Sapaiones \& Sagoines, aut verbo Americae Simias ab illis, quas antiquus orbis nutrit, mirum quantum differre concedo; nihilo tamen fecius eas animantes effe, quae corporum, morum, vivendique ratione noftris quam maxime congruunt, nemo inficiabitur; ideoque perfimiles has inter fe beftias antiquo in orbe ad tricefimum feptimum usque, in novo autem ad vicefimum modo quintum adfeendere gradum, notatu mihi quidem digniffrmum videtur. Lx quo confictur, Americae fimiis folam coeli plagam, quae ab aequatore, fi computandi initium fe-

ce-

(b) Voyages de Damipier $\Gamma$. III.

(c) Bermandez Thefaur. rer. mèdic. nov. Hifpan. Cap. VII. p. 3 I8. " offenduntur juxta calidiora novae Hifpaniae loca cercopiticci, quos Me"xicani Ocumatlos vocant, varia magnitudine atque colore.

(d) Nec Solis in defriptione thereotrophei Motezumae in Mexic ofi miarum mentionem ullam fecit. vid. Solis Mexicani regni invajio T.I. p. 487 . 


\section{$G$ E $O G$ R A P H I C A E.}

ceris, vicefimum quintum latitudinis gradum attingit, falubrem nec noxiam effe; quum illae, quas $A / i n A f r i-$ cnque habet, ad riceffrnum feptimum \& fic duodecim gradus ulterius progredi valeant. Si haec cum reliquis, quae paffim jam adducta funt, argumentis conjunxeris; iis iplis Americam antiquo orbe fub iisdem latitudinis gradibus longe frigidiorem effe, eo certius convinceris. Pleraque in: orbe novo fimiarum genera folius fere Guianae, Peruvii, Paragitayal /uperioris \& Brafiliae habitatores funt:; in meridionali vero America ultra vicefimum quintum gradum pofita, earum nec volam nec veftigium invenire mihi licuit; nec unquam in $\mathrm{Cbill}$ aut bonae aurac (Buenos Ayres) regnis Simias dari me relatum legere memini; quum e contrario Africae bamadryas ad bonae fpei promontorium usque defcendat. Quum autem vetus orbis non tam late meridiem verfus, quam America procurrat; fieri nequit, ut utriusque partes ad meridiem fpectantes pari ratione, atque illas, guuae ad feptentrionein verguht, inter fe comparemus.

\section{A. Simiae cuudis prebenflibus.}

\section{Simia Beelzebul.}

6. III. Simia caudata barbata nigra, cauda preThenfili extremo pedibusque brunneis. Limnaci Syft. Ed. XII. Num. r2. Outrine. Bufforn. Tơn. XV. pag. 6. In mappa Zoologica japajou I. eft. Hujus beftiae fedes patria Guiana (e) Orenoki ripae funt \& Brafilla $(f)$, tbi filvas gregatim pererrat, \& offis cujusdam in gula latentis ope ululatum immanem tollere, ideoque uili:lans nơminari folet.

$3 i-$

(e) Bancrofts Guiana p. 133. Ea. Gern.

(f) Maregra\%. Hift. Brafil. p. 226. 


\section{SPECIMEN ZOOLOGIAE}

\section{Simia Seniculus.}

0. IV. Simia caudata barbata, rufa, cauda prehenfili. Linnaei Sylt. Ed. XII. Num. I3. Allowate. Buffon. T. XV. pag. 7. In tabula Zoologica Japajou $\in f 2$. Pennanus $(g)$ hanc beftiam, eodem fere ululatu notam, folam Ouarinne varietatem effe exiftimat, quod tamen injudicatum relinquimus. Eadem cum antecedenti patria quidem gaudet, plures tamen regiones inhabitare videtur. Nam Carthagena (b), Veragua (i), Surinama (k), Guiana, Maranoni ripae (l) \& Bra/jlia (m) ipfam alit. A Campecbi itaque finu omnes calidiores Americne meridionalis occidentem verfus pofitas terras occupat; parumque abeft, guin perfuadear, vel hanc, vel antecedentem humana facie longiorique cauda praeditam effe beftiam, quae Verapazae (regni ea Mexici provincia eft ) incolis ingentem metum incutere dicitur (n). Scbreberus utrisque rugientium fimiarum cognomen impofuit (o) Merito autem miramur, nullam adhuc utrarumque animantium, licet acervatim proficifcentibus obviae fint, imaginem datam effe, quae veram ipfarum formam fpeciemque gerat.

\section{Simia Panifcus.}

0. V. Simia caudata imberbis, atra, cauda prehenfili, palmis tetradactylis. Linnaei. Syft. Ed. XII. Num. 14. Conita. Buffon. Tom. XV. Tab. I. p. I3. In mappa

(g) Synopr. p. I23. (h) Jacquin. Secund. Schreber. p. II3.

(i) Oexmelin Hift. des Flibuft. T. II. p. 214.

(k) Fermin Holluade Equinox. p. 43.

(m) Marcgrav. l. c. (n) Allgem. Reif. T. XIII.

(b) Saeugthiere p. I 12. 


\section{G E O G R A P H I C A E.}

pa Zoologica eft fap. 3. Pollicis, vel quinti, quo caret, digiti defectu fimia haec a reliquis, quas novimus omnibus diftinguitur. Guianam inhabitat, a cujus indigenis Quato nuncupatur; quod Bancroftizis $(p)$ adfirmat, qui tamen, quum teftis autortrns fuerit, quod dictu \& mirabile \& inapprehenfibile videtur, eam cauda carere tradidit; caeterum in Peruvii $(q)$ etiam filvis aliisque calidioris Americae partibus ipfam vivere certo conftat.

\section{Simia trepida.}

ઈ. VI. Simia caudata imberbis, capillitio arrecto, manibus pedibusque coeruleis, cauda prehenfili villofa. Limn. l. c. num. 20. Bufch-tailed Monkey. Edwards Gleanings 3. Tab. 3.12. In mappa Zoologica fap. 4. Eáwardis loco citato eam Surinamae etiam habitatorem effe fribit. Per omnem itaque Guianam difperfam eandem reperiri autumo.

\section{Simis Fatuellus.}

6. VII. Simia caudata imberbis, cauda prehenfili, capite fafciculis pilorum duobus corniculorum aemulis. Linn. 1. c. num. 28. Sapajou cornu. Briffonii regn. anim. Edit. Parif. pag. I95. Sajou gris. Buffon. Tom. XV. Tab. V. In tabula Zoologica Jap. 5 . Simia haec cum antecedenti easdem quidem regiones incolit, Americam tamen meridionalem ejus patriam generatim effe perhibent.

$\mathrm{Si}$

(p) Bancroft Guiana p. 73. Fermin 1. c. p. 44.

(q) Ulloa Voy. T. I. p. II3. 


\section{SPECIMEN ZOOLOGIAE}

Si cum cercopitbleco cinereo cirrato capite - nigro eadens beftia eft, cujus Ferminus mentionem fecit $(r)$, inte: rioribus etiâm in Surinamae terris, raro tamen - obvia effe debcr.

\section{Simia Apella.}

6. VIII. Simia caudata imberbis, cauda füb prekenfili corpore fufco, pedibus nigris, natibus tectis. Linzaeus l. c. Num. 29. fajou. Buffon. T. XV. Tab. IV. Et P'ennantus \& Buffoñius hanc antecedentis varietatem efre ftatuunt, praecipue quum eadem cum priori in regione commoretur. In mappa Zoologica fap. 6. eft.

\section{Simia Capucina.}

6. IX. Simia caudata imberbis fufca, cauda prehenfili hirfuta pileo artibusque nigris natibus tectis. Linnaeus 1. c. Num. 30. Cercopitbecus totus niger Fers min. Holl. Equinox. p. 44. fai \& fai à gorge blanche Buffor. l. c. Tab. VIIII. In tabula Zoologica Sacp. 7: Praeter Buffonium Linnaeus etiam optimam fimiae hujus icona dedit $(s)$., Pennantus eam Apellain Trepidamque varietates tantum effe putat; Buffonii tamen Sajam capucinam effe negat (i), licet utraeque ibi fint fimillimae. Harum fapajonum aliquas dari varietates \& lubens concedo \& ipfe perfualum habeo. Quis autem in animantium iftarum hiftoria, cujus adhuc incertiffimi fumus, eø procedet audaciae; ut cerri

ali-

(r) Fermin l.c.

(5) Mul. Addolph. Frideric, Tab. II. (n) Synopf. pa. 


\section{GE O GRAPH I C A E.}

aliquid ftatuat. Tutiora itaque fecutus omnes has fpecies inter fe difcrevi, donec a naturae quodam ejus regionis venatore de beftiarum natura certiores facti fuerimus. Sajam interim, quam fauce alba-natura ornavit, varietatibus annumerare non audeo. Simia haec Guisnae Brafliaeque (u) feffor eft, mofchum redolet, \&, quia infantium more fubinde ejulat, hoc ipfo ab alis omnibus facillime diftingui poteft. A Scbrebcro cjulatoris nomen accepit $(v)$.

\section{Simia Sciurea.}

ஏ. X. Simia caudata imberbis, occipite prominulo, unguibus quatuor plantarum fubulatis natibus tectis. Linznaeus 1. c. Num. 3. I. Simia moria. Simia caudata imberbis fpasicea ore fufco, cauda nuda fquamofa, Linnaeus ibid. Num. 32: Saimiri. Buffon. Tom. XV. Tab.X. Scbreber. 1. c. Tab. 30. In mappa-Zoologica Sap. 8. Sapajonem hanc idcirco Buffonizus ultimo loco pofuit, quoniam cauda fua prae fimits antecedentibas minus commode uti poteft. Sebreberus etiam fatis exacte depictam eanden exhibet, qui eidem, ficut Ferminius ca pitis mortui nomen indidit $(w$ ). Hujus varietatem etiam. efre fimian autumo, quam fub cercopitbeci minoris lutei appellatione ferminius defcripfit: Scbreberus faltem beftiam, cui Barrerius fimiae minoris luteae nomen impofuit, hujus varietatem effe putat $(x)$. Et Briffonizus luteo ipfam colore infectam effe teftatur $(y)$. In Guico

(u) Dampier Yoy. T. 1II. p. 53. (v) L. c. p. 120.

(wv) Fermin l. co. Saprojou Cepput mortuum.

(x) Barrere France Eguninox. p. $15 \mathrm{I}$.

(y.) Regne Anim, po 19\%. Lid. fio.

$$
\text { Ii i. } 3
$$




\subsection{SPECIMEN ZOOLOGIAE}

$n a(z)$, ad Amazonum fuvii ripas (a), \& in Brafilia (b) commorari dicitur. Praeter has, quas ordine percenfui, Sapajones, alius cujusdam $P$ ennantus mentionem intulit, quam, quia ab Antigua ipfi miffa fuit,. Antigune Smiam (Antigua.Monkey) nominavit; cujus autem, quum patria non certo fatis conftet, eam tabulae Zoologicae - inferere nequivi. Oeto igitur tantum caudis prehenfilibus fimias numerare tabulaeque noftrae inferere potui.

\section{B. Americne fimias caudis faccidis.}

\section{Simia Pithecia.}

6. XI. Simia caudata imberbis, vellere nigro, apice alto, cauda nigra villofiffima. Limnaeus 1. c. Sinki. Buffon. l. c. Tab. XII. Propter caudam villofam ab aliquibus Simine cauda vulpina praeditae nomen accepit. Guianae (c) indigenae, quos inter vivit, ipfam Sakkawinkee vocitant. In tabula Zoologica çag. I. eft.

\section{Simia Jaccbus.}

0. XII. Simia caudata auribus villofis patulis, cauda hirfutiffima curvata, unguibus fubulatis pollicum rotundatis. Linn. ibid. Num. 24. Ouifliti Buffon. Tom.XV. Tab. XIV. p. 67. Striated Monkey. Pemnane fynopf. p. I32. In mappa Zoolog. çag. 2. Edwurdus (d), Kleinius $(e)$

(z) Barrere \& Fermin. (a) Abbeville Miffion au Perou p. 252.

(b) Marcgrav. 1. c. p. 22y. (c) Bancrofft 1. c. p. 80.

(d) Edward's Glean. I. Tab. CCXVIII.

(e) Klein. Quadrup. Tab. LII. 


\section{GE O G R A P H I C A E.}

\& Buffonius effigies beftiolae hujus, quae, quantum conftat, Brafiliam $(f)$ incolit, exactiffimas dederunt.

\section{Simia Oedipus.}

¡. XIII. Simia caudata imberbis, capillo dependente, cauda rubra, unguibus fubulatis. Linnacus l. c. Num. 25. Pinche. Buffon. Tom. XV. Tab. VI. p. 79. Litle lion Monkey. Edwards Tab. 195. In tabula Zoologica çag. 3. Cum antecedentibus fuvii Amazonum ( $(5)$ ripas \& Brafiliam (b) inhabitare traditur.

\section{Simia Rofalia.}

๑. XIV. Simia caudata imberbis, capite pilofo, faciei circumferentia, pedibusque rubris, unguibus fubulatis. Limn. 1. c. Num. 26. Marikina Buffon Tom. XV. Tab. XVI. p. 75. Sylky Monkey. Pennant. Synopf. Tab. XV. p. I33. 'Tabula Zoologica çag. 4. In Cayenna (i) ripisque fluvii Amazomum (k) vivit.

\section{Simia Midas.}

0. XV. Simia caudata imberbis, labio fuperiore filio, auribus quadratis nudis, unguibus fubulatis, pedibus croceis. Linnaci Syft. Edit. XII. Num. 24. Tamarin. Buffon Tom. XV. Tab. XIII. p. 64. Little black Monkey. Edwara's Tab. 197. Mappa Zoologica çag.

(f) Marcgrav. l. c. pe 227. (g) Voy. de Condamine p.165.

(h) Marcgr. I. c. (i) Barrere France Equinox. p. $15 \mathrm{I}$.

(k) Miffion du Perou par Allbeville pag. 252 . 


\section{SPECIMEN ZOOLOGIAE}

çag. 5. Cayennam, Guianam (l), Amazonum fluvii $(m)$ ripas, infulam Gorgonam ( $n$ ) quae in oceano meridionali haud procul a P'anama jacet, tenere dicitur.

\section{Simia Argentata.}

๑. XVI. Simia caudatal imberbis exalbida, facie rubra, cauda fuscefcente. Limmsei Manti/f plantar. ult. p. 25I. Mico. Buffon T. XV. Tab. XVlil pag. 84. Cerropitbecus ex cinereo albus argenteus, fácie auriculişuue rubris fplendentibus, cauda caftanei coloris. BrisJonit regn. animal. Haec Bryfonii deferiptio animantem perpulchram optime depingere videtur. Condamminus eandem ex Amazonim fluru ripis, ubi fedem fixit, in Gailiam transtulit (o). In mappa Zoologica fub çag. 6. denominatione notata reperitur.

ఏ. XVII. Hae funt, quas America nutrit, Simiac nobis adhuc notae, quarum patrias, quantum licuit, add di. Hinc eas fere omnes tropicis inclufas contineri fingulaque illarum genera una eademque regione congregatas confpici, pulam fit. 'Hernandezius itaque in partibus Mexici regni meridionalibus diverfiffmas inveniri fimias his verbis aperte teftatur: "reperies (juxgs ta calidiora novae Hifpaniae loca) cercopithecos ni"g gros, pallentes fufcosque, magnos, mira parvitate, \#) ac mediocres $(p)$., Condaminius de regionibus, quas

(i) Voyage à Cayenne par Binet p. 34.r.

(m) Condam. Voy. in-Goetingifchen Reifen T. II. p. 303.

(n) Dompier Voy. T. I. p. r7.:.

(o) Condanine Voy. in Goetting. Reir. T. II. p. 304.

(p) Hernandes Thefaur. p. 318 . 


\section{G E O G R A P H I C A E. 44}

quảs Amazonum amnis alluit, idem confirmat: „, du\% rante, inquit, navigatione mea tot fimias vidi, tot " aliarum fpecierum enumeratas audivi, ut eas omnes. $\Rightarrow$ ordine percenfere \& longum foret \& difficile (q): "Aliae canum venaticorum, aliae glirium magnitudi" nem habent ". Hoc idem etiam e frepius laudati Marcgravii relatione patet, \&z Ferminizus in cola Guiana decem \& amplius eorum genera numerat. Et Corcalis ( $r$ ) beftias iftas propemodum omnes uno eodemque loco, feu, 'quod idem eft, in qualibet calidioris Americae parte quáfi collectas \& congregatas reperiri confirmat; quod in antiqui orbis fimiis longe aliter effe, experientia docet. Quamquam enim Colcbes, Madagafcar, Malabaria, aliaeque veteris orbis partes fub meridionali coeli plaga, quae ardentiffimo fole calefcit, varia quoque genera conjunctim nutriunt : ex antedictis tamen apparet, antiqui orbis fimias generatim prae Amcricac indigenis latius diffipatas effe diffurasque.

$$
\begin{gathered}
\text { S E C T I O V. } \\
\text { Lemures }(a) \\
\text { Profomia }(b)
\end{gathered}
$$

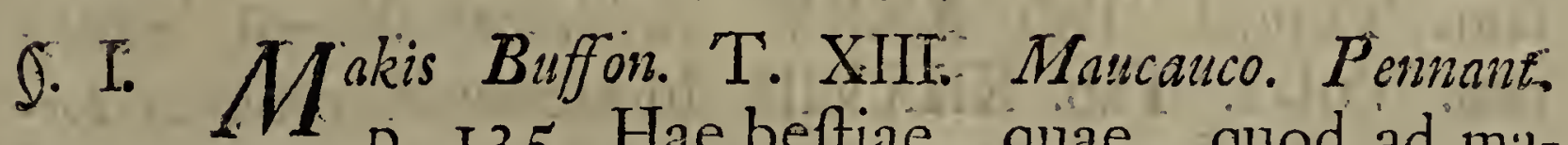
p. I35. Hae beftiae, quae, quod ad manus fimiis quidem fimiles, roftri autem ratione, quod vulpium ritu mucronatum eft, ab illis difcedunt, exi-

guum

(-q). Condamine 1.c. $\mathrm{p} \cdot 303$ :

(i) Voyages de Corecil 1. I. I. p. 95: \& paffim.

(a) Lininei Sytt. Eid. XII. Genus III. p. 44. (b) Brifonii Regn. Ainim. K k k 


\section{$442^{\circ} S P_{\mathrm{C}} \mathrm{EI} \mathrm{MN} \mathrm{ZOO} \mathrm{OGIAE}$}

guum moda, quantum nobis hucusque conftat, terrarnm Ipattum, occupant. Quaedam carum Indiage orientalis proprie fic dictae, aut, quod idem eft, Afice maxima aeftus vi calentis feffores funt; plurimae autem Madagafiarem, infulasque haud procul inde diftantes tenent. Africae tamen promontoria contra infulas hafce pofita iisdem etiam fcatere magna cum probabilitate colligo; licet propter horum obfcuritatem ignorationemque, in qua adhuc verfamur, certi nihil hac in re ftatui queat. Quod Buffonio placet, vero admodum fimile eft, animalia nimirum, quorum Ludolfus in Aby/finiae hiftoria fub Fonkium Guerizaranzque nominibus (c) meminit, quasve Sagouinibus adnumerare nemo facile audebit, quasdan Lemurtm fpecies effe. Quum autem nemo naturae indagatorum regiones iftas peragraverit, res ea usque in dubio minusque explicabilis eft. Lemures, ut fpatio in tabula Zoologica parceremus, numeris adjecta vocula lemur notatos, patriisque fuis, quas nunc dispiciamus, adfcriptos invenies.

\section{Lemur Tardigradus.}

Q. II. Lennur ecaudatus. Linnaei Syft. Ed. XII. p. 44. Loris Buffon. Tom. XIII. Tab. XXX. p. Seba Thefaur. Tom. I. Tab. XXXV. Scbreberi animal. mammal. Vol. I. Tab. XXXVIII. In tabula Zoologica $L c-$ mar I. Profminia haec, quae, quod cauda caret, a reliquis omnibus dignoficitur, in Ceilone $(d), 2$ r l'ennanto anctore $(e)$, in Bengala habetur.

(c) Ludolph Commentar. Aethiop. p. 58. . (d) Seba l. c。

(c) Synopf. p. 13.5 . 


\section{Lemur Mongoz.}

ઈ. III. Lemur caudatus, grifeus, cauda unicolore. Linnacus 1. c. Num. 2. Monrooz. Edward's Gleanings I. Tab. CCXVI. Mongouz Buffon. Tom. XIII. Tab. XXVVI. pag. 95. In mappa Zoologica Lemur 2. Scbreberus hujus animantis fex varietates effe adfirmat $(f)$, earumque magnam fatis copiam dari facillime difces, fi, quas Buffonius \& Edwardus ipfarum effigies depingi curaverunt, inter fe comparaveris. Briffonius profimins tres nominavit I.) fufcam fcilicet, 2.) nafo, gutture pedibusque albis, \& 3.) fufcam, rufo admixto, facie nigra, pedibus fulvis. Praeterea Edwardus tres vel quatuor ipfarum uno eodemque tempore Londini, fibi invicem fimillimas, diverfiffimi tamen coloris vidiffe refert; quarum una ex India orientali advecta fuit; caeterum $M c^{-}$ dagajicaris incola $(g)$ eft, \& Pennantus eas ad Celcbis usque infulam progredi teftatur $(b)$.

\section{Lemur Macaco.}

0. IV. Lemur caudatus niger, collari barbato. Linw nacus 1. c. Num. 3. Blak. Macauco. Eidwardus Gleanings. 217. Vari Buffon. 1. c. Tab. XXVII. pag. 95 In Zoologica tabula Lemur 3. Hujus etiam demuris varietates quaedam numerantur. Quem Edwardus depinxit, totus niger, Buffonii autem Vari niger albo diftinetus eft, \& Cancbius quendam totum abbum vidit, quem

(f) Sacugthierre Tom. I. p. I37.

(iv) Flacout Madagafcar p. 153 . (i) Synopr. 1. o

$\mathrm{K} k \mathrm{k}$. 


\section{SPECIMEN ZOOLOGIAE}

quem Antavarram nuncupat $(i)$. An diverfae fint fpecies, certo nec quis adfirmabit, nec inficiabitur. Madagafcaris filvas gregatim pererrat.

\section{Lemur Cattia.}

๑. V. Liemur caudatus, cauda albo nigroque annulatus. Linnaeus 1. c. Num. 4. Mococo. Butffon 1. c. Tab. XXII. Mancauco. Eawuard's Birds. 197. In tabula Zoologica Lemur 4. Madagafcarem (k) \& Jobannam incolit (l); fed ipfam Franciae etiam infulani (Isle de France) nutrire recentiorum neminem fcribere memini.

\section{Lemur Flavus.}

5. VI. Lemur cauda prehenfili Mellow Maucauco. Pennant. Synopr. p. I38. Tab. XVI. Ut beftiam hanc nofcamus, totius Pcrnnanti munus eft, qui ctiam optime ipfam depingi curavit: Jamaicae montes inhabitare dicitur; quod, licet nondum fatis exploratum fit, e cauda tamen prehenfili, qua ab omnibus reliquis $L_{e-}$ muribus difcedit, magna cum verifimilitudine colligi poteft. Antiqui enim orbis animalibus, quantum mihi quidem conftat, ejus generis caudis deftituuntur, quas contra Americae beftiis fatis frequentes-Fcimus.' In mappa Zoologica Jamaicae infulae Lemuris quinti nomen adfriptum leges.

\section{Potto.}

D. VII. Bosmannus in Guinea (13) animantem, cui Pot-

(i) Cauche Rélation de Madagafe. p. 127.

(k) Flacourt I. c. \& Iyes Reife T. I. p. 29 \& 30.

(l) Groffe Voy. I758. p. 42. (mi) Allg. Reif. T. IV. 


\section{G E O G R A P H I C A E. : 445}

Potto nomen regionis feffores dederint, vidiffe refert, ideoque hoc ipfum nomen in tabula Zoologica eidem regioni appofui; imago permediocris quam Bosmannus addidit, \& ejusque defrriptio animali manus fimiarum manibus fimiles, mucronatum prominensque roftrüm, caudamique denique longam tribuit, quae omnia profamiis propria funt. Quum quae cujus generis fit, beftia ex Barboti Bosmannique relatione adhuc certo definiri nequeat: exfpectemus oportet, donec folerti cuidam naturae fpeculatori iftas regiones peragrandi earumque animalia curatius indagandi occafio detur.

\section{Lemur. Volans.}

0. VIII. Lemur caudatus membrana ambiente vo. Iitans. Limnaei Syft. Ed. XII. p. 45. Num. 5. Vespem tzlio admirabilis. Bontius hift. nat. Ind. Orient. apud $P i$ fon. p. 68. \& 69. cum iconibus. Felis Volans. Ternatana Seba Thefaur. Tom. I. Tab. LI. Fig. 23. Quoniam hoc animal medium quafi Lemures inter \& ves. pertiliones eft, Linnaeus optime \& commodiffime ab illo ad vespertiliones tranfiit. Utrum vero a fubfequente multum differat, dijudicare nequeo. Moluccas $(n)$ in. fulas \& inter Pbilippinas $(o ;$ Guzuratam $(p)$ incolere dicitur; ubi ipfam in tabula Zoologica fub lemuris Jexti nomine notatum invenies.

\section{SECTIO}

(n) Pennarit. Synopf. p. I40. (o) Seba 1 c.

(p) Petiver. Gazophyl. p. 14. \& Allg. Reir. T. XI. p. 428.

$\mathrm{Kk} \mathrm{k} 3$ 


\section{SPECIMEN ZOOLOGIAE$$
\text { S E C T O VI. }
$$$$
\text { Vespertiliones. }
$$

o. I. U niverfa Vespertilionam claffis maximam telluris fuperficiei hucusque nobis cognitae partem occupat; ipfos tamen terras feptentrionem verfus fpectantes abhorrere, ex eo colligimus, quod peregrinantium neminem, qui Groenilandiam, lslandam, Lapponiam, Samoicdian, Hudfonis frinum \& caeteras, quae mare glaciale adjacent, regiones, peragraverunt, ullam eorum ibidem viforum mentionem facere memini. Nec mirandum eft, illos infames frigoribus tractus deteftari; quum temperatioribus in locis per hiemem ipforum corpora gelu rigefcere foleant. Ceterum aliae omnes terrae, fi prope axem pofitas exceperis, unum alterumque illorum genus alunt, eosque ad fexigefimum tertium latitudinis gradum progredi, Succia Norvagiaque docent, ubi $\nu_{\text {espertiliones adhuc conficiun- }}$ tur. Tametfi generatim quodvis ipforum genus modicis tantum terrarum orbis terminis circumfcribatur; nonnullos tamen fatis etiam late disperfos obfervamus. Quos enim primo loco pofui, quoniam reliquis corporum magnitudine praeftant, tantopere dilatatos reperimus, ut, nifi quibusdam fpatiorum intervallis disjungerentur, domiciliaque minus cohaerentia haberent, jure locum in fecundo jam capite occupare poffent. Mappae interim Zoologicae anguftia cogente, eadem methodus, qua in fimiis defignandis ufus fum, in his etiam animalibus adhibenda fuit, ut Vesportilionis vo- 


\section{G E O G R A P H I C A E. 447}

culas numerus adfcriberetur. Antiqui orbis quidem: $\nu$ espertiliones reliquis Americam inhabitantibus praemifi; numeri tamen alio heic ordine, quam illic, nullo nimirum difcrimine antiqui novique orbis habito procedunt. Ne quis tamen error offundatur, non in tabula tantum, fed hoc ipfo in capite, quae beftiarum genera. fingulis numeris indicentur, aperte enodavi.

\section{$V$ espertilio Vampyrus.}

פ. II. Vespertilio ecaudatus, nafo fimplici, membrana inter femora divifa. Linnaeeus l.c. pag. 46. Num. I. Rouflette \& Rourgette Buffon. Tom. X. Tab. XIV. \& XVII. Great Bat. Edwurd's Tom. IV. Tab. CLXXX. In tabula Zoologica Vespertilio I. Buffonius. quidem Rouffettam a Rougetta feparavit, quamvis utraeque easdem regiones incolant, nec externa modo forma \& habitu, fr magnitudinem exceperis, optime inter fe conveniant, fed Daubentonio auctore (a), utrarumque etiam fceleta fibi fint fimillima. Ideoque $P$ ennantun $(b$ ) ducem jure fecutus, Rougettam quae minor eft, Ronffectae varietatem effe autumo. Vespertilionem hunc, reliquos omnes magnitudine fuperantem, latiffime per terrae fuperficiem diffufum inveniri, dignumque fuiffe, qui capiti fecundo.infereretur, jam dixi, quem tamen, ne a. reliquis fui generis diffociaretur, huic refervatum volui ; praecipue quum, quod in illius capitis animalibus fecus fe habet, interrupto potius ordine $\&$ intervallis quibusdam intermiffis progrediatur. In Africa ad Senegae ri-

pas

(a) Daubenton ap. Buffon. 1. c. p. 46 . (b) Synopf. p. 352 b. 


\section{SPECIMEN Z OOLOGIAE}

pas (c) commoratur, \& Montis promontorium (Cap monte) ubi Tonga (d) nominatur, ingentem eorum copram nutrit. In omnibus $G$ uineac regionibus vivit $(e)$; cui, quoniam Congi regnum propinquam \& finitimum eft, in quo Pigafetta $(f)$ dracones volantes dari refert; parum abeft, quin perfuadear, virum majores $V$ espertiliones, quos libere paffim volitare viderat, in draconum numero habuiffe. Quando autem dracones fuos. vervecum magnitudinis effe ait, quoniam id vespertilio nibus hifce minus convenire libere fateor, ex eo conftat, partim ipfum in animantibus:aliisque rebus naturalibus defcribendis haud femel hallucinatum effe, partim quosdam vespertzlionum majora anatibus noftris \& corpora \&. alas habere, quae in. fexpedum longitudinem extendantur. Mea quidem opinione facile fieri poterat, ut draconam appellationem inufitatis hifce animantibus imprudens: imponeret. A Congi finibus ad bonae jpei promontorium progreffus nulla plane vesperiilionum veftigia ab auetoribus fide dignis obfervata inveni; fed caufa in promtu eft. Omnes enim iftae regiones adhuc penitus. ignorantur: Ingens itaque hoc intervallum, quod a Guinea vel Congi regno ad orientales infulas porrigitur, in quo horum animantium nulla fit mentio, potiffimum effecit, ut ad hoc caput tertium illos remiferim. Si

quis:

(c) Allg. Reif. T. II. p. 398 . (d) Ibid. T. III. p. 336 .

(ie) Ibid. T. H.. p. 383 .

(fi) - Vi fono anco certi altri animale, che grandi quanto un montone in à guifa di Draghi, hanno le ali e la coda, - \& il mufo longo con diverft. g., ordine di denti e mangiano carne cruda. Pigafetta Relaz. del Regn. di(3ongo R. 33. \& 33: Beliqua quac. addidit, fabulas aniles fapere videntur.. 


\section{GE O G R A P H I C A E.}

quis oppofuerit, bonae fpei promontorium \& Barbariam majori frigore afflari, quam cui tolerando vespertiliones pares fint, ejus affenfor effe idcirco non polfum, quia deinceps eos Aflae quasdam regiones inhabitare commonftrabitur, quae iftis longe funt frigidiores. In Africac parte orientali \& quam maxime in infulis ibidem jacentibus denuo comparent. Madaga/carem ( $g$ ) enim, Francine (b) infulam (Isle de France) Borboniam (i) Rodriguamque $(k)$ frequentant. In $A$ fia usque ad gradus frigidiores adicendunt. Quamvis enim Strabonis relatio de vespertilionibus fingularis magnitudinis, The fopotamiam inhabitantibus $(D)$, recentioris nullius auctoris teftimonio confirmetur; in Cbinenfum tamen provincia $S c h e n / 2$ fub tricefimo feptimo vel octavo circiter gradu obvii funt $(m)$, praeterea in plerisque calidiffmae Alae regionibus, in Guztrata ( $n)$, Malabaria (o), Siama $(p)$, Sumatra, Java $(q)$, in Maldivis $(r)$ Pbilippinisque $(s)$ infulis, in nova Guimen $(t)$ novarque Hollandine partibus orientalibus (u) \& verbo in univerfo fere orbis antiqui trąu inter tropicos pofito inveniuntur. In Americae etiam regionibus, in Carthagena (v) fcilicet, Guisma (w) \& praeter Ainazj-

natiz

(g) Ives Reil. T. I. p. 30.

(il) Journal. diun Voy. an Cap. par la Caille. p. 233. (i) Voyage à l'stle de lirance e de Bourbon, lectre 9. (k) Voy. de le Guat. I. p. 107 ( (l) Strabo Googr. Lib. XVI. (m) Allg. Reir. T: VI. p. 9.5. (n) Mandeino Reif. (0) Tranquebarfche Miffions bcrichte. (p) Turpin Hift. du Roy. de Siam T. I. p. 3ro. (q) Osber ineire naeh China p. 137. 138. qui ebfervavit, vefpertiliones iftos fingulis vefperis a Snmatrz Javam verfus avolare; cujus tamen rei caufam addere néquit. (r) Voy. de Pyraril T. I. p. I32. (s) Allg. Reif. T. XI. p. 40.4 (t) Dampier Voy. 'I. II. p. 7 l. (u) Cook's Voy. round the Wiorld Hawkesworth Account T. III.p. 626. (v) Allg. Reif. T. IX: p. 48 ? (w) Brancoft Guiana p. 8T. 


\section{$45^{\circ}$ SPECIMEN ZOOLOGIAE}

sum $(x)$ amnem vespertiliones jam recenfitis perquam funiles conficiciuntur; quos tamen, quum nondum fatis nofcamus, ad evitandam ofcitantiae aut incuriae notam dictis hifce terris fub $V$ ampyrorum nomine appofuimus. Tempus autem docebit, an cum Linnanci $Y$ ampyris congruant, nec ne? Interim qui nunc vespertiliones fequuntur, omnes arctioribus longe finibus contineri difces.

\section{Vesperiilio Spasma.}

6. III. Vesperitilio ecaudatus, nafo foliato obcordato. Linnaci Syft. Ed. XII. p. 47. Num. 4. Vespertilio fubrufus, auriculis duplicibus, nafo gemino. BrifJonii regn. anim. Ed. parif. p. 226. Glis volans Ternatanus. Sclia thefaur. Tom. I. pag. 90. Tab. LVI. fig. I. In tabula Zoolog. vespertilito 5. Optimam hujus animantis effigiem Seba nobis exhibuit, cujus apographum non Scbreberns folum in animalibus mammalibus, fed Mcierus etiam in animantium depietoruin appendice dedit. Quantum jam conflat, in Ceilone Moluccisque $(y)$ infulis vivit.

$$
\text { Vespertilio Nigrita }(z) \text {. }
$$

0. IV. Chauve -Souris ćtrangère. Buffon. Tom. X. Tab. XVIII. Marmotte volante. Daubenton Mén. de l'Académie des Jciences de Paris. 1759. In mappa Zoologica vespertilio 9. Admanonius hunc vesperitilionem ex Senegae regno, cujus indigena eft, attulit.

\section{Vespertilio Barbatus.}

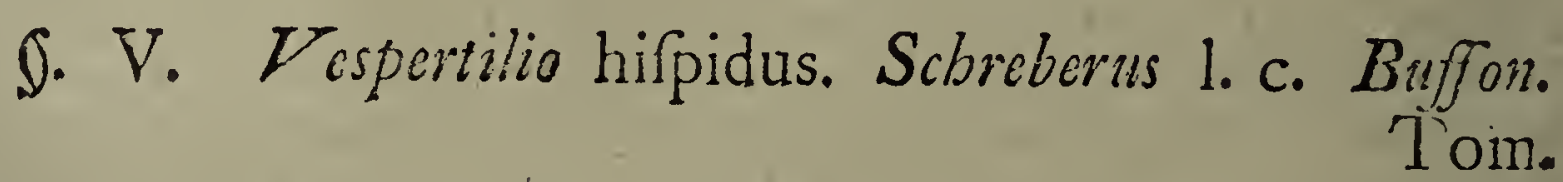

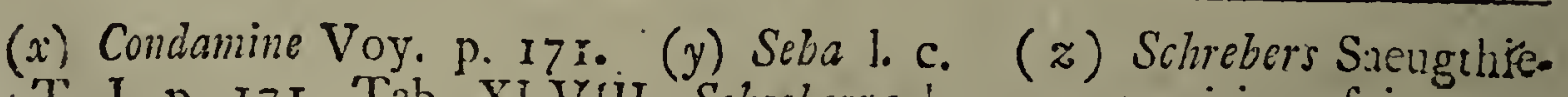
re. T. I. p. 177. Tab. XLVIil. Schreberras hoc nonen ei impofuit, 


\section{GEOGRAPH I C A E.}

Tom.X. Tab. XX. fig. 1. \& 2. p. 53. Compagnol volunt Daubenton Mén. de l'Académie des Jicences de Paris 1759. Bearded Bat. Penzant. Synopr. p. 367. In tabula Zoologica vespertilio ro. Et hunc Adanjonius e Senega, quae ejus patria efi, apportavit (a). Uterque vero hic \& antecedens a Linnnaco filentio praetermiffus efto Vespertilio Pictus.

0. VI. Vefpertilio caudatus, nafo fimplici, auriculis infundibili-formibus appendiculatis. Gronovii Z Zoophyl. p. 7. Num. 25. Mujcardin volant. Datbenton Mem. de $l$ Acad. des fienc. de Paris 1759. Autre Chauvefouris. Buffon: Tom. X. tab. XX. fig: 3. In mappa Zoologica vespertilio in. Pallafurs hunc propter fafciatas fecundum digitos alas pitci Vefpertilionizs nomen dedit (b). Ceilonienfes, guos inter habitat, Kiriwoulans ipfun vocitants Ex Pallafii teftinonio Moluciaruns etiam infulurunn eft incola.

0. VII. Verpertilio Cepbalotes. Pallas Spicileg. Fafcic: 3. pag. Io. Tab. I. Hanc beftiolam perfpicaciffimo; quein jam honoris caufa nominavi, Zoologo acceptum referimus, qui illi nomen ab ingenti, guo gaudet, capite, impofuit. In Moluciis infulis patriam habere dicitur. In tabula Zuologica $V$ espertilio 13. efts

9. VIII, Vefpertilio mutrinus. Vespertitio caudatus, nafo oreque fimplici, auribus capite minoribus. Linnaei Syft. Ed. XII. Num. G. Chauve-Souris Buffon. Tom. Vill. p. 67. Tab. XVI. In tabula Zoolegica VeppertiVio 14. Hie uftatus nobis ac pervulgatus $\gamma_{\text {efpertalio a }}$ Nor-

(a) Buffon l. c. (b) Pallas Spicileg. Fafcic. 3. p. 7\% 


\subsection{SPECIMEN ZOOLOGIAE}

Norvagia (c), Sueciaque (d) ad Germaniam, Galliam, Italiam omnesque propemodum Europae (e) terras defcendit, quantumque nunc conftat, in Aful prope Gurjefum ad $\mathcal{F}$ aiki $(f)$ fluminis ripas jacentem, \& procul dubio alias multas regiones inhabitat.

\section{Ve/pertilio Noctula.}

5. IX. Nociule. Buffuiz. Tom. VIII. Tab. XVIII, fig. 1. p. 7o. Great Bsat. Pennant. Britt. Zool. Taba CiII. In tabula Zoologica Vefpertilio I5. Angliace, Germaniae, \& quod vero eft frimillimum, alias Lüropac. partes inultas incolit.

\section{$V$ cspertilio Solen.}

๑. X. Vefpertilio ferrun equinum. Sclireber. 1. c. pag. Tab.LXXII. Chanve-four ris fer-à-cheval. Buffon. Tom. VIll. p. 70. Tab. XVII \& XX. In mappa Zoologica Vefperiilio 16. Membrana quaedam labrum fuperius ambiens, foleamque equi ferream referens, huic $V_{\text {espertilioni no- }}$ men dedit. Daubenitonias eorum duos, majorem fcilicet, minoremque, quos varietates effe putat, commemoravit Tam Gallin $(g)$, quam Gormania (b) eos nutrit. Vespertilio auritus.

6. XI. Vefpertilio nafo oreque fimplici, auriculis duplicatis capite majoribus. Linnaeus 1. c. Num. 5 . Oreillar. Buffon Tom. VIII. p. 74. Tab. XVII. fig. I.

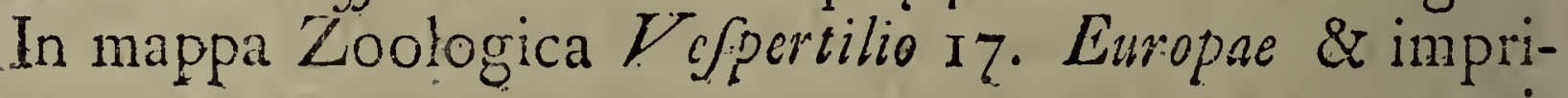

mis

(c) Pontoppid. Norweg. T. II. (f) Pallas lieifun T. I. p. q28. (g) Buffon 1. c. (h) Schrebers Saeugt riere. 


\section{G E O G R A P H I C A E. 453}

mis Succiae (i), Gcrmaniae (k), Angliae (l) Galhuleque $(m)$ eft indigena.

\section{Vefpertilio Strotinus. .}

6. XII. Sérotine. Buffon Tom. VIII. Tab. XVIII. Daubenton Mém. del'Académie des Sciences de Paris 1759. In mappa Zoologica Vespertilio 18. Quantum adhuc conftat, in Gallia (n), in Ufonfi provincia, quae Aface $R$ ufficae pars eft $(0)$, \& quod vero admodum eft fimile, in aliis etiam regionibus vivit.

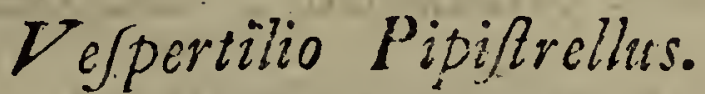

Q. XIII. Pipillrelle. Buffon Tom. VIII. p. 75. Tab. XIX. Mémuires de l'Académie 1. c. In Tabula Zoologi. ca Vefpertilio rg. Non in media tantum Europa Galliam $(p)$ Germaniamque $(q)$, fed in ejus etiam finibus Novogrodiam $(r) ; \&$ fortaffis finitimas Afae regiones tenet

\section{Vespertitio Barbaftellis.}

6. XIV. Barbafielle. Buffon Tom.VIII. p. 76. Tab. XIX. fig. r. Mémoires de l'Académie dies Scienc. l. c. In mappa Zoologica Vespertilio 20. In Gallia ipfum Daubentanius detectum primus protulit.

\section{B. Vefpertiliones Amcricae.}

§. XV. Enarratis hactenus antiqui orbis $\nu_{\text {cfper }}$ tilionibus Americanos nunc etiam, qui nobis innotuerunt, inveftigemus. Horum alii funt ficut in vetere

(i) Faun. Suec. (k) Schreber l. c. p. 165. (l) Pennnnt. l. c. p. 372. (m) Buffon 1. c. (n) Buffon l. c. (o) pallas R ilf T. II. p. 62 .
(p) Buffon l. c. (q) Schreber. 1. c. (r) Pallas Reif. T. l. p. 41 \& $56 \%$ Lil 13. 


\section{SPECIMEN ZOOLOGIAE}

orbe, caudati, alii contra fine cauda. In Tabula quidem Zoologica hunc ordinem fervavi; ut ecaudes primo loco pofiti fuis numeris progrediantur, quos deinceps caudati pari modo fequuntur. Sed quo. niam patriae ipforum hoc in capite quam maxime ratio habenda eft; alia hic via incedere fubdivifionemque in $V$ ifpertiliones tam veteris quam novi orbis caudatos \& ecaudes omittere, quin \& a praeftantifîimi Scbreberi methodo, qua beftiolae hae ex primorum dentium habitu ac difpofitione ordinantur, difcedere placuit.

\section{$V$ espertilio spectrum.}

0. XVI. Vepperilio ecaudatus, nafo infundibuliformi lanceolato. Linnasi Syft. Ed. XIl. Num. 2. Albdira-guact. Pifo de Indine utriusque reb. natural. p. 290. Canis volans maxima aurita foem. ex Nova Hifpania. Seba thefaur. T. I. pag. 92. Tab. LVIII. fig. x. Vampire. Buffon Tom. X. P. 33. In Tabula Zoologica $V_{e *}$ $\int$ pertilio 2. Hic maximis novi orbis Vefpernilimnibus adnumerandus eft. Pifo enim ipfum, quem Andira-guacu nominat, corporis magnitudine columbas ni vincere, faltim aequiparare exhibet." Buffonius Vampiri nomen illi impofuit. Sed quum Pifo, eun homines dormientes exfucto fanguine interimere, quod aliis majoribus Maranbae regionem inhabitantibus $V$ efpertilionibus ufitatum effe adftruit, ne verbulo quidem meminerit; an $V$ ampiri nomen ipfi competat, merito dubitamus. Tabula noítra Zoologica in America meridionali $V$ ampiri nomen aliquoties habet, hoc ipfo tamen non Limnaci Vefpertilionem Vampirum (licet fieri poffe concedam, ut utrique unius ejusdemque fint ge- 


\section{G E O G R APH I C A E.}

neris) fed illum potius intellectum volumus, cujus Ulloa (s) \& Maryr ( $t$ ) mentionem faciunt, cujusque aliqualem minus tamen expletam defcriptionem habemus. Vespertilio hic Spcetrum appellatus novae Hispanine (u), Grimna, Brafiliae (v) \& forfan aliarum calidioris Anericae regionum habitator eft; forfan idem eft cum magno Vefpertilione, quem Ferminums etiam in Guiana (w) vidiffe teltatur.

\section{Vespertilio baftatus.}

๑. XVII. Pallas Spicileg. Fafcic. 3. p. 7. La Cbauve-fouris fer de lance. Buffon Tom. XIII. Tab. 23. Javelin Bat. Pennant. Synopr. p. 363. Americas quidem meridionalis, nefcimus tamen, cujus regionis incola fit. In Tabula Zoologica fub Num. 3. ipfum Guinnae adpofui, licet adhuc dubius fim, an huic, an $B r a / 2-$ line, aut cuicunque alii regioni adponi debeat?

\section{$V$ ejpertilio perspicillatus.}

ઈ. XVIII. $V_{e}$ pertilio ecaudatus, nafo foliato, plano acuminato. Linnaei Syft. Edit. XII. Num. 3. VcSpertilio Americanus vulgaris. Seba Thefaur. Tom. I. pag. 90. Tab. XV. fig. 2. Scbreberi animal. mammal. Tom. I. p. 46. Pallajius $(x)$ hunc \& praecedentem, quos Buffonius eosdem effe fatuerat, inter fe differre tuetur, cui ut tefti autotorn, qui utrorumque vifendorum crebriorem habuit occafionem, fidem habeamus oportet. Et hic in America meridionali habitat, \& in Ta.

(s) Alg. Reif. T. IX. p. 48.

(u) Pifo l. c. (y) Marcgrav. Hift, Brafil. p. 213 . (w) Hollande Equinux. p. 8. (x) Pallas. Spicileg. Fafcic. 3. 
$45^{6}$ SPECIMEN ZOOLOGIAE

Tabula Zoologica fub $V$ espertilionis quarti nomine indicatur.

\section{Vespertilio leporinus.}

0. XIX. Vefpertilio labio fuperiore bifido. Limnaei Syft. Edit. X. Num. 5. Noctilio Americanus. Noctizilo labio inferiore varicofo. Linnaei Syft. Ed. XII. p. 88. $V_{e-}$ pperitilio cato familis Americanus. Seba Thefaur. Tom. I. p. 89. Tab. LV. fig. I. In tabula Zoologica Ve/pertilio 7. Linnaeus in duodecima Syftematis fui editione hunc $V$ espertilionem fingulare quoddam genus conftituere idcirco autumat, quod glirium more duobus tantum dentibus primoribus armatus. fit. Qui vero vel ex Daubentonii vel e Scbreberi fcriptis librisque didicit, quam mirum in modum $V$ e/pertilionum dentes varient; is propter tantillam dentium differentiam haud facile eo perducetur, ut nova ftatim genera condat. P'eruviae (y) eft indigena; qui in Mosquiti littoribus $(z)$ decimum tertium quintumque inter latitudinis feptentrionalis gradus habitat.

\section{$V e$ pertilio Lepturus.}

๑. XX. Schreberi animal. mammal. T. I. p. 173 . Tab. 67. Hic folus in praeftantiffimo opere fuo hane beftiolam optime \& defcriptam \& depictam exhibet; quae duabus exiguis plicatilibus crumenis, quas utraque in ala, fi extenfa fuerit, prope cubitum oblique direetas deprehendes, a reliquis omnibus diftinguitur. Hinc Scbreberus ei nomen germanum (die Bututel-Fledermaus) Ve/pertilionis crumenis praciliti indidit. Co-

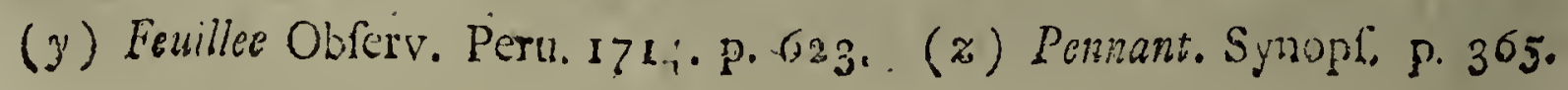


G E O G R A P H I C A E. 45y

Ioris eft fubfufci, \& Surinamam patriam habet, ubi in Tabula Zoologica fub Vespertilionis 23. appellatione reperitur.

\section{Vespertilio Soricinus.}

0. XXI. Pallas fpicileg. Fafcic. III. pag. 24. Tab. III. la Feuille Buffon. Tom. XUII. p. I27. Dattbenton Mém. de l'Acad. des Jc. 1759. In mappa Zoologica $V_{\epsilon}$ pertilio 6 . Palla/io auctore, qui magna ipfum diligentia defrripfrt, fummaque cura depingendum curavit, in caraibicis infulis \& Surinama aetatem degit. Buffonii autem \& Daubentonii Vespertizio folium prope Senegae ripas patriam habet; utrum ambae ejusdem gesneris fint beftiae, adhuc parum conftat.

\section{Vespertilio Canaden/so.}

(I XXII. Nea-jork-Bat. Pennant. Synopf. p. 36\% Tab. XXXI. fig. 2. Quum Pennantus animalculum hoc, cujus \& figuram dedit \& defcriptionem, novi Eboraci in Americae feptentrionalis regione vivere dixerit: fub $V$ espertilionis duodecini appellatione ip fum in Tabula Zoologica eodem pofui,

\section{Vespertilio Molosus.}

.5. XXIII. Pallas. Ficileg. Fafc. III. p. S. Mulot volant. Daubenton. Mém. de l'Acad. des Focences 1759. Buffono Tom. X. Tab. XIX. fig. I. \& 2. Utrasque, quas $V$ espertilionis hujus imagines Buffonius dedit, quarum altera majoris paulo ftaturae obfcuriorisque coloris eft, unius ejusdemque generis effe Daubentonius exiftimat. Uterque Americam inhabitat, fed quo loco, quibus terris, nos hucusque fugit. In notarum indice, quem $\mathrm{M} \mathrm{mm}$ 


\section{$45^{8}$ SPECIMEN ZOOLOGIAE}

Tabula Zoologica cxhibet, eum Vefpertilionis oct ava: nomine infignivi. Lit fic abfoluta funt $V e$ efpertilionutis. genera, quae nunc cognita habemus. E. quibus omnibus, quorum funma unum \& viginti efficit, $V_{e} /$ pertilicnem Vampyrun Linnaeus, quem primo loco pofuimus, folum latiffime (quod jam fupra dictum eft) per: orbem diffufum videmus; ad quem. $V$ espertilio murinus. hac in re quam prosime accedit. Sed idcirco fieri poffe non inficior, ut partim multa aliahorun animalium genera fuperfint, quorum cognitionem adhuc nullam. habemus, partim ut multa, quae nobis nota funt, genera late admodum per vaftos illarum regionum tractus. diffipentur, quas nemini hucusque peregrinantium perveftigare licuit.:

\section{S E C T I O V.I.}

\section{Ordo Secundus. Limnnei.}

Q. I. Bruta dentibus primoribus utringue mullis. Gènus XV. Elepbas. De hoc vid. Cap. II..

6. II. Genus.XVI. Tricbocbuss. fpecies I. Rosmamus. De hoc vid. Cap. II. fpecies 2. Dugono. Buffono. Tom. XIII. pag. 205. Tab. LVI.

Primus, qui beftiam hanc rite defcriptam nobis exhibuit, Buffoninus eft, qui dicta in tabula duo ejuscapita corio carnibusque denudata depingi curavit, quae ad Rosmari firmilitudinem accedunt; cuique foli dentes canini Dugonis dentibus multo funt longiores. Accedit, quod. hujus etiam patria a Rosmari domicilio admodum diftet; guippe qui Indici in maris infullis, Moluccis, Sundaicis 


\section{G E O G R A P H I C A E.}

Pbilippinisque fedem fibi fixiffe dicitur (a). Barcbewitzius ipfum prope Leytam, quae Bandae infularum una eft, Dugungum appellari teftatur (b). Animal hoc ad boncle fpei promontorium usque progredi, Buffosius e Biervillafii (c) loco quodam conjectari poffe, autumat. In tabula Zoologica illud in mari indico fub Dugonis nomine pofitum invenies.

5. III. Species 3. (d). Manatus. Vid. Cap. I.

j. IV. Ne quid praetermifife videar, duo animalia, quae forfan huc referri poffunt, breviter tantummodo attingam. Perpauca enim funt, quae de illis novimus. Alterum famia eft marina, cujus in Kamtfobatkae hiftoria mentio fit $(e)$, cuique Stellerus id nominis idcirco impofuit, quod variis gefticulationibus Simias imitetur. Idem auctor beftiam hanc prolixius quidem, fed quoniam extra maris fuetus, quibus immerfa cinetaque fuit, paululum modo eminuit, non totam defcripfit. Maris, quod Afam ab America dividit, incola eft.

(a) Allg. Reif. 'T. Xl. p. 429. (b) Barchewitzens Reifen pag. 180. (c) Voyages d'Innigo Biervillas Part. I. p. 37 \& $38 . \quad$ (d) Quae in Linnaeo fpecies eft fecunda.

(c) Hujus quidem regionis Stelleri hiftoriae, editio Germanica nuper admodum in lucem emiffa, dictae animantis mentionem facit nullam. Itaque in translatione anglica ea, quae attuli, quaerenda effe, fufpicor. In prino guidem Germanicae editionis capite Simia marina nominatur; beftiae autem definitio praetermiffa eft. E Pennanti Synopfi haufta funt, quae heic loci adducta legis. Bielugan Stellerus pag. Io6. Editionis Germanicae animantems effe dicit, quae bovis magnitudinem caputque bovino fimile habeat, cujusque corium pilis albis fplendentibus, tectum fit. De pedibus autem binisque foraminibus, quibus aquam ejiciat, altum eft filentium. Mancam igitur mutilamque hane editionem effe credo, quae tamen beftiae thujus domicilium ad Uti \& Ochotae fluminum ripas effe addidit. 


\section{SPECIMEN ZOOLOGIAE}

Altera, quam idem Stellorus Bielugam feu Beluram appellat, phocarum pedibus qui priori deeffe vifi funt; \& vaccae dentibris praedita balaenarum ritu aquam e duobus. cervicis foraminibus ejaculatur, finum Ocbotz: cerifem, mare Kurilen/e \& generatim magnorum in mare glaciale effluentium fluviorum, verbi caufa, Jeni/ei oftia frequentat $(f)$. Utrasque beftias in tabula Zoologica nominatis jum in locis reperies. . P'ennmum ducem fecutus, hunc utrisque locum attribui.

6. V. Bradypus. Limnai Sylt. Ed. XII. gen. 7: p: 50 : Slotb. Pennment. Synopf. p. 319: Nifi Ceilonentis bratypusab Cnavo diverfus fuerit, hujus generis duas tantum fpecies cognitas habemus; quarum artera Bradypus tri: dnctylis eft, qui a Linnneo Num. I: Bradypus pedibus tridactylis, conda brevi, a Buffonio Tom. XIII: p: I g: Táb. V \& VI. $A i$, \& a Pennanto 1. c. Tab. XXIX:. Tbrceioed Slotb nuncupatur. Quadrupes hic- Mexici: (y), Guinune (b), Peruziz (i), Bralliae (k), \& nerbo, regionum calidiffmae novi orbis Zonae omniun. Habitator eft.

2.:) Altera fpecies eft Bradypus dianctylus. Rradypus manibus didaclylis cauda nuila: Limaezis 1. c. Num. 2. Tnau. Buffon l. c. Tab. I. Tuo toed Slotb. Pennant. p. 321. Hoc idem illud animal eft, de quo jam fup: in capite fecundo latius exponendi facultas mihi dabatur.; quum de quibusdam. quadrupedibus fermo effet, quos Anerica meridionalis cum Afia communes habeat. Hoc:

(fi) Stellers Befchrëibung von Kamtfchatka. l. c. $(g)$ Edward. Glean. 2. p: 3 10. (h) Bankroft Guiana . . 88. (i) Allg, Reifo. T. IX, (k) Marco. gray. Hint. Btafilo. P: 221.. 


\section{G E O GR A P H I C A E. $46 \mathrm{r}$}

Hoc illud eft, quod Euffonius, qui Rradypodes onncs ex antiquo orbe relegare fuitinet, folius Amoricae fesforem fecit; ideoque lectorem eo remittimus. Tan Ai, quam Unauum in Tabula Zoologica Linnati nominibus defignatos reperies.

\section{Myrmecoptiang.}

0. VI. Myrmecophaga, Limnaeus 1. c. gen. 8 : Briffon regn. anim. p. 24. Edit. Parif. Et hoc animanrium genus aeque ac proxime antecedens Buffonius foli Americae inclufum voluit. Secundo itaque jam capite', quicquid hic viri praeftantiffimi opinioni opponi queat, fufius adductum habes. Interim hiujus generis fpecies, quantum hucusque conftat, \& plures: \& copiofiores Americam prac antiquo orbe inhabitare, ex eo etiani difcimus, quod Kobbilus unius tantum in bonae Jpei pro: montorio habitantis meminit (l); quum e contrario: America tres ipfarum numeret, nimirum:

\section{r.) Myrmecophas am didactylam,}

quarn Myrmecopliagan palmis dictaclylis, plantis tetradactylis, cauda villofa, Limnaeus l. c. fipec. I. appellat. Buffon Tom. X. Tab. XXX. P. 84: feq. le Four miller. Pennantus 1: c. Tab. XXX. P. 333. Left Ant eater, Eidwardus Tab. CCXX. Little Ant-eater. In: Tabula Zoologica eft Myrmecophaga 2. Minima haec: Myrmecophaga Gutianae $(m)$ \& fortaflis aliarum etiant Americae calidioris partium feffor eft. Quam enim: Eid:-

(i) Kolbe Befchreib. d. Vorgeb. p. 165. (n) Barrere Trance Eqgijonox: p. 163 . Fermin p. 23 . 


\subsection{SPECIMEN ZOOLOGIAE}

Edwordus depictan dedit, ex America Hifpanica accepit. Ipfam interim cauda fubprehenfili inftructan esfe, e Pennanto Edwardoque colligimus.

\section{2.) Myrmecophaga jubata.}

Myrmecopbaga palmis tetradactylis, plantis pentadactylis, caudata jubata. Limnaeus.1.c. Num. 3. p. $5^{2}$. Tamandua-guacu. Marcgrav. Brafil. p. 225. Tamanoir. Buffon Tom. X. Tab. XXIX. p. 85. Kleinii Quadrup. difpofit. 1.p. 45. Tab. V. In Tabula Zoologica Myrmicopbaga. Hanc eandem cum illa animantem effe, quam Linnaeus Myrmecophagam tridaclylam appellavit, ex eo furpicor, quod naturae feetator adhuc nullus praeter Seban Myrmecophagae tridactylae meminit, qui tamen, quod Buffonius haud immerito ftatuit, hac in re erraffe videtur. Accedit, quod Limnaeus Lonizii teftimonio, quod pag. 320. invenerat, nititur; hoc ipfum non Bontii, fed Pifonis teftimonium effe, ex eo conftat; quod Bontii Indiae Orientalis defcriptio ad paginam 320, non extendatur; Pifonis potius liber, qui Bontii relationibus adnexus legitur, eo usque \& ultesius procurrat. Deinde Bontius de Myrmecophagis nihil plane foriplit; ipfa potius effigies a Linnaeo adducta. e Pifone defunta eft, cujus finittro in pede quatuor digiti aperte fatis numerantur; \& Limnaeus ipfe Mymmecophagam jubatan décripturus ad eandem figuram provocat, quae optime etiam cum defcriptione data congruit. Tridaciyla igitur effe nequit. Secundam ergo tertiamque, quas Limnazus diffinxit, fpecies unam eandemque animantem, \& quidem Tamanduan - guacu es$\mathrm{fe}_{2}$, mihi perfuadeo. Haec maxima Myrmecophag arun 


\section{G E O G R A P H I C A E. 463}

fpecies cum priori eandem in Guiana $(n)$, Brafilia $(0)$ \& Permuia ( $p$ ) patriam habet.

3.) Myrmecophaga tetradaclyla.

Mymecophaga palmis tetradaetylis, plantis pentadaetylis, cauda calva. Linnaeys l. c. Num. 4. Tamandita Buffon Tom. X. p. 48. feq. Seba Thefaur. Vol. II. p. 48. Tab. XLVII. fig, 2. \& Vol. I. Tab. XL. In Tabula Zoologica Myrmecopbaga 3. Haec beftia. quam maxime cauda calva \& magnitudine a praecedente diftat; iisdem vero in locis, Gliana nimirum $(q)$, Brafilia ( ) Perusinque habitat. Ex quo elucet, hujusgeneris animalia, quae fatis comperta nobis cognitaque funt, meridionalibus praecipue, feu, quod idem eft, calidioribus novi orbis partibus ali. In Tabula autem Zoologica myrmecophagae nomen etian bonce' Jpei promonturio appofitum videbis; quo genus quoddam defignatum nolui, cujus cognitionem fatis exactam. nondum habemus.

\section{Manis.}

6. VII. Linnaei Syft: Ed. XII. genus 9. Genus Pholidoli. Brijfonii regn. anim. p. 29. His beftiis quibus pari cum antecedentibus ratione dentes defunt, Linnaeus in naturae Sy/temate convenientifimum locum tribuit:. Integrum genus duas tantum fpecies continet, quae utraeque antiqui orbis funt indigenae. Prior: illarum eft:

I..)

(n) Fermin 1, c. p. 22. Barrere 1. c. p. 162. (0) Marcgray. 1. c. 1.. 225. (p) Ailg. Keif. T. XVI. p. I35. (q) Barrere 1. c. (v) Marcger. 


\subsection{SPECIMEN ZOOLOGIAE \\ I.) Mrams pentadactyla.}

Manis pedibus pentadactylis Linnaei Syft. Num. r.Pangolin Buffon T. X. p. 104. Tab. XXXIV. Armodillus Squamatus major Ceilonicus. Seba Thefaur. Vol. I. p. 88. Tab. LIV. fig. I. Pangolmus hic infulam Taioanem, quam \& Formojam nominant, incolit, ubi; Bontio auctore (s), filvas frequentat. Seba tefte $(t)$, in Ceilone \& Malabaria (u) vivit. Praeterea \& Guineae, Africae regionis, feffor eft, cujus cives ipfum Quoggelo nuncupant $(v)$. Alia ejus domicilia adhuc nulla cognita habemus

Pofterior eft

\section{2.) Manis ietradaclyla.}

Manis pedibus tetradactylis : Linnaeus 1. c. Num. 2. Plotagin Buffon T.X. p. IO5. Tab. XXXV. Phatagini nomen ab Indis Oricntalibus datum effe dicitur ( $w)$; quo autem Indiae in regionibus loco fedem patrian habeat, fcimus cum ignariffimis. Butfonius hunc quadrupedem fub Quoggelonis appellatione comprehendi autumare videtur. Quod Limneus ipfr impofuit nomen cum interrogationis figno Guinene terris adfcripfi, conec certi quod de patria fua adferri queat.

6. VIII. Dafypus. Limnaeus l. c. Num. 10. Genus cataphraeti. Briffonii regn. anim. p. 37. Armodillo. Pennant. Synopfis p. 323. Sicuti genus praccedens antiqui, ita hoc novi orbis eft incola. Seba quidem nonnullas

(s) Bontius Hift. Nat. Ind. Orient. p. Co. (t) Scba l.c. (u) Tranquebarfche Miffions Nachrichten. (y) Allg. Reifen 'I. IV. p. $2 \sigma_{3}$. \& T. III. p. 6I3. (\%) Hift. de l'Acad. des Scien. de Paris i 793 . 


\section{G E O G R A P H I C A E}

nullas hujus fpecies ex Oriente originem trahere exiftimat; vir autem caeteroqui diligentiffmus, ut aliis non paucis in locis, fic heic etiam \& quidem uti fufpicor, a $P$ Pfone in errorem abreptus eft, qui armodillos in orientali India reperiri feripfit $(x)$, \& nihilo fecius illos tantummodo enumerat, qui Americam inhabitant. Quum vero peregrinantium, quibus fides haberi debet, quantum milhi quidem conftat, nulli, animantes has in Orientali India vivere, omnes potius uno quafi ore, eas Americae indigenas effe, fateantur: exinde certo colligimus, tam Pifonem, quam qui hunc fecutus êft, Scbam, hallucinatos effe. Forfitan factum eft, ut paulo ante commemoratae animantes hujus erroris anfam viro praeftanti dederint. Ipfun enim l'angolinum etian Armodilli nomine infigniviffe, in antecedentibus notatum eft.

In tabula Zoologica Armodillos numeris addita $D a-$ Jypodis vocula abbreviata ( $D$ a/yp.) defignavi ; numeri vero, qui nullo ordine progredientur, notan cingulorwint quantitatem indicant. Species; quas hujus generis novimus, fequèntes funt.

\section{r.) Dafypus Unicinclus.}

Dafypus tegmine tripartito, pedibus pentadactylis. Limnaeus I. c. Num. I. Cirquincon Buffon. T. X: p. I27. Tatu. Scba Tom. I. p. 47. Tab. XXX. Fig. 3. \& 4. In tabula Zoologica Da/ypus I. Patriam ad Amazonuni fluminis ripas habet $(y)$.

2.)

(x) Pifo pag. 100. 'Tacu S. Amodillo. Cum Oecidentalis non folum, fed \& Ornentalis lndiae partibus fit hoc inufitatae conformationis animal \&is: (y) Abbeville Mifion au Maranon p. 248. 


\section{SPECIMEN ZOOLOGIAE \\ 2.) Dafypus Tricinctus.}

Dafypus cingulis tribus, pedibus pentadadylis. Linnaeus 1. c. Num. 2. Apar. Buffon. Tom. X. p. I I9. Sebe Tom. I. p. 62. Tab. XXXVIII. Tatu-apara Marcgravii hift. nat. Bra/2l. p. 23.2. In tabula Zoologica DaJypus 3. In Antillis (z) \& Brafilia (a) habitare fertur. 3.) Dafypus Sexcinctus.

Dafypus cingulis fenis. Limnseus I. c. Num. 4. Eir coubert. Buffon. 1. c. p. 7. Tab. 42. In Tabula Zoolom gica Dafypus 6. Brojiliam (b), ubi a Lufitanis Encubertado appellatur, Guinnam que (c) inhabitat.

\section{4.) Dafypus Septemcinctus.}

Dafypus cingulis feptenis, palnis tetradaezylis. Linmaeus 1. c. Num. 5. Tatucte. Buffon. T. X. p. r22. Eightlonded Amodille. P'ennant. Synopr. p. 32. In Tabula Zoologica Dafypus 8. Oeto cingulis beftice hujus tegmen diftinctum efre, Biffonitus adituit, ideoque in Tabula Zoologica hunc fecutus a Linnaen disceffi. In Brafilia (d) \& forfan etiam in Mexico habitat, fi cum Hernandezii Ayotocbtlio idem eft animal, cujus effigies, quam fedentem depingi curavit $(\varepsilon)$, non: tam aperta \& evidens eft, ut, utrum octo an novem cingulos habeat, dignofci, \& an huic, an fequenti fpeciei adnumerari debeat, judicari poffit.

(z) Rochefort Hitt. des Antilles p. I23. (a) Marcgr. l. c. (b) Ibid. (c) Bancroft. (d) Marcgra\%. 1. c. (e) Lernandez Rer. Mexic. Hiirt. p. 314 . 


\section{GE O G R A P H I C A E.}

467

5.) Dafypus novem cingulis.

Dafypus cingulis novem, palmis tetradactylis, plantis pentadactylis. Limnaeus 1. c. Num. 6. p. 54. Cacbicame. Buffon. T.X. p. I24. In Tabula Zoologica DaJypus 9. In Mexici littore Mosquitenfi $(f)$ Guiancieque $(g)$ regione \& Brafalia (b) invenitur.

\section{6.) Dafypus duodecim cingulis.}

Catapbractus feutis duobus, cingulis duodecin. Brisfonii regn. anim. p. KabafJou Buffon. T. X. pag. 1250 Tab. XL. \& XLI.Twelve banded Armodille. Pennant. 1. c. p. In Tabula Zoologica Dafypus I 2. Sicco pede hanc Linnaeus beftiam ( $i$ ) praeteriit, quae tamen fui generis maxima \& fine cauda tres pedes longa eft. Bro filiam $(k)$ \& $G$ uianam incolit.

Et haec armodillorum, qui hucusque innotuerunt, rumma eft. Linnacus quidem quadricincti quoque cujusdam Dafypodis meminit, quem e Columna mutuatus eft; quem tamen, quoniam e confracta modo, qua veftitus fuit, tefta defcriptus eft, nec Buffonius, nec $P$ tnsantus admiferunt. Futura igitur demum aetas, an ir rerum natura fit, nec ne? docebit. Interim ex hactenus dictis totum hoc genus in calidiffmis tantum Amesicae partibus domicilia fua habere, cognofcimus.

SeCtTo

(f) Pennant Synopf. p. 325 (g) Bancroft l. c. (h) Marcgr. 1. c. p. 235 . (i) Forte Linnaei unicinet!ns. (k) Marcgr. l. c.

Nn $n z$ 


\section{SPECIMEN ZOOLOGIAE $S$ E C C $\quad$ T I}

Ferac. Linnaci Syft. Nat. Ed. XII. p. 55 .

5. I. Pboca. Linn. Genus II. Genus phocae. Brisnopis p. 339 .

Sonii regn. anim. p. 229. Seal. Pennant. SY-

I.) Phoca un fnna. Limnaens l. c. Vid. caput I.

2) Pboca leonina. Linnacus ibid.

3.) Pboca vitulina. Limnaeus ibid.

Secundo jam capite aliquot phocarum genera, quantum fieri potuit, commemorata funt. In mappa Zoologica tres earum fpecies adductas videbis.

x.) Phocam minorem, 2.) majorem, \& 3.) criftatam;

fed aliquibus in Tabulae Zoologicae locis, neceffrtate jubente, phocae folum nomen apponere mihi licuit, quia genus ipfum determinate fatis indicatum nullibi gentium reperire potui.

5. II. Cakis. Linnaci Syft. Ed. XII. genus I2. Genus caninum. Brifoniii regn. anim. p. 234.

r.) Canis familiaris. Linnaeus. Vid. Caput. I.

2.) Canis lupus. Linnaeus ibid.

Graviffmis argumentis lupum canini generis auetorem effe, comprobaviffe exiftimo. In capitis. primi collectione mihi occupato praeftantiffima $P$ ennanti Synopfis nondum in manus pervenerat; ex qua lupos. cum canibus coïre ftirpemque propagare alio nunc teftimonio probari poteft. Brookius enim quidam, qui animalibus vendendis vietum-tunc temporis in Anglia quaefivit, lupum canemque feminam (Cbien-loup) inter fe committens decem exinde catulos nactus eft, 


\section{G E O G R A P H I C A E.}

quorum quosdam ipfe Pennantus vivos confpexit, eosque patris quam maxime indolem retulife obfervavit: In primo jam capite, lupum per plerasque propemodum telluris partes diffipatum reperiri, multisque varietatibus foecundum \& uberem erre, commonftravi; cujus rei teftes omnes habeo, qui terras orasque feptentrionem fpectantes peragraverunt. Quia vero aliquam ibi varietatem a me praetermiflam effe, animadverto, locus, ubi inferatur, hic commodus erit. Ea ipfa Limnei fpecies fecunda eft, quam canem mexi. camum nominat. Lupus eft ab Hernandezio defcriptus (a) \& a BrifJonio canis cinereus, maculis fulvis variegatus, appellatus. Etfi Linnaeus, qui diverfae \& fingularis lupum hunc fpeciei efle contendit, excufandus videtur, Buffonium tamen, qui ipfum lupi noftri varietatibus adnumerat, ducem potius fequor. Qui autem fieri poflit, ut Limnaus eundem felem efle montanam autumet, \& ad Sebam, qui felishujus imaginem dedit, provocet, animo comprehendere nequeo. Si effigiem lupi ab Hernandezio datam noftrate cum lupo comparaveris; utrosque hac fola in parte inter fe diftare invenies, quod illius pellis ruriori pilo fit obfita. Quae autem felis montanae effigies in Sebae Thefauro confpicitur (b), ne minimam quidem canis fimilitudinem, fed felis potius pedes, rotundum caput, brevioresque aures refert; ideoque non polfum, quin eandem felis ferae junioris imaginem habeam, quae, quum itriata fit, folo colore a reliquis felibus differt. Ee

hae

(a) Hernander 1. c. p. 472. c. fig. (b) Seba Ther. Vol. I. F.XLIL $\mathrm{Nn} \cap 3$ 


\section{$47^{\circ}$ SPECIMEN ZOOLOGIAE}

hae ipfae ftriae in culpa fuiffe videntur, cur Linnuens eam cum lupo mexicano commutaverit. Has enim folas utraeque beftiae communes habent. Hunc autem ab Hernandezio depictum lupum mexicanum caeteris, quos per orbem difperfos cernimus, lupis, a quibus folo colore difcedit, adnumerare non cubito, praecipue quum hujus animantium generis colores fingulis fere in regionibus mirum in modum variare foleant.

3.) Hiyena. Vid. Caput. II.

4.) Hiycna maculata.

Spotted Hyena. Pemnant. Synopr. p. i62. Tab.XVII. Hujus beftiae Kolbius in bonae fpei capitis Hiftoria fub tigrini hupi nomine meminit $(c)$. Bosmaimus Jakbalem, quem defcripfit, itidem tigridum more maculatum effe tradit. $(d)$. P connantus primus eft, qui animal hoc ab Hyena feparat. Guineam, bonae fpei promontoviumb \& forfan alias plures Africac regiones inhabitat.

5.) Vulpes. Canis cauda reeta, apice albo. Linnacus. Alopex. Canis cauda recta apice nigro. Lagro. pus. Canis cauda. Vuipes alba. lfatis. Vulpes coerulefcens. Limmaens. His accenfeas I.) vastpcm argentean, feu canem e cinerco argentcum, Milfirippi ripas (e) \& Lappian incolentes; 2.) vulpem nigram Bereforii, Mangafeae \& Jakuzkit oras habitantem $(f)$, \& 3.) vulpem totam albam auribus pedibusque nigris ornatam, quae in Lappiac $(g)$ quidem finibus, perraro

(c) Kolbe 1. c. p. 17r. (d) Allgem. Reif. T. 1V. p. 257. (e) Catesby Carolina I. II. p. 8. (f) Mullers Sammlung Rufitcher Gefch. T. 1II. p. $53 \mathrm{I}$. (s) Leems Nachrichecn von den Lapper 177 I. Cap. XII. p. 102. 


\section{G E O G R A P H I C A E.}

raro tamen cbvia eft. Hae pleraeque vulpis varietares, quod admodum probabile eft, unius ejusdemque funt generis. Caeterum conferas caput primum.

Heic loci errorem quendam revocandum corrigendumque fas duco, quen primo in capite imprudens admifi; vulpem nimirum canemque diverfi generis animalia effe, demonftraturus juxta cum alis has attuli rationes, quia inter fe progenerandorum catulorum gratia non coëant, nec vulpes eum in modum, quo canes, manfuefieri queant. Quorum utrumque quum teltimoniis auctoritate certifima comprobatis refelli \& commonftrari polfit, canem feminam in ducatu megalopolitano cum vulpe vinculis inclufa congreflam catulos tres enixam, quorum unus, quem educaverunt, patris quam maxime naturam retulerit $(b)$, aliamque vulpem ab infita feritate ita mitigatam efre, ut venaticis cum canibus feras venando agitaverit. Utraque quidem nunc argumenta ilta rejicio, rem tamen, quam confirmaturus eram, generatim adhuc in tuto efre, perfuafum habeo. Linuseus in plantarum mantifla CorJacein etiam, qui in Sibiriae campis frequentifime occurrit $(i)$, quemque canem Corfacen, canem cauda fulva, bas apicegue nigro. appellat, huic vulpium generi fubjecit ; qui quidem' reliquis minor, morum tameni formaeque ratione tam fimilis eft, ut eum ab illis fegregare non audeam. In Tabula Zoologica vulpem una:

qui-r

(b) Canicula paftoritia ejus ftirpis erat, quam Germani propter: roftrum peracute finiens Spitz vocant. Haec parvula cum vulpe itidem parvula. educata primo partu tres tantum catulos edidic. Utrumque exemplum a teftibus oculatis confirmatur. (i) Mullers Simml T. III. \& Gmelin (fen. J) paffim. 


\section{SPECIMEN ZOOLOGIAE}

quidem tov $\mathrm{V}$. littera indicavi; varietates tamen appofitis voculis: nigr. argent. corfac. defignavi. Quousque beftia haec dilatata reperiatur, capite jam primo docuii

6.) Lupum aureum, Jakbalem in capite fecundo quaeras.

Exactiorem tamen beftiae hujus \& defcriptionem \& $t$ figuram Gmelino juniori $(k)$ acceptam referimus, qui in tertio itinerum fuorum Tomo, Tabula tertia pag. 80 . cam coloribus inductam exhibuit. Scbakal inquit, tres circiter dimidiumque pedem longus, ratione exteriòris formae proxime quidem ad Lupum accedit, vulpis vero $\&$ mores \& aftutiam habet. Superiores pilorum extrenitates fubluteolae at radices fubalbidae funt. Color vulpinus per totius corporis figuram dominatur, dorfum autem fufcum eft, cauda teres, recta, denfiffimisque pilis luporum ritu tegitur. Inferior colli pars duplici fafcia ornatur, quarum quaevis dimidium pollicem lata, femi circulum efficit. Caput feptem fere digitos longum in acutum roftrum excurrit, \& fingularem aftutiam prodere videtur. 'Oculi magni prominent, quorum iris ex fufco canet, membrana nictitans craffior grifei coloris eft. Aures oblongae, cordisque formam habentes arrectae ftant, obtufe exeunt, \& in bafi finduntur. Labia nigra funt, dentiumque refpectu quadrupes hic a reliquorum canum fpeciebus haud differt. Collum craffum \& cylindriacum in quinque digitos porrigitur. Luporum more animalia haec inter fe conjunguntur \& in coïtu cohaerent. Nec ratione interiorum cor-

(k) Gmelins (jun.) T. II. Tab. XIH. 


\section{GEOGRAPHICA E.}

corporis partium a lupis differunt. Foeminae femel per annum mares admittentes per quatuor tantum hebdomadas utruin gerunt, qua in re admodum a lupis difcedunt. Sex \& ad lummum octo catulos uno partu enituntur, totidemque rumina habent. Schakal carne pomisque vefcitur, cum lupis coïre dicitur, quod tamen conflimatione adhuc indiget.

7. Canis Thouf. Canis cauda deflexa laevi, corpore fubgrifeo, fubtus albo. Limnaeus. Num. 9. p. 60. De ifto animante hoc unum, quod fio, dicere poffum, cum Surinama incolam haberi. Forfan idem eft, quem Seba canem fylveftrem Americanum appellat; quemque a Tiburonis promontorio contra infulam Martinicam pofito acceperat. Ferminizus $(t)$ hanc quam Seba beftiam depingendam curavit, Kuparam (Krabbenbund) feu canem ferum majorem effe exiftimat, cujus Barrerius ( $u$ ) mentionem facit ; cujusque itidem Guiana patria eft. $B$ uffonium Sebae hanc effigiem omifife miror. In Tabula Zoologica Guinnae lupum hunc appofui, Kuparacque nomen addidi.

0. III. Felis. Limnaeus. p. 60.

I.) Lco. Vid. cap. 2.

2.) Tigris. Buffon. T.IX. p. 69. Tab. IX. Infertisfimus hic omnium animantium hoftis, qui, quibuscunque potiri poteft, jugulat, quantum mihi quidem conftat, Afiac folius eft indigena. Quum Buffonius eum mediam quoque Africam incolere contendat; omnia quidem, quae potui, peregrinantium diaria confului, nec

(l) Fermin 1. c. Seba Thef. Vol. I. (m) Barrere l. c. p. I49•. 


\section{SPECIMEN ZOOLOGIAE}

nec volam tamen. nec vefigium tigridis frintae, Africnm incolentis deprehendere potui $(n)$. In Alia vèro non Malabariam (o) modo, Bengalam (p), favam (q). \& Siamenfe $(x)$ regnum habitat, fed per Chinom alte fatis feptentrionem verfus adfcendit. In Mongolia enim fub quadragefimo fexto, quin feptimo latitudinis gradu reperiri dicitur $(s)$. Ipfam itaque, quod antiqui teftantur, in Hyrcanin etiam ad Ararotis montem commorari, non improbabile videtur. Cbinne provincias Jumnan \&: Quang- $/$ frequentare, fama eft - ( $)$. Sunt, qui belluae hujus pelles aliquas fubluteas nigris, aliquas albis cinereisque ftricturis ornatas perhibent $(u)$. Quam Neubofus (v) illius effigiem perbene depictam exhibuit, ftriis maculisque caret; ex quo multas ejus varietates dari, colligimus.

\section{3.) Pardus. Felis Pardus.}

Felis cauda elongata, corpore maculis fuperioribus orbiculatis, inferioribus virgatis. Limnaei Syft. Ed. XIl. Num. 3. Panthere. Buffon. Tom. IX. p. 8r. Tab. XI. \& XII. Beftia haec, quod Pinnantus \& reete quidem confrmat, pari ratione in Africa, qua tigris, in $A / r a$, quicquid obvium habet, occidit. Eam tigridis quoque propemodum magnitudinem habere, ex co difcimus, quod Bubalum aequiparare dicitur. Ipram plerasque Afri-

(n) Quod Ponnantus itidem confirmat. Synopf. p. 107.' ( $(\theta)$ Voyages de Dellon p. 104. (p) Pennant. 1. c. (q) Bontitus l. c. p. 53 . (x) Turpin Hift. de Siam T. I. p. 296. Allg. Reif. T. X. Tachart. (s) Allg. Reif. T. VII. p. 76: (t) Neuthofs Gefandfehaft p. 372. (2i) Quos inter dus Haldius eft. (y). Noulafs Gefandlchaft p. 372 


\section{G E O G R A P H I C A E. 475}

Africae regiones, quas cognitas habemus, incolere, exinde conjicio, quod generatim Africae feffor \&fie perhibetur. Scbawwius eam in Rarbarin (w), Bosmanmus $(x)$ furb tigridis nuncupatione in Gutinea oraque alk $r a(y)$ vivere contendit. l'igafetta $(z)$ hanc tigridem in Congi regno, cujus incolae ipfan Engoi nominent, ejusdem cum leone roboris folisque maculis ab illo diftinctam effe tradit; ideoque Engoi. hunc minime leopardis minoribus fed pantberis adnumerandum effe cenfeo. A Folbio, qui idem tigridis nomen ipfi dedit, bonae ppei promontorii (a) colonis, a Ludolfo autem Abyfininice animantibus accenfetur $(b)$; ex quo ommes notas nobis Africae partes pantheras alere patet. Limnacus, parstherae mentionem faciens, Hermanderium quoque laudat, \& effigiem, ab illo datam, pantborac tigridis mexicanae perfimilem effe, fateor. Daubentonius (c) autem 'faguarem, quem defcripfit, exterioris formae ratione itidem parum a panthera differre adftruit. Fabri etian feu potius Gregarii de Bolivar defcriptio (d) cum panthera quoque noftra congruere videtur. Sed quum vir hic animal iftud non in America, ubi confpicitur, fed poftea memoriter defcripferit, quod ex alio quodam libri fui loco, qui de feli Zibetico agit, facillime perficimus, quumque Gregorii aetate animalibus e felium genere omnibus, five maculis five ftriis variegata effent, modo feles magnitudine fupera-

(y) Shaw Reif. p. r5: ( $x$ ) Allg. Reif. T. IV. p. 254. (y) Ibid. T. III. p. 311 \& 312 . (z) Pigafetta Relaz. p. 29. (a) Kolbe l. c. p. I56. (b) Ludolf. Hitt. Aethiop. Lib. I. Cap. X. \$. 46. \& Conmentar. p. I5 r. (c) Buffon I. IX. p. I I I. (d) Hernandez.l. c. p. 498. 


\section{$47^{6}$ SPECIMEN ZOOLOGIAE}

rarent, tigridum appellatio adderetur: non improbabile mihi efl, ipfurn quicquid de pantberis \& tigridibus vel noverat, vel audiverat, mexicmme etiam tigridi adtribuille: Sic fabulam quoque, tigrides nigrorum magis, quan alborum hominum carnibus delectari, illosque prae his libentius aggredi ac devorare, paucis mutatis, de mexicana tigride narrat (e). Quin \& iple Pennntus pantherans non antigui folius, fed novi etiam orbis indigenam ftatuit $(f)$. Quod ut demonftret, partim ad fimilitudinem, quae inter imaginem ab Hernandezio allatam, interque veteris orbis pantheram offenditur, partim ad pelles quasdam, eandem cum pantherarum noftrarum pellibus facien formamque gerentes, provocat, quas in pellionum officinis viderit, qui illas ex Hifpanoruni America iftuc delatas effe, teftati fuerint. Praeterea Ulloam ( $g$ ), Cartbagenae tigrides jumentorum minorum magnitudinis elfe, fribentem allegat. Hac itaque corporum mole ac fpecie, hoc a equali vifarum ab ipfo pellium colore, hac datae ab Hornondezio figurae fim:litudine motus, Africae pantheras etiam in Kimerica reperiri, vir folertiffmus fibi perfuadet: fed fi, quae fentiam, libere proferre licet, ingenue fateor, me his Pennanit rationibus nondum eo perduci, ut ipfi afrentiam. De Hernandezio enim jam fupra mentem mean aperui; nec pellionis quidem teftimonium ita comparatum videtur, cui fides haberi poffit; \& quoties den:que factum eft, ut homines timidi animantes procul confpectas commemorando deinceps longe majores, quam

(e) Hernandez l. c. p. 507. (f) Synops. p. $17^{2}$. Allg. Reif. T IX. p. 45 .

(g) Cilloa in 


\section{GE O G R A P I C A E.}

quam revera erant, fecerint, quod emiffarios etiam facerdotes, naturalis plerumque fcientiae rudes, facpius feciffe, una patris E/lavanae $(b)$ narratio teftabitur, qui tigrides prope Boni aëris (Buenos Ayres) oppidun commorantes, ejus longitudinis effe, tradidit, ut pater Cattius a caudae initio feu corporis fine os beftiae extentis brachiis contingere nequiverit. Nemo itaque mihi vitio vertet, fi rem vel fietam penitus, vel faltem anctam nimis ecusque habeam, donec ulterior probatio accefferit. Et fac, fingularis amplitudinis beftias ibi maculatas ftriatasque dari: idcirco tamen nondum concludi poffe autumo, illas, pantherasque noftras eastem effe; quod faltim ex mutuo defectu reliquorum Zonae torridae animalium in novo antiquove orbe obviorum colligi deberet, qua de re capite quarto fulius agemus.

4.) Uncia. Vid. Caput Secundum.

5.) Leopordus.

Léopard. Buffon Tom. IX. p. 90. Tab. XIV. In iisdem cum Pantbera regionibus, Barbaria (i) nimirum, Guinea $(k)$, Aby/finia $(l)$, bonaeque Spei promontorio $(m)$ haec animans vivit. Pcmantus de minoris ftaturae leopardo $(n)$ loquitur cujus maculae, quibus fignatus eft, ab illo differunt, quem Buffonizus defcripfit. Beftiam quoque a Buffonio Guipardam ( 0 ) appellatam Penmantus huc referendam exiftimat, quam venato: rem (Hunting - Leopard) nominat, cujusque effigiem clegantiffmam dedit $(p)$, Indiae quoque Oricntalis in-

di-

(h) Lettres éutiantes l'om. XXX. Reif. T. III. p. 3I2. (l) Lidolf J. c. (m) Kolbe l. c. (n) Synopf. p. I73. (1) BuJon I.XII. p. 140. (p) L. c. p.17.t. Tab. XVIII. fig. Ra 


\section{$47^{8}$ SPECIMEN ZOOLOGIAE}

digenae. Haec enim ejus eft patria; pari ratione atque Uncis ad agitandas capiendasque antilopas utuntur. Tria haec animalia, quaee fortaffe ut varietates tantummodo inter fe difitant, Limnnaeus ficco pede praeteriit.

\section{6.) Felis Serval.}

Serval. Buffonizus Tom. XIII. p. ri 1 .. Tab. XXXXIV. Malabarian terrasque ad Gangis oflia ( $q$ ) pofitas hoc animal, quod indigenae Marapaté nuncupant, inlabitat $(r)$. Buffonius Servalem hunc felem tigridem $(s)$ cujus Kolbius meminerit, effe putat ; qui quam ex Kolbii defcriptione admodum illi fimilis fit, minus improbabile videtur. Nec hujus beftiae Limacus mentionem fecit.

7.) Caracal feu Syab-gush. Vid. Caput Secundum.

8.) Lyzix. Vid. Caput Secund.

9.) Felis catus. Vide Caput Primum.

Felis hic noftras eft, cui ultimum locun hac de caufa tribui, quod utrique fere terrarum orbi ipfun natura communem effe perfuadeor; nuinc faltem, quantum conftat, ubique gentium euin reperies $(t)$.

Percenfitis nunc hujus generis animalibus, antigumm orbem inhabitantibus, ad ea, qui novum incolunt, transgredior.

10.) Felis Onca. Felis cauda mediocri, corpore Aavefcente, ocellis nigris rotundato angulatis, medio flavis. Limnaeus 1. c. Num. 4. Jaguara Marcgravii

Hift.

(q) Voyages du Pere Vincent Maric apud Buffon. (r) Nouveau Voy. de Luillier Rotterdan I 726. p. po. ( $s$ ) Kolbe l. c. 'Tieger-wolf. (t) Hic etiam pertinent tria animalia Arabiac, fc. I.) Schenfar 2.) Ackfich \& 3.) Uabr, generis felini. Vid. Defcriptiones animalium quae obfervivit Forskael. Havniae 1775 . 
Hift. Brafil. p. 235. Faguar. Buffon Tom. IX. p. Ios. Tab. XVIII. Tigris Americana. Briffonii regn. anim. p. 270. Hanc beftiam, quae in America fui generis maxima eft, tigridem mexicanam, ab Hernandezio (u) defcriptam, effe puto, quam Linnaets veteris orbis - pantberam credidit. Omnes ea promemodum tam calidiflinas, quam temperatiores Americae partes inhabitat. In Mexici (v) enim regno, in Guiana (w), Peruvii $(x)$ Chilique regionibus invenitur, \& ad terram usque magellanicam $(y)$ adfcendit. Adulta ejus eft magnitudinis, ut panthera noftra vix minor fit.

I1.) Tigris fulva. Tigris ex flavo rufefcens, mento $\&$ infimo ventre albicantibus. Brifonii regn. anim. Couguar. Buffon Tom. IX: p. Tab. XIX. Qui faetum fit, ut Lunnaeus quadrupedem hunc omiferit, quem tamen BrifJonius \& multo ante Marcgravius (z) fub Cousacouramae appellatione defcripferat, haud intelligo; magisque comprehendi poffet, fi folus Buffonius, qui alia plura felium generis animalia primus in notitiam noftram pertulit, ejusdem meminiffet. Haec beftia in maximis fui generis in America locum occupat, altiusque praccedenti feptentrionem verfus habitat. A Canada enim, ubi inter Iroquoen/es (a) vivit, totam fere Americam, Mexici nimirum Guinneque (b) regiones, quin Amazonum fluvii ripas (c), Brafiliam Paragoiamque (d) pervagatur. 12.)

(u) Hernandez 1. c. (v) bid. P. 498. (w) Bancroft P. 82. (vi) Allg. Reif. T. XVl. p. I29. (y) Byron's Voy. round t. W. in Hawkeswortle Acc. T. I. p. 21 . (z) Marcgrav. Hift. Brafil. p. 245 . (a) Clarlevoix Hift. de la Nouv. France T. I. p. 27z. (b) Barrere Frane iquinox. p. I66. (c) Allg. Rif. T. XVI. p. I34. (d) Coreal Voy. T. III. p. 2400 


\section{SPECIMEN ZOOLOGIAE}

12.) Tigris Gaguarete. Pifo pag. Io3. Marcgravii - Hift. Brafil. p. 235. Black Tiger. Pennant. Synopl: p. 180 . Tab.XVIII. Optimam hujus animantis $\&$ defcriptionem \& imaginem $P$ emanto acceptam referimus. Rarioribus annumeratur beftiis, \& in Brafitia Guiannque (e) patriam fedem habet.

I3.) Felis Pardalis. Felis cauda elongata, corpore maculis fuperioribus virgatis, inferioribus orbiculatis. Linnaci Syft. Nat. Edit. XII. Num. 5. Tlalocclotl. Catus pardus mexicanus. Hernandezii thefaur. P. 5 I 2 . cum icone. Ocelot. Buffon. Tom. XIII. p. I 34. Tab. XXXV: \& XXXVI. Mexici $(f)$, Terrae frmae (g), Brafiliaeque (b) eft incola. Parum abeft, quin Lomfanae quadrupedem, qui a provinciae incolis P'ichou vocatur, Occlotum effe, crediderim, licet Buffonius fub Pichou nomine Margayam, qui mox fequitur, latere autumet. Du Pratzius (i) enim expreffis verbis rov Pibou ad tigridis americanae magnitudinem accedere adfirmat; quum tamen Margayzs longé minoris fit ftaturae.

I4.) Felis filveftris tigrina.

Telis ex grifeo flavefcens, maculis nigris variegata. Brifjonii regn. anim. p. 266 . Telis filveftris tigrinus ex Hifpaniola. Seba thefaur. Tab. XLVIII. fig. 2. Mnraguno. Marcgrav. 1. c. p. Margay. Buffon. Tom. XIII. p. I39. Tab. XXXVII. In Mexico $(k) ; \operatorname{Guiana}(l)$, ad Maranonem ( $m$ ), in Brafilia (n), \& verbo, per to-

tam

(e) Margr. \& Pifol.c. (f) Hernandez l. c. (g) Dampier Voy. T. UII. p. 306. (h) Penmant l. c. (i) Hif. de la Louifiane par du Pratz T. I1. p. 92. (k) Fernandez ap. Hornand. p. 9. hic nomen habet sou Tepernaxtiaton. (l) Barrere 1. c. p. I53. ( $m$ ) Miffion d'Ableville p. 250. (n) Margray. lo c. 


\section{GE O G R A P H I C A E. $48 \mathrm{r}$}

tam Americam meridionalem hoc animal reperiri dicitur. Abfolvimus nunc hujus generis quadrupedes, quos cognitos habemus, quorum aliquos Linnoeus omifit. Vero interea fimillimum eft, ipforum haud exiguan arthuc nunerum in calidiffinis antiqui novique orbis regionibus degere, quos tempus demum diesque manifeftabit.

đ. IV. Viverra. Limnaeus '1. c. genus XIV.

I.) Icbnethinon. Vid. Caput Secundum.

Si beftiae hujus dentes, quod Daubentonius confirmat, cum martis faginae dentibus conveniunt, non huic, fed muftelarum generi adnumeranda erit. Sed vera ut fatear, quafcunque Linnaeus cum viverris confociavit, haud procul a muftelis diftare, exiftimo. Nullius enim fere momenti ipfarum differentia effe videtur.

2.) Zibctba. Vid. Caput Secundum.

3.) Gcnetta. Viverra cauda annulata, corpore fulvo nigricante maculato. Limnaeus I. c. num. 6. Hi/paniac (o), Syriac ( $p$ ) Turciacque ( $q$ ) habitator eft.

4.) FofJana. Vid. Caput Secundum.

5.) P'utorius capen/is.

Stinkbink fem. Kolbias in bonae fpei promontorii defcriptione p. 167. Blercau puant. La Caille Goumnal d'un Voy. au Cap. p. I 82. Kolbius putorium hunc viverris noftratibus fimilem fecit. La Caille autem duabus ftriis albicantibus eum ornatum, auribus autem externis nullis praeditum effe adferit. Ex ejus defcriptione ipfuni quam proxime ad Buffonii Conepatlam accedere difcimus.

Nifi

(*) Buffen l. c. (p) Bellon Obferv. fol. p. z3. (q) Pennant. 1. c. p. 23 7. 


\section{SPECIMEN ZOOLOGIAE}

$\mathrm{Nifi}$ in orbe antiquo vireret, cum Mouffetorum genere ipfum copulavilfem. Quum Conepatlus auribus externis utatur, \& multis, putorius autem in utroque tantum corporis latere fingulis albis ftriis ornetur, ipfum fingulare quoddam genus conftituere exiftimo.

6.) Viverra tetradactyla.

Surikate. Buffon. Tom. XIII. pag. 40. Tab. VIII. Et hanc animantem Buffonii induftriae debemus; praeter quem nemo ejus icona dedit Quatuor digitis, quibus quilibet ejus pes inftructus eft, ab omnibus reliquis fui generis diftinguitur. Buffonizs novi orbis eam incolam effe idcirco ftatuit, quia, qui iftam ex Batavia ei transmifit, idem adfeveraverat. Pennantus $(r)$ autem Indiom orientalem iftius patriam effe, \& a facae indigenis Tispe appellari, e Rumpbio comprobavit. Palla/us beftiam in Africa \& in bonae quidem Spei promontorio vivere tefta. tur $(s)$. Kolbius arimantis cujusdam meminit, quam mu rem crepitantem (Rattel five Klappermaus) nominat $(t)$. Hanc furicatam effe, quae, Buffonio auctore, itidem fonum crepitaculi inftar edit, vero eft fimillimum. Hic enim ipfe fonus ratio denominationis Kolbis fuit. Ex quibus animal hoc antiquo etiam orbi proprium effe, magna cum probabilitate colligo. In Tabula Zoolologica illud in Fava \& bonas jpii promontorio notatum videbis. Heic autem ipfi inter antiqui orbis viverras ultimum idcirco locum tribui, quoniam, Buffonio tefte, cum Contis, quae nunc fequentur, admodum congruit. 7.) Viverra Najua. Viverra rufa cauda albo annulata.

(r) Synopf. p. 229. (t) Ralibe l.c. p. 158 .

(s) Pallas Mifcellan. Znolog. p. 59 \& 60 . 


\section{G E O G R A P H I C A E.}

lata. Linnaeus 1. c. Num. Urfus nafo producto \& mobili, cauda annulatim variegata. Briffonii regn. anim. Coati. Buffon. Tom. VIII. p. 204. Tab. XLVII \& XLVIII. Duplex videtur hujus ftirpis familia. Altera enim annulatam, altera vero unicolorem caudam habet. Utraque tamen ceterum fibi fimillima eft. Buffosius itaque aeque ac Pennantus, utrasque folas varietates effe, ftatuunt; etfi Linnaeus illas in duas fpecies diftinxerit, quarum alteram Viverram Naricam, alteram Jubfu/cam, cauda concolore praeditam, appellat. Utraque unius etiam terrae tractus, Brafiliae (u) nimirum $\& G$ utianae (v) habitator eft,

8.) Viverra Izquiepatl.

Meles Surinamen/is. Meles ex faturate fpadiceo nigricans, cauda fúfca, annulis flavicantibus quafi cineta. BrifJonii regn. anim. p. 255. Icbneumon de Izquiepatl. Seba Tom. I. Tab. XLII. fig. I. Coafje. Bufforn. Tom. XIII. p. I6r. Tab. XXXVIII. Tres qui fequuntur, \& quadrupes hic, integram eorum claffem conftituunt; quos Buffonius idcirco mepbiticos (Muffetos) id eft, putidos nominat, quoniam, inimicorum fuorum impetus propulfaturi, eo foetore aëre contaminant, quo tam homines, quam beftias, ni fugiant, aegrotos reddunt. CoafJam Mexicana (w) aliaeque ejusdem plagae regiones nutriunt.

9.) Viverra-putorius. Viverra fufca, lineis quatuor dorfalibus parallelis albidis. Linnaeus 1. c. Num. 4. Putorius Americanus ftriatus. Catesby Carolin. 2. pag. 62.

Co-

(u) Marcgrav. J. c. p. 228 . (v) Barrere Fr. équinox. p. 16?. (w) Hersundez 1. c. p. 332.

$$
\text { Ppp } 2
$$




\section{SPECIMEN ZOOLOGIAE}

Concpatl. Buffon. Tom. XIII. p. I6r. Tảb. XL. Viveprae hajus ftriarum non idem femper numerus efre videtur. Alii enim auctores quinque, alii plures, alii pauciores, alii femellis folis, maribus nullas plane tribuunt. Louifanam, Penfylvanianz $(x) \&$ Carolinam $\left(y^{\prime}\right)$ patriam habet. Io.) Viverra Cbinclue.

Cbincbe. Buffon Tom. XIII. p r65. Tab. XXXIX. Imago ejus Buffonii donum \& patria America meridionalis eft. In Brafilia enim \& P'eruvii $(z)$ terris reperitur cujus indigenae, quod Buffonius ex Acofta $(a)$ commonftravit, ipfam Chincilili appellant. Hinc ad magelianicas $(\dot{b})$ usque regiones, quas itidem incolit, progreditur.

I. ) Viverra Zornlita

Zorille. Buffon'Tom. XIII. pag. 16 $6_{5}$.Tab.XLI. Peruvia gos (c) inter \& Mexicanos. (d) vivit, a quibus Ortobua vocatur. Una quatuor cnumeratarum hactenus: viverrarum ea fit neceffe eft, quam $P^{\prime} i f o$ (e) Mat $^{-}$ mitacacam aut Biaratacacam nuncupat; quae tamen illarum: fit, minus evidens eft. Quatuor digitis in pedibus anticis \& quinque in potticis. CoafJa fola utirur; reliquarum vero pedes omnes quinque digitis armati funt; Confla autem ftrias albas nullas habet, quas tamen fuae $P i f o$ viverrae tribuit. Interim has ipfas ftrias admodum variare conftat.

6. V. Mutfcta. Limmans lic. Genus XV. Genus muftelae. Briffonii regn. anim. p. 242.

I.)

(a) Kolins Reif. T: I. p. 412 \& feq. (y) Catesiyl. c. (z) Feuil: He Obferw Peru. 1714. P. 272. (a) A Cofta Hift. Nat. des Ind. apud Buff fon. 1. c. (b) Byron's Voy. in Hawhesw. Acc. l. c. ( $(c)$ Garciafofo de lit Vega Mint. du Per. p. 33r. (d) Fernandez Hint. nov. Hifp.p. 6. apud Hernand. (4) Pifa de Ind. utrillsque re med. p. $3^{24}$ 
: GEOGRAPHCA E $4{ }^{\circ}$

r.) Lutris. Lutram marinam vide in Capite $\mathrm{Se}$ cundo.

2.) Lutra Braflien/is. Saricoviene. Bufjon ibid. Caufas, quas propter haec animalia ab antecedentibus fegregaverim, fecundo in capite adduxi.

3.) Lutra. Vid. Caput Secundum.

4.) Lutreola. ibidem.

5.) Gulo. ibid.

Huic beftiae non immerito alius locus tribuendus erat: 6.) Martes ibidem.

Buffoniii Pekan \& Wijon martes mihi parum inter fe diftare videntur.

7.) Muffela Putorius. Mufela pedibus fifis, corpore flavo, nigricante ore, auriculis albis. Linnaeus $1 . c$. Num. 7. Putorius Gesneri Quadrup. pag. 767. Meiers Thicre Tom. II. Tab. V. Putois. Buffon Tom. VII. pag. 1 14 . Tab. XXIII. Pole-cat. P'ennant. Brit. Zool. I. P. 77. Quodfi hunc etiam animantem. MIonffetis addideris, fex eorum habebis fpecies. Hic $\mathrm{Eu}^{-}$ ropae quam maxime incola eft; fed non eousque, quo martes, ad feptentrionem adfcendit. Pontoppidanus enim, Hog/troemius Leemiusque eum in Norvagid, Lappiaque, ubi tamen martes vivit, reperiri non indicarunt, \& Limaneus in Fauna Succica ipfuin in Scania $(f)$, Sueciae provincia meridionali, habitare adfirmat. Admodum mibi probabile eft, animalia, quorum Kacmipferus fub Tini, Itskini \& Tamuli nominibus meminit $(g)$, quaeve 'Putoriis martibasque perfimillia effe dixir,

(f) Habitare fercur in Scania campenti. (g) Kacmpfers Japan wid. dil IIalic T. 4. ver. german. 


\section{SPECIMEN ZOOLOGIAE}

dixit, huc referenda effe, quae forfan utrarumque tantummodo varietatibus adnumerari debent. Polonia ipfum alit, \& hinc plerasque Europae regiones pervagatur. Eundem Afiae quoque partes, quae parili cum Europa aëris coelique temperie utuntur, incolere $\mathrm{Pal}$ lafus teftatus (b) eft, qui haud procul a Simbirskio ad Volgae ripas albicantem ejus varietatem vidit. Reliqua peregrinantium diaria mentionem ejus nullam intulerunt.

8.) Muffe'a Peregu/na pedibus fiffis, capite \& corpore fubtus aterrimo, corpore fupra brunneo luteoque ore, fafcia frontali, auriculisque albis $(i)$. Gylden/fedt $\mathrm{Nov}$. Comment. Petrop. T. XIV. pag. 44I. Muftela Sarmatica Peregusna. Pallas Reifen Tom. I. p. 453. App. Magnitudo paulo infra putorium, facies fimillima; caput, pedes $\&$ corpus fubtus totum aterrima, cervix $\&$ corpus fupra brunneo-nigra. Ambitus oris albus, fascia alba fupra utrumque oculum oblique verfus parotides defcendens, anterius faepe ifthmo trans frontem connectente. Auriculae femiorbiculares, pilis albis fimbriatae. Cervix fafcia utrimque lutea longitudinali, interftitio fubmaculofo; fafcia lutea utrinque per fcapulas oblique divergens difformis, aliae faepe ante femora ab utroque hypochondrio verfus caudam concurrentes. Intermedium dorfi fpatium totum pallide luteo maculofum. Cauda nigricans, pilis longioribus albis, fed apice tota atra. Pedes, ungues, myftaces, ut in putorio. Mammae feminis decem abdominales. Obfer-

(b) Pallas Reif. T.I. p. I 29. (i) An forte Peruafca Rzaczynski (AuEtar. Hift. natur. Eolon. p. 328.$)$ ? 


\section{GE O G R A P H I C A E.}

fervatur in auftralioribus a Volga occidentem verfus re. gionibus.

9.) Muflela Sibirica. Kulon. Pallas Reifen Tom. I. p. 701 . App. Magnitudo fere putorii, fed forma potius Erminiae, longiores tamen pedes \& cauda. Roftrum ad oculos usque nigrum, fed circa nares album, guttatum verfus oculos. In reliquo toto corpore intenfe fulvus, fubuniformis, tamen fubtus \& verfus caput paulo dilutior. Gula faepe guttis albis fparfa. Palmae plantaeque fubtus hirfutiffimae, cano argenteae: Cauda dimidia animalis longitudine, villofiffima, intenfiore quam dorfun colore. Vellus ubique laxius, longius. que quam in putorio vel Furone. Longitudo corporis 12 " cuudae 6" fed dentes minores. Habitat in Sibiriae montanis filvis denfilfimis, praecipue in provincia $K u s$ nez \& Kranojarfk, omnivorus ad pagos hieme non raro accedens.

ı.) Muftela Furo. Mufla pedibus fiffis, oculis rubicundis. Linnaeus 1. c. Num. 8. Viverra. Furo. Iltis Gesneri Quadrup. p. 762. Furet. Buffon. Tom. VII. p. I 20. Tab. XXV \& XXVI. Nonnullas hujus beitiae varietates difcolores dari, e Buffonio difcimus. Eam ex Africa in Hifpaniam primo delatam efre, locus quidam Strabonis ( $k$ ) docet. Barbaria (l), \& fine dubio aliae Africae regiones eandem feram alunt. In Germania vero Galli, ltali aliique Europae coloni manfuefacta illa ad cuniculos venandos utuntur.

II.) Mufela Voang - sbire.

(k) Strabo'lib. 3. (l) Shaw 1.c. p. I53. 


\section{$48 S$ SPECIMEN ZOOLOGIAE}

Vanfire. Buffon Tom. XIII. p. 92. Tab.XXI. Priori nomine ipfan Madagafcaris patriae fuac indigenae infigniverunt. A folo Buffonio veram hujus beftiae cognitionem acceptam habemus; dentibus maxime molaribus a marte difcedit, cui caeteroqui perfimilis \& forfan cadem eft cum Infira, Congi feffore $(m)$.

12.) Muffela Galcra.

Galera fubfurca, cauda elongata, auribus fubnudis appreffis. Brourwhs Hitt. of Jamaica pag. 485. Tab. XLIX. Tayra ou Galera. Buffon. Tom. XV. Peiznantus quadrupedem hunc, qui Guincam inhabitat, cum illo congruere autumat, quem Bosmannus in Guinea tub Kokeloe nomine defcriptum dedit $(n)$.

13.) Muffela Zibellina. Vide Caput Secundum.

14.) Mufela vulgaris. Erminea. Vide Caput Primum, ubi rationes, cur Linnaeain fecutus Hermellanum \& maftelam vulgarem unam eandemque beftiam effe thatuam, attuli; \& quousque dilatetur, commemoravi.

15.) Muffela nivalis. Muffela pedibus filis, corpore albo, caudae apice vix pilis ullis nigris notabili. Limnaci Syft. Num. I I. Haec fortaffe antecedentis fola varictas eft, quae immutata paulifper corporis ftatura differt. We errobotbniam (o) Lappianque ( $p$ ) incolit.

16.) Muffela favamica.

Muffela fupra rufa, infra dilute flava, caudae apice nigricante. Briffonii regn. anim. p. 245. Koger-angan Javanis dieta. Seba Thef. I. p. 77. Seba nobis notam hanc

(m) Allg. Reir. T. V. \& Pigafotta l.c. (n) Allg.Reir. T.IV. (o) Lin. ngeus 1. c. (p) Leem Lapplaud p. IIg. 


\section{G E O G R A P H I C A E. 489}

hanc beftiam reddidit, quae muftela noftrate minor, patriam favam habet.

\section{7) Muftela Barbara.}

Muftela pedibus fiffis, atra, collo fubtus macula alba triloba. Linnaeus 1. c. Num. 4. Muftela maxima atra mufcum redolens. Tayra. Barrere France équinox. p. I55. Animal hoc, quod in Guiana \& Brafilia vivit, propter hanc patriam fuam ultimo hoc loco pofui.

\section{I8.) Mufiela Quoll.}

Cuoks Voyag. round the World in Hawneswortbs Collection. T. 3. p. 626. Haec muftelarum fpecies muftelae putorio perfimilis in novae Hollandiae parte orientali degit; dorfum fufcum albis maculis notatum: venter vero totus albus eft. Haec fola funt quae de beftia illa adhuc mihi innotuerunt.
D. VI.
Ur uns Linnaei Syft.
ft. Ed. XII. Genus XVI. Genus urfinum. Brifonii regn. anim. p. 258.

1.) Urfus arEtos. Urfus cauda abrupta. Limnaeus Num. x. Vid. Caput Secundum.

2.) Urfus albus. Vid. Caput Secundum. Pennantus in Syncpfi fua Tab.XX. effigiem ejus exacte excudi curavit:

3.) Urfus Meles. Taxus. Vid. Caput Secundum.

4.) Urfuts lufcus. Urfus cauda elongata, corpore ferrugineo, roftro fufco, fronte plagaque laterali cor poris. Linnaeus Num. 5. Urfus freti Hudfonis. Brifjonii regn. anim. p. 260. Quickbatcb. Edward. av. p. IO3. Wolverene. Pennant. Synopf. p. 195. Tab. XX. fig. 2. Buffonius. Pennantusque $W^{2}$ olverenam Gulonis varietatem effe autumant. Cur hac in re Linnaeum potius ducem fecutus Gulonem a Wolverena fegregaverim, rationes jam capite fecundo attuli. Wolverena Hudfonis fretum 


\section{SPECIMEN ZOOLOGIAE}

Canadamque (q) incolens ad Michilimakinaci fretun $\&$ fic ad quadragefimum quintum circiter latitudinis gradum procedit; idemque animans effe dicitur, quem la Hontanus fub Carcajou nomine defcripfit $(r)$; cui tamen opinioni ut affentiar, nondum perfuafus fum.

5.) Urfus lotor. Uifus annulata fafcia per oculos. transverfali nigra. Linnueus Num. 3. Raton. Buffon. Tom. VII. p. 192. Tab. 43. Buffonius quidem hanc beftiam in calidioribus tantum Americae partibus habitare, nec ad Canndam usque progredi, adferit; nihilo tamen fecius in Penfaloania, cujus coloni ipfam $R$ acoonem ( $s$ ) appellant, commode fatis vivit, \& quadragefimum tertium latitudinis gradum, fub quo Americae regiones vehementiori jam frigore vexantur, tolerare valet. In Mexico fub Mapachiae ( $t$ ) appellatione, praeterea in Famaica (u) etiam aliisque Antillis infulis occurrit. Dampierins eam in meridionali oceano jacentibus Mariae infulis, quae fub vicefimo primo latitudinis gradu haud procul a California pofitae funt, vidit $(v)$. In calidiffimis autem Americae regionibus, exempli gratia, in Guiana Brafiliaque nulla ejus veftigia reperire mihi licuit.

0. VII. Didelphis. Linkraus I. c. Genus.XVII, Genus philandri. Briffonii regn. anim. p. 285. Opoffum. Pennant. Synopf. p. 204. In Secundo quidem Capite, plerasque hujus generis fpecies Americae feffores effe, me.

(q) Account of a Voyage for the Difcover. of a N. W. Paft. Vol. 2. p. 3. \& Ellis Reif. p. 40. \&. Pemant. Syn. p. I26. (r) Allg. Reir. $T$. XVII. (s) Kalins Reir. T. Il. p. $246:$ ( $t$ ) Fernandez l. c. p. I. (a) Slonz Famaica T. 2. p. 329. (y) Allg. Reif: T. XII: p. 400. 


\section{G E O G R A P H I C A E.}

memoravi; idcirco tamen Buffonii opinionem, qui totum hoe genus folis novi orbis terminis circumferibendum effe autumat, probari poffe, negavi ; quum ex argumentis ibidem adductis unam faltim hujus generis fpecien in orientali etiam India confpici patefcat. Quo jure quibusve rătionibus quis univerlum quoddam ani: mantium genus uni tantum telluris noftrae parti vindicare audebit? Interim tamen unam modo alteramque Didelpbidum fpeciem in Orientali India, fi Holldndiam novam huic attribueris, hucusque obvias fuiffe, largior. Quoniam in citato jam Capite Secundo haec fufus tractata funt; lectorem eo remiffum volo, \& varias tantum generis hujus fpecies earumque domicilia commemorabio.

r. Didelpbis marjaptalis. Didelphis mammis oeto intra abdomen. Limnaeus 1. c. Vide Caput Secundum:

2. Dislclphis Opoffum. Didelpbis cauda femipilofa fuperciliortum regione pallidiore, mammis binis. Lirinaeus 1. c. Num. 3. Duas hafee fpecies Buffonius unam effe ftatuit, Sebamque, qui utrasque diffociavit, utrarumque etiam effigies feparatas dedit, erraffe tradit. Differentiam enim, quae inter utrasque intercedit, quaeque in rùminum maxime numero confiftit, nullius fere ponderis effe, multis verbis hac potiffimum dé caufa contendit, quia ruminum numerus in canibus, muRelis, fuibus, alliisque beftiis faepiffme variat. Quod equidem haud inficior; interea tamen, quemque mecum faffurum credo, difcrimen hoc inufitatum plane, quin' enorme exiftimandum effe, quo unius ejusdemque fpeciei animanti atii duas, alii octo maiminas tribuant. In máppa Zoologica additis voculis: Didelpbis marfup. iis

$$
\text { Qq }{ }^{2}
$$




\section{9? SPECIMEN ZOOLOGIAE}

in terris invenitur, in quibus eum habitare Secundo jan Capite diximus.

3.) Didclphis Pbalander. Didelpbis cauda bafi pilofa mammis quaternis. Linnaeus Num. 2. Hanc beftiam Seba Marcgravii Tajibium (w) effe putat, quod hac de ratione Buffonius negat, quoniam. Marcgravius Tajibium l'bilandro, cujus mox mentionem fecimus, fimilem effe dixit. Praeterea Sebae $(x)$ Tajibi five rattus $\left(B_{i i} / c b\right.$ ratte) marfupio nullo, folis autem ruminibus nudis praeditus eft; quod in Didelphide marfupiali longe aliter fe habet; tox. Tajibi itaque Americae incolam nondum fatis cognitum nobis perfectumque effe opinor.

4.). Didelphis murina. Didelphis cauda femipilofa mammis fenis. Linnaeus 1. c. num. 4. Marmofe. Buffon Tom. X.p. I9r. Tab. XLII \& XLIII. Philander faturate fpadiceus in dorio, in ventre dilute flavus, pedibus als bicantibus. Briffonii regn. anim. p. 29I. In Guinns (y) aliisque Americae meridionalis regionibus vivit.

5.). Didelphis dorfgera. Didelphis cauda bafi pilo$\mathrm{fa}$, corpore longiore, digitis manuum muticis. Linnaets 1. c. Mus filve/tris, cauda longiffima, fupra dilute fulvus, infra albicans. Ferminii Hift. de la Hollande équinox. p. 25. Merianias Infeet. Surinam. Tab. LXXV. Seba Tom. I. pag. 40. Tab. XXXI. fig. 4. Hallenius. (z) huic beftiolae, quae Surinama indigena eft, Aeneae quidem nomen dedit, cujus tamen fignificatio heic invertenda eft, quum mater quidem catulos, catuli vero, guod in Aenea factum effe, fcimus, nusquam parentem in dorfo gerant.

(w) Marcgray. Biafil. fo. 2:2. (x) Seba Thefaur. Vol. I. p. 57: Tab. 36. ( $($ ) Seba b. c. p: 46. ( $\approx$; Lallens Natur, hift. Vol. 1. . 


\section{GEOG R A P H I C A E。}

6.) Didelpbis Cayopollin. Philander faturate fpadiceus in dorfo, in ventre ex albo flavicans, cauda ex faturate fpadiceo rinaculata. Cayopollin. Buffon. T.X. p. 200. Tab. L.V. Sedem in Mexici montibus habet, cujus indigenae ipfum Cayopollin (a) appellant.

7.) Didelpbis Pbalanger Pbalanger. Buffon. T' XIII. p. 5r. Tab. X, XI. Pennantus hunc Brifoniz Philandrum e rufo luteum in dorfo, in ventre e flavo albicantem, capite craflo effe credit (b). Buffonio auctore Surinamam inhabitat.

8.) Hifce animal Phalangero fimile adjungamus; quod Bankius in nova Hollandia vidit, cujus jam capite fecundo mentionem injeci. (c).

Poftquam, quae de Philandro reperire poteram, collecta in ordinem redegeram; duo adhuc auctores ino: pinanti mihi in manus inciderunt, quorum relationes ut fubnecterem, eo digniores eredidi, quoniam $D_{i-}$ delpbidem marjupialem, vel ipfum, vel beftiolam eidem perfimilem, in Orientali etiam India obviam effe comprobant. Alter eorum, isque memoratu digniffimus, Barcbewitzius eft, qui itinerarium $(d)$ in lucem emifit, quod Buffonius quidem. in Diggonis defcriptione laudat; quia vero germanico idiomate confcriptum eft, vix mihi perfuadeo, Comitem ipfum, vel integrum, vel ex parte tantum, legiffe. Auctor ipfe in Damma, quae Bandaicas, (e). vel, uti alio loco easdem

(a) Fernandez p. 10. Vivit in montibus Tepeztlanicis. (b) Regn. anim. p: 293. Philander capite crafio. (c) Cooks Voy. 1. c. p. 626. (d) Neur

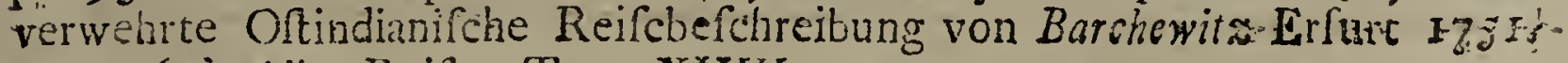
syo. (e.) Allg. Reifen Tom. XVIII. p. 54:.

$$
\text { Q.9. 9. 3: }
$$




\section{SPECIMEN ZOOLOGIAE}

dem nominat, Timoren/es inter infulas, Africam verfus jacentes, nuimeratur, fat multos fe Didelpbides, quos indigenae Cuffos vocitent, non folum vidiffe, fed etiam cibi loco appofitos comediffe, teftatur. En ipfa viri verba $(f)$. „Cufcuss inquit, feu Cuffos, qui in Damina "vivit, quod ad colorem formamque attinet, ab alpi"no mure parum diftat, oculis rotundis exiguisque, \%. fat tamen lucidis, ornatus, brevioribus parvisquie pe"dibus incedit, longiori vero depilique cauda, gliris $\%$ in modum, inftructus confpicitur, \& feiuri more ex " arbore in arborem tranfilit, quo faeto ramos cáuda , "quam pro lubitu incurvat, apprehendit, tamque fir" me tenet, ut fine lapfus periculo dependeat. Vuil$\Rightarrow$ pem redolet. Inferiori ventris parti marfupiün, feu " facculus adnatus eft, in quem pulli, fub cauda, li\% berrime ingredi regredique folent; quibuscunin in facs "culo latentibus parentes audaci faltu in arbores ex"filiunt". Barcherwitzius, hac ipfa itineris fui deferiptione, fe nulla quidem fcientiarum doctrina inftitutum fuiffe, commonftrat: quum autem res ipfas, ficut eas oculis perceperat, fine ullafuci aut vaniloquentiae fufpicione, narret; fe virum antiquae fidei ac probitatis praeftitiffe videtur, cui fides haberi tuto queat. In Dumma itaque infula permulta animalcula marfupia fúb alvo ge* ftantia, caudisque prehenfilibus praedita, offendit: qui quum praecipui Marfupialinum Didelphidum characteres fint; hos etiam Indiae orientalis indigenas effe, nemo in dubium vocaverit. Haec Barcbewitzii relatio, ut,

quam

(f) Barchewitz 1. c. pag. 532 . 


\section{G E O G R A P H I C A E.}

quam fupra conjecturam expofui, fieri nimirum potuisfe ut beftiola illa navi quadam ex America huc tranflata fit, revocem, potiusque opiner me commovet, Didelpbides Indiae Occidentalis ab Orientis fefforibus differre; licet ipfam differentiam, propter nimiam rei obfcuritatem, certo adhuc determinare nequeam. Altera, cujus nunc mentio facienda eft, relatio in Moluccaralls defcriptione occurrit; ubi fequentia relata legimus $(g)$ : "Quaedam Cuniculorum fpecies cui Cuzos nomen inco"lae indiderunt, heic loci reperitur, quorum color "cinereunin inter rufumque medius eft; oculis rotundis "\& vegetis, pedibus parvis, longiore auten \& ele- ganti cauda utitur, qua arborum ramos amplecti, ", firmiterque tenere pollet; ceterum vulpem redolet". Quodii haec cum Barcbewwitzii verbis contuleris; facile deprehendes; Cuzos feu CuJjos hosce ad Didelphidum. genus referendos effe; licet iis contradicere non aufim, qui has beftiolas ab occidentalis Indiae habitatoribus nonnihil diftare adfirmare maluerint; quod temporis demum fucceffus clariori luci exponet.

0. VIII. Talpa. Linnaeus 1. c. Genus XVIII. Genus Talpae. Briffonii regn. anim. p. 280.

I.) Talpa Europea. Talpa pedibus pentadactylis. "Linnacis l. c. Num. I. De talpa hac noftrate jaun primo in capite egimus. Ex certo Kolbii loco fufpicabar, ipfam per utrumque aequatoris latus dilata$\mathrm{ri}$; libere tamen confiteor, me nondum fatis convinci, ut talpam, quae in bonae Jpei promontorio obvia eft,

(g) Hitoire de la Conquête des Moluques T. II. p. II?. \& Allg. Reif T. VIII. p. 33\%. 


\section{SPECIMEN ZOOLOGIAE}

eft, noftratemque unius generis, uniusque fpeciei effe ftatuam. Kolbium enim multis variisque in rebus hallucinatum effe, quis ignorat? Sat multas quidem talparum dari varietates, totae albae pulcherrimeque maculatae teftantur, quae tamen fpecies fingulares nullas conftituunt. Talpas etiam primo in capite commemoratas varietatibus adnumeravi; fed quoniam fieri poteft, ut fpecies revera inter fe diftinctae vel fint, vel effe queant; easdem hoc loce ordine fuo quafi diverfas enarrare fatius duco.

2.) Talpa Afratica. Talpa ecaudata palmis tridactylis. Limnacus 1. c. Num. 2. Talpa ecaudata ex viridi aurea pedibus anticis tridactylis, pofticis tetradactylis. Briffonii regn. anim. Talpa Siberica verficolor. Seba Tom. I. Tab. XXXII. fig. 4 \&5. Taupe dorée. Buffor Tom. XV. p. 98. Seba, qui folus hujus animantis meminit, Siberiam ipfi patriam dedit, in cujus tamen defcriptionibus nullum ejus veftigium offendere potui.

3.) Talpa Flava. Pellow Mole. Pennant. Synopf. p. 312. Noftrati talpae haec caeteroqui perfimilis fola magnitudine illam antecellit, pilorum praeterea extremitates fubflavidas habet, \& in America Septemtrionali commorari dicitur $(b)$.

4.) Talpa Criftata. Sorex Criftatus. Sorex naribus carunculatis, cauda breviore. Linnaeus 1. c. p. $73 . R a-$ diated Mole. Pennant-1.c. p. 3 I3. Tab. XXVIII. fig. I. Hanc Limnacus foricibus adjunxerat, quoniam utrarumque dentes inter fe convenire vidit. Pennantus vero, qui

(Ii) Eemant. loc. 


\section{G E $\odot$ G R A H I C A E.}

qui optimam ejus effigiem vulgavit, eam talpis, quibuscum \& totius corporis \& pedum, qui in talpis characteris loco funt, praecipue forma admodun congruit, adfcribendam cenfet. In Penfilvania vivit $(i)$.

5.) Talpa Caudate. Long-tailed Mole. Penmant. 1.c. p. 3 I 4: Tab. XVIII. Caudae inprimis longitudine, quale corpori fui dimidio aequalis eft, talpam hanc memorabilem Pennantus, cujus folius beneficio eamnovimus, ex America feptemtrionali accepiffe teftatur.

6.) Talpa fusca. Brown Mole. Pennant. 1. c. p. 3 I 4. Sorex aquaticus. Sorex plantis palmatis, palmis caudaque breviore albis. Linnaei fytt. p. 74. Quoniam hoc animal pedum anteriorum plantas extrorfum verfas habet, reliquoque corporis habitu talpis non abfimile eft, Pemantus a Linnaeo digrediens illud talpis adnumerat; cujus patria Novum Liboracuin $(k), G$ Giana $(l)$ \& Virginia $(m)$ efre dicitur.

7.) Talpa Rubra Americana. Soba Tom. I p. $5^{\text {I. }}$ Tab. XXXII. fig. 2. Toucain forte? Fernandez animal. nov. Hispan. p. 9. Vid. Caput Prinum. In Mexico \& Guiana (n) commoratur.

Duo heic loci animalia apponamus oportet, quae apte quidem commodeque fatis Talpis adnecti pofiunt. Talpas tamen cum rattis magis, quam cum foricibus copulant. Cum Talpis in eo conveniunt, ut oculis auribusque aeque minutis utantur, perfimilesque iis pedes, murium vero dentes habeant. Guldenflaedtius \&

Lax-

(i) Linn. \& Penn. (k) Pennant. 1. c. (l) Fermin. l. c. p. 45. Taupe noire? (ni) Seba Thefaur. Vol. I. p. 51. Tab. 32. fig. 3. (n) Ferarin. l. c.

$\operatorname{Rr} x$ 


\section{$49^{8}$ SPECIMEN ZOOLOGIAE}

Laxmanmas bina haec animalcula fingulare quoddan genus; cui fpalaeums nomen impofuerunt, conftituere, quo natura mures cum Telpis arcte conjungat, recte exiftimant. Prius ipforum eft

8.) Mus myofpalax, palmis maximis, cauda brevi, oculis adnodum parvis. Laxmannus in Academiae Suecicae commentariis hoc non folum defcripfit, fed figuram etiam addidit, quae monftrat, illud capite brevi obtufoque g. roftro crafinori praeditum effe. Aurium. externa vefligia nulla apparent. Dentes murium dentibus fimillimos \& in utraque quidem maxilla primores. duos habet. Collum corpusque craffuni eft. Pedes. ad effodiendam terram, minime vero ad currendum facti videntur. Antici, Talamum mere, quinque digitis robuftioribus inftructi, poftici vero exigui, anticisque bis terque tenuiores itidemque pentadactyli funt. Integram fi animantis longitudinem dimetiere, novem fere digitos anglicáe menfurae invenies. Caput in duos pollices, collum in fex lineas, corpus in quinque dimidiumquedigitum, \& cauda in unum pollicem tresque: lineas extenditur. Coloris grifeo-coerulei eft. 'Tirdiffme movetur, nec unquam currens conficicitur. Sub: terra vivit, Talparumque ritu magnos terrae egeftae acervos exRruit. In Siberiae regionibus, quae inter

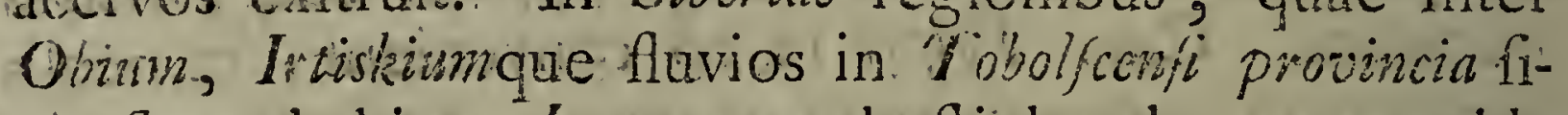
tae funt, habitat. Laxmonnus beftiolam hane a provida: natura ea potiffinum fine, in Siberiam pofrtam effe autumat, ut humum frugibus aeftivo tempore nafcentibus earumque radicibus alioquin inpenetrabilem, fodiendo aperiat, laxioremque reddat. Aviculae in fcrobibus, quass fibi faciunt, nidificare dicuntur. 


\section{GE O G R A P H I C A E.}

9.) Spalax micropbtbalmus. Glis dentibus primoribus in utraque maxilla cuneiformibus planis, roftro probofcideo, pedibus pentadactylis, Gulden/edt. Nov. Comment. Petrop. T. XIV. p. 409. Caput depreffo rotundatum, roftrum cartilagineum. Rictus oris parvus. Lingua carnofa, craffa. Dentes primores in utraque maxilla duo, canini nulli, molares a primoribus remoti, utrinque fupra $\&$ infra tres, truncati, minimi. Oculi plane nulli per cutem apparent, nee ulfom foraminis, veftigium detagendum, quod forte adeo anguftum, ut omnem vifus aciem effugiat. Auriculae pariter nullae. Collum brevifimum, truncus cJlindricus. Pedes breves, pofteriores vix anterioribus longiores, debiles, calcaneis incedentes, pentadactyli. Cauda omnino nulla. Pellis delicatula. Color inferius grifeus, fuperne grifeo rufus. Longitudo animalis 8. poll. 6. lin. Animal ingreffu tardiffimum fub terra fodit canales horizontales, vivit mere vegetabilibus. Coëunt aeftate, gregatim tunc in terrae fuperficie apparent. Femina parit pullos duos ad fummum quatuor. Habitat frequentiffme in campis apricis tanaicenfibus atque in vicis hortisque vicinis.

0. IX. Sorex. Limaei Syft. Edit. XII. Genus XIX. Briffomii regn. anim.

I.) Sorex aranezs. Sorex cauda mediocri, corpore fubtus albido. Limnaeus 1. c. Num. 5. Mufaraigne. Buffon. Tom. VIII. p. 36. Tab. X. -Mas araneus. Brisfonius 1. c. p. Sorex hic noftras a Sutecia occipiens inde ad Poloniam (o) tranfit, \& fic plerasque Europae regiones

perm

(o) Rzacynsk. Hift. Pol. anim. fubterr. 


\section{SPECIMEN ZOOLOGIAE}

pervagatur $(p)$. In mappa Zoologica eum vocula de curtata Sor notatum invenies.

2.) Sorex Fodiens. Musaraneus, dorío nigro ventreque albo. Merket Pinax p. 167.. Mufarnigne d'eau. Buffor Tom. VIII. p. 40. Tab.II. L ater-fbrew moufer Britt. Zoolog. Tab. CII. Pallafus eum in Germania (q) $\&$ in Provincia Orenumrgen/2( $r)$, \& Daubentonius in Gallia $(s)$ offenderunt. Anglia nunc ipfum alit $(t)$. Hinc in tabula Zoologica voculis, Sor. fod. defignatur.

3.) Sorex Mofibatus. ${ }_{x}$ Caflor Mofchatus. Caftor cauda longa compreffa lanceolata, pedibus palmatis. Linnacus 1. c. p. Desman. Buffon Tom. X. p. r. Tab. II. Biefam Ratze. Gmelin (Sam. Georg.) Reifen Petersburg. 177 r. Tom. I. p. 28. Tab. XXXIIII. Linnaeus Brifjoninsque hunc quadrupedem, quem minus recte noverant, caftoribus attribuunt; Pallafius vero $(u)_{x}$ cui uberiorem ejusdem contemplandi perquirendique facultatem occafio obtulit, illum foricum generi adfcribendum effe arbitratur, quare animanti heic locum dare non dubito. Gmelinus junior eundem denuo depingendum curavit, ipfumque fic definit:. occiput ejus latius, finciput autem anguftius. eft, \& in longius roAtrum porrigitur, quod fupra nigri, infra rubidioris coloris eft; oculi parvi brevibus albidisque pilis circumdantur; aures, quae rotundi foraminis foramam habent 2 : cute tectae latent; maxilla fuperior fedecim dentes, quos inter duo incifores o.toque molares numerantur;

in--

(p) Buffon. 1.c. (q) Pennant.1.c. p. 308. (r) Pallás. Reir. T. $\mathrm{I}_{\text {: }}$ 1. II. (s) Buffon. lo s. (t) Pennant. l. c. p. 308 . (u) Pallas Reif: 2. I. p. $156_{0}$ 


\section{GE O GR A P H I C A E. 50r}

inferior oetodecim in iisque quatuor primores continet; (e quibus manifeftum elt, beftiam ex Linnaci definitione foricibus adjudicandam effe ) collo brevi, longiori vero corpore gaudet; pedes antici: breviores funt, $\&$ a corpore guafi contecti videntur. Cauda corpore aliquanto brevior a principio rotunda eft, poftea pla. nior exit, \& ab utroque latere parvis rotundisque fquamis praedita, quas inter pili breviores multi prominent, dorfum colore nigricante, venter autem fubalbido aut cinereo potius diftinguitur. Caudae initium mediumque inter cutem exteriorem \& utrosque: mufculi rectoris tendines octodecim folliculis in tres ordines difpofitis inftruetum eft. Quivis ordo fex foiliculos habet, qui Zibethum gignere \& exfudare folent. Ne minimum quidem ductus alicujus, quod tamen inglandulis conglobatis ufitatum eft, veftigium obfervare: poteris. Zibethum, cujus forex ponderis circiter fcrupulum profert, nulla in re ab-illo-diftat, quod felis Zibethicus fuppeditare fuevit, ejusdem potius taim odoris, quam naturae eft. Quovis vere ingruente inter $\mathrm{fe}$, $\&$ anno quidem vertente femel coëunt; nec a littoribus: unquam difcedunt, ubi vermibus, hirudinibus, infeetisque aquaticis vefcuntur; penfi vix fedecim unciarum pondus excedunt. Peregrinis, quibus Gmelini relationem ipfam legendi copia nondum datur, operae: praetium facturus, ipfam animantis hucusque non fatis. cogniti defcriptionem apponere volui. Lappiam $(v)_{y}$ RR uJjiam, Ca/ani (w) terras, IV olgas Samaraeque ripas $(x)$ :

(y). Faun, Suec. 28. (") Pallas. 1. c. (x) Gmelin. \& Pallas 1. Go: R.r. 3 


\section{SPECIMEN ZOOLOGIAE}

inhabitat. In Tabula Zoologica Desmani nomen ei datum eft.

4.) Surex mimutus. Sorex roftro longiffimo, cauda nulla. Linnaeus 1. c. Num. 2. Animalculum hoc, quod uno tantum excepto omnium quadrupedum minimum eft, \& vix librae drachmam efficit, Laxmamus, Profefior, in Siberia detexit $(y)$.

5.) Sorex murinus. Sorex cauda mediocri, corpore fufco, pedibus caudaque cinereis. Limaeus l. c. Num. 4. pag. 74. Unus Linndeus hanc beftiolam, quae $f a-$ vae fellor effe dicitur, defcriptam dedit.

6.) Sorex Brafilienfis. Mas araneus figura muris. Marcgrav. 1. c. p. 229. Mataraigne de Brefil. Buffor. Tom. XV. p. 107: Hocce animal fi aliquem hic locum recte occupat, poft foricen mofibitum reliquos fui gencris omnes corporis magnitudine longe poft fe relinquit. Cum cauda enim leptem pollices longum eft, tribusque nigris fafciis, quibus corpus fufcum notatur, a reliquis omnibus diftinguitur. Brafiliae eft incola.

7.) Sorex albus minor. Fermin Hollande équin. p. 45 . Utrum hic animans huc referri debeat, certo quidem adfirmare non poffum; eum tamen hoc loco ponere, quam omittere malui. I fum totum candido colore pulchrisque oculis coeruleis praeditum, \& in remotiffimis Surinamae filvis perraro obvium effe, Ferminius tradidit. Beftiam toto corpore candicantem fub tam flagrantis aeftus climate reperiri, Buffonizs nunquam furpicatur.

0. X. Erinaceus. Limmaei Syft. ed. XII. Genus XX. Brifjonii regn, anim.

(y) Laxmans Siberifche Briefe. 


\section{G E O G R A P H I C A E. 503}

I.) Erinaceus Europaeus. Vid. Caput fecundum.

2.) Erinaceus Auritus. Pallas. Nov. Comment. Petrop. T. XIV. p. 519. \& 573. Tab. XVI. Majoribus. praecipue auribus externis haec beftiola a nontrate difinguitur. Inter Kirgifenfes ad Jaiki ripas orientem: ipectantes degit, vitamque infectis tolerat, nec cantharrides canibus cattisque mortiferas refpuit. In Orenbur$g \mathrm{en} / 2$ provincia reperitur $(z)$.

3.) Erinaceus Madagascaren/is. Tendrac \& Tanrec. Buffon. Tom. XII. pag. 256. Tab. Quadrupedes hi varietates paulum tantummodo inter fe diftantes effe videntur, \& in Madagafcare (a) nonnullisque oceani indici infulis $(b)$ vivunt.

4.) Erinacaus inatiris. Erinaceus auribus nullis. Linwacus 1. c. Num. 3. Erinaceus Americanus albus. Scba. Guianam patriam habet $(6)$.

$$
\text { S. E C } \quad T \quad I \text { O I X. }
$$

Glires. Dentes primores bini fupra ${ }^{\circ}$ infra: approximati, a molaribus remoti. Linn.

6. I. Hy/rix. Linnaeus 1. c. genus XXI. Briffoniz: $M$ regnum anim. p.

1.) Hyfrix crifiata. Vid. Caput Secundum. Erinacaens, quem Limacus melaccen/is nomine infignivit, procul dubio hace ipfa beftia eft, quam idcirco antea: filentio praetermifimus.

2.)

(z) Pallas. l. c. \& Reif: T.I. p. 429. (a) Flakkourt.l.c. (b) Perb. mant. 1. c. p. $317^{\circ} \quad$ (c) Dankroft. 1. c. Fo. 86. 


\section{SPECIMEN ZOOLOGIAE}

2.) Hy/trix macroura. Hy/trix pedibus pentada\&ty. lis, cauda longiffima, aculeis clavatis. Linnaeus $1 . \mathrm{c}$. Num. 4, Hyfrix cauda longiffma, aculeis undique obfita in extremo panniculata. BrifJoniuss. Hy/trix Orientalis fingularis. Secba Ther. Vol.I. p. 84. Tab. LII. fig. I. Silvas infulasque Arcbipclagi indici tenet (a).

3.) Hy/lrix dorfata. Hyj/rix palmis tetradactylis, plantis pentadactylis, cauda mediocri, dorfo folo fpinofo. Limnaeus 1. c. Num. 3. Hy/trix aculeis fub pilis occultis; cauda brevi \& craifa. Brifjonius. Porcupine of Hudfonsbay. Edwards av. 52. Tab. 52. Urren. Buffon. Tom. XII. p. 250. Tab. LV. Canadam, novam Antgliam (b), Terram novam (c) \& Hudfonis fretunn inhabitat.

4.) Hy/trix prebenflils. Hy/trix pedibus tetradactylis, cauda elongata prehenfili feminuda. Limnaeus Num. 2 . Hoitzlacuatzin. Hernandez Mex. p. 322. Coendou. Buffon. Tom. XII. Brafilin Porcupine. Pennant. l. c. p. 264. Tab. XXIV. Optime Pennantus hanc animantem depingi aerique incidi curavit. In America meridionali Guianae $(d)$, Brafiliae $(e)$, quin \& Mexici $(f)$ regionum feffor eft. Hyftrices in Tabula Zoologica, neceffitate flagitante, paucis interdum litteris notandae fuerunt; notarum tanlen, quae addita eft, explicatio facillime, quid intellectum voluerim, enodabit.

§. II. Lepus. Linneeus 1. c. Genus XXII. Brifoniii regn. anim.

I. ) Lipus timidus. Vid. Caput Primum. Citato in capite

(a) Seba 1. c. (b) Echwards 1. c. (c) Pennant. p. 266. (d) Bargere l. c. p. I53. (c) Marcgr. Hift. Brafil. p. 233 . \& Pifo l. c. p. 99. (f) Herrandez"1.c. 


\section{G E O G R A P H I C A E. 505}

pite quasdam beftiae hujus degenerationes várictatibus adrumeraveram, quae quum fortafie fingulares fint, aut effe poffint fpecies, illas heic loci feparatas percenfere libuit.

2.) Lepus alpinus. Pallas Reife durcb Rusiand Tom. II. p. 7or. Tab. A. Sibirian Hare? Peinant. 1. c. p. 250. Magnitudo muris porcelli; aures magnae, fuborbiculae volae palmarum \& plantarum lana denfisfima atra veftitae. Cauda nulla, fed tuberculum pinguedinofum mole nucis. Pondus circiter Unc.XV : coftae in fceleto 18. parium: Vivit in alpinis rupeftribus Sibeviae. Has animantis notas Pallafurus attulit; quae tamen cum effigie, quam Lcporis Sibirici Pennantus dedit, minus congruere videntur. Hic eundem Lappine Scutiacque lepori fimilem effe contendit. Parum abeft, quin Scotiae leporem noftratis varietatem effe ftatuam.

3.) Le pus pufillus. Pallas. Noo. Commentar. Acad. Petropol. Tom. XIII. p. 53 r. Tab. XIV. Hic quidem, qui fex parifienf:s menfurae digitos longitudine vix aequat, generis fui pumilio jure dici poteft; multis tamen in rebus, praecipue, quod ad inteftina coftasque, quarum feptendecim paria poffidet, antecedenti propemodum refpondet; cofta unque numero plerosque quadrupedes fuperat. Pallafüus, qui \& minutum ipfum leporem nuncupat, acervatim eum ad Samarae ripas $(g)$, in provincia Tobolsken/i (b) aliisque Siberiae locis vidit, ubi fefe invicem coturnicum voce noctu alliciunt.

4.) Cuniculus. Vide Caput Primum. P'ennantus varieta-

tis

(E) Pallas. Reil. T. I. p. $155 \& 220$. (h) Ibid. T. II. p. 3 If.

Ss.s 


\section{SPECIMEN ZOOLOGIAE}

tis cujusdam fubruffici cuniculi nomine ( $R$ uffan R R abbct) meminit, cujus totum fere corpus duplici pelle munitum fit.

5.) Cuniculus infogniter candatus, coloris leporimi, GmeIin. nov. Comment. Acad. Petropol. Tom. V. P. 35\%。 Tab. II. Lepus cauda in fupina parte nigra, in prona alba. Briforiii regn. anim. Tolai. Buffon. Tom. XV. p. 94. Gmelino Jeniori tefte, haud procul a Baikalis la$\mathrm{cu}$ in Tartarian Mongolica domicilium habet. Buffonius eum leporis noftri varietatem effe contendit.

6.) Lepus caperi/sis. Lepus cauda longitudinis capitis pedibus rubris. Limnaeus Num. 3. Ex Linnaei teftimonio. borne Jpei promontorium incolit.

7.) Lepus Braflien/is. Lepus cauda nulla. Limnaeus 1. c. Num. 4. Lepus ccaudis. BrifJon. regn. animal. Ta. peti. Pijo. p. 102. Buffon. Tom. XV. p. 109. Mexici $(i)$, Grianae (k), Brafliaeque (l) indigena eft. Alia procul dubio hujus generis animalia dantur, qualia $V i$ cacbos (wi), quorum Acofa \& Fenillée (n) mentionem faciunt. Et Dsmpierius \& alii etiam in Patagosia $(0)$ novaque Hollandia $(p)$ cuniculos fe confpexiffe adfirmant. Sed utrum huic an fequenti generi fubjiciendi, an leporis varietates fint, plane ignoramus.

\section{CAVIA}

9. III. Cary. Pennant. Synopis. p. 243 . Novunz hoc Caviarum Genus invitus appofui. Si Linnaeo om-

nia

(i) Fernandez 1. c. p. 2. ubi Citli nominatur. (k) Bankroft. p. 84. (l) Marcgray. 1. c. p. 223. (m) Purchas Piigrims T. III. p. 906. (n) Obferv Peruv. I725. p. 32. (o) Allg. Reif. T, XII. p. 32 (p) Allg. Reir. T. XII. p. 226 . 


\section{G E O G R A P H I C A E. 507}

nia, quae illi fubfunt, animalia conjunctim percenfere placuiffet, lubens illa eo loco, quo ipfa pofuiffet, enarrarem; quod quia neglexit, huc ea omnia rerocanda exiftinavi. Kleinius $(q)$ primus eft., qui fingulare caviarum genus conftituit, quod $P$ allafus his verbis definivit $(r):$ caviis vulgo os $\&$ dentes, quales hyffrici; pedes antici in quatuor femper digitos finduntur; poftici yero plerumque tridactyli. Parvis praeterea auribus quafi orbicularibus \& vel perbrevi vel nulla cauda inftructae funt. Orbis antiquus, quantum conftat, hucusque duas tantum; novus autem ad mininum quinque ipfarum fpecies poffidet.

r.) Cavia capen/ss. Pallas. Ppicileg. Fafcic. 2. p. 16. Tab. II. In bonac Spei promontorio reperitur, ubi melis capen/is nomen accepit $(s)$.

2.) Cavia javen/is. Klcinii difpor. quadrup. p. 50 . Mus leporimus. Limnacus 1. c. p. So. Java Hare. Catesby Carolina. Append. Tab. XVIII. Solius Catesbii beneficio hanc beftiolam novimus, quae in Sundaicis $I n \bullet$ fulls obvia eft.

3.) Cavia Aperea. Kleinii Quadrup. difpor. p. $5^{\circ}$. Cuniculus ecculdatus auritus ex cinereo rufus. Briffoninss. Aperea. Buffon. Tom. XVV. Vide Caput primum, ubide leporibus actum eft. Braflicin inhabitat.

4.) Cavia Aguti. Klein. 1. c. p. 50. Mus Aguti. Mus cauda abbreviata, palmis tetradactylis, plantis tridactylis; abdomine flavefcente. Linnaci Syft. p. 80. Aguti.Buffon. Tom. Vlll. p. 215. Tab. L. Guiana ( $(2)$, Bra-

(q) Klein. Quadrup. Difpof. p. 49. (r) Spicileg. Zoclog. Taficic. 2. p. 17. (s) Kitbe l.c. p. $14 . \mathrm{r}^{\circ}$ (t) Barrere 1. c. p. 153. 
508 SPECIMEN ZOOLOGIAE

Brafslia ( $i$ ) aliaeque calidiores Americae regiones $A n$ : tillaeque infulae ( $v$ ) eam nutriunt.

5.) Cavia Akoucbi. Cuniculus minor caudatus, olivaceus. Barrere. France Equinox. pag. I 53. Akouchy. Buffon. T. XV. Ab Agouty in eo tantum difcedit, quod cauda, quae ifti deërat, gaudet, nec rubra, ut ifte, pelle veftitus, minorisque corporis eft. Guianam patriam habet $(w)$.

6.) Cavia Paca. Klevin. Quadrup. Difpof. pag. 50. Mus. Paca. Mus cauda abbreviata, pedibus pentadactylis; lateribus flavefcenti lineatis. Lin. Syft. Edit. XII. pag. 8 I. Paca. Buffon. T. X. p. Tab. XLIII. P'ennantus $(x)$ ex Lacto commonftrat, horum animalium varietates quasdam prorfum candidas ad fancti Francijci flumen reperiri. Calidiffimas novi orbis regiones v. g. Guianam (y), Brafiliam ( $z)$, Maragnonisque fluvii ripas, generatim incolere perhibetur ( $(a)$.

7.) Cavia Cobaya feu Mus Porcellus. Vide Cap. II.

5. IV. Caftor. Linn. Syft. Edit. XII. Gen. 23. Briffon. regn. anim. p. 133 .

I.) Caltor Fiber. Vid. Cap. Secund.

2.) Caffor Zibetbicus. Caftor cauda compreffa, Ianceolata, pedibus fiffis. Linn. Num. Ondatra. Bufforr. T. X. p. I. Tab. I. Rat musqué. Mém. de l'Acad. des. Sc. de Paris de l'année 1726. p. 323. Curradae (b), wova Argliae Virginiaeque (c). eft indigena.

3.) $P i_{0}$

(31) Marcgrav. 1. c. p. 224. (y) Rochefort. Hitt. des Ant. (wv) Baro rere 1. c. $(x)$ Pennant. Synopf. p. 245. (y) Barrcre 1. c. 152 (z) Marcgrax. p. 224. (a) Abberille Miffion. p. 25I. (b) Allg. Reif 'T. XVII. p. 230. (c) Smith's Virgino p. 2? 


\section{G E O G R A P H I C A E. 509}

3. Piloris. Rochefort. Hift. des Antilles. p. I 24. di Tertre Hifl. génér. des Antilles Paris 1667. T.II. p. 302. Num beftia haec jure huc referri queat, nec ne, certo adfirmare nequeo, quum naturae inveftigatorum nemo eam adhuc exaete fatis defcripferit. Hunc interim locum ei magis convenire exiftimo, quam quem $P$ cnnontus ipfi Cavias inter adfignavit. Rochefortius enim eam: rattis noftris formae refpectu non abfimilem effe, dicit, quos tamen magnitudine multum fuperet, \& ficut Ondatra, mofchum peroleat, abdomen albi, dorfum autem fufci coloris eft. Ab Ondatra vero praecipue: corporis proceritate caudaeque brevitate difcedit. I'iloris gregation in Martinica multisque aliis Antillis infulis: confpicitur (d).

\section{MUS:}

6. V. A. Marmotta. Limn. Gen. 24.

I.) Mus Marmotta. Limb. Num. 7. la Marmotre \&z te Bobac. Buffan. Vid. Cap. II.

2.) Mus monax. Linn. Num. 8. Vid: Cap. II. ubi: utrasque has animantes, bobncum nimirum marmottamque unam eandemque, monacem autem marmottac rarietatem effe fcripferam; nec dum rutionem adefle autumo, quam propter ab hac opinione difcedam.

3.) Mus citcliws. Linn. Num. 4. Soustic \& Ziefel. Buffon. Vid. Cap. II. Forfan Vormela, cujus Agricola: meminit (e), variegatus tantum Sousticus eft. Pennantas in Syncpfi pag. 27\%. aliud adhuc animalculum huice

(d) Du Tertre \& Rochefort. 1.c. (e) Agricoia de animal. fubterran. p. 48.86 .6
Ss S 3. 


\section{IO SPECIMEN ZOOLOGIAE}

huic generi adjunxit, cui nomen CircaJlani marmouti (maris alpini Circafjenfis) impofuit, quod Scboborus $(f)$ fic defcribit: In fpeluncis ad Terki Circalfiae fuminis ripas beftiolae commorantur, quas indigenae muribus campeftribus adnumerant, magis tamen fciurorum generi fubjici merentur. Caftanei coloris funt, \& cricetos magnitudine aequiparant, dorfa longioribus pilis tecta funt, \& fciurorum inftar prolixioribus caudis utuntur, rubris fplendentibusque oculis ornatae. Aures murium auribus fimiles habent, roftra multis acutisque dentibus armantur. Pedes antici ungulis acuminatis praediti, pedibusque pofticis breviores funt. Hinc fit, ut facillime montes afcendere, difficulter autem defendere poffint.

\section{B. Mures proprie fec dicti.}

I.) Mus Lemmus. Mus cauda abbreviata, pedibus pentadadylis, corpore fulvo nigro-vario. Limn. Num. 5 . p. 80. Lening. Buffon. T. XIII. Haec murium fpecies, quia de improvifo Lapporum regiones magnis acervis occupat infeitatque; derepente tamen difparere folet, memorabilis quidem, fed regionis etiam incolis formidolofa eft. Hinc factum legimus ut publicas eidem diras olim fint imprecati. Optimam ejus \& defcriptionem \& imaginem Linnaeus in actis Acadomine Suecic. T. II. pag. 75. Tab. dedit. Lappin \& potifimum montes, qui Norvagiam a Sutcia dirimunt $(g)$, Lemmorum patria eft. Lappi eos ex nubibus decidere credunt. Lee-

(f) In memorabilibus $R$ uffae Afraticae in Muelleri collectione Ruficae Hiltorias T. VII. p. I24. (g) Pontoppilan. 1. c. p. 80. 


\section{G E O GRA P H I C A E $55_{j}$}

Leemiusque aliquos ipforum ex aëre in terras cecidiffe, teflis eutronths adfirmat $(b)$, quos vel ab accipitribus vel turbonibus in altum fublatos ftatuas oportet, fi probabilem rei rationem dare fuftinueris. In quarto capite plura de ipforum migratione adducta invenies. In Amevicae feptentrionalis defcriptione quadam, me de fimilibus animalibus nonnulla legere memini; fed nec liber nec auctor, qui mihi excidit, jam fuccurrit.

2.) Cricetus. Vide Cap. lI. Cui hoc tantum addo; atran animantis varietatem, cujus loco dieto mentionem feci, non in Cafanenfum tantum terris, fed in noftris etiam Germaniae regionibus reperiri, quod Suclzerus in praeftanti fua Criceti bifloria naturali, quae Gothae 1774. prodiit, teftatur, cui exiguam etiam varietatis hujus effigiem addidit.

3.) Surmulotus. Vid. Cap. II.

4.) Mis Rattus. Linna. Vide Cap. I.

5.) Mus ampbibius. Linn. Vid. Cap. II. Hanc quo. que beftiam in Lappia degere, fatis probabile eft ( $i)_{0}$

6.) Mus muscullus. Linn. Vid. Cap. I.

7.) Mus terreltris. Linn. Vid. Cap. II.

8.) Mus ylluaticus. Mus cauda longa, palmis tetradaetylis, plantis pentadactylis, corpore grifeo, pilis nigris, abdomine albo. Linn. Num 17. Muliot. Buffor. T. VII. p. i86. Tab. Long tailed ficld moufe. Pennant. Britto Zoolog. T. I. p. I03. Quantum conftat, Lappiae (k) Succiae (l), Angliae, Germaniae, Galliaeque eft incola. g.) Mus fylvaticus minor. Less. long talled field moule. Pen-

(h) Lecmius de Lappis p. I2I \& 122 . (k) Leemius 1. c. (l) Fann. Suec.

(i) Lecmius 1.c. p. I24: 


\section{$5 \times 2$ SPECIMEN ZOOLOGIAE}

\section{Pennant. Britt. Zoolog. T. II. A.pp. p. 499. Dimi-}

diam fere antecedentis magnitudinem habet. $\boldsymbol{P}$ ennantus eum in Hantonien/i Angliae provincia vivere adferit $(m)$.

ro.) Mus gregarius. Mus canda corpore triplo breviore fubpilofa, corpore grifeo fubtus pedibusque albis. Linn. Num. 16. Germaniae Sueciaeque (n) eft incola. I'allafuls hune murem focinlent unum idemque animal effe adftrucreque videtur. Qua in opinione fi nor erravit, mus hic ad Faiki etiam fluvium in Orenburgen/is provincia commoratur (o). Quum Pallafii itinera, quae praeftantiffimis operibus merito adnumeranda funt, nondum fatis innotuiffe fufpicer, hoc loco magni hujus naturae fcrutatoris verba ipfa eorum gratia inferere liceat, qui Germanicae linguae minus gnari funt : vir celeberrimus murium genera, quae in $A$ fia $R$ uffica nuper detexit, fic percenfet.

ir.) Mas agrarius. P'allas. 1. c. T. I. p. 454. Paulo minor \& tenerior mure mufculo, roftroque acutiore; myftaces parciores, caput oblongius, auriculas minores intus villofas habet. Corpus luteum fubtus artubus canefcenti-album. Linea fpinali atra a capite ad caudam. Palmae unguicula pollicari minutiffima obtufa. Cauda pilofa 3.. annulis circiter notata. Pondus 3-4. Drachm.

12.) Mus tamarifcinus. Pallas. 1. c. T. II. p. 702 . Magnitudo ultra Rattum, habitus fere muris quercini. Dentes primores fulvi, fuperi fulco exarati. Myftaces longiffimi. Oculi majufculi. Auriculae magnae ovales, nudiufculae. Palmae fubtetradactylae, verruca

pol-

(m) 1. c. \& Syn. of Quad. $\mu w$ (n) Linn. I. c. (.0) Pallas. itin. per Rufliam T. II. p. 703 . 


\section{GEO GRAFH I C E.}

pollicari, plantae pentadactylae. Cauda longitudine circiter corporis, fubfloccofa, annulis fufcentibus. Color fupra grifeo-lutefcens, fubtus albus, fupercilia albent. Animal elegantiffimum, longitudine 6" 6 "'. Habitat in falfis verfus mare $\mathrm{Caf}$ pium. Pafcitur forte fructibus Tamaricis vel Nitrariae, fub quarum radicibus cuniculos fodit profundiffimos.

1 3. Mus migratorius. Ibid. pag. 7.03. Magnitudo fupra murem terreftrem, habitus diverfiffimus. Roftrum craffum carnofum obtufum; facci buccarum usque ad humeros protenfi, ut in Criceto. Myftaces exiles. Auriculae reclinatae; nudiufculae, ovales. Palmae tetradactylae, veftigio pollicis obfoletiffimo, inermi. Corpus breve, craffum. Cauda breviffma. Color fupra grifeo cinereus, fubtus candidus. Extrema roftri \& pedum alba. Longitudo animalculi fere 4": Occurrit in graminofis ad faikum, diciturque certis annis copiofiffme e defertis adventare, infequente infigni vulpium copia.

14.) Mus fungorws. ibid. p. 703. Tab. B. fig. I. Forma tota Criceto fimillimus, fed magnitudine infra murem terreftrem. Caput breviufculum buccatum. Buccae ut in antecedenti. Auriculae ovales, nudiufculae. Cauda breviffima. Palmae tetradactylae, rudimento pollicis mutico. Color in dorfo cinereus. Striga a nucha ad caudam nigra. Subtus omnia albent. Longitudo $3^{*}$. cauda $4^{\prime \prime \prime}$. Habitat in campis elatis aridis aufralioribus ad Irtin.

15.) Mus arenarius. ibid. p. 704. Tab. I3. fig. 2. Praecedenti paulo major, agilior, roftro argutiore, cauda longiore, magisque attẹnuata. Palmae fubtetradactylae rudi- 


\section{SPECIMEN ZOOL OGIAE}

mento pollicis minutiffime unguiculato. Color fupra \& in lateribus uniformis canus. Longitudo $3^{\prime \prime} 8^{\prime \prime \prime}$. Habitat in auftralioribus ad Irtin.

16.) Mus baraberifis. ibid. p. 704. Praecedenti maxime fimilis. Palmae tetradactylae pollicis rudimento vix ullo. Buccae ut in praecedentibus. Color corporis grifeo lutefcens, taeniola nigra fpinalis a vertice ad caudam, fubtus fordide pallet. Habitat in arenofis ad Obii fluvium.

17.) Mus lagurus. ibid. p. 704 \& 705 . Magnitudo fere muris terreftris, quo brevior omnibus partibus. Roftrum obtufiffimum, hirfutiae tumidulis labiis. Myftaces exiles. Auriculae multo minores, quam in mure terreftri, rotundatae nudiufculae. Corpus ventricofum, artus exiles. Palmae fubtetradactylae, verruca carnea loco pollicis. Cauda breviffima vix vellere exferta. Color murinus. Striga inter oculos incipiens usque ad caudam. Longitudo $3^{\prime} 8^{\prime \prime \prime}$. Habitat ad faikum rarius, ad Irtin copiofiffime.

18.) Mus fubtilis. ibid. p. 705. Minutiffimus (praeter murem minutum ). Habitus muris minuti, fed auriculae majores \& cauda multo longior. Palmae fubtetradactylae, verruca infigni callofa loco pollicis. Color fupra cinereus fufco mixtus, fafciola latiufcula a fcapulis ad caudam. Cauda corpore multo longior circulis circiter 170 annulata. Liongitudo animalculi $2^{\prime \prime} 1^{\prime \prime}$. Ad Jaicuin occurrit.

x.) Mus minutus. Pallas. T. I. P. 454. Totius generis minimus. Vix dimidia mole muris mufculi. Pondus plerunque fesqui drachm. raro duarum drachmarum. Myftaces tenues, auriculae minores intus fubvillofae. 


\section{G E O G R A P H I C A E. 5 I5}

Corpus grifeo lutefcens. Cauda pilofa tota circulis fere 130 annulata. Internis cum mure fylvatico $\&$ amphibio convenit. Cyftis nulla (nec in mure agrario). Obfervatur, uti \& mus agrarius, ad $V$ olyam.

20.) Mus talponus. Rufilis Slepufcbt-fchonka. Pallas. nov. Commentar. Petrop. T. XIV.

Magnitudo muris amphibii. Caput grande, roftrum breviffimum. Nafus truncatus, fufcus. Labium fuperius usque ad nares late bipartitum, hians, dentesque fuperiores usque ad bafin detegens; $a b$ utroque latere vero tumidulum pubefcens, intraque os connivens, $\mathrm{pa}$ lato pone dentes primores deficiente; inferius labium uti in muribus omnibus. Dentes primores denudati, quafi extra porrecti. Myltaces nigri breves deorfun vergentes. Oculi vertici, \&r nafo propiores, minutiffimi, vellere ferme latentes, nigrio. Aurium apertura mediocris. Corpus breve, ventricofum. Artus breves, robustiffmi. Pedes nudiufculi, albidi, omnes pentadactyli, digitis fubsquatnatis. Palmae majores, latae fofforiae. Cauda brevifina, teres, truncata, vix alto vellere clunium eminens. Vellus murinum, tenerum fub armis $\&$ in ventre rariufculum aeftate, hyeme vero ubique largum. Color capiti fubater, mentum albet, reliquum corpus murinum, fubtus $\&$ in artubus canescens. Longitudo animalis 3 poll. In Orenburgenfibus $\&$ aliquibus Germaniae regionibus habitat $(p)$.

2 I.) Mus paludofus: Mus cauda mediocri pilofa, plantis pentadactylis, auriculis vellere brevioribus, ater. Linn.

(p) Pallas. itiner. T. I.

\section{Tt 2}




\section{SPECIMEN ZOOLOGIAE}

Limn. Mantifja plantar. altera. p. 523. Habitat ad Suc. ciae folarum introitum fub ipfa aqua.

22.) Mus friatus. Mus cauda mediócri fubnuda, palmis tetradaetylis, plantis pentadactylis, corporis ftriis punctatis. Linn. Num. I 8. Mus orientalis. Seba Thefaur. Vol 2. p. 22. Tab. 2r. fig. 2. Indine incola eft, ubi ex Pennanit teftimonio ( $q$ ) a Lufitanis Cberofo appellatur. In Guinea (r) ipfum etiam commorari, Barbotus adfirmat.

23.) Mus avellanarius. Mus cauda elongata pilola, corpore rufo, gula albicante, pollicibus pofticis muticis. Linn. Num. 3. Mufcardin. Buffon. T. VIIl. Táb. XXVI. Dormoufe. Pennant. Britt. Zoolog. T. I. p. 95; Europam incolit, ad Sueciam usque progreditur $(s), \&$ calidiores alias Europae partes, verbi gratia, Galliom, Italiam pervagatur $(t)$.

24.) Mus quercinus. Mus cauda elongata pilofa, macula nigra fub oculis. Limn. Num. I5. Mus avellanarius major. Gesn. Quadrup. p. 735. Lerot. Buffon. T. VIII: T. XXV. In temperatioribus Europae partibus, exempli caufa, Gallia, Italia, Hifpania (u) habitat; \& hine adPoloniam $(v)$ usque pergit, ideoque dubio procul in Germania quoque reperitur.

25.) Glis fciurus. Linn. Vid. Cap. II.

26.) Sciurus friatus. Sciurus. flavus Atriis quinque longitudinalibus. Linn. Le Suifje. Buffon. T. X. p. 74 . Tab. XXVIII. Ground fquirrel. Pennant. p. 289. \& Ed-

(a) Synopf. p. 304. (r) Barbot. Guinea p. 214. fec. Ponnant. p. 304. (s) Linn. Iraun. Suec. Edit. 2. Num. 35. (t) Buffon 1. c. (u) Bujsfon l. c. (y) Raacyzsski Hitt. Polon. 


\section{G E O G R A P H I C A E. 5 I ?}

Edwards. Avef. T. I8r. Buffonius hanc beftiolam in America tantum feptemtrionali habitare, 1. c. dixit; nec negandum eft, eam dictas quam maxime, imprimisque Pbiladelpbiae regiones $(w)$ magnis acervis pererrare. Nihilo tamen fecius magnis etiam gregibus $A$ fá regiones ad Euronotum fitas infeftat. Pallajüus enim eam non tantum in $K u / c h v a$ \& Tomska vidit, fed per totam quoque Siberiam omnibus in locis, qui abiete veftiuntur, reperiri narrat $(x)$. In America hic quadrupes haud longe meridiem verfus defcendere videtur, quoniam foli auctores, qui Americam feptemtrionalem defcripferunt, quales funt, la Hontanus $(y)$, Deky. frus $(z)$, Theodatus $(a)$, aliique illius mentionem faciunt. Animantibus itaque accenfendus videtur, quae \& Aflam ad Euronotum pofitam, \& Americam feptentrionalem inhabitant. Europa vero ipfum penitus ignorat.

Quas ultimo loco enumeravi animantes, Linmnaeus quidem aliique foiuris proprie fic dietis accenfent, fed tam forma, quam fingularis ipforum vitae ratio me movet, ut muribus potius fimiles eas habeam. Quoniam tamen tranfitum mihi a muribus ad foituros facillimum aptiffimumque praebent, haec ratio eft, quam propter hunc iis locum dederim. Ad fciuros enim me percommode transducunt.

\section{VI. SCIURUS}

I.) Sciurus palmarum. Sciurus fubgrifeus ftriis tribus fla-

(w) Kalms itin. T. II. p. $402 . \&$ fq. (x) Pिallas. itin. 'T. II. p. 20 \& 605. Tomskenfes indigenae illos Barundukios nominant. (y) Allg. Reif. T. XVII. p. 231. (z) Defcript. de l'Amérique feptentr. 1032. Tor. II. p. 33I. (a) Voyage de Sagard Theodat. p. 305.

$$
\text { Tt } \mathrm{t} 3
$$




\section{SPECIMEN ZOOLOGIAE}

flavicantibus, caudaque albo nigroque lineata. Linn. Num. 5. Le Palmifle. Buffon. T. X. p. 74. Tab. XXVI. Striarum numerus hoc in animalculo creberrime differt, in aliis enim tres, in aliis plures numerantur. Africae partes feptemtrionales, Barbarian feilicet vicinasque illi regiones incolit.

2.) Sciurns getulus. Sciurus fufcus, ftriis quatuor albis longitudinalibus. Linn. Num. 6. Le Barbaresque. Buffon. 1. c. Tab. XXVII. Barbarian fquirrel. Edwaidi Av. Tab. CXCVIII. Pennantus hunc antecedentis varietatem habuiffe videtur; $\&$ revera inter fe non modo fimillimi funt, fed iisdem etiam in regionibus vivunt $(b)$. Nunc quidem fciurus, cujus fub Num. Io. mentio fit, apponi debuifet, quia vero Americae fciuros divellere nolui, de illo deinceps fermonem faciam.

3.) Sciurus purpureus. Bombay Squirrel. Pennant. Synopf. p. 28 I. Caput, dorfum, latera, fuperiores pedum partes, \& cauda purpurei quidem, fed fqualidi coloris iunt, abdomen flavum. Pemantus, qui folus beftian hanc defcriptam dedit, prope Bombay eam reperiri, dicit. Idem auctor ex $T$ bevenoto beftiae hujus varietatem aliquam attulit, quam in Moca emtam fuiffe fcribit $(c)$. 4.) Sciurus macrourus. Pennant. Indian Zoology Tab. I. Sciurus Ceilanicus pilis in dorfo nigricantibus. Rukkaja dictus a fono. Raji. Synopf. quadrup. p. 2 I 5. Noftrate triplo major eft, Caudaque utitur corpore duplo longiori. Nigro alboque colore infecta, aures atris pilorum penicillis ornatae. In Ceilane patria fua Dandoelanae nomen habet.

(b) Elwward loc. (c) L. c. 


\section{G E O G R A P H I C A E:}

5.) Sciurus favus. Sciurus auriculis fubrotundis, pedibus pentadactylis, corpore luteo. Linn. Num. 4. Acervatim circa Amadabatbaie urbem, quae ejus patria eft, comparere, della Valle teftatur (d).

6) Sciurus vulyaris $\sigma^{2}$ sciurus cinereus. confer. Cap. I. ubi non improbabilibus rationibus fciurum vulgarem rubri fuscique coloris unius ejusdemque $f$ peciei, cinereumque tam veteris, quam novi orbis fesforem, \& plerosque reliquos folas inter fe varietates effe, comprobare aufus fum: partim quoniam penicilli, qui ipforum aures veftiunt, eorumque defectus ad novum genus quoddam conftituendum parum mihi fufficere videntur, partim quia ejusdem fpeciei fciuri, \& coloris \& magnitudinis refpectu admodum inter fe differre folent. Interim tamen plerosque fingulares fpecies effe, eousque concedam, donec res exactius inveftigata \& expedita fuerit: ideoque fingulas nunc feparatim enumero, quia nondum fatis certo evictum eft, eas revera cum fciuro vulgari tam exacte congruere, quemadmodum cinereus minor cum cinereo majori, cujus fub N. 6. memini. Hi enim ita inter fe conveniunt, ut coecum effe oporteat, qui utrosque varietates effe negaverit. Notatu memoratuque dignum eft, hunc etian fciurum in $P e$ ruvia obvium $(e)$ effe.

7.) Sciurus niger. Linn. N. 2. Black fquirrel. Catesby Carolina T. II. p. 73. Tab. LXXIII. Ubicunque locorum rufos fuicos cinereosque Cciuros inveneris, atros etiam obvios habebis, quod paffim \& in Germania accidit.

(d) P. 84. L'Leureuil blond. Peirnant. p. 283.. (e) Ovale in Churs: chills Coilect. Vol, III. g. 4t. 


\section{SPECIMEN ZOOLOGIAE}

dit. In ipfo Ducis noftri fereniffimi Gazophylacio, quod Brunswigae colligitur, fciurus niger reperitur, qui in ducatus hujus fylvis captus eft. Sat multi ejusdem coloris, quin \& eorum varietates in $A f i a$, in $S i$ beria prope fakuzkum \& Nertsibiskum occurrunt (f). Nonnulli eorum, quibus Siberia patria eft, nigrum femper colorem retinent : nonnulli vero aeftatis tempore pallefcunt. America nigros nutrit, quales Fermtmio tefte $(g)$ in Penfyluania (b) \& in Mexico ( $i$ ) usque ad Guinnam inveniuntur; Quidam illorum maculis notantur $(k)$.

8.) Sciurus ver/fcolor. Coguallin. Buffon. T. XIII. Tab. XIII. Varied fquirrel. Pennant. Synopf. p. 285. Superior pars corporis atra, mixto albo \& fufco variegata; animal hoc noftrate altero tanto majus eft, nec in arboribus, fed humi vivit. Quam ejus effigiem Buffonius dedit, noftrati fciuro eft fimillima. Ficrnandezius eum Mexici indigenam efre, ibique Quaucbtecollotl-quapacktli, feu proprie Coztiocote-qualiin (l) appellari tradit; hinc Buffonius nomen Coquallin formavit. An vero hic Buffonii Coquallin in America etiam meridionali vivat, incertiffimus fum.

9.) Sciurus aeftuans. Sciurus grifeus fubtus flavefcens. Linn. Num. 9. Sciurus coloris ex flavo \& fufco mixti, tae-

niis

(f) Mullers Sammlung Ruffich. Gefe. T. III. p. 518. \& Gmelin (fenior.) Reif. T. II. Praefat. (g) Fermin l. c. Ecurcuil. ( $h$ ) Kalms Reif. T. II. p. 466 . (i) Fernandez p. 8. (k) Pennant. p. 284. (l) Fernaniez Nov. Hifp. p. 8. ubi fciurorum fex fpecies enumerat, qui omnes folius novi orbis tint incolae, quod tamen de cinereis affrmari nequit; \& utrum iftorum plerique varietates fint, nemo nec affrmare nee negare cer. to pollucrit. 


\section{G E O G R A P H I C A E.}

niis in lateribus albis. Briffon. Reg. animal. Brafalian Squirrell. Pennant. Synopr. p. 286. Hic fine dubio fciurus eft, cujus Bancrofizus in Guianae defcriptione p. 85 . meminit. Pennantus hunc etiam fciurum Bráilien/om, pilofa atris albisque maculis notata cauda praeditum effe putat, cujus Marcgravius in biforia Brafilien/a p. 230. mentionem injecit. Americae itaque meridionalis feffor eft.

Io.) Ssiurnus mexicanus. Sciurus rariffimus ex nova Hipania. Seba Thefaur. T. I. Tab. XXXXVII. Tlamototii. Fernandez nov. Hifp. p. 8. Pennant. Synopr. p. 286. Cinerei coloris, fex ftriis albis ornatus. Cauda quatuor in ramos exit, in Mexico deget. Nullum eft dubium, quin tam in veteri quam novo orbe per multi adhuc fciuri commorentur, quos adhuc penitus ignoramus. Quibus etiam T/ut fibi in Madagafcare annumerandus eft $(m)$. Multos tamen ipforum folas varietates effe, perfuafiffimus fum.

r...) Sciurus volans. Linn. Polatoucbe. Buffon. Vid. Cap. II. Hic quintum Fernande $i$ ii genus conftituit. Pallafio tefte $(n)$ beftia haec in omni Siberna, ubicunque fylvae ex betulis conftantes inveniuntur, obvia eft : Qui loco citato addit animalculi hujus pullos coecos cife, talesque ad quartum decimum diem manere, quod ceterorum omnium quadrupedum nulli ufitatum eft.

12.) Sciurus fagitta. Sciurus bypochondriis prolixis volitans, cauda plano - pinnata lanceolata. Linn. Num. I I. Sailing fquirrel. P'ennant. Synopl. p. 292. Tab. 27. Ani-

mans

(m) Flacnurt Madagafcar. vel Allg. Reir. T. VII!. (n) Pallafii itia, T. I1. p. 439. 
522. SPECIMEN ZOOLOGIAE:

mans ifte non folum Polatoucbium magnitudine vincit, fed loco pollicis, quo ille praeditus eft, os quoddam: longius prominet, quod usque ad membranam extenditur, cujus beneficio volat : quove frmul efficit, ut. membranam iftam eo facilius extendere poffit. $\quad y_{a}$ vae $(0)$, aliarunque fub codem coeli tractu jacentium infularum, forfan aliarum etiam ejusdem plagae regionum indigena eft.

\section{ઈ. VII. JERBOA:}

Dentes primores, inferiores duo, fuperiores duo vel plures:

Pedes anteriores adeo breves, ut iis incedere nequeat, pofteriores longiffimi. Cauda longiffima.

I.) Mus faculas. Mus canda elongata floccofa, palmis fubpentadactylis, femoribus longiffimis, brachiis. breviffimis. Linn. Syft. Num. 20. Gerbua. Edwards. Av. Tab. 219. Aegyptian Terbua. Pennant. Syn. Tab. XXV. Gerbo. Buffon. T. XIII. p. 7 8: Thus Jagitta. Ruflis Tarbagautfchiki. Pallas. itin. T. II. p. 706 . Primi hujus 2 erbuarum generis fine dubio quaedam dantur varietates. Pallafius enim murem, quem defcripfit $S_{a g} i t-$ tam, cum Arabum Yerboa, hoc folo excepto, exacte convenire teftatur, quod fagitta duos pollices illö brevior minorque fit; alius tamen minoris adhuc cujusdam fpeciei meminit. In Pboenicia ad Libani montem ejusque vicinia, major quaedam hujus generis beftia repe: ritur $_{2}$ quam Ifraelis Damanem appellant, quam isco

nan-

(o) Hamiltons Voy., T. II. P. 13 I ... 


\section{GE O G R A P H I C A E. , 523}

nantus cum Jaculo mure unam eandemque effe putat. Sebarvizs hanc Damanem cum Ferboab, ratione pedunn pofticorum congruere afferit $(p)$, quae cuniculi magnitudinem habeat. Alpinus quadrupedem hunc cuniculis fimillimum effe $(q)$ teftatur: quae tamen differentia magnitudinis refpectu plane extraordinaria effet. Quum enim cuniculus in pedem pedisque dimidium extendatur, \& Ifraelis Daman prope ejusdem magnitudinis fit; utraeque animantes integrum pedem a fe invicem diftarent. $x_{e}$ erbab enim dimidiun plerumgue pedem: mus vero Sagitta quinque tantummodo pollices longus eft. Ex quibus collige, in utrarumque beftiarum dimenfione caudas licet fatis longas, omiffas, ha rumque longitudinis nullam habitam effe rationem. Quoniam difcrimen hoc nimium mihi vifum eft: $B_{u} f-$ fonium fequutus. Ifraelis Damanem diftinetam a Perboa animantem effe putavi, eamque dicto firb nomine in Tabula Zoologica loco fuo adnotavi; donec tempus diesque veram hujus animalis naturam formamque docuerit. Non magnitudinis modo, fed pedum etiam, digitorumque, quibus pedes armati funt, ratione haec animalia admodum imter fe differunt. Scbawius enim pedes anticos $\boldsymbol{P}_{\text {crboae tridactylos }}(\boldsymbol{r})$, pofticos vero tetradactylos effe, perhibet, quibus pofterioribus infuper pedibus duos digitos, alios minores, quos Germani in Gallis Gallinaceis calcaria appellant, addidit $(s)$. Hafjelguiftiuls contra $(t)$ ipforum pedibus digi-

(p) Schaw. Itin. p. $30 \mathrm{r}$. (q) Profp. Alpin. Aegypt. T. I. p. 232. (r) Schaw. l. c. p. I57. (s) Schaw 1.c. p. I57. (t) Halfelquijt p. 278 \& Sclwwed Abhandl. T.XIV. p. I? I. 


\section{S.PECIMEN ZOOLOGIAE}

gitos anticos quatuor, pofticos tres, tribuit, quae ansnia Limnaeus his verbis expreffit:

¿ Palmae fubpentadactylae, pollice obliterato mu" tico, plantae tridactylae fub medio plantae verruca "

conica (ui) "..

Utraeque tandem animantes ex $P^{2}$ ennanti teftimonio coloris quoque ratione a fe invice.m difcedunt. Dubia. haec omnia ex induftria appofui, ut iis temporis fucceffu eo facilius folvendis anfa. praebeatur. Quodfi interim hi quadrupedes, quos varii auttores fub rerbose appellatione commenoraverunt,, revera ejusdem funt generis: quantum huc usque conftat in Barbaria (v), in Aegypto (w) \& confinibus huic arenarum folitudini: bus, in Paleffina $(x)$, Perfan, Circalfia ad mare Cas: pium $(y)$, in Sibieria: ad Irtj cbii ripas allisque ejusdern regionis.locis ( $z$ ) obvii funt.

2.) Cunicullus pumilio faliens, cauda longinifima. Nov. Act. Petrop. T. V. p. 35., Tab. IX. fig. 1. Gmelin; Jun. Itin. T. I. p. 26. Tab. II. Siberiun Ferboa. Pennant. Syn. p. 296. Limnaeus hanc beftiolam \& Arabiac fer boom eandem efre his de caufis exiftimat, quia

\section{utrae-}

(u.) Linn 1. c. (y) Schaw ). c. p. 157. (w) Haffelquift 1. c. (x) Schasy. p. 30 r. $(y)$ Olearii Reif, Schleswig I 647. p. 519 . Schoberus in memorabilibus Ruffico-afiaticis, quac in Multeri: Rufficae Hiftoriae collectione T. VII: p. I.24. extat. Haec ipfa beltia, eft, quam Zits-ian vel potius Zits-kan nominant; ejus enim deferiptio non folum exacte in Texboam quadrat; fed Schoberus etiam hane illam. Arabum Yerboam effe exprefis verbis ad'ftruit. Nefcio itaque, cur Pennantus, Zitfamum a Brunio deferiptum, qui hic ipfe quadrupes eft, muribus alpinis adnumeraverit $(*) . . \quad(z)$ Pallas itin. T. II. p. 486.

(*) Peminito. Syropr. $D, 278$. 


\section{GEOG A P H C A E.}

utraeque eodem vitae gonére utuntur Quomam vero Gmelinus jun: expreffe feribit, pumitionis hujus falien-: tis tam anticos quam pofticos pedes pentadactylos es$\mathrm{fe}(a)$, ejus praeterea aures utrarumque Perboarun: auribus multo effe majores: Pennantum potius fequutus, ambas ut fingulares fpeciés tamdiu confiderare: malui, donec res majori luci expofita fuerit. Licet. non diffitear, fiesi polfe ut ultima haec antecedentis, tantum fit varietas. Cofackorum, Circafformm, Siberizaeque: regiones (b) incolit, variisque in locis Alagtngae no-; men habet.

3.). Mus longipes. Mus cauda elongata pilis veftita, palmis tetradactylis, plantis pentadactylis, femoribusi longiffimis. Linn. p. 84. Num. i 9. Pallajüt animal hocce in Cafanenfobus Orenburgenfibusque terris vidiffe autumat: murem enim, cui meridiani nomen impofuit, defcripfit , quem muri longipedi perfinilem effe tradit (c). " Habitat, inquit, in deferto arenofo quod verfus mare. "Cafpium \& quidem. Jaisum. Kolgamque interjacet". "Linnacus autem, nefcio cujus auctoritate fifus, eum in. torridis regionibus habitare feribit. Buffonius longipedem hunc murem; Israclis Damanem effe exiftimavit, qui tamen, quum illo multo major fit, virum celeberri-; mum hac in re erraffe fufpicor:-

4.) Rerboa. Tarfer Buffon. T. XIH. P. 49. Tab. IX. Indian Terboa. Penn. Synopf, p. 298 , Manibus pedibusque, praedita eft, pentadactylis, qui hominum vel fimiarum manibus ac pedibus fimillimi funt, a praeceden-

(a) Gmelin jun. itin. T. I. p. 26 : (c) Pallis Reif. T. II. p. 702.

(b) Gmelin fen, \& jum 1. G $\mathrm{V} v \mathrm{~V}$ 


\section{SPECIMEN ZOOLOGIAE}

dentibus omnibus difcedit. Pennanto \& Buffonio auctoribus Indrae. Orientalis incola eft.

5.) Yerbon gigantea. Kanguroo. Cooks voyage round the World in Hawnesworth's Collect. T. III. Tab. 20. Animal iftud, ex Cokii vel Banckii relatione, guod ad formam, rerbuae fimillimum eft, cujus etiam progre* diendi vel faliendi potius mores modumque exacte imitatur. Magnitudine vero ceteros omnes hujus generis animantes mirum quantum fuperat: quippe quae ovem aut canem venaticum feu vertagum aequiparat, \& centum fere libris par eft. Pullus ejus nondum adultus octoginta jam quatuorque librarum pondo excedebat $(d)$. Caput ejus cervi junioris capiti perfimile eft. Labia auresque leporis habet. Maxilla fuperior fex inciforibus fat magnis, inferior autem duobus tantum armatur. Pedes antici corpori ftricte adhaerentes, octo pollices longi funt, \& quinque digitos peracutis unguibus praeditos habent (e). Ex ungulis fi judicare licet, magis. ad fodiendam egerendamque lrumum factae videntur. Pedes poftici, quibus folis incedit aut falit, viginti duos digitos longi in quatuor fub finem digitos diftinguuntur, quorum duo fatis longe tergum verfus fefe extendunt. Caput, collum humerique totius corporis refpectu jufto funt graciliores. Cauda totius fere corporis longitudinem habet, ubi corpori adhaeret, crasfior eft, \& pededentim tenuior exit. Cutis pilis brevioribus murini coloris tecta eft. Novum hoc perrazumque animal in novae Hollandiae promontorio Orien-

ta-

(d) Cook 1. c. p. 5:6. Kanguroi carnes optimi faporis funt. (c) Quod Banckius in Gentieman Magaz. Julio I7.74. retulit. 


\section{G E O G A P H C A E. 527}

ali, cui novae Valliae meridionalis nomen impofuerunt, inventum eft. Incolit quoque partem Africae meridionalem, unde viyum in Hollandiam fuit delatum, atque accurate depictum \& defcriptum eft ab ALLAMANDO in ipfius ad Buffoniumb additamentis.

$$
\begin{gathered}
\text { S E C T I O X } \\
\text { PECOR A }
\end{gathered}
$$

Ordo quintus Linnaei.

Dentes primores fuperiores nulli, inferiores fex aut octo a molaribus remotiffimi. Pedes ungulati. Mammae-inguinales.

\section{Ø. I. CAMELUS. Lim.}

r.) Camelis Dromedarius. Linn. Num. I. Vid. Cap.II.

2.) Camelus Bactrianus. Linn. Num. 2. ibid. Binas. hafce animantes tanquan varietates conjunxeram; neque, ut ab hac fententia fecedam, ulla adhuc ratio fuccurrit. Quo usque per orbem difperfae reperiantur, fupra jam copiofe oftendi.

3.) Camelus Glama. Camelus corpore laevi, topho pectorali. Linn. Num. 3. Lama. Buffon. T. XIII. p. IO. Pelon Icbi-atloquitli: Hernandez nov. Hifp. p. 660. Lama.: Pennant. Synopf. p. 64. Cameli bi, quibus. gibber deeft, Ulloa auctore (a) proprie Clacmafii nuncupari deberent, \& folius novi orbis feffores funt. A feptemtrione $\mathrm{fi}_{1}$ initium feceris, in Mcxici regno primum illud animal invenies, ubi Corneras di. Tierra. (oves.)

ter-

(a) Notizias Americanas fobre la America meridional y feptentrional autore Don de Ulloa. Madrid. 177.2. 4.to... 


\section{SPECIMEN ZOOLOGI AE}

ierrrae) five oves Peruvicnfos nominantur (b). Hernan. dezio tefte ibi raro funt obviae $(c), \&$ ex áliis locis eo allatae videntur. Hinc fi progrediere, eas omribus in Orientalis Athericie partibus, in primis autem in Peruvia (d), Cbili (e) \& Briafilia $(f)$ offendes. Illarun autem in Surinama nulla milhi fieri mentio videtur, cujus tamen incólis forent utiliffimae. Férae in naturali fuo ftatu fub Guanacoe vel Gümanicoes nomine in Andilus, Anericae meridionalis nontibus, vivunt, unde ad $M a$, gellanicam usque terram defcendunt $(g)$.

4.) Camelus Pacos. Camelus tophis nullis, corpore lanato. Livin. P'aco: Buffon. 1. c. P'acos. Pemnant. 1. c. p. 66. Pecus hoc prioribus minus quidem, ceterum vero parum ab illis diffinitum, eandem enim patriam eademque domicilia habet. Vicunna etiam vocitatur. Ulloa tripiices eorum fpecies dari (b) fcribit, quas Alpacas, Clacmas \& Vicumnas appellant, quae omnes parum inter fediftent \& Guanacoubus perfumiles fint. Vix comprehendi poteft, qui factum fit, ut pecudes hae domefticae nec dum melius curatiusque defcriptatae fint ac depietae. Plures varietates Ulloa \& obfervavit \& depingendas curavit. a) Quas illarum icones Ulloa, Marcgravius b) Matbiohusque c) dederunt, optimae miki omnium videntur (i)

5. II.

(b) Allg. Reif. T. XIII. p. $65 \%$ (c) Hernandez 1. c. p. 660 .

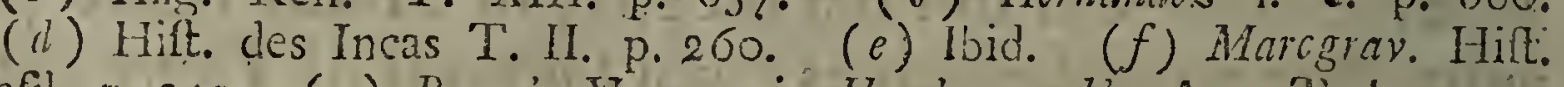
Trafil. p. 243. (g) Eyron's Voyage in Haspkesworth's Acc. 1. 1. p. I5. \& 18. \& Wallis Voy. ibid. p. 375. (12) Notizias Americanas.

(i) Tandem venutam exactanque fatis Guanikoes effigiem datam effe vidi, quae in iconibus Cookiz itinerario nuper additamenti loco adjunotis numero fecunda eft. 


\section{G E O G R A P H I C A E. 52}

6. II. Moscruv.s. Linr.

т.) Mofcbus mofcbiferus. Mofchus folliculo umbificali. Mufc. Buffon T. XII. p. 212. Tibet Mujc. Pènnant. Synopf. p. 56. Tab. 10. fig. r. Animal hoc, quod mercatoribus magni momenti, magnaeque utilitatis eft, in Afiae tantum parte aliqua, $R$ uffeca nimirum, prope Altaicos $(k)$ montes in Irkuzcen/ique provincia vivit, ubi Saiga (b) nominatur. Prope Ilimskimm (m) ad Baikalis lacum, ad Jeriføi fluvii ripas (n), verfus Orientem \& in omnibus ejusdem tractus regionibus montanis occurrit; in Cbinae praeterea provincia $X_{c \text { in- }}$ $f(0) \&$ Sucbuen, in Tibeto \& quam maxime in Bouto. $n 0(p)$, ubi \& plurimi \& optimi illorum reperiuntur, quorum mofchus praeftantiffimi odoris eft. Eos etiam in Tinquino \& Pegu obvios effe, Scbrockitrs (q) teftatur. Tavcriierius loco in margine laudato, beftiam hanc aegerrime ad quadragefimum quartum latitudinis gradum defcendere, lubentius autem feptemtrionem verfus progredi adfirmat. Quodfi itaque Tuzquini Peguique calores aegre ferre valeret; Tavernicrius tamen nimis anguftis ipfam finibus inclufit, quia Boutani regio, quae praecipua ipfius patria eft, ultra trigefimun gradum extenditur. Interim animans haec interioribus quam maxime in regionum partibus aut circa montes commorari videtur, quod exinde colligo, quia in terris, quas mare al-

luit

(k) Pallas Reir. T. II. p. Cgб. (l) Gmelin (fen.) Reif. T. 1. p. 2 rz. (m) Ibid. T. 11. p. 207. (n) Mullers Sammlung. T. III. p. $56 \mathrm{r}$. (o) Neuliofs Gefandfchaft p. 273. cum icone. ( $p$ ) Tayernier Voy." Rouen 171 3. T. IV. pag. 75. \& feq. . (q) Schrockii Hiftor. Mofchi. Vienaae I.682. p. $5 \%$ 


\section{SPECIMEN ZOOLOG FAE}

luit, nullum ejusiseftigium reperire mihi licuit. Haec forfan cauffa eft, cur nec in $\mathcal{f} a p a n i a$ hucusque inventa fit.

2.). Morchus Pygmaeus. Mofchus pedibus humano di. gito anguftioribus. Limn Num. 3. Cbevrotain des Indes Buffon T. XII Tab. XLIII. P. I83. Tragulus Guineenfis. Brifjon. Regn. animal. pag. 65 . Edit. Leidenf. Guinea Musk. Pcinant. 1. c. p. 59. Buffonio Sebaque tefte $(x)$, Indiac Orientalis incola eft. Pennantus ipfum promontorii Guincen/os fefforem effe dicit $(s)$. Eorum inftar, quorum jam memini animantium, longos duos prominentes dentes caninos habet. Cornibus caret. Hxc potiora figna funt, quibus genus hoc a $m i-$ sori Antilope, quae ejusdem magnitudinis eft, quamque poftea commemorabo, penitus diftinguitur, licet permulti fatis autotores utrasque beftiolas hafce per errorem inter fe permutaverint.

3.) Mofchus meminna. Indian musk. Pennant. Synopr. p. 59. Tab. X. fig. 2. Knox in Ceilonis (t), quam edidit, hiftoria, hanc animantem infulae hujus indigenam effe, tradit. Pemnanto optimam ejus tam effigiem, quam defcriptionem debemus.

4.) Tragulus Surinamon/ss. Tragulus ex rufoluteus, maculis albis variegatus. Brifon. regn. animal. p. 96. edit. Parif Ceroula Surinamen/is fubrubra, albis maculis notata, Ssba Ther Vol. ro p. 7 I. Tab. XL. Buffonius hanc beftiam, in novo orbe reperiri negat, quoniam, minimae formae cervulos ('I ragulos filicet vel Chevrotains) in antiquo tantum orbe fedem patriam ha-

bere

(r) Seba Thefaur: T. 1. p. 7o. (s) Synopf. p. 5\%. (i) Knoa H. Aloire de Ceilan: Lyon I 693. p.-go, der Aigemein. Reifen T. VIII. 


\section{GE O GR P H I C A}

bere opinatur. Sebam itaque, qui alioqui faepius erravit, in hujus etiam quadrupedis domicilio hallucinatum efle, putat. Ferminizus vero \& Bincroftius utrique -teftes locupletes expreflis verbis fribunt $:$ cervorun höfe pygmaeos circa Surinamam copiofe fatis reperiri; \& W irrebocorran cervulum effe, cui cornua defint (u), quive ex rufo lutei coloris fit $(v)$. Bina haee teitimonia ad refutandum Buffonitum fatis milhi ponderis habere videntur; nec ulla conftat ratio, cur integra animantium genera unius alteriusque tantum orbis finibus includenda fint. In Tabula Zoologica fub Tirrebocerrae nomine beftian hane loco fuo appofitam invenies. Suffciat, cervulum hunc ab antecedente diverfiffimi generis effe. Interim annotandum exiftimo, fi duo prominentes incifores in fuperiori maxilla praecipuum hujus generis characterem conftituunt, utrasque beftiolas lo. cum heic nullum invenire poffe, quin potius, quod Klcinio etian vifum eit, fingulare quoddam Tragulorim genus conftituere.

6. III. Cervas. Linn. Gen. 29. Genus cervinum. Briffoil. regn. anim. p. 85. edit. Paris.

\section{a. Cornibus palmatis.}

I.) Alce. Lim Num 2. Vid Cap. II.

2.) Tarindus Lin. Num. 4. Vid. Cap. II. cui addo, quasdain machles ad Uralis montem fub quinquagefimo quinto ad quinquagefimum fextum latitudinis gradum (vi) commorari \& hanc eandem Beftiam in Tata-

ria

(u) Fermin Hollande Equinox. p. 6. Artic. Cerf. (v) Bencroft Guiana p. 73. (1V) Pallas. itin. T. II. $\mathrm{Xx} \times 2$ 


\section{SPECIMEN ZOOLOGIAE}

sia Kalkaf/en/f fub quinquagefimo circiter latitudinis gradu, fub Oronis appellatione $(x)$ reperiri. Quum regiones iftae magis ad meridiem vergant, quam quae in Europa macbles nutriunt : hinc mea quidem judicio fluit, illas majori frigoris vi premi. Fines itaque quos inter macbles vivunt, fi ab Europa numerandi initium. feceris, femper oblique magis meridiem verfus ad Americam decurrunt ejusque quadragefimum quintum circiter gradum attingunt. Quodfi. America jeptemtrionalis pluribus fucceffi temporis incolis frequentabitur; fines. ifti Europam verfus magis afcendent.

3.) Dama Linn. Num. 5. Vid. Cap. II.

ß. Cormibus teretibuis.

4) Cervas Elaphas Linn. Num. 3: Vid: Cap. II.

5.) Cervus, Axis.l'Axis. Buffon. T. XI. Tab.XXXVIII \& XXXIX. qui nomine cervi maculati Beng.alen/is infig; niri poffet. Bengalam enim $(y)$, Ceeilonem Favamque in. habitat $(z)$. Pennantus majorem hujus generis animantem fub great Axis, nomine addidit. Vide etiam Cap. P. fub Cervo:

6.) Cervis porcinus: Porcine Deer. Pennant: Syn: p. $5^{2}$. Tab. VIII. fig. 2: Cornubus tricuspidibus \& corpore multo craffiore brevioribusque cervo noftro pedibus praeditus eft. Clivius nobilis. Angliae hunc ex lindia Orientali in Angliams attulit, qui forfan fola noftratis varietas eft.

7.) Dama Virginiana. Virginian Deer. Pennante Sy=-

(x) Allgem. Reir. T. VII. p. 2 .r. I. VIS. $(z)$ 'Pennasst. L c. p. $5 z^{2}$ (y) Voyages des Hollandois: 


\section{G E O G R A F H I C A E. . 533}

Synopf. p. 5 r. Tab. IX. fig. 2. cornua depicta dedit: Americam Septemtrionalem, Carolinam (a) nimirum Loutifannamque, gregatim pervagatur $(b)$ : Jant capite fecundo docui, Pennantum hanc beftiam jure a Damis noftratibus fegregaviffe. Forfan etiam Panumae ferae generis cervini huc $(c)$ referri debent.

8. ). Cervus Capreolus. Vid. Cap. I.

9:) Cervus Pygargus. Pallas. Itin. T. I. P 453, Vid: Cap. I. fub cervi nomine, ubi, quam Pallafuns hujus animantis defcriptionem dedit, adjunctam invenies. Ipfum quidem ibi. varietatem capreosic nofri effe, dixi= interim tamen fieri poteft, ut fingularcm aliquam fpeciem efficiat. Me tamen in eo ibi errafe fateor, quod verba 'quaedam ex Pallafii itineribus, quibus' Saizgam, feu capran tartaricam defcripfit, ad pygargum hunc applicui: Quum enim pygargus a Tatariae quibusdam incolis Saigae etiam nomine appelletur, haec erroris mei anfa fuit.

10.). Cervus (vel potíus) Caprevilus mexicanis. Mexican Deer. Pennant. Synopf. p. 54. qui Tab. IX. fig. 3 . cornua fola exhibuit. Cervess major corniculis breviffit mis. Barrere. France équinox. p. I 5 I: Pernantus hane animantem a capreolo. noffro plane diftirezant-fpeciem, eamque Teutlalmazamem effe ftatuit, quam Hernandes zius in Mexico \& Guiana habitare dicit (d). Huc alis adhuc quidam nondum exacte determinati quadrupedes referri debent; verbi caufa, Tonkongus, qui haud pró

cull

(a) Lawfons Carolina p. 123. (by Du Miona Mém. fúr la Louifiane T. I. p. 75. \& Allg Reif. T. XVII. p. 87. (c) Allg. Reit. T. XVI - p . 115. (d) Hernanilez l. c.. p 324 !

$\mathrm{X} x \mathrm{x}-3$ 


\section{SPECIMEN ZOOLOGIAE}

cul a Guinca habitat (e), Scoaffu Amcricae meridionalis indigena $(f)$, \& fortaffe permulti alii, quorum nonnullos nominibus quibus indigenae ipfos appellant in Mappa Zoologica annotavi, ne qui deeffe viderentur.

I I.) Cervus camelopardalis. Cervus cornibus fimpliciffrmis, pedibus anticislongiffrmis. Linn. Num. I. Giraffe Bulfon. T. XIII. p. 3. Camelopard. Pcmant. Synopf. p. 20. Huic beftiae non idcirco hunc locum de$\mathrm{di}$, ac $\mathrm{fi}$ convietus effem eum ipfi jure deberi. Sed quia fub judice adhuc lis eft, utrum cervorum inftar cornua annua gerat? praeterea ad infequentis claffis quadrupedes fatis prope accedit $(g)$, heic potius ejus mentionem facere, quam novum \& tingulare quoddam genus rarioris hujus animantis conftituere malui. Animans autem haec quantum quidem invenire mihi licuit, in Africae regionibus minus nobis cognitis commoratur. Buffonizus quidem eam tam Afiae quam Africae meridionalis provincias incolere tradit, quam tamen fententiam, Aface refpectu, certa nulla auctoritate munivit; nec ejusdem uila teftimonia in peregrinantium diariis reperire potui. In Africa feptentrionaii camclopardalis fere ad Senegallian usque adfcendit. Parum enim abeft, quin perfuadear, quadrupedem, qui fub Gbiamalae appellatione in Fagae Gaduaeque regionibus fub nono longitudinis \& decimo tertio quartoque latitudinis gradibus degit, nullum alium, praeter Gireffan effe. Praecipue quum Gbiamalac huic, cameli forma praelongique pedes

(e) Alig. Reif. T. III. p. 72. (f) Ibid. T. XVI. p. 269. (g) Aptius $P$ tillas reique accommodatius inquit ; Camelopardalis prorfus anomala atque inter Antilupas \& Camelos media quari beltia eft. Spiciles. Talcic. I. p. $\sigma$. 


\section{G E O G R A P H I C A E. 535}

pedes antici $(b)$ tribuantur: licet Bainbouci incolae Compragrono hanc beftiam feptem cornibus armatam effe narraverint, quem tamen numerum plus jufto auxiffe videntur. Porro haec beftia in terris prope transque Atlanten fitis confpicitur (i). Eam vero in promontoriis minus notam effe, exinde colligo, quoniam nec Bosmonnus, nec Artus, nec alii ejus in Guinea, nec P'igafecta in Congo, mentionem ullam faciunt. Trans bonae Jpei promontorium autem eam rurfus comparere Kolbius $(k)$ \& Bougainvillius teftantur (l). Poft in Zan. gutlaria \& quod unus Marcus Polus affirmat, in Madagafcare (m) occurrit. Quod quidem haud improbabile effet, quoniam in Zanguebariae (n) littoribus vivit, Quum vero praeter Marcun Polum nullus alius, eum Madagafcaris fefforem effe adftruxerit, res adhuc dubia mihi videtur. Fortaffe genus hoc poftea fato quodam in Madagafcare extinctum eft. In Abiflinia $(0)$ etiam degit, \& hinc ad Aegyptum ( $p$ ) usque adfcendit, ex. quo palam fit, eam calidiffimas tantum Africae terras. incolere.

\section{IV. ANTILOPE.}

Cornua annulata vel contorta vel redunca. Dentes. primores octo inferiores, fuperiores nulli. Corpus clegans caprisque elegantilus. Antilope Penmant. Synopio. p. 22. Hoc animantium genus, Buffonizin Pallualum, Pinnantumque, quihac in re confentiunt, fecutus fum-

1110

(i) Compagnon in Alig. Reil. I. II. P. 5l3. (i) Leo Afric. p. 337.

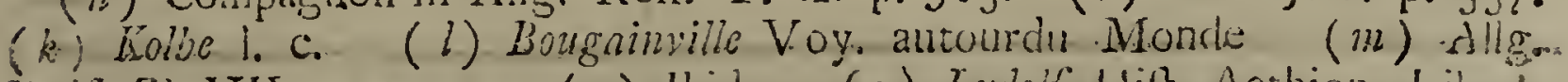

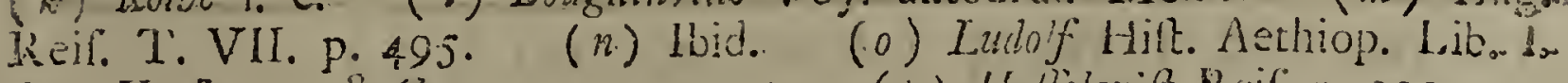
Cap. X. 2. 33. \& Commentar. p. 149. (p) Hulje!quifa Rei!. p. 203. 


\section{SPECIMEN ZOOLOGIAE}

mo jure a capris fejungo, illique cervos inter caprasque aptiffimum locum tribuiffe autumo. Optime nos animantis huajus hiftoriam Buffonius T. XII. Pallafrus fafciculo prim. fpecileg. Zoolog. \& Pennantus denique 1. c. docuerunt. Buffoniuss tamen, qui primus de iis nos certiores fecit, de Antilopis his optime omnium meritus eft. Species Antiloparum P'alla/usus 1. c. inquit, per Afram \& inprimis per Africam numerofae vagantur, \& praeter Sażyam, Capram Tatarican Limnaei, I'ennazztus in Europa nullam invenire potuit. Ut vera fatcar, nunquam perfuadebor ut Rupicapram, quam Pallafus, Antilopis adnumerat, huic generi fubjiciam. Sedem itaque praecipuam in calidioribus antiqui orbis locis Antilopae habent: novus enim quantum hucusque conftat, Gazellas nullas alit. Seba quidem earum nonnullas in Americam transpofuit. Vir autem hic ceteroqui celeberrimus, quod Buffonius faepius in operibus fuis notavit, multos ejus generis errores admifit. A/ân vero \& Africa non folum permultas earum (pecies, fed magnos etiam greges alit. Bosmannus in fola Guinea vel viginti caprarum, fic enim Antilopas nominat, fpecies dari fcribit (q). Se praterea pernagnum earum numerum quibusdam in locis vidiffe adferit, \& Kolvius variegatorum caprorum $(\boldsymbol{r})$, fub quibus fine dubio Antilopas intelligit, tantos' greges in bone fpei promonorio interdum obvios effe, perhibet, qui vel fexcentos vel aliquot millia contineant, quos beftiarum carnivorarum magni acervi infequantur. Hoc idem auctor Itinerarii

ad
(1) Allg. Reif. T. IV.
(r) Kolbe 1. c. F. $281 \& 390$. 


\section{G E O G R A P H I C A E. 53 .}

ad Franciae infilam (I/le de France) $(s)$ confirnat.

In enarrandis quae nobis innotefcunt antilopis $P$ ennantum potiffinum fequar, earumque patrian, quantum fieri poterit, apponam. In Tabula Zoologica fpatii anguftia coactus, varias antiloparum fpecies, quod in fimiis \& vefpertilionibus fieri debebat, numeris, quibus yocem decurtatam Ant. (antilopant) praepofitam videbis, defignabo. In tabula ipfa numerorum iftorum explicationem ftatim additain habes, \& fic, minus errare poteris. Ubi vero f́pecies ipfarum determinari haud potuerunt, quia peregrinantitum praecipue antiquiores, beftias has fub communi forarnin caprarum denominatione comprehendunt: ibi voculas Antil. var. (Antilopae variae) appofui, quod in Abyfinia aliisque locis factum cernes. In genere obfervamus, animalia haec, exceptis duabus antilopae filicet Scytbicae \& Tzeiranae fpeciebus, quae ad quinquagefimum fextum feptimumque latitudinis gradum afcendunt, tráctus terrae frigidiores nullos incolere. Reliquae enim omnes calidiores plagas occupant. Hinc fiet, ut fi in A/ia \& Africa a dictis jam gradibus aequatorem verfus progrediare, omnia iis referta invenias. Quoniam itaque temperatiores tantum antiqui orbis plagas occupant, easdem in America fruftra quaeres $(t)$. Si antilopas fec undum. cornuum formas ac rationem, quod Pallafius \& Pennantus fecerunt, difpofueris, fequentes habebis claffes.

A. Antilopas cornubus rectis, vel ammalatis vel contortis:

B. Cor:

(s) Voyage al'Isle de France \& do Bourbon. lettre 22. (t) Vid. Cap.IV: Yy y 


\section{SPECIMEN ZOOLOGIAE}

\section{B. Cormibus redunculis.}

C. Cornibus in lyrae antiquae formam tortuofis.

D. Cornibus retro aut caprarum noftrarum more curvatis. Ab his ultimo loco nominatis, Pcunantus \& $P$ allafus numerandi initium fecerunt, quod idem in Tabula Zoolog. feci. Quum vero cornibus rectis armatae, propius ad Giraffam accedant \& quas cornibus. retro flexis Natura ornavit, capris noftris fimillimae fint ; ordinem hune potius fequentem in modum mutare. mihi placuit.

A. Antilopae cornibus wectis annulatis vel contortis.

I.) Antilope Bezoartica. Pallas. Fpicileg. Zoolog. fafc. I. p: 1.4: Capra Gazella. Capra cornubus teretibus rectiffimis longiffmis in bafi annulatis.. Linn. p. 96. Num. 7. Pafan. Biffon. T. XII. Tab. XXXIII. fig. 3. Sola cornua exhibet. Bezoar Antilope. Pennant. Synopr. p. 26. Juxta Pallafum haec varietas modo caprae bezoarticae eft (u) Linn. (Algazel. Buffon.) Pennantus. duas hafce beftias quidem diffociat : fed fi. cornua, quorum imaginem Buffonius dedit, confulueris, difcrimen: nullius fere momenti efre invenies. Pofterioris enim cornua vel parum vel plane non arcuata funt. Quodfi tamen differentiam iftam exacte dijudicare voluerimus, animantem ipfam infpieiamus oportet. Species iftas nimium multiplicare nolui: hinc illarum nonnullas omifi. Gazellarum haec fpecies, fr Gazella Linnaeique Bezoar:tica capra unum idemque funt animal, quod-Pallafius. affirmat, quam latiffime per orbem dilatata reperitur. In

A/ra

(u) Capra cornibus teretibus arcuatis totis annulatis. Cornua quae Infforius depicta dedit, ${ }_{y}$ ex minima tantum parte arcuata funt. 


\section{G E O G R A P H I C A E. 539}

Afia cnim \& in Perface potiffimum Cbovafanae (v) Laarisque provinciis vivit. Praeterea in India (w) Plosilippimisque $(x)$ Infulis obvia eft. Prope Aleppum (y) Syriac urbem celeberrimam occurrit. Dein Arabiam $(z)$ quoque incolit. Aegypti (a) porro Africae regni, \& fortitan Guineae, bonaeque spsi promontosii incola eft. In Tabula Zoologica voculis Antil. 2. eam indicavi.

2.) Antilope Oryx. Pallas. 1. c. p. 15. Coudou. Buff. fon. T. XII. Tab. XLVI. b. cornua exhibet. Annon haec Kolbii eft Alce capen/is (b). Pennantus hanc beftiam Nylgbavum effe, credit (c), qua in re tamen affenfum ei idcirco praebere nequeo, quia, quam Hunterus Nylgbavi defcriptionem dedit, ab Antilope Oryge admodun difcrepat. Quippe quae, quod Pallafifus ex novif/imis Batavorum relationibus probat, in bonae spei promontorio vivit. In mappa Zoologica fub Ant. 3. voculis notata cernitur.

3.) Antilope fcripta. Pallas. 1. c. P. I5. le Guib. Bufforr. 1. c. p. 180. Tab. 40. Adnusonius, elegantiffimae hujus beftiae ad Senegae ripas in Podoris regione greges obvios habuit $(d)$. Adniodum mihi probabile eft, animantem hunc eundem effe cervum, cujus Bosmanzwus fub Num. 3. mentionem fecit $(c)$, quem molochino colore infeetum, albisque ftriis ornatum effe fcribit. Mappa Zoologica ipfum tibi fub vocula Ant. 4. monftrabit.

(v) Kacmffer Amoenit. p. 398. (w) Monardis de lapide Bezoar 1605. (a) Allg. Reif. T. XI. p. 4.37. (y) Ruffel Natural Hittory of Aleppo. (z) Buffon l. c. e Garcia ab Horto. (a) Defcriptiones animal. quae in itinere Orient. obfervav. P. Forskael. Havniae 1775 , p. 4. (b) Kolbe 1. c. p. 145. $\quad$ (c) Synopr. p. 20 . (d) Buffonl.c. (e) Bosmanr Guinea 'Tab. $1 \mathrm{~L}$.

$$
\text { Yy y } 2
$$




\section{0 \\ SPECIMEN ZOOLOGIAE}

4.) Antzlope Grimnia. Pallas. 1. c. p. 38. Tab. 3. Mojcbus Grimnia: Linnatus. Guinea Antilope. Penn. 1. c. p. 27. La Grimme. Buffor. 1. c. p. IS г. Dr. Grimmius primus eft, qui antilopam hanc in Ephemeridibus nat. curiof. defcripfit. Cujus femellam in bonae Spei promontorio cornubus carentem viderat. Hinc factum eft, ut Linnaeus ipfam mofcbis adnumeraverit. P'allafuns autem maris icona cornubus armati elegantiffimam dedit, eamque exacte defcripfit. Quam $P$ alláfus beftiam vidit, ex Gunnea ad ipfun delata fuit. Cujus vero quadrupedis Kolbius fub capri cani (Greisbocks) nomine $(f)$ meminit ; dubio procul Grimmia eft. Ex quo ipfam in bonae etiam $\int p e i$ promontorio nutriri colligo. In Tabula Zoologica eft $A m t .5$.

5.) Antilope pygmaea. Cervula parvula africana. Seba Thef. Vol. I.p. 70. Tab. XLIII. le Cbevrotain de Guinée. Buffon 1. c. p. I 32. Tab XLIII. fig. 2. Cornua fola habet. Royal antelope. Penn. Synopr. p. 28. Adcuratam animantis hujus effigiem adhuc nullam habemus. Cujus autem cornua Buffonius l. c. depingenda curavit, fatis comprobant, eam jure antilopis adnumerandam effe. Beftiola haec elegantiffima in Guinea degit $(g)$, cujus indigenae eam $G$ ulevei, \& propter pulchritudinem fuam icivorum reginam falutant. In Tabula Zoologica eft Ant.6.

$B$. Cornibus in frontem redunculis.

6.) Antilope Tragocamelus. Pall. 1. c. p. 9. Traga. comelus. Parfon. Philosoph. Tranfact. Vol.43. p. 463. Indoftan Antelope. Pennant. 1. c.p.29. Parfon folus eft,

qui

(f) Kolbe l. c. p. 15 I.

(g) Allg. Reif. T. IV. \& Adanfon Voy. 


\section{G E O G R A P H I C A E. 54I}

qui beftiae hujus imaginem, \& quidem fatis elegantem, exhibuit. Mandelslob (b) quadrupedem hunc, füb Biggelii appellatione, Goae in proregis theriotropheo vidit. Interiora Indoftanen /s regni incolit. In mappa eft. Ant. 7 .

7.) Antilope leucopus. WWbitefooted anterope Peinnant. 1. c. p. 29. Tab. VI. Uni Pennanto antilopae hujus effigiem \& defcriptionem debemus; fi ex icone judicare licet, multis in rebus cum Dama, quae mox fequitur, congruit. Eam vero Nylgbavomn effe, quem Hunterus defcripfit ( $i$ ), perfuadere mihi nequeo, quod tamen Cl. Beemannus profeffor ftatuit $(k)$. Antilope haec ex India Orientali advecta fuit.

8.) Antilope Dama. Pallas. l. c. p. 8. le Nanguer. Buffon 1. c. p. I25. Ex Adan/onii relatione (l) Scregae ripas incolit.

9.) Antilope redunca. Pallas. 1. c. le Nagor. Bufforn. \& hujus beftiae patria prope Senegam eft. An tres

(12) Biggelium, inquit, quendam vidi tam colore quam magnitudine macnli non abfimilem, nigris duobus isque brevioribus cornibus, quibus juvenci nottri praediti effe folent, armatum : Caput equini capicis formam nigrunque colorem habebat. Collum longioribus pilis afinorum more tectum crat. Pedes nigri ungulisque bifidus armati erant. Vid. Man. tielf. itin. p. 86.

(i) An account of the Nylghau by IVill. Hunter Prilof. Transaz. 177 1. Art. 21. Animantium ruminalium omnium, fi bovem exceperis, hic maximus eft, locumque bovem inter majoresque feras reliquas jure oc: cupare videtur. Duodecim palmas alta eft. Corpus, cornua caudamque bovis: Caput vero, collum pedesque cervi habet. Ny:ghavis feu vacca' cacrulca, quod etiam nomen ipli imponitur, fingulare quoddam genus ccnfticuit, quod interioribus Inchoftani in regrionibus degit. Lemierius (*) ipfum Cachemirien/is provincial ir dig znam effe, fcribit.

(k) Phyfical. Oeconom. Biblio:hec. T. III. (l) Ap. Bufou l. c:

(*) Voy. de Dernier.

$$
\text { Yy y } 3
$$


542 SPECIMEN ZOOLOGIAE

hi, quos hactenus fub 7.8 . 9. numeris commemoravi quadrupedes, ut varietates tantum inter fe differant, quod mihi videtur, tempus demum dicsque docebit.

C. Cornua cocbleae EO lyrae antiquae in modum flexwos/s foit tortuofa.

10.) Antilope firepficeros. Pallas. 1. c. p. I7. Condoma. Buffon. 1. c. p. г 78. Tab. XXXIX. Cornua tantum dedit animal anonymum. Houtuyn Natur. Hiff. Vol. III. Tab. XXVI. In bonae Ppei promontorio invenitur, cujus indigenae ipfum, Pallafio tefte, Coudou appellant: quam tamen denominationem Buffonius Orygi, cujus fub Num. 2. jam mentio facta eit, impofuit. . Sola quain Houturynius dedit, effigies, beftiam hanc integram nobis exhibet, quam Mucllerus in commentario, quo Linnaei Jyilema naturae illuftrat, depingere curavit. Cornua beftiae in variis naturae Gazophylaciis \& in mufeo etiam Brunswicenfi affervantur.

I I.) Anzilope cervicapra. Pallas. 1. c. p. 19. Tab I \& II. Capra cervicapra. Capra cornibus teretibus, dimidiato annulatis, flexuofis, contortis. Limn. Syft. p. 96. Antilope. Buffon. 1. c. Commoun Antilope. P'cnnant. Buffonius inprimisque P'allafus animantem hanc exaEtiffime depictam defcriptamque nobis dederunt. In Africa \& in Barbaria praecipue habitat, cujus incolae ipfam Lidmec nominant $(m)$. Thevenotus $(n) \&$ Maindelffob $(0)$ eandenn magnis gregibus in Orientali India confpici afferunt. Nec dubium eft, quin pluribus

etiam

(uz) Shany l. c. p. I52. (ii) Thicvenot Voyages aux Indęs Part. III. p. I I4. (o) Mandelfoh Reir. Cap. XIl. 


\section{G E O G R A P H I C A E.}

$543^{3}$

etiam in Afiae Africaeque regionibus alatur. A $S_{c b a-}$ wio commemoratam Lidmceam, aliam animantis fpeciem effe, Pennantus opinatur. In Mappa Zoolog. eft $A n t .8$.

12.) Antilope Dorcas: Pallas. 1. c. p. Ix. Gazelle. Buffon 1. c. p. I 9: Tab. XXHI. Barbary Antilope. Pennant. p. 23. Capitis figuram in Pennant. Libr: titulo videbis. Gazella Africana cornibus brevioribus ab imo ad fummum fere annulatis \& circa medium inflexis. Raji. Synopf. Quadrup. p. 8o. In ( $p$ ) Barbaria Natollaque, prope Aleppi (q) urbem, \& in Aegypto (r) ubi magni ejus greges oberrant, patriam habet.

I3.) Antilope Kevella. Pallas. 1. c. le Kevel. Buffon 1.c. p. 144. Tab. XXVI. Pallas teftis curontns confirmat, Gazellam, cujus Bufforius fub Corinnae nomine meminit, Kevellae femellam efre. Quin \& ipfe Buffonius (s) Gazellan Africanam eandem cum Kevella, \& Corinnam, quam tefte Adanfonio Senegae ripa nutrit, illius modo varietatem effe, autumat.

14.) Antelope Tzeiran: Cbinese Aintelope. Pennant. 1. c. p: 35. le Tzeiran: Buffon. T. XII. p: I22. edito germ. $4^{\text {to }}$. Capracampeftris gutturofa. Nov. Comment Pe. trop. T. V. p. 34\%. Tab. IX. Huec forfan Antilope Pygargus eft, cujus cognitionem Pallafio debemus. Tzeiranus ruffici imperii civis eft, domiciliumque prope: Cbinae fines habet, ubi Gmelinus fenior ipfum ad OruLengruivis ripas obvium habuit $(t)$. Porro maris Cafpiz littora, Pers iam fpectantia (u) \& nonnullas interioresi

Pere

(p.) Schanv 1. c. p. 15 r. (q) Rufel Aleppo. p. I3o. (r) Buffons 1. c.

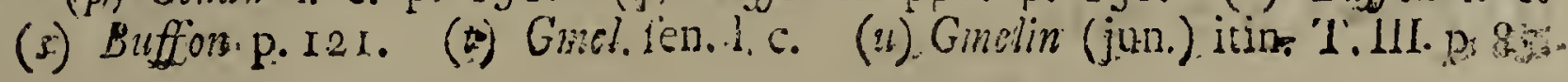




\section{SPECIMEN ZOOLOGIAE}

Perfane regiones inhabitare dicitur, ubi ab indigenis $A b u$ (v) vocatur.

15.) Antilope Scytbica. Pall. 1. c. Capro tatarica. Capra cornibus teretibus, rectiufculis perfecte annulatis, apice drøaver (pellucida) gula imberbi. Linn. Saiga. Buffon 1. c. p. I 17. Haec fola Antilope in aliquibus etiam Luropae terris pafcitur. Pennantus (w) enim eam in Transfyluania degere, certo fibi conftare confirmat. Et Herberfecinius ad Gesnerum $(x)$, itemque Gmelinus (y) Senior eam in Borifbenis Tanaisque ripis vivere, teftantur: ipfan autein veram Saigam esfe, ex cornuum pellucidate colligimus, qua potiffmum a reliquis fui generis omnibus diftat. Ad regni Aftracani metropolin magni ejus acervi confpiciuntur, quod Ginelinus jun. T. II. itin. pag. 174. confirmat $(z)$. In Jaiki etiam Irtichiique (a) ripis vivit, \& parum abeft, quin credain, eam Sinenfum capram efle, quam luteam $(b)$ dicunt.

16.) Antilope bubalis. Pallas. 1. c. p. I2. Bubale: Buffon 1. c. p. 174. Vacte de Barbarie. Mém. de l'Académ. des Sciences T. I. In Barbaria habitat, cujus indigenae eam Bekkcr-el-wash nominare (c) feruntur. Buffonius etiam Kolbii Alcen Boubalin effe autumat, quod tamen nondum fatis evictum eft, licet largiar, fieri poffe, ut in aliquibus etiam Africae terris nutriatur.

I7.)

(v) Olearius Reil. 16.7. p. 316 . (w) Pennant. Syn. p. 35 . (x) Gesn. Quadrup. p. $36 x$ (y) Nov. Comment. Petrcp. T.V. p. $345 \& 46$. (z) Ibi etiam optima ejus imago nobis data elt Tab. XII. (a) Pallas Jeir. T. I. p. 2 i. \& pafim. (b) Du IIalde China T. II. p. 280. (c) Schaw l. c. p. 151 . 


\section{GE O GR A P H I C A E. "545}

I7.) Antilope Koba. le Koba. Buffon T. XII. Tab. XXXII. fig. 2. Senegal Antelope. Pennant. p. 33. Num. 33. ubi ejus quoque effigiem vides. Ex Adimfoniz tcftimonio in Senegae ripis commoratur (d). Fortafre Buffonii Köba hujus animantis varietas eft. Beftia quiaedam, quae duabus Grzellis, quas hactenus commemoravi, perfimilis procul dubio Sinenfunm vacca falina eft, cujus imaginem Ncubofius (e) fatis exactam pag. 370 . dedit. Hanc feram beftiam, ratione formae, parum a vacca recedere, duoque illius cornua eboris alborem referre pag. 369. Fcribit. Effigies ipfa cuin binis, quas hactenus defcripf, beftiis, admodum congruit, \& quia fumma cum aviditate fali inhiat, inde nomen accepit.

D. Cornua retro aut caprarum noftrareisin more curvata.

18.). Antilope leucopbaea. Pallas. 1. c. p. 6. Blue Aintelope. Pennant. p. 24. qui folam capitis figuram p. 39. depictam dedit. Caper caeriulcus. Vid. Kolbii defcriptio bonae fpei promontorii p. I $4 \mathrm{r}$. In dicto promontorio domicilium habet. Aliquando tamen altius in Africas terras penetrat. In Mappa Zoolog. eft Ant. I. Quum cornuum ratione quam proxime ad capras accedat, ultimum inter Antilopas locum illi adfignare volui, ut fic eo facilius commodius que ad capras tranfire poffim. Praeter quas hactenus enumeravi Anitilopas dubio procul multae aliae fpecies dantur, quarum peregrinantes hiftoriae naturalis minus gnari fub cervorum enprarumque nominibus mentiomem fecerunt; harum aliquae in Pbi-

(d) Adanjon apud Buff. 1. c. p. $37^{\circ}$.

(e) Neuhifs Gefandfch. p. 369. figur. Zz z 
546 SPECIMEN ZOOLOGIAE

Pbilippinis infulis $(f)$, Aly:finia $(g)$, \& multis aliis Africat partibus $(b)$, pafci dicuntur.

$$
\text { f. V. Capra. Limn. }
$$

x.) Capra Hircus. Capra domeftica. Vid. Cap. I. ubi non modo quousque dilatetur, fed praecipuas etian. ipfius varietates, Angoricam fiilicet, mambrinam, revierfam , compreffam, aliasque percenfui.

2.) Capra Ibex. Quam hirci domeftici patrem effe: exiftimo. Vid. ibid. Hic adjungo Gulven/ledffum, qui in epilfola quadam confirmavit, Bbices etiam in monte: Cancelfo, \& Fortskaelium qui docet in Aegypto (i) degere. Huc \& Buffonii capricornus referri debet.

3.) Capra rupicapra. Capra cornibus erectis uncina. tis ( $k$ ), quam Ridingerus fub nomine germanico Gems, in Tabula XXV. animantium aeri inciforum eleganter depinxit.. Rupicapra Gesner. Quadrup. Vid. Cap. I. Hanc caprarum fpeciem ex rationibus jam adductis cum. capricorno eandem effe minime gentium ftatuere potui, licet Buffonius id fecerit.. Rupicapra in Alpibus, Pyrenaeis, Carpaticis, in Graccia \& Cretae infula: (l), nec non: in Cascalib. jugis commoratur, quiod Guthdenffedffus jam: atiquoties laudatus confirmat.

$$
\text { 5. VI. Ovis. }
$$

x.) Cäpra Ainmon. Capra cornibus arcuastis Semiciricest. luribus fubtus planiufculis, patearibus: laxis pilofis, gula: inn-

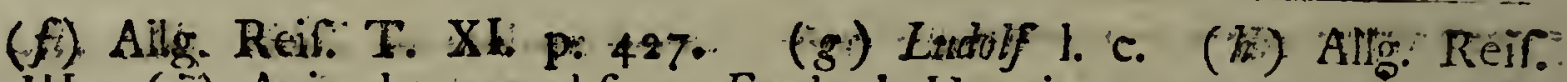
1. III. (i) Animal. quae obferv. Forskael. Hawniae 1775. pag. 4. (k)

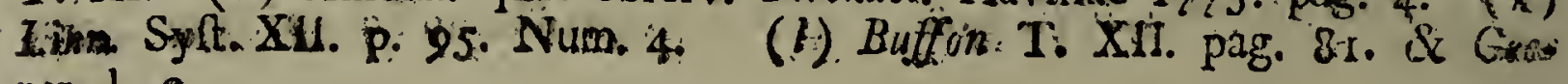
1.6 . 


\section{GEOGRAPHICAE.}

547

imberbi Linn. p. 97. Moufton. Buffon. T. XI. p. 204. Tab.XXIX. Argali. Nov. Comment. Petrop. T. IV. p. 8.38. Tab. VIII. Jam fupra magna cum probabilitate evincere ftudui, quod Buffonius jam opinatus eft, Ammonem hunc totius oviun generis auctorem effe. Licet negare non audeam, fieri poffe, ut hac in re cum Buffonio erraverim. Ex Gmelini feniovis (m) teftimanio, fub Stepnie Baranni feu ferarum ovium nomine, ad Irtifcbium verfus Tatariam Calmukcensem, praecipue in Bucbturmae ripis, porro contra orientem usque ad montes fuperiores ad Obium feifeumque pofitos, \& hinc ad juga lacum Baikalem cingentia ulteriusque progreditur.

Ex junioris autem Gmelini (n) itineribus patet, quadrupedis hujus numerofos greges Caucafi montem inhabitare, \& in Perfane provinciis, quas mare Calpium alluit, Gilana nimirum \& Manderana confpici. Beftia. itaque haec jam fub fexagefimo longitudinis \& trigefimo fexto ac feptimo latitudinis gradibus in $A$ /ia cernitur, \& hinc usque ad Kam/cbatkam, quin ad American e regione pofitam pergit $(0)$. In Europa praecipue Graeciam, Corficam $(p)$, Sardiniamque incolit. Quodfi Schawii. Ti ifb-tall Argali eft (q), in Africa etiam \& quidem in Barbaria vivit, ex quibus elucet, eum \& calidioribus \& frigidioribus terrae plagis tolerandis parem effe.

2.) Ovis aries. Vid. Cap. I. ubi praecipuas ejus varie-

(m) T. I. itin. p. 368. in nota fuppofita. (n) Gmelin jun. itin. T. III. p. 486. Tab. 55. (o) Vid. Cap. IV. ubi commontrare aufus fum, ca. Iiforniae Tagum Argali effe. (p) Belon. Obferv. 5\%. \& Buffor. 1. c. \& Gefner. Quadruped. p. 823. (q) Schaw 1. c.

$$
\mathrm{ZZ} \text { ' } 2
$$




\section{$54^{8}$ SPECIMEN ZOOLOGIAE}

rietates, \& quousque dilatetur enumeravi. Huc etians Cretae Hungariaeque feffor, quem ovem Arep/ceron vocitant, itemque Adimainia Africae incola referendus videtur.

\section{VII. Bos.}

r.) Bos Taurus. Vid. Cap. I. ubi bonafum urumque Butfonii duEtu, quin \& Americae bifontem bovis varietates effe adferui, quasque ibi opinionis hujus rationes adduxi ejus adhuc ponderis mihi effe videntur, ut eadem in fententia perftandum cenfeam. bifontis albi, cujus Gosnerus in appendice meminit, Pennanto tefte, in $S$ Sotia. $(r)$ adhuc veftigia reperiuntur. Urorwm genus in Germania plane evanuit, \& in folis Poloniae fylvis tantum obvium eft (s). Utrum Bonafus adhuc in Africa vivat, quod Ariftoteles teftatur $(t)$, ex peregrinantium recentiorum relationibus haud fatis liquet, licet ferarun vaccarum quae $A /$ fae fint ( $u$ ) incolas, crebriorem mentionem injiciant.

2.) Bos grummiens. Bos cornibus teretibus extrorfum curvatis vellere propendente, cauda undique jubata. Limn. p. 99. N. 4. Vacca granmiens villofa, cauda equi$n$.. Nov. Comment. Petrop. T. V. p. 339. Gmellin fenior Rubruquizus \& Le Brumaius hanc beftiam $T_{a}$ rariae Calmukcen/s colonum, ubi Sarluk nominetur, canque nec ceteris Tataris peregrinam effe, adfirmat Huc etiam 7 ibetcinfun Buchom (v) referendum autumat. 3.) Taurus mexicamas. Hicrmanlez 1. c. p. 587 . Qui

(r) A sour surough Scolland. (t) Arifot. Hift anim. Lib. IX. cap. 45 . (s) Rzacynski Hiit. Pol. p. 214. fo. (y) Allgemein. Ruifar I: VII. 


\section{GE O G R A P H C A E 549}

a Sontibus veteris orbis hac fola in re differt, quod mofsbum magnopere redolet. Magnam Americae feptentrionalis planitiem ad Hudfonis usque promontoriun occupat ( $w)$.

4.) Bos Bubalis. Vid. Cap. II.

5.) Bos Gnou. Vid. Cap. II.

6.) Bos Indicus. Bos cornubus aure brevioribus, dorfo gibbo, juba nulla. Limn. Zebus. Buffon. T. XI. Tab. XLII. p. 248. in Edwardi avibus Tab. CC. In Mauritania degit ubi Bekkerel- $W_{a} f b(x)$ appellatur, \& hinc ad Senegani usque fub Dentis $(y)$ nomine defcendit. Belon (z) ipfum in $A$ / $/ a$ quoque reperiri ad ferit. His animantes nonnullas minoris ftaturae adnumerandas.cenfeo, qualis Anon, Celebis feffor (a), qui ovis quidem magnitudinem habet, eam tamen ferocitate inirum quantun vincit; Item Ceilonis Gauvera (b). Q Quoniam vero., quod capite jam primo comprobare ftudui, boves a coeli climate, fub quo vivere coguntur, admodum immutantur, certo nec affirmare nec negare quis poterit, an non quaedam fpecies folae fint varietates.

$$
\text { S E C T I O X I. }
$$

B ELLUA F Linn. p. 100.

Dentes primores obtufe truncati, pedes ungulati.

$$
\text { o. I. EQuUs. }
$$

I.) Equus Caballus. Vid. Cap. I.

( $w$ ) Allg. Reif. T. XV1!, p.229. \& Chasituoix 1. c. 1. V: p. 193. (x) Schaw i.c. $(y)$ Alg. Reif. T.1I. p. 81. p. 119 . (a) Prnsnnt. Synop. p. G. (b) Ally. Reir, T. X. (z) Belon: Voy. $\mathrm{Z} z z 3$ 
2.) Equus afmus. Vid. Cap. I. ubi etiam de Onagre \& Mangarsaboc actum eft.

3.) Equns Zebra. Equus fafciis furcis verficolor. Linn. N. 3. Zebre. Buffon. T. XII. p. I. Tab. L inter Edwardi aves Tab. CEXXII \& CCXXIII. Quantum hucusque conftat, formofa haec beftia tantum in Africa eaque media ac meridionali domi eft. Nec enim Barbariae, nec Aegypti indigenae, nec Senegae accolae, nec Guinene fuperioris cives ipfam norunt. In Africa autem occidentali, in Congi nimirum regno $(a)$, primum confpicitur, \& hinc ad bonae spei promontorium (b) progreditur, a quo deinceps ad Aby/finiam (c) adfcendit, ex quo magna cum probabilitate conjicio, eam interiores etiam Africae regiones, \& fic plus quam dimidiam orbis partem hanc pervagari. .

\section{б. IL Hippopotamus.}

I.) Hippopotamus ampbibius. Hippopotamus pedihns quadrilobis. Linn. P. IOI. N. I. "Hippopotame. Buffon. T. XI. p. I 5. Tab. III. Pennont. Synopf. p. 78 . Houttuyn Natur. Hift. T. III.Tab. XXVIII. \& Ludolf Hift. Aetbiop. 60. Si Zerengi $(d)$ relationem, ad quain Buffonius provocat, Daubentoniique defcriptionem, quam de foetu quodam hajus animantis dedit, exceperis, nihil adhuc certi hac de beftia in medium proferre poffumus, nondum enim ad nos pervenerunt quae de ea confcripfit Allamandus in additamentis ad Buf-

(a) Pigafetta 1.c. p. 30 (b) Koibe (c) Ludolf. 1.c. 56. (d)

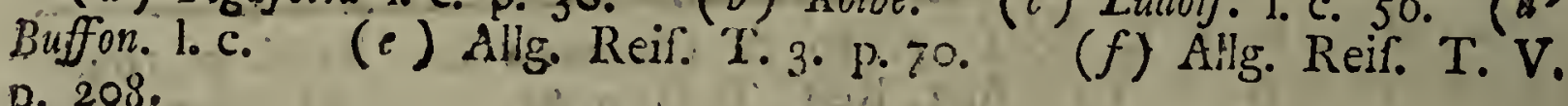
p. 208. 


\section{G E O G A P H I A E. 55}

fonii opus. Eam tamen in majoribus Africae, Senega (e) fcilicet, Gambia, Zaire $(f)$, Coanza, bonae que Jpei promontorii $(g)$, Aby:finiac fluminibus $(b), \&$ in meridionalibus denique $N_{i l i}$ partibus domicilium fuum habere $f_{c i-}$ mus; in reliqua einm (i) Alegyto pentus fere ignoratur. ఏ. III. Sus.

r.) Sus forofa. Aper. Vid. Cap. I. ubi tam varietates, quam quousque diffeminetur, enarravi:

2.) Sus Aetbiopicus. Pallas." Vids ibid. Qui naximo tepore calentes Africae terras incolit, nec cumn noftrate coire videtur; ad: quod tamen demonftrandum una experientia non fufficit.

3.) Sus Tajacu. Sus dorfo cyfifferos cauda nulla: Livn. N. 3. Pecari. Buffon. T. X. p. I.3. Mexican Hog.

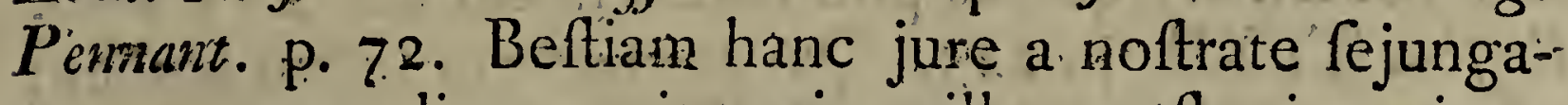
mus oportet, licet capite primo illam noftratis varietatem effe, probare fuftinuerim. Non enim fola dorfi conftitutione a noftro recedit, fed nec cum fero, nec cum cicure noftro $(k)$, quantum hucusque innotuit, mifcetur. Integram fere Americam pervagatur. A.Mexico (l) ad Cbiliv regmam procedit, \& Panamam, Terram firmann (m), Brafiliam ( $n$ ) Peruviamque peragrat. America autem feptentrionalis Magellamique terrae, quas. evitat, minus ipfi conducere videnturs.

4.) Sus Babyraffat. Sus dentibus duobus caninis fronti innatis. Linn. N. 5. le Babiroufa. Bufforn T. XII. p. 223. Sus caudatus dentibus caninis fuperioribus ab.

or:-

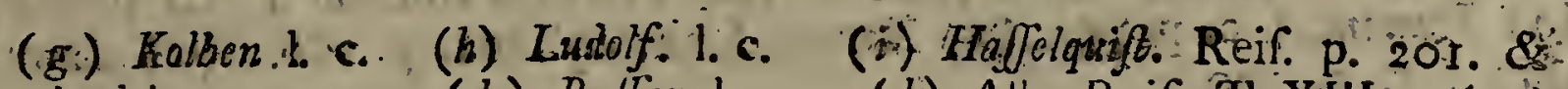
Forskael 1. c. p. 4 (k) Buffon 1.c. (l) Allg. Reif. T. XIII. (mb) Eankroft. Guiana. (in) Marcgravi Hift. Braf. p. 22.2. 


\section{$55^{2}$}

\section{SPECIMENG ZOOLO GIAE}

origine furfum verfus arcuatis, cauda floccofa. Briffon. regn. anim. Indian Hog. Pennant. Synopr. p. 73. Tab. XI. qui finguhris hujus beftiae icona optimam dedit. $\mathrm{Ca}$ put ejusdem in variis naturae Gazopbylaciis affervatur, faepius etian depictum monftratur. Quasdam Archipelagi Indici infulas, Bueronem (n) Ccilicet, Ainboinam, Celebem $(p)$, Bornconem aliasque inhabitat. Eam autem in aliquibus continentis Afrae partibus inveniri, idem auctor negat (q), quod quidem, fi certo conftaret, memoratu obfervatuque dignum effet. Sed quis hominum omnes Afrae partes fic perveftigavit, ut certi quid hac in re in medium proferre queat?

5.) Sus Hydrocboerus. Sus plantis tridactylis, cauda nullar Linnaeus, qui pedibus quoque fubpalmatis addere debuiffet, quibus potiffimum notus eft. Le Cabiai. Buffon. T. XIl. p. 225. Qui animantem fuibus frmilem effe negat, licet, quam dedit, beftiae figura, quae omnium adhuc optima eft, fatis commonitrat, eam fuum claffi non immerito fubmittendam êfe. Soli enim pedes funt, qui ipfam excludere ac fegregare videntur: Ultimum ipfi inter fues locum idcirco dedi', ut fic ad Tapiros, quibus a Pennanto adnumeratur, eo propius accedereny. In calidiffimis Americae partibus, Terra nimirum Fisma $(r)$, Brafiliaque $(s)$ vivit.

$$
\text { J. IV. TAPIR. }
$$

Hippopotamus terreffris. Hippopotamus pedibus pofticis trifulcis. Liza. Syst. nat. Edit. Io.

Ta-

(0) Seba T.ber. Tom. I. p. 80 .

(p) Valentyn Amboin T. III. p. 268. (q) Pennant. l. c. p.74. (r) Barrere Fran; équinox. p. 160 . (s) Marc: gray. 1.c. p. 230. 


\section{G E O G R $\Lambda$ F H I C A E. 553}

Tapir. Buffon. T. XI. p. 250 . Tab. XLIII. Loing-noSed Tapir. Pennant. 1. c. P. 82. Qua de caufa Linnacus hanc belluam, quae fingularem claffem conftituit, in duodecima Syftematis naturae editione plane omiferit, conjectura nulla affequor. Satis exactam ejus imaginem ac defcriptionem Buffonius Condaminii auxilio dedit. In Jucatana ( 1$)$, Pamama, Terra Firma (u), $\operatorname{Brafila}(v)$, \& verbo, iisdem in provinciis $(w)$, in quibus proxime antecedens beftia confpicitur, habitat. O.: V. Rbinoceros. Vid. Cap. II.

\section{A $\quad$ P $\quad$ U. T. T. I V.}

In quo generation de quadrupedum per tolluris fuperficiens diperfione agitur, cui confétaria nornulla tolhuris hiforiam illiufrantia adduntur.

\section{$S$ E C T I O I.}

Q. I. In prolufione opufculo huic praemiffa naturam 1 omnia animantibus fic explevife, ut regnunz quod animale Phyfici vocant, reliqua duo, vcretabile nimirum \& minerale, immenfum in modum fuperet, pro virili commonftrare ftudui. Quum autem rerum opifex omnia tam fapienti ratione difpofuerit, tamque ratis ordinibus fit moderatus, ut unam femper ad metam collineent, idemque finis usque obtineatur: mea me opera abufurum effe, non vereor, fi modum, quo infinita illa

ani-

( $t$ ) Allg. Reir. T. XIII. (u) Bancroft Guiana. (v) Marcgr, l.c. p. 229. (y.) Condam. Voy. p. 82.

A a a a 


\section{SPECIMEN ZOOLOGIAE}

animalium feries per orbis noftri fuperficiem difperfia fit, fi fortem, qua aliquibus terrae partibus majores: illoruin copiae obvenerint, fi denique rationem, cur loca aliis minus illis conferta fint, disquifivero: Sic enim terras, quarum animalia jam cognita habemus, cum regionibus, quarum indigenae nos adhuc latent, comparandi, \& commoda, quae animantium migratio geographiae univeralil praeftet, commonftrandi facultas dabitur aptiffima.

0. II. Quod fi orbis hujus fuperficiem, quoad nobis innotefcit, uno quafi ietu perluftraveris: numerum animalium, quae terrae continentis feffores funt, ex ratione directa caloris humorisque compolitum effe; aut, quod forfan lucide aperteque magis dictum apparebit, terras aequa humorum calorisque vi exuberantes, copiofisfimos etiam animantium greges alere, regiones autem nimia ficcitate \& frigore laborantes pauciffmas eorum fpecies fovere., invenies. Praemonendum tamen lectorem duco, me istud nec de animalium. generibus, nec de quadrupedibus, avibus infectisque: folis, fed de omnibus fingulisque fummatim acervatimque fumtis intellectum velle, cuicunque caeteroqui: regni animalis claffi a naturae venatoribus adjudicentur.

o III. Conftat autem, telluris tractibus intenfififmo frigore infamibus generatim vel minimos ineffe humores. Quum enim in oris fub \& hand procul ab. axe pofitis vapores e terris aquisve folis igne excitati, qui calidioribus in Zonis imbre pluviaque defluurty per plurimos anni menfes folito gelu conftricti in nivem glaciemque tranfeant; quum porro humus, quae fxigore affiduo induruit ${ }_{2}$ ibidem rariffine moiliatur, \& 


\section{G E O G A P H I C A E. 555}

seftiva tantum calore (qui, quod in Aface auftralis trac. tibus fieri fuevit, vix unum alterumque pedem in terFae fuperficiem penetrat) tepefactus fine ullo camporum emolumento tabefcere videatur: hinc efficitur, ut deciduus ifte humor congelatus terram vix ac ne vix quidem humeetet. Ex quo id incommodi oriatur necefie eft, ut regiones illae vel nullis vel pauciffimis tantum plantis ftirpibusque producendis alendisque aptae fint, quia fruticibus arboribusquue potiffinum praealtis ingens illa, qua conferventur \& augefcant, humorum copia, quae tamen ibiden deficit, opus eft. Accedit, quod vafa tubulique arborum, quibus fucci alibiles per omnes earum partes deferantur, gelu disrumpantur. Quae omnia peregrinantium obfervationes certiffimae confirmant, qui Groenlandiam, Spizbergam, Kamt/chatkam, Ignisque terram, vel pauciffinas vel nullas magnae proceritatis arbores, perexiguasque numero plantas proferre teftantur. Fons itaque foecundiffimus ditiffimusque, ex quo vietum animalia haurire debebant, illis hoc ipfo praecluditur. Ex iis enim, quae in opufculi hujus prolufione ventilata funt, luculenter patet, frutices, plantas, ftirpes, caeteraque vegetabiiia omnia incredibili animantium multitudini \& vitam praebere $\&$ victum.

8. IV. Oppones forfan: fieri tamen poffe, ut tam hoorrida frigore loca eo major carnivorarum beftiarun cunulus expleat, quod, uti poftea commonftrabitur, in oceano ufu venire folet. Sed quam parvus infectorum numerus terribili, quod regiones fub utroque coeli axe infeftat, frigori tolerando par eft? quam exilis avium quadrupedumque frequentia firitum ibidem duA a a 2

cere 
cere pollet? quippe quorum fucci gelu rigere, quorum corda ita conftringi folent, ut omnis denique, motus i.jis eripiatur. Quod ut eo lucidius in oculos incurrat, percenfeas quaefo, quot aut quae animalium genera in Groenlandiae, Kumt/chatkae, samogediae aliisque plagae terris reperiantur; quam tenuis nafcentium ibi infectorum (a), quis papilionum in Groenlandia aut Siberia obviorum numerus in praeftantiffmis ampliffmisque rerum naturalium thefauris deprehendatur? quum e contrario moderatiores Europae regiones mirandam eorum copiam fubminiftrent, \& exigua Guianae regio, Surinama graviori folis aeftu ardens aliquot ipforum centurias nutriat. Hanc eandem cum infectis quadrupedum rationem effe, exinde perfpicies, quod frigida, quam dicunt, Zona, vix quatuordecim vel quindecim horum generi alit, qui luftra domiciliaque fua fub ea condant; (b) quum moderatiori fub coelo ad minimum quinquaginta, \& fub meridiano fole reliqua, quac ex ducentis fuperfunt, generibus habitent omnia. Notandum tamen effe puto, me nec frigidiffimas regiones circuli polaris finibus circumfcriptas; nec calidiffrmos tractus tropicorum cancellis terminatos, utrisque potiusgradus nonnullos additos velle. Thermometri enim fcalis potius, quam vulgato quinque Zonarum fpatio terrarum orbis calorem, frigora, temperiemque dimetienda efle exiffimo.

Q. V.

(a) Conf. Pontopjidnni Norvagla \& Crawaii Groenlandia.

(b) Sequentia quan maxime animaniun genera frigidiorum regionum incclas clie exitimo $\left.I_{*}\right)$ taraluds, 2.) alce, 3.) woivercne, 4.) urjus, 5.) vulpes, 6.) lepris, 7.) guio, 8.) cafior, 9.) hyfirix canaderifis, 10.) iutris Linanei, in.) muftehi Zivellina, 12.) lemmis, 13.) polatuche. 


\section{G E O G R A P H I C A E. 55 ?}

f. V. Torpentes quidem contraseasque frigore plagas certis anni temporibus magnos etiam unius ejusdemque fpeciei infectorum acervos gignere \& fovere, nifi omnem fidem infirmare velimus, concedamus oportet. Sic Labradoris, Groenlandice Lappiaeque habitatores tot mufarum per aeftatem turmis vexantur, ut vix, nec nifimulto labore \& ftudio, ab ipfarum incommodis fe tutos praeftent. Quo ipfo meam tamen opinionem confrrmatam magis quam fractam diffolutamque cernes. Quoties enim illius orae populis dies exoritur, qui per totam deinceps aeftatem durare, ipforumque campos continuo folis taetu calefacere folet, quicquid vehementior frigoris vis falvum illachumque reliquit, refotum progerminat, \& plantarum, infectorum, animalimque genera, quibus natura vel fatis roboris fuftnendae algoris vehementiae, vel ingenii folertiam in hibernis bene conftitutis vitam fuftentandi confervandique conceffit, orientibus denuo, terramque aliquamdiu tepefacientibus folis radiis novum vigorem easque vires recipiunt; ut brevi tempore ingentibus incrementis augeantur. Simulac vero fol occidens horizontem deferit, animalia vel ad calidiores paulo regiones descendunt, vel fuis fe latebris abdunt. Ideoque guadrupedum pauciflmi, quos natura denforibus contra frigoris impetum pilis armavit, quales i/atides Ur/2que albi funt, totam ibi hiemem commorantur. Infecta vero vel ovulis factis \& in tuto pofitis intereunt, vel glebis abfcondita \& marmotae inftar totam hiemem frigore enecta jacent $(c)$. Deficiente itaque calore om-

nia

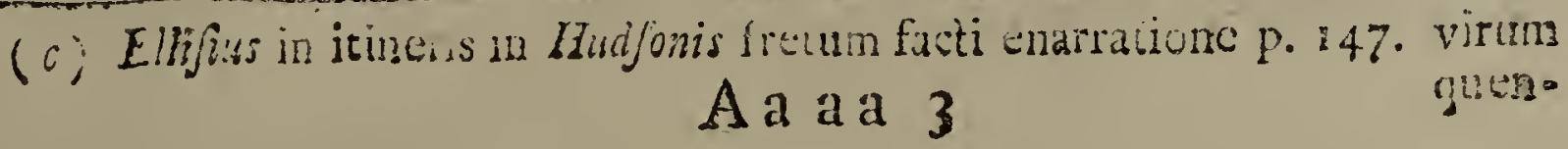




\section{$55^{8}$ SPECIMEN ZOOLOGIAE}

nia ibidem mortua comparent: Oceanus folus eft, qui fub polo eadem, qua reliquarum Zonarum tractus, animalium multitudine fcatet; cujus rei rationem ftalim fubneetam.

0. VI. Quodfi uno te quaf: faltu hinc in regiones flagrantinimo acfu calentes immiferis, quam diverfa ibi, quam contraria omnia habebis? Omnia enim innumeris animantium catervis, \& cadem quidem, quam antea jam dedi, proportione abundare, non omnes tamen partes fimili ratione expletas videbis. Arida enim Africae arena, praeter exiguos quosdam ferpentes, beftias propemodum nullas producit $(d)$; quum contra denfiffimae infectorum nubes Bengalae paluftris habitatoribus diem interdum tenebris obruant. Sic Eques Forbinius, , nobis, inquit $(e)$, vix ozto milL liaria marina a Mafulipatama remotis a terra conti$\Rightarrow$ nenti atra quaedam fpiflaque nubes obviam fereba, tur, quam quoniam tempeftatem, vitaeque pericu, lúm allaturam verebamur, vela illico fubtrahenda , curabamus. Poftquam autem leni vento navi appro" pinquaverat, ipfam ex incredibili mufcarum multituو, dine conglobatam effe perfpeximus, quae a tergo ", violacei coloris, caeterum Europaeis perquam fini" les erant; tantumque moleftiae nautis excitavere, , ut iisdem fe fubtracturi latebras, quibus aliquamdiu , abfconderentur, quaererent. Et maris fuperficies , im-

quendam pedis lapiu glebain nigrain arboris radici adhacrentem pedibus obtriviffe refert, totam ex mufcis gelu coactis confiftentem, quae igni admotae vitam receperint. Idem raras per hiemem congelatas fine vita motuque effe teftatur. (d) Adanfon. Voy. p. I 70 . (e) Allgemeine Reifen Iom. XVIII. p. 103. 


\section{G E O G R A P H I C A E.}

9) immenfa ipfarum multitudine operiebatur, navisque

" iisdem fic redundabat, ut huic expurgandae plus

g quingentis aquae amphoris opus effet. Quatuor

g, circiter marina milliaria ab urbe disjuncti, aliam quan-

" dam animadvertebamus nebulam, quae urbis pro-

„ fpectum omnem adimebat: quove propius accedeba-

"mus, eo latius diffundebatur; donec tandem faltus

" camposque circa fic intexuit, ut praeter montium

" juga niril plane oculis noftris percipere liceret. In

$\Rightarrow$ ipfius autem rei confpectum progreffif fupentes obfer-

"vabamus, nebulam ex alius cujusdam fpecieimufcis,

g) quas quatuor natura alis inftruxerat, confiftere: pro-

"pius nobis fuccedentibus infinitun denfumque ipfarum

2 agmen tam late diftendebatur, ut \& lucem \& terrae

$\Rightarrow$ adrpectum, ad quam non nifi bolide ejecta fundo-

" que maris explorato appellere poteranus, prorfum

"nobis eriperent". Hactenus Forbinius. Guinean easdem fere animantium myriades alere, Bosmanmus auctor eft $(f)$, gui immenfurabili fcorpionum, millepedum aliorumque infectorum vi omnes non folum dietae regionis oras, fed caftelli etiam angulos fatere confirmat, \& formicas, quae fcrobes penuarias in duodecim pedum altitudinem \& amplius effodiant, \& in proceriffmarum arborum cacumina evadant, tam ineffabilis interdum copia caftelli cubilia occupare addit, ut inquilini ipfis cedere, conclaviaque fua relinquere cogantur. Una, pergit, interdum nocte quascunque beftias: volatiles deprehendere poffunt, quin unam quoque: al-

(6) Resmalmni. Guineae defcriptio p: 326. \& feq: \& Allg. Reir. T. IV. 


\section{SPECIMEN ZOOLOGIAE}

alteramque ovem, confumunt; nec glires velocitate caeteroqui fat pernices ipforum voracitati fe fubducerie pollent. Adanfonius ( $\mathrm{g}$ ) eundem formicarum in Senegalliae freto degentium, quas indigenae Vaguagas nominant, \& numerum effe \& morem, adftruit. Alio tempore vir folertiffmus locu/arum tam fiffas confertasque nubes obfervavit, ut folcm diemque obfcuraverint $(b)$, quod idem cun incredibilibus Maringoinfumm (culictum pipientium) agminibus, qui repentinae noctis inftar coacervatim ingruant $(i)$, fieri adfeverat.

0. VII. Calidi uliginofique Americae campi, minus hominibus falubres, ejus generis animantibus pari \& interdum majori ratione abundare dicuntur; quibus agri femitaeque fic ftratae confpiciantur, ut vix quisquam fine metu multos illorum conterendi proculcanaique pedem referre fuftineat. "Infolito fane mirabi„ lique fpectaculo oculi implentur (k) (du Tertri "verba funt) quoties poft primum vel in Aprili vel "Majo effufum imbrem majores minoresque de mon" tium jugis defcendentes cancri, quos Turluruxos ap$\Rightarrow$ pellant, campos eum in modum inundant, ut fi ipforum " vitae parcere, nec pedibus necem iis confcifcere volue"ris, vi quadam illos propellere cogaris. Integros enim $\%$ exercitus efficiunt, qui fpatium fesqui miliaris longig) tudinis, \& quadraginta pluresque paffus latum occu.

" pant,

(g) Adar.fon 1. c. p. 99. '(7) Adanfonius p. 87. 11 s'éleva au defiús de nous un nulage épais de Salterelles, qui obfcurcit l'air en nous privant des rayons du foleil. (i) Idem p. 36. Il y a des tems, où ces petirs animaux fortent en fi grande abondance, que l'air en eft obfcurci. $(k)$ Hift. der Antilles. T. II. p. 329. \& feg. 


\section{G EOG R A P I I C A E. 56I}

2) pant, quod multitudine fua tam arçe contegunt, " ut folum, cui infident, vix emicet.".

Nec, quos Guianace regio animantes profert, numero funt pauciores. Buncroftius (l) enim fexaginta ferpentum fpecies in confpectum fuum cecidiffe, infectotrumque in humida illa calidiorique terra prognatorum eam \& ubertatem effe \& varietatem perhibet, quae omnem hominum fidem excedat. Mop/rcaen/es, gentem olim fatis magnam Paragoyae confinem, inenarrabilis avium, pafferibus noftris haud abfimilium, copia e patria fua expulit $(m)$. Simulac Portus putcbri (Portobello) tam. arva quam moenia pluviis irrigantur, omnes urbis plateae, quod Ulloa teftatur (n), bufonibus fex pollices longis contectae \& quafi ftratae comparent. Cartbagena immenfas vefpertilionum catervas nutrit, quae circa folis occafum, fpiffarum nubium more, ita fe intendere plateasquie adobruere foleant, ut incolis adfpectum condant. Immanis infectorum frequentia Guayaquillae habitatores adeo fatigat, ut accenfas candelas exitinguat, \& proxime adfidentibus fpiritum fere intercludens vix reciprocare animam finat $(0)$. Quae omnia certiffimis ftant auctoribus, ejusque funt generis, ut illis, qui fub temperatiori coelo habitant, fidem humanam excedere videantur, quippe quibus ea naturae oftenta penitus ignota funt; \& quamlibet aliqua infectorum mufcarumque agmina moleftias interdum ipfis adferant; non tamen aëra tam ftupendum in modum illis expleri nec terras contegi cernimus. Quodfi pecudum

(l) Guianae defcript. p.I37. (m) Hift. du Paraguay Tom. L. p. 273. (n) Allgem. Reifei Tom. IX. p. 80. (o) lbir. p. 132. $\mathrm{Bb} b \mathrm{~b}$ 


\section{SPECIMEN ZOOLOGIAE}

moderatioribus in locis educatarum greges illis oppo fueris, tam-mirandam harum paucitatem, tam exiguum deprehendes numerum, ut vix centefiñam; quin nec. millefimam illarum partem efficiant. Silentio praeteribo, calidas quoque regiones fuos pecorum greges alere, quos tamen non relicta fibi natura, fed hominum potius folertia \& nutrit \& auget.

5. VIII. Dantur", quod concedimus, infulae fub eodem quidem cum fupra nominatis-regionibus coeli climate jacentes, vel nullis tamen, vel pauciffimis tantum. animantibus habitatae, quae tam parvulae tamen tamque exigui orbis fuperficiei particulae, tamque exigui momenti funt, ut illarum vix ratio haberi debeat. Legem itaque eandem univerfo terrarum orbi aequaliter, lingulisque ejus partibus convenienter a natura fäncitam effe, manibus: quafi palpamus, ut, quod fupra jam dixi, regiones pari aeftu \& uligine maximas animalium copias, terrae vero aequo frigore. $\&$ ariditate laborantes. minimum ipforum numerum proferant.

6. IX. Nunc ea contemplemur \& diffolvere ftudeamus, quae maris intuitu opponi poffunt. Ea nimirum, quam in terris demiramur, proportio, oceano deeffe videtur. Licet enim fub auftro \& feptemtrione propter longinquum folis abfceffum glacie pruinisque perpatuis obrigeat; nihilo tameń minus tot piccibus cum. infeEtisque fcatere, experientia docemur, quot illice: maris partes $x$ quas circulis tropicis circumferiptas cerni. mus, redundant. Immenfa ifta $\&$ infinita fere balcoutit vis, quaae certis ftatisque anni temporibus e Norvag ing: Grocnlandiaeque oris impetu quafi facto prorumpit , \& immanis gadur man moxbuarum copia, qquae ex Texrae No- 


\section{G E O G R A P H I C A E. $5 \sigma_{3}$}

wae (Terre-neuve) maribus arefacta ad nos deferrifolet, fatis fuperque evincunt, animalium frequentiam non eadem proportione in mari, qua in terris, cum crefcentibus latitudinis gradibus decrefcere. Porro ad calculum revoces inexhauftam minorum oceani animalculorum multitudinem quibus glacialis oceani gigantes fingulis propemodum horis ad famem reftinguendam utuntur. Nonne meridiano role clarius inde elucebit, tantum abeffe, ut gelu, quo animalium terreftrium corpora fub axe boreali rigent, maris incolis noceat, ut glaciales potius Zonae iisdem innumerabilibus animalium agminibus abundent, quibus calidiora marium freta affuunt?

f. X. Ratio , quam propter regula, quae in terreftribus animantibus locum habebat, ad oceani habita. tores accommodari minus queat, hinc evidentiffme deducatur oportet, quod frigus tantam in oceanum ejusque aquas vim \& potentiam, quantam in terras, exercere non polleat. Certam enim fi aquae marinae portionem cum eadem aquae dulcis quantitate frigori acriori expofueris : illa propter varias, quas continet, bituminis fpiritusque particulas, longe difficilius feriusque, quam haec, congelafcit. Oceani praeter haec fuperficies longe vehementius caeteris terrae lacubus Aluviisque commoveri folet, quod lunae partim efficacia, partim continuis ventorum flatibus fieri conftat. Nonne quotidiana propemodum experientia utrumque confirmat? Quoties enim aquas ftagnantes jamdudum gelu duratas videmus, quando in maris littoribus vix ulla glaciei veftigia confpiciuntur? Nec nifi afperrimo hiemis tempore aliquot tantum maris milliaria glacie tecta invenies. 


\section{SPECIMEN ZOOLOGIAE}

6. XI. Mare quidem glaciale objicies, quod per hibernos menfes \& quam maxime fub polo totum gelu ftrictum confiftit. Sed fi penitius rem inquifiveris; folam fuperficiem concreviffe cernes. Poft aliquot enim altizudinis orgyias, aquas habebis liquidas; \& perfuafiffimus fum, etfi res nullo hucusque cognofci potuerit experimento, nec prope Spizbergam, nec fub eadem ocea$\mathrm{ni}$ auftralis latitudine medium maris multoque minus. fundum ejus congelatum effe. Non ea igitur frigoris vehementia, non intolerabili illo algore aquae marinae rigent, cujus vi animantium vafa conftricta torpeant, quin penitus rumpantur. Hiems ergo in oceano nulla proprie dominatur, cujus rigore, quod in terris ufu venit; animantes vitam motumque amittant; maris potius habitatores aquarum temperiei adfueti femper fere in eodem caloris frigorisque gradu, fi utrumque ad thermometri fcalam dimetieris, fatis commode vivunt $(p)$; faltim non iis, quae telluris fuperficiei fufti-

nen-

(p) Marfgglius id veritati confentaneum effe, experientiaque confirma$r i$, in eximia, quam edidit, maris phylica ( $P h y \int$ fque de la Mer pag. $1 \sigma$. Tab. VI.) teftatur. Docet enim, thermometrum mari 10. 20. 20.30 . quin 120. orgyias in Decembri, Januario, Februario, Martio \& Aprili immerfum ad quartam modo gradus unius partem defcendiffe; quod contra iisdem menfibus libero aëri expofitum per tres gradus mado afcenderit, modo ceciderit. E quo aurae ad maris mutationem nti Ia ad I feu quod idem eft, duodecies majorem effe difcimus. Thermometrum quidem, quo vir egregius tunc ufus eft, non tam fenfibile fuit, quam quibus nos ntimar, nec, quod dolemus, ejus fcalam, ad quam calorem dimenfus ef, indicavit, ideoque cum noftris comparari mon potuit. Accedit, quod ipfe obfervationes aetatis tempore factas, guae noftris heic loci factis minime refpondent, tales effe negat, e quibus certi quid determinari queat. Interim tamen pari mecum ratione fatuit, idque dilucidius adhue probat, caloris gradus in mari omni fere tempore vel eosdem efie, vel parum fal- sem inter fe differse. 


\section{G EOG R A P I C A E.}

nendae funt, hiemis aeftatisque viciflitudinibus exporsuntur.

6. XII. Ex adverfa parte intenfiffimus fub aequatore folis ardor non nifi per paucas tantummodo orgyias in maris aquas penetrat. Et quum oceanus perpetuo fervore commoveatur, profundisque voraginibus fuis ita conturbetur ac permifceatur, u.t aquae calefactae frigidis locum femper dare cogantur: hine fieri neceffe eft, ut animalium marinorum propagatio proventusque magis uniformis, facilior, feliciorque fit. Nulli enim ibidem campi deferti arenis fterilibus obruti fe aperiunt, nec frigorum vis mortifera nec aeftus, qui fpiritum intercludat, ibi faevit; omnia aequabiliter animata, omnia animantibus ibi plena \& pleniora quidem, quam in terra funt continente. Unus ibi pifcis numerofiorem longe fobolem edit, quam integrum vel infectorum vel murium genus; cujus rei caufas, quantum per virium imbecillitatem licuerit, explicabimus, \& pofiea illuftrationis gratia, excmpla quaedam in medium proferemus.

ઈ. XIII. Si mare cum terra penfitaveris, hujusque fuperficiem in quinque partes diviferis : mare illarun tres propemodum habere invenies: Er quoniam hoc propter nimias, quibus infectum eft, falis acorisque particulas, plantis minus, quam terra, quae aquis dulcibus irrigatur, conducere videtur: longe minorem inibi plantarum numerum invenies; illarum certe adhuc perpaucas nofcitamus, fi eas cum inexputabili, quin immenfa, quam continens terra profert, copia contuleris. Nunc autem alio jam loco commonftratum eft, herbas, gramina aliaque e terris nata quam maxime efle, quibus animalia vivant \& nutriantur, Quum itaque 


\section{SPECIMEN ZOOLOGIAE}

creator fcopum vivis animalibus omnia complendi, quem toti naturae praefixerat, adfequi vellet: alia extra plantas (q) alimienta, quibus vitam ducerent, dare debuit; quae vero practer animantes dare potuerit, noftra quidenn folertia, noltro ingenio eruere nulla valemus. Animantes igitur producendi erant, quibus animantes reliqui ad famem fedandam vefcerentur; feu, quod idem efre puto, animantes procreandi erant, qui propemodum omnes carnibus comefis vitam tolerarent. En principalem caufam, quam propter infinita animalium copia oceanus redundet, quorum longe minorem partem terra nutrit. Id autem per aequabilem, quae in mari obfervatur, temperiem fieri potuifie, paulo ante jam commonftravimus.

0. XIV. Praeter hunc finem omnipotens rerum conditor ad alium quendan ejusdem, ni forte majoris adhuc, momenti confilia fua contuliffe videtur. Si numero pauciores nimirum animantes carnivori maria incolerent: non fieri poffet, quin ipforum agmina fenio confecta \& mortua denique putrescerent, aquasque marinas, quamvis, quia multo fale conditae funt, fermentationi diu fatis reftitisfent, fic tamen vitiarent, ut interneciva oceanus populatione vaftatus brevi tempore, aquarum loco, foetore \& finie compleretur. Pone e contrario innumerabilem, quae maria referciat $\&$ carnibus victitet, animalium multitudinem; nonne horrendum illud ipfique naturae deteftabile fpectacu-

lum

(q) Vid, Donati fcripta, in quibus Corallia aliaque maris germina non plantas, fed ab animantibus confecta efie ortumque trahere docetur. Vid. etiam Bomaro Diction. Art. Corail. 


\section{G E O G R A P H I C.A E. ${ }_{56}^{6}$ ?}

lum penitus evanefcet? Nonne fapientifimmam fummi rerum arbitri difpofitionem venerabundus demiraris, qua factum eft, ut, dum animantes, quibus oceanus fcatet, fe vivos devorant, eorum propemodum nulli putrefcendi tempus relinquatur? Accedit quod e nondum manducatis alii quidem generantur, qui eodem inftinctu adacti minores imbecillioresque deglutiunt, vitamque eo usque confervant, donec ab aliis codem fato abforpti intereunt. Nihil itaque in maribus perire vides; \& veluti naturae ordo in continenti terra ab animalibus ad vegetabilia, \& hinc ad mineralia progredis tur, \& continuata ferie fic omnia combinat: fic idem," alia licet ratione, in oceano facere, resque creatas omnes admirabili quadam continuatione interfe nedere $\&$ conjugare, $\&$ in hoc uno a contextu, quem in terra confpicimts, recedere videtur, ut ubivis non ad. inanimata, fed ad animata corpora tränfeat, longeque diutius in his commoretur, quam ad illa pergat, quae rita carent. Maris igitur inteftina perenni titrage funt: infania, quam tamen, quun univerfi requirat confervatio, folam juftain, folam legitimam falutandam effe arbitror.

6. XV. Sed alia forte caufa adhuc fuben, cur oceani ratio carnivora poftulaverit animalia. His enim perpetuus aquarum motus, fine quo nec ftare nec durare: earum falubritas unquam potcrat, quam optime \& commodiflime impetrari videtur. Quamvis enim fumma mundi effectoris providentia fat inulto fale aliisque re. bus maria condiverit, quae, quo minus putrefcant, impediunt: fieri tamen nunquam potuiffet, ut immenfurabilis illa aquarum moles, quae multa nec facile: 


\section{SPECIMEN ZOOLOGIAE}

computanda cubica milliaria efficit, $f_{1}$ motum ipfi jactationemque demferis, a putredine farta tectaque diu confervaretur; quae deinceps, quod pejus adhuc \&z perniciofius fuiffet, pefte per univerfum orbem diffipata, reliquos animantes cunctos internecione funeftiffima peffum dare debuiffet. Quam quidem perniciem naturae auctor varia eaque fapientiffima ratione depulit; quippe qui legibus motui praefcriptis effecit, ut fingulis diebus ingens aquarum vis lunam verfus in ardua adfurgat. Ventis idem imperavit, ut flatu nunquam remittente mare turbent, ejusque aquas inter fe commifceant. Tandem \& maris fundun fic dispofuit, ut vorticibus, gurgitibus fluminibusque, quibus abundat, aquas nunc abforbendo, nunc evomendo, aliisque modis fic concutiar, ut perpetuo motu agitentur.

0 . XVI. Lunam maritimos aeftus in oceano maximos concitare, aquarumque ac fluctuum jactationes \& univerfum pene oceanum turbidum reddere, non equidem nego; idcirco tamen permultas adhuc ipfius partes tranquillas manere, nec loco fuo deturbari, ex aliis rationibus conftat; quas, quum in aretiffimum omnia nunc mihi contrahenda fint, attingere non licet $(r)$.

6. XVII. Quod autem ad ventos procellasque attinet, ex Boylli narrationibus $(s)$ admodum credibilibus docemur, ens nec ad medium maris usque penetrare, fed folam duntaxat fuperficiem turbare. Magni illius naturae fcrutatoris verba digna funt, quae ipfa ad-

po-

(r) Vid. Luilolfi Geograph. Desaguiller Lectures, Halley in Philofoph. Tranfact. n. 226 art. 2.

(s) Rob. Boyle de fundo maris SeEt, III. p. 5-8. 


\section{G E O G R A P I I C A E 5 क}

ponantur. "Oblervatur, inquit, in fundo maris tran" quillitas aquae, fi diftet a fuperficie longius. Quum

$\#$ ab urinatore quaererem, an ventorum ullam opera-

" tionem in fundo maris fenferit? refpondit, vento

o vehementiori flante, cum fluctus feptem pedibus

"f fuperficiem aquae excefferant, ad orgyias quinde-

$\Rightarrow$ cim ne fignum quidem ejus obfervaffe. Pro ulte-

" riori confirnatione addam, quae retuilit magnus

$\Rightarrow$ aliquiis peregrinator, qui lucrofae unionum pifcatio-

$\Rightarrow$ ni in India Oricntali interfuerat. Interrogatus enim,

$\Rightarrow$ an non e converfatione cum urinatoribus quaedan

\%, de tempeftatibus ad fundum maris non penetrantibus

" cognoverit? vidiffe fe refpondit, eo tempore, cum

\% adeo faeviret mare, ut portu exire vererentur naves,

\# urinatores mare ingredientes, qui inde reverfi omnia

\% fe in fundo tranquilla inveniffe, narraverant. Quod

" eo magis confiderari meretur, ob fitum loci. Eft

\#, enim prope littus Mainar, quod intra infulam Ceylors

" \& caput Comory fitum eft, locus maribus procellofis

" maxime obnoxius".

Et pag. 7. " Incidi denique in magnum aliquem na, varchum, qui in obfervationibus maritimis curiofus " narravit, fuiffe fe non ita pridem in loco, ubi pro" cellis \& tempeftatibus fatis agitatum mare certisque " fibi fignis cognitum, quod procellae non ad quatuor "orgyias infra fuperficiem aquae cum efficacia quadam " pertingant". Etiamfi ergo fummus rerun direčor motui maribus tam neceffario fic optime providit: vix tamen perfuadeor, fieri potuiffe, ut fine incomprehenfibili illa animalium carnivororum copia omnes \& fingulae, quas oceanus includit, partes, quae tamen fine $\mathrm{Cc} \mathrm{cc}$ mo- 


\section{$57^{\circ}$ SPECEMEN ZOOLOGIAE}

motu putrefcere debuiffent, commotae mifcerentur. Quoniam vero nunc aeterna bella, aeternae dimicationes maris inteftina turbart, omniaque in perfecutiones. fugasque ibi:vertuntur: ut altiffimae profunditates, quae: forte caeteroqui fumma requie fepultae immotaeque jacuiffent, nunc continua \& perenni agitatione moveantur, non folum oportuit, fed etiam neceffe fuit.. Fluctus quidem maris incolae nullos excitant, aquas tamen inter fe mifcent; quae permagni jam ponderis res eft; quam. fi cum reliquis concufil oceani rationibus copulaveris, novum häbebis argumentum, qui fiat, ut aquae marinae putrefcere nullo modo queant:.

0. XVHII. Ex quibus omnibus caufam primariam octlis : quafi cernes,y cur oceani habitatores partim tam aequabiliter difpertiti fant, partim cur ipforum plurimi crudis carnibus pafcantur... Quin etiam hinc patefcit, neceffitatem poftulavife, us maria prae terra pluribus longe: animantibus explerentur.- Fac enim, illa minorem ipfarum alere numerum, an is tot tantisque ufibus comparandis unquam fuffecturus fuiffet? Parum abeft, quin patium, quod oceani aquae occupant, terrae fuperficie duplo fit majus, cujus indigenae perpetua inter fe bella gestnt, cujus immanes belluae, immenfurabilium iftarum faucium tyranni, uno hauftu aliguot centena milliaaminorum animantium capacifimos in ftomachos $\mathrm{dc}$ mittunt, minores identidem pumiliores deglutiunt ; $\& t$ religuae omnes eodem ordine progrediuntar : quis du-bitat, quin oceanus brevi tempore exhauftus putrisque jeceret, niffnaturatam prodiga in proereandis animantibus: fuifet, maxisque freta longe uberioribus prae te!jare agminibus eumulaviffet?

Q. $\mathrm{XIX}$. 


\section{- GEOG RA A H C A E. 5\%}

6. XIX. Et hoc ipfan experientian rei magiftram docere facillime perfpicies, fi modo ad pifciuma quoFundam nobis notorum propagationem numerofiniman attenderis. Quam inexhauftos offendes thefauros! "Totam Bcrgae provinciam" Pontoppidap verbis $(t)$ utor, , teitem habeo, femel demifa reti eam hale, cum molem captam effe, quae centum, quin cen"tum quinquaginta naviculas pifeatorias expleve" rit, quarum quaevis centum cadis: oncrata fuit." Uno igitur retis bolo tot haleces extractae funt, quae decies mille cados opplerent. Si autem cuivis cado aliquot faltem ipfarum centurias dederis, quam ftupendam habebis pircium non minutiffimi tamen incrementi numerum! Ubi locorum tot ejusdem magnitudinis animalia terreftria aequa proportione invenies? Sed fac: naturam fe in dandis halecibus parcierem exhibuifie: qua quaefo ratione balaenae aliaeque ejusdem molis belluae marinae, quae uno hauftu vel decem halecum millia devorant, vitam toleraturae famemque depulfurae fuiffent? qunm ex Cranzii relatione (u) intra duorum, feptuagefimi fcilicet feptimi \& reptuagefimi noni, graduum intervallum, duobus vix menfibus elapfis, duo interdum cetorim millia capiantur. Et afellorum abundans multitudo inexputabilem oceani fertilitatem fatis fuperque comprobat. His enim millena hominum millia \& amplius vitam fuftentare certum eft. E folius enim Bergae regione duodecim quotannis centum pondiorum millia exportari folent. (v)

(t) Hiftor natural. Narvagiae Tom. II. p. 278 .

(u) Hift. Groenlandiac p. 14.4. Barby 8vo. (y) Cranz 1. c. p. 1.2\%. 


\subsection{SPECIMEN ZOOLOGIAE}

Et quod his omnibus immenfum quantum antecellit; sadorum callariarum femen eft, quo duodecim plerumque fingulis ferme annis naves ibidem oneratae alias in terras transvehuntur. Quum vero feptem propemodum feminis dieti ovula granum, ideoque $40320 \mathrm{gra}$ na libram efficiant, ducentae octoginta librae, quas pondus nauticum appellant, I I 289600 ovula contineant oportet: nunc quaefo nauticorum ponderum numerum tecum reputes, quibus una tantummodo navis referci tur; num animo comprehendere, num vel fuspicione ovulorum iftorum multitudinem, quae fingula tamen pifces futura erant, attingere poteris? \& haec omnia unius duntaxat fpeciei portionem, quin portiunculain fatis tenuein efficiunt. Has autem fertilitatis qua pifces augentur, rationes recke fubductas effe, permultis aliis exemplis demonftrari poteft; quorum nonnulla, ut rei veritas extra omne dabium collocetur, apponere placet.

S. XX. Lecuentoeḱkius ( $w$ ) in uno sado morbua millena ovulorum millia numeravit. T bomas Harmerus in Scombro quodam $54668 \mathrm{I}$, in folea 1357400 , \& in alio ejusdem fpeciei decies centena ovulorum millia invenit $(x)$. Pallafuis $(y)$ unius acipenferis buronis femen ducenta faepe pondo excedere teftatur; quamque granum quinquie, \& libra ipfa 28800 ovula aequet, hinc hufonem unum quotannis 5760000 circiter fuae fpeciei pifces edere fequetur. Quodfi eadem ratione parique diligentia in alias pifcium fpecies-inquifferis, nonne infi-

ni-

(w) Leewenhoek. Oper. Tom. IV. p. $21 \sigma . \quad$ (x) Philor. Trancact. I 267 . (y) lcineris per Ruifiarn faeti leferrigtio Tom. I. p. r38. 


\section{G E O G R A P H I C A E.}

nitam pifcium vim habebis? Quid? fi imperfcrutabilis oceani profunditas, omnes voraginum fuarum incolac adfpectui tuo retecti proponantur: annon immenfitas illa omnes numeros fupergrediens caliginem oculis tuis offundet? \& fi oculos inde in terram deflectens continentem nudam propeinodum, maris faltim refpectu paucisfimis habitatoribus cultam confpicies. Quibus fi inexputabilem maris infectorum noctu oceanum luce fua totuns colluftrantium \& igneum quafi reddentium copiam adnumeraveris, quorum Bastcrus una in gutta vel duodecim diverfas fpecies obfervavit, (cujus rei in praemiffa huic operi prolufione $(z)$ jam mentio facta eft) \& hinc, quanta aliorum maris infectorum abundantia effe debeat, collegeris; quae partim, quia homines minus animos iis intenderunt, partim quoniam inacceffam marium profunditatem incolentia oculis fenfibusque noftris percipi nequiverunt, adhuc ignorantur: nonne incomprehenfibilis multitudinis admiratione obftupefces?

6. XXI. Poftquam lucide perficicueque fatis oceani in procreandis animalibus ubertatem hujusque caufis expofuiffe puto: nunc ad terras continentes transgredior; quumque legem, fecuridum quam animantium numerus in illis generatim partim augetur, partim deErefcit, jam ante determinaverim, nunc disperfionem illarum praecipue contemplabor, quae noftra quans maxime confideratione dignae videntur, \& de quarun dilatatione percenfenda haec Zoologica noftra geographia quain maxime occupata fuit. De quadrupedibus heic:

(z) p. л6. ubi alia mirae foecundicacis exempla ex Hillio aliisque andori. bus allata reperies. 


\section{SPECIMEN ZOOLOGIAE}

heic loci fermonem effe, nemo non intelliget. Ante omnia vero, quae fummae quadrupedun nobis hucus, que notorum ad numerum regionum, quae in noftran adhac notitiam pervenerunt, quasve a peregrinantibus peragratas effe conftat, fit proportio, disquirendum eft: ex qua comparatione deinceps probabiliter confici poterit, an quotve non modo quadrupedum, fed omnium univerfe animalium genera quae nos hucusque latent, fuccefiu temporis per totum regni animalis ambitam detegi forfan noscique poflint. Ad quadrupedum deinde migrationem tranfibo, quam ex geographia Zoologica quam maxime optimeque explicari polfe credo; \& hac ratione nonnullas ad geographiam, feu potius ad terrae noftrae hiftoriam acceffiones adlatum iri, certo perfuadeor. Hunc igitur ordinem confervaturus regiones nobis cognitas cum is conferam, quas necdum indagare nec peragrare cuidam adhuc licuit. Mirabundi difcimus, quam exigua illarum pars, quas notas vocitare folemus, cognita nobis perfpectaque fit.

6. XXII. Terram noftram globi forman habere, ejusque diametrum, e vulgari computandi ratione, mille feptingenta viginti milliaria germanica continere, fupponimus. Non equidem nefcio, diametrum ex diligenti celeberrimorum mathematicorum dimenfione ad axin fuum effe ut 200. ad 199. quam tamen differentiam quum mihi boc loco nullius fere momenti fit, nunc miffam facio, mihique, terram glcbi inftar dimetiri, fufficiat $(a)$. Si dati jam diametri menfuram fundamen-

(a) Exaetion rem forae faeroidis formam habentis dimenfionem Berghanns, Maupertuifius, Malletus \& Lulolfuts in fuis, quas dederunt, geogrạphiis fuppedicarunt. 


\section{GE O G R $\mathrm{E}$ H I C A E. $575^{\circ}$}

ti loco pofueris; integram orbis fuperficiem 9288000 milliarial germanica quadrata continere invenies; quorum partem dimidiam nonnulli aquis, dimidiam terrae tribuunt $(b)$. Omnium tamen, quas viri rei gnariffimi in lucem hucusque emiferunt, tabularum geographicarum infpectio facile nos convincit, fpatium jufto minus aquis datum effe: Cui errori ut aliqua ratione mederer in prolufione telluris fuperficiem ex aliorum quorundam auctorum fententia in tres partes aequas divifi, quarum duas aquis, unam terrae addixi ; fed quoniam maribus fic plus jufto conceffifle videor, aequiffme veritatique convenientiffme omnem telluris planiciem nunc in quinque partes difpertientes tres quintasą̣uis, duas vero terme continentis adfcribainus.

5. XXIII. Ex Tempclmanni calculo Europa I7. 834 milliaria quadrata germanicae menfurae occupat $(c)$, Aine autem 641093. milliaria geographica vir doctiffimus dedit $(d)$.

6. XXIV. Si Afáe Tabulam Geographicam generutim adfpexeris, primo obtutu in eam opinionem ab. ripieris, paucas admodum ejusdem terras fupereffe, quarum cognitio penitior nos fugiat. Quodfi vero fingulas ejusdem regiones cuiatius conteniplabere; heu! quot

(b) Die l'Ifle in introdustione in Geographiam p. 23 .

(c) Luropa quidem longe minor fpano \& ex recentiorum dimenfionibus 356150 millaribus germanicis quadratis circumferibitur. Interim tamen hane Tompelmanini fummam ea de caufa aliis praetuli, quia fingularum etiam $F u$. sopa regionum fingula fpatia determinavit, \& haec ipfä differentia, licet nagfa fatis fit, heic tamen loci, propofici mei refpectu, vel nullius, vets exigni tantum pondexis effe poteft.

(d) Afia ex recentiurum computo circa: 850000 milliatia Geographica" quisurata continct. 


\section{$57^{5}$ SPECIMEN ZOOLOGIAE}

quot invenies, quarum adhuc fumus ignariffmini? Quod ut eo magis dilucidetur, quamque anguftis cognitio noftra cancellis hac in re circumferipta fit, eo certius appareat: aliquot ejus provincias enumerabo, quarum quidem fitus neminem fere latebit, de quarum ftatu conditioneque interiori vel nihil plane, vel faltim certi. nihil adhuc fcimus, quarumque notitian phyficam plane nullam habemus. Quantulum enim eft, quod de Tartariae magnae habitu \& qualitate cognitum habemus! Quamquam enim aliquot romanae ecclefiae emisfarii facerdotes, qui in Chinerfium imperatoris regia quondam verfati funt, eandem intraverint, \& in tabulis depiEtam exhibuerint: nihilo tamen minus certum eft, cos neque in Eleutberorum terris, nec in Tibeti tractibus tam diu commoratos effe, ut eain regionum, incolarum, animalinmque notitiam fibi comparare potuerint, quae ad pleniorem utrorumque cognitionem requiritur. Quodfi ergo Tompelmannus (e) magnum hoc Tartariae liberac regnuin per 48643 milliaria quadrata extendi atfirmat, iis tuto 30000 fubtrahere poteris, quorum ftatus interior \& hiftoria naturalis nos latet. Eadem ratione Tartariae Chinen/ss, Usbekiae, Gasgavis, Lafae, Laofii, magni Mogolis imperii immenfi tra Gus fuperfunt, quos adhuc penitus ignoramus. Quis enim peregrinantium, cui fides haberi queat, in Gangis latere Orientali a Purbeti montibus usque ad Tarta riam, quae nullius imperio fubjecta eft, penetravit? quis $A$ vae regni interiora unquam vidit $(f)$. Et om-

nes

(e) Vid. a News urview of the Globe, London 1753. fol. (f) Vid. Carte des indes \& de la Chine par G. de l'Hle chez Covens \& Mortier: 


\section{G E O G R P I C A E.}

nes ab Orixae littoribus ad Narvariam regiones nos penitus fugere, ex praeftanti, quam Anvillius edidit, Tabula Geographica difcimus $(g)$. Quodfi nominatale bae regiones fummatim 200000 milliaria quadrata efficient, eorunt 550000 erunt, quae pro incognitis habeamus oportet. Quis unquam Arabiae interiora peragravit? cujus fuperficies, fi petraeam eidem adjunxeris, circa 44000 milliaria quadrata continere dicitur. Minus itaque a vero illum aberrare crediderim, qui 30000. milliaria obfcura nobis \& ignota ftatuerit. Quis medias maximarum in orbe antiquo jacentium infularum, Sumatrae nimirum, Bornei, Favae, Celebis, Manitlae \& Mindani partes perluftravit, quarum omnium quidem littora aliquatenus, terrarum atitem continentium vel minimam partem cognofcimus? Quibus omnibus fi fummam 36000 milliarium quadratorum dederis, certe 25000 minus nota inde fubtrahenda erunt.

0. XXV. Sed cave credas, incognitas nobis terras fic plus aequo exaggerari. Quot enim partim regiones, qualis Siberia eft, quam ex omni quafi parte notam compellavimus, licet magna ejus fpatia nos lateant, partim infulae minores funt, quas ficco pede praeterii. Sic Moluccarum, Malsivarum, Papous aliarumque fat multarum nullan plane mentionem feci. Hac itaque in orbis parte 2 I 5000 milliaria quadrata, quod minimum fit, ratione regni animalis, quin refpectu cujuscunque: cognitionis humanae, non modo ignorantur, fed quafi nec quidem exiftunt; quae tamen neutiquam fub $\mathrm{Zo-}$

na

(g) Carte de l'Inde dreffée pour la Compagnie des Indes par d'Anwidle 1752 . 


\section{SPECIMEN ZOOLOGIAE}

na frigida, omnium fere ad vitam confervandam ne. ceffariarum rerum indigente, fed co fub clinate, ubi folis calor ad producenda nutriendaque animalia efficaciffimus effe folet, fub quadragefimo nimirum gradu, ad ipfum usque aequatorem, \& in ea orbis noftri parte, Afia fcilicet, pofita funt, quae ab initio rerum ab hominibus potiffimum frequentata fuit.

6. XXVI. Operae pretium facturum puto, fi Africam quoque \& Americam curatius perveftigavero, \& quae utrarumque hac in re conditio fit, disquifivero. Africam per 531683 milliaria germanica quadrata extendi Geographiae periti adfirmant; quorum vix \& ne vix quidem I50000 Europaeis innotuerunt. Quam mirabilis haec aliertio mea cuiquam fortaffe vifa fuerit, tam facilis tamen erit probatu. Ex omnibus quaefo in circuitu lateribus Africam confidera, \& ex quo Europaei tribus vei quatuor gradibus altius in hanc orbis antiqui partem penetraverint, prode. Des cuique gradui quindecim milliaria germanica $(b)$, \& perpende, quam exiguum, quod peragraverint, fit fpatium. Leo quidem Africanus a mediterraneo mari altius proceffife, ejusque interiora adiiffe videtur. Sed quamvis libro fuo defcriptiowis Africae nomen indiderit; idcirco tamen, fi Feffae, Maroccique regna, \& aliquas prope Atlantem Aegyptamque regiones exceperis, de reliquis ejus partibus parum certi continet. Et quicquid de aliis ejusdem populis retulit, de auditu narravit; enmque cancri tropicum unquain tranfiifie, vehementer dubito; \& hic

(b) Sic folent Geographi, 


\section{G E O G R A P H I C A E.}

hic tamen, quod mirabere, folus eo usque progreffus eft. Marmolius enim, Dapperus aliique fua pleraque ex Leone defcripfiffe videntur. Vincentius quidem Blancus in itinerario fuo, quod uspiam nec expifari, nec infpicere mihi licuit, jactaviffe dicitur, fe omnem a borea ad meridiem usque Africam peragraviffe; ejusmodi autem narrationes cum itineribus Gaudentii de Luc$c a$, qui poft Aby/finiam, nationem cultiffimam perfecteque politam offendiffe gloriatus eft, priorum feculorum fabulis adnumerandas cenfeo, quibus lippi tonforesque fidem habeant. Perraro enim iis temporibus accidit, ut viri a neceffaria dexteritate rerumque cognitione inftructi ejusmodi itinera facerent. Europacos Sarae deferta unquam transgreffos effe, vix credibile eft, paeneque perfuadeor, antiquos, quibus nimia Africae cognitio tribui folet, ulteriores ejusdem regiones neutiquam perluftraviffe. A mari mediterraneo eos altiffi$m e$ in terras iftas flagrantiffimo fole calentes penetraviffe, vero eft fimillimum; praecipue fi Aegyptum ipfis penitius notam fuife fupponimus. Has itaque $F_{e} \int f a e$, Marocci, Tafileti, Algeriae, Tuneti, Tripolisque terras, fi unam in fummam collegeris iisdemque Aegyptum addideris, circa 44000 milliaria numerabis quadrata; $\&$ hoc maximum eft totius Africae fpatium, quod perfpectum cognitumque habemus; quod tamen fine dubio adhuc multa ad hiftoriam naturalem facientia continet, quae nos adhuc fugiunt.

6. XXVII. Si occidentem verfus progredieris; tunc longe propius a promontorio tibi fubfiftendum eft. $S_{e-}$ negae, Gambiae, magni fuminis (Rio Grande) Camaronum \& Gabonis fluviorum oftia cum littore Granorums.

$$
D d d d 2
$$




\section{SPECTME ZOOL O GIAE}

non quidem nobis obfcura funt; fed fi inde fecundum: longitudinem interiores in partes progredieris, vix quatuor vel quinque gradus ipfarum, nec hos quidem curate, nofces. Comparnonus (i) quidem regnum. Bom. boucum, quod prope decimum longitudinis \& decimum quartum latitudinis gradum pofitum eft, defcripfit; fed utrum longitudinem exacte defniverit, adhuc anbigitur. Licet autem breviter ftrictimque tantum omnia comprehenderit, optime tamen fecit, qui-aliquam faltem ejus cognitionem dedit. Stibbfars in Gambio fumine ultra Barracondam provectus vix ad oftavum longitudinis gradum pervenit, $(k)$ cujus fpatii dimetien-.. di li a mari initium feceris, vix quinque gradus habebis; quum Compagnonus Senzeg a amne delatus ad octavam usque gradum pervenerit. It hi ultimi Africae fines. funt, an quos unquam whopaei procedere futinue-. runt. Nihilo tamen fecius dictorum virorum relatio.. nes fubleftae admodum fidei, \& longitudinis refpectu: tam incertae funt, ut nec mediae, quas Sunga. Gambiaque perluit, partes certo determinari queant. $\mathrm{Cu}$ jus de rei veritate ut eo magis convincaris, tres Africne tabulas, quas Deflilius edendas curavit, (l) quasgue neutiquam peffimis adnumerandas cenfeo, inter fe compara; quarum prima Africam in genere delineavit; fecunda regionum feptentrionem verfus fitarum. partem dimidian, quae ad occidentem magis vergit, exhibet; tertia denique African gallicam, cui nunc

ma-

(i) Allg. Reifen. T. II. p. 511 . \& fe]. (k) Stibbs Reir. in Allg.

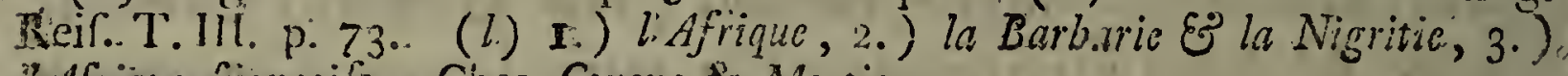
औAfrige frongoila: Chez Covens \& Mortier. 


\section{G E O G R A P H I C A E. 58 .}

majori jure Africae anglicas nomen imponi poteft, continet. Saperti lacum, in prima penitus omiffum, in fecunda fub decimo longitudinis gradu offendes; maximoramque Senegae Gambineque fluviorum curfus fub decimo jam longitudinis gradu in omnibus mappis tain vilrie diverfeque pofitos videbis, ut exinde ftatim elucescat, magnum hunc geographum, fimulac interior: Africae conditio determinanda erat, fic haefife, ut quid eligeret, aut quo fe verteret, nefciverit; quod tamen vitio ipfi vertere fapientum nemo poteft. Quis enim poftulabit, ut rebus incertis obfcurisque lucem, quae adhuc nulla datur, adferret?

0. XXVIII. Si meridiem verfus a Guinzea progrederis, ad Congi regnum pervenis, quod Lufulani a trice ist mo ad tricefinum fextum vel feptimum longitudinis, \& a primo ad decimum tertium latitudinis auftralis gra dum fortaffe peragraverunt. Et licet ejusdem ftatus variis adhuc in rebus in occulto jaceat; illud tamen ut: cognitum fupponamus ; eique cum Benguelae terris, quae illud attingunt, ex tabularum geographicarum dimenfione $180^{\circ}=0$ milliaria quadrata demus. Sed a Benguela ad Saldanae finum, quid quantumque eft, quod nefcimus!: Nonne hinc ipfa maris ora-noftrae: notitiae ita fubducuntur, ut aliquot fluminum, vcrbi caufa Cinneni oftia vix certo definiri queant? Et parum abeft, quin liaud ineptis levibusque rationibus commotus credam, nec figuram nec fines Africae orientalis" reete adhuc exploratos effe defcriptosque. Batavi, qui bonate $p p c i$ promontorium per longa fatis temporum intervalla fumma cum tranquillitate in ditione fua terimerunt, vix tamen a tricefimo tertio ad tricefimums

$$
\text { Dd dd 3. ne }
$$




\section{SPECIMEN ZOOLOGIAE}

nonum latitudinis gradum interiores in regiones penetraverunt. Quas colonias capricorni tropicum verfus deduxerunt, vix triginta milliaria germanica ab ipfo Capitis promontorio abfunt $(m)$. Et quoties vicinas regiones exploraturi, vel jufto belli more in proximos fines excurrunt; vix ultra centum \& viginti milliaria feptentrionem verfus progrediuntur; quod cum nominatis ante gradibus fatis exacte convenit. Quodfi tamen aliqua Africae penitius cognofcendae fpes erat, a Batavis ea exfpectari poterat. Quam enim unquan terrae noftrae nationem invenies, cujus diligentiam cum indefeffa illorum fedulitate comparare poteris? qui nihilo tamen fecius vel nunquam, vel rariffine ad cerram usque Natalem adfcendunt; cujus littora nifi Hamiltoniuus nobis referaviffet $(n)$, adhuc tenebris circumfufa jacerent. Africae igitur partes, quas Batavi non quidem occuparunt, fed vel inviferunt, vel exploraverunt, 7000 milliaria quadrata efficere concedamus.

0. XXIX Si paulisper hinc furfum evaferis, ad Lufitanorum fedes pervenies, quas tamen in folis fere maris littoribus fibi fixerunt.' Barretus in terras etiam interiores alte fatis enitebatur. Ipfum enim ad quadragefimum fextum longitudinis gradum usque penetrafe, fama fert $(0)$. Sed audax ejusdem conatus, qui magna ex parte propter infeftum perfidi cujusdam monachi odium fecus, quam fperandum erat, cecidit, nihil plane lucis ad illuftrandum regionum indigenarum habitum adtulit. Hoc unum exinde didicimus, venas ibi-

dem

(m) Voyage à Tille de France \& de Bourbon. (n) Allgem. Reifen T. V. (o) Faria Allg. Reif. T. V. p.218. \& feg. 


\section{G E O G R A P H I C A E. 583}

dem auri feraciflimas effe; ipfos tamen Lufotanos iftas poffeffiones fuas haud maximi facere, ex co liquet, quod Mofambici regnum nuper admodum certa argenti fumma venale aliis detulerint. Utcunque interim res fe habeat, hoc omni certe dubio caret, ex immenfo illo a terra Natali ad Guardafui promontorium traetu, duos ad fummum longitudinis gradus a littoribus, nec ipfa tamen littora nobis hucusque recte innotuiffe; nifi fortaffe Lufunai, quam iftarum regionum cognitionem ha. bent, fupprimentes in filentio ponant. Aby/finiae magna $\&$ ampla fatis deferiptio exftat, cui fi terras intra $Z \mathbf{Z n}$. gricharis littora Aeguptumque fitas, quae pro cognitis haberi folent, adjunxeris; eas vix ad 10000 milliaria quadrata extendi intelliges. Nunc quicquid ex latiffimis Africae campis cognoficere opinamur, unam in fummam confer, \& fac, eam 150000 milliaria quadrata efficere, nonne 4,00000 adhuc milliaria in obfcuro la. tere, nec noftro tantum adipectui, fed toti quain terrarum orbi fublata vides? Optimam exactiffmamque Africae Tabulam Geographicam Anvillius nobis dedit $(p)$; qui littora, quanta potuit cura, expreflit. In ipfa autem hac orbis parte regionum \& urbium nomina appofita fraftra quaeres. Expreffis enim praeftantiffmus hic aevi noltri Geographus verbis fatetur, fere omnes, quin magnos etiam maritimarum orarum tractus ignorari, quos gcrmani mapparum editores ex ingenio fuo fietos confiatosque adicripferunt. Notatu digniffrmum eft, quas cognitas Africae partes appellavimus,

(p) l'Afrique par d Ariville 3 fewilles. 


\section{SPECIMEN ZOOLOGIAE}

tales quidem ex mente Geographorum ratione fpatii effe, quod ipfarum fuperficies continet: fi vero illarum naturam, incolas, animalia, herbas, frutices \& quascunque res alias fovent, ac nutriunt, fpectaveris, quarum tamen onnium heic loci maxima habenda eft ratio, eas maximis adhuc tenebris obductas effe cernimus. Quamvis enim Sbawius Barbariae, Alpints aliique Acgypti, Adanfonius \& Demanetus Seneyae, Bosmannus Guineae, Pigafetta Congi, Kolbius bonae Spei promontorii, Ludolfis Abyffinise defcriptiones dederint: vix tamen unus alterque illorum dilucide omnia \& erudite, caeteri fere omnes leviter ac jejune narraverunt; quippe qui non folum res alias plurimas fcitu dignas, fed ipfas etiam oras maritimas; in quarum tamen regionibus exponendis potiîimum occupantur, filentio praetermiferunt. Quid enim de terris erant dicturi, quas nee ipfi viderant, nec pedibus unquam tetigerant?

פ. XXX. Opponi quiden fuevit, interiora Africae in univerfum vafta $\&$ inculta, nec hominibus frequentia efie? Quot enim funt, qui hanc orbis partem animis cogitationibusque fuis ut traetum depingunt, qui nimio folis aeftu torridus, arenis fterilibus obductus, ob coeli fitum defertus, nihil ad naturae hifforiam, niliil ad humanam cognitionem amplificandam, nihil denique ad humani generis commoda conferat, nec dignius fit, ut in ejus contemplatione commoremur? Quas tamen objectiones facili negotio redargui refellique poffe autumo.

Primo enim permiagna ex Africa interiori flumina lapfu curfuque fuo ad mare profluere, is folus negaverit, cui Senega, Gambia, fluvius magnus (Rio Crande) 


\section{G EOG R I H I CA E. 583}

Zaira, Coanza, Cuncmus, Cuama allique fat multi amnes plane fuerint ignoti: Buffonio cnim auctore $(q)$ a Nigro promontorio, quod fub decime fexto latitudinis auftralis gradu jacet, ad Gonzalvezi promontorium fub primo ejusdem latitudinis gradu pofitum, quod intervallam ducenta circiter \& viginti quinque milliaria germanica continet, viginti quinque fluviorum non ignobilium oftia numerantur. Non autem mirandum eft; Anvillizm a Nigro promontorio ad Hottentotas, qui trecenta milliaria \& amplius abfunt, trium tantummodo huviorum mentionem feciffe; quum has omnes regiones in fumma adhuc ignoratione verfari teftet?r. Quis unquam vero ex aridis tot tantaeque magnitudinis fluvios oriri vel oculis vel auribus percipit? Annon potius experientia ratiogue omnium tam Europae, quam Afae novique orbis fluviorum, qui hucusque nobis innotuerunt, docet, altiores folum montes tantae aquarum vi, quae magnorum fluminum perennitati fufficiat, colligendae \& fubminiftrandae pares efre? ex quibus neceffaria quadan confecutione colligimus, remotiorem minusque adhuc notam Africam montibus editis, perennes aquas, e quibus flumina generantur, profundentibus inftructam effe. Haud itaque Buacbius ( $r$ ) quem, quod ad montes attinet, in Tabula Zoologica ducem potisfimum fecutus fum, errafe mihi videtur; qui in tabula Africae geographica Atlantis montem cum aliis conjunxit, quorum perpetua dorfa ad Lunae usque. Montem, \& tandem ad Bonae Spei promontorium procurrunt. Viri doctiffimi conjecturae probabi-

li-

\footnotetext{
(q) Allg. Hiift. der natur. T. I. ( $r$ ) Cartes Phyfiques. Ee e e
} 
litatem non exiguam partim ipfe Atlas confirmat, quene ad coelum usque attolli, \& nenorofum fcatebrisque fontium riguum effe, celebrati auctores prodiderunt, partim Romerus adffruit, qui in Guineae littoribus praealta montium juga interioribus in terris furgentia confpici wirotins teftatur $(s)$, quae procul dubio, ex Buacbii opinione, cum Ailante cohaerent. Et in ipfo Africae meditullio praecelfos montes inveniri, ex eo conjicio, quod, qui adverfis Senegae Gambiaeque fluminibus, quousque poterant Africae interiora fubire tentaverunt, (pervenere autem ad decimum circiter longitudinis gradum) utraque flumina femper ejusdem fere magniEudinis fuiffe, \& paululum faltim ripas fuas contraxiffe, obfervaverunt; quod evidentiffino eft indicio, fontes, e quibus nafcantur, remotiffmis \& quan longiffme diffitis in regionibus quaerendos effe. Neminen enim dubitaturum exiftimo, quin Africae amnes eodem stum noltris more exiguis e fcatebris promanent, rivulos efficiant, qui dein pedetentim confluentes ingentes illos fiuvios conftituant, qui maxima tergis fuis navium onera perferre in aliasque terras commode trans. portare valeant: Quod idem Zairae \& Coanzae amnium fatum eft. Quousque enim indagari potuerunt, ejus: dem propemodum femper magnitudinis inventi funt, eooue ipfo e longinquo ipfos advenire, certo conjicimus. Africam itaque interiorem etiam montibus vallibusque alternis variari, vallesque rivulis fuviisque alluentibus irrigatơs, nec fteriles efie, nec arenofis folitudinibus adnumerari poffe autumo. Nec fieri poffe,

(s) Rocmers Nachrichten roin des Kültc Guinea 1769. p. s. 


\section{GEOGR A P H I C A E 58 \%}

ut campi arido inutilique fabulo obducti, planeque fteriles fint, ex eo jam vero eft fimillimum, quod aguaruni rivuli, priusquam in magna flumina concrescunt, \& e collibus in valles delabuntur, ab arenis abforpti exficcatique penitus evanefcerent.

6. XXXI. Hisce rationibus commotus longe alians Africat imaginem, quam vulgo fierifóiet, animo oculisque meis reprefento; licet varias etiam hinc inde partes illius fterilefcere libens largiar. A Zaarae enimi deferto, quod majus plerumque appellatur, nullus plaine fingularis cujusdam magnitudinis amnis in mare mediterraneum, cujus littora fatis perfpecta \& explorata habeinus, decurrit; quodfi etiam propter obitantia .4tlantis juga fieri nequiret; nullus faltem notus eft, qui interioribus in montibus ortus a meridie feptentrionem verfus Atlaitis radices alluat: alioquin enim Leo Africanus ejus mentionem feciffet. Ex quo quidem conjici poffet, ultri Zawan, fcat urigines quasdan fat multas largasque eam aquarum copiam porrigere, quae tamen deferti arenis haufta prius exarefcat, quam in flumen aliquod majus coïre, viamque fibi per fabula aperire valent. 'Ab orientis autem $A$ fricae partibus annes fat magnos nobilesque in mare deferri, Magnica, Cuama, Mombaza \& Zebe teftantur, quorum nullius adhuc fcaturigines notae funt: quicunque iisdem adverfis ad ipforum origines navibus ire conati funt, quod quam maxime in Cuama factum fcimus, illos fat latos femper altosque repererunt: ex quo probabile fit, nec hac in: parte fterilia arenarum deferta inveniri. Demus itaque Jeptentrionalis Africae regionibus folitudines vaftas, arerarum mole tectas; nonne \& in Afia tales 'obviae. Ee e e 2 funt? 


\section{S PECHMEN ZOOLOGIAE}

funt? nonne Perfane quoque, praecipueque Cobi Tar: tariacque tractus permagni reperientur, qui illis funt fimillimi? quis autem idcirco calidiores. Ajiae regioness pro incultis fterilibusque habiturus effet?

5. XxXII. Hos autem Africae montes nulla in re a noltris differre, \& varia in inteftinis fuis metalla, cryftallos \& alia ejusmodi continere, quae noftris e montibus effodi folent, ex iis partim, quae Guinene flumina ex montibus abluta fecum vehunt, partim ex Barreti; Compagnonique relationibus fole clarius elucet. Quicunque igitur hanc telluris noftrae partem alius naturae: ac dispolitionis quam. Afam Ainericamque effe autu: mant, meo guidem judicio perperam judicant. Qui fieri potuiffet, ut natura, quae abique locorum eadem: eft, ubique vitam foecunditatemque per orbem diffeminat, immenfos iftos Africac campos fub mitiffina fertilifinimaque coeli aërisque plaga poítos inanes, vaftos ${ }_{2}$ : intutiles mortuosque reliquerit? Perfuafiffurus fum, Africab intimas etiam regiones immenla frugun plantarumgue copia abundare. Quum enim mantes-valles: que aquis uberioribus irriguae plantas, etiam proceras ar-bores, denfas.fy'vas variaque animalium genera \& gene: rare \& nutrire foleant: necelTario fequitur, Africae etian. terras interiores hornm omniüm largiflimam copiam \& proferre \& alere. Novum itaque jụcundiffinumque oculis soitris frectaculum omnis generis animantium fraximam: partem nobis hucusque ignotorum Africa praebebit ${ }_{2}$. \& non dubito, quin tailia foveat, quorum ftupenda. magnitudo immanisque ftatura adinirationem 'no bis'nag-. natn movere polfic : praecipue quum GHotquot eomm jain novimus, corporum mole fingalarique forma fua 


\section{G E O G R A P H I C A E.}

589

reliqua omnia vincant, qualia, Hippopotamus, Tauroalepbas, Camelo-pardatis, Zebra, Rbinoceros funt \& Elepbas $(t)$.

6. XXXIII. Reftat, ut Americam quoque paucis contemplemur, quam in duas partes, in meridionalen \& aquilonalem Geographi dividere folent. 'T $\mathrm{cm}$ pelmannus (al) pofteriorem e 23 II93., priorem vero c. 340979 . milliaribus quadratis conftare tradidit, qua in dimenlione vetuftiores tabulas fecutum effe credo: Bergmanus enim in 700000 milliaria \& amplius hane orbis partem extendi adferit (v), qui tamen American feptemtrionalem cum regione a Becringio deteeta, quam noviffmae maris pacifici tabulae intra centefimum octogefimum nonagefinumque longitudinis \& quinquagefumum fecundum as tertium latitudinis gradum pofuerunt, colncrere, procerto putavit ; quamvis adhuc lis fub judice fit. Ex quo tempore Angli Americam borcalem fub ditione fua tenuenunt, fatis quidem exacte illam defcribendam curaverunt. Quoniam vero perpaucos vel nullos plane Europaeorum, regiones intra 275. longitudinis, \& quadragefimum latitudinis gradum fitas unquam.peifcrutatos effe mihi perfuadeo, facile fieri pottut , ut his etiam in terris aliquot millia quadratorum milliarium nos adhuc fugiant, licet Califorsiam fatis bene nobis innotefcere concedamus, quod. tamen fecus habet. Objoctio interim quam in Africa.

(t) Bougainvillius Kolbiusque Pocplagi quoque mentionem faciunt, quem tamen tam incerte ambiguecue definiver inc, ut hoc unum exinde difcänus; ipfum herbis quiden pafci, caeterum tamen nobis penitus jghotum che? (u) Thion. Tempelinan a new furvicw of the Globe. (y) Torbern Berg;

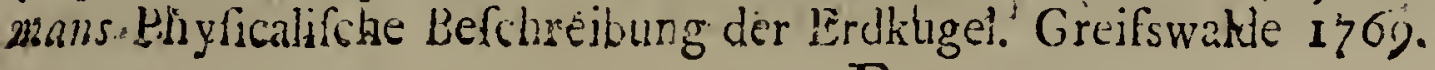

Ee e 3. 


\section{SPECIMEN ZOOLOGIAE}

irritam effe commonftravimus, vafifimos nimirum campos fterilefcere, hic locum habere videtur, quia fecundum legem a naturae conditore latam, quam fupra attuli, quamque experientia ipfa confirmat, hae regiones ad Caurum jacentes infefto rigore aeternoque gelu preffae longe minorem animalium numerum prae aliis nutriunt, quac ejusdem quidem fpatii, fub meliori vero moderatiorique coelo pofitae funt. Nihilo tamen fecius fatis probabiliter confici poffe exiftimo, his etiam in locis exiguum quendam animantium latere numerum, quos penitus ignoremus; qua occafione ea quaefo in memoriam revoces, quae in capite fecundo, quum in alces patriam inquireretur, de $W_{\text {ampooose }}$ adduximus. Quid ni ftatuamus, quadrupedes ibi ab illis, quos novimus, genere, figura formaque diverffimos inventum iri? Quomodo enim tantos tamque immenfos novi orbis campos natura, quae omnia animantibus complere folet, inanes incultosque penitus reliquerit, nulla probabilis ratio poffet. Concedam tamen, hunc animantium numerum, propter triftem afperamque coeli $\&$ aëris temperiem, magnum effe nequire; quod etiam ex $A /$ fa prope fatis adjacente, quam illi quondam confinem appofitamque fuilfe, infra commonftrabo, quamque penitius perfectam habemus, colligere licet.

6. XXXIV. Caeterum de magnitudine incogniti hujus Americae trątus quam incertiffimi fumus. In fumna enim verfamur ignorantia, annon vel ad Euronotum , vel ad Caurum lacubus majoribus redundet, an potius e Kamt chatkat regione \& fub iisdem latitudinis gradibus, tota continens fit terra? Dubia enim 


\section{G E O G R A P H I C A E. 59t}

ab Engelio (w) contra Fucae Fontisque affertum mota tanti ponderis effe videntur, ut, cui hac in re fides habenda, cui deneganda fit, haereamus. Utcunque interim res fe habeat, modum is non egredi videtur, qui a Tompelmanni 23 I 193 milliaribus quadratis 70000 , quae pro ignoratis habeantur feduxerit. Si vero Berg. mannum, qui American septentrionalem I 30000 milliaria quadrata prae Tempilmanno majorem fecit, fequeris : 150000 milliaria ignorabuntur; quoniam ille American ad gradum centefimum nonagefimum extendi au-: tumat.

5. XXXV. Haec eadem Americae meridionalis conditio eft; cujus littora fola exacte novimus; generatim tamen nobis magis, quam Africa innotefcit. Pauciffimae enim fuperfunt littorum partes, quas minus compertas habemus. Emiffarii praeterea lacerdotes a $P_{a}$ raguaya ad Moxas usque Baurosque mediae fere Americae meridionalis indigenas penetraverunt $(x) ; \&$ guod potiffimum eft, Condwininitss, aliique poft illum fecundo Amazonum flumine vecti, ingentem hunc tractum totum peragraverunt. Nonne 'mirandum eft, orbis partem ante trecentos circiter annos detectan melius curatiusque illa perquifitam effe \& inveftigatam, cujus fitus \& littora a quatuor millibus pluzibusque annis jam nota fuerunt \& frequentata? Sic nova femper antiquis praeferri videmus. Forfan tamen \& moderatior Ance. rucae aeftus indigenarumque animi debilitas, qui vix ca-

nUII

(14) Mémoires Géographiques \& critiques fur la fituation des pais fepr tentrionaux d'Afic \& de l'Minerique. Laufinas 176.5.

(x) Voyage de Coreal Tom. III. Rélation de la Mifion de Moses p.23\% 


\section{SPECIMEN ZOOLOGIAE}

num noftrorum impetum repellere aufi funt, Euro. paeos ad vifendam, pernofcendam, occupandamque hanc telluris partem invitavit. Et novo hoc non exigui penderis argumento Pawii rationes, quibus Ame. sicac indigenas reliquis telluris incolis imbecilliores effe demenftravit, confirmari poffunt. Quodfi enim Perluviani Hispanis pari virtute atque $C_{a f f r i}$ Barreti copiis reftitifent $(y)$ : fane necdüm vičti illorumque jugo frbjecti effent. Cave, ne armorum, quibus utraeque gentes ufae funt, disparitatem opponas? Lu/ttani iisdem quibus Hispani Amcricae gentes, Africae incolas adoriebantur, \& jam univerfum pene orientem, in ditio nem redegcrant; quin illi ipfi erant, qui in defenfione urbis Diu $(z)$ tam admirabilem fortitudinem, tam incredibile animi robur commonftraverunt. Nec a perfido Monclaro, ordinis Jefu fodali, contra Barretum concitatam discordiarum molem folam crediderim caufam effe, cur expeditio illa fecus, quam fperandum erat, ceciderit. Licet enim Navarezius etiam pari prope modum conatu in medio Mexici regno contra Cortezilum animum manusque extulerit: hic nihilo fecius regnum occupabat. Accedit, quod Lufftani magis jan climati Africano, quam Hispani vix e patria fua egreffi Americino adfueti erant. Barretus enim exercitusque fui pars maxima jam ante, quam iftam contra Mongas expeditionem fufciperent, aliquamdiu in Africa commorati fuerant; e quibus fequitur, Caffros vel fortiores vel prudentiores Americanis fuife, quod ipfum rei caput fuit,

f. XXXVI.

$(y)$ De Expeditione Barreti vid. Allg. Reif. T. IV. p. 2 IS. Allg. Reif. T.I.

(z) Vido 


\section{E O G R A P I C A E.}

6. XXXVI. Ut autem ad Americam redeamus, omnino Orinokum inter \& Maranonem, itidemque a $\mathrm{Ma}$ ranonis latere meridionali permagnos adhuc campos notitiae noftrae fubductos fcimus; quos fi unam infummam contuleris, \&, quid ex Cbilienfibus Magellanisisque terris nos adhuc latet, addideris.; facile numerum: ro0000 milliarium quadratorum habebis. Quum $L u$. fitani, quas Brafiliae oras maritimas incolunt, haud facile deferere, nec altius in regiones iftas penetrare audeant; ad minimum 20000 milliaria quadrata fuperfunt, quorum cognitio nos fugit: Haec fi prioribus. addas, 120000 milliaria Americae meridionalis, quae ig. norantur, invenies. Hiftoriae autem naturalis maximi \& pluris quidem intererat, haec penitius cognoviffe, quam illa I 50000 vel 160000, de quibus in America jeptentrionali nihil certi conftare demonftravimus ; quoniam ex lege jam crebrius adducta, quam ipfa fibi natura pofuit, calidiores tractus prae frigidioribus plus animantium fovent: quod ex moderatioribus Anericae meridionalis regionibus palam fit, quae, quod neminem latet, immenfos ipforum greges nutriunt. Interim tamen, Africae partes, quas adhuc ignoramus, multo ampliores uberioresque prae America meridionaIi non quadrupedum modo, fed generatim plantarum animaliumque catervas continere, eaque penitius cognita perfectaque nostram ip forum cognitionem mirum quantum auctum iri, perfuafisfimum habeo.

0. XXXVII. Quodfi nunc orbis partium, quarum nos in Afan, Africa, Americaque infcii rudesque adhuc fumus, fummam feceris: eam 80000 m milliaria quadrata efficere perf́icies. Quoniam vero dictae tres 


\section{SPECIMEN ZOOLOGIAE}

partes, univerfe in 1700000 quadrata milliaria extendi dicuntur, folum orbis noftri dimidium quod cognitum effe Geographi plerumque adftruere folent, reftabit, licet pleraeque geographorum tabulae etiam reliqua tanquam nota nobis apponere foleant. Vix itaque dimidium terrae continentis fpatium in notitiam hucusque noftram pervenit; \& illud quidem dimidium, quod paucifimas $\&$ animantes $\&$ res alias magnis hominum commodis fruetibusque infervientes profert. Ex induftria vero immenfae magnitudinis terras ad Luronotum jacentes, novan nimirum tam Hollandiam, quan. $Z$ cclandiam ficco pede praeterii, quanvis pofterioris $\mathrm{fi}_{-}$ tus nunc optime, orae vero prioris bene fatis innotuerint. Prioris fuperficies Europae, fi Ruffam Europaeam detraxeris, eft aequalis; \& licet, quod minimum fit, 100000 milliaria quadrata habere tradatur, cjus tamen vix littora neque ea omnia nota, orarum. enim maritimarum partem, quae a Dimenis finibus ad: Levini regiones porrigitur, hucusque nec vifam a quopiam, nec pertentatam effe, ex Cookii itinerario $(a)$ evidenter difcimus.- Brevi tamen tempore ab Anglis, qui eo ipfo omnium laudes merentur, hoc in negotio jam occupatis, regionem hanc inveitigatum iri, fpes eft. Cur autem Batavi, quibus hae terrae jam ab anno 1620 . innotuerunt, quibusque, poftquam colonias fuas in favae Moluccenfesque infulas miferunt, maximo ufui effe potuifent, e tam longo temporum intervalto acquieverint, nec de occupandis iisdem cogitaverint,

haud

(a) Hawkeswatth T. Lu, Yide etiam tabulam yovac Hollandiae generalem. 


\section{G E O G R A P H I C A E.}

haud facilequis intelliget, cogitationeque comprehendet. Idcirco tamen dubitare nulli poffumus, eos graviffimis ex rationibus, quae comperta habuerunt, tacita etiam habere voluiffe.

ઈ. XXXVill. Quanquam interim Angli fola terrae iftius novae littora ad auftrum vergentia tetigerint; duos vel tres tamen quadrupedes, nunquam antea : quopiam vifos, offenderunt, Kanguroum fcilicet, aliumque, qui pibivudrortm generi adjici debet, \& ab incolis Q Qroll nuncupatur; \& hinc jan certi effe poffumus, fore, ut in regionibus tam benigno moderatoque coelo fubjectis, temporis fucceffu plures ipforum reperiantur:

6. XXXIX. Ex omnibus hactenus allatis computationibus generatim fequitur, regiones, quas phyfice cognitas nunc effe dicunt, fi Europam ipfis adjunxe. ris, ad fic dictas minus cognitas effe, uti 1000000 ad 900000 , feu, quod perinde eft, ut 10 ad 9 , ideoque cognitas decima tantum parte illas antecedere. Monendum autem cenfeo, me neque exigue, neque exiliter nimis calculos fubduxiffe, quippe qui numerum disparem evitaturus millefinas cen tefinasque partes omnes omifi,partim quia tam exacte certoque determinari nequeunt; partim ut proportionem comparationemque haberem, quae ad veritatem quam proxime accedat, \& uno quafi obtutu infpici dijudicarique poffit. Quum. ergo hinc eluceat, dimidiam adhuc telluris noftrae continentem fupereffe, in qua peragranda perfcrutandaque operam ponere naturae venatores poffint: hinc eocertius fperandum eft, eos totidem faltim animalia teriestria adhuc obfervaturos effe \& offenfuros, quot huc- 


\section{\وó SPECIMEN ZOOLOGIAE}

usque cognita habemus; quia pleraeque hae regiones? vel fub Zona torrida vel tamen fub temperatiffimis coe li plagis pofitae funt, e quibus naturae hiftoria maxima incrementa exfpectare poteft.

5. XXXX. Nunc fpeciatim ad quadrupedes tranfeuntes fatis magnam quidem ipforum copiam, varietates autem vel nullas, vel pauciffimas opperiamur oportebit; ut pote quae folo fere hominum domitu/a domefticis tantummodo pecudibus provenire folent; quibus fubtractis numerus ducentorum circiter $\&$ viginti quadrupedum remanet. Ex fuppofita jam proportione centum nonaginta \&. amplius. octo genera, quae hucusque ignoramus, nobis fperanda forent, quorum plurima: Africa procul dubio dabit, partim quia maximum fuperficiei fuae Spatium, 400000. nimirum milliaria quadrata adhuc in occulto latent, partim quod haec ipfa vehementiffimo folis aeftui fubfunt. Nec illum hallucinari. crediderim, qui calidiffimis in regionibus iftis maximae. molis ampliffimaeque magnitudinis beftias generari nutririque ftatuerit. Id enim magna cum probabilitate ex illis confici poteft, quas. Africam jam incolere fcinus; quantumvis etiam largiar, \& Americam, IV ampoofes, y. Afam que Sucotarios (b) fuos alere, qui Africae indigenis mole parum minores. funt $\&$ inferiores...

is

$S E$

(bi). Aicuhofs, Voyage in Churclills. Colle eq. Tom. II. 5.36c. 


\section{G E O G A P H I C E.}

$59 \%$

\section{$S$ E $\quad$ C $\quad$ T I I O I I.}

v. I. D oftquam omnium quadrupedum univerfe, \& 1 illorum etiam fpeciatim fummam non fine magna, ut mihi quidem videtur, probabilitatis fpecie fubduxi, qui phyficorum adhuc diligentiae inveftigandi perfcrutandique fuperfunt; ad illorum difperfionem transgrediar, \& primo quidem, quomodo generatim per totius orbis noftr: fuperficiem nune difpertiti reperiantur; deinceps autem qui factum fit, ut prima fua domicilia relinquentes in alias telluris noftrac regiones demigraverint, contemplabor. Hoc enim to: tius hujus disquifitionis \& omnium, quae in Zoologica Geographia hactenus enumeravi, obfervationum caput fummaque eft primaria. Poftea quid utilitatis haèc quadrupedum migrationis ac dilatationis enarratio ad telluris noftrae hiftoriam dilucidandam, ejusdemque fuperficiei immutationes explicandas conferat, videbimus.

D. II. Ante omnia quaeftiones quasdam generales praemittamus, quibus diffolutis reliqua omnia facillima etiam cognitu fore exiftimo. Cardo nimirum réi in eo verfatur, utrum vero fit fimile, ut animalium genera $e x$ uno eodemque domicilio tanquam e prima patria fede fua exierint, \& inde vel per totam terrae feperficien fe diffipaverint, vel magnos faltem ejus amplosque tractus occupaverint; aut an potius praefumendum fit ac praeoptandum, a rerum ftatim initio varia hujus illiusque generis ac fpeciei animalia per varias procul inter fe diffitas regiones fub variis latitudinis longitudinisve gradibus jacentes transpofita effe? Alia quaeftio effe poffet, an quodvis animalium genus ab uno mare ac: 


\section{SPECIMEN ZOOLOGIAE}

femina, quos rerum conditor ab initio produxerit, ortum, totaque deinceps ejusdem progenies a duobus hifce parentibus propagata fit, nec ne; quae tamen fententia per fe jam tantopere a naturae indole ac ratione abhorrere milhi videtur, ut neminem noftris temporibus, nifi qui inani riomen fcriptis illuftrandi cupiditate laborat, eam refutaturum efle crediderim. Quis enim eft, cui non primo adfpectu, omnium fere animantium perniciem atque interitum iftatim $a b$ ortu fuo fubfequi debuiffe, palam fit? Nonne enim fic futurun erat, ut primi leones primos vix conditos leopardos, inediae explendae gratia, devorarent, qui fortaffe eadem de caufa Gazellas jam ante deftruxiffent? Prima tigris ex tauri vixdum producti ac ftatim difcerpti carnibus famem reftinguere coacta fuiffet, panthera primum equam, is fic valentior quaevis beftia, quae carnibus vivit, imbecilliorem enecatum haufiffet, ut exiguo a rerum creatione temporis intervallo integrum animale regnum runditus everfum, \& , praeter robuftiffimas ferocillimasque belluas, folasque illas, quae gramine pafcuntur, \& 2 haud facile ab aliis violari poffunt, nullae propemodun fuperfuifient; quas tamen, juxta cum reliquis adhuc Elepbantis \& Hippopotamis, illae victus inopia fameque externa fubactae tandem quoque direptas abfumiffent: \& fic uno guafi eodemque fere tempore regnum animale \& initium \& interitum fuum habuiffet; guem tamen in finem a rerum conditore minine gentium productum erat; quo ipfo haec quaeftio uno quafi icu proftrata concidit. Caeterum in folvendis illuftrandisque, quas movi, quaeftionibus lectores fuppono, quî mundum hune a fummo quodam opifice procreatum 


\section{G E O G R A P H I C A E. 599}

effe, originemque fuam habuife fatuunt. Scrus enim autumantibus disquifitio haec nullius pretii utilitatisque futura eft.

f. III. Utitaque prior quaeftio: utrum fcilicet quadrupedes a patria fua, quain ipfis mundi effector molitorque a principio adfignaverat, egredientes, fe ipfos diffipaverint; anine potius, fritim a rerum initio, fine allo ordine, refpectu \& confilio omnibus in terrae locis collocati, poftea ipfi convenientes naturae fuae coeli plagas terraeque tractus fibi elegerint? recte dijudicari queat: quaedam heic loci e Zoologica Geographia erunt repetenda. In ea enim commonftraviffe credo, quosdan animantes per totum terrarum orbem diffufos, omnibus coeli climatibus perferendis. idoneos effe; quorum exempla, juxta hominem, canis, talinis, vulpes, omnesque effe poterunt, quos primo in capite enumeravi. Alios aretioribus cancellis circumfcribi, iisque tantum in regionibus vivere dixi, quae nec adeo inter fe diffitae, nec caloris, frigoris, humiditatis ficcitatisque ratione nimis fibi diffimiles fint; quorum in numero macblidien, alcen, elcpbaniem, urfunit aliosque pofui, qui tuti, \& fine vitae fuae vel damno aliquo, vel periculo, fines fibi praefixos tranfflire mimus poffunt. Huc omnes illos refero, quorum in capite fecundo mentio facta eft. Tandem de quadrupedibus actum eft, qui certis quibusdam iisque, reliquorum intuitu, anguftiffmis finibus conclufi, unam tantum alteramque orbis noftri partem, \& quidem extguum ejus fpatiun occupant, quod ipfis domicilii init tar adfignatum videtur, quodque deferere, \& cum alio fub alia coeli regione jacęnte commutare fine vitae fune 


\section{SPECIMEN ZOOLOGIAE}

fuae difcrimine nequeunt; quibus fmias, tigres caeteraque in tertio capite enumerata animalia tribuo.

§. IV. Notatu autem digniffmum eft, illorum, quibus natura tantuln roboris impertivit, ut totum pene telluris orbem pervagari polleant, pauciniima; eorum vero numerum, quae magnos tractus inhabitant, longe majorem, \& iftorum tandem, quae natura arctiffmis tantum orbis fuperficiei locis quafi adftrinxit, copiam effe maximam. Nec filentio praetermittere licet, haec ultima tertio capire commemorata, ficut capitis ctiam fecundi pleraque, fub Zona torrida fedes fuas habere domefticas; ea vero, quae omnes coeli plagas tolerare valent, temperatiorum effe plagarm feffores. Equibus confici credo, non fieri potuiffe, ut omnia fingulaque animalia per totam telluris fuperficiem dilatarentur; nifi ipforum naturam temporis fuccelfu totam inverfam plane \& immutatam effe ttatuere volueris; quod tamen concedi nulla ratione poteft; \& quodfi concederetur, iftius rei natura nec animis noftris circumfpici nec agitari poffet. E quibus omnibus, jam a rerum exordio animalia per orbem difpertita effe, patere colligo. Cujus igitur illorum generi certam telluris nontrae plagan \& regionem naturae fuae convenientiflimam deftinatam fuiffe \& praefinitam, fundamenti loco ponamus.

6. V. Obfervationem tamen non exigui momenti hoc loco commode addendam effe puto, pleraque nimirum animalium genera, quae carne vivunt, trucisque $\&$ faevioris ingenii funt, fub flaggrantiffmo folis aeftu luftra fibi fua condidiffe; quod iplum quidem ex nimio domicilii fui calore provenire, vero eft fimillimum. In- 


\section{G E O G R A P H I C A E. бor}

terim tamen fingularis rerum directoris prudentiae documentum eft, immaniffimas ibi voraciffmasque be'luas domi effe, ubi maximi uberrimique animalium greges quibus famem fuam fedent, reperiuntur (a). Nonne inconfulte ac dementer acturus efiet, qui leones, tigres, leopardos., jaguaras omnesque ejusdem feritatis animantes, quibus carne nutriri mos eit, in Samojedac aut Groenlandiae fines transponeret; ubi ouo iftorum genera, qui interdum modo carnibus cibi loco utuntur, ar fis nimirum \& ifatis vix faturari poffunt, ideoque, ut famem fedent, ad pirces confugere coguntur. Coecum effe \& excordem oportet, qui exinde fapientiffrmum fummi opificis confilium, admirabilemque difpofitionem non perficicit, eoque ipfo naturae legem ab initio disquifitionis hujus fundamenti loco pofitam negare $\&$ infringere audet, quacum tamen animalium per orbem dilatatio exactififime congruit.

6. VI. Oppone: animantes has ab initio a creatore fuo incompolitis agminibus hinc inde per terrarum orbem difperfas temporis fucceffiu proprioque inftinctu ea fibi loca, eas coeli plagas elegiffe, quae caloris frigorisque ratione naturae fuae quam maxime convenerint. Sed quam abfona haec fit adfertio, manibus quafi palpabis. Si viarum ambages $\&$ circuitus tecum reputaveris, perquos, verbi gratia, leo e Nova Zemblia in Bilidulgeridiam, aut rangifer e Congi regno in Labradoris terras, ire debuerint; quis iis viae incertiffmis \& faepe errantibus breviffima certaque itinera

mon-

(a) Conf. Tabula Zoologica, ubi e. g. in Africa plura longe quadrupedum gencra, quam in Europa, \& in hac orbis parte plura quam in Groenlandia offendes.

$\mathrm{Gg} g \mathrm{~g}$ 


\section{SPECIMEN ZOOLOGIAE}

monftraviffet? Quis victum per tot anfractus neceffarium praebuiffet? Quis eos tantas tamque inter fe diverfas coeli terraeque plagas peragrantes ab aliis periculis, quin a certifíma morte fartos tectosque praeftitiffet? quae tamen propter fubitas ancipitesque climatum mutationes ipfis inftabat; nifi forte in hanc descendere fententiam malueris, fingulis regionibus fingula animalium genera data effe, quorum, folis iis, quae terrae clima ferre potuerint, fuperftitibus, reliqua iisdem in locis perierint omnia. Quicunque unquam rerum, quae in natura conftant, quaeque moventur, effeetorem exiftere perfuafum habet, \& vel limis oculis fapientifimum illum ordinem comtemplatur, ad quem omnia difpofuit \& gubernat; is hanc opinionem ridendam miferandamque potius, quam refutandam exiftimabit: Interim pone, omnes omnis generis animantes uno conditoris nutu in cunetis telluris. noftrae partibus prodifffe; eosque illorum, quibus. germanae fuae patriae clima interneciale fuerit, interiiffe: cur non in gradibus oppofitis, qui ab aequatore, intervallo: aequali diftant, aut illis faltim in regionibus,, quac eadem aëris folique vel benignitate vel. inclementia utuntur, acqualia animalium genera deprehendimus? Cur Hispania, Bonacque.Jpei promontorinm, quae iisdem fere fub coeli gradibus oppofitae latitudinis jacent, non iisdem beftiis. fcatent? Cur $M a$. dogafcaris terra profimias, (Makis) Arabia contra Per. fraque nullas; cur Magellani tractus Guanacos \& Canada nullos nutrit? verbo, fi fub eodem oppofitae latitudi-. nis gradu, fub eadem caloris frigorisque temperie, cosdem animantes quacfiveris; in maximos defereris. 


\section{GEOGR A P H I C A E: $\quad 603$}

errores. Fieri quidem potuife, quin factum effe, ut interdum in ejusmodi loca dedueti fint, largior; cos autem a mundi exordio ibi exftitiffe, ratio \& experientia repugnat.

ઈ. VII. Ut eo clarius dilucidemus, cuique animali patriam fuam $\mathrm{ab}$ ipforum conditore datam ac deftinatam effe, ad ea provoco, quae paffim in Geographia Zoologica adduxi. Sic, exempli caufa, rangiferis citra quinquagefimum nonum fexagefimumique latitudinis gradum, faltim in frigoris adhuc remiffioris terra, multisque fiminam . peciebus in noftris regionibus, intereundum effe; Europae animalia fub Zonae torridae aeftu breviffimam tantum vitam agere, quod equis, \&, quod canibus accidit, mutefcere; Ourrangum Outangum in Gallia, licet igne arte facto refotum praemature occubuiffe; elepbantum nec calidiorem quidem Italiam fuStinere potuife, \& e contrario equmm a/mumque in Arabiae, leones in Lybiae terris, capricornum in Alfibus, bovem juxta cum bomine, cane \& capra fub Afaie tepore optime provenire, vegetiffimisque ingeniis \& corporibus enitefcere, aperte fatis commonftratum eft $(b)$. Nonne prono inde quafi alveo fuit, quodvis animalium genus fingularem olim habuiffe patriam, quam ab initio inhabitaverit; ipfamque quadrupedum dilatationem nec fine fapientifimo ordine praeftantiffimaque illa concordia, quam per univerfam rerum naturam demiramur, factam effe difpofitamque.

0. VIII.

(b) Hoc loco de ftatu animalium, liberiori aurae expofitorum, non auiem in vivariis altorum mihi fermo eft; alioquin eleplas Petropoli etiam ca. lure artificiofo nutritur.

$\mathrm{Gg} g \mathrm{~g} 2$ 


\section{SPECIMEN Z OOLOGIAE}

6. VIII. Quaeri quidem polfet, cur non omnest: quadrupedes eo naturae robore ac firmitate fint praediti, qua canes bovesque inftructos cernimus; cujus beneficio per totam teilturis fuperficiem diffipari, \& om $\downarrow$ mes ejusdem vicifititudines tolerare polleant? Ad quam: quaeftionem, licet ad propofitum meun nihil attineat, pauciffimis refponderi poffe autumo; rei nimirum hujusce rationem in cujasvis animantis natura \& conftitutione quaerendam effe. Nifi enim omnium opifex unum rantummodo idemque animalium genus formare vellet; facere nor potuit, quin, quum ipfam rerum naturanx varia \& multimoda arte exornaffet, animalium etianx genera ad has ipfas naturae varietates \& $\&$ vicifitudines accommodaret: alioqui enim unum animantium genus producere, illique omnes, quae univerfi telluris orbis, fingularumque terrartun incolis opus erant, ingenii hat Eilitates corporumque vires addere debuiffet; quod an fieri potuerit, vix crediderim; effectus faltem contrarium probat: Poftquarin itaque hanc Deus naturae faciem, quam nunc habet', induerat; animalium etiam naturam ac difpofitionerr fic, uti nunc eft, pro fapientia fua effingere debuit: Caeterun vero fummo conditori gratiae habendae \& agendae funt, qui, quod in primo libri hujus capite demonftravi, omnia hoc ordine digeffit, nec alia quadam difpofitione moderatus ef: Eertae igitur regiones modo huic, modo illi, animaliun generitam funt propriae, ut nullum aliud ipforum genus, praecipue in praefenti. telluris noftrae ftatu fituque, $f_{10}$. ne:vitae fuae periculo illass.intrare, fedemque ibi figere: valeats. Patriam vero unius. alteriusque animantis non fingularibus exiguarum quarundam provinciarum limitix 


\section{G E O G R F H I C A E. 605}

bus inclufam ftatuo. Saepiffime enim evenit, ut quadrupedes, quod in leonibus, elepbantis, rangiforisque fupra jam cognovimus, ingentem vel novi vel antiqui orbis tractum occupent. Haud raro tamen alii, quod in fat multis fomiarum fpeciebus, in profimiis , gazellis aliisque, quos in capite tertio nominavimus, fiericonftat, peranguftis tantum terrae finibus circumdantur.

6. IX. Quodfi ergo', fuppofitis hifce, cuivis animalium generi certam aliquam patriam adffgnare volumus; res omniseo quam maxime redibit, ut modum \& rationem, qua nune per tellurem diffipata fint, inveftigemus, \& in caufas', quas propter unum alterumque' proram genus in multis maximum faepe fpatium a $\mathrm{fe}^{\prime}$ invicen diffitis regionibus luftra-fibi futa condiderint, inquiranius.

Q. X. Primo itaque quótuplici ratione ifta quadrupedum migratio \& dilatatio fieri potuerit, quibusve caufis coacti primos patriae fuae fines vel extenderint, \& amplificarerint, vel plane deferuerint, difpiciamus: Duplex autem caufarum genus invenio, quarum alterum naturales, feu quod idem eft, tales continet, quae cum animantis natura tam arete conjanctac funt, ut ab ipfo divelli plane nequeant: alterum extcrnas $\&$ strventitias conplecitur. Prioris generis funt, fi ani: malia tot tantisque incrementis augefcunt, ut uno eodemque loco fimul effe non poffirnt: Quum enim pritmi generis fri auctores catulos procreaffent, qui progeniem fuam multiplicaverant; non majori folum 'f $\mathrm{a}^{\text {- }}$ tio', fed largiori etiam vietu ipfis opus crat; ideoque neceffitas resque ipfa cogebat, ut, quo numerofiores fostus poft ederent, co fufius diffiparentur; alimenta";

$$
\text { Gg } 8 g
$$




\section{SPECIMEN ZOOEOGIAE}

quac unus idemque locus iis omnibus fufficientia minus fuppeditare poterat, alibi quaefituri : cujus.rei veritatem quam maxime in immanibus illis, quae carnibus vivunt, belluis deprehendimus. Quicunque igitur gramine herbisque pafcuntur, diutius, quan qui carne vivunt, confociationem congregationemque colunt \& fervant. Multo enim facilius prae illis neceffaria fibi pafcua invenire. valent. Primos autem cujusvis quadrupedum generis patres non uno eodemque loco omnes ita pofitos mihi fingo, ut alter quam proxime ab altero habitaverit; quin potius eosdem hinc inde, aut fub aequalibus, aut modice faltem a fe invicem diffitis latitudinis gradibus, ejusdemque fere temperiei climatibus vel binos, vel fi mavis gregratim per certasyue familias dispofitos cogitatione depingo; ut quaelibet illorum familia eo usque fit progreffá fefeque diffuderit, quo usque corporum nervorumque vires permiferint.

б. XI. Priusquam pergo, mentem de carnivoris meam apponere liceat. Probabilius nimirum mihi videtur, naturam longe minores numero animalium patres, qui carne, quam qui gramine frugibusque terra natis vietitant, produxiffe. Quum enim immanes audacesque illii gulones fingulis fere diebus horum aliquot enecare fame, quae fedanda erat, cogerentur: fieri nnon potuiffet, quin permulta horum genera ab initio itatim e medio tollerentur, fi par utrorumque numerus \& bini tantum cujusque generis conditi fuiffent. Hanc forte fententiam fracturus oppones: perniciofas iftas, quae carne fola faturantur, belluas reliquis minus foecundas effe? Quae tàmen objectio, quum experientiae repugnet, ftatim corruet, fi lenenam crebrius 


\section{G E O GR A P H I A E.}

607

brius pluresque catulos prae vacca, \& lupum copiofiorem prae cerva prolem edentem, idemque aliis multis animalibus ufui effe, tecum reputaveris.

0. XII. Nec fingulare illud admirandae creatoris fapientiae documentum filentio premeńdum eft, maximos vaftiffimorumque corporum quadrupedes gramine, herbis frugibusque vitam tolerare. Quodfi enim elepbas, taurus, bos aliique ad ingens abdomen explendun carnes pofcerent; quot quaefo vivas animantes per diem occifuri, quas carnis copias devoraturi effent? Hac ipfa ratione, quam etiam experientia confirmat, convicto mihi minus probabile eft, belluam iftam, cujus fceletum ad tou Obio ripas repertum eft, quaeve ex offibus dijudicata eleppantem magnitudiné aequavit, carnivoram. fuiffe, quod e folis dentibus demonftrare viri doctiffmi: funt annifi. (c).

5. XIII. Nechoc loco praetereundum eft, omnium: ferme, quae per totum fere terrarum orbem diffunduntur, animalium genera primam fuam originem temperatiori quam maxime Zonae debere. Si modo primi capitis quadrupedes perluftraveris; facile invenies, fi a/inum eqummque exceperis, nullum ipforum propriam fedem domiciliumque nimis calente in traetu quodam. habuiffe; ; reque afintum equsm que tantum, quantum bos cazisque folet, aquilonem verfus progredi; torridae vero Zonae animalia fera nunquam frigida in plaga obvia esfe. Quae omnia etiam intellectu illis facilia funt, qui fecum perpendunt, fibras nervulosque corporum nec: nit.

(c) Philofoph. Transact. Vol. 58. 


\section{COS SPECIMEN ZOOLOGIAE}

nimio frigore compreffos, nec nimio aeftu laxatos optime agillimeque contrahi diftendique poffe. Nonne autem hic ipfe ftatus eft, in quo temperatiorum Zonarum

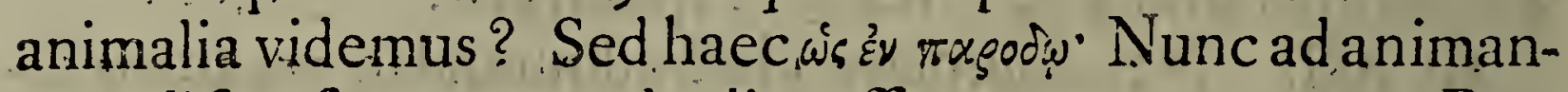
tium difperfionem, unde digreffus eram, revertor. Bestiae itaque carnivorae, cibos, qquibus famem toleraret, quaefiturae brevi tempore plures variaeque regiones petagrandae erant; ; quum e contrario quae herbis frugibusque vefcitur, pedetentim, \& poft aliquat demum generationes, quoties vel nimis anguftis fe finibus claufanm fentit, aut pafcua ad vitam funtentandam minus fuffisiunt, lento greffu progrediatur. Hic ulterius pergendi feque per orbem diffundendi modus ipfi quidem naturae aeque proprius eft \& peculiaris, atque illa generis fui augendi propagandique innata cupiditas.

j. XIV. Caufae, quibus animalia, ut jam progresfiones dilationesque fuas maturent, jam fedes priftinas, quatenus id ipforum conftitutio permittit, penitus relinquant, compelluntur, quafve adventitias nominavi, variae funt. Quibus primo vim dominium que hominis adnumero. Hic quum corporis robore, quo pollet, \& fapientia, gua praeditus eft, terrae fuperficiem fuae ditionis feciffet; beftias rapto viventes modo ex his, modo aliis e locis, quos fedes fibi conftituerat, armis fuis pro lubitu deturbavit, eoque animantes, e quibus fructus \& commoda fperabat, invitos fecum abduxit, quod in geographia Zoologica paffim demonftravi. Certum itaque, \& quod jam in primo capite evicimus, evidens eft, animalia domeftica hominis auxilio potisfinum tam late per orbem diffeminata reperiri; qui, quum conftitutionem ipforum firmam viresque corpo- 


\section{G E O G R A P H I C A E.}

609

ram robuftas fatis effe cxperiretur, utrasque, quantum poterat, ad fuam utilitatem retulit. Hic ipfe tamen fimul in culpa fuit, ut alii quoque animantes, quibus tantum firmitatis vigorisque natura dederat, circum circa diffipárentur. Sic enim noxias quasdam beftiolas, rattum fcilicet muremque, invitus tamen, ex alio climate in aliud, \&, novitatis lucrique aviditate motus, fimias Gibraltariam usque fecum duxit; nec dubitari poteft, quin forte eadem lucri cupiditate aliguot novi orbis quadrupedes, quorum fub capitis fecundi finem mentionem injeci $(d)$, in noftras terras continentes tranfulerit. Porro hic idem, licet alia quadam ratione, anfam dedit, ut non folum aëris ter-: rarumque aliquarum temperies mutaretur ; fed etiam, quod neceffario inde confequi debebat, varia animantium genera patriam fuam deferentia emigrarent. In fecundo quippe capite, ubi de rangifero fermo erat, jam commonfratum eft, hunc ipfum cum alce e Ge:manine Gallineque regionibus, quae hominis ope calidiores redditae funt, decedentes altius feptentrionem verfus adfcendiffe. Hominem autem fuiffe, gui hujus migrationis viam ipfis aperuerit, \& loco jam citato docui, \& Buffonius pridem comprobavit (e). Homo itaque aliud aliudque animantium genus e domicilio fuo, ubi. fortaffe diu fuiffet commoratum, inopinato in alias terrae plagas evocavit.

0. XV. Objectionibus quibusdam, quae hoc loco moveri polfunt, obviam ituri hüic migrandi modo aliquantifper immoremur. Quum, quae nunc addufta

funt

(d) Unau \& Fhilander. (e) Allg. Hift. der nat. T. XII.

Hh hh 


\section{Gro SPECIMEN ZOOLOGIAE}

funt, veritate fundentur, terrasque tam hominum fre: quentia, quam agrorum cultura calidiores reddi mutarique commontraverim; annon fieri potuerit, ut has illasque regiones aliquot abhinc feculis longe alia diverfaque animantium genera, quam quae nunc ibi offenduntur, incoluerint; frigidaeque nunc Zonae habita. tores ad torridam usque defcenderint? $\mathrm{fi}$, quod fentiam, libere fatendum eft, hoc a vero penitus abhorrere mihi videtur.. Putaresne, fi globi terreftris fitum: recte confideraveris, unquam: accidere potuiffe, ut: animal quoddan a borea ad aequatorem usque perrexerit? Finge tibi tractum, fub flagrantiffmo folis. aeftu pofitum, aquis olimpenitus inundatum, ideoque: diu plane incultum, quod immenfae paludes denfifimaeque fylvae poftea natae, quibus opplctus erat, inpediverant: concedes quidem, folis radios in illius fun- dum aquis. opertum arboribusque obumbratum non: fic, ut in ficcum., pronum apricumque exercere poffe. Sed num etiam concedes, rectis folis radiis expofitos planos aequabilesque campos, licet omni ratione ino-.. pacentur, glacie unquam conftrictum iri ? Num tibi: perfuaderi patiere, vel aquarum humiditatem vel filvarrum opacitarem vehementiffimum folis aeftum ita hebetaturas effe, ut terrae intra tropicos jacentes gelu: cogantur? Quamvis. itaque largiar, non fieri folum polfe, fed re ipfa quoque fieri, ut regionum qualitas* \&: condutio: folis ardores mirum quantum rel infingat: minuatque; , wel intendat \& augeat; perfuafifimum ta men habeo's, nec alcen nec jatidem unquam gentium Guinna fefforem fuiffe?

Q. XYL. Utinterim difcas, quantopere terrae yuidam 


\section{G E O G R A P H I C A E. GI}

Tractus incultus hominibusque vacans horum cultu frequentiaque immutetur: tabulam geographicam infpice. Allcen nunc in Europa fub quinquagefimo demum primo latitudinis gradu vivere, intelliges, $(f)$ quae in A/jia ad quadragefimum quintum \& quartum aliquando; in America vero ad trigefimum nonum usque defcendit, quod idem in rangif cro fieri, ex eadem tabula confpicies. Hanc vero nec fictam, nec ex ingenio compofitam, fed permultis iisque itinerariis, quorum auctoribus fides comnino haberi debet, multo labore conquifitam effe \& collectam, quum alia ratione res haec neque inveftigari neque intelligi poffet, animo tecum voluta. Lynci quidem aliisque quibusdam quadrupedibus parili modo fines fui defcribi potuifent; fed verendum erat, ne lineae fe nimium $\&$ crebro nimis interfecantes magnam tabulae obfcuritatem feciffent. Hinc evidentiffime fequitur, animalia, regionum temperie fenfim ac pedetentim correcta im. mutataque, e priftina fede fua elici $\&$ in alias terras transferri. Quae enim frigeri fic adfueta erant, ut fub mitiori calidiorique coelo ipfis pereundum fuiffet, illo decrefcente, altius polum verfus recedent; eorum vere locum calidioris climatis incolae occupabunt. Sed quod antea jam monui, cave credas, aëris coelique temperiem, quae fub polis dominatur eandem effe, quam fub tropicis etiam circulis offendis. Quaecunque enim pericula hac in re facta funt, eo recidunt, ut is frigoris modus, quo nunc quinquagefrmus latitudinis gradus horret, olim, quum terrae minus cultae, minus

ho-

(f) In alia quadam difquifitione variarum regionum temperaturas, vitan it Leus viresque concefferit, inter fe comparabo.

Hhh h 2 


\section{I2 SPECIMEN ZOOLOGIAE}

hominibus frequentatae efrent, fub quadragefimo, trìcefimo odtavo aut fexto etiam fentiretur. Et haec tam novi quam antiqui orbis proportio \& differentia quatuordecim ad fummum gradus efficiet. Interea tamen, in quo cardo rei mihi nunc vertitur, haec ipfa mutatio animantes, ut patriae fuae germanae valedicerent, aliasque fedes fibi quaererent, adigere poterat.

J. XVII. Priusquam ad ultimam migrationis caufam tranfeo; paucorum quorundam quadrupedum itionem reditionemque enarremus oportet, quae jure quidem migrationibus annumeranda videtur, licet ad propofiti mei enodationem parum vel nihil conferre videatur. Aliquot mihi exempla innotuerunt, quae quidem non ejusdem plane funt generis; fed tamen, five beftiolas, five rem ipfam fpectes, admodum inter fe conveniunt. Alterum in Norvagiae muribus lemmis $(g)$, alterum in Jurmuiotis obfervamus; quorum illi ex patria fede, alpibus nimirum Lappiae montibusque Koclenßabus fubito fe movent, immenfisque agminibus, quae ex multis millibus conftant, partim occidentem verfus, partim ad finum botbnictim progrediuntur, in itinere fuo omnia, quibuscunque potiri poffunt, defolantur, rectaque femper via fic pergunt, ut, fi foeni metas obftantes -ibi habent, eas perrodendo viam fibi aperire, quam circumire malint, majorique periculo $\mathrm{fe}$ in cymbam conjiciant, quam aquas obvias transnaterit. Hanc profectionem fingulis decem aut viginti tantum annis fuscipere dicuntur; \& quia hoc iplo magna regionis ca-

(g) Vid. Cap. III. 


\section{G E O G R P H I C A}

Iamitate afficint, incolae has beftiolas adjuratione divini nominis fugare olim tentaverunt $(b)$. Quodfi, quae vera demigrationis hujus caufa fit, quaefiveris, eam ex ipfarum foecunditate nimiaque multiplicatione oriri, exinde mihi vero prope effe videtur; quoniam primo poft magna temporis intervalla, intra quae ipfarum progenies miro incremento augeri potuit, demum exeunt. Limnaeo enim tefte $(i)$, mater uno partu quinque vel fex pullos enititur, quod forfan aliquoties per annum fieri folet. Deinde in iis regionis partibus vivunt, ubi praeter vulpes albas, fera, quae carnibus vefcatur, nulla reperitur; quae voracitate fua murium huic multiplicationi obftet. Lapporum enim canis, qui itidem iis delectari traditur, victus quaerendi caufa, haud facile alpium feptentrionalium juga, quae mures quam. maxime incolunt, perveftigabit. Interim huic opinioni eo usque tantummodo aditipulor, donec, qui fepten trionis naturam indagantur, dilucidius explanaverint, unde haec demigratio derivanda fit, \& qui fiat, ut recta femper via progrediantur. Lubens enim fateor, me in fumma hujus rei ignoratione verfari; nifi cuidam id innatae beftiolis ftupiditati adfcribere placuerit. Quodfi vero mus ifte domicilia fua permutat, quod nimiis auctibus glifens uno eodemque loco nec fuftineri nec fuftentari queat, fed colonias alias in terras mittere cogatur; haec migratio priori difpertitionis generi jure adnumeranda effet.

§. XVIII. Altera, quae fubita mutatione folum patrium

(h) Cl. Wormii Hift. Septentr. Lib. 18. p. 55. (i) Schwed. Abhand: lung. Vol. 2. p. 75 .

Hh hh 3 


\section{I SPECIMEN ZOOLOGTAE}

:trium vertit, beftiola mus furmulotus elt, de quo jaar capite fecundo, ubi in dilatationis fuae fines ac terminos inquifivi, memoratu dignum effe diximus; murens hunc jan iis in locis confpici, ubi nulla, olim cjus veftigia inventa fuerint; ubi fingulare hoc a Pallafio obfervatum effe addidi: hos furmulotos in urbem faizkoi Go. rodocam tranfeuntes in occidentali ejusdem parte conAtitiffe, nec usque adhuc magnam plateam tranfire \& occidentalem ejus dimidiam occupare conatos effe. Forfitan \& hos accrefcens multitudo nutrimentorumque. adegit inopia, ut novas emiferint colonias. Beftiae huic natura plus roboris, \& flexibiliora habilioraque prae lcmmo corpora dedit; itaque non mirandum eft, eam fenfim progreffuram, victusque gratia alias terras fibi vindicaturam effe: Pallafus enim expreffis verbis teftatur $(k)$, eandem; quum magnis regio ficcitatibus coque ipfo nutrimentorum penuria laboraret, alia domicilia, alias fedes petiviffe; eam vero in altera tantum urbis parte commoratam effe, c fociabili beftiae confortione, qua reliquae omnes viae duces fuos fequi folent, originem habere autumo ; nullusque dubito, eas aucto multiplicatoque numero, ideoque decrefcente tam $r_{p}$ atio, quan wietu, reliquas etiam urbis partes invifuras effe.

j. XIX. Et Krajchemnikovius in Kamtichalkae, quam edidit, hiftoria (l) cujusdam rattoram generis imeminit, quorum ingentia agmina patriam fuam relinquunt; qua ex re Kanitfcbadalenfes annum fibi infauftum, \& praecipue venatus ratione minus prosperum praefignifi-

cari

(k) Reifen durch Rusiand T. I. p. 304. (l) Allg. Reif. T. 20. 


\section{G E O GRA PHICAE. 6 I}

eari credunt. Nemo his animalculis facultatem atmosphaerae mutationes praefentiendi, facile denegabit, qua multas alias etiam animantes praeditas effe obfervamus. Quodfi ergo ratti venationem minus felicem fuga fua praenunciare feruntur, eo ipfo etiam feras, quibus venatores infidias ftruere plagasque tendere folent, difcerfuras commodioresque fibi locos electuras effe indicare videntur. Fortalfis etiam herbae plantaeque nonnullae, quibus unum alterumque ferarum genus vi. vit, propter ficcitatem aliumque coeli ftatum frugibus: noxium male procefferunt; quarum inopia beftiae mothe victum quaefiturae alias. in regiones commigrant; quas carpivori dein quadrupedes, quorum praeda victusque funt, perfequuntur. Quae frugibus itaque victitant animalia, inediae necelfitate urgente, migrationis iaitium faciunt, quique quadrupedes illorum carnibus famem propulfare fueverunt, eadem neceffitare commoti iftorum veftigia premunt. Sic equidem aliqua ra-tione rem iftam explicari illuttrarique polfe autumo; fed inultas adhuc caufus alias fubeffe, quae nos lateant, temporisque fucceffu accuratis obfervationibus indagari polïnt, ingenue confiteor. Aurae vento rumque vim \& efficientiam \& generatim atmosphaerae vicifftudines haud raro in caufa effe, cur varia animantes modo hinc demigrent, modo illic pedes. figant, nemo naturae fcrutatorum inficiabitur. "Nec clubium eft, quin conftans diuturnaque attentio effectura-fit', ut ex hac etiam -parte aniles multae fuperfititio-nes, quibuscum hucusque conflictandum eft, penituss opprimantur.. Separatim hurjus emigrationis mentio-: nen faciendam effe putavi ; partim quoniam omness 


\section{I6 SPECIMEN ZOOLOGIAE}

ejusdem caufas nondun cognitas perfectasque habemus, quas illius regionis phyficis fuo tempore expiscandas relinquimus;. partim quia perexiguae tantum beftiolae funt, quarum fingularis haec emigrandi ratio itinerisque directio cognationem aliquam inter fe habet. Interim non nego, eandem non inepte priori generi fubjici potuiffe, quod de naturali quadrupedum, feu quod idem eft, de illa migratione agit, qua animantes vel patriae fedis anguftia vel nutrimentorum penuria commoti domiciliis fuis renunciantes alia quaefitum exeunt.

6. XX. Nunc ad alteram eamque meo quidem judicio graviorem, quin graviffiman diffuforum, per orbem noftrum dilatatorumque hinc inde animalium caufam progrediar, quae ex commutatione \& converfione, quam in terrae fuperficie factam effe difcimus, ortunin traxit. Quotcunque adhuc fyftemata naturae venatores. excogitarunt, quorum ope docent, qui fieri potuerit, ut pifces, animalia, herbae aliaque hujusce modi lapi-: dum duritiem naturamque induerint; ut montes e plano fürrexerint; ut lapidum, arenarum, metallorum, aliaque ftrata ordinatim digefta inveniantur; \& quantocunque opere invicem difcrepent; pleraque tamen in eo concordant, magnos telluris noftrae tracius maris olim aquis inundatos, infulas e mari prognatas; terram continertem variis locis uno quafi ictu difruptam fejunetamque effe, \& certas fuperficiei noftrae partes ad maris olim fundum pertinuiffe. Ad tot tantasque immutationes ac viciffitudines explicandas minime novis hypothefibus opus eft, quibus pariundis neque aptum nic nee difpofitum fateor. Sufficiat mihi, cerra nec 


\section{GE O G R A PH I C A E. 617}

ambigua in regno etiam animali reperiri dócumenta, quibus, tot tantique momenti converfiones orbis fuperficiem perpeffam effe, dilucide probari poteft; quibusque enumerandis, quia jam a Bergmanno, Luloffio Ra. $j$ pioque $(m)$ in praeftantifimis operibus fuis $\&$ ab aliis multis collecta funt, fuperfedere poffum.

0. XXI. Videamus itaque, quid ex his omnibus refpectu quadrupedum migrationis argumentari liceat; feu, ut perficue magis loquar; disquiramus, an ex domiciliis ac fedibus, quas hoc vel illud animal nune occupat, demonftrari poffit, noftram telluris fuperficiem magnopere immutatum effe? Hanc itaque everfionem ex animantum migrationibus effecturi nec hominem ipfum, nec illa animalium genera, quae homo commodi fui caúa fecum abduxit, teftium loco adrocari poffe credimus; quum ille, ubicunque locorum fit, confilium a fe ipfe repetat, ex infula in infulam tranfiturus fibi naves aut fultim 'cymbas aedificet, ideoque nihil ipfi invium fit. Rations enim auxilio, ingenii docilitate corporisque flexilitate ac robore adjutus nihil intentatum relinquit, omnes fummae telluris angulos perveftigat, a poli antaretici frigoribus ad aretici algorem remotis obftaculis pergit; vaftas Arabiae folitudines pervagatur, habitabilesque fibi reddit; nec Peruvinnorum Andium catenis, nec oceani omnes terras ambientis, fluctibus, quo minus utrosque tranfeat, deterretur.

ઈ. XXII. Cave credas, cultiffimas tantum fubactique ingenii nationes eo audaciae procedere, ut fragilem

(iil) Specimen hiftoriae natural. globi terraquei \&c, $\Delta$ mittelod. 1763. Ii ii. 


\section{I8 SPECIMEN ZOOLOGIAE}

lem truci committant pelago ratem, \& ab infulis ad infulas inoffenfo quafi pede progrediantur. Quaevis enim hominum confociatio, ad quam colendam nati \&r cafloribus ipfis procliviores funt, quanvis rudes caeteroquin \& imperiti fint, fcaphalas naviculasque fuas habent, quibus, licet infornibus faepe \& imbecillis, nihilo tamen fecius, aut confulto aut cafu vel fexcentorum interdum milliarium curfum conficiunt. Cajus rei fi exempla quaefiveris, non folum infeliciffima Aethiopuns in gente, quam longe cultiores majorique confilio \& fapientia praediti Eurupaei peffime tractare folent, oculos defige, quae ejusmodi itinera magno fiepe fui commodo \& folatio fufcepit (n), fed praecipue Otabitae incolas haud ita pridem detectos animo tuo confidera, qui quidem ad fexcenta fere milliaria a Nova Seelandia disjuneti nihilominus eadem cum hujus regionis habitatoribus lingua utuntur $(0)$. Quot deinde naufragia accedunt, qualia Bontekovii $(p)$ aliorumque innumera funt, quae invitos creberrime homines quam latiffme per orbem diffeminari, perfpicue docent?

6. XXIII. Haec itaque hominum difperfio aeque ac pecudum domelticarumn migratio, quas homo, ut dominus fervitia, per omnes fecum regiones abduxit, nihil plane ad demonftrandas telluris noftrae everfiones efficiet. Sic enim cancm tam cis, quam ultra aequatorem aliisque in locis omnibus, qui hucusque detecti funt, reperimus; eo autem herum fequi fuum coactus eft.

(n) Voyage a l'lle de France \& de Bourbon: lettre I $2 . \quad(0)$ Cook's Voyage in Hawkefworth's Colledion T.IIL. (p) Allg, Reif. T. VHII, p. $335 . \& 395$. 


\section{GE O G R A P H I CA E. $\sigma_{19}$}

eft. Si maris pacifici terras aliquot abhinc feculis peragrandi inveftigandique nobis copia data fuiffet, ubi cames jam peregrinantibus pafim obvii funt, forfan ibi oves offendiffemus, quas nunc vel aëris temperies minus ipfis conveniens, vel nutrimenta non fatisillis apta, vel morbi inopinabiles pridem forfan deleverunt. Nec parem omnium reliquorum quadrupedun rationem nunc effe quam olim, probe notandum eft: animantem enim, quam e domefticarum numero jam excludinus, olim \& $\mathrm{ab}$ initio feram fuife, certo adfirmari nequit. Quas jure nunc feras appellamus, illae folae funt, quae magnitudine reliquis antecedunt, carnibusque vefcuntur, quibus tamen folum lupun, qui hominibus nunc perutilis factus eft $(q)$, eximo. Quae enim venando nunc excitantur agitanturque beftiae, forfan olim cicures fuerunt; ad comprobandam faltim orbis fuperficiei immutationem nullius fere funt ponderis: quippe quae, quum vefcendo fint, faepius ab homine in peregrinas redes infulasque, quas occupavit, transportatae funt. Hac enim ratione apri, qui gregatim nunc Aimericae filvas pervagantur, Cervi autem juxta cum illis in Americam \& in Franciae infullam (Isle de Trance) translati funt; quod laudatus fupra auctor in itineris in hanc infulam inftituti defcriptione $(r)$ autumat. Batavos autem noxia /2miarum animalia primos eodem devexiffe, abbas de la Caille perfuafum habet $(s)$, quod àequali fere tmodo cum famiis, quae Gibrallariae nunc fines incolunt,

(q) Videantur argumenta, qubus cupite primo Gugra siliae Zoologicae lupum canemque idem effe animal, probare conatus fum. $(r)$ Yoyage à lille de France: lett. I 5. (s) Journal d'un Voyage au Cap de bonne Efpérance. 


\section{SPECIMEN ZOOLOGIAE}

lunt, factum effe, jam capite tertio dixi. Quamvis itaque ad commonftrandam evincendamque telluris fuperficiei immutationem, non ad quoslibet animantes provocare poffis, nonnulli potius caute deligendi fint: attamen, debitam $f_{1}$ hac in re curam adhibueris, \& ad regionum quam maxime fitum attenderis; ni certi quid, faltem id efficies, quod permagnam probabilitatis fpeciem habebit.

6. XXIV. Quum ad loci naturam fitumque curate attendendum effe dixerim, id nunc ut perfpicue magis explanem, rei ratio poftulat. Si, verbi gratia, temperatioris aut calidioris plagae infulam aliquam, praecipue longius a continenti remotam is tantum praetereaque nullis animantibus frequentatam videmus, qui victus caufa venando ab hominibus agitari folent, neque ulla penitus, qua eo perrenire potuerint, nunc via patet, nifi quam homines vel navium vel fcapharum remigio aperuerunt; tunc cos, propter nimium fpatii intervallum, non per fe illuc demigraffe, fed folo hominis auxilio transvectos effe, infulamque ipfam cum terra continente nunquam olim cohaeflfie, probabiJifime ftatuanus neceffe eft. Fac enim, hominam vel cafu vel confulto eandem ad infulam navi appulíum, cujus folum impenfas laboresque fuos magno toetu remuneraturum fperabat, illuc hábitatum abiiffe, nonne perípicua conjectura augurandum eft, eum, quoscunque animantes fibi profuturos credidit, fecum eo abduxiffe? Finge vero infulam fub frigidifimo coelo pofitam ab a jimalibus guidem, nemine tamen mortalium frequertat $m$; num ifta hominum ope illuc tranlata esfe, uncuan tibi perfuadebis? Nonne majori potius 


\section{GEOG R A P I C A E. 62I}

probabilitate hanc proximas olim terras tetigiffe, \& fato quodan abruptam elfe, autumabis? Quod duohus exemplis memoratu dignis dilucidari poteft. Spizberng enim tarandos, vulpes alhosque urfos nutrit; quorum bi glaciem haud raro tranfeuntes cum magnis ejusdem cruftis, quibus fe crediderunt, vento fluctibusque ablati peregrinas in regiones deferuntur. Vulpes quidem alba pifcibus perfaepe vitam ibidem fuar tolerat; ipfam autem in glacie tantum, quantum $u r / i$, unquam progredi, nullo adhuc documento, nullo teftimonio probari poteft. Rangifor autem, qui mufco vivit, nec maris vifendi, nec glaciei ingrediendae ulla voluptate ducitur. Accedit, guod Sfizberga eo fub coeli climate fita eft, quod ipfi etiam Grocilandi abhorrent.. Magna itaque verofimilitudine percufus tarandan non illuc perductum, Spitzlergam potius cum proxima quondam terra connexam, temporisque fucceffu divulfam effe exiftimo: praefertim quum nec vilpes fe glaciei committere foleant; haec ipfa tamen animalia, quae Spitzbergam incolunt, circumjectae continenti communia fciamus. Quoniam e contrario in Societatis infulis, aut. in una Otabita nulli praeter canes futque quadrupedes. inveniuntur: e felicifimo illius fitu fundique ubertate, ex hominum jbi degentium multitudine ferarumque beftiarum abfentia; \& quam maxime e longinqua illius. ab aliis terris diftantia haud perperain colligitur, hafce infulas omnes nunquam continenti fuiffe junctas.

6. XXV. Quim vero infulitum etiam naturae rationem habendam effe dixerim; me hoc loca fundi : 0 lique naturam \& conflitutionem intellectam velle iddo. Quodi enim infula e faxis fopulisque quafi conflruta 


\section{SPECIMEN ZOOLOGIAE}

videtur, \& reliquias e cinerum, favillarum arenarumque exuftarum ( Lava) mole concretas habet: eam nullo tempore cum continenti cohaefife, fed ardentem e maris fundo ignis vi \& efficacia fublatam, hominumque poftea cultu ac diligentia habitabilem factam efre, autumo. Sic enim praeftantiffimus itineris in Francine in. Jublam facti auctor $(t)$ Adfcenfonizis infulam totam fere cinerei fluvii, igne aliquando liquidi \& dehinc indurati rivo, quem Itali lavam (Scoriae vulcanorum) appellant, fuperfufam, \& praeter macilentas aliquot capras a nulla alia animante frequentatam reperiit: Ex utrisque, cineribus nempe concretis macilentisque capris probabilem ejusdem originem difcere poffumus, fieri nimirum potuifie, ut, veluti Santorini infula ex archipelago, fic haec ex oceani fundo adfcenderit, Europaei forte fortuna ad illam delati periculum facientes, utrum naves poftea aliquo fuo commodo huc appellere operae pretium fit, nec ne? capras aliquot huc expofuerint, quarum progenies rupes nunc vaftas inaniaque faxa pererrent. Si e contrario infulas prope fatis a continente jacentes magna \& cicurum \& ferarum animantium copia fatentes, quac cum proximae terrae incolis ejusdem \& generis \& naturae funt, deprehenderis; fi praeterea pulvinos marisque brevia infulam inter \& continentem obfervaveris: hinc ingenti cum verifimilitudine colligere licebit, infulam adjacentis regionis aliquam olim particulam fuiffe. Sic, exempli caufa, Ceilonem quondam Coromandeliae oris adhaefiffe, non pecudes tantum, \& ferae inprimis, teftantur, quas in addita

ta-

$(t)$ Voyage à l'Ine de France: letcre 25 . 


\section{G E O G R A P H I C A E:}

tabula geographica enumeratas invenies; fed ingens ctian pulvinorum dorfum, cui pontis Adami nomen daturin eft, quodque a Maravae littoribus in Madurae regno occipit, \& cum Manarae infula, quae Ceiloni adnumerari folet, terminatur, aperte commonftrat. Quibus fi dorfa ex aggeftis arenis indurata, quae ad boream vergunt, exiguasque Amflelodami \& Delphorum ingulas haud procul a Gafrapatama fitas contingunt, addideris : eas omnes arete olim inter fe copulatas fuiffe, perfpicies. Quae omnia multo evidentius partim e tabula geographica, quam Ribeirius Ceilonis defcriptioni fuae adjecit, partim ex illa, quam $V i f c b e r u s$ emifit, cognofces.

0. XXVl. Quodfi diftriße fatis mentem meam filpra jam explicui; nemini dubium erit, ex animalium migratione, eque fitu \& conditione unius alteriusque regionis, illius etiam fata, quibus aliquando fubjecta fuit, aliqua faltim probabilitate colligi, dijudicarique poffe, utrum haec vel illa iñfula jam a mundo condito ibi fuerit, aut temporum fucceffiu fit exorta? Varios autem modos dari, quibus hae, quas Originales appellare liceat, cxiftere potuerint, nemo negabit ( $u$ ). Aliae enim frufta ampliffimae cujusdam regionis effe poterant, quae per fe ipfa continens nullis aliis terris adhaefit, cujusve pars major voraginibus maris fubmerfa nunc evanuit. Aliae forfan igne fubterraneo, ignem ipfae Vulcani more evomentes, e maris fundo elatae in

ar-

(u) Liceat terrae tractui, qui minori, quam 100000 quadratorum milliarium fpatio circumferibizur \& oceano circumfufus eft, infulae nomen imponere. 


\section{SPECIMEN ZOOLOGIAE}

ardua evaferunt. Aliae, quod Dairymplitus ex Robinfii centurionis relatione docet. $(v)$, e coralliis marinis vento fluetibusque unsm in locum congeftis condenfatisque conflatae, aliae ex montibus in littore quodampofitis, qui cineres, flammas, arenasque (Lavam) in oceanum eructaverant, hoc ipfo conjectu exftrui potuerunt. Sed quum hae omnes, \& quotquot aliae infularum origines adduci poffunt, ad propofitum meum nihil plane conferant, eas omnes miffas facio; fufficiatque mihi infulas effe Originalcs, quae nulli unquam continenti annexae fuerunt. Interim tamen fieri poffe concedo, ut ex infulae conflitutione \& folo, unde originem traxerit, admodum probabiliter conjectetur.

6. XXVII. His praemiffis, praecipuas nunc telluris noitrae infulas enumeraturi, a polo arctico initium faciamus, \& quae Orgininalibus accenfendae fint, quae minus, conteraplemur. Spitzbergae, Cumbriae 'Terraeque novae infulas cum America olim; Noonnque Zennliliam cum Alin copulatam fuiffe, vero mihi quidem videtur fimillimum. Ang ham vero Scotamique a Galliae continenti avulfas effe, is folus ibit inficias; qui quacrupedes utrisque regnis communes, Dueranas Caletar masque rupes \& ftrata unius ejusdemque generis, materiei \& ordinis effe ignorat. Sola Iflandia, in oceano boreali fita, me adhuc incertum reddit, ut quo me vertam, adhuc dubitem. Parum abeft, quin cum Anderfonio Originalibus eandem tribuam (w). Horrchovius enim, praeter Heclam, ingentem montiun, ignes eructantium, numerum ibi reperiri \& omnia pene gla-

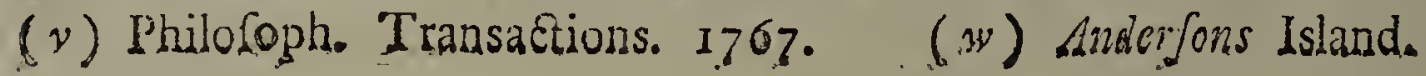




\section{G E O G R A P H I C A E. 625}

glacie nunc obruta juga (Foekel) vulcanos olim fuiffe, Guorum ignes nunc exftinci filuerunt, totumque infulae folum, quod vitro quafi obduEtum compareat, fluvio e lapidibus cineribusque olim liquentibus confato, inundatum effe teftatur $(x)$. Multas autem adhuc voragines ful pharofas ibidem hinc inde offendi, Malletus ( $y$ ) adftruit. Accedit, quod iftis glacialis oceani vorticibus multae jam infulae abforptae fint, quarum veftigia adhuc confpiciantur $(z)$. Hoc ipfo Horrebovio auctore noftra adhuc aetate fingulis propemodum annis magnae in 1/landiae montibus mutationes obfervantur; e quibus omnibus conjunetim fumtis permagnas ibi rerum converfiones \& quondam factas effe, \& nunc etiam fieri, certo colligere licet. Notatu praeterea dignum eft, tarandos ibi nullos ali; vulpes autem urfosque albos, folos quadrupedes ab jllis ibi repertos effe, qui primi naves ad infulam hanc appulerunt. Quis autem inficiari conabitur, utrosque hos animantes a vicinis Groenlandiae littoribus, quae multo propius ab Iflandia, quam a Spitzberga abfunt, glaciei cruftis majoribus, vento fluctibusque eo delatos efre? His igitur ita pofitis, quid obftat, quo minus I/fandia iis adfcribamus infulis, quae vel ex oceano prodierunt, vel e reliquis majoris cujusdam regionis, quam infefti aquarum gurgites hauferunt, exorta fit?

ઈ. XXVIII. Maris mediterranei Siciliam. Calabriae olim partem fuiffe, non ab antiquiffimis tantum fcriptori-

(x) Allg. Reifen T. I9. p. IO.

(y) Hif. de Dannemark T. I.

(z) V. het verfunkene Eiland van Bus in mappa Ifiandiae Anderfonï. $\mathrm{Kk} \mathrm{k} \mathrm{k}$ 


\section{SPECIMEN ZOOLOGIAE}

toribus traditum, \& Ovidii (a), Claudiani (b), Strai bonnsque (c) teftimoniis confirmatum eft; fed quicursque Meflinae Regiqque fitum attentis oculis contemplabitur, utraque quondam conjuncta fuiffe, facile inveniet. Quodfi praeterea \& talparum, \& cicurum ferarumque animantium copiam in utriusque campis obviam confideraveris; ulteriores hujus rei probationes nullas poftulabis. Hoc idem de Sardiniae Car/sicaeque infulis nón inmerito ftatuendum eft, quarum utraque vulpes, martes, aliasque feras alit $(d)$, quae, qua ratione ex altera in alteram transmigraverint, haud facile explicaveris. Corficam olim Jimias habuiffe, Procopius quidem teripfit $(e)$; utrum vero infulae fuerint indigenae, an aliunde eo, ficut in Gibrallariam tranflatae, nec addidit, nec planum jam facies. Bulcares autem multis ablinc feculis cum continenti copulatas fuiffe, ex eo liquet, quod non feras modo beftias, fed erinaccos etiam nutriant $(f)$. Nullas itaque mediterranei maris infulas majores Originalubus, feu iis adnumerandas effe, quae cafui cuidam fingularioriginem fuam debeant, nec ante jam exftiterint, probabile, quin ad fidem pronum mihi videtur; quum e contrario minorum plerasque, quales Liparae aliaeque funt, fenfim pedetentimque vel igne fubterraneo e mari fublatas, aut ex ejectis nontium ignivomorum haud procul inde jacentium arenis, lapi.

(a) Zancle (hoc eft Meffina) quoque juncta fuife dicitur Italiae. Metamorphol. lib. I5. v. 290. (b) De Raptu Proferp. lib. I. (c) Strabo lib. Vl. (d) Boswell's Corfica p. 42. \& feq. (e) Pracopius de bejlo guthico lib. IV. Cap. 24. (f) Armftrong's Minorca p. I $\sigma_{3}$. 


\section{GE OGRA F H I A E. 62?}

Tapidibus cineribusque exftructas effe, mihi perfuadeam. Eundem Archipelagi infulas ortum habuife, majoresque ipfarum continentis quondam partes fuiffe, quas maris poftea reftagnationes fuctusque vehementiores refciderunt; minores vero aut e maris fundo adfcendiffe, aut alio quodam modo prognatas effe, nullus ambigo. Non injuria itaque Buffonitus omnes mediterranei maris infulas majorum terrae tractuum, quos vehementior maris aeftus inundaverit, abforpferitque, particulas esfe relictas autumat $(g)$.

0. XXIX. Hac tamen occafione requiri poffet : quid de mari mediterraneo ftatuendum fit, an illud a mundo condito, aut recentiori potius aetate locum quem nunc tenet, occupaverit; feu, quod idem fere eft, utrum Africa cum Europa quondam conjuneta fuerit? quod ipfe quidem adfirmat, cui tamen opponi polfet: qui fiat, ut italia, Hi/pania, Graeciaque non cosdem, quos Burbaria, quadrupedes nutriat? Quam tamen difficultatem, fi modo animalium naturae rationem habueris, planiffime enodari poffe, exiftimo. Experientia enim docet, ea, quae A/ricam inhabitant, in Italiam translata nec commode, nec diu vivere; quod elephantis accidere videmus, utpote quibus ea coeli temperies jam frigidior, ideoque minus falubris eft. Hinc factum effe conjicio, ut quadrupedes, Africae aeftui adfueti, antequam mediterraneum mare irruit, terrasque continentes disjunxit, nunquam eo usque feptentrionem verfus progrederentur, ut vel Hispaniae vel

Italiae

(E) Iiift. der Natur. T. I.

$\mathrm{Kk} \mathrm{k} 2$ 


\section{SPECIMEN ZOOLOGIAE}

Itnliae fines attigerint. Quum itaque mare mediterraneim fluctus attollerer, vaftosque illos traetus, quibus. Africa cum Lirropa colligabatur, inundaret abforberetque, animantes naturae fuae inftinetu concitati vel ad terras conftitutioni fuae convenientes aufugerunt, vel aquis fubmerfi perierunt, vel, fi qui longius ultra fines. fuos ex Africa progreff, farti aliquamdiu tectique fervati funt, poftea tamen, loci aërisque infolentia, prole nulla relicta, interierunt. Pone igitur, Europam Africamque adhuc conterminas effe; idcirco tamen fruftra leones, tigrides aliosque hujus incolas in illa quaefiturus effes; quippe qui illius frigora naturae fuae minus tolerabilia abhorrent. Haec itaque objectio, Buffoniz: opinionem minime frangit; praecipue quum, alia quaedam monumenta, quantulacunque fint, accedant, quae priftinam utrarumque telluris partium conjunctionem. teftantur. Unius tantum Procopii nunc mentionem facio, qui Corfacam olim Simias aluiffe fcribit $(b)$, quae. fine dubio Magotorun ( Sim: Inuss). Ppecies aliqua fuit, quae in. Matritnniae totiusque Barbariae finibus nunc inveniri dicuntur. Et quia mediocri frigori tolerando pares funt; fortaflis co usque boream verfus procedere aufae funt; id quod byftricam in Hispania degentium: exemplo probari potent.

0. XXX. Ex iis, quae de praecipuaram maximique momenti infularum, quae quam proxime Europam attingunt, origine diximus, multa ad reliquarum etiam: orbis noftri partium infulas commode transferri poffunt.

Paus-

(b.) Procosid l. co. 


\section{G E O G R A P H I C A E G 629}

Paucis itaque obfervationibus additis, an \& quomodo terrae, quas continentes appellamus, cohaereant, ad quas maris mediterranei infulae me inopinatum perduxerunt, confiderabo; cui tamen rei de induftria non diuimmorabor; quoniam, qui mentem meam plene planeque affecuttus fuerit, facile perficiet, ea quae generatim funt propofita, in quasvis alias etiam infilas fpeciatim quadrare. Sic, exempli gratia, $\mathfrak{Y}_{\mathfrak{a}-}$ poniam, Borneonem, Sumatrain, Javam, P'bilippinasque infulas, Afule partes fuiffe, cui olim annexae fuerint, cuilibet planum erit, qui Tabulam Zoologicam noftram infpexerit, \& animalium genera, quae continentem frequentare videt, in vicinis etiam infulis obvia effe obfervaverit : quod idem in majoribus Antillis, in Madagafsare multisque paffin deprehendet. Praemonitum interea lectorem volo, de pernultarum adhuc infularum ortu nihil certi conjici poffe; quoniam partim de infulis ipfis, partim de animantibus, quas nutriant, in fumma ignoratione verfamur. Quis enim explicaverit, unde illae, quae Euronotum verfus jacent, quaranr: rationes, fitum fi exceperis, nullas cognitas habemus, exftiterint? Harum in numero Pbilippinge novae, Mo. luccae permultae, Guinea iovia, \& nef́cio, quot aliae: habendae funt. Cave itaque, ne has, quio ceteras, modulo metiaris, hisque eandem originem prius tribuas, quam phyfici aliique viri periti illarum quadrupedumque, quos habent, conditionem plenius curatiusque detexerint. Quot ex altera parte littora, quot aliae continentis reliquiae adeffel poffunt, quarum ftatum. \& conditionem penitus adhuc ignoramus, \& de quárum hiftoria naturali certi nihil adfwuere licet? Hinc.

$$
\text { Isk k k } 3 \text {, }
$$

non: 


\section{SPECIMEN ZOOLOGIAE}

non improbabile eft, animantes in infulis occurentes, in continenti terra etiam ex adverfo jacente, nobis adhuc incognita, habitare; quod Madaga/cari accidere mihi perfuafiffinum eft. Haec enim infula profimins nutrit, quasilli procul dubio Africae littorum e regione fitorum incolas offendent, quibus olim oras iftas hucusque plane ignotas vifendi facultas dabitur. Quae omnia fufrus adnotanda duxi, quod telluris hujus tam defcriptioni, quam hiftoriae haud exiguan lucem addunt; cujus generis plura deinceps, de continentium terrarum cohaefione acturus, adferam.

6. XXXI. Ab. America fit nunc principium, $\&$ an Europac unquam, vel Afiae contermina fuerit, nec ne, difquiramus, \& quae de Nova Hollanidia probabilis conjectura capi queat, adponam. Conjecturam enim duntaxat hoc de novo terrarum orbis tractu, cujus. nec littora quidem, fed fola fitus ratio innotefcit, capere poffumus: quum America e contrario ab omni propemodum latere pertentata jam \& inveftigata fit; mirandum non eft, quadrupedes, qui permagnam hane telluris noitrae partem inhabitant, tam nobis cognitos tamque peripectos elfe, ut citra erroris timorem rectum certumque de illis judicium ferre queamus. Afram fub orbis noftri incunabulis cum America connexam fuiffe, maxima cum probabilitate exinde colligi poterit, quod utraeque telluris hujus partes tam fibi vicinae funt, ut parum abfit, quin fe invicem contingant. Nonnulli enim geographorum Americae fines ab Aliae orientalis terminis vix duos aut tres, alii ad fummum quinque gradus, diffociant. Quodfi vero probari poffet, Tcbirikovii regionem a Defllio Beeringioque detectam Americae 


\section{G E O G R A P H I C A E}

continentis partem effe (i); hoc ipfo de connexionis veritate certiîime convinceremur. Objectio, linguas, quibus Kamt/chadales \& Americae ex adverfo pofitae habitatores utuntur, quam maxime inter fe dicrepare, nullius hac in re ponderis eft. Pone enim, unam eandemque utrosque populos linguam loqui; num exinde, utrorumque regiones inter fe quondam cohaefiffe, probaturus effes? Nonne fieri potuiffet, ut navibus homines ex altera in alteram terram tranfiffent? Quum vero omnes propemodum A/zae feptentrionalis quadrupedes in Ainerica etiam boreali reperire liceat; hoc ipfo, quod Buffonius etiam fuo confirmavit teftimonio, utrasque terrarum partes multis abhinc feculis conjunctas inter fe fuiffe, multo certius, quam quibus conjecturis geographi eandem veritatem demonitrare folent, firmatur.

f. XXXII. Laudatus jam Buffonizus viginti quinque numerat $(k)$ quadrupedum genera, quae $A / i a$ aeque cum Amerza atque cum Europa communia habeat. Interim tamen eorum nonnulla non exigui monenti adhuc Americae deeffe putat, quibus deficientibus priftina haec utrarumque orbis noftri partium cohaefio admodum ipfi dubia \& incerta adhuc videatur. Nec enim capram anmon:m, nec martem fcytbicam vel zibellinam, quarum utraque in Afiae tractibus ad euronotum fitis pascatur, in feptentrionali America obvias elfe ait. Quod autem ad polteriorem attinet, Pennanti rationibus in

fe-

(i) Conf. Buache cartes phyfiques, Bufslinggii novam Ruffiae $\&$ denique maris pactici tabulam in atlante berulinenfi obvian, \& Staeizelias Kelationem de archipelago novo rufico, vel nuftram mappam zoolugicana

(k) Hift, der Nat. Tom. 9. p. 53 . 


\section{SPECIMEN ZOOLOGIAE}

fecundo jam capite, ubi muflclae zibellinac mentio facta cft, allatis, quibus eandem Americae etiam borealis incolam effe probavit, tantum fidei, auctoritatis \& firmamenti veritati rei adjunctum effe credo, ut nullus dubiis locus relictus fit; Ammonem vero capram Americae quoque feptentrionalis fefforem effe, $V$ enegas, ordinis Jelu fodalis, planum fecit, qui in Californiac historia, quam edidit $(l)$, duo ibidem ferarum genera inveniri docet, quae nec rovale, nec antiquac Hispaniae indigenis hucusque innotuerint, quorum priori lingua monquifchenfi Tagae (Tage) nomnen datum fit, cujusque tam forma, quam magnitudo vaccam fesquianniculam referat; caput autem, quod rupicaprae capiti fimillimum fit, cornibus permagnis, arietino more intortis armetur; beftiam ceterum, boum ritu, ungulis magnis, rotundis, bifulcis praeditam, \& arietum quidem inftar pelle maculofa, pilis tamen tenuioribus mollioribusque, brevique cauda inftructam effe, narrat. Quis eft, qui ex animantis magnitudine, e capite rupicaprae capiti fimili, mollioribus pilis, brevi cauda, $\&$, in quo rei cardo verfatur, ampliffimis e cornibus arietinis Californiae Tagen antiqui orbis Ammonem effe, non furpicetur? Opponi forfan poffet: quia California prae Kamtscbatka magis meridiem verfus porrigitur, vero vix effe fimile, ut Tage fit eadem cum capra Ammone? fed penfitemus, Californiam nihilo tamen fecius cum illa Americae parte fupera connecti, quae fub codem cum Kamtfchatka parallelo circulo jacet. Praeterea obfervemus, fuperio-

(l) Gefchichte von Californien T. I. p. 34 . 


\section{GEO GRAPHICA E. $\quad 6_{33}$}

riorem Californiac regionem nọn ea aeftus vèhementia ardefcere, quae Ainmonem fugare \& depellere valeat. Quum enim Americam reliquis telluris hujus partibus multo frigidiorem effe, jam faepius notaverim, nihil capram impedire potuit, quo minus a Kamfcbatka ad Califormian defcenderet, gelidioremque illius te mperiem toleraret; praecipue fi nobiscum reputamus $A r$ galim etiam in Graecia vivere poffe. . Tandem nec Venegas Californias regionem locumque, quo Tage commoretur, denominavit. Accedit, quod Californiae tractus fupra Mendocisum promontorium pofitos omnes adhuc ignoremus, ideoque nec dignofcere queamus, annon Tage in altioribus etiam Californiae locis reperiatur? Binae igitur hae animantes, capra nimirum nimmion \& muftela zibellina, quae Afiac, qua ad Euronotum vergit, quafi proprii funt indigenae, firmiffimis nos graviffimisque, Americam olim cum A/in copulatam fuiffe, teftimoniis \& argumentis evincunt. Quibus, quod ultro fateor, fi aeque caruiffem ac Buffonius isdem caruit, utrarumque dictarum mundi partium cohaefionem priftinam cum $B$ iffonio adhuc in dubium vocarem, quam e contrario nunc ab omnibus fere objectionibus tutam certamque exiftimo. Clariffimus quidem Buffonius animal etiam mo/cbiferum his addidit, quod Afrae borealis habitator in America feptentrionali defideretur: quoniam autem iftud nec in Kamt/cbatkaler/ls oceani. littoribus, nec in Kurilenfibus infulis, nec circa Anadirskoien/es, nec $C z u k z e n / e s$ oras usquam confpicitur; fed prope Chinae fines, in mediisque utplurimum regionibus vivere confuevit; heic autem loci nobis de Kamtfcbaikae infularumque Kurilienfum cum America con- 


\section{SPECIMEN ZOOLOGIAE}

jundione fermo eft; jpfum facile \& fine ulla dubita tione miffum facimus.

6. XXXIII. Quemadniodum vero fentertia haec noftra, Americam feptentrionalem, qua ad Caurum vergit, cum $A / \beta a$ olim cohraefiffe, nunc propius ad veritatem accedere videtur: fic, an Americae etiam tractus ad Euronalun fitus priftinis feculis cum Europa connexus. fuerit, nec ne? in fumma hacusque caligine maximisyue in dubiis verfamur: Engelius, (1n), qui, unde: America incolas fins nada fit, commondrare conatus. eft, varias quidem non ineptas, at mirabiles etiam nuklaque fundamento nixas hypothefes excogitavit, iterque ab Europa borcali per Aulantidem, quam pridem fubmerfam ferunt, eodem patefacere tentavit. Quum autem, quae Plato de hac infula retulit, admodum dubia fint \& inexplicabilia; nec adfirmare certi quidquam, nec negare de illa valemus $(n)$. Ut autem de quadrupedibus conjecturam capiamus; Europa nec byfrices canadenfes, nec urfos.lufcos aliosque quadrupedes, qui in Hudfonis freto obvii funt, nutrit; qui tamen, quum nec in Grobnlandia, quam cum America conjunctam efre, certo fcimus, inveniantur; ad dijudicandame hanc quaeftionem parum vel nihil certi conferunt. Ex

qua

(m) ETa fur la popuation de l'Amérique T. I. livre 2.

(n) Quat llato de Atlantide hac in Timase tradidit, licet breviora ent, iis, gliae in critia relata legimus, mihi tamen lestu notatuque videntur dighiora. In Timate enim infulá licum multo certius trictiusque defrnivit: de qua judicare licet, Accipurum infrom (Azores) Atantidis reliquias es. fe, "quas tanten neutiquam Awericam attigerit fed late tantuminato occideacem verfus ad Amevismin fe excenderit, opinari mallem; quo ipfo quidcm tam homines, gum befiae navibus transwehi, non autem pedibus tran. sre posuificato 


\section{GEOGRAPH I C A E 635}

quo difcimus, male illum conjeêurum effe, qui, quoniam vix nominatas aninantes in $A /$ a fruftra quaerit, ideirco, eandem cum America unquam conjunetani fuiffe, inficiari auderet. Dantur enim quadrupedes, qui parce paucosque partus enituntur, \& aegre loco fuo moventur, ideoque anguftos tantum traetus, in quacunque telleris parte vivunt, occupant. Quibus fi regio ex adverfo pofita caret; inde minime gentium colligere poteris, utrasque terras nunquam ante fuifre combinatas; quandoquidem ifti, modica fua fede $\mathrm{pa}$ tria contenti, fines ejus vix egrediuntur.

ஏ. XXXIV. Sed ut ad Americae cum aliis terrisconjunctionem redeamus, praeter animantes; quae ipfi cum $A / i a$ feptentrionali communes funt, nonnullac quoque reperiuntur, quas Eiropa alit; licet in Aja, qua ad Euronotum vergit, nondum fint confpectae; quales lutra $(0)$, lutreola, meles aliaeque funt, quas tanm Europae boreali, quam Americae ex adverfo pofitae proprias effe conftat; e quibus quidem utrasque has telluris partes olim cohaefifre, aliquali conjectura augurari poffemus. Sed aperte \& ingenue confiteamur oportet; integram nec Americam borealem, quae contra Afram jacet, nec Ajiae partem, quae contra Americam feptentrionalem pofita eft, adhuc nobis cognitam, ideoque dictu difficillimum effe, an eaedem etiam ibi beftiae pafcantur, an minus? Nemo enim peregrinatorum $A$ fiam Euronotum verfus ita peragravit, ut, quas ani-

(o) Conf. Cap. II. hujus Zoolog. Geograph. ubi de lutra egi, \& objectiones addidi, quibus phyficorum nonnulli lutram a farcoviene disjunxerunt, \& utrasque diverfi generis animantes effe ftatuerunt. 


\section{SPECIMEN ZOOLOGIAE}

animantes, aliasque res communis rerum omnium pat rens natura ibidem protulerit ac nutriat, penitius inveftigaverit.. Argumenta igitur, quae Europae Americaeque conjunctionem aliqua ratione probare videbantur, eo usque feponamus neceffe eft; donec tarn Americae feptentrionalis regiones, ad occidentem fpectantes, quam Afiae orientalis partes exploratas perfpectasque habemus.

6. XXXV. Interim Aface Americaeque terras vix ac ne vix quidem ad quadragefimum usque latitudinis gradum inter fe colligatas fuiffe, calidioresque Americae partes nec a dextra cum Africa, nec a finiftra cum Afis çohaefiffe, milhi perfuafiffimum eft; quam eandem nuper opinionem Buffonius magna cum probabilitate ex eo convicerat, quod Americae calidioris \& Africae quadrupedes mirum quantum a fe invicem diffident. Vir praeftantiffimus primum fe fuiffe autumat, qui memoratu dignam hanc animalium in calidioribus utrarumque jam nominatarum orbis partium regionibus habitantium difcrepantiam, hujusque difcriminis caufam exaete explanaverit. Sed hoc iplo ei Abrabami Mylii libellum, quem de animalium origine $\xi^{\circ}$ migratione populortim anno 1667. Genevae in duodecima forma edidit, riec vifum unquam nec lectum fuiffe, aperuit; alioquin opinionem hanc jam peracto abhinc feculo inventam litterisque proditam fuiffe perfpexiffet. - Mylius enim in praeftanti hac fua disquifitione multa jam planius \& conifidentius proponere ac demonftrare aufus eft, quam aevi fui ratio permittere videbatur. Argumentis enim proxime ad veritatem accedentibus, partim nec univerfum terrarum orbem aquarum eluvie inundatum, 


\section{G E O G R A P H I C A E.}

partim nec quadrupedes Americam meridionalem incolentes in orbe antiquo natos hominumque auxilio eo perductos effe, evincit. „, Dicam, inquit, quod for" talfis videbitur magnum maximum paradoxon, quod is,

" qui animalia plantasque fecit, collocavitque in $A / \mathfrak{i} a$,

" idem quoque eorum fpecies \& femina conftituit at" que produxit in America Quod quidem firmum cla2) rumque redditur hoc pacto : quod, cum ibi fint, 2, aut eo delata oportere neceffario aliunde, aut a Deo " ibi locata \& producta. Innumerae autem fpecies ", omnis generis ibi funt, quae alicubi nunquam funt ", repertae. Ergo illae faltem a noftris hominibus ", aliunde non funt importatae, ac proinde ab ipfo Deo , ibi factae \& collocatae. Uti porro aliquae illae innu"merae fpecies ibi a Deo funt factae, cur non omnino "omnes"? ( $p$ ) Mylius igitur Americam meridionalem, quoniam immenfis oceani fretis a reliquis omnibus terris diremta eft \& disjuncta, indigenas tantum quadrupedes, nullos vero aliunde allatos nutrire ftatuit. Quae tamen nec fummae Buffonii auctoritati, nec admirabili nominis fui famae detracturus adducta volui. Conftat enim, maximi facpe ingenii fummaeque eruditionis viris perfaepe accidiffe, ut exiguae molis libellorum nofcendorum vel occafio ipfis nulla data fit, vel, $f \mathrm{i}$ in manus eorum inciderunt, eos propter auetorum obferritatem fusque deque habuerint, licet arduas interduna

quac-

(p) Hace pag 5 . in dicto $M$ gy hii libello leguntur, \& pag. 58 . animalia etiam infulas inhabitantia non eo transveeta, fed itidem ibi procreata cfe, adferit; quac tamen ejus opinio cx hactenus allatis partim emendari, pas: tim aretioribus limitibus circumicribi poteft.

\section{L1 113}




\section{SPECIMEN ZOOLOGIAE}

quaeftiones contineant, quarum illi primos fe repertores, minus recte tainen, crediderunt. . Id autem laudis foli Buffonio jure tribuendum eft, quod rem multo dilucidius expofuit, gravioribusque argumentis memoratuque dignioribus teftimoniis, ex hiftoria naturali petitis, illuftravit, guod a Mylio nec factum eft nec tunc temporis, fieri poterats Interim nobis fufficiat, feculo jam peracto virum extitiffe, qui hac de re fcite $\&$ accurate differuerit. Engclius Americam auftralem animantibus expleturus, eandem, quam Mylius Buffoniusque, viam iniit. Quodfi vero Myliz libellum prius infpexilfet, quam quinque volumina de hac quaeftione, quae uno tomo abfolvi poterant, in lucem emififfet, multa fine dubio ftrictius exactiusque fuiffet perfecutus. Accedit, quod in hiftoriae naturalis cognitione minus videatur verfatus; alioquin enim Labati opinionem non ftatim fuo excepiffet affenfu, fingulis fere diebus in Africa nova animalium genera occurrere tradentis, quae in Americae terris antea fuerint obvia $(q)$.

6. XXXVI. Sec ad id, unde digreffus fum, revertendum eft. Probandum enim milhi fumferam, nec Africam cum America, nec Americae terras infra quadragefimum latitudinis gradum fitas cum Afia unquain copulatas fuiffe, quod facillime' breviffimeque hac fieri ratione poffe autumo. Si elepbantum, rbinocerotum, bippopotamum, camelarum, camelopardalorum, zebraram, Jmminrum, proprie fic dictarum gazellartm, quarum viginti fpecies numerantur, nullos; fi nec leones;

nec

(a) Engel Eifiai fur la population de l'Amérique T. I. p. 139. 


\section{G E O G R A P H I C A E. 639}

nec tigrades, leoparlos, byenas, foffanas, genettas, nec profimiarum yerbuarumque ullos, verbo, nec animantium, quorum fedes propria in Afiae, Africae aliarumque orbis antiqui terrarum regionibus, flagrantiffimo aeftu torrentibus, quosdam, in calidiffimis Amcricae traetibus reperis; tunc hofee unquam cum illis calidioribus connexos fuiffe, jure inficiabere. Quodfi e contrario omnes tredecim cercupithecorum, Jagoin \& Sapajous nominibus infignium, fexque armodillortm fpecies, fi cuguaram, jagunram, jaguaretum, ozelotum, marguayum, quatuor pbilandrorum, tres myrmecophagorum todidemque muffetarum fpecies, hystricem prebenfilem, tapirum, bydrochoerum, mutrem pacam \& aguti, viverram nafuam, apaream, \& verbo, omnes torridae Zonae Americae habitatores in orbis antiqui partibus e regione pofitis fruftra quaefiveris; f fumma cum probabilitate confici poffe credo, novum orbem a tricefimo quinto aut quadragefimo latitudinis gradu nunquam cum antiquo conjugatuin fuiffe. Leryus autem $(r)$, qui fuo jam aero, anno nimirum ${ }^{1} 55^{6}$. nullum plane animalium genus, quod Americam orientalem habeat, repertum fuife, quod aliquam noftratium fimilitudinem gerat, expreffe teftatus eft: hoc ipfo univerfalem novi veterisque orbis animantium diverfitatem omnium optime comprobavit.

6. XXXVII. Haec argumentatio a quinquaginta pluribusque animalium generibus defumta, quibus viciffim modo vetus, modo novus orbis caret, ita mihi

qui-

(x) Lery in Allg. Reif T. XVL. p. 269. 


\section{SPECIMEN Z OOLOGIAE}

quidem firmata videtur, ut vix quaedam alicujus momenti objectio opponi queat $(s)$. Licet enim philandrorum, bradypodum, myrmecophagorumque fpecies aliquae, quod in fecundo libelli hujus capite notatum eft, in orbe etiam antiquo vivant: quid quaefo una talis alteraque beftia cum ingentibus illis gregibus, quibus -America fcatet, collata pollebit? Nonne fieri poterat, ut fingulae illae numeroque pauciffimae beftiae homirium cura antiquum in orbem transferrentur? Quod factum effe, facile comprehendimus, quum e contrario cogitatione percipere nulla g̨ueannus, qui fiat, ut reliqua animalium genera partim Amcricae, partim Afiae Africaeque defint. Praeterea fub judice adhuc lis eft, an tres illi, quos modo nominavimus, quadrupedes in oriente obvii ejusdem etiam cum illis, quos occidens. alit, fpeciei fint, an potius eidem tantum generiadnumerari debeant? Quamvis enim ex. gr. aparea cuniculo, cuniculus autem lepori perfimilis fit; idcirco tamen, nec a parcam cuniculum, nec hunc leporem effe, fcimus. Quid obftat, quo minus pisilander, mavus \& tamandua veteris orbis incolae aliquem Americac fefforum corporis orisque habitum referant; licet horum fpeciei nequaquam accenferi debeant? Quis unquam adfirmaverit, , unum idemque animantium genus a natura huic: vel illi telluris noftrae parti fingulatim fic tributum effe $\&$ adfrictum, ut alibi nusquam reperiatur?. De folis ani-

(s) Facile lectorem intelligere exiftimo, me heic leci non de animantibus quos Etropaei huc \& illuc traduxerunt, fed de quadrupedibus in ftatu fino traturali viventibus logui. 


\section{G $\mathrm{E} O \mathrm{GR}$ A P I CA E. G I I}

enimalium Speciebuis id probabile mihi vifum eft, etfi non negem, idem cum generibus etiam fieri poffe. Buffonius, quod jam fupra dixi, ex eo, quod Africa \& Aimerica nunquan cohaeferint, rationem, quam propter animalia tantopere inter fe difcrepant, derivavit; $\&$ vice verfa, e fingulari \& mirabili quadrupedum diverfitate effici opinatus eft, ut jam dietae mundi partes ab initio diductae feparataeque femper fuerint. Quam rem ut comprobaret, eo usque confidentiae progreffus eft, ut graviffimorum locupletiffimoramque auctorum, pbilandros bradyfodesque in antiquo etiam orbe inveniri teftantium, fidem dubiam redderet; quanquam, Pennan. to tefte, veritatis fuerint ftudiofiffimi. Cur autem vir eximius ipforum teftimonia omni exceptione majora in fuspicionem vocaverit; haec fubeft ratio: praevidebat nimirum, fore, ut argumentatione fatis probabili utrarumque orbis partium priftina quaedam conjunctio, quam tamen negaverat, conjectaretur.

0. XXXVIII. Poftea autem vir excellentiffimus, opinione hac repudiata aliam adoptavit. In decimo enim quarto hiftoriae naturae univerfalis fuae tomo, Americam Africamque olim inter fe conjunetas combinatasque fuiffe, planiffime \& apertiffime adfeveravit. Operae pretium eft, mentem viri ex fuis ipfius verbis cognofcere, quibus deinceps, quid de illis fentiam, apponere liceat. Sub praeftantiffimae de animalium degeneratione differtationis finem $(t):$ " cum fana, „2 inquit, ratione magis congruit, ut has (Africae \& "Ame-

( $t$ ) Hift. der nat. T. XIV. P. 222 .

$\mathrm{Mm} \mathrm{mm}$ 


\section{SPECIMEN ZOOLOGIAE}

39

99

9)

,)

9. XXXIX. Quamvis omni, qua poffum, obfervancia Buffonim, feculi noftri, propter eximiam qua pollet, rerum, \& inprimis naturalis hiftoriale cognitio- 


\section{G E O G R A P. H I C A E. 643}

nem decus \& ornamentum, colan ac venerer; id nihilo tamen fecius ingenue mihi fatendum eft, hanc, quam verbis fuis expoittam legimus, opinionem, a rei, quam. demonftraturus erat, natura alieniffmam, quin eidem contrariam mihi videri. Quicunque enim ad rationem, qua animalia per orbem dilatata confpicimus, attenderit, ea vel per totam telluris noftrae fuperficiem difperfa effe, vel magnos modo fecundum longitudinem tractus, vel anguitas denique regiones occupare, discet. : Ubi quaefo locorum quadrupedes a jeptentrione meridiem ver/us intra quadraginta, octoginta plures paucioresque latitudinis gradus, \& fex feptemque modo \& ad fummum decem longitudinis diffeminatos vel inclufos potius invenies? Talis tamen ipforum dilatatio, hoc eft ex $B$ fffmii mente, talis elfe debebat, qualis nec cxítitit, nec unquam exiftet. Ponamus interim, Africae Americaeque priftinam conjunctionem oceani illuvie interruptam elre, \& videamus, num aliqua ratio reddi queat, quomodo \& unde factum fit, "ut quinquaginta animalium genera in oppofitis fibi invicem littoribus obvia non lint? Fingamus, exempli caufa, fagoinos a ducentefimo feptuagefino ad trecentefimum trigefimum longitudinis gradum, \& fic per centum pluresque latitudinis gradus circa univerfum telluris nostrae globum per Americam., Africam, interjacentesque, qui marium voraginibus depreffi funt, tractus diflipatos fuiffe; fac oceani fluctus a meridie ad boream exortos utrasque jam nominatas continentes fic difrupisfe, uti jam disjunctae confpiciuntur: tunc omnino comprehenfu fuiffet facile, qui factum fit, ut Africa fagoinis careat. Sed tecum fimul reputa, quam mira$\mathrm{Mm} \mathrm{mm} 2^{2}$ bilis 


\subsection{SPECIMEN ZOOLOGIAE}

bilis tunc \& quam longe \& ab animantium natura, $\&$ ab ipfa veritate remota fupponenda fit quadrupedum. dilatatio. Et haec tamen unica fuiffet ratio, qua Africo ab America disjungi potuifet.. A meridie nimirun exortos oceani fuctus, adfepicintrionem proruentes (u), vi fua continentes terras ita, uti nunc eas confpicimus, difcidiffe, nec alio quopiam modo diremtionem iftam. perfici potuife, autumo.

6. XL. Praeterea Buffonnus, quod eo magis mirabere, hypothefin fuam probaturus, oceanum ex eo latere-irrumpentem fingit, ex quo fi reftagnationis initum feciffet, dietae orbis partes disjungi nequirent. Maris enim inundationem ponit, quae ab oriente pro-currens ad occidentem progrediatur, primasque origines. ab oceano pacifico capiens, medias quidem $A /$ ine, Africae Americaeque partes obrutas fubmerfifiet, Africae vero Americacque connexionem, fi tatis unquam exftitit, ad utriusque fines inferiores quod attinet, intactam irruptam-que reliquiffet: Solae igitur mediae partium terrae evanuiffents. Quoniam hoc ab illuftriffimo viro fuppo-: fitum exemplum cum utriusque tam veteris, quam-novi: orbis dispolitione \& ordine, qualis nunc eft, non cohaeret, quin potius puginat;:; locum hic ullum habere! nequit; quod tamen, fi eum modo in finem dedit, ut, commonftraret, mariam incurfu generatim certa ani-mantium: genera ab aliis telluris partibus fecludi poffe: ac divelli, idinemo quidem fanae mentis ibit inficias..

Quod-

(u) Goncedi poffet, inumdationem a feptentrione ad meridicm praecipitalle. Quun antem innumera meridiem verfus promontoria excurrant, quod a $P$ ? sinetian ubferyatum ent., prius, quad probabilius videbatu, , eligere malui.- 


\section{G E O G R A P H I C A E. 645}

Quodfi vero, qua ratione America a reliquarum orbis. partium continente difcilfa fit, quaefiveris: tunc quam: maxime, ex quo latere aquarum incurfio vel facta fit, vel fieri debuerit, attendas oportet. Situm itaque tam Africae, quam Americae praefentem contemplare; quomodo a fe invicem nune feparatae fint $\&$ appareants infpice; an alio quodam oceani impetu, quam qui a feptentrione ad meridiem perrexerit, fi- continentes fuiffent, dirimi potuerint, perpende; tandem an, quam Buffonius fuppofuit, maris irruptio ab oriente ad occidentem id efficere valeat, dijudica. Vir: celeberrimus. ipfemet forfan agnovit, ex oceani reftagnatione, a meridie boream verfus progrediente; demonftrari nulla. ratione poffe, cur uterque antiquus nimirum \& novus. orbis certis vicifim animalium generibus careat; quod. tamen, ut probaret, aliam yiam ingreffus maris irruptionem $a b$ oriente ad occidentem factam eligit;: qua tamen nunquam, quod cogitabat, . perficere poteft; quenjam, uti jam diximus, folus a meridie ad borean feu vice verfa factus aquarum impetus African ab America quidem divellere, minime tamen gentium memorabilem illam quadrupedum diverfitatem, quam in veteri novoque orbe offendimus, producere poterat. Id onim ratio, qua dilatari-folent, impedit. Fingas quaefo. immenfam oceani ab auftro excitatam boreamque verfus furentem eruptionem, quae Aby/finiae promontoria, omnem Arabiam, Peryiam, vicinasque R/zae. quin \& multas Europae regiones difruptas vaftatasque: inundet \& maris facie atque habitu induat; annon oln=rres tunc tres orbis antiqui partes, \& ipfam Americam; fi. illis adhaeferit, diffindet, \& in vaftas immanesque inMm min. 3 .

fin: 


\section{SPECIMEN ZOOL OGIAE}

fulas convertet? Et haec una aut huic fimilis quaedan maris eruptio eft, quae ad dirimendam Africam \& Americam excogitari poteft. Noli vero tibi perfuadere, ejus etiam auxilio fieri polfe, ut huic orbis parti haec, alii alia animantium genera defint. Elcphas enim, camelus, rbinoceros, leo, gazellarum multae fpecies \& plerique alii quadrupedes, qui per exiguos tantum tractus diflipantur, fejunctis inter fe partibus iftis, Aluae tamen Africaeque communes manfilfent. Qui, quae hảtenus expofui, recte adfecutus fuerit, tabulamque geographicam fimulattento oculo infpexerit, facili negotio intelliget, ullam oceani illuviem reputando evolvi nequire, quae Africam fic ab Anerica fejunxerit, uti eam nunc fejunctam videmus. Hinc neceffaria etiam confecutione conficitur, tali marium redundatione nulla explicari polle, qui fiat, ut altera vicillim orbis pars hifce, altera iftis animantibus careat. Mihi itaque non modo probabile, fed etiam perfuafum eft, Anericne latera, qua occidentem fpectant, nunquam cum calidioribus antigui orbis regionibus conjuncta fuiffe.

ઈ. XLI. Unum hoc mihi objici poffe praevideo; an non quadrupedes, qui nunc Amerisae felfores funt, antiquo in orbe, licet hic eos jam peregrinis adnumeret, primos tamen generis fui audtores habuerint, qui poftea fub alio coeli tractu, in novo orbe qui aeque, ac reliqua terra, crebrioribus oceani inundationibus mirum quantum mutatus fit, locati, formam quoque, mores, ingenia, habitumque $f_{1 c}$ mutaverint, ut tepares \& cuniculi in aparcas, agutos; pantberes aut lcopardi in cuguaros \& jaguaros, \& fic alii miris degeneratioribus in alios fibi aliquo modo fimiles fint converfi. Putasne 


\section{G E O G R A P H I C A E.}

\section{7}

vero, accidere potuiffe, ut elephas tam faciem quank ftupiditatem tapiri, leoque timiditatem pumae juba carentis indueret? ut camelus in clamam, ourungus in varimum (qui Linnaeo Jimia beezcbul eft) mutaretur? Canes noftri, in Guineam translati, mutefcere latrandique ufu deftitui folent. Buffonius quosdam ecaudes vidiffe teftatur; hi tamen muti, calvi ecaudesque omnes cum pilofis, caudatis \& latrantibus, quantumcunque temporibus intervallum a degeneratione fua praeterlapfum fit, rurfus coëunt, fuique fimiles generant. Qui autem cameli in Braffiliam deportabantur, nunquam cum clamis $(v)$ fe commiscuerunt, neque ullam coëundi cupiditatem commonftrarunt. Nec leonem cum puma, nec elephantem cum tapiro, nec alios antiqui orbis cum reliquis Americae animantibus unquam conjunetum iri, perfuafiffimum habeo. Sed concedamus, quod minime tamen gentium prius concedi poteft, quam rerum teftimonia adfunt; concedamus, inquam, ifta novi orbis genera, quae aliqualem cum veteris orbis quadrupedibus fimilitudinem gerunt, ex antiquo orbe originem fuam traxiffe, variisque tandenn, quas poftea perpeffi funt, degenerationibus eam quam nunc habent, faciem habitumque nactos efle; quod nec Buffonizss. quidem adfirmare fuftinuit; num inde utrosque olim: orbes cohaefifie conficies? quum non fingula folum animalia, fed, quod cohaefioni illi quam maxime ad́verfatur, tota etiam eorum genera alterutri orbi peri vices defint, quae forma, moribus \& natura fecum

con-

(v) Ileruıngue glama, fed minus recte fcribitur; guum slanas fcribers: dum effet. 


\section{SPECIMEN ZOOLOGIAE}

congruant (w). In qua enim Americae regione bestias ungula folida praeditas, equos fcilicet a/nnos zebrasque reperis? Ubi gazellas, rbinocerotes, proflnwias, bippopotamos, \& camelopardalos obvios habes? Ubi locorum vice verfa in orbe antiquo pacas, bydrocboeros (capibaras) armadillos aliosque plures ejusmodi quadrupedes confpicis? Quibus argumentis, hos omnes in novo, illos in antiquo orbe penitus occubuiffe radicitusque exftinctos effe, firmabis? Reputa tecum, an aequitas fanaque ratio permittat, ut tot tamque memorabilia animalium genera e rerum natura eo fine deleas, ut fyftema quoddam ftabilias, quod tamen ulla nec ratione nec probabilitate ftabiliri poteft? E quibuscunque ergo velis partibus, hanc priftinam, quam fingis \& probare conaris, terrarum conjunctionem comtemplare; nonne inexfuperabilibus illam totque difficultatibus implicatam cognofcis, quam expedire nullo modo queas; quum rei contrarium tam certis firmisque fulciatur documentis, quae nemo nifi praejudiciis excoecatus inficiabitur? Non itaque probabile folum, fed evidens effe videtur, African Americamque a rerum principio diffociatas fejunctasque fuiffe.

§. XLII. Nunc ad aliam telluris noftrae partem, ad immenfum illum qui ad orientem fpectat, Oceanum, quem Pacifcum vocitare folent, qui intuentibus admirationem movet, progrediamur; quasque continet, infulas difpiciamus, quarum jam fupra quidem, quum de infulis

ge-

(w) Onnia guidem animalium calidiflimas Americae partes incolentium genera antiquo orbi deefle, minime gentium contendo; interim tamen id de ppeciebus adfirmari polle, concedo. 


\section{GEO GRA PH I C A E 649}

generatim nobis fermo effet, mentionem facere, \&, an cum veteri vel novo orbe connexae fuerint, disqui- rere potuiffem: quoniam autem reliquarum, omnium - noviffime demum innotuerunt, earumque fitus, ftatns $\&$ natura maximam adhuc partem nos latet; eas in hunc locum refervatas volui. Poftquam ominem, quam potui, operam dedi, ut, quidquid de animantibus, hominibus, aliisque rebus, quas natura ibidem produxiffe relatum legimus, colligerem, id praecipue memoratu dignum mihi vifum eft, quod in omnibus dicti maris infulis, $f_{i}$ ab illa ordiamur, quae a Joanne Fernandezio nomen accepit, \& ad novam usque $G u$ ulnean pergimus $(x)$, praeter cancs, fues $\&$ interdum etiam rattos, nec feri nec cicures alii quadrupedes usque huc inventi funt. En ipfos auctores, quos perluftrare mihi licuit! en eorum verba, ne quis fibi perfuadeat, me hypothefium effingendarum ftudio tale aliquid excogitaviffe. "In Pa/chatos infula (O/ler-Infel) "Roggeveenfius (y) inquit, fub vicefimo feptimo gra" du pofita, exceptis volatilibus, beftias alias nullas " confpexi ;in media tamen ejusdem regione nonnullas "vivere, inde colligo, quia indigenae, poftquam " quos fues navibus noftris advectos viderunt, eos " noffe \& ante jam vidiffe videbantur. Mairius in navigationis fuae defcriptione $(z)$ e Cammm infula pracrer herbas quasdam, memoratu dignum nihil ad ipfum

per-

(x) Excipias quaefo novam Hollandiain, quam, propter fingularem magnitudinem, novam telluris noftrae partem vocare poffes. (y) Roggevens Reifen in Allgem. Reif. T. XVIII. p. 559 . ( $z$ ) Navigation auftrale de $\mathscr{F}$. ie. Maire dansla Collection des Voyages de la Comp. des Ind. T. VIII. p. 14 It 


\section{$65^{\circ}$ SPECIMEN ZOOLOGIAE}

perlatum effe memorat; nauticos autem operarios tres catellos, qui latrandi facultate caruerint, confpexiffe addit, a quibus infulae deinceps nomen fit additum. Infula quaedam Marcbioniffae Mendocae, cui Cbri/tia. nae nomen eft, fues \& gallinas, aliud vero majoris formae animal nullum nutrit (a.). Proditorum \& Horniz infulas fues alere $(b)$, Salomonisque infulas funm greges. pafcere (c), Mindana \& Mairius teftantur. Otabeitam cum reliquis, quas Angli-Societatis infulas appellant, praeter cines fuesque, quadrupedes nullos habere, Cookius (d) \& Bougainvilluss, (e) adfirmant. Reginae Carolina infulae fues quidem, canes vero nullos alere dicuntur $(f)$. Sancti foanmis infulae coloni navis praefecto fues obtulerunt $(g)$. In Nova Zeclandia jues, canes \& ratti obvii funt $(b)$. Tasmannus in. Rotterudami infula fues gallinasque offendit ( $i)$. Quis tot tantaque auctorum gravifimorum teftimonia fide digniffima in dubium vocaverit? quibus certo, plane \& uno quafi ore docent, nominatas infulas dictos quadrupedes fo. los, praetereaque nullos, nutrire, quibusve reliqui fummo omnes filentio premuntur. Quiros quidem in infula hucusque nobis incognita, cui $\widetilde{M}$ anicolae nomen effe dixit, majora etiam animaiia pafci adferit, $(k)$;

quae

(a) Andere Reife des Mindana. Allgem. Reif. T. XVIII. p. 499. \& 500: (b) Le Maire l. c. p. 169. (c) Mindana l. c. p. 494 . (d) Cook's Voyage round the World in Hawkesworth's Collection T.II. p. 187. (e) Voyage antour du Monde p. 213. (f) Carterts Voyage in Hawkesworth's Collect. T.I. p. $58 \mathrm{r}$. ( $g$ ) Lo Maire I. c. p. 196. (il) Cook's Voyage 1.c. p. $438 . \quad$ (i) Tasmans Reifen in Barrow's Sammlung T. I. p. 405. (k) Quirns Reiren, Aligem. Reer. T. XVIil. p. 531. Bougain- 


\section{GIOGRAPHICAE $6 \mathrm{CH}^{\circ}$}

quae tamen fi haud longe a Cirrolinas infulis diftat; vix comprehendi poffet, qui factum fit, ut harum fefrores tam prope a Municola habitantes iisdem animantibus, e quibus non mediocria tamen emolumenta capere poteraht, potiri nequiverint. Ut vera fatear, Quiri narratio fableftae mihi fidei videtur; quippe qui Hispanae regi, ut colonos eo mitteret, perfuafurus commoditates infulae, quam primus detexerat, forfan multo gloriofius, quam par erat, laudavit. Accedit, quod e Qurr relatione patet, ipfum ex aliquibus tantum incolarum indiciis conjeciffe, interioribus in $M a$ : nicolae regionibus majora quaedam animalia inveniri; licet ipfe, praeter fues, nulla viderit. Praeterea Qui. rus, quam defcripfit, regioni non infulae mediocris, fed terrae latius patentis faciem effe tradidit.

6. XLIII. Opponi quidam pofret: quum Europaei in ularum in oceano meridionali vel pacifico jacentium littora modo tetigerint; hinc factun quidem efle, ut. extra canes, rattos fuesque alii ibidem quadrupedes ipfis nulli occurrerint; quis autem idcirco negare aufus fuerit, medias illarum partes multis aliis frequentari? Id equidem fieri poffe, lubens largior; cur tamen minus probabile habeam, Cookii me auctoritas movet, qui Novam Zeelandiam, maximam propemodum oceani paci- fici infulam, exceptis tribus iftis animantibus, alias nullas fovere, ex eo conjicit, quod ejusdem habitatores, qui beftiarum indigenarum tam pellibus quam dentibus fe ador.

yillius nas ab Quire defcriptas regiones easuem efie purat, quas ipfe fub magnarum cycladum nomine vidıt. Sed mirandum eft, cur Bougainvillius ron idem, quod Quiros fecerit, littorique appulfus ierram infulat attigerıo? $\mathrm{Nn}$ in 2 
adornant, fine omni dubio ferarum quoque ceterarum, fi quas habuiffent, pellibus ac dentibus decorati incelfisfent; quum contra nec $A$ ingli, nec alii, qui peregrinando eo pervenerunt, dentes pellesque in ipforum ornatu nullas viderint, quam quas canibus marinisque liconibus fubtraxerunt ( $l$ ). Plerarumque autem, quae hujus oceani infulas incolunt, nationum eadem, aprorumi fe dentibus ornandi, confuetudo, idem eft inftitutum $(m)$ Pone infuper, ipfarum patriam alius cujusdam generis feras alere; cur fola carne canina famem tolerant? cur ferinam, quae tamen melioris forfan faporis illis foret, nec guitarunt, nec ejus dulcedine captae ad feras ipfas nancifcendas venationibus exercentur? cur nec feras jpfas harumque carnes nautis ex Europa appulfis venum obtulerunt? Nonne omnia haec facturos fuife, colligendum eft, fi quadrupedes alios cognitos habuiffent? Probabiliffme igitur ad fuspicandum ducor, aliis has infulas cunetis animalibus carere; certiffimisque teftimoniis convietus duo tantum $\&$ ad fummum tria illorum genera, \& quidem domeftica, quas homines undiquique fecum abducere poterant, fola effe, quae, quod mirandum eft, omnes ac fingulae, quas novimus, oceani meridionalis infulae, nouz Hollandia excepta, ad hunc diem poffident.

6. XLIV. Non itaque poffumus, quin verofimillime hinc argumentemur, ittas, quas faepius jam nominavi, infulas, a ducentefimo octogefimo ad centefinum usque Septuagefimum longicudinis gradum, reliquasque in eodem

(l) Cook I. c. p. 433. (m) Bougainville 1.c. p. 24.5. \& Alls. Reifco T. XVHII. p. 870 . 


\section{G E O G R F H I C A E.}

653

dem mari \& fub eadem coeli plaga fitas, nec veteri nec novo cum orbe unquam connexas fuiffe. Probabile mihi potius eft, eas vel magnae cujusdam continentis, aquarum illuvie dudum fubmerfae, aut terrae motu quodam concuffae, particulas relictas, vel igne fubterraneo ex oceani fundo quondam fublatas effe; hane tamen opinionem, quia certioribus monumentis in mari pacifico obviis firmatur, priori potiorem habeo. De Otabiti enim infulae folo Bankius ( $n$ ), id maximam partem ex arenis cineribusque igne liquefactis, \& poit induratis compofitum videri, manifeftaque acerrimi cujusdam incendii veftigia ubique locorum confpici $(0)$, teftatur. Accedit, quod in eodem oceano permulti adhuc montes, vulcani more ignem flammasque eructantes, exempli gratia, prope Cbrifianae Mendocae $(p)$ Carolinaeque infulas (q) numerantur, quorum Tasmannus etiam quinquagefimum inter decimumque latitudinis gradum duos $(r)$, \& Dampierius inter novam Guineam novamque Britumnam tres obfervavit (s). Quodfi hinc Indiam Orieintalcm verfus porrexeris, plures adhuc habebis, quibus fingulis percenfendis nunc fuperfedeo; quoniam

(n) Virum hune excellentifimum nunquam fine fumma obfervantia \& renerdtione nonino. Quis enim opulentiorum eft, qui divitias fuas tam honorifice impendit, \& folo fuientiarum amore ductus, fe vitamque fuam tot tamque manifeftis expofiit periculis? Vitam enim opesque fcientiis harumque augmentis impendere, cam demum veram animi magnitudinem effe autimo, quam in Angliae regno rebusque publicis maxime reperire tibi licet, alibi vero plerunque fruftra quaefiveris. (o) Cook's Voyage l. c. (3) Mindana l. c. (q) Carteret's Voyage in Hawkesworti's Collect. 'T. I. p. 582. (r) Tasman Reif. I. c. (s) Videatur noyae Britanniae tabulics in Cartereti jtincrario. Ficri tamen poseft, ut ex uno ignivomorum mon* tium peregrinatores duos e diwobus tres fecerint.

$\operatorname{Nnn} 3$ 


\section{SPECIMEN ZOOLOGIAE}

häctenu's memorati auctores rem abinde confirmant, \& partin oceanum ipfum, \& quas continet, terras magnis quondam everfionibus convulfas effe, partion montes ignivomos ingentibus commutationibus anfam dediffe probant.

6. XLV. Quin ipfi homines his in infulis lospites quâfi nóvique funt, qmippe qui (quod mirabile dictu) e multis aliis gentibus heic congregati collectique videntur. Ex coeli climate, aërisque temperie, tam colores hominum, quam eorum naturae rationem plerumque dependere ac mutari, in primi jan Zoologiae hujus capitis principio commonftratum eft, quod $B_{u} f f o-$ shius etiam aliique naturae venatores folertifinimi evincere ftudent. Si enim ubicunque locorum tota hominis fuperficies aurae folique expofita colorem ducit, quein coeli pofitio dare poteft; neceffe erat, ut natio quae, (quod in plerisque regionibus accidit) diu fatis vel easdem oceani meridionalis infulas, vel exiguo intervallo inter fe diffitas inhabitaverat, eundem denique vel faltim parum differentem colorem perbiberet, eosdem crines, eandemque incueret naturam, vel faltem parum fibi diffimilis evaderet. Unde itaque erenit, ut his infulis omnia contraria, onnia diverfa deprehendantur. Roggeveenfiuts enim ejusdem Pälcbatos in/ulne $(O / e r-\operatorname{In} f e l)$ alios albae, alios rufae, alios fufcae faciei incolas vidit ( $($ ). Quirus idem in Spiritus fancti infula obfervavit (u). Sañcti Bermbardi infulae habitatores olivarum colore tincti videntur (v). Pulcbrae nationis

\&

(t) Roggeveris Reife 1. c. p. 558 . Reif. T. XVHI. p. 515.

(u) Quiros 1. c.

(y) siug. 


\section{G E O G R A P H I C A E. 655}

\& Batmmanii infularum coloni albent (w), quum, qui novam Britamiam tenent, flaveant, \& qui novam Guineam poffident, nigrent $(x)$. Otabitz fefíores Boubgainvillio auctore $(y)$, duplicis funt generis, quorum alterum proceri corporis, promifforumque capillorum, alterum vero humilis ftaturae crisporumque crinium eft $(z)$. Otabiti \& Novae Zeelandiae cives, licet magno oceani fpatio inter fe disjungantur, eadem tamen lingua loquuntur, eodemque olivarum fcilicet colore infeeti funt (a), quum e contrario qui in Neuzeelandia nowique Hollandia vivunt, licet multo propius a fe invicem abfint, toto coelo differant. Nec enim eodem fermone utuntur $(b)$, \& quo fit, ut alter alterum ne quidem intelligat, quin etiam colores variant: hi enim. fubfurci funt, quum illi, quod jam dixi, oliva:um more flaveant. Haec documenta, quorum fi neceffitas flagitaverit, permulta alia coacervari poffunt; annon evidentiffime probant, haud ita multa abhinc fecula elapfa effe, ex quibus infulaeiftae ab hominibus frequentari coeperint, mareque pacificum hac etiam de caufa memoratu digniffimum effe, quod ex omnigenis fere gentibus homines congregatos contineat; quodque nos eo attentiores reddit, inter Otabiti \& Neuzeelandiae colonos rumor dudum increbuit, ipforum patres e longinquo adveniffe. E quibus omnibns certo conjectari licet, hofce colonos ex aliis \& forte rematiffmis terrae tractibus na-

vi

(w) Ibid. p. 519. (x) Roggeveen l. c. (y) Voyage autour du M. (z) Vix perfuadeor, minoris ltacurae homines in Otahiti regione inde ortum trahere, quod mature nimis veneri. dent operam, quod Cookins tamen Itatuit. Cook l. c. p.631. (a) Cook lo c. p. 438 . (b) Ibid. p. 645. 


\section{SPECIMEN ZOOLOGIAE}

vi huc advectos, domefticaque animalia, fortaffis etiam alia, quae facili negotio deportari poterant, fecum adduxiffe; quorum tamen pofteriora vel pabuli defectu vel climatis injuria jam pridem interierunt $(c)$.

ఠ. XLVI. Quemadmodum ex allegatis hactenus rationibus, mea quidem opinione, prono quafi alveo manat, tenues parvasque maris pacifici infulas nec cum Amcrica, nec ex altera parte cum India orientali unquam cohaefifre; ita nec Novam Zeclandiam, nec alias, quas paulo ante commemoravimus, infulas novann Hollandiain unquam attigiffe, certo perfuadeor. Hic enim terrae tractus, etfi totam ejus magnitudinem adhuc ignoramus, tantus tainen effe debet, ut haud immerito nova telluris noftrae pars appellari queat; plures etiam quadrupedes nutrit, quam nominatae hactenus infulae omnes. Quanquaim enim unum modo alterumque illorum genus adhuc cognitun habeamus; ea tamen, quae novimus (quae magni momenti res eft) fera, necdum domita funt, majoremque fummam efficiunt, quam quae in dictis jam infulis parcuntur. Cookius Anglos, qui primi ejus promontoria ad orientem vergentia navibus inviferunt, quibus novae IV alliae orientalis nomen dederunt, fequentes vidiffe animantes refert $(c) ;$ I) canem, 2) kanguroonem, qui hucusque nullibi locorum nec obvius nec confpectus fuit, $\&$ jerbua gigantea appellari poteft, 3) quadrupedem,

(6) Philofophis \& hiftoricis operam hane rểicam volo, ut diverfarum nationur \& gentium origines, e quibus hi fint oriundi, indagent. Hypo thefum creatores \& eigmologiae fudiof optinam hine votis fuis facisfaciendi: occafionem habebunt,

(d) Cook l.c. p. 626. 


\section{G E O G R A P H I C A E. 657}

qui ad phalangcri formam quam proxime accedit, 4) muftelarun aliquan fpeciem, quae viverrae haud ablimilis, \& ab incolis quolli nomine infignitur, 5) ves. pertilionem maximum, qui vampyrus dicitur. (la Roussfette): 6) nautae quidam beftiam, litpi habitum faciemque gerentem, vidiffe adfirmaverunt: 7) Tasmanni nautae in orientali novace Fiollandiae littore, \& quidem in regione, quam Diemenis vocitant, veftigia quaedam tigridis fimilitudinem habentia obfervaverunt $(e)$. Dampierius in parte occidentali, inter vicefimum quintum vicefimumque primum latitudinis gradum beftiolas cuniculis fimiles vidit; quae omnia ad minimum feptem vel octo genera folis in littoribus confpecta funt $(f)$; licet exiguae tantum laterum in occidentem, meridiem, feptentrionemque fpectantium particulae ingentis hujus regionis hucusque innotuerint. Haec itaque telluris pars quadrupedes \& feros quidem nulla hominum opera domitos nutrit indigenas, quorum aliquot, kanguroo nimirum quolliusque nullibi terrarum hucusque nec viff funt, nec auditi : \& quosdam illorum fingulares foliusque rovae Hollandiae proprias effe \& conftituere fpecies, non improbabile eft. Quodfi nova Zelandia novae Hollandiae olim adhaefiffet; nonne vero effet fimillimum, kanguroonem etiam ibidem inveniri; quippe qui in littore orientali, quod contra infulam eft, fre-

quens

(e) Tasmans Reifen in Allg. Reif. T. XII: p. 2 r8. (f) Cook l. c. \& Dampierius in promontorio occidentali ejusdem generis animalia vidit. Allg. Reif. T. XII. p. $22 \sigma$.

Oo 00 


\section{$65^{3}$ SPECIMEN ZOOLOGIAE}

quens commoratur, \&, quod ex animantis celeritate colligere licet, facillime eo tranfire ulteriusque propagari poterat? Quoniam igitur, quas nominavi, beftiae novae folius Hollandiae feffores funt, quibus ceterae oceani pacifici infulae carent; magna probabilitate percutior, has cum illa nunquam conjunctas fuiffe.

ఏ. XLVII. Utrum vero nova Hollandia novaque Guinea, quae, quod nunc certo exploratum habemus; freto, quod a nave Endeavour, cujus ope via ifta tentata eft \& inventa, nomen habet (Endeavours - Strait) disjunguntur, copulatae olim fuerint, propter novas Guineae fummam, in qua adhuc verfamur, ignorantiam, nec dijudicare nec perficere pollemus. Interea tamen notatu dignum eft, hanc terram non ab hominibus modo fingularis cujusdam diverfaeque plane fpeciei habitari, (quibus quidem folis haec lis dirimi non poterit) fed a capris etiam fuibusque frequentari; quas tamen peregrinantium hucusque nullus in nova Hollandia offendito $\mathrm{Si}$ quis tamen has domefticas pecudes, ut dominos fuos. hue migrantes fequerentur, olim coactas fuiffe, objecerit; quid ipfi refpondeam, non habeo. Verbo: nova Guinec ante penitius cognofcenda, hujusque animantes curatius inveftigandae funt, quam certi quid de illa conftituere valemus. Sed quod majorem admirationem movet, 'Timor eft infula, quam aliquot tantum gradibus a nova Hollandia disjungi conftat, quae tamen bubalos; Jies, capras, oves, quin \& apros fimiasque alit $\underset{\text { Fie- }}{(g)}$.

(ga) Dampier in Allg. Reif. T. X1I. p. 260 , 


\section{G E O G R A P H I C A E. 659}

Fieri quidem potuiffe fateor, ut iftorum quadrupedum plerique ab Europaeis aliisque populis navibus iftuc fint deportati, num id vero fumiis etiam acciderit, fcio cum ignariffimis; licet id penitus negare non aufim. Quis generatim priftinus Moluccarum ftatus, quae olim conditio fuerit, quadrupedum auxilio adhuc explicari nequit. Quamquam enim illas jam pridem cognitas habemus; idcirco tamen, quod ad animalia ibi degentia eorumque hiftoriam naturalem attinẹt, in magna obfcuritate verfamur. 'Utinam Batavi, qui ei negotio praecipue pares funt, huic hiftoriae naturalis defectui confulerent ac mederentur! Maximarum enim infularum, quas inter Gilolo ac Colebes funt, conditio tam incognita nobis eft, ut, fi pauciffmas pecudes domefticas exemeris, parum certi de reliquis ibi degentibus beftiis in medium proferre queas. Et hacc ratio eft, quam propter illas jam fupra iis telluris noftrae partibus adnumeravi, quarum natura habitatorumque ratio minus comperta eft. Multas autem variasque peregrinas animantes ibidem dari, non Pallafur modo $(b)$, qui iftarum aliquot defcriptas in lucem emifit, fed univerfalis etiam peregrinantium hiftoria docet, quae itidem quarundam mentionem facit. Tunc itaque demum, quae Moluccarum infularum facies olim. fuerit, conjecturis áfequi forte poteris, quando praefentem illarum habitum melius percallueris.

5. XLVIII. Priusquam capiti huic fummam manum ad-

(72) Vid. ejus Mifcellanea \& Spicileg. Zoolugica.

$\mathrm{OO} 0 \mathrm{O} \quad 2^{2}$ 


\section{SPECIMEN ZOOLOGIAE}

adjicio; ad pbocas, Baikalis lacum inhabitantes, quarum capite primo mentio facta eft, redeamus oportet (i); quoniam ad animalium tam migrationem, quam disperfionem illuftrandam nonnihil conferre videntur. Oceanum olim vel integram telluris noftrae fuperficiem inundaffe, aut maximis faltem eluvionibus mirifice immutaffe, negari nequit. Quid ergo impedit, quo minus plocas hafce maris Cbinen/ss, aut Koreanici potius, ab. Euronoto reftagnantis, vel teftes habeam vel reliquias? Quum enim iftas e mari glaciali ad Baikalem certis fluminibus defcendiffe, probabilibus argumentis nullis, quod dicto jam capite primo commonftratam eft, evinci queat; ex acutiffimis autem $P$ awii obfervationibus appareat, pleraque terrae noftrae pronontoria ad meridiem Spectare; e quibus vir folertiffimus, oceani irruptiones a meridie exortas, \& feptentrionem verfus progreflas effe, colligit: magna fane cum probabilitate inde confici poffe exiftimo, dictas jam beftias fimili maris alluvie ad Baikalis lacum delatas efle; praecipue quum Coream; feu potius Coreae littora phiocas nutrire conftet $(k)$. Quod autem ad Cafpii maris pbacas attinet; eas canalibus fubterraneis, quibus cum maribus proxime adjacentibus conneetitur, eo demigraviffe credo.

j. XLIX. Sic maximas maximique momenti tel-luris.

(i) Stellerus phocas has argentei coloris effe dicit, quod ex ejus KamtJehatkat hiftoria, quae germanice nunc etiam prodiit, pag. 108. difcimus. (k) Alig: Reir. T. VII. p. 32. 


\section{G E O G R A P H I C A E. 66r}

Iuris noftrae terras earumque formas, quas olim habuerint, quantum probabiles conjecturae \& permiferunt, \& fuppeditarunt, perluftravinus. Ex quo labore, qui non exiguus fuit, fi nihil aliud mercedis-mihi redundaverit, id tamen affecutus videor, ut viris, eraditionis laude infignibus, ex praefenti quadrupedum per terrarum orbem dilatatione telluris noftrae fata \& hiftoriam penitius inquirendi anfam dederim. Lubentiffimo interim animo collectanea haec illorum ufui permitto, qui hominis hiftoriam, philofophorum more, judicio, ac diligentia confcribere conabuntur. Quodfi ea mente eoque folo confilio haec conquifiviffem, ut rerum opificem in disfeminandis per terrae fuperficiem animantibus omnia fapientiffimo ordine dispofuiffe commonftrarem : hoe propofitum nec a fapientum quopiam reprehenfun nec despectum iri crediderim. Addendum cenfeo, quaecurque appofui confectaria omnia certis firmisque graviffmorum auctorum teftimoniis niti. Fortaffe factum eft, ut, qui tantum materiae undique locorum congeffi, domum quidem inchoaverim, tugurium tamen exfruxerim, neque illa fic ufus fim, quemadmodum po. tuiffem. Sit interim quid fit, eam omnem novorum fyytematuin conditoribus \& offero. \& trado. Quibus fi hac induftria mea ad augendam rerum cognitionem, anculi ritu, neceffaria quaedam fubminiftravero, me abunde compenfatum exiftimabo.

$$
\text { F I N I S }
$$


62.

\section{A D D I T A M E T A E $T$ \\ E M E N D T I O N E S.}

A broluta demum Zoologia hac, quae Pallafus nuA per publici juris fecit opera praeftantiffima, unzdecinius nempe Spicileg. Zoolog. fafcicashus, tertiusque Itineris per. Siberian facli Tomus, in manus meas incidit. Uterque liber, quum multa ad illuftrandam naturae hiftoriam contineat, notatu digniffima excerpere, \& dum licuit naturae ferutatorum commodo hic loci, una cum aliis quibusdam emendationibus', adjungere volui.

I. Pag. 45. Fafcic. XI. Caprarum cujusdam fpeciei vir eximius mentionem facit, cui Aegagri nomen dedit. Illa ipfa eft capra, quam Kampferus (a) Capricervam nuncupat, quamque major Zoologorum pars Antilopis hucusque adnumeravit, quam \& $\&$ ipfe $A n-$ tilopam bezoarticam effe credidi. Gmelinus junior,

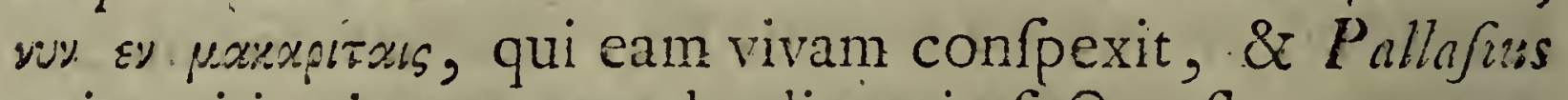
cui capicis ejus contemplandi copia faEta eft, eam non Antiloparum, fed' caprarum potius claffi fubjiciendam effe contendunt. His, magnae auctoritatis teftibus permotus, quam primo in capite fententiam, Buffenio duce, 'amplexus ctam, qua Ibicem caprarum noftrarum auctorem ftatueram, nunc fere dimitto, majori forte jure

(a) Ambenitat. cxot. p. 392. 


\section{A D D I T A M E N T A.}

663

jure hunc Aegagrum domefticarum caprarum patrem autumans. Interim pleraque quae ibi de degeneratione Ibicis dicta (b) funt, etiam ad Aegagrum adplicanda erunt. En brevem Aegagri, qui in Hyrcaniae \& Perfiae montibus habitat, defcriptionem. Sunt verba $\mathrm{Cl}$ : Pallafii. "Aegagrus, fecundum Gmelini deforiptio"nem (c) Kampferiana paulo pleniorem \& transmis. "fum cranium, eft Ibice aliquanto minor, multoque "-minor Mu/mone Hyrcanine; Hircos domefticos vero " maximos fuperat. Caput caprinum, antice nigrum, "lateribus rufefcente fufcoque mixtum. Aruncus in"fignis, una cun gula, caftaneo fufcoque mixtus. " (Reliquum corpus fecundum Kamipferum, a cervi"no, forma colore \& agilitate nihil differt.) Animal " totum grifeo, vel cinereo - rufefente piloveftitum, "loro per fpinam longitudinali a collo ad caudam atro; $\Rightarrow$ cauda item atra. In feminis Gmelinus cornuum vet

". ftigia nulla invenit; Kompferus vel nulla, vel exi"gua effe prodit". Cranii cum cornibus figuram \& defcriptionem Pallaf $u$ s adjecit.

II. Idem hic auctor, quam ex du Haldii Cbinae hiftoria, opinionem fecundo in capite p. 354. attuli: in Mongolia feilicet ferosadhuc Camelos nutriri, majori veritatis fpecie, pag. 3. Fafcic. XI. confirmavit. Interim diffimulare nequeo, pergratum mihi fuife virum praeftantiffimum quae de quadrupedum degeneratione hinc inde fufpicatus fueram, auetoritate fua partim probabiliora

red-

(b) p. Irg. \& fq. Tom. HI. p. 493.

(6) Sain. Georg Gmelins Reife durch Rusisnn? 
564 A D DI T A M E N TA.

reddidife, \& Argalidem, quod in capite quarto conjicere audebam, Americae \& Californiae maxime, fesforem autumat $(d)$.

III. In cap. tertii ( pag. 459.) quae de Manato agit paragrapho, de animali locutus fun quod Stellerus \& poft illum Pennantus fub Bielugae nomine Phocis adnumeravit. Pallafius vero pag. 84. (Reijerz durch Ruslard Tom. III.) demonftrat Bielugam hanc maris glacialis habitatorem ad Delffni genus effe referendam, hinc non quadrupedibus fed cetaceis accenfendam.

IV. Iis quae capite fecundo de Mele, Lutra \& Mure amphibio fcripfi, ex Pallafii Itinere pag. I $\& 87$. addo, Melem \& Lutram fub fexagefimo tertio latitudinis gradu, quin haud procul ab urbe Berefof , in locis umbrofis, feu fylvaticis, Murem vero amphibium in feptentrionalibus \& prope Obbii flumen pofitis regionibus inveniri.

V. Quum ex Pallafii, tam Tomo fecundo quam tertio itinerum, pateat, Murem citcllhum feu Soustikum $(e)$ in Afia ejusque infulis feptentrionalibus, ad Kamtfebatkam usque progredi, in Tabula Zoologica id loco fuo notatum offendes. Sic alia etiam quaedam animalia, pluribus in mappae locis quam in libello ipfo indicata cernes. Faciliori enim ratione, quae nuperrime detecta funt, tabulae quam libro ipfi, prelo jam fubjecto inferi poterant.

VI. In cap. primi fectione de Phocis agente (pag. 248.)

(d) Fafc. XI. p. ro. not. i. (e) Vid. Cap. Sccund. pag. 34I. 


\section{A D D I T A M E N T A. $\quad 665$}

248.) Carpii maris phocas e nigro, non autein e glaciali mari originem ducere tradidi, \& huic opinioni ponderis quiddam daturus, rationes, quibus Cafpium Nigrumque mare cohaerere poffint addidi. P'allafuss autem pag. 569. fg. (Reif. durch Rusl. Tom. III.) magna cum veritatis (pecie docet, bina haec maria, olim inter fe cohaefiffe, licet nunc penitus disjuncta fint: fcribit enim, Cafpii quondan maris littora eo usque extenfa fuiffe, ut Calmuccorum, Cumanorusnque deferta (fteppen) complexa obundataque fuerint, quod e praefenti utriusque deferti folo fatis fuperque parere credit; quippe quod nigra fertilique terra plane ceftitutum, fabulum tantummodo fale permixtum contineat. Hinc fieri ut adhuc nec frutices nec herbas, nifi quibus fal gratus eft, proferat. Accedit quod in dictorum jam defertorum folo magna oftrearum, quas Peclines (Oftrea pecten Linn.) adpellant, copia reperiatur, quibus Cafpium imprimis mare fcateat. $E$ quibus omnibus, magni ingenii Vir colligit, Cafpium mare Euxinumque pontum, duas unius ejusdemque maris paullo profundiores fuifre voragines. Cui opinioni, a vero minus abhorrenti, fi affenferis; facile Tournefortii $(f)$ quoque fententiam approbabis, ftatuentis Bosphori montes olim connexos, mare nigrum a mediterrazeo, feparaviffe: quibus autem poftea, quodam terrae motu disruptis, Archipelagum extitifie, Cafpiumque mare, ad ea usque, quibus nunc coercetur, littora fub: merfum fublatumque effe.

VII.

(f) Voyage an Levant Tom. 1. p. 'So. \& Tom. II. p. 6s. uli etiam Salias. cit. 


\section{A D D I T A M E N T A}

VII. Quae Pallafuus Tom. III. Reif. durch Rusland p. 2.17. fqq. de Dsbiggeteo (Dshiggetci) leetu digna collegit, contraeta adjungam. Nomen animantis beftiam longioribus auribus praeditam denotare adftruit. Dshiggetei eft nova quaedam generis equini fpecies, \& a feris equis, de quibus in primo capite pag.I 4o. noftrae Geograph. Zoologicae actum eft, \& qui a Tatario, Tarpanen nominantur, differt. Nec eundem, cum Onagro, quem Calmucci Culanum nominant, quique Calmuccorum, Perfiae \& Indiae regiones gregatim pererrat, permutandum effe, $\mathrm{Cl}$. auctor contendit, quum ejus formae fit ac indolis ut nec af 1 nus proprie nec equus nominari queat. Formam enim primo ftatim adfpectu monftrare, animanti, muli inAtar, medium inter utrasque beftias locum deberi. Quo etiam factum fit ut $M_{\varepsilon}$ fer $\int$ cbinidius Dshiggeteium, mulum Dauricum foecundum vocitaverit: qui ab afino levi facilique corpore, gracilioribus membris, fero vagoque vultu dilutoque colore difcedat; ceteroqui tamen longiori aurium proportione, quas arrectas gerens fingularem mentis alacritatem prodat, dorfo autem recto \& cauda vaccinae funili, \& ininus fpeciofa, propius ad afinum accedens ab equo diftet. Muli minoris magnitudinem, caput craffius graviusque, peetus magnum, angulatum compreffumque, aures mulinis minores, equinis majores, jubam brevem \& afinorum more hirtam habet. Color e luteo fufcus. Interiores tamen nafi membrorumque partes ex albo fufcae, juba vero \& cauda nigrae. Prope dorfi finam linea quaedam furca, latior ad femora usque, ad caudam vero iterum anguftior decurrit. Quoties beftia ftat, caput attollit, naresque aurae opponit, acri odoratu fuo e 


\section{A D D I T A M E N T A.}

longinquo quid obvium fibi futurum fit, inveftigans. In Datria Mengolicaque Tattaria (ubi eum in mappa pofttum vides) gregatim tamque citato curfu difcurrit, ut nec celerrimus equus beftiam adfequi polleat. Telis quidem hucusque configi, perraro vero vivam capi \& minime cicurari potuiffe dicitur. An propius ad Onagrum accedat ac $P$ Pallafius fibi perfuadet, tempus docebit.

VIII. Felis Manul (funt verba latina Pallafii , vide Ap. pend. defcript. animal. Reif. Tom. III. p. 692.) Magnitudo vulpis; caput majufculum, artus robulti, unde facies lyncis. Color in toto corporelyncis, fcilicet fulvefcens albido. \& pilis raris fufcis inumbratus, fubtus pallidus. Caput in vertice punctis atris, \& lineis utrinque binis obliquis, ab oculo per genas parallelis. Pedes lituris fufcis, vagis obfoletiffime virgati. Maculae in corpore omnino nullae. Cauda paulo longior, quam in catto, denfis undique pi: lis incraffata, cylindrica, apice annulisque circiter fenis atris. Frequens in rupeftribus, apricis totius. 'Tatariae Mongolicaeque defertae, vietitans animalculis variis.

IX. Lepus dauricus, Mongolo - Buraetis Ogotona. Mag. nitudo paulo infra Leporem alpinzin, cui fimillimus, Differt forma magis ad Lep. pufiblum accedente, proportionibus quibusdam, colore \& forma aurium teneritudine velleris, colore \& anatomicis quibusdam momentis; deinde moribus. Auriculae rotundato-fubtriangulae, albidae. Vellus tenerrimum, nitidum, totum fupra gryfeo-pallidum. Palmae pentadactilae: plantae tetradactylae, dentesque ut in cognatis. Cauda nulla, neque coccyx adipofo tuberculo prominula. Vivit in campis, montiumque declivibus arenofis, per totam Dauricam cu-

$$
\text { P p p } 2
$$

ni- 


\section{A D D T T A M N T A}

niculo labyrinthico; fub autumnum foeni acervos globofos congerit \& compingit. Vox fere Leporis alpini:

X. Mus oecona:mus Buraete-Mongolis Urugundshi Cholgona. Magnitudo, praefertim foeminis, multo fupra murem terreftrem; facies ceteroquin fimillima \& color idem, fed velleris natura tenerior atque nitidior. Auriculae minimae, plane nudae, anterius deficientes, $\&$ meatum auditorium non cingentes. Cauda paula longior quam in mure terreftri totusque truncus plane elongatus. Palmae unguiculo pollicari minimo, obtufo. Per omnem Siliriam etian in borealibus, \& ad orientem usque in Kamt.jihatkam vulgatiffma, propterque promptuaria radicibus repleta, celeberrima fpecies. Certis locis \& annis turmatim migrat praefertim e Kamtjichatka. (Haec erit fpecies ifta migratoria Kamtfcbatkac de qua in quarto capite actum eft? )

XI. Ad pag. 283. Eं 53 r. Zoolog: Geograph: Linea quae tarandi fines determinat aliquanto qu:dem altius obliquiusque in tabula zoologica ducta videtur; fed ex Pallafii obfervationibus novifimis elucet id jure: recteque factum effe. Quodfi jam linea haec longius producka fuiffet, illam propenzodum attigiffet, quac. Americae tarandorum terminos definit

XII: Ad pag. 89. Ev I 89. Quam beftiam Dampie rizs cuniculo fimilem in nova Hollandia obviam habuit, noftratem quidem effe putavi: Omnibus autem quae in quarto capite de nova liac orbis parte allata legis rite penfitatis, me hac in re erraffe credo: qua de caufa mappae in nova Hollandia voculas Cunic $\because$ affin: (animal cuniculo aftine) appofitas videbis, forte nova cam viarum erit fpecies.

Quum 


\section{A D D I T A M N T A}

669

Quum eodem loco, réfpectu $L u p i$ eundem errorem admiferim, illum fimili ratione correctum cernes. Beftiam enim quam Dampierii nautae luptsm nominarunt, verum lupum fuiffe minime conftat.

XIII. Ad pag. 260. Quum ex Pernetty itinerario $(g)$ \& imagine Leonis marini feu Pbocae leoninae quam Scbreberus inde mutuatus eft, eluceat, duas a fe invicem diffidentes harum animantium fpecies dari, quod in primo jam capite, priusquam Pernetty itinerarium infpexeram, fufpicabar, utrasque fpecies tabulae zoologicae feparatim inferendas, alteramque fpeciem, pbocam leoninam, alteram autem phocam leoninam jubatum nominandam, curavi.

XIV. Ad pag. 339: Aliquam myrmecophagarum fpeciem in Africa reperiri ex Purcbafio (b) iterum disco, qui de quibusdam Zangibaricae orae regionibus, quas Cuamae flumen attingit, fequentia e Foanne dos Santos aliisque auctoribus collecta dedit. " Vivit, " inquit, ibidem Vermis quidam ab incolis Inbazaras g appellatus, magnitudine \& figura ad canem acce" dens, pilis nigris quinque digitos longis veftitus "Pedes anteriores tetradactyli, pofteriores penta" dactyli, unguibus longis armati funt. Cuniculos و fub terra agit, duobus vel tribus oftiis, quibus libere \% ingredi egredique pófit, "praeditos. Formicis vefci, tur, ad quarum nidos fimulac penetrat, eas ungui" bus conterit, linguamque teretem, duas dimidiam, que

(g.) Voyage de Pernetty aux Isles Malouines. Torm. II. P. A7. Tat, X..

(b) Purchaff. his Pilgrims Tom. II. pig. 1545. P. P. P 3 
670 ADDITAMENTA. :

פ) que fpithamas longam inferit. Caro beftiae optimi \% laporis \& fuillae fere fimilis eft. Roftro longo ac: "F terete munitus, auriculas mulorum fimiles, pilis ca" rentes habet. Cauda denfa \& fub finem rufticarum " colo (fashioned at the end like a Diftaffe) haud " abfimilis fpithamam longa eft".

"Quodíi hanc cum aliis animantium defcriptionibus comparaveris, facile myrmecophagam agnofces. Cur autem audor vermem eam adpellat, fortaffe gracilis, vel totius beftiae, vel linguae faltem figura in cauffa fuit. An vero Africana haec myrmecophaga una earum fpecierum novi orbis fit, multum dubito; interim hoc ipfo, pondus iis quae Pallafus Pennantusque Buffonio opponunt, accedit. Tabulae zoologicae myrmecophagae vocem Africae regionibus in Sofalae adjacentibusque terris appofitam invenies.

XV. Ad pag. 458. Baldeo tefte (i) Dugon etiam mare circa infulam Zeilam frequentat; ibi itaque in mappa nomen hocce invenies.

XVI. Ad pag. 463. Effluxerat, Buffonium Dausbentoniumque expreffis verbis confirmare, manem tetradactylam quinque etiam digitis inftructam, ideoque pentadactylis adnumerandam effe, quod heic loci addere volui.

XVII. Ad pag. 496. Liber Baro de Hiip $/ c b$, folers naturae-fcrutator, in Eiffalia (Germaniae tractu inter domin. Batavor: \& Trevirens:) aliquam talparum fpe-

ciem

(i) Ballaei befcreib. des Kuften Malabar und Coromandel \&c. fol. p. 378 . 


\section{A D D I T M E $\mathrm{N} T \mathrm{~T}$.}

ciem offendit, quae ab aliis fui generis cinerea quam maxime colore diftinguatur, qui color in ventre in luteolum tranfeat, ftrigamque cinereo luteam inferiores tam capitis quam ventris partes tegere confirmat. Huic talpae, Baro-de Hiipfch Bifliacae cinerece nomen indidit. Et ex la Faille EfJai fur l'biloire naturelle de la Taupe, quem librum hucusque nec noffe nec vidiffe fateor, duas adhuc alias talparum fpecies, Galliae incolas adducit, quarum alteram majorem $R$ uppellenfem cervicolorem, alteram citrinam Aleficnsem nominat $(k)$.

XVIII. Ad pag. 54I. Vix mihi perfuadebam $\mathrm{Cl}$. Becmannum Antilopam leucopoda, jure, unam eandemque cum Nylgbau, beftian habuiffe; fed omnibus rite penfitatis nunc in viri doetiffimi fententiam tranfeo.

XIX. Ad p. 524: In nota, yerboae defcriptioni addita, in qua de animalculo Ziztjan dicto egi, immerito Clar. Pernantum me carpfiffe confiteor. Quum enim tunc temporis Bruinii, quam de hoc animalculo dedit figuram non in promptu effet, Scboberi Zilzjan, feu yerboam, pro uno eodemque animali cum illo Bruinii habui, quod tamen fecusfe habet. Bruinii enim Zitzjan, uti figura aperte docet $(l)$, eft animal a yerboa plane diverfum, \& forte Zemni uti Pennantus credit; Zitzjan apud Tattaros fignificat mus, quod Muellerus docet $(\mathrm{m})$, itaque hoc nomen tam yerboae quam animalcúlo Bruimii facile applicari potuit.

$\mathrm{xx}$.

(k) Naturforfcher 3 . Nuk p.98. \& fq. ( (l) de Bruins Reifen over Moscovie \&c. Amfterdam I 7 I I, fol, pag. 43. . (m), Mueller famml. Kuff. Gefch, T. VII. p. 124. 


\section{$672 \mathrm{~A} D \mathrm{D}$ I T A M N T A.}

XX. Ex nova, de itinere altero Cookii circa orbem relatione, patere videtur urfum in Terra magellanica dari, nomen itaque urfi in mappa zoolog. ibidem additum invenies.

XXI. Clar. Scbreberus in figuris, eximio fuo de mammalibus opere, additis, tria animalia depicta dedit, nimirum Viverram tigrinam Tab. I1 5. Viverram capenfem Tab. 125. \& Viverram vittatam Tab. 124. fed quum defcriptio ipfa nondum prodierit, nec mihi animalia haec nota fint, ea operi meo addere non licuit. Ad Capitis Ounrti Sectionem Secundam. Ne vel ignorantiae denegati viro, cui tota fere phyficorum fannitia affurgit, honoris fufpicione arguar: Limnaei quoque, quam in amoenitatum academicarum volumine fecindo pag. 402. hypothefin propofuit adferendam cenfeo. Vir praeftantiffinus orbis hujus continentem a rerum primordio infulae maris fluctibus cinctae formam, $\&$ in medio immenfae altitudinis montem habuiffe opinatur, ubi omnes \& plantarúm \& animaliumm fpecies convenientiffimum fibi locum occupaverint.: Quum enim fumma montis juga eadem frigoris vi, quae regiones mundi polis vicinas conftringit, afflata fuerint: fingulas \& plantas \& animantes ibidem commode ali, confervarique potuiffe exiftimat, quae Zonae nunc frigidae, terras incolunt: Quaecunque vero fub temperatiori climate fedes fibi fuas vindicant, in montis medio habitaffe, reliquum autem montis infulaeque fpatium iis xelictum effe tam beftiis quam fruticibus vir eximius autumat, quam natura majorem folis aeftum poftulet. ist hactenus quidem optime omnia $\&$ ingeniofiffime effieta videri vix fapientum quisquam negaverit. Quod- 


\section{A D D I T A M E N T A.}

fivero interrogaveris, qui fieri potuerit, ut herbae befliaeque deinceps per univerfum terrarum orbem ita diffipari potuerint, quemadinodum eas nunc diffipatas cernimus : tunc nodis te implicatum videbis, quibus expediendis folvendisque vix te parem fenties. Quum enim infulam oceano undiquaque circumdatam, reliquamque continentem nec repente, nec uno eodemque momento, quin potius vel exficcato vel recedente paullatim mari emerfife vir eximius fuppofuerit, nunc qua ratione beftiae v. g. Tarandus \& Alce, ad ea, quae nunc incolunt domicilia penetrare potuerint, circumpiciamus. Primo enim a montis dorfo e fummo frigore iis defcendendum, poft temperatioris coeli campi peragrandi, deinceps ad montis radices pofitae ferventiffimo folis aeftu calentes terrae transgrediendae erant. Et quia nec uno faltu curfuque ad congrua naturae fuae luftra provolare, fed pedetentim eo procedere, posfent, quas vias ipfis eligere licuerit deliberemus. Ad infulae fines, donec tellus omnis e mari prodierit, ex. fpectandum, dein per regiones fub tropicis $\&$ ipfo aet quatore jacentes, intenfilfimo calore ardentes, ad moderatiores, \& dehinc ad poli oras ire cogebantur: quis unquam vero fibi perfuaferit, Tarandum, qui vix fexagefimi latitudinis gradus calorem tolerare pollet, tot, tantas, tamque naturae \& corporis fui dispofitioni contrarias coeli aërisque viciflitudines, fine fummo vitae difcrimine fuftinere valuiffe? Quis eft qui tam longum, grave, \& infolitum iter \& Tarando \& Alci, reliquisque omnibus frigidiori adfuetis coelo animantibus, priusquam congruas fibi fedes attigiffent, certiffimam mortem allaturum fuiffe dubitaverit? Omitto vias tam diffi-

$$
\text { Q q q }
$$

ci- 
- 674 A D D I T A ME N T A.

ciles incertasque beftiis easdem emetientibus ni prac fentiffinam perniciem, maxima faltim vitae pericula, vix quidem fuperanda, minitatas fuife : omitto alia, quae plantarum arborumque per tellurem dilatandarum. ratione, opponi poffent, \& jam pleraque a Zinnio collecta, fufiusque expofita leguntur.

Prolufionis (. XIX. articulus, sequenti modo legi debct. Si vel fola metallorum genera cum plantarum turba contuleris, quantus jam harum tibi fuborietur exceffus! octodecin millia plantarum, quae jam nofcitantur $(d)$, cum quadringentis metallorum $(e)$ fpeciebus comparatae eandem habent rationem, ut 45 . ad $I$. licet etiam. fperandum fit, temporis fucceffu pluribusque orbis noftri partibus, quae adhuc quafr abditae latent, revelatis indagatisque utriusque generis numerum ingentibus allEtibus cumulatum iri. Quodfr metalla ad aliquäm exrythmiae regulam compofita detraxeris: proportio hace maximopere increfcet; eoque ipfo plantarum feries non exiguo incremento augebitur. - Nunc ulterius progredientes eadem plantarum animaliumque collatione utamur.

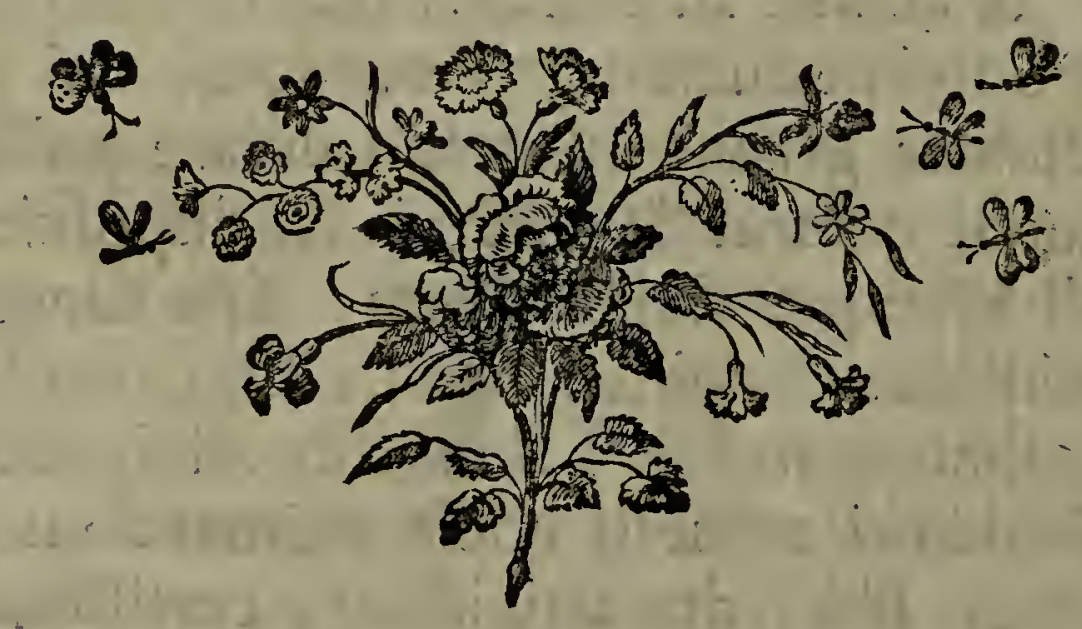




\section{I $N$ \\ D E \\ $\mathrm{X}$ \\ ZOOLOGIAE GEOGRAPHICAE.}

Numerus indicat paginam, $n$ notas.

A.

Acanfas natio pulchra, ubi? Pag. 66. Acores Aclantidis forte reliquiae $\sigma_{3} \% n$. -Adimain feu oris guibeenfis.

$13 \mathrm{I}$. Adfcenfionis infula quondam mons ignivomus.

622 .

Acgagrus Cervicapra Kampferi. onz. cund. Pallafium.

Aelkfch.

Aër montium faluberrimus

606.

$478 . \mathrm{n}$.

12 I.

- quantopere hominem premat \& praccipue urinatores.

45 .

Aethiopiae boves camelos magnitudine aequiparant.

IID.

Acthiopum color, ubi cjus fedes? 77.

__ cerebrum fubnigrum. ibid.

_ colorem a climate oriri pro-

batur.

74. req.

Africa ejus magnitudo.

573.

- interior montes continet. 585 . ejus flumina multos montes fup-

ponunt.

536.

Africae vix 150000 milliaria quadrata cognita. 578.

- interiora $\triangle$ fiae regionibus non fteriliona.

584 .

Africam intcriorem an vatio flava lon.

Ai.

gisque pilis incolat?

Aigrette.

Alce.

_- ejus dilatatio. 79. nia effoffa. 400. 426. $285:$ $28 \%$. Hibercum Tarando quondain Germaniam Galliamque inhabitavit, quid inde fequatur. 239. dus.

Algazel.

Allamandus laudatur. is

Taran-

Allouate. 285. 538.

Alpium alcitudo fec Scheuchzerum. 434.
Amarok feu Gulo in Grocnlandia: 314. America, ejus magnicuso fec. Tempelmanni calculum. Slig.

- ejus partes calidae immenfum animalium continent numerum: 5 ro. fé.

- leones non nutrit. $\quad 35 \%$.

- reptentrion. an cum Alia quondam \& ad quenram latitud. gradum collaeferit. $\sigma_{30} \sigma_{3} 5$.

- meridionalis queta ejus pars nobis lateat. 503. meridionalis nunquam cum $A$ fis colaetit.". 040 . feptentrionalis, ejus dimenfio fec. Bêrgmannum. 580. tentes. ibid. - ineridionalis magis quam Africa innotefcit. $\quad 50$ !. - an quondam Europae juncta. 634. - nunquam Africae juncts. $0_{3} 6$. - cur nulli ibi dentur Aethiopes. 78. Andira-guacu. 454. Angliae cum Gallia quondam cobaefio. Animalcula infuforia. 19.624 . Animalia in animalibus vivunt. $16-18$. - non ab uno patre \& matre pro. pagata - al 580. - carsivora pieraque fub Zona torrida. 600. rida alba etiam dartur in Zona torrida. 239.326 . - Antoecis non eadem funt 602. Animaliam fpecies fecundum Muffchenbroek.

-

- numerus terraqueorum in ra-

tione directa caloris humorisque. 554 .

Antiloparum dilatatio: $53^{6}$. Seq.

- - generis definitio. 535 .

Antilope fubdivifiones. 537 .

Antilope bezoartica. $\quad 538$.

Qq $9 q_{2}$

544 .

An: 


\section{$676 \quad 1 \quad N \quad$ D $\quad$ E $X$}

Antilope cervicapra.

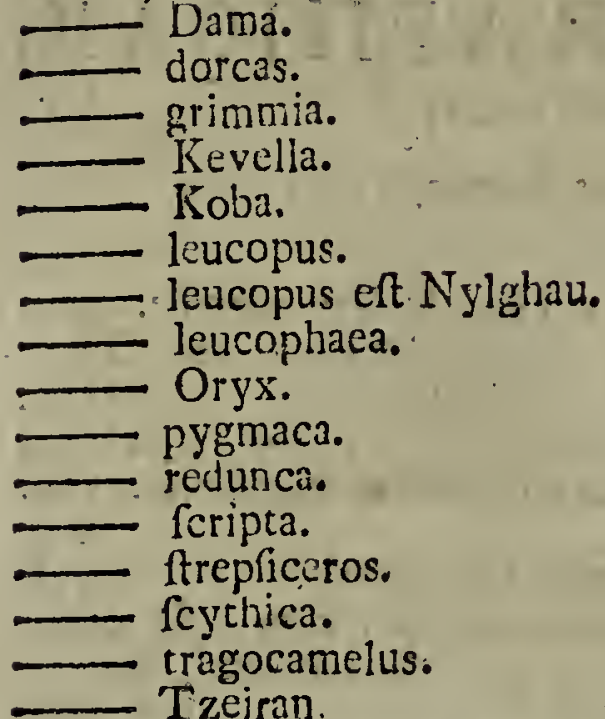

A noa minima fpecies generis bovini. 549 .

d'Anvillius laudatus.

Apar.

Arbuchnotus de aëre laudatus.

Argali.

pater ovis. rica quid probet.

Armodillorum fpecies.

577.583

405.

$12 \%$

$5+7$.

114. feq.

Afia ejus magnicudo

num.

- prima hominis, bovis, equi, ovis, caprac, afinique patria. $\quad 10.7$. feq.

Afiae. partes minus cognitae.

Afinus melius equo aeftum tolerat. 145 .

- minus frigori refiftit quam equus.

139. ejus patria.

ferus ulvio

146: 150.066

Atmofphaera fua animalia haber.

Axis:

\section{B.}

Babiroefa.

Babouin.

Bahr.

Bajkal lacus Phocas alit.

Bakkaleyor.

Bandicotte fpecies muris.

Banks laudatur.

Barbaresquez (le)

Barchewiczius laudatus.

baromecri altitudo in montibus minus valians quam in plano.
166. $55 \mathrm{~T}$. 417. 309.

2.19. 660.

105.

348.

$653 . \mathrm{n}$.

518.

493 .

122.
Barretus metallorum vonas in Africa detegit.

Pag. 583.

Bafteri obfervationes de animalculis ma. rinis lucentibus.

573.

Batavi, ab illis cognitio Africae intetioris exfpectanda. 582. - vix ultra 120 milliaria a Capire B. Sp. in Africam progreffi, ibid. Bebe. 59.

Bekker:- el - Wash.

547.

Bengala immenfum animalium numerum continet.

Bieluga non quadrupes fed fpecies D:fini.

Biggel.

664.

Bifon, hovis varietas.

531.

Blanc - nez. 102.

425.

Blanc (Vincent le) dubiae fidei. 579.

Bobak jdem quod Marnosta. . 31 s.

Bombay Squirrel. 5 .

Bonafus. 548.

Bonnet chinois. $\quad 427$.

Bos grunniens. $\quad 548$.

- indicus. $54 \mathrm{C}^{\circ}$.

- late per orbem dilatatur. $\quad 90$.

- nofter cum Bifonte coüt. 102.

- ejus patria in partibus calidioribus Afiae.

Bougainvillius laudatus.

105 .

Bouceemus villofus Indiae.

Boves indici praeftant noftris.

Boylii obfervationes de fundo masis.

Bradypodis fpecies in orbe antiquo, con-. tra Buffonium.

Bradypus.

33. Buachius laudatus.

337 .

Bucha.

460.

Buffonius 548 .

585.
370 feq.
548.
lupum a cane diftinguit, refellitur: 85 . feq.

- - ejus rententia de conjunctin. ne Americae \& Africae refellitur. $\sigma_{72}$. Bufonum abundantia is Porto ballo. 56 :

C.

Cabiai.

Cachicame.

552.

Caffri, Americanis fortiores.

457.

Caiıfornia ibi datur hrgali.

.592.

Callitricbe. 


\section{ZOOLOGIAE GEOGRAPHICAE.} Calmuccorum regiones Onagris abun:
Pag. 606 .

Calorịs naturalis gradus fummus. 42.

Cam gradus in Quito.

Camclus, ejụs dilatatio.

_ ferus, ubi?

300.

- aequatoris aeftum, abhorret.

animal orbis antiqui $\quad 359$. - Pacos.

360. 528.

Camelopardalis.

Campagnol volant.

Canis Thous feu Koupara.

- diver ffimis ciborum generibus uti-

- tur.

- quibus in rebus cum homine conveniat.

93. feq.

yjus varietates magis inter $\mathrm{fe}$ di-

ftant quam hominum.

- poft hominem maxime dilata-.

. tus.

mexicanus.

po, cinum idemque an

Capra mambrica.

- angorentis.

- ejus dilatatio.

Cjus varietates.

Caprae non tancopere quam oves incer fe differunt.

Capreolus mexicanus.

- nofter an in America invenia.

tur.

Carakal. ejus dilatatio.

209.

Cirigueibe an idem cum lutra marina. 303.

Cáspum inare an cum nigro cohaeferic. 248.

- Phocas alit.

Caftor ejus dilatatio. 249. 060 . 295. Seq.

Corum numerus decrefcit.

Cafto:um varietates.

Cataphrafti" genus au detur in orbe 300 . tiuguo. ciquo.
Cattus montajus Scbae videtur cfle Catrus ferus.

Cavia:ium genus.

Cavia Aguii.

17.5 .

505.

so\%.
Cavia Akouchi.

Pag. 508.

- Aperea \& ejus defcriptio. 507. Capenfis. ibid. 508. 507. Paca.
Ceilon, olim cum continenti cohacfit. Cervus Dama.

- cjus dilatatio.

622.

352.

195.

in Franciae infulam (Isle de Fran-

ce) delatus. 019.

- ctiam in Africa vivit. 195.

- $\triangle$ xis. $\quad 53^{2}$.

- porcinus. . jbid.

— Pygargus. 5.33. 206.

nolter datur in America meri. dionali. $19 \%$.

- arduennenfis, Brandhirfch. 2 co.

- minimae ftaturae. 190.

- varietaces. ibid.

Cervorum forma maxime ab alimento. rum copia ciepender.

jbid.

Cherofo.

Chevrocin des 516 .

Chevrotain des Indes. $\quad . \quad 530$.

Chimpanzee.

Chinche.

Cirquinçon.

Citellus idem cum Souslic.

Clama. cjus dilatatio.

Coaira.

Coalle.

Coati \& ejus varictates.

Cocndou.

Commerfonus notatus.

402 .

489.

405.

$3+\%$.

371. $\mathrm{CO}_{4}$.

527.

431.

483.

483.

504.

Compagnonus in $\triangle$ fricae interiora: 6 i.

usque penetraverit.

Condoma.

Conepacti.

Coquallin.

Corinue.

Corfac.

$57 \%$.

$5+2$.

$48 \%$.

520.

543 .

471 .

Corficaminimae ftaturae animalia produ. cit.

Corfica, ibi olim S:miae.

$2 \mathrm{co}$.

Coudou.

Couguar.

626 .

539.

$4 \div 9$.

Cranzius laudatus.

S2:

Cugua cu apara.

210.

Cu:ziculus minus frigus perfert 1 spore. 188 .

(2) 993

Cuns: 
Cuniculus ejus dilatatio \& varietatcs. Equi Patagonum aquam marinam biPag. 187. feq. tibus vivat. an in aquilonaribus terrae par.Cuzos, animal e generi didelphidum in infulis Moluccis. 494. req.

\section{D.}

Dama, cervus, frigus abhortet. Dana, virginiana.

Daman Israel.

Dandoclana.

Dani fub 7.2 lat. grada virunt. 58. - corum magnitudo $\&$ quid inde concludi pollit.

6. feq.

nant, non femper Tapirum indicat. 11 .

Dafypodes in America tantum.

$$
\text { tae. }
$$

Demanctus laudatur.

Denlinii tabulac ejusdem Africac partis, inter fe difierences.

Didelphis.

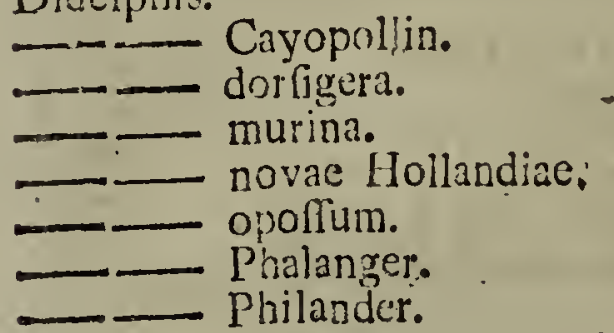

- Philander.

Didelphidis fpecies orbis antiqui incola contra Buffon.

Doebelius laudacur.

Dormoufe.

Douc. volans Pigafettae forte Vefpertil. Vampyrus.

Dromas Cameli varietas.
Dshiggetei, animal generis equini. 605.

E.

ciwardi Dorcas Groenlandica forte Ta. randi varietas.

Elephas ejus dilatatio.

Elephantes optimi, montes inhabitant.

- albi.

377.

Empakaffa \& Impegueza. Encoubert.

37 I.
- bunt.

Equus minimae ftaturae.

Pag. 50. 150. - verfus polarem circulum minoric ftaturac. 138. - quousque verfum feptentrionem procedat.

pjus patria.

— fenus ubi \& ejus defcriptio. 140.

arabicus.

feq.

Erinaceus auritus.

244.

503.

\begin{tabular}{ll} 
D- luropacus. & 347. \\
\hline - inauris. & 503.
\end{tabular}

- madagafcarcofis. ibid.

Efquímavii cur tam parvi. $\quad 60$.

Europa an cum Africa cohacerit. 627.

- ejus nuagnitudo fec. Tempel.

manuum.

575 .

F.

Faach. 368.

Faille (la) ejus defcriptio talparum. 06 I.

Falanuc feu Zibetha. 384.

Farafe, Hyena. $\quad 360$.

$\mathrm{Fe}-\mathrm{fe}$, an Gibbon?

Felis dilatatio. 372 . feq.

- non tolerat frigus. $\quad$ ibid.

melius perfert calorem. $\quad \quad \quad 733^{\circ}$

- cjus varietates. $\quad 175$.

Fer de lance. $\quad \therefore \quad 455$.

Feuille. 457.

Fines inter quos funt optimi equi. 149.

35. Formicarum agmen incolas fugat. 559. 5I6. Follana. 335 . Fourmiller. 461 .

Frigus dectefcit crefcente incolarum numero. 64. Frigoris naturalis fummus gradus obfervatus.

38.

G.

Gadi Morrhuae ovulorum sumerus. 572.

Gambiae curfus incognitus. $58 \mathrm{r}$.

Gauvera. $\quad 549$.

Gazelle. 543 .

Genetta. 48 r.

ibid. Germania olim majore frigore inhorruit.

460. Ghiamala.
65.

534. 


\section{ZOOLOGIAE GEOGRAPHICAE.}

Gibbon.

Gilli magnitudo.

Giraffe.

Gliris dilatatio.

Gnou ejus defcriptio.

Goat - Monkey. na.

Gradatio naturae.

C - inter fimias.

Groenlandi exhalationibus fuis fe calefaciunt.

Guepard.

Guib.

Guinea nova capras nutrit.

Guldenftedcius laudatur.

Gulo an idem cum Wolverene. 3 Io feq.

- ejus dimentio.

- ejus dilatatio.

- datur in America: 3 I0. 11.

$3 \pi$. $3.1 \%$

\section{H.}

Hamilton de natalis terra quaedam aperuit.

Haemisphaerium terrae auftrale longe majore frigore premitur quam borea. le.

$6 \kappa$.

Hermellanus fub Zona torrida. 239. Hippopocamus.

Hollandia nova an reliquis terris quon. dam juncta?

- - ejus quadrupedes.

656.

Homo caufa adventicia migrationis quadrupedum. óo3.

- quadrupedum robuftifimus. 30.

- per totam terram dilatatur. 37.

non tam a mente quan a corpore fuo depeidiet.

52. 58.

- maximum \& caiorem \& frigus fuftinet. 38.42.

— in aëre leviflimo vivere poteft. 46.

$\begin{array}{cc}\text { omnis generis cibos digerit. } 47 . \\ \text { nullibi plane hirfutus. } & 80 .\end{array}$ Hlomines aquam marinam bibunt. 50. - fub mitiori coclo formeficres. 63. fub frigidiore robuitiores. ibid. quomodo colo"e difterant. 74.
Homines ftatura, reliquis quadrupedibus minus inter fe diffcrunt. Pag. 73. Hudfonis freti terra immenfa copia caftorum abundat.

Huepfch (Baro de) novam talparum - Speciem detexit. 670 .

Hufonis ovulorum numerus, $57 \%$

Hyena maculata ubi.

Hyena ftriata.

Hyftrix.

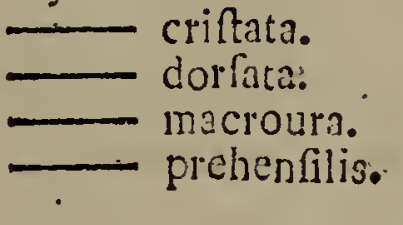

470. req. 360. 350.

$350.5 \mathrm{C} 3$. 504. ibid. ibid.

I.

Jaguar. $4 \%$.

jaguarete. 480.

Jakkalis defcriptio \& patria. 361.472. Ibex pater caprae fec. Buffon. I 10 .

- defcendens de montibus degrenerat.

I 2 .

Ichneumonis dilatatio \& varietates. 380 . Jevrafchka idem quod Sounic. $\quad 3+2$. jiya latrae fpecies. 303.

Infulae [3aleares non originales. 626 . __ Liparae originales. $\quad$ ibid.

- quaenam olim Afiae junctas fuerine. $0_{23}$

- Moluccae parum cognitae. 577.

- Sundaicae parum coguitae. ibid.

In originales quaenam. 023.

Infularum Afiae magnitudo fec. Tempelmannum.

577.

- originalium ortus. $\quad 623$.

Jocko \& Enjocko Ourangi nomina 410. Joekel, Islandiae montes. Jonftoni cervus burgundicus quid. 281 . lfatis. 379.181 .470$. Islandia infula originalis. 624 . feq. Islandize vaccae fine cornibus. 111 . Inquicpact. 128. Izquiepatl. 483.

K.

Kabafrou.

Kamtfchatka, varias murium fpecies nu. trit.

Kanguroo. $5 \div 6$.

Koe- 
Kocchlani, nomen Equorum nobilium Arabiae.

Koleboe.

Kulbius notatus.

Kruegeri Syltoma terraqueum falcum 65.

Kulan.

Kulon.

\author{
Pag. 144.
}

295. ก. 438 .

195.

66గ.

487.

L.

Labat notatus.

Lamantin.

Lappii cur tam parvi. tur.

Lava infulas producit.

L.emur Catta.

Mavus.
Macaco.
Mongoz.
Potto.
$=$ tardigradus.
volans.

Lcmures.

Leo ejus numerus imminutus.

- dilatatio \& varietates. mam deferuit.
jam Africanus

pervenerit.

Leopardus.

Lepus Groenlandiae femper albet.

Ljus dilatatio.

- alpinus.

- pufillus.

Lepores nigri \& cornuti.

Lerot.

Lcry laudatus.

Lidmee.

Linnacus de prima telluris facie notatus.

Loris.

Loup-renard ubi.

Lowandou.

Lupus.

ab Americanis cicuratus, quid inde concludendum?

Lutra, ejus dilatatio. 301. Peg. 672.

442.

Lutreola. canadenfis noftrae varietas. ibid.

Lynx 20 detur in Africa. $30 \%$.
Lycs ejus dilutatio \& varittates. Pilg. 30\%. 1eq. M.

Macnque. 422 : Maimon Buffonii, Nemeftrina Linnaci.

Makis.

Malbrouc.

Mandrill.

263. Manati dilatatio.

59. Mangabey.

416.

441.

422.

414.

205 .

Mangarfahoc.

$42 \%$

147.

15 I. n. Mangufte Icliseumonis varietas. $\quad 880$.

624. Manregar an Simia Mormon. 412.

441. Manicola, quaenam terra? 650.

ibid. Manis. 403.

443. Manul. $657^{\circ}$

ead. Mapich. $\therefore$. - 450 .

445. Marapute. 478.

442. Mare ubique immenfa animalium copia

445. fcatet. 562. 565.

441. —- cemperic femper fere aequali gau-

337. ' der. $5 \pi 3$.

390. - ejus animalia pleraque carnivora.

leq. 5 s.

Margay.

Marikina.

48.

Maritacaca.

493.

Marmofe.

484.

477. Marmoca cur nec in Succia nec Lappia.
135.

18?. - ejus dilatatio \& varierates.

505. 319. fec.

ibid. Marmotte volante. 450.

187. Martis dilatatio \& varietates. 200. 293.

516. Mazame \& Temamazane. $\quad 207$.

$\begin{array}{ll}\text { 633. Mebbia forte Jakkal. } & 304 . \\ \text { 543. Meckel laudatus. } & 77 .\end{array}$

Melis varietates \& dilatatio. $\quad 323$.

Metallorum \& plantarum proportio numerus.

Migratio lemmi.

420. - furmuloti.

614.

- ratti cujusdam Kamt Cchatkalen-

fis. 014.

ftichinum, animaliumque dome. fticorum ad elucidandam telluris biftoriam minus apta.

Miko.

618.

Mink \& Norkidem quod Lutreola 440. 
Mococo.

Pag. 444. Muftela Voangsinire.

Pag. 487 .

Moluccae infulae paruin cognitae.

Monax, marmota Americae.

Mouftac.

320.

Moufta. 424.

Moofe deer eft Alce Americae. 288.

Mopficaenfes avium copia e patria expulfi.

Mofchus, ubi?

501.

229.

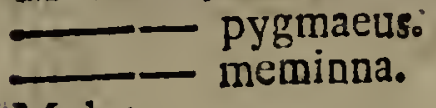

530 .

Mulot.

ibid.

Molant.

5 II.

Musamphibius albus in infula Java.

457.

- amphibius datur in America.

agrarius.

- arenarius.

- avellanarius.

- barabenfis.

_- gregarius.

_ lagurus.

- longipes.

- Lemmus.

- mufculus.

- migratorius.

- minutus.

326.

ibid.

512.

$\sin 2$.

516.

514.

512.

214.

525 .

210.

250. 551 .

513.

514.

- omnium quadrupedum minimus $\mathrm{ib}$.

_ oeconomus.

608.

paludofus.

515.

330.

5 เб.

sio.

.534.

513.

SII.

ibid.

5 I2.

326.

515.

516.

Mufcardio.

$45 \mathrm{I}$.

Mufcarum immenfa guantitas Mafulipatamae.

559.

Mufcae gelu obrigefcunt.

Muftela barbara feu 'Tayra.

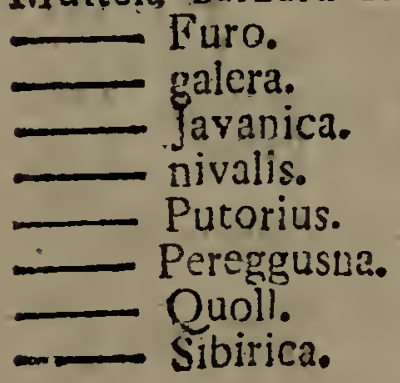

55\%. $\mathrm{n}$.

480.

487 .

483.

480.

438.

435.

4136.

439.

487.

Hermellano.

Muftelae gevus.

- dilatatio.

Mylii de animalium migracione 230. laudatus.

Myrmecophaga in orbe antiquo conita Buffon. fententiam.

- - didactyla.

-

Myrmecophagae genus ubi.

N.

Nagor.

Nanguer.

$54:$

Noçule.

$5+4$.

Norvagia immenfun Vuipium numerune nutrit.

Noftalgiae caufa verifimilis.

Novae Guineae ftasus.

Nylghau.

179. $\mathrm{n}$.

$12 \%$

65 色.

$.542 .07 \%$

O.

Oecum Chamnam Scarabaeis vefcitur. 4 .

Ogotona. $60 \%$

Ondatra.

Osbekii obfervatio de Vefpert. Vamp.

Ordo fapientiffinus in diftributiore 449. drupcium per teras in diftributiore qua-

Ortapedum per terras. 601.

Orohua. 484.

Qtaheita infula originalis, $62 \mathrm{r}$.

Ottay martis variecas.

Ourang Outang.

390. feq.

- 401 .

- ejus patria \& nomina. 402. 403 .

- non datur in America. 404.

Ougn ejus numerus olim major fuic, ibid.

Ouanderol.

Ovale.

420.

Ouarine.

$310 . \mathrm{a}$.

Ovis Islandica. 433.

- laticaudata. $\quad 129$.

- itrepficeros. $13 \%$.

- dilatatio. 13.

- catdin adipofara climare produci

per Mateliefun probatur. $\quad 130$. $\mathrm{R} \cdot \mathrm{r} \cdot \mathrm{I}$ 


\section{I}

$\mathrm{N}$

D

Ovis varictates.

Pag. 127. 133. - degenerationes a climate dependipnt. 130. Ores Kirgifienfum praeftant noftris. Ouiftiti. Ozelot. 132. 438. 480.

\section{P.}

Pacificum mare; ejus infulae originales. 052. multos continet Vulcanos. 653. colarum diverfitas. mira in ejus infulis in. ejus infulis.

Palmifte (le) 654.

Pangolin. quadrupedes, quinam in

japiones ron dantur in America.

Pardus, an in America.

649. 518. 409.

Patagones, natio robuftifima, non vero

P. gigantea.

-70 .

Patas.

424.

Pawius gravis nimis in Byronium \& Lin. nacurn.

09. 400 .

Pecari. 551.

Pecherais natio ubi?

68.

Pckan \& Wifon Martis varietates. 292.

Pennantus laudacus. 280. $\mathrm{n}$.

Pernetty notatus. 72. $\mathrm{n}$.

Phalangeri, fpecies Novam Hollandiam inhabitat.

Phatagin.

336.

Phoci leonina, \& ejus fpecies variac.

__ mitrata, feu criftata perperam cum leone marino confufa. 258 . Plocae minus adhuc cognitae. $\quad 242$. - ubique in mari inveniuntur. 245 . I'hocarum fpecies Pontoppidanus qua. tuor, Cranzius quinque numerat. 242. Pholicloti genus.

piloris.

Pinche.

$4 \sigma_{3}$. 509.

439.

Pifcium propagatio immenfa. 57 I. feq. Pithecac patria.

plinius uotatus. 408.

Poephagus forte Gnou.

277.

Pons Adami, quid inde colligi poffit.

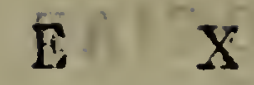

Poppingius auctor dubiac fidei \& credu. lis.

Pag. 2?. n.

Potio. 337.

Probabilis animalinin omnium numerus.

Promontoria plaraus 25 . Promontoria pleraque verfus meridiem.

Proportio quaenam inter notas ignotasque terrace partes.

Puina, Conguar.

Putorius capenfis.

505 . 391 . 485.<smiles>[Os]</smiles>

Quadrupedes Africae, nunquam vi clima: tis in quadrupedes Americae transfor: mari pocuerunt.

$642:$ - an cuivis generi patria fingu: laris.

ac reliqui. carnivori, an aeque foecundi — corum migrationis cauffae. 605.

_- eorum plurimae fpecies, per orbem latiflime difperfae, homini in: nocuae. 267: merus. 303. - illorum, qui naxime dilatati funt, patria Zona temperata. 608. - maximi, herbis vivunt. $60 \%$. - quomodo fecundum Geographiam dividendi. 209. feq. - tigrini, feu maculis vel fa. fciis notati, propemodum omnes $\mathrm{Z}_{0}$ : nae torridae proprii.

Quickhatch.

Quimos pygmaei. 306: $\mathrm{n}$ : Quoil.

489. 057.

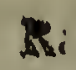

Raton.

490.

Rattus. 220.551. Rattus \& mus mufculus ex Europa in Amcricam, novam Zclandiam, Africaeque partes auftrajes delati. $2 ? 3$.

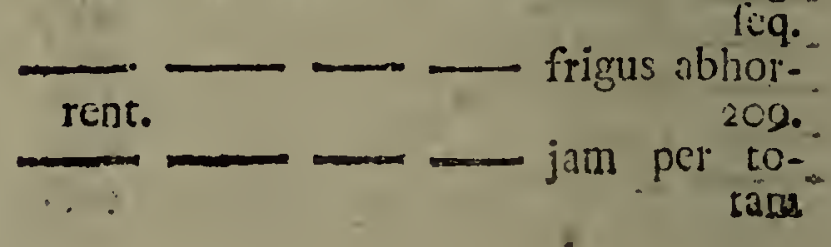


tam fere terram dilatàti. Pag. 200. feq. Rhinocerotis dilatatio.

Rhinocerotum cornua plura, fenectae tantum indices.

379.

Richmannus magnum caloris gradum tolerat.

Rillure.

43.

Roemerus Africae montes concatenatos effe probat.

Rosmari dilatatio.

Rouffette \& Rougette.

Rukkaja.

Rupicapra.

Rupicapra. non idem animal cum ibice \& capra.

580.

$33 \mathrm{I}$.

447.

518.

Rufforum hypocaufta ad quem caloris gradum calefiant..

\section{S.}

Sai.

Saiga.

Saimiri.

Sajou gris.

Saki.

Sapert lacus minus cognitus.

Sarcovienne luträe fpecies.

Sarluk.

Schenfar, Arabiae animal generis felini.

Schreberus de inammalibus, laudacus.

Sciuri varietates \& dilatatio. 2 16. 397.

\section{Sciurus aeftuans.}

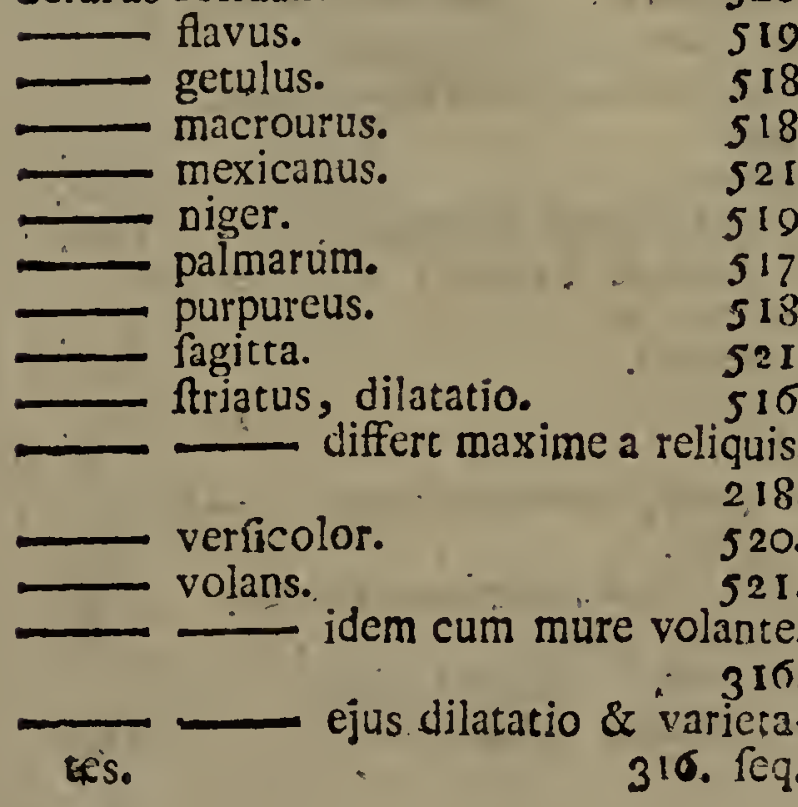

Sciurus vulgaris, idem cum cinerco. Pag. 213. feg. que afcendit. ad circulum arcticum us215. Scoafu, cervini generis. 534 . Senegae curfus parum cognitus. 581 . Serotine. $\quad 453$. Serrefii tertimonium de admirando Galliae frigore. anno 1543 .

Serval.

Sicilia, quondam Calabriae juncta. 626 .

Sifac.

Simia marina.

Simiae Americae. Simia Apella.

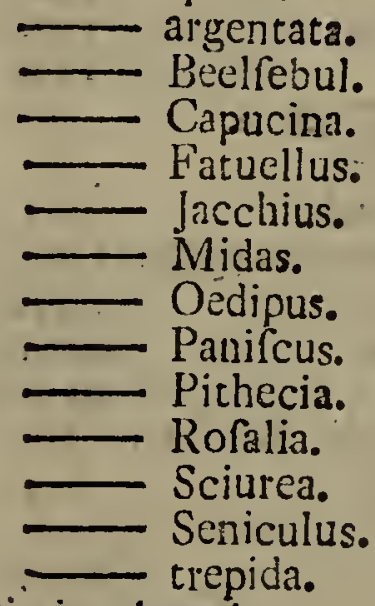

234. 428. 459. $43 \mathrm{I}$. 436. 440. 433. $43^{6}$. 435. 438. 439. 439. 434. 438. 435. - Rofalia. $\quad 439$. $581 .-$ Seniculus. 437. 30.3. trepida. 434. 548 . Simiae Americae, ex earum domiciliis concluditur novum orbem antiquo effe frigidiorem.
Simiae orbis antiqui caudis longioribus. Simia Aethiops.

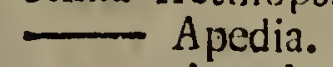

- Aygula.

Cephus.

Cymamoigos.

- Diana.

- Faunus.

- Niaimon.

427.

416. 426. 424. 42 . 423. 420. 419. $41 \%$. 428. 423. 414. 427. 415. 425. 424. 425 . 428 . $4 ? \sigma$. Simia 
Simia Silenus.

Pag. 420.

- Sinica.

427 .

a Buffonio habetur.

a Syrichta.

— Talapoin. - Veter.

Simiarum claffes.

Sin domiclia.

Sin-Sin an Pitheca?

Smitten Simiarum fpecies.

Sorex albus minor.

- araneus.

- Brafilienlis.

- criftacus.

$\Longrightarrow$ fodiens.

$\longrightarrow$ minutus.

- mofeacus feu Desman.

Soricis mofchati Zibetum. . 502.

Spälax, novum quadrupedum genus Guldenifedt.

$\longrightarrow$ microphtalmus.

myofpalax.

Spallanzani de animalculis infuforiis: 20 .

Spitzberga olim cum continenti cohae.

fit.

Stellerus laadatus.

Suiffe. (le)

Sulzeri defcriptio Criceti.

Surikate.

Stirmulntus.

Sus Aethiopicus.

- Rabiroefa.

- frigus abhorret.

- Hydrochoerus.

- nofter Americae non proprius.

-

- numero dentium variat.

254.262.

$62 I$.

Si6.

511.

482.

346.

100. 551 .

521.

15.1.

252.

153.

155 .

- per Zonam temperatam \& torridam dilațatus.

- quousque ad feptentrionem proce. dat.

- folichurgula. .

- Tanar.

- terreftris Kolbii Myrmecophaga. 353 .

Ssum dratium enumeratio. 438.
429. 429. 420. 395. 398. 408 . 402.

502 .

499.

502 :

496.

500.

502.

500.

502.

497.

Tare eft Argali:

Tajefru.

Pag, $\sigma_{32}$

551.

Tajibi.

402.

Talgoi Bradypus Ceilonenfis. $\quad 339$.

Talpa Afiatica.

496.

- Capesiss, non eadem cum noftrate.

_ criftata.

406.

496.

497.

671.

_- Eifliaca cinerea:!

496.

- flava.

- fufca.

Talp rubra.

$497 \ldots$

Talpae dilatatio.

497.

233 .

Tenus frigus abhorret. . . 235.

Tamandua.

Tamanoir.

Tamarin.

403 .

402.

Tanrec.

Tapeti...

Tapir.

219. 500 .

459.

503.

Tarandus ad climatis temperiem deter minandam infervit. ejus dilatatio. eft idem cum Caribu.

283 .

- eft idem cum Caribu: . 281.

Tarfier, Yerboae fpecies.. 225.

Taupe doréc.

Tauro elephas.

Taurus mexicanus.:

Tawny monkey.

Tayra.

Tendrac.

Terra nova, (Terre nenve) an cum continenti cohaeferit.

$49^{5}$.

109.

548.

430.

488.

503 .

Tibeci rognum minus cogaic $62 \%$.

Tibeti regnum minus cognitum. $57 \%$.

Tigris.

Tiaekko.

473.

Timoris infulae quadrupes $\quad 426$.

Tin Tzin \& Tanuki, Japoniae quadrupedes.

Thamototli.

485.

Tolai.

Tonga.

I91. 506 .

155. Tonga. Tong, cervini generis. 352. 533 .

32. Tretre tretre, papionis fpecies. $\quad 4.30$. 5.30

richechi genus.:

458.

Tucan talpae fpecies edulis.

Turluruxium guantitas. soo.

U. 


\section{ZOOLOGIAE GEOGRAPHICAE.}

U..

Uahr.

Unzia.

Urfus albus marinus:

- ejus dilatatio \& varietates. 275

$\begin{array}{ll} & \\ \text { citur. } & 270 . \\ \text { Urfon. } & \\ \text { Utfuk, phocal forbis quam carnibus ves- } & 273 . \\ & 490 . \\ & 504 . \\ \text { V. } & 244 .\end{array}$

Vacuum datur in natura.

Vampyrus Ulloae forte differt a Vefp. Vamp. Linnaei.

Venti non ad medium maris pertingunt.

Vefpertiliones Americae.

Vefpertilio Canadenfis.

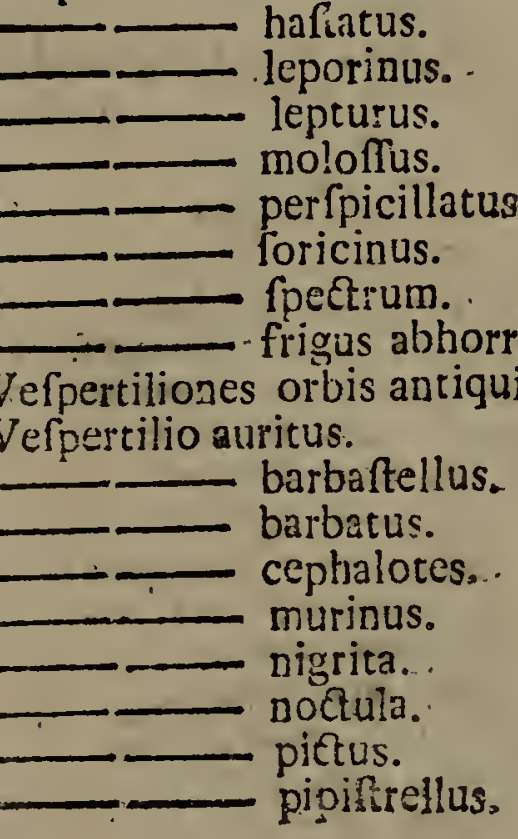

568.

454.

4.57.

455 .

450.

456.

457.

455.

454.

440.

447.

453.
Vefpertilio ferotinus.

- folea.

fpasma.

Pag. 453.

452.

450. latatur.

Viverrae genus.

Viverra putorius.

Viverra tetradactyla.

Vulpes cicuratur.

447. fq.

$48 \mathrm{r}$.

481.

482.

471.

490. - ejus dilatatio \& varietates. 178 . $47 \%$. interdum cum cane coirt, $47 \mathrm{I}$.

- non idem cum cane animal. 132.
175.

nigra..
non idem cum cane animal. 132.

req.

frigus omnium quadrupedum optime

178.

W.

457. Ycrboa, ejus dilatatio \& varietas. 522.

453. Zebu.

451. Zibellina, an in America? 327. $540 \mathrm{co}$.

451 .

45I. Zibetha animal orbis antiqui. 2830.

450. Z ejus dilatatio \& varietates. 284 .

452. Zuna glacialis minimum animalium nu-

$45 \mathrm{I}$. trit numerum.

453. Zorilia.
$25 r_{0}$.

$48 \%$ 


\section{C $O A \quad R \quad R \quad I \quad G \quad E \quad N \quad D \quad A$.}






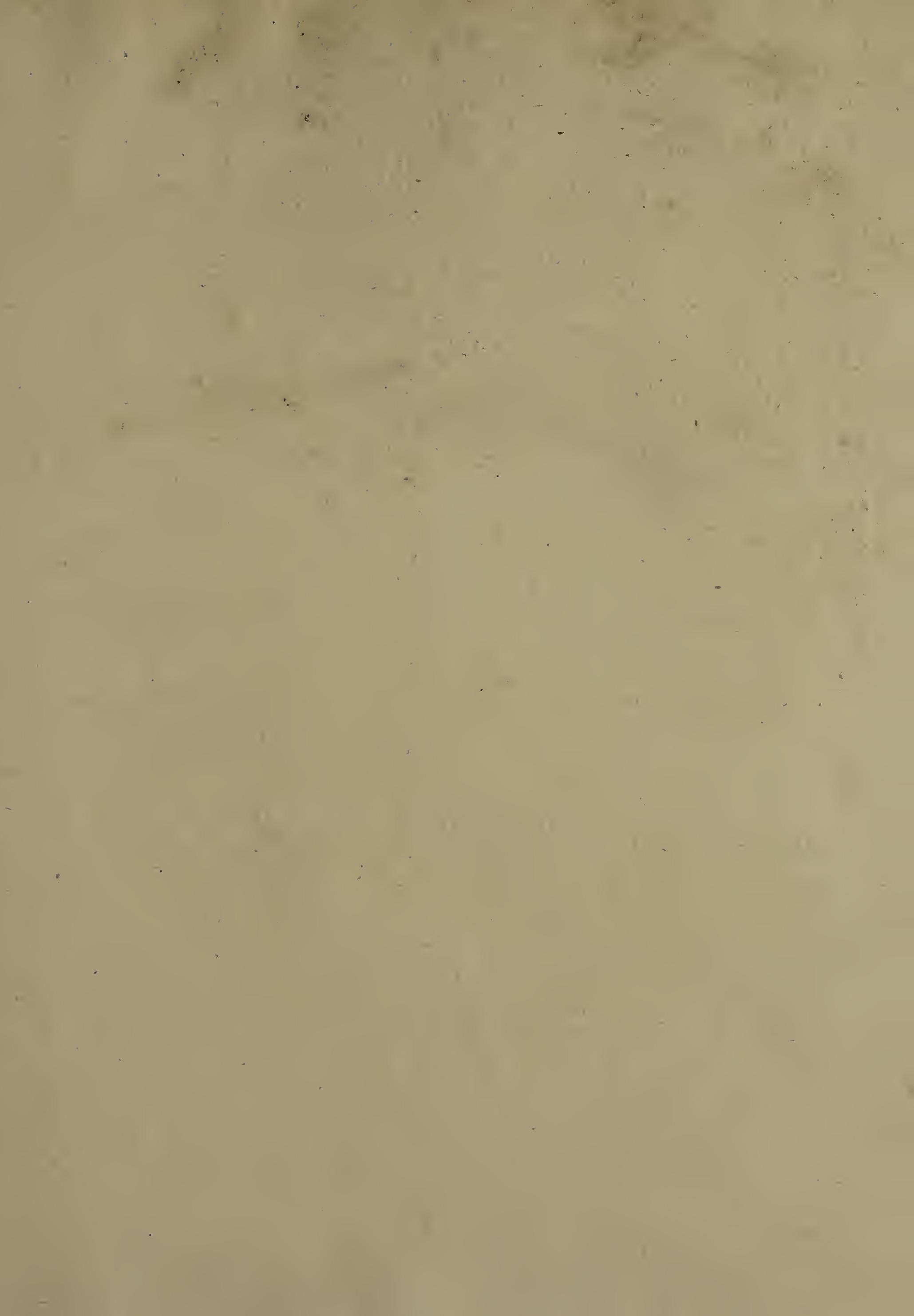





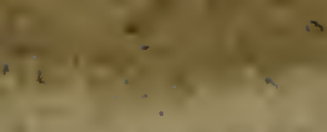

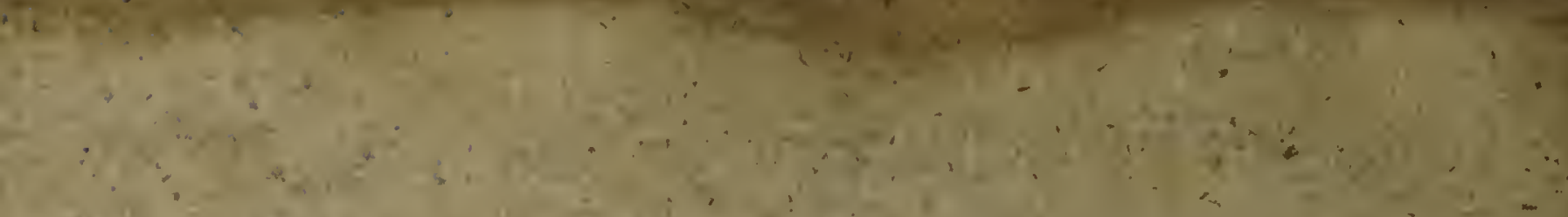

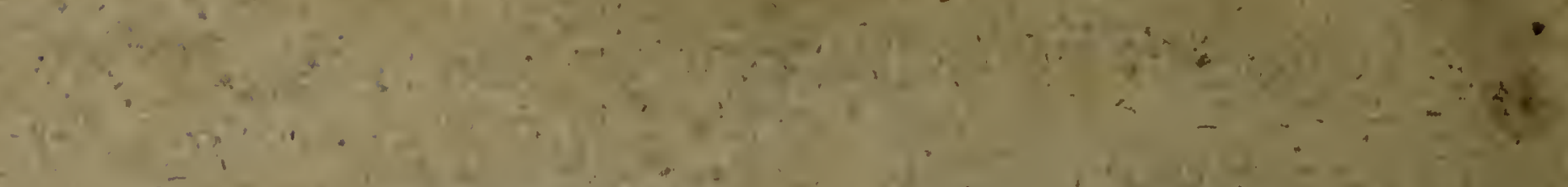

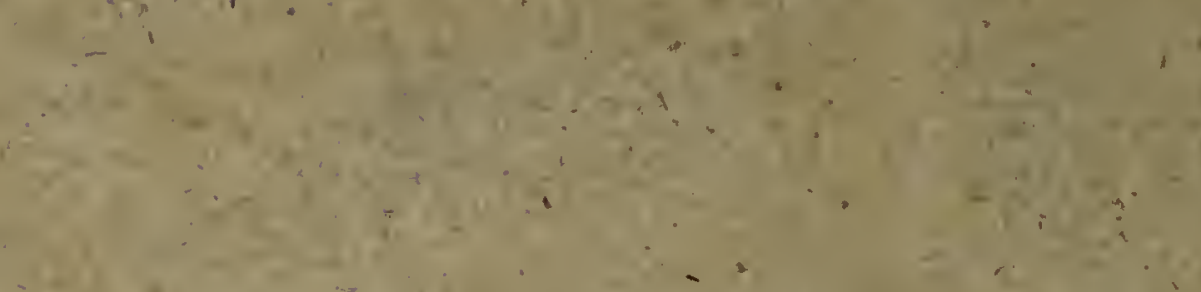

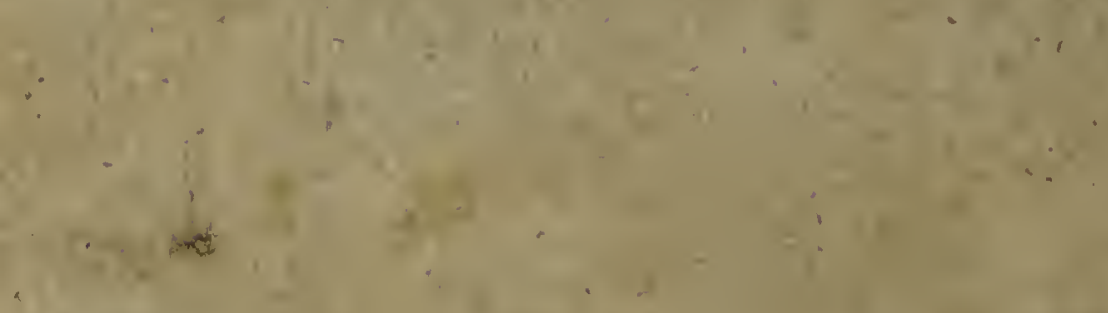
is 1.

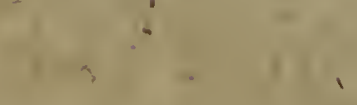

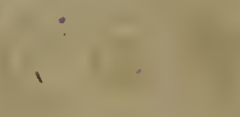

$+\cdots+\infty$

$\begin{array}{ll}: & 1 \\ 1 & 1 \\ 1 & \end{array}$ (1) $+\infty=n^{11}$

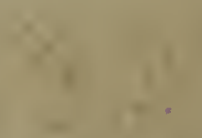

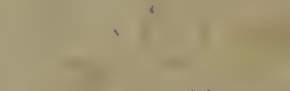

Mr n

-

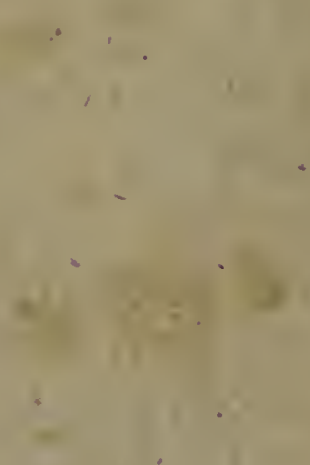

$-1$

b
$=$

\section{.}

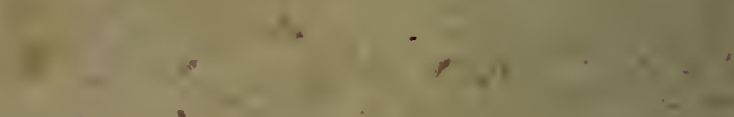



$x$

$30 \times \frac{-6}{2}$

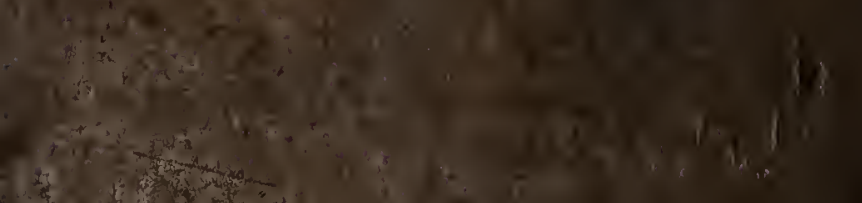

